\title{
AGC-1 Experiment and Final Preliminary Design Report
}

Robert Bratton, Idaho National Laboratory Tim Burchell, Oak Ridge National Laboratory

August 2006

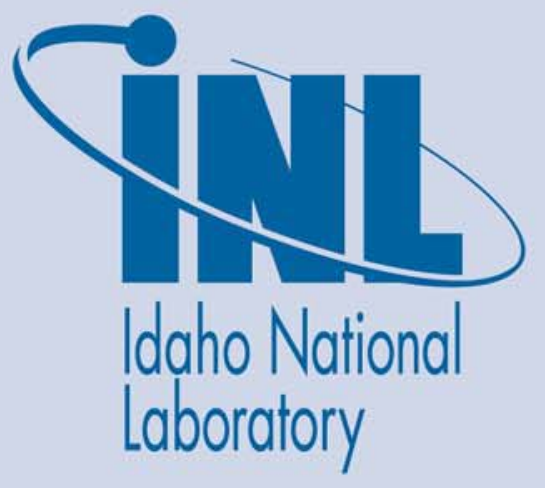

The INL is a U.S. Department of Energy National Laboratory operated by Battelle Energy Alliance 
INL/EXT-05-00622

Rev. 2

\section{AGC-1 Experiment and Final Preliminary Design Report}

Robert Bratton, Idaho National Laboratory

Tim Burchell, Oak Ridge National Laboratory

August 2006

Idaho National Laboratory

Idaho Falls, Idaho 83415

And

Oak Ridge National Laboratory

Oak Ridge, Tennessee 37831

Prepared for the

U.S. Department of Energy

Office of Nuclear Energy, Science and Technology

Under DOE Idaho Operations Office

Contract DE-AC07-05ID14517

$$
\text { And }
$$

Under DOE Oak Ridge Operations Office

Contract DE-AC05-00OR22725 
This page intentionally left blank. 


\begin{abstract}
This report details the experimental plan and design as of the preliminary design review for the Advanced Test Reactor Graphite Creep-1 graphite compressive creep capsule. The capsule will contain five graphite grades that will be irradiated in the Advanced Test Reactor at the Idaho National Laboratory to determine the irradiation induced creep constants. Seven other grades of graphite will be irradiated to determine irradiated physical properties. The capsule will have an irradiation temperature of $900^{\circ} \mathrm{C}$ and a peak irradiation dose of $5.8 \times 10^{21}$ $\mathrm{n} / \mathrm{cm}^{2}[\mathrm{E}>0.1 \mathrm{MeV}]$, or 4.2 displacements per atom.
\end{abstract}


This page intentionally left blank. 


\section{SUMMARY}

This report contains the objectives, technical plan, design as of the preliminary design, and schedule for the Advanced Test Reactor (ATR) Graphite Creep-1 (AGC-1) irradiation experiment. Experiment AGC-1 will be irradiated in the ATR south flux trap to a peak irradiation dose of $5.8 \times 10^{21}$ $\mathrm{n} / \mathrm{cm}^{2}[\mathrm{E}>0.1 \mathrm{MeV}]$, or 4.2 displacements per atom (dpa), at an irradiation temperature of $900^{\circ} \mathrm{C}$. Graphite specimens will be stressed in compression at two levels, namely $2 \mathrm{ksi}(13.8 \mathrm{MPa})$ and $3 \mathrm{ksi}$ (20.7 MPa).

The key data to be obtained from this experiment include:

- Irradiation creep design data and data on the effects of irradiation creep on key physical properties (e.g., strength, elastic modulus, coefficient of thermal expansion)

- The effects of neutron irradiation on the properties of a wide range of next generation nuclear plant (NGNP) relevant graphites, including dimensional changes, strength, elastic modulus, thermal conductivity, and coefficient of thermal expansion.

- Data on the single crystal irradiation behavior of graphites to be derived from highly oriented pyrolytic graphite (HOPG).

These data are critical to the design licensing of the NGNP graphite components and support ongoing work in the area of model development (e.g., irradiation effects model such as dimensional change and creep strain, structural modeling, and fracture modeling). Moreover, the data will be used to underpin the American Society of Mechanical Engineers (ASME) design code currently being prepared for graphite core components.

The report reviews the background and theory of irradiation induced creep in graphites, and details the graphite grades to be irradiated in the experiment along with the rationale for their inclusion. Details of the irradiation test conditions are reported. Detailed AGC-1 layout plans are given for each of the specimen channels in the capsule, and the specimens are tabulated by grade, location, and anticipated fluence. The process of pre and postirradiation examination (PIE) is reported, and details of the tests to be performed and the data to be acquired are given.

The second half of the report details the design to date for the AGC-1 capsule. Detailed discussions are given for the capsule requirements and how the design incorporates those requirements. The experimental plan is fully developed because all details and theory are known at the present time. This report is a snapshot of the AGC-1 design as of the preliminary design review. The final design review will occur after this report is released. Capsule insertion in the ATR is expected in November 2007. The final design will use an assumed neutronic model of the ATR core because the actual November 2007 core configuration is not know at this time. This prevents the development of a final neutronic, thermal, and mechanical analysis. The complexity of the cross-sectional geometry requires a translator to be developed to read the output of the neutronic analysis and provide a database for use by the finite element thermal analysis. The finite element model is expected to use over 150,000 elements. The database will alleviate the need to enter by hand the gamma heat generation in every element. In FY-06, ATR operations required that the schedule for design and fabrication of the AGC-1 capsule and gas control system be realigned to fit ATR's available limited resources. A resource loaded schedule was prepared and accepted by ATR operations. This scheduled split the AGC-1 gas capsule and gas control system into two separate activities. The final design for the AGC-1 capsule is expected by the end of September 2006. Fabrication of the capsule is slated to start the second quarter of FY-07. The AGC-1 gas control system design and 
fabrication will start in FY-06 and will finish at the end of FY-07. This extended period of time is necessary to allow ATR personnel to install tubing and equipment in restricted ATR areas during planned outages. 


\section{CONTENTS}

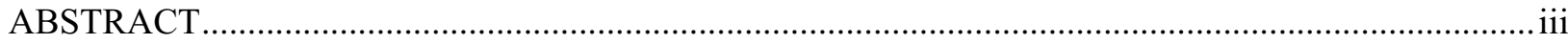

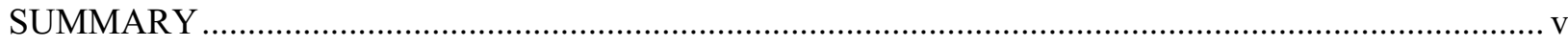

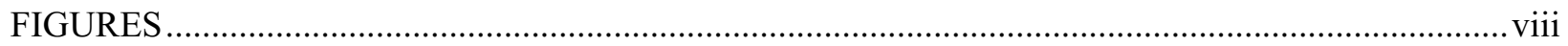

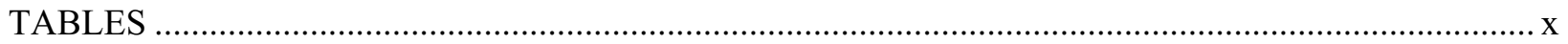

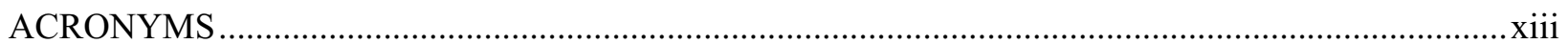

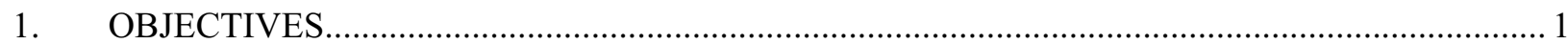

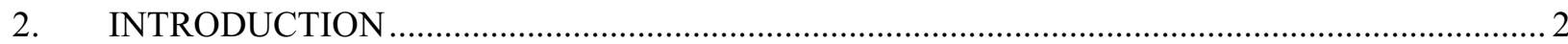

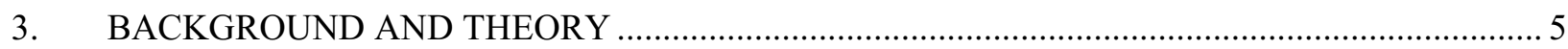

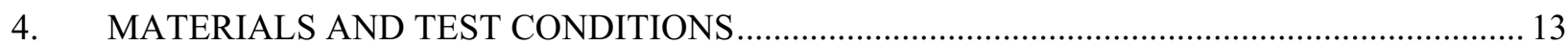

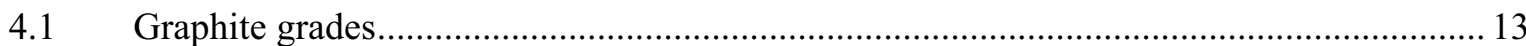

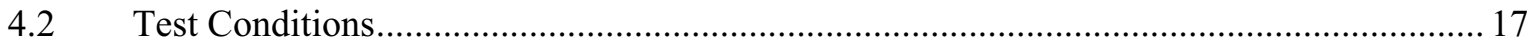

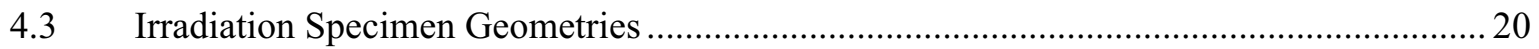

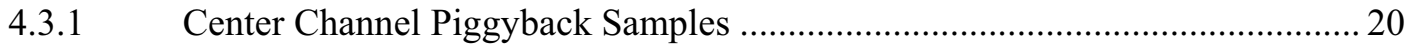

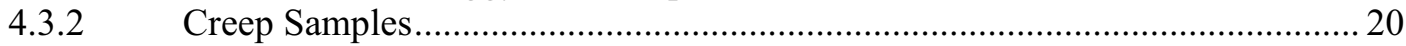

4.3.3 Peripheral channel piggyback samples .................................................. 21

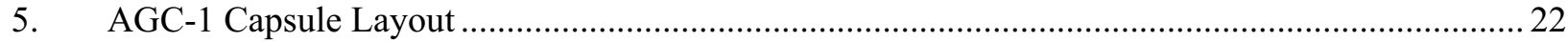

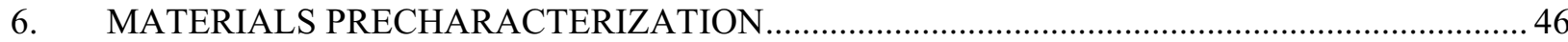

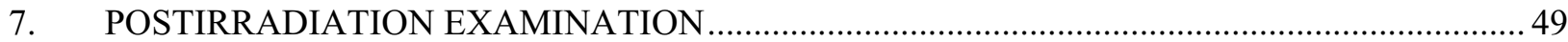

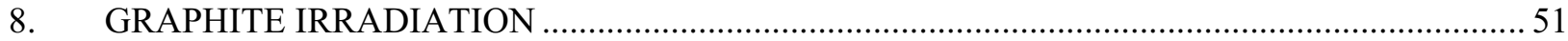

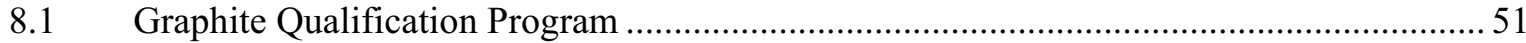

8.2 Experimental Position in the Advanced Test Reactor ................................................... 52

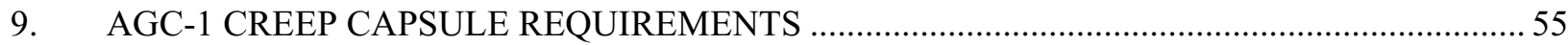

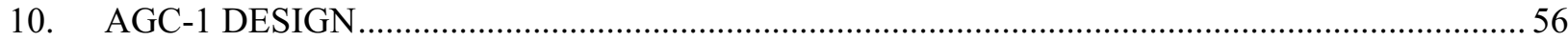

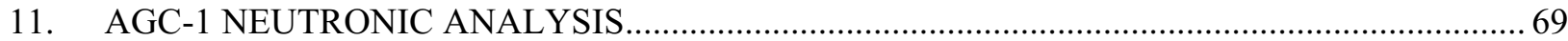

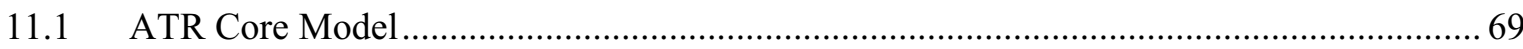

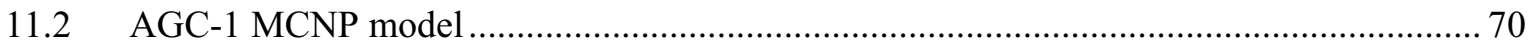




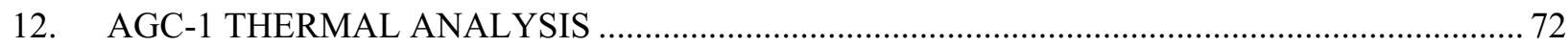

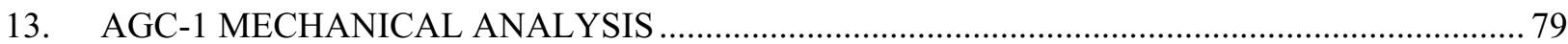

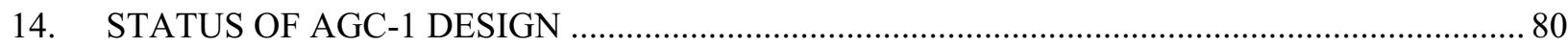

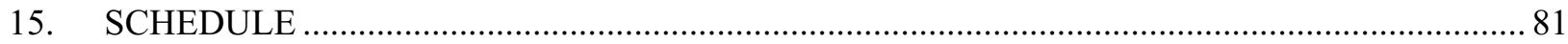

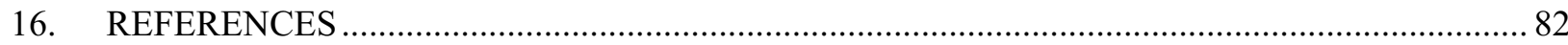

\section{FIGURES}

Figure 1. Capsule AGC-1 drawing showing the central and six peripheral channels and the location of the pneumatic pistons.

\section{4}

Figure 2. Irradiation-induced dimensional change in stressed and unstressed graphite.

Figure 3. Schematic representations of the transient and steady state creep strains as a function of neutron dose.

Figure 4. Schematic representation of the total (transient plus steady state) creep strain as a function of neutron dose.

Figure 5. Grade $\mathrm{H}-451$ graphite irradiation creep strain as a function of dose at an irradiation temperature of $900^{\circ} \mathrm{C}$ and at two compressive stress levels (13.8 and 20.7 MPa).

Figure 6. The variation of coefficient of thermal expansion with neutron dose for unstressed and stressed $\mathrm{H}-451$ graphite samples irradiated at $900^{\circ} \mathrm{C}$.

Figure 7. The variation of $X_{T}$ with neutron dose for H-451 graphite at several irradiation temperatures... 10

Figure 8. The variation of the true creep strain with neutron dose for $\mathrm{H}-451$ graphite irradiated at $900^{\circ} \mathrm{C}$ and at two stress levels.

Figure 9. Neutron flux distribution in the AGC capsule channels within the ATR south flux trap........... 18

Figure 10. Cross-sectional dimensions of the $\mathrm{SiC}$ temperature monitors to be used in AGC-1............... 19

Figure 11. AGC-1 central channel graphite and SiC sample cluster.

Figure 12. Neutron dose map for AGC-1 peripheral Channel 1 (North) showing the spatial location and total neutron damage dose (dpa) per specimen/graphite grade

Figure 13. Neutron dose map for AGC-1 peripheral Channel 2 (North-East) showing the spatial location and total neutron damage dose (dpa) per specimen/graphite grade.

Figure 14. Neutron dose map for AGC-1 peripheral Channel 3 (South-East) showing the spatial location and total neutron damage dose (dpa) per specimen/graphite grade. 
Figure 15. Neutron dose map for AGC-1 peripheral Channel 4 (South) showing the spatial location and total neutron damage dose (dpa) per specimen/graphite grade.

Figure 16. Neutron dose map for AGC-1 peripheral Channel 5 (South -West) showing the spatial location and total neutron damage dose (dpa) per specimen/graphite grade.

Figure 17. Neutron dose map for AGC-1 peripheral Channel 6 (North-West) showing the spatial location and total neutron damage dose (dpa) per specimen/graphite grade.

Figure 18. Neutron dose map for AGC-1 center channel showing the spatial location and total neutron damage dose (dpa) per specimen/graphite grade. 26

Figure 19. Preirradiation data process flow chart for irradiation creep experiment AGC-1 ................... 48

Figure 20. The postirradiation examination process for ATR experiment AGC-1 _............................... 49

Figure 21. Experimental positions in the Advanced Test Reactor core................................................. 53

Figure 22. Cutaway of the ATR core showing the space above and below the experiment will occupy...54

Figure 23. Arrangement of the lower pneumatic rams used to upset the graphite specimens during outages

Figure 24. AGC-1 pressure boundary inside the ATR pressure vessel

Figure 25a, b, and c. Grooved AGC-1 pressure boundary and broaching operation at the ATR machine shop

Figure 26. Cross section of the AGC-1 capsule located in the ATR core.

Figure 27. From top to bottom: graphite upper holder body, graphite lower holder body, and graphite lower spacer body

Figure 28. Symmetry of the axial flux profile in the south flux trap.

Figure 29. Comparison of the symmetry between the northeast and southeast position in the south flux trap. The vertical bars are the percent difference in the fast flux symmetry.....

Figure 30. Haynes 230 thermal radiation shield. The spaces between pieces are drafting breaks to signified material removed to accommodate space on the page.

Figure $31 \mathrm{a}$ and $\mathrm{b}$. Laser weldment of two Haynes $2300.010 \mathrm{inch}$ foil coupons

Figure 32. Cutaway of the out of core portion of the experiment showing the six pneumatic rams and pushrods. The yellow leads from the oval couplers are for the load cells in the couplers.

Figure 33. Cutaways showing the stainless steel pushrods entering the graphite holder body above the core and meeting the graphite push rods that will transfer the load on the specimens in the core. The center column is unloaded. 66

Figure 34. Layout of graphite specimens in the ATR core. 
Figure 35. Sketch showing the specimen layout at core centerline. This sketch shows the separator which allows the loading of the upper portion and keeps the lower portion unloaded.

Figure 36. Standard power levels in the ATR core. All values are in MW and total to 108.4 MW. North is straight up on the page.

Figure 37. ATR PALM cycle power levels. All power levels are in megawatts and total to $185 \mathrm{MW}$. North is vertically straight up .70

Figure 38. Tally map for the AGC-1 capsule cross section. Each color is a explicitly modeled feature.... 71

Figure 39. MCNP model separated into 6 azimuthal tally regions. Center specimen stack is not divided into azimuthal regions.

Figure 40 Finite element model for the capsule pressure boundary .................................................. 72

Figure 41. Finite element model for the graphite holder body ........................................................... 73

Figure 42. Finite element model for the thermal heat shield ............................................................. 73

Figure 43. Finite element model for the specimen stacks 1 through 6 . Note the smaller spacers between

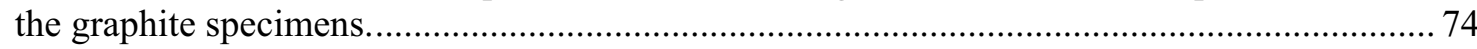

Figure 44. Finite element model for the center specimen stack .......................................................... 74

Figure 45. Fast Flux distribution in the AGC-1 in the south flux trap. Units are neutrons $/ \mathrm{cm} 2 / \mathrm{sec}$. North is at two o'clock

Figure 46. Fast flux distribution in the AGC-1 capsule in the south flux trap. Units are neutrons $/ \mathrm{cm} 2 / \mathrm{sec} 76$

Figure 47. Gamma heat distribution in the AGC-1 capsule in the south flux trap. Units are MeV/gm.

North is at two o'clock 76

Figure 48. Gamma heat distribution in the AGC-1 capsule. Units are $\mathrm{MeV} / \mathrm{gm}$

Figures $49 \mathrm{a}$ and $\mathrm{b}$. Temperature distribution in specimen stack. Upper figure is the top of the stack. The lower figure is the bottom of the stack. Temperatures are in degrees $\mathrm{F}$.

\section{TABLES}

Table 1. Linear creep model terms for H-451 graphite.

Table 2. Experiment AGC-1 graphite materials test matrix. 13

Table 3. Capsule AGC-1 graphite grades, vendors, and available processing information. 14

Table 4. Graphite grades and the number of samples included in the central channel of irradiation capsule AGC-1. 
Table 5. The number of stressed/unstressed samples and their graphite grades included in the peripheral channels of irradiation capsule AGC-1

Table 6. The number of piggyback samples, and their graphite grades, included in the peripheral channels of irradiation capsule AGC-1. 16

Table 7. ATR south flux trap neutron flux model coefficients. 18

Table 8. Stress levels in the stressed samples in the AGC-1 experiment...... 20

Table 9. Summary of the stressed/unstressed creep samples by graphite grade (3 ksi channels). 26

Table 10. Location and dose of stressed and unstressed grade NBG-17 creep samples in 3 ksi channels. 27

Table 11. Location and dose of stressed and unstressed grade NBG-18 creep samples in 3 ksi channels. 27

Table 12. Location and dose of stressed and unstressed grade PCEA creep samples in 3 ksi channels.....27

Table 13. Location and dose of stressed and unstressed grade IG-430 creep samples in 3 ksi channels. .. 28

Table 14. Location and dose of stressed and unstressed grade IG-110 (reference) creep samples in $3 \mathrm{ksi}$ channels.

Table 15. Location and dose of stressed and unstressed grade H-451 (reference) creep samples in $3 \mathrm{ksi}$ channels.

Table 16. Summary of the stressed/unstressed creep samples by graphite grade ( $2 \mathrm{ksi}$ channels). 29

Table 17. Location and dose of stressed and unstressed grade NBG-17 creep samples in 2 ksi channels. 29

Table 18. Location and dose of stressed and unstressed grade NBG-18 creep samples in 2 ksi channels. 30

Table 19. Location and dose of stressed and unstressed grade PCEA creep samples in 2 ksi channels..... 30

Table 20. Location and dose of stressed and unstressed grade IG-430 creep samples in 2 ksi channels. .. 30

Table 21. Location and dose of stressed and unstressed grade IG-110 (reference) creep samples in 2 ksi channels.

Table 22. Location and dose of stressed and unstressed grade H-451 (reference) creep samples in 2 ksi channels.

Table 23. Summary of the piggyback samples by grade included in 3 ksi peripheral channels. 31

Table 24. Summary of the piggyback samples by grade included in 2 ksi peripheral channels. 32

Table 25. Summary of Grade NBG-17 piggyback specimens located in peripheral channels of AGC-1. . 33

Table 26. Summary of Grade NBG-18 piggyback specimens located in peripheral channels of AGC-1.. 33

Table 27. Summary of Grade PCEA piggyback specimens located in peripheral channels of AGC-1...... 34 
Table 28. Summary of Grade IG-430 piggyback specimens located in peripheral channels of AGC-1.... 35

Table 29. Summary of Grade IG-110 piggyback specimens located in peripheral channels of AGC-1... 35

Table 30. Summary of Grade H-451 piggyback specimens located in peripheral channels of AGC-1...... 36

Table 31. Summary of Grade HOPG piggyback specimens located in peripheral channels of AGC-1..... 36

Table 32. Summary of A3 Matrix piggyback specimens located in peripheral channels of AGC-1..........36

Table 33. Summary of Grade HLM piggyback specimens located in peripheral channels of AGC-1....... 36

Table 34. Summary of Grade PGX piggyback specimens located in peripheral channels of AGC-1........ 37

Table 35. Summary of Grade PPEA piggyback specimens located in peripheral channels of AGC-1...... 37

Table 36. Summary of Grade NBG-25 piggyback specimens located in peripheral channels of AGC-1. . 37

Table 37. Summary of Grade 2020 piggyback specimens located in peripheral channels of AGC-1 ........ 37

Table 38. Summary of Grade PCIB piggyback specimens located in peripheral channels of AGC-1....... 38

Table 39. Summary of Grade BAN piggyback specimens located in peripheral channels of AGC-1........ 38

Table 40. Summary of Grade NBG-10 piggyback specimens located in peripheral channels of AGC-1.. 38

Table 41. Summary of Grade HOPG piggyback specimens located in the central channel of AGC-1...... 38

Table 42. Summary of Grade A3-Matrix piggyback specimens located in the central channel of AGC-1.39

Table 43. Summary of Grade HLM piggyback specimens located in the central channel of AGC-1 ....... 40

Table 44. Summary of Grade PGX piggyback specimens located in the central channel of AGC-1........ 40

Table 45. Summary of Grade PPEA piggyback specimens located in the central channel of AGC-1...... 41

Table 46. Summary of Grade NBG-25 piggyback specimens located in the central channel of AGC-1 ... 41

Table 47. Summary of Grade 2020 piggyback specimens located in the central channel of AGC-1........ 42

Table 48. Summary of Grade PCIB piggyback specimens located in the central channel of AGC-1....... 43

Table 49. Summary of Grade BAN piggyback specimens located in the central channel of AGC-1....... 43

Table 50. Summary of Grade NBG-10 piggyback specimens located in the central channel of AGC-1... 44

Table 51. Location and dose of the SiC temperature monitors in the central channel of AGC-1............. 45

Table 52. Graphite grade marking codes to be used for the AGC series of experiments........................ 46 


\section{ACRONYMS}

\begin{tabular}{|c|c|}
\hline AFCI & Advanced Fuel Cycle Initiative \\
\hline $\mathrm{AG}$ & against grain \\
\hline AGC & ATR Graphite Creep \\
\hline ASME & American Society of Mechanical Engineers \\
\hline ASTM & American Society for Testing and Materials \\
\hline ATR & advanced test reactor \\
\hline dpa & displacements per atom \\
\hline GA & General Atomics \\
\hline HOPG & highly oriented pyrolytic graphite \\
\hline INL & Idaho National Laboratory \\
\hline JAERI & Japan Atomic Energy Research Institute \\
\hline MNCP & Monte Carlo N-Particle Transport Code \\
\hline NGNP & Next Generation Nuclear Plant \\
\hline $\mathrm{OC}$ & ORNL-creep \\
\hline ORNL & Oak Ridge National Laboratory \\
\hline PBR & Pebble Bed Reactor \\
\hline PBMR & Pebble Bed Modular Reactor \\
\hline PIE & postirradiation examination \\
\hline $\mathrm{SiC}$ & silicon carbide \\
\hline VHTR & very high temperature reactor \\
\hline WG & with grain \\
\hline XRD & X-ray diffraction \\
\hline
\end{tabular}


This page intentionally left blank. 


\section{AGC-1 Experimental Plan and Design Report}

\section{OBJECTIVES}

The of irradiation capsule Advanced Test Reactor (ATR) Graphite Creep-1 (AGC-1) provides irradiation creep design data and data for the effects of irradiation creep on key physical properties for several candidate graphites for the Next Generation Nuclear Plant (NGNP) program. It further provides design data for the effects of neutron irradiation on the properties of a range of NGNP relevant graphites, with such data to include: dimensional changes, strength, elastic modulus, thermal conductivity, and coefficient of thermal expansion. Moreover, this experiment will provide valuable data on the singlecrystal irradiation behavior of graphites to be derived from the inclusion of highly oriented pyrolytic graphite (HOPG) in this experiment. 


\section{INTRODUCTION}

AGC-1 is one of a series of ATR irradiation creep capsules designed to provide graphite irradiation creep data for NGNP relevant graphites. The AGC-1 capsule provides design data on the effects of irradiation on NGNP relevant graphites over the neutron dose range $0.53 \times 10^{21} \mathrm{n} / \mathrm{cm}^{2}-5.8 \times 10^{21} \mathrm{n} / \mathrm{cm}^{2}$ [E $>0.1 \mathrm{MeV}]$, or 0.39-4.2 displacements per atom (dpa), at an irradiation temperature of $900^{\circ} \mathrm{C}$. Additional advanced graphite reactor (AGR) capsules are planned for irradiations at 600 and $1200^{\circ} \mathrm{C}$ to provide design data over the anticipated graphite in-reactor operating temperature.

The data to be obtained from this irradiation capsule include:

- Irradiation creep design data and data on the effects of irradiation creep on key physical properties (e.g., strength, elastic modulus, coefficient of thermal expansion) needed for design, accident analysis, and licensing for the selected NGNP reactor technology.

- The effects of neutron irradiation on the properties of a wide range of NGNP relevant graphites, including dimensional changes, strength, elastic modulus, thermal conductivity, and coefficient of thermal expansion on extruded, iso-molded, and vibrationally molded graphites fabricated from coal and petroleum pitches.

- Data on the single-crystal irradiation behavior of graphites to be derived from HOPG.

The NGNP has chosen a single graphite grade for each of the reactor concepts proposed for the NGNP. Graphite grade NBG-18 has been selected for the pebble bed reactor design while grade PCEA has been selected for the prismatic reactor design. The graphite grades to be included in the AGC-1 capsule can be categorized as follows.

\section{A. Major Grades}

These graphites are reactor vendor's candidates for the core structures of NGNP, and include four new grades (NBG-17, NBG-18, PCEA, and IG-430) as well as two historical (reference) grades (H-451 and IG-110). These grades are most likely to receive reasonably large neutron doses in their lifetime and will be subjected to significant stresses in operation. Consequently, these grades occupy the stressed and companion unstressed position in the capsule and yield irradiation creep data. These grades provide a comparison between extruded, iso-molded, and vibrationally molded graphites.

B. Minor Grades

These grades are relevant to the NGNP graphite component design by providing irradiation data on different graphite grades. The irradiation information will be used to further the understanding of all graphite irradiation behavior in computational graphite performance models used to predict graphite lifetimes for different grades.

C. Alternate Grades

These grades are chosen to evaluate the difference in irradiation performance between petroleum and coal coke and between extruded and iso-molded grades. The irradiation information will be used to further the understanding of all graphite irradiation behavior in computational graphite performance models used to predict graphite lifetimes for different grades. 
D. Experimental Grades

Two experimental graphites are included in AGC-1 (BAN and A3 matrix). BAN is an experimental grade, secondary coke graphite whose manufacturing process and raw materials are such that it should offer superior irradiation stability. BAN will be studied for future use as well as an analog to recycled graphite. A3 matrix is the blend of graphites and carbonized phenolic resin used as the matrix in the NGNP fuel compact or fuel pebble. Samples of A3 are to be obtained from the Advanced Fuel Cycle Initiative (AFCI) program and will be produced at Oak Ridge National Laboratory (ORNL).

\section{E. Single Crystal Graphite}

The dimensional change behavior of graphite is particularly significant to the behavior of polycrystalline (polygranular) graphites. Therefore, samples of HOPG are included in AGC-1.

A more complete description all the graphite samples included in capsule AGC-1 is given in Sections 4 and 5 of this report.

The AGC-1 irradiation capsule contains six pneumatic pistons that apply a controlled stress to the graphite creep samples accommodated in six peripheral channels of the capsule (see Figure 1). A more detailed description of the capsule may be found in the AGC-1 capsule design report. Two stress levels will be used in AGC-1, 13.8 MPa (2 ksi) and 20.7 MPa (3 ksi). These stress levels were chosen based on: (a) historic norms from experiments performed at ORNL in the 1970s and 1980 $\mathrm{s}^{1}$ and (b) detailed discussions with reactor vendors via the American Society of Mechanical Engineers (ASME) graphite core design project team. In addition, each of the six peripheral channels in AGC-1 contains companion unstressed graphite specimens. The apparent irradiation creep strain may be determined from the difference in the dimensional changes between a stressed and unstressed sample irradiated at the same temperature and to the same neutron damage dose. In addition to the unstressed creep control samples, each peripheral channel contains a number of smaller, so-called "piggyback" samples of Very High Temperature Reactor (VHTR) relevant graphites. These piggyback specimens do not provide irradiation creep data, but do provide valuable physical properties data.

In addition, the center channel of capsule AGC-1 accommodates a large number of piggyback samples as well as silicon carbide ( $\mathrm{SiC})$ temperature monitors. The $\mathrm{SiC}$ temperature monitors provide a post irradiation check on the irradiation temperature and allows for affirmation of the real time temperature data from the capsule thermocouples. Details of the capsule loading plan are given in Section 5 of this Plan. 

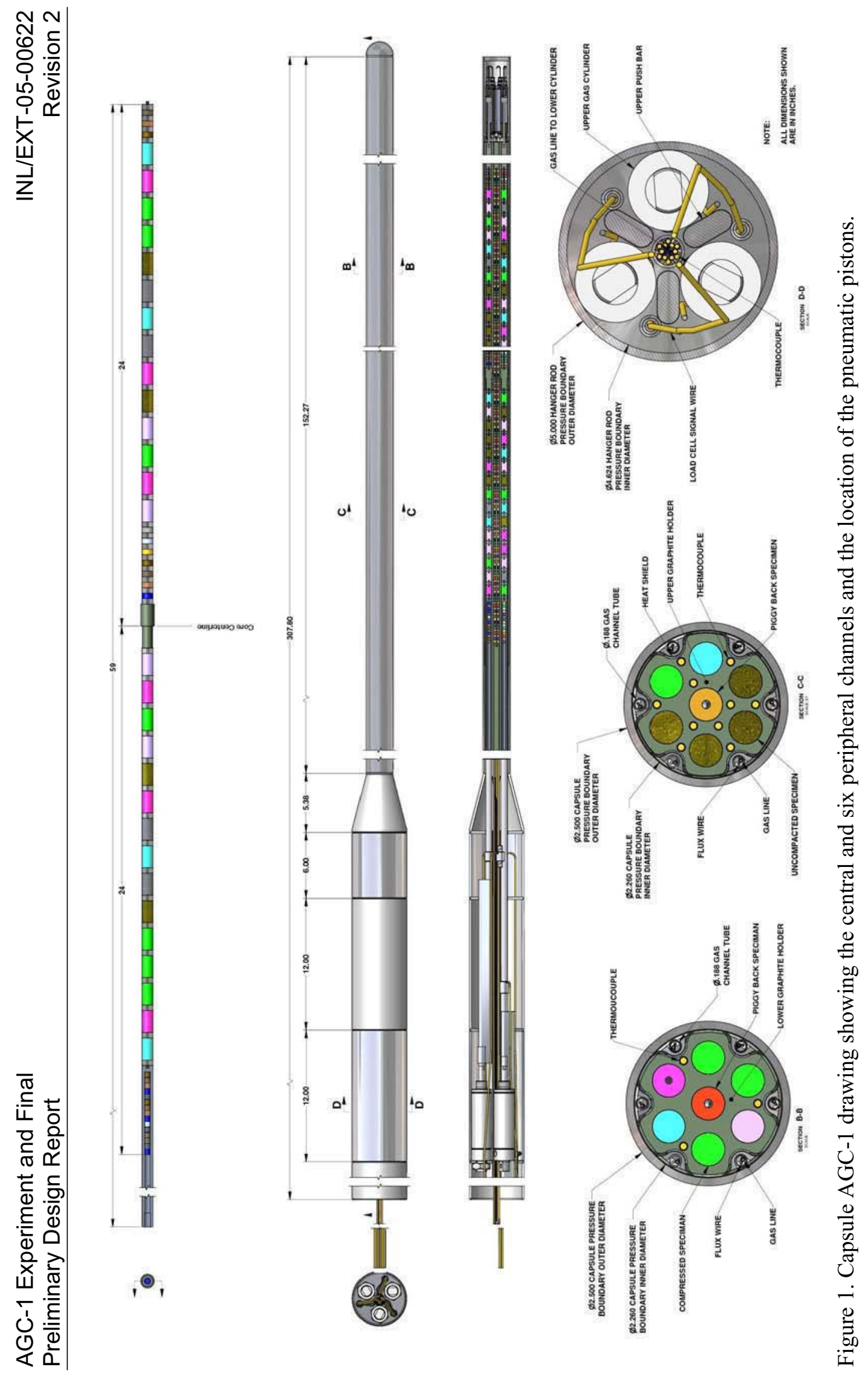


\section{BACKGROUND AND THEORY}

Graphite does not thermally creep at temperature below $\sim 1700^{\circ} \mathrm{C}$. However, graphite subjected to simultaneous neutron irradiation and temperature will creep (i.e., exhibit a nonreversible, time [neutron flux] and temperature dependant strain in response to an applied stress). The conventional definition of irradiation creep strain is the difference in dimensional changes between a stressed sample and an unstressed sample irradiated under identical conditions. Figure 2 shows this graphically. ${ }^{2}$ The mechanism of irradiation creep is thought to be one of irradiation-induced, in-crystal, basal plane dislocation pinning/unpinning. The creep rate is proportional to the rate of atomic displacement, the applied stress, and the unirradiated elastic compliance.

Irradiation-induced creep may be represented by a linear viscoelastic creep equation:

$$
\varepsilon=\frac{\sigma}{E_{0}}+\frac{a \sigma}{E_{0}}[1-\operatorname{Exp}(-b \phi)]+k \sigma \phi
$$

where

$$
\begin{array}{rll}
\varepsilon & = & \text { total strain } \\
\sigma & = & \text { applied uniaxial stress } \\
\mathrm{E}_{0} & = & \text { Initial (preirradiated) Young's Modulus } \\
\phi & = & \text { fast neutron fluence }
\end{array}
$$

$a, b$, and $k$ are creep constants ( $a$ is usually $=1$ ).

The first term represents the elastic strain, the second term the transient or primary irradiation creep strain, and the third term the steady state or secondary irradiation creep strain. Since the experimentally determined creep strain is the result of postirradiation measurements on the unstressed control samples and the stressed samples measured unstressed, the first term in Equation 1can be neglected.

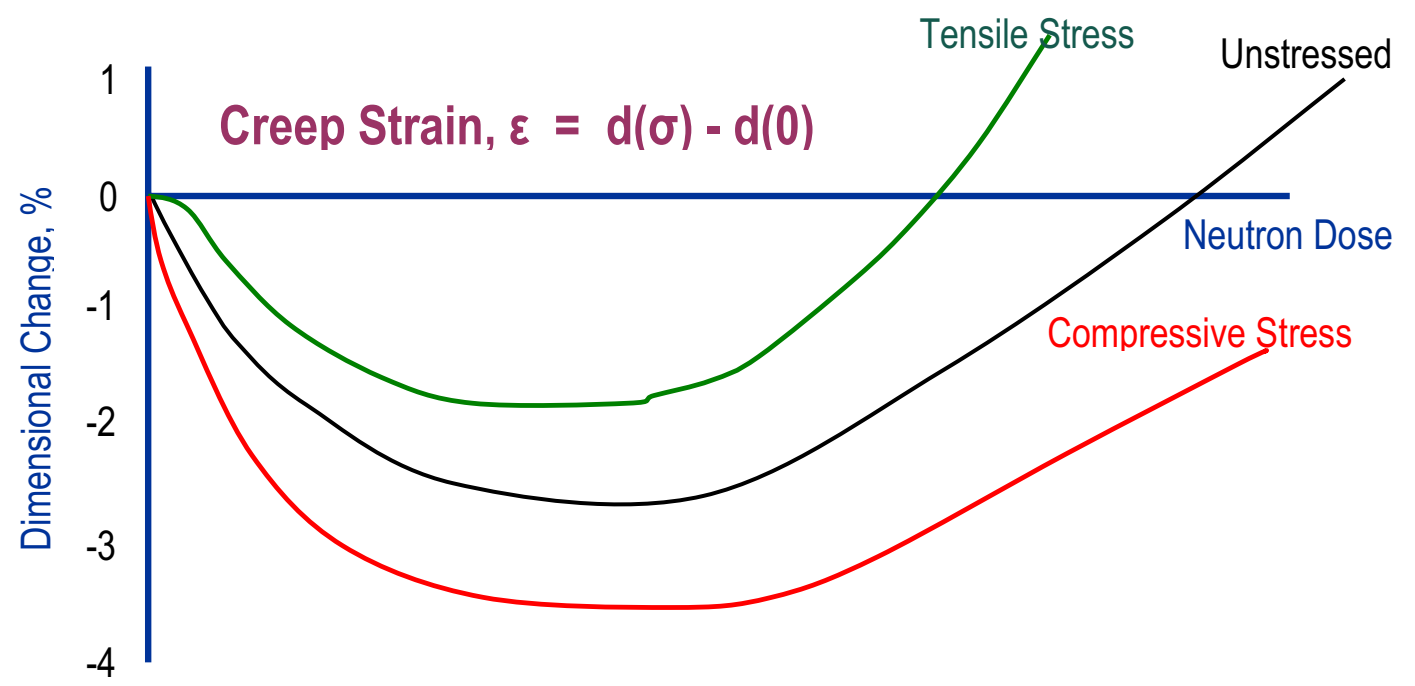

Figure 2. Irradiation-induced dimensional change in stressed and unstressed graphite.

The primary (transient) irradiation creep strain is usually small and is not significant compared to the secondary (steady state) irradiation creep strain, especially at high dose. The second term in Equation 1 
suggests that the transient creep strain saturation value should be approximately one elastic strain (applied uniaxial stress divided by unirradiated Young's Modulus), assuming $a=1$, as is typically found experimentally in low dose creep experiments. ${ }^{3,4}$ Thus, the saturation transient creep value is approximately equal to one elastic strain (Figure 3), and the steady state creep strain is linear with dose passing through zero strain at zero dose (Figure 3). Note that dose is expressed in units of $\mathrm{n} / \mathrm{cm}^{2}[\mathrm{E}>50$ $\mathrm{keV}]$ in this section. The accepted conversion factor is $\mathrm{n} / \mathrm{cm}^{2}[\mathrm{E}>50 \mathrm{keV}]=\mathrm{n} / \mathrm{cm}^{2}[\mathrm{E}>0.1 \mathrm{MeV}] \times 0.932$ [5]. Conversion factors from the popular dose scales to dpa are given elsewhere. ${ }^{5}$

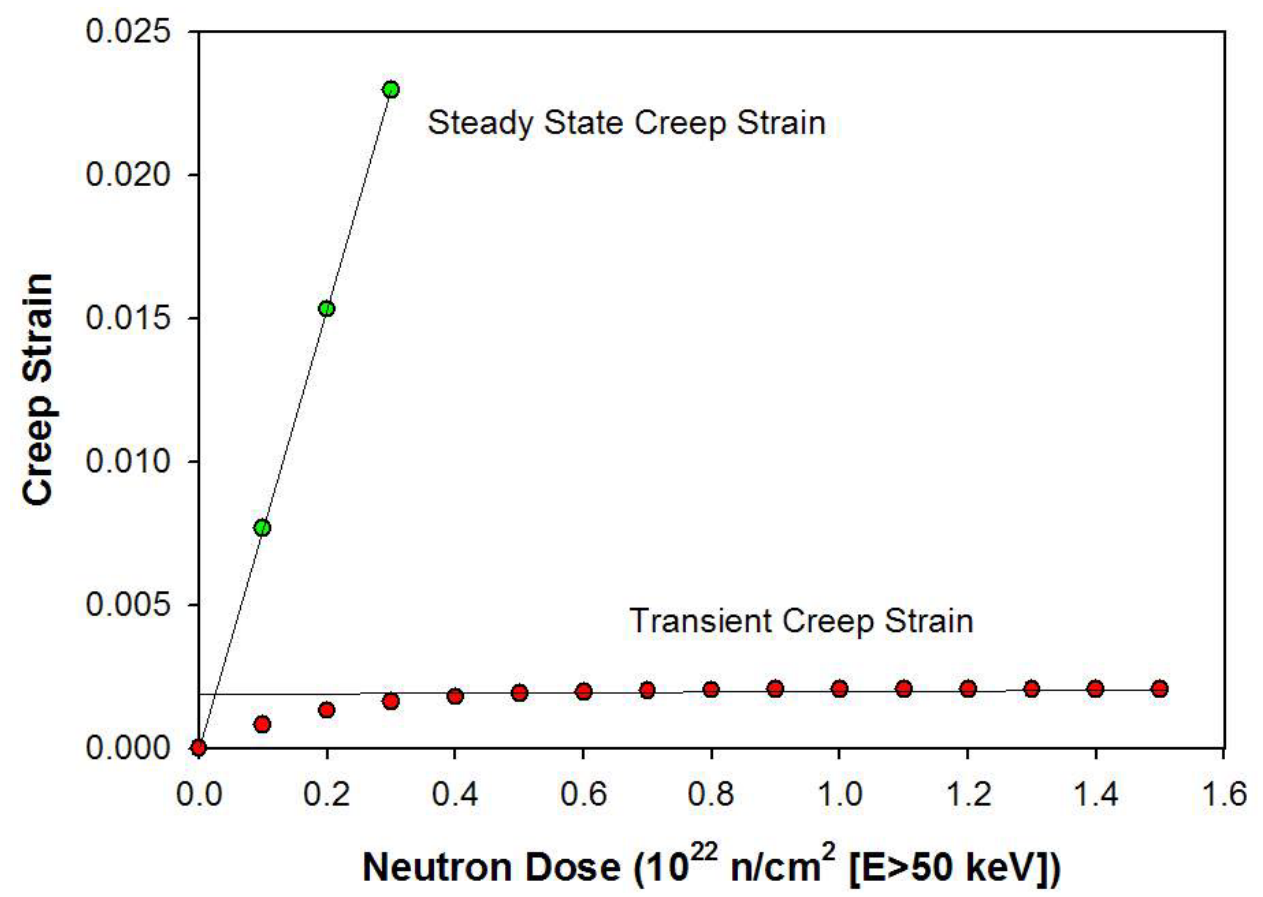

Figure 3. Schematic representations of the transient and steady state creep strains as a function of neutron dose.

The observation that the saturation value of the transient creep strain is approximately equal to the one elastic strain allows a simple linear creep model (Figure 4) of the form:

$$
\varepsilon=\frac{\sigma}{E_{0}}+k^{\prime} \phi
$$

where

$$
\begin{array}{rll}
\varepsilon & = & \text { total irradiation induced creep strain } \\
\sigma & = & \text { applied uniaxial stress } \\
\mathrm{E}_{0} & = & \text { initial (preirradiated) Young's Modulus } \\
\phi & = & \text { fast neutron fluence }
\end{array}
$$

$k^{\prime}$ is the steady state creep coefficient $(k / \sigma)$

In Equation 2 the transient creep strain is given as one elastic strain and the steady state creep strain as $(k \sigma \phi)$ (from Equation 1). 


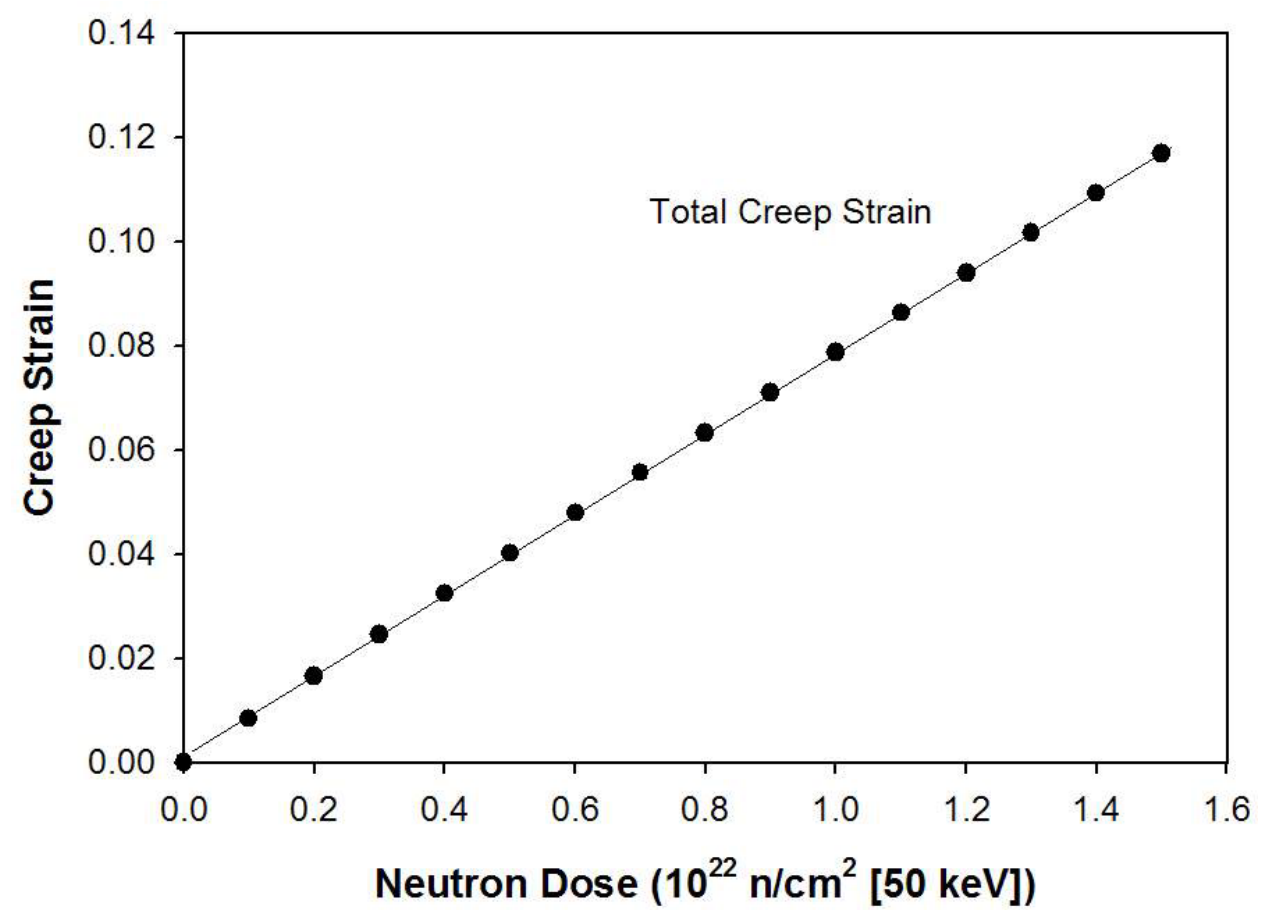

Figure 4. Schematic representation of the total (transient plus steady state) creep strain as a function of neutron dose.

Typical irradiation creep strain data for grade H-451 graphite irradiated in the Oak Ridge Research Reactor at stress levels of 20.7 and $13.8 \mathrm{MPa}$ and at an irradiation temperature of $900^{\circ} \mathrm{C}$ is shown in Figure 5.

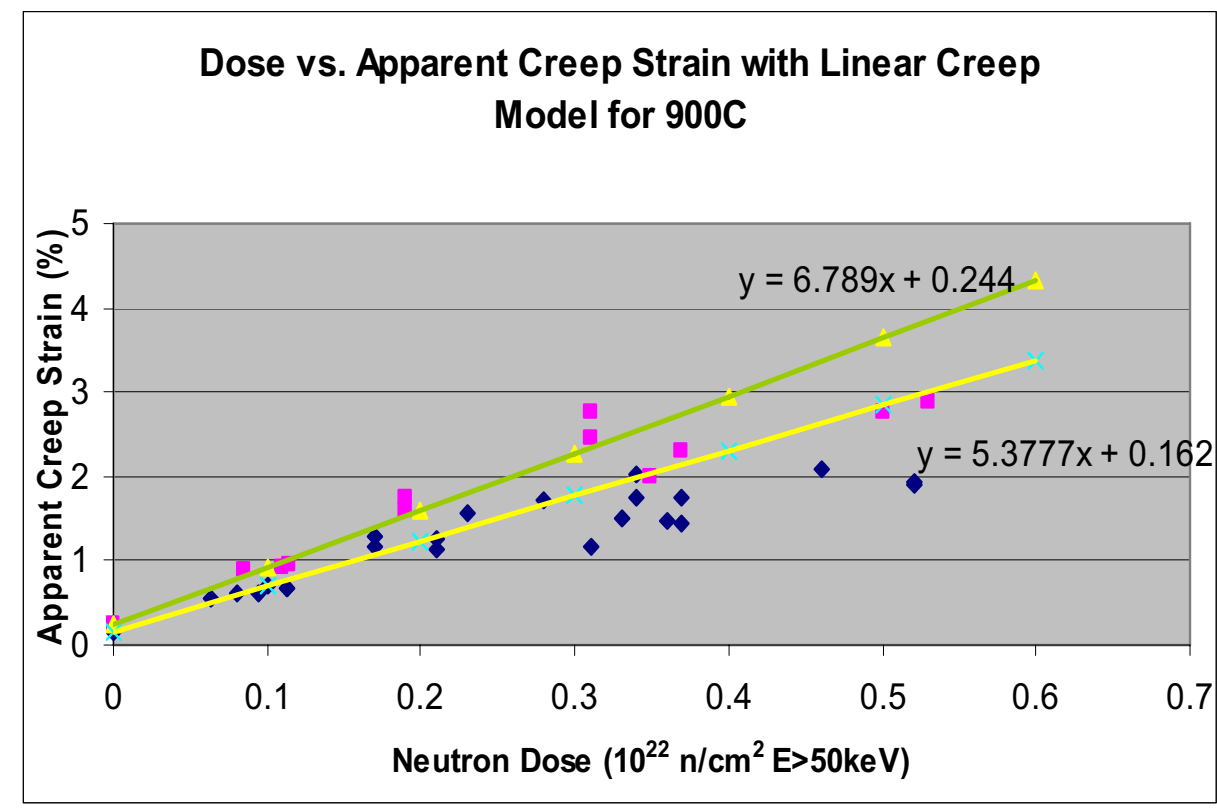

13.8 MPa

$20.7 \mathrm{MPa}$

Linear Creep Model for points 1-7(13.8 MPa)

Linear Creep Model for points 1-7 (20.7 MPa)

Figure 5. Grade H-451 graphite irradiation creep strain as a function of dose at an irradiation temperature of $900^{\circ} \mathrm{C}$ and at two compressive stress levels (13.8 and $\left.20.7 \mathrm{MPa}\right)$. 
The apparent creep strain (measured post irradiation as discussed above) is well represented by the linear model (Equation 2) at moderate doses; but, at higher doses the fit is unsatisfactory. This observation has led to the development of a new creep model in which the apparent creep strain (determined as described above) is corrected to allow for the effect of creep strain on the dimensional change component of the graphite. ${ }^{6}$ Indeed, the current definition of creep that is the difference in length between a stressed and an unstressed control specimen is only correct if the dimensional change component in the stressed specimen is the same as that in the control. ${ }^{7}$ In fact, creep produces significant modifications in the dimensional change component of the stressed sample as compared to that of the control sample, and this should be accounted for in the correct evaluation of creep strain. Actually, the true (corrected) creep strains are always greater than those obtained from the current definition of creep strain.

The rate of change of dimensions with respect to neutron dose $\gamma\left(\mathrm{n} / \mathrm{cm}^{2}\right)$ in appropriate units is given by the Simmons' theory for direction $x$ in the graphite (see Reference 5):

$$
g_{x}=\left(\frac{\alpha_{x}-\alpha_{a}}{\alpha_{c}-\alpha_{a}}\right)\left(\frac{d X_{T}}{d \gamma}\right)+\frac{1}{X_{a}} \cdot \frac{d X_{a}}{d \gamma}
$$

where

$$
\begin{aligned}
& \alpha_{x} \quad=\quad \text { the thermal expansion coefficient in the } x \text {-direction } \\
& \alpha_{c} \text { and } \alpha_{a}=\text { the thermal expansion coefficients of the graphite crystal parallel and } \\
& \text { perpendicular to the hexagonal axis respectively, over the same temperature }
\end{aligned}
$$

The parameters $\left(1 / X_{c}\right)\left(d X_{c} / d \gamma\right)$ and $\left(1 / X_{a}\right)\left(d X_{a} / d \gamma\right)$ are the rates of change of graphite crystallite dimensions parallel and perpendicular to the hexagonal axis, and

$$
\frac{d X_{T}}{d \gamma}=\frac{1}{X_{c}} \cdot \frac{d X_{c}}{d \gamma}-\frac{1}{X_{a}} \cdot \frac{d X_{a}}{d \gamma}
$$

The imposition of a creep strain is known to change the thermal expansion coefficient of a stressed specimen, increasing it for a compressive strain and decreasing it for a tensile strain compared to an unstressed control (see Reference 4). This is illustrated in Figure 6 for $\mathrm{H}-451$ graphite irradiated at $900^{\circ} \mathrm{C}$. Thus, the dimensional change component of a stressed specimen at dose $\gamma\left(\mathrm{n} / \mathrm{cm}^{2}\right)$ is given by:

$$
g_{x}^{\prime}=\left(\frac{\alpha_{x}^{\prime}-\alpha_{a}}{\alpha_{c}-\alpha_{a}}\right)\left(\frac{d X_{T}}{d \gamma}\right)+\frac{1}{X_{a}} * \frac{d X_{a}}{d \gamma}
$$

where

$$
\alpha_{x}^{\prime}=\text { the thermal expansion coefficient of the crept sample. }
$$




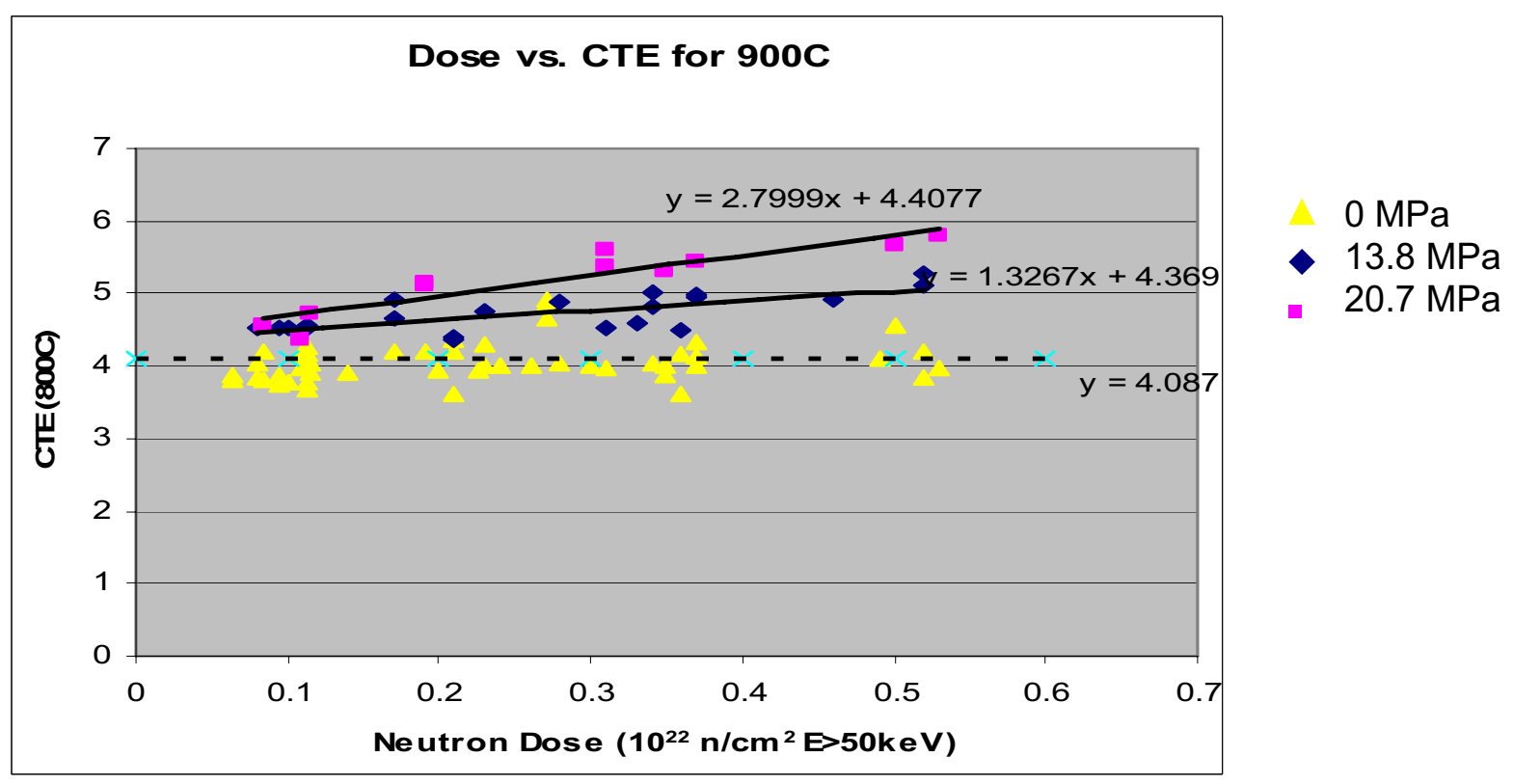

Figure 6. The variation of coefficient of thermal expansion with neutron dose for unstressed and stressed $\mathrm{H}-451$ graphite samples irradiated at $900^{\circ} \mathrm{C}$.

The difference between Equations 3 and 5 is the dimensional change correction that should be applied to the apparent creep strain.

$$
g_{x}^{\prime}-g_{x}=\left(\frac{\alpha_{x}^{\prime}-\alpha_{a}}{\alpha_{c}-\alpha_{a}}\right)\left(\frac{d X_{T}}{d \gamma}\right)-\left(\frac{\alpha_{x}-\alpha_{a}}{\alpha_{c}-\alpha_{a}}\right)\left(\frac{d X_{T}}{d \gamma}\right)=\left(\frac{\alpha_{x}^{\prime}-\alpha_{x}}{\alpha_{c}-\alpha_{a}}\right)\left(\frac{d X_{T}}{d \gamma}\right)
$$

The true creep strain rate can now be expressed as

$$
\frac{d \varepsilon}{d \gamma}=\frac{d \varepsilon^{\prime}}{d \gamma}-\left(\frac{\alpha_{x}^{\prime}-\alpha_{x}}{\alpha_{c}-\alpha_{a}}\right)\left(\frac{d X_{T}}{d \gamma}\right)
$$

where

$\mathrm{E}=$ the true creep strain

$\varepsilon^{\prime}=$ the apparent creep strain determined experimentally in the conventional manner.

Thus the true creep strain $\left(\varepsilon_{\mathrm{c}}\right)$ parallel to the applied creep stress is given by:

$$
\varepsilon_{c}=\varepsilon_{c}^{\prime}-\int_{0}^{\gamma}\left(\frac{\alpha_{x}^{\prime}-\alpha_{x}}{\alpha_{c}-\alpha_{a}}\right)\left(\frac{d X_{T}}{d \gamma}\right) \cdot d \gamma
$$

where

$$
\begin{array}{ll}
\varepsilon_{c}^{\prime} & =\text { the induced apparent creep strain } \\
\left(\alpha_{x}^{\prime}-\alpha_{x}\right)= & \text { the change in coefficient of thermal expansion as a function of dose }
\end{array}
$$




$$
\begin{array}{ll}
\left(\alpha_{c}-\alpha_{a}\right)= & \text { the difference of the crystal thermal expansion coefficients of the graphite } \\
& \text { parallel and perpendicular to the hexagonal axis } \\
\mathrm{X}_{\mathrm{T}} & =\text { the crystal shape change parameter given by Equation } 4, \\
\gamma & \text { the neutron dose. }
\end{array}
$$

Inspection of Equation 8 indicated that the true creep strain is always greater than the apparent (measured) creep strain. For compressive creep loading, the apparent creep strain is negative and $\left(\alpha^{\prime}{ }_{x}-\alpha_{x}\right)$ is positive, so the true creep strain is greater than the apparent creep strain. For tensile creep loading, the apparent creep strain is positive and $\left(\alpha^{\prime}{ }^{-}-\alpha_{x}\right)$ is negative, so the true creep strain is also greater. The parameter, $X_{T}$, is determined from the dimensional change behavior of single-crystal graphite, or its close analogue, HOPG. It can also be determined from the polycrystalline graphite behavior if there is sufficient anisotropy in the irradiation-induced dimensional changes. The parameter, $X_{T}$, is linear with dose at low doses, as shown in Figure 7. The term $\left(\alpha_{c}-\alpha_{a}\right)$ in Equation 8 is the difference between the graphite single-crystal thermal expansion coefficients (unirradiated) and has the value $27 \times 10^{-6 \circ} \mathrm{C}^{-1}$. The application of the correction to the apparent creep strain for $\mathrm{H}-451$ graphite irradiated at $900^{\circ} \mathrm{C}$ is given in Figure 8 . The true creep strain (i.e., the experimentally measured apparent creep strain corrected for in the manner described above) is well represented by the linear creep model (Equation 2). The fit to a linear relationship, with an intercept of one elastic strain is clearly demonstrated and correlation coefficients of 0.9 or better were attained.

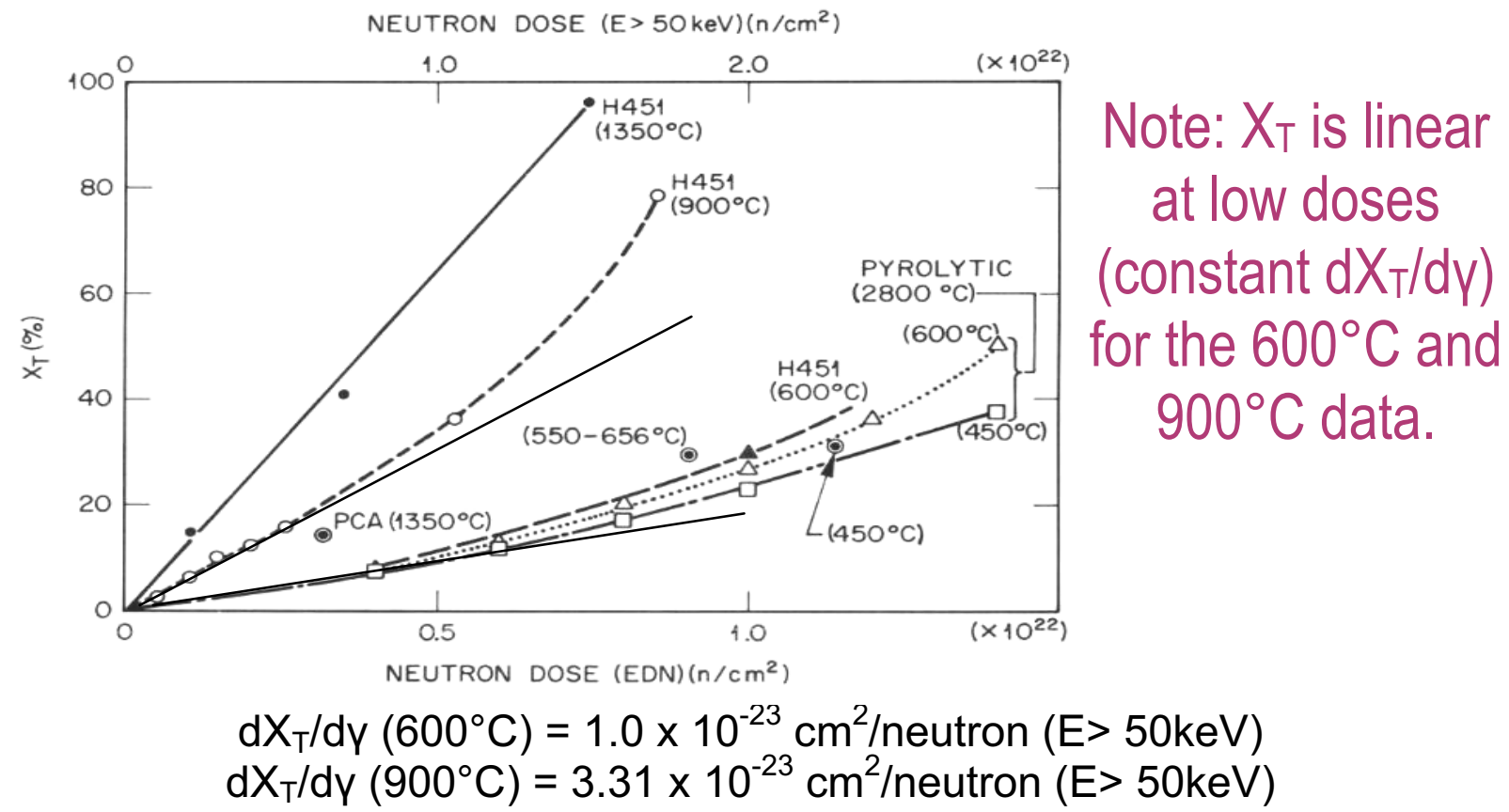

Figure 7. The variation of $X_{T}$ with neutron dose for H-451 graphite at several irradiation temperatures. 


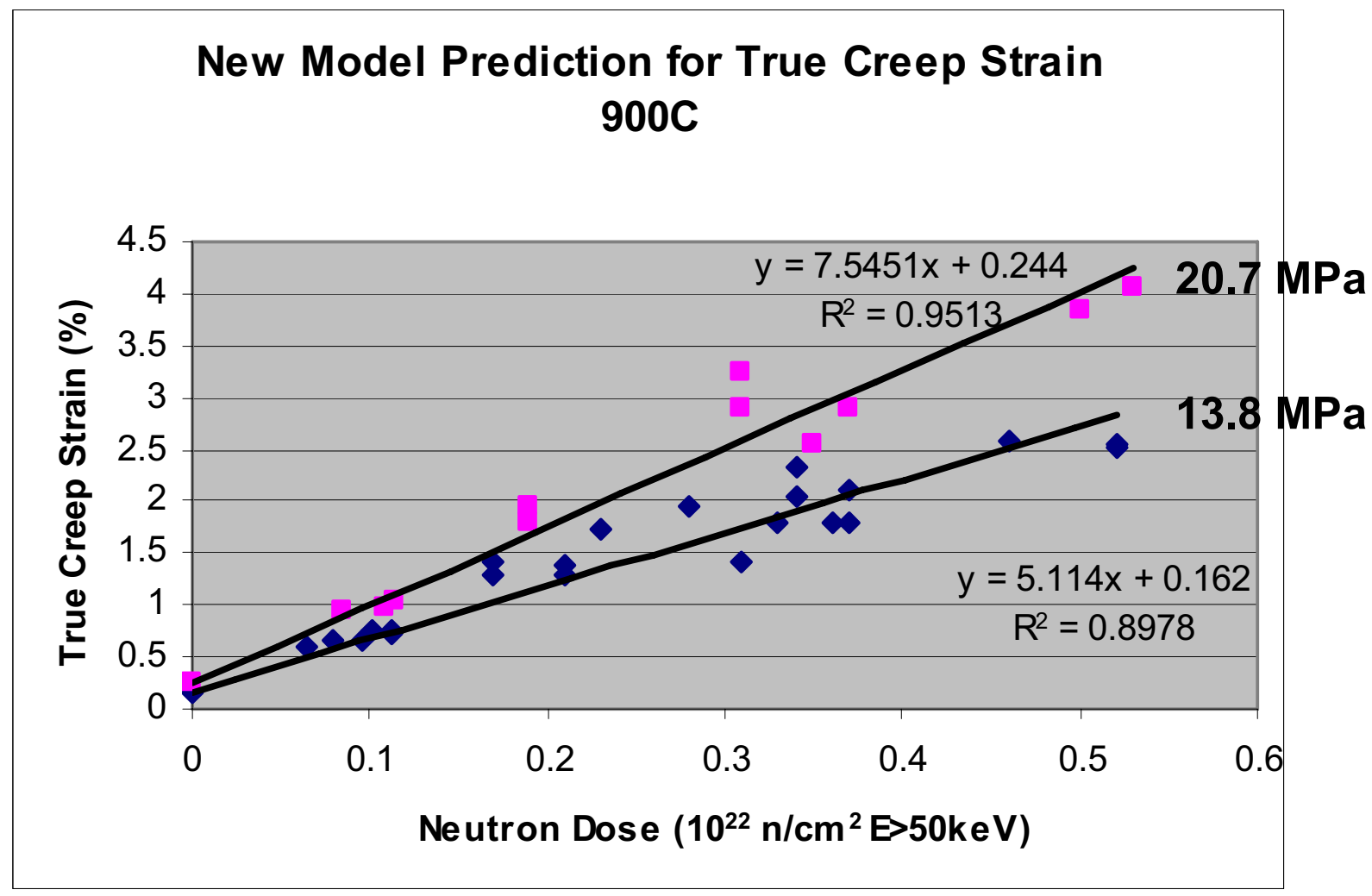

Figure 8. The variation of the true creep strain with neutron dose for $\mathrm{H}-451$ graphite irradiated at $900^{\circ} \mathrm{C}$ and at two stress levels.

Table 1 reports the terms of the linear creep model for true creep strains for $\mathrm{H}-451$ graphite determined from the prior experiments conducted in the Oak Ridge Research Reactor. For any applied compressive stress level the true creep strain in H-451 graphite is given by:

$$
\varepsilon_{\mathrm{c}}=\sigma / \mathrm{E}_{0}+k^{\prime} \sigma \gamma
$$

And from Table 1 at 900 and $600^{\circ} \mathrm{C}$, respectively, the compressive creep strain is given by:

$$
\begin{gathered}
\varepsilon_{\mathrm{c}}=10^{-1} \cdot \sigma / \mathrm{E}_{0}+0.37 \sigma \gamma(\%), \text { and } \\
\varepsilon_{\mathrm{c}}=10^{-1} \cdot \sigma / \mathrm{E}_{0}+0.20 \sigma \gamma(\%)
\end{gathered}
$$

Table 1. Linear creep model terms for H-451 graphite.

\begin{tabular}{|c|c|c|c|c|}
\hline $\begin{array}{c}\text { Irradiation } \\
\text { Temperatures }\end{array}$ & $\begin{array}{c}\text { Stress } \\
(\mathrm{MPa})\end{array}$ & $\begin{array}{c}\sigma / \mathrm{E}_{0} \\
(\%)\end{array}$ & $\mathrm{k}$ & $\begin{array}{c}\mathrm{k} \\
(\mathrm{k} / \sigma) \\
10^{-29} \mathrm{~cm}^{2} / \mathrm{n} . \mathrm{Pa}\end{array}$ \\
\hline $900^{\circ}$ & 13.8 & 0.162 & 5.114 & 0.37 \\
\hline $900^{\circ}$ & 20.7 & 0.244 & 7.545 & 0.37 \\
\hline $600^{\circ}$ & 13.8 & 0.162 & 2.748 & 0.20 \\
\hline $600^{\circ}$ & 20.7 & 0.244 & 4.164 & 0.20 \\
\hline
\end{tabular}


To apply the correction to the experimentally observed (apparent) creep strain data, the effects of neutron dose on $X_{T}$ and the thermal expansion coefficients (of the stressed specimens and the unstressed control specimens) must be determined. Consequently, the AGC series of experiments will contain graphite samples of sufficient size to allow the determination of the coefficients of thermal expansion and samples of HOPG to yield direct data for the effects of neutron dose on $X_{T}$.

Finally, the proper definition of creep strain (i.e., true creep strain) is "the difference in dimensions between a stressed sample and a sample with the same properties as the stressed sample irradiated unstressed." 


\section{MATERIALS AND TEST CONDITIONS}

\subsection{Graphite grades}

The graphites to be included in AGC-1 are given in Table 2 along with information on their potential application in an NGNP. Creep data will be obtained for six major graphite grades (i.e., both stressed and unstressed samples of these grades are included in the capsule). The major grades are H-451 and IG-110, both of which are included as reference graphites, and four new grades: PCEA, NBG-17, NBG-18, and IG-430. These four graphites are all contenders for use in potential NGNP designs, such as the Pebble Bed Modular Reactor (PBMR), or prismatic block reactors, such as the General Atomics' design Gas Turbine Modular Helium Reactor or Framatome/AREVA's prismatic reactor design. In addition, AGC-1 contains ten minor grades of graphite. These minor grades are not located in the stressed section of the capsule. Thus, no creep data will be generated for them. However, as previously discussed, they will subsequently yield significant amounts of design data. The minor grades include candidates for lower dose locations in the prismatic reactor designs. The prismatic reactor designs include permanent reflectors and core supports components, such as grades HLM, PGX, PCIB, NBG-25, and 2020. Three additional grades of graphite are included in AGC-1 because of their interest to the NGNP program: NBG-10, PPEA, and BAN. Grade NBG-10 is an extruded grade, and its behavior is of interest in comparison with the vibrationally molded grades NBG-17 and -18. Grade PPEA provides a comparison of the performance of identical pitch-coke and petroleum-coke graphites. BAN graphite is an experimental grade that is expected to exhibit superior irradiation behavior. A3 fuel matrix (a graphite filler carbonized resin binder material) is included to yield dimensional change and physical property data for the AFCI research program. Finally, samples of HOPG are included to provide vital data on the crystal dimensional change rates and, hence, the parameter $X_{T}$. Capsule AGC-1 graphite grades, vendors, and available processing information are given in Table 3.

Table 2. Experiment AGC-1 graphite materials test matrix.

\begin{tabular}{|c|c|c|c|c|}
\hline Graphite & $\begin{array}{l}\text { Reactor } \\
\text { Vendor }\end{array}$ & Proposed Use & $\begin{array}{l}\text { Capsule } \\
\text { Location }\end{array}$ & Remarks \\
\hline H-451 & $\begin{array}{l}\text { General } \\
\text { Atomics }\end{array}$ & $\begin{array}{l}\text { Prismatic fuel element and } \\
\text { replaceable reflector }\end{array}$ & Creep & $\begin{array}{l}\text { Historical reference } \\
\text { Only a few samples }\end{array}$ \\
\hline IG-110 & $\begin{array}{l}\text { JAERI, } \\
\text { INET }\end{array}$ & $\begin{array}{l}\text { Prismatic fuel element, } \\
\text { replaceable reflector, and core } \\
\text { support pedestals } \\
\text { Pebble bed reflector }\end{array}$ & Creep & $\begin{array}{l}\text { Historical reference } \\
\text { Only a few samples } \\
\text { Currently being used in the } \\
\text { HTTR and HTR-10 }\end{array}$ \\
\hline PCEA & AREVA & $\begin{array}{l}\text { Prismatic fuel and replaceable } \\
\text { block }\end{array}$ & Creep & $\begin{array}{l}\text { AREVA wants to construct } \\
\text { the entire graphite core out of } \\
\text { the same graphite }\end{array}$ \\
\hline NBG-18 & $\begin{array}{l}\text { PBMR } \\
\text { AREVA }\end{array}$ & $\begin{array}{l}\text { Pebble bed reflector structure } \\
\text { and insulation blocks } \\
\text { Prismatic fuel element and } \\
\text { replaceable reflector }\end{array}$ & Creep & $\begin{array}{l}\text { Candidate for PBMR } \\
\text { replaceable reflector }\end{array}$ \\
\hline NBG-17 & $\begin{array}{l}\text { AREVA } \\
\text { PBMR }\end{array}$ & $\begin{array}{l}\text { Prismatic fuel element and } \\
\text { replaceable reflector } \\
\text { Pebble bed reflector structure } \\
\text { and insulation blocks }\end{array}$ & Creep & $\begin{array}{l}\text { AREVA wants to construct } \\
\text { the entire graphite core out of } \\
\text { the same graphite } \\
\text { NBG-17 is finer grain than } \\
\text { NBG-18 }\end{array}$ \\
\hline
\end{tabular}


Table 2 (cont.)

\begin{tabular}{|c|c|c|c|c|}
\hline Graphite & $\begin{array}{l}\text { Reactor } \\
\text { Vendor }\end{array}$ & Proposed Use & $\begin{array}{l}\text { Capsule } \\
\text { Location }\end{array}$ & Remarks \\
\hline IG-430 & JAERI & $\begin{array}{l}\text { Prismatic fuel element, } \\
\text { replaceable reflector, and core } \\
\text { support pedestals }\end{array}$ & Creep & $\begin{array}{l}\text { JAERI wants to use this } \\
\text { graphite in the GTHTR } 300\end{array}$ \\
\hline HLM & & $\begin{array}{l}\text { Prismatic large permanent } \\
\text { reflector }\end{array}$ & Piggyback & $\begin{array}{l}\text { Fort St. Vrain permanent } \\
\text { reflector. Similar to PGX }\end{array}$ \\
\hline PGX & $\begin{array}{l}\text { AREVA } \\
\text { JAERI }\end{array}$ & $\begin{array}{l}\text { Prismatic large permanent } \\
\text { reflector }\end{array}$ & Piggyback & $\begin{array}{l}\text { AREVA may use this } \\
\text { material; preference is to use } \\
\text { PCEA or NBG-17 for } \\
\text { permanent reflector. HTTR } \\
\text { permanent structure. }\end{array}$ \\
\hline NBG-25 & & Core support candidate & Piggyback & Isostatic fine grain \\
\hline 2020 & & $\begin{array}{l}\text { Prismatic core support } \\
\text { pedestals and blocks }\end{array}$ & Piggyback & $\begin{array}{l}\text { Fine grain isotropic } \\
\text { NPR candidate material }\end{array}$ \\
\hline PCIB & & Core support candidate & Piggyback & Fine grain isotropic \\
\hline BAN & & & Piggyback & $\begin{array}{l}\text { Experimental graphite with } \\
\text { potentially superior } \\
\text { irradiation life }\end{array}$ \\
\hline NBG-10 & PBMR & $\begin{array}{l}\text { Prismatic fuel element and } \\
\text { replaceable reflector } \\
\text { Pebble bed reflector structure } \\
\text { and insulation blocks }\end{array}$ & Piggyback & $\begin{array}{l}\text { PBMR's original choice for } \\
\text { replaceable reflector } \\
\text { Price/performance will be the } \\
\text { basis between NBG-18 and } \\
\text { NBG-10 }\end{array}$ \\
\hline PPEA & & $\begin{array}{l}\text { Needed to provide comparison } \\
\text { with PCEA }\end{array}$ & Piggyback & $\begin{array}{l}\text { Provides direct comparison of } \\
\text { pitch coke and petroleum } \\
\text { coke graphite performance }\end{array}$ \\
\hline HOPG & & $\begin{array}{l}\text { Needed to determine change in } \\
\text { crystalline structure }\end{array}$ & Piggyback & $\begin{array}{l}\text { Provides insight to single } \\
\text { crystal changes during } \\
\text { neutron irradiation }\end{array}$ \\
\hline $\begin{array}{l}\text { A3 } \\
\text { Matrix }\end{array}$ & & $\begin{array}{l}\text { Needed to determine fuel } \\
\text { compact irradiated material } \\
\text { behavior }\end{array}$ & Piggyback & $\begin{array}{l}\text { Provides dimensional change } \\
\text { and thermal conductivity data } \\
\text { for matrix materials }\end{array}$ \\
\hline
\end{tabular}

Table 3. Capsule AGC-1 graphite grades, vendors, and available processing information.

\begin{tabular}{|l|l|l|l|}
\hline \multicolumn{1}{|c|}{ Graphite Grade } & \multicolumn{1}{|c|}{ Source } & \multicolumn{1}{c|}{$\begin{array}{c}\text { Country of } \\
\text { Origin }\end{array}$} & \multicolumn{1}{|c|}{ Process Details } \\
\hline NBG-17 & SGL Carbon & Germany/France & $\begin{array}{l}\text { Pitch coke, vibrationally molded, } \\
\text { medium grain }\end{array}$ \\
\hline NBG-18 & SGL Carbon & Germany/France & $\begin{array}{l}\text { Pitch coke, vibrationally molded, } \\
\text { medium grain }\end{array}$ \\
\hline $\begin{array}{l}\text { H-451 (Reference } \\
\text { Grade) }\end{array}$ & SGL Carbon & USA & $\begin{array}{l}\text { Petroleum coke, extruded, medium } \\
\text { grain }\end{array}$ \\
\hline
\end{tabular}


Table 3 (cont.)

\begin{tabular}{|c|c|c|c|}
\hline Graphite Grade & Source & $\begin{array}{c}\text { Country of } \\
\text { Origin }\end{array}$ & Process Details \\
\hline PCEA & $\begin{array}{l}\text { Graftech } \\
\text { International }\end{array}$ & USA & $\begin{array}{l}\text { Petroleum coke, extruded, medium } \\
\text { grain }\end{array}$ \\
\hline $\begin{array}{l}\text { IG-110 (Reference } \\
\text { Grade) }\end{array}$ & Toyo Tanso & Japan & $\begin{array}{l}\text { Petroleum coke, isostatically molded, } \\
\text { fine grain }\end{array}$ \\
\hline IG-430 & Toyo Tanso & Japan & $\begin{array}{l}\text { Petroleum coke, isostatically molded, } \\
\text { fine grain }\end{array}$ \\
\hline $\begin{array}{l}\text { Highly Oriented } \\
\text { Pyrolytic Graphite }\end{array}$ & Advanced Ceramics & USA & $\begin{array}{l}\text { Gas phase deposition, high } \\
\text { temperature annealed }\end{array}$ \\
\hline $\begin{array}{l}\text { A3 Matrix } \\
\text { Graphite/Carbon }\end{array}$ & ORNL & USA & $\begin{array}{l}\text { Blend of natural flake and } \\
\text { manufactured graphite powders, } \\
\text { phenolic resin bonded, hot pressed } \\
\text { and carbonized }\end{array}$ \\
\hline HLM & SGL Carbon & USA & $\begin{array}{l}\text { Petroleum coke, extruded, medium } \\
\text { grain }\end{array}$ \\
\hline PGX & $\begin{array}{l}\text { GrafTech } \\
\text { International }\end{array}$ & USA & $\begin{array}{l}\text { Petroleum coke, molded, medium } \\
\text { grain }\end{array}$ \\
\hline PPEA & $\begin{array}{l}\text { GrafTech } \\
\text { International }\end{array}$ & USA & Pitch coke, extruded, medium grain \\
\hline NBG-25 & SGL Carbon & Germany/France & Isostatically molded, fine grained \\
\hline 2020 & $\begin{array}{l}\text { Carbone of } \\
\text { America }\end{array}$ & USA & Isostatically molded, fine grained \\
\hline PCIB & $\begin{array}{l}\text { GrafTech } \\
\text { International }\end{array}$ & USA & $\begin{array}{l}\text { Petroleum coke, isostatically molded, } \\
\text { fine grained }\end{array}$ \\
\hline BAN & $\begin{array}{l}\text { GrafTech } \\
\text { International }\end{array}$ & USA & $\begin{array}{l}\text { Petroleum (needle) coke, } \\
\text { secondary/green coke process, } \\
\text { extruded, medium grain }\end{array}$ \\
\hline NBG-10 & SGL Carbon & France & Pitch coke, extruded, medium grain \\
\hline
\end{tabular}

Tables 4 through 6 report the numbers of major (stressed/unstressed creep) samples and minor (piggyback) samples per grade in the AGC-1 capsule. Details of the locations of these specimens are given in Section 5.

Table 4. Graphite grades and the number of samples included in the central channel of irradiation capsule AGC-1.

\begin{tabular}{|l|l|c|}
\hline \multicolumn{1}{|c|}{ Graphite Grade } & \multicolumn{1}{c|}{ Source } & \multicolumn{1}{c|}{$\begin{array}{c}\text { Number of Central } \\
\text { Column Samples }\end{array}$} \\
\hline Highly Oriented Pyrolytic Graphite (HOPG) & Advanced Ceramics & 20 \\
\hline A3 Matrix Graphite/Carbon & ORNL & 20 \\
\hline HLM & SGL Carbon & 19 \\
\hline PGX & Graftech International & 19 \\
\hline PPEA & Graftech International & 19 \\
\hline NBG-25 & SGL Carbon & 19 \\
\hline
\end{tabular}


Table 4 (cont.)

\begin{tabular}{|l|l|c|}
\hline \multicolumn{1}{|c|}{ Graphite Grade } & \multicolumn{1}{c|}{ Source } & \multicolumn{1}{c|}{$\begin{array}{c}\text { Number of Central } \\
\text { Column Samples }\end{array}$} \\
\hline 2020 & Carbone of America & 19 \\
\hline PCIB & Graftech International & 19 \\
\hline BAN & Graftech International & 19 \\
\hline NBG-10 & SGL Carbon & 19 \\
\hline Total & & 192 \\
\hline
\end{tabular}

Table 5. The number of stressed/unstressed samples and their graphite grades included in the peripheral channels of irradiation capsule AGC-1.

\begin{tabular}{|l|l|c|}
\hline \multicolumn{1}{|c|}{ Graphite Grade } & \multicolumn{1}{c|}{ Source } & \multicolumn{1}{c|}{$\begin{array}{c}\text { Number of } \\
\text { Stressed/Unstressed } \\
\text { Peripheral Column Samples }\end{array}$} \\
\hline NBG-17 & SGL Carbon & 34 \\
\hline NBG-18 & SGL Carbon & 34 \\
\hline H-451 (Reference Grade) & SGL Carbon & 20 \\
\hline PCEA & Graftech International & 34 \\
\hline IG-110 (Reference Grade) & Toyo Tanso & 20 \\
\hline IG-430 & Toyo Tanso & 32 \\
\hline Total & & 174 \\
\hline
\end{tabular}

As reported in Table 5, a total of 40 reference grade specimens will be included in AGC-1 compared to 134 candidate graphite specimens. The reference samples provide a link to historic creep data, thus giving confidence that the capsule has functioned correctly and our experiment has been successful. A sufficient number of reference grade specimens are included to cover the experiment dose range.

Table 6. The number of piggyback samples, and their graphite grades, included in the peripheral channels of irradiation capsule AGC-1.

\begin{tabular}{|l|l|c|}
\hline \multicolumn{1}{|c|}{ Graphite Grade } & \multicolumn{1}{c|}{ Source } & \multicolumn{1}{c|}{$\begin{array}{c}\text { Number of } \\
\text { Peripheral Column Samples }\end{array}$} \\
\hline NBG-17 & SGL Carbon & 20 \\
\hline NBG-18 & SGL Carbon & 20 \\
\hline PCEA & Graftech International & 20 \\
\hline IG-430 & Toyo Tanso & 18 \\
\hline IG-110(Reference Grade) & Toyo Tanso & 9 \\
\hline H-451 (Reference Grade) & SGL Carbon & 9 \\
\hline HOPG & GE Advanced Ceramics & 6 \\
\hline A3 MATRIX & ORNL & 6 \\
\hline HLM & SGL Carbon & 5 \\
\hline PGX & Graftech International & 4 \\
\hline PPEA & Graftech International & 5 \\
\hline
\end{tabular}


Table 6 (cont.)

\begin{tabular}{|l|l|c|}
\hline \multicolumn{1}{|c|}{ Graphite Grade } & \multicolumn{1}{c|}{ Source } & \multicolumn{1}{c|}{$\begin{array}{c}\text { Number of } \\
\text { Peripheral Column Samples }\end{array}$} \\
\hline NBG-25 & SGL Carbon & 5 \\
\hline 2020 & Carbone of America & 5 \\
\hline PCIB & Graftech International & 5 \\
\hline BAN & Graftech International & 9 \\
\hline NBG-10 & SGL Carbon & 4 \\
\hline Total & & 150 \\
\hline
\end{tabular}

\subsection{Test Conditions}

Capsule AGC-1 is the first of a planned series of graphite creep capsules to be irradiated in the ATR. Capsules AGC-1 through AGC-6 are all planned for the south flux trap, and capsules AGC-7 through AGC-9 are tentatively planned for an "A-hole" position in ATR. The A-hole irradiations are very high neutron dose and would only be relevant to a PBMR version of the NGNP. The high dose irradiations (AGC-7 through -9) will be considered at some point in the future when the NGNP concept has been selected. Capsules AGR-1 and 2 will be $900^{\circ} \mathrm{C}$ irradiations, AGR-3 and 4 will be $1200^{\circ} \mathrm{C}$ irradiations, and AGR-5 and 6 will be $600^{\circ} \mathrm{C}$ irradiations. The family of AGR capsules will, therefore, provide graphite irradiation effects data (especially creep data) across the anticipated in-reactor operating range for the candidate graphites discussed here.

Capsule AGC-1 will be irradiated for 170 days to an estimated peak neutron dose (fluence) of $5.8 \times 10^{21} \mathrm{n} / \mathrm{cm}^{2}[\mathrm{E}>0.1 \mathrm{MeV}]$ or 4.2 DPA. Estimated doses have been obtained for the specimens in the capsule from prior ATR dosimetry models. The flux prediction model is a polynomial function of the form.

$$
\text { Flux } \phi=\mathrm{A}+\mathrm{B} x^{2}+\mathrm{C} x^{2}+\mathrm{D} x^{2} \quad\left(\mathrm{n} / \mathrm{cm}^{2} . \mathrm{s}\right)[\mathrm{E}>0.1 \mathrm{MeV}]
$$

where

$$
x=\text { the distance from the reactor core bottom in inches. }
$$

The coefficients A, B, C, and D are given in Table 7 for the center channel and six peripheral channels in the AGC-1 capsule. The flux distributions are graphically shown in Figure 9 for the six peripheral channels and the center channel. The flux center line is not coincident with the core centerline, the flux centerline being located approximately $2 \mathrm{in}$. below the core centerline. Moreover, the flux distribution is not completely symmetrical about its centerline within the ATR core. 
Table 7. ATR south flux trap neutron flux model coefficients.

\begin{tabular}{|l|c|c|c|c|}
\hline \multirow{2}{*}{\multicolumn{1}{c|}{ AGC-1 Channel }} & \multicolumn{4}{c|}{ Flux Model Coefficients } \\
\cline { 2 - 5 } & A & B & C & D \\
\hline Center & 0.7371 & 0.2748 & -0.007253 & 0.00002842 \\
\hline 1-North & 0.8309 & 0.3011 & -0.007991 & 0.00003242 \\
\hline 2-North East & 0.7984 & 0.2893 & -0.007618 & 0.00002927 \\
\hline 3-South East & 0.7244 & 0.2538 & -0.006594 & 0.00002380 \\
\hline 4-South & 0.6613 & 0.2379 & -0.006214 & 0.00002329 \\
\hline 5-South West & 0.7029 & 0.2550 & -0.006588 & 0.00002371 \\
\hline 6-North West & 0.7966 & 2.8318 & -0.007335 & 0.00002679 \\
\hline
\end{tabular}

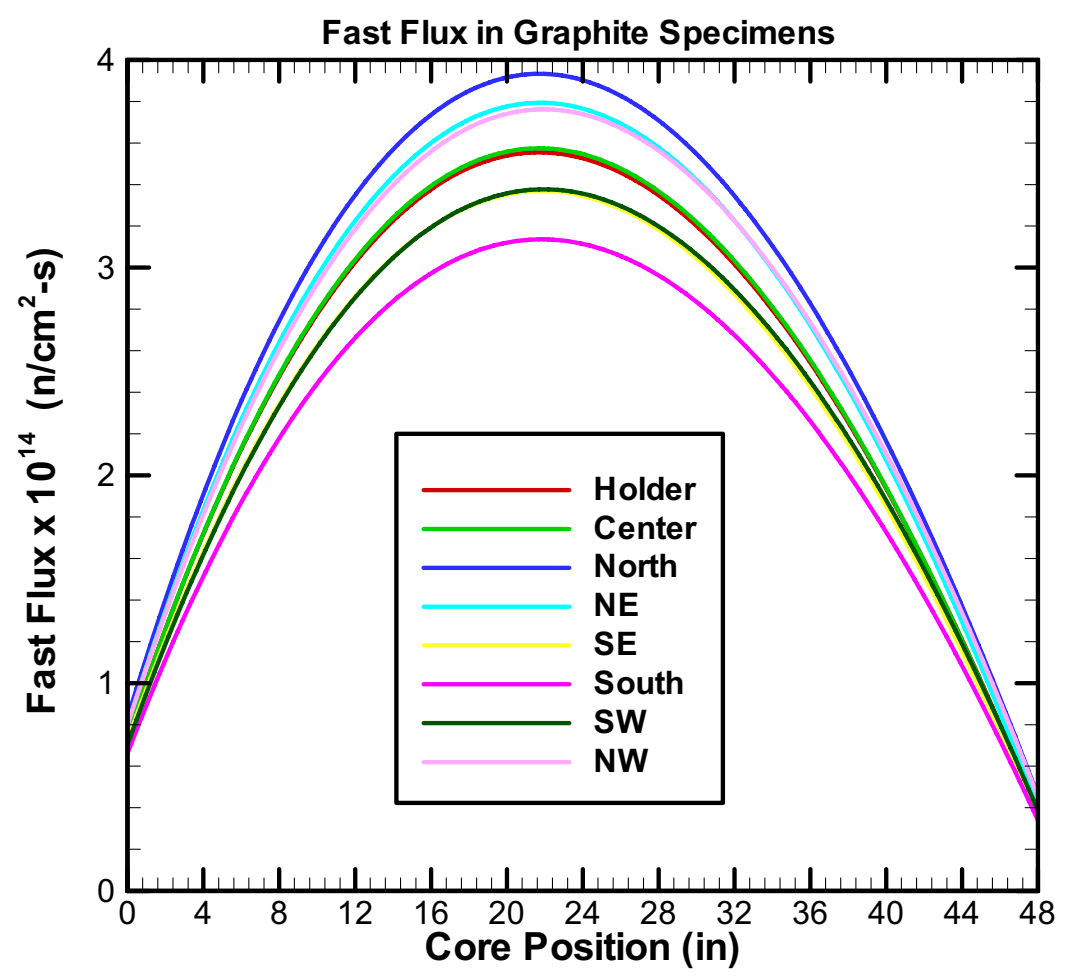

Figure 9. Neutron flux distribution in the AGC capsule channels within the ATR south flux trap.

The AGC-1 experiment will contain a series of flux wires located at intervals throughout the capsule. The postirradiation data from these wires will be used to calibrate the flux models and yield improved dose estimates for each specimen in the capsule.

The planned irradiation temperature for AGC-1 is $900^{\circ} \mathrm{C}$. The capsule will be fully instrumented, containing a sufficient number of thermocouples to allow calibration of the thermal hydraulic code used to estimate the specimen temperatures. In addition, capsule AGC-1 will contain $19 \mathrm{SiC}$ temperature monitors that yield postirradiation estimates of the maximum irradiation temperature attained in the capsule at each $\mathrm{SiC}$ monitor location. 
$\mathrm{SiC}$ has been used as a postirradiation temperature monitor material for more than 40 years. Current usage is based on measurable electrical resistivity changes that occur when the previous maximum irradiation temperature is achieved due to annealing of dangling bonds by mobile point defects. ${ }^{8}$ Thus, a series of isochronal anneals at discrete temperature intervals, followed by determination of the electrical resistivity using a four-point probe technique, yields an estimate of the actual maximum irradiation temperature. As discussed by Snead, et al. (See Reference 6), in experiments that have had both thermocouples and have used $\mathrm{SiC}$ monitors, the agreement between the in situ irradiation temperature and the postirradiation temperature determined for SiC monitors has been good, with indicated differences as small as $20^{\circ} \mathrm{C}$. The $\mathrm{SiC}$ temperature monitors will be rods $44.5 \mathrm{~mm}$ in length and $2 \mathrm{~mm}$ in diameter with a flat ground on one side for ease of the four-point probe resistivity measurement (see Figure 10). The SiC monitors will be located in the central channel of capsule AGC-1 inside the graphite specimen clusters (see Figure 11).

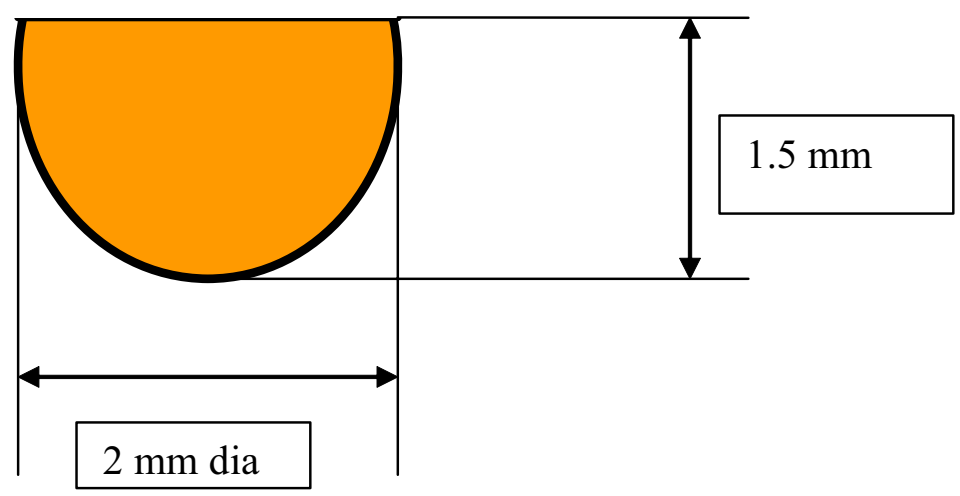

Figure 10. Cross-sectional dimensions of the $\mathrm{SiC}$ temperature monitors to be used in AGC-1.

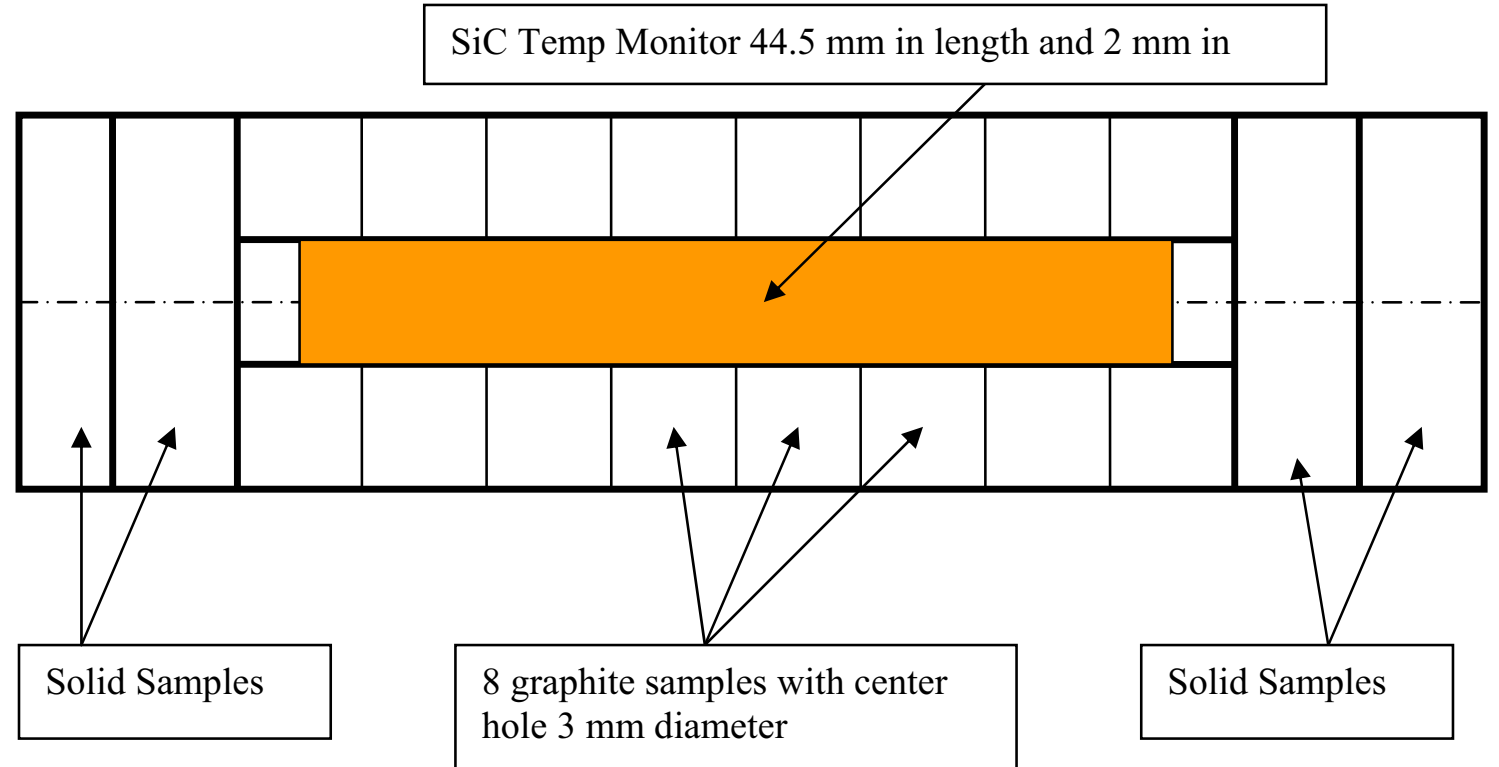

Figure 11. AGC-1 central channel graphite and $\mathrm{SiC}$ sample cluster. 
The stressed samples in the peripheral channels will be subjected to an applied compressive stress by means of a pneumatic piston. The anticipated stress in each channel/specimen stack is given in Table 8 .

Table 8. Stress levels in the stressed samples in the AGC-1 experiment.

\begin{tabular}{|c|c|c|c|}
\hline $\begin{array}{c}\text { Peripheral Channel } \\
\text { Number }\end{array}$ & $\begin{array}{c}\text { Peripheral Channel } \\
\text { Designation }\end{array}$ & $\begin{array}{c}\text { Applied Compressive } \\
\text { Stress } \\
(\mathrm{ksi})\end{array}$ & $\begin{array}{c}\text { Applied Compressive } \\
\text { Stress } \\
(\mathrm{MPa})\end{array}$ \\
\hline 1 & $\mathrm{~N}$ & 3 & 20.7 \\
\hline 2 & $\mathrm{NE}$ & 2 & 13.8 \\
\hline 3 & $\mathrm{SE}$ & 3 & 20.7 \\
\hline 4 & $\mathrm{~S}$ & 2 & 13.8 \\
\hline 5 & $\mathrm{SW}$ & 3 & 20.7 \\
\hline 6 & $\mathrm{NW}$ & 2 & 13.8 \\
\hline
\end{tabular}

The load on each stressed graphite column will be continuously monitored by means of button-load cells located in line with each pneumatic cylinder at the top of the channel. The pressure within each pneumatic piston will be continuously controlled to maintain the design stress level.

Each peripheral channel will have a second pneumatic piston at the bottom of the capsule that is capable of loading the graphite sample stack. Periodically, the load applied by the primary piston will be relaxed, and the graphite specimen stack will be "upset" by loading from the second piston. This procedure will ensure that the graphite stack is not jammed in the channel and that the applied load is actually being transmitted to all the stressed specimens in the channel. This provision is based on prior creep capsule operating history and experience (see Reference 1).

\subsection{Irradiation Specimen Geometries}

Only nominal specimen dimensions are given here because the final dimensions are dependant on the capsule design thermal and mechanical analysis, which has not been completed at this time. Billet cutting plans will be developed for each of the graphites to be included in AGC-1. The cutting plans will take into account spatial variations and anisotropy considerations resulting from graphite forming (textural effects). In addition, the cutting plans will identify a specimen numbering scheme that will ensure a unique identity for each specimen traceable to the grade, billet numbers, and position within the graphite billet. The billet cutting plans will be reported in the AGC-1 preirradiation data report.

\subsubsection{Center Channel Piggyback Samples}

The center channel of AGC-1 is occupied by 19 clusters of graphite samples. Each cluster is made up of eight piggyback samples of nominal diameter 0.5 in. $(12.7 \mathrm{~mm})$ and height 0.25 in. $(6.35 \mathrm{~mm})$. Each of these samples has a central $3 \mathrm{~mm}$ diameter hole into which the $\mathrm{SiC}$ temperature monitor will be inserted (see Figure 10). Each eight-sample cluster has two solid graphite samples [nominal diameter 0.5 in. $(12.7 \mathrm{~mm})$ and height $0.25 \mathrm{in} .(6.35 \mathrm{~mm})]$ located above and below it. The center channel contains a total of 192 samples (Table 4).

\subsubsection{Creep Samples}

The stressed/unstressed graphite creep pairs are of identical geometry (i.e., solid cylinders of nominal length 1.0 in. [25.4 mm] and nominal diameter 0.5 in. [12.7 mm]). 


\subsubsection{Peripheral channel piggyback samples}

The peripheral (creep) channels each contain numerous piggyback specimens. The piggybacks are not stressed. As indicated in Figure 1, the upper section of the peripheral channels contain a hollow graphite thimble within which are located 15 solid graphite specimens of nominal thickness $0.5 \mathrm{in}$. $(12.7 \mathrm{~mm})$. The diameter of these specimens is as yet undetermined. An additional ten piggyback specimens are located in the lower portion of each peripheral (creep) channel above and below the unstressed companion specimens. These specimens have nominal dimensions of 0.5 in. $(12.7 \mathrm{~mm})$ in diameter and 0.25 in. $(6.35 \mathrm{~mm})$ in height. 


\section{AGC-1 Capsule Layout}

As previously discussed, the prime objective of experiment AGC-1 is to provide irradiation creep rate data. This requires matched pairs of stressed and unstressed samples to be irradiated. In previous experiments (see Reference 1), this has been achieved by having stressed and unstressed samples in adjacent channels within the capsule. However, the unique design and operational characteristics of the ATR cause a significant transverse flux gradient across the capsule, thus precluding the adjacent channel design. Therefore, the AGC series will have the matched specimens within each channel (i.e., the stressed specimens above the core centerline and the unstressed specimens below the core centerline in each channel). A further complication to this approach is the non-symmetrical flux distribution and the offset of the flux and core centerlines (see Figure 9). Consequently, the layout of the stressed and unstressed specimens is not symmetrical. In fact, there are fifteen stressed specimens above the core center plug and fourteen unstressed specimens below the core center plug, but further offset by a short stack of piggyback specimens. One of the unstressed samples (Number U11) serves as the unstressed companion to two of the stressed samples (S11 and S12) in each channel. The irradiation samples (and hence graphite grades) are distributed throughout the peripheral channels in the AGC-1 capsule. This is so the failure of any one of the channels will not jeopardize the entire data set for any single graphite grade.

Channel loading plans are given for each of the six peripheral (creep) channels and the center channel in the Appendixes A thourgh G. The peripheral channel specimens are numbered from the reactor top downward such that piggyback sample 1 (PB1) is at the top of each channel and piggyback sample 25 (PB25) is at the bottom of each channel. The 15 piggyback specimens in the top of each peripheral channel are located inside a graphite thimble that is part of the push rod assembly. The channels are numbered clockwise one through six, corresponding to the N, NE, SE, S, SW, and NW channel designations, respectively. Each channel loading plan gives:

- The specimens location within the channel

- The grade of graphite

- The specimens unique identification number (this will be laser engraved on the specimen)

- The nominal length and diameter of the specimen

- The cumulative specimen stack distance from the core bottom

- The samples centerline distance from the core bottom (used in the calculation of the estimated specimen dose)

- The calculated fast flux (from Equation 11)

- The specimens estimated neutron damage dose in $\mathrm{n} / \mathrm{cm}^{2}[\mathrm{E}>0.1 \mathrm{MeV}]$ and dpa.

The final column in the peripheral (creep) channel loading plans indicates which stressed and unstressed specimens are paired (companion specimens). The center stack loading plan is identical in layout with the exception that the last column indicates which piggyback samples have a SiC temperature monitor inserted in their center. The loading plans are color coded for ease of interpretation. The peripheral channel piggyback samples are colored blue, stressed and unstressed creep samples are colored pink, the core center plug is colored red, and the graphite spacers are colored white. The center channel loading plan has the specimen clusters colored tan and the end pair piggyback samples colored pink.

Figures 12 through 18 provide a visual representation of each channel/specimen stack in the AGC-1 capsule. The specimens and their graphite grade are represented by bars, the heights of which are equal to the estimated total dose in dpa. The widths of the bars are representative of the specimen height, and the bars are color coded to identify the graphite grade. 


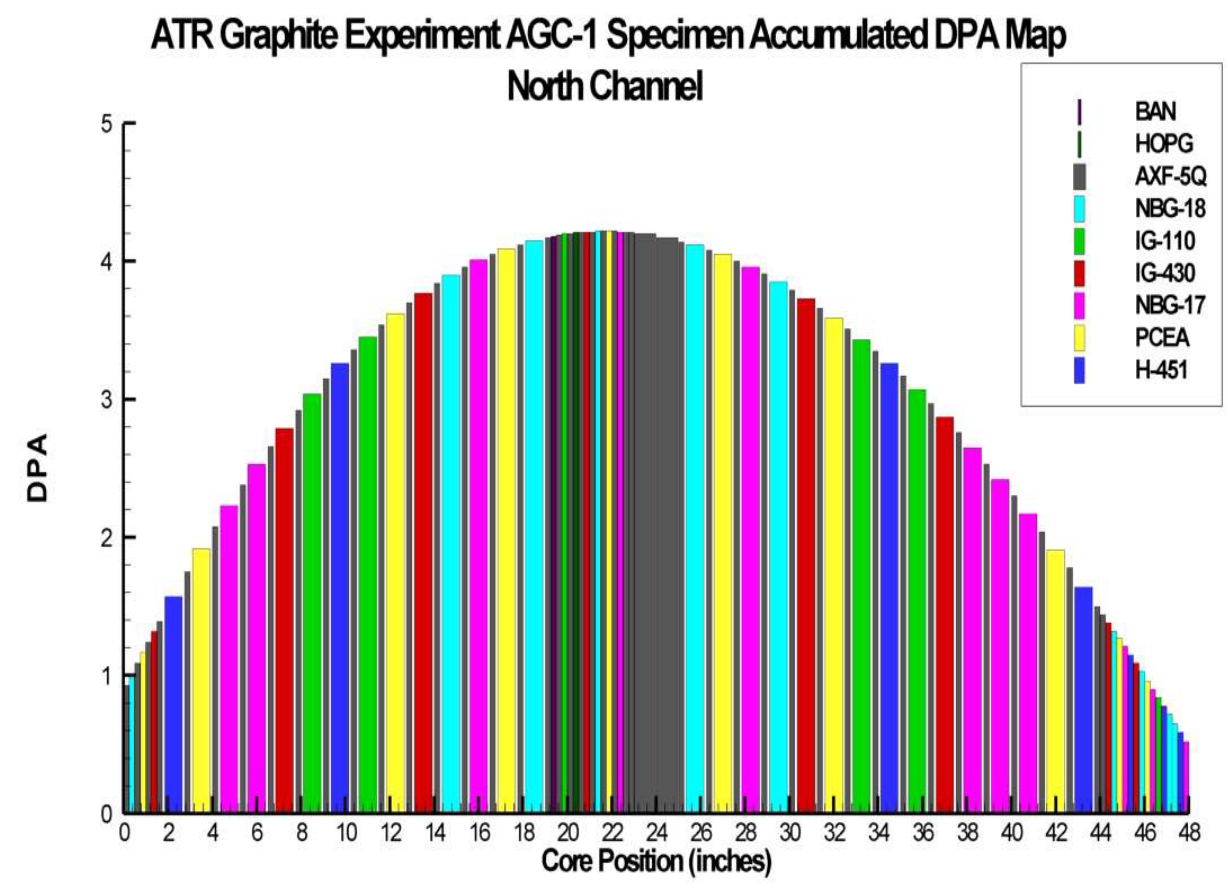

Figure 12. Neutron dose map for AGC-1 peripheral Channel 1 (North) showing the spatial location and total neutron damage dose (dpa) per specimen/graphite grade.

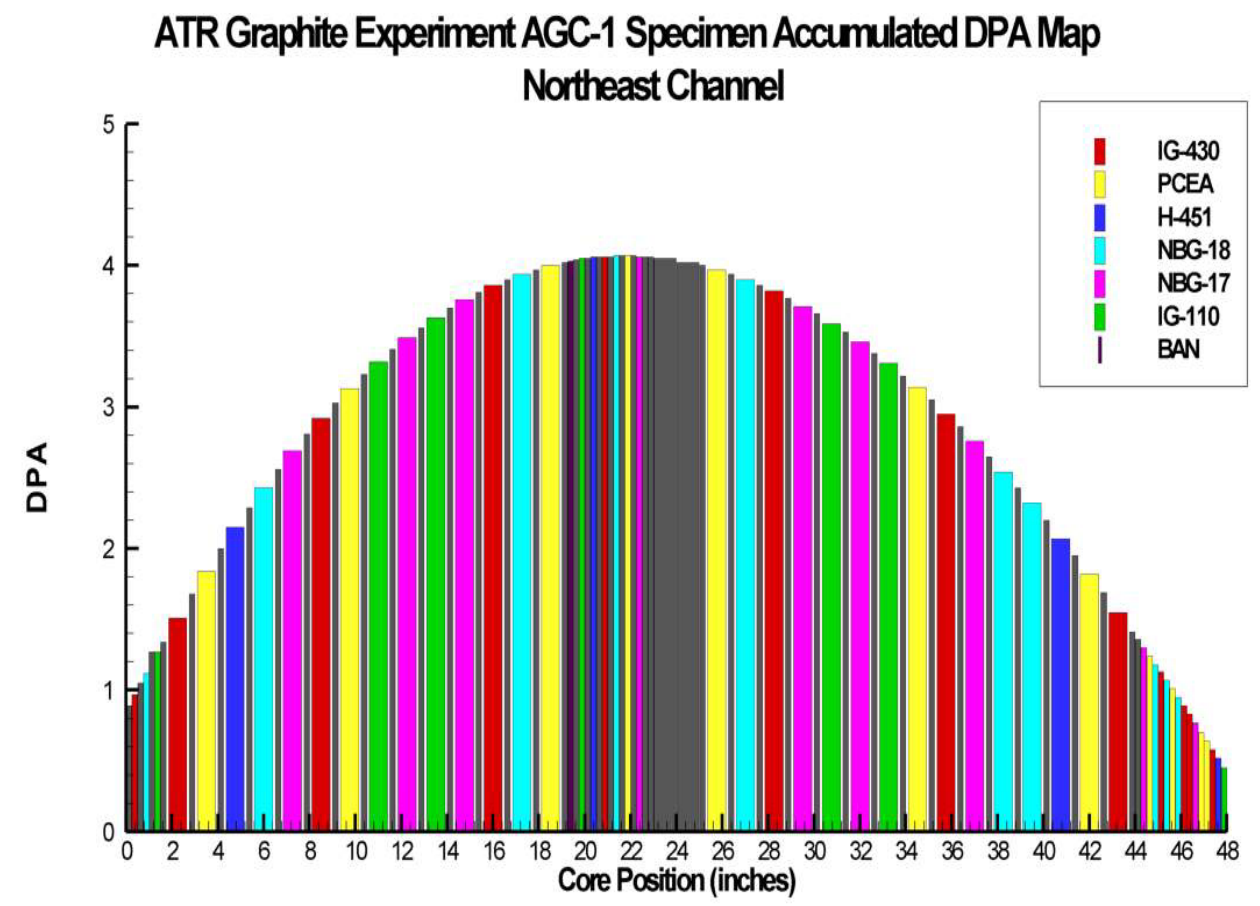

Figure 13. Neutron dose map for AGC-1 peripheral Channel 2 (North-East) showing the spatial location and total neutron damage dose (dpa) per specimen/graphite grade. 


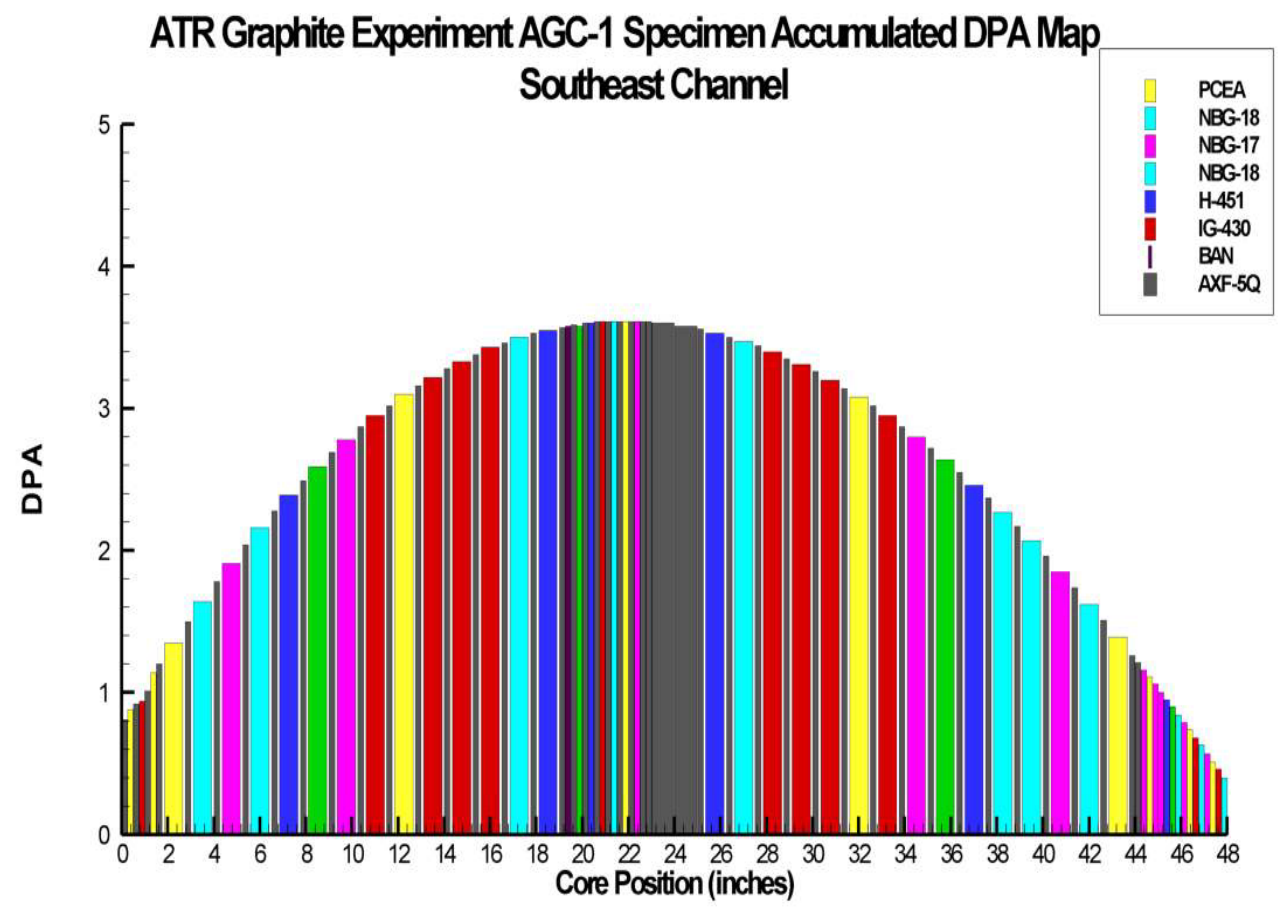

Figure 14. Neutron dose map for AGC-1 peripheral Channel 3 (South-East) showing the spatial location and total neutron damage dose (dpa) per specimen/graphite grade.

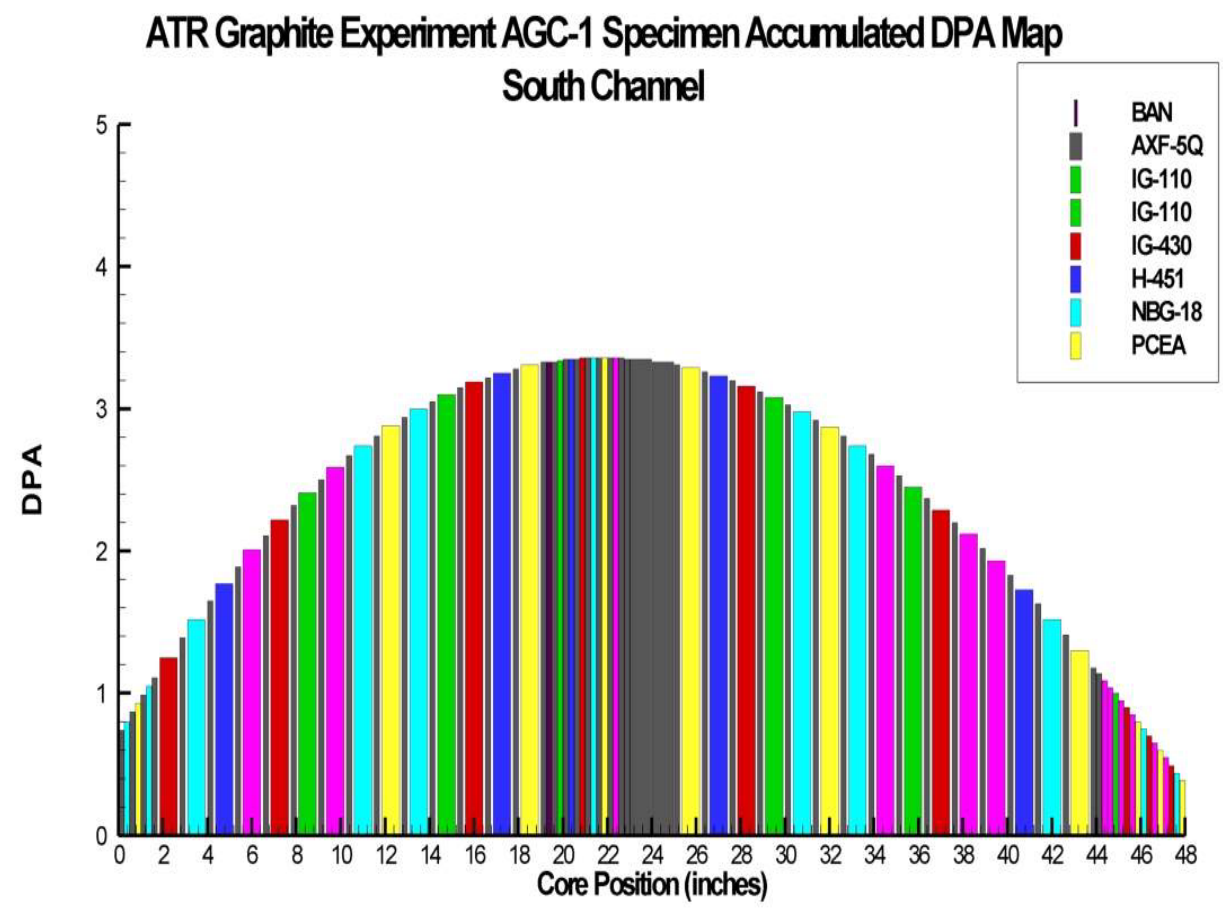

Figure 15. Neutron dose map for AGC-1 peripheral Channel 4 (South) showing the spatial location and total neutron damage dose (dpa) per specimen/graphite grade. 


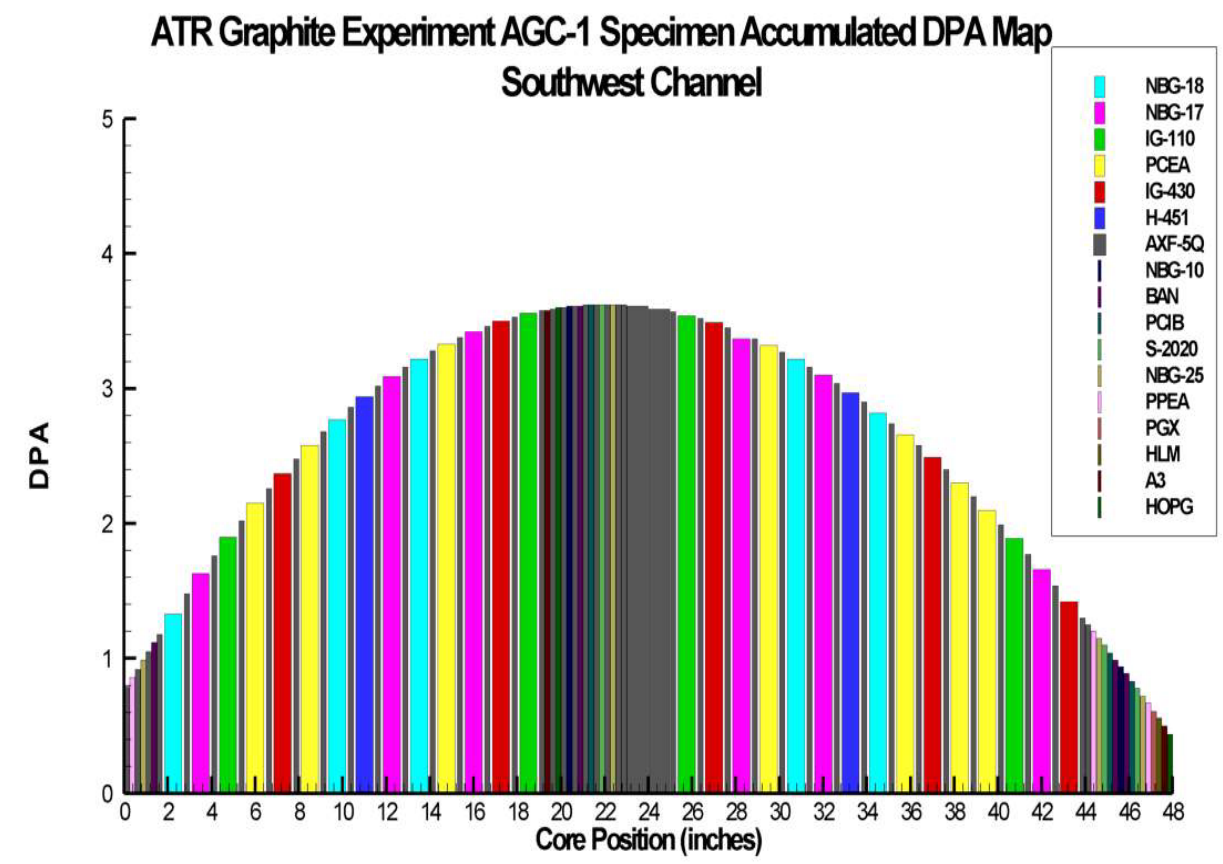

Figure 16. Neutron dose map for AGC-1 peripheral Channel 5 (South -West) showing the spatial location and total neutron damage dose (dpa) per specimen/graphite grade.

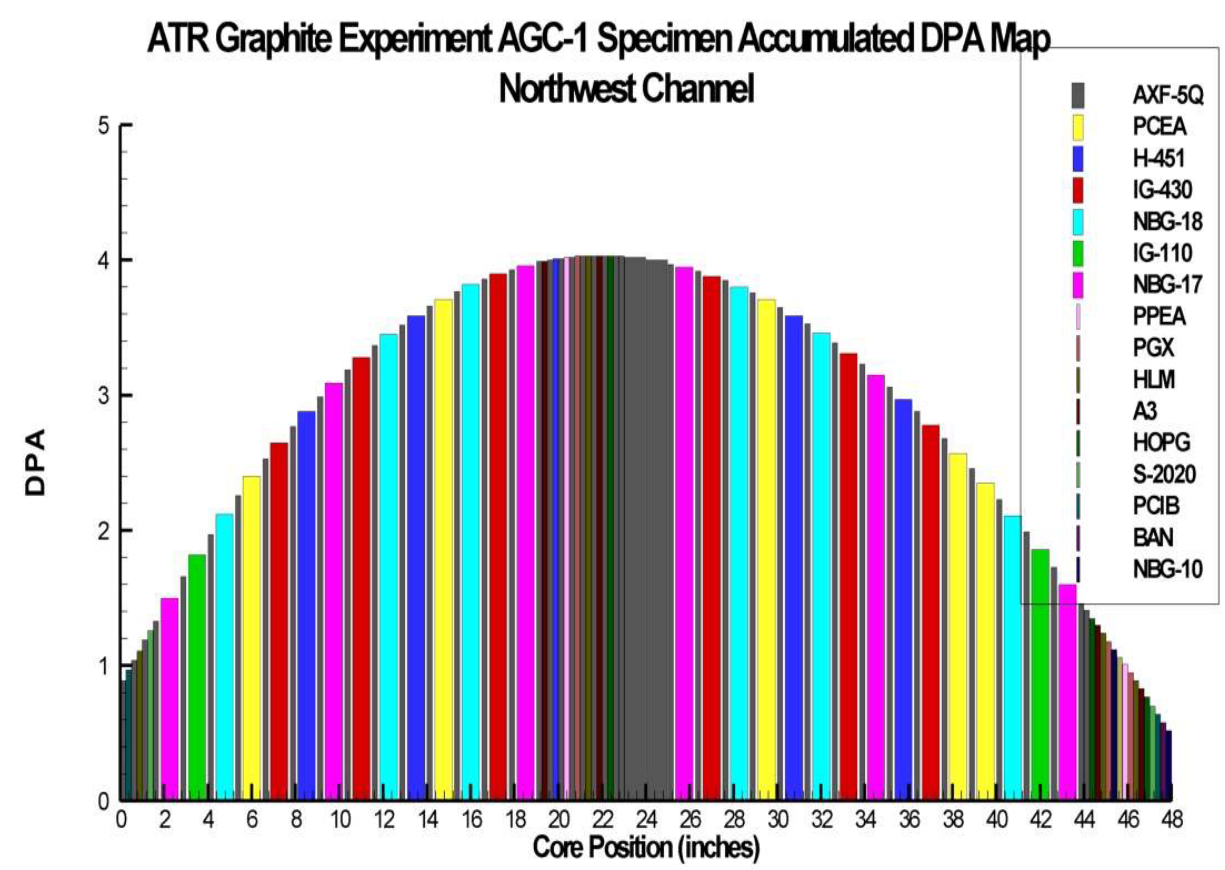

Figure 17. Neutron dose map for AGC-1 peripheral Channel 6 (North-West) showing the spatial location and total neutron damage dose (dpa) per specimen/graphite grade. 


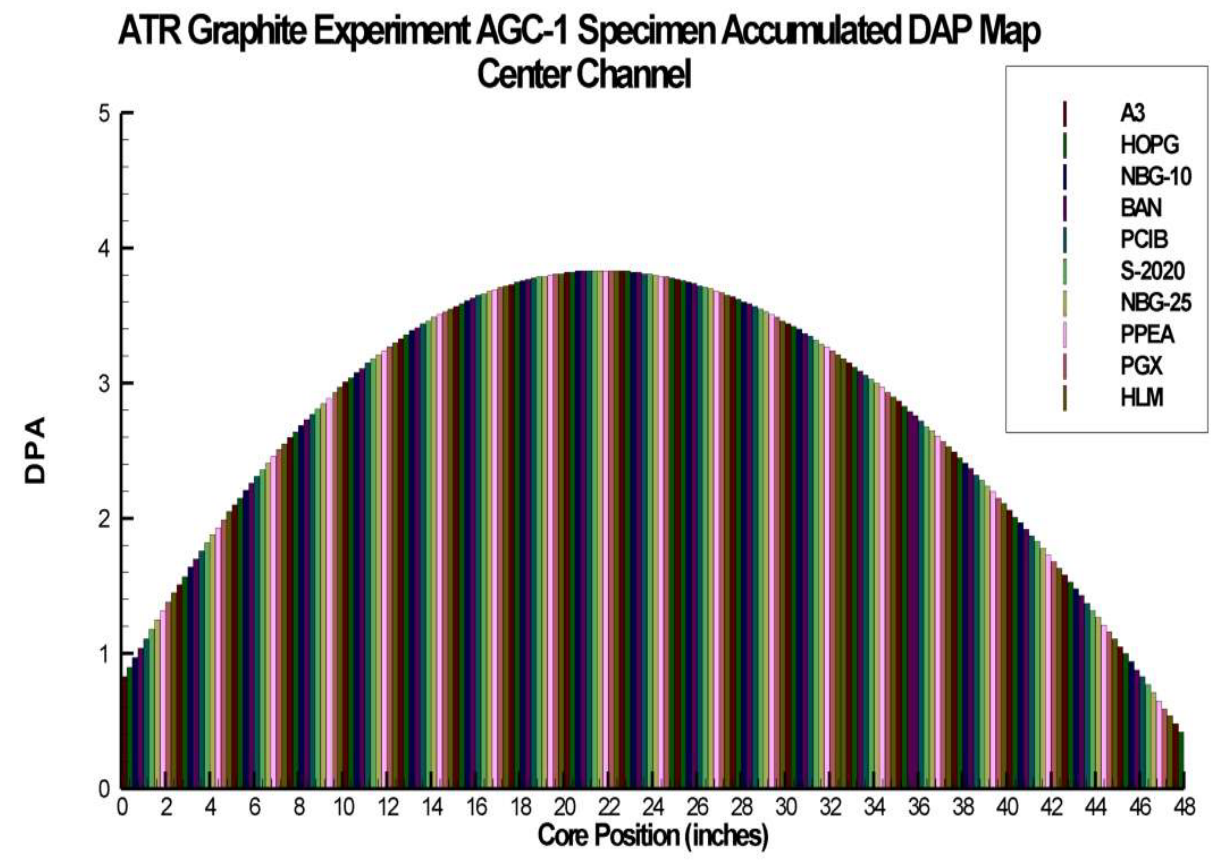

Figure 18. Neutron dose map for AGC-1 center channel showing the spatial location and total neutron damage dose (dpa) per specimen/graphite grade.

The following series of tables reports the numbers of samples (stressed, unstressed, and piggybacks) for the peripheral channels. Tables 9 through 15 pertain to the $3 \mathrm{ksi}$ stress level channels $(1[\mathrm{~N}], 3$ [SE], and 5 [SW]) and summarize the numbers and locations of the creep samples (Table 9) and the locations and doses (dpa) of the specimens by graphite grade (Tables 10-15). Tables 16 through 22 pertain to the 2 ksi stress level channels (2 [NE], 4 [S], and 6 [NW]) and summarize the numbers and locations of the creep samples (Table 16) and the locations and doses (dpa) of the specimens by graphite grade (Tables 17-22).

Table 9. Summary of the stressed/unstressed creep samples by graphite grade ( 3 ksi channels).

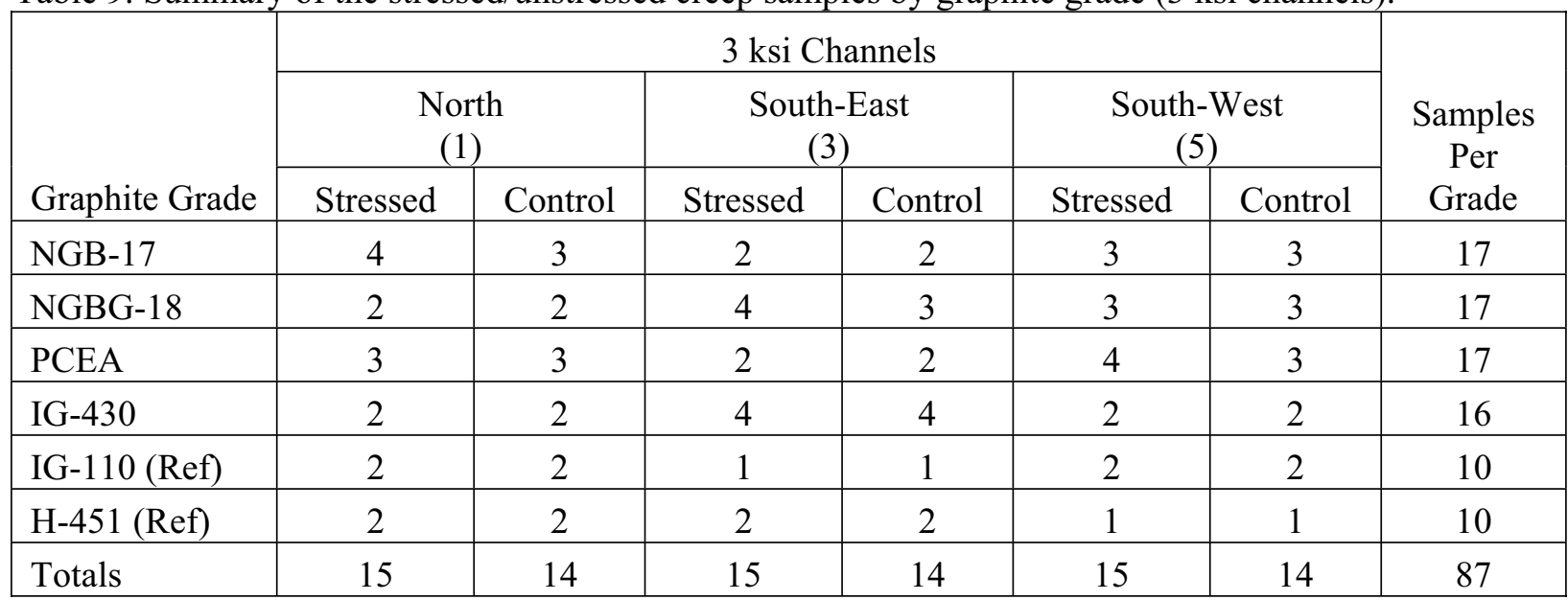


Table 10. Location and dose of stressed and unstressed grade NBG-17 creep samples in the $3 \mathrm{ksi}$ channels.

\begin{tabular}{|c|c|c|c|}
\hline \multicolumn{3}{|c|}{ Grade NBG-17 } \\
\hline Stressed Samples & Cocation & Dose (dpa) \\
\hline Location & Dose (dpa) & $5 \mathrm{U} 13$ & 1.63 \\
\hline $5 \mathrm{~S} 14$ & 1.66 & $3 \mathrm{U} 12$ & 1.91 \\
\hline $3 \mathrm{~S} 13$ & 1.85 & $1 \mathrm{U} 12$ & 2.23 \\
\hline $1 \mathrm{~S} 13$ & 2.17 & $1 \mathrm{U} 11$ & 2.53 \\
\hline $1 \mathrm{~S} 12$ & 2.42 & $1 \mathrm{U} 11$ & 2.53 \\
\hline $1 \mathrm{~S} 11$ & 2.65 & $3 \mathrm{U} 8$ & 2.78 \\
\hline $3 \mathrm{~S} 8$ & 2.80 & $5 \mathrm{U} 6$ & 3.09 \\
\hline $5 \mathrm{~S} 6$ & 3.10 & $5 \mathrm{U} 3$ & 3.42 \\
\hline $5 \mathrm{~S} 3$ & 3.41 & $1 \mathrm{U} 3$ & 4.01 \\
\hline $1 \mathrm{~S} 3$ & 3.96 & & \\
\hline
\end{tabular}

Table 11. Location and dose of stressed and unstressed grade NBG-18 creep samples in the $3 \mathrm{ksi}$ channels.

\begin{tabular}{|c|c|c|c|}
\hline \multicolumn{3}{|c|}{ Grade NBG-18 } & \multicolumn{2}{c|}{ Control Samples } \\
\hline & Stressed Samples & Location & Dose (dpa) \\
\hline Location & Dose (dpa) & $5 \mathrm{U} 14$ & 1.33 \\
\hline $5 \mathrm{~S} 15$ & 1.42 & $3 \mathrm{U} 13$ & 1.64 \\
\hline $3 \mathrm{~S} 14$ & 1.62 & $3 \mathrm{U} 11$ & 2.16 \\
\hline $3 \mathrm{~S} 12$ & 2.07 & $3 \mathrm{U} 11$ & 2.16 \\
\hline $3 \mathrm{~S} 11$ & 2.27 & $5 \mathrm{U} 8$ & 2.77 \\
\hline $5 \mathrm{~S} 8$ & 2.82 & $5 \mathrm{U} 5$ & 3.22 \\
\hline $5 \mathrm{~S} 5$ & 3.22 & $3 \mathrm{U} 2$ & 3.50 \\
\hline $3 \mathrm{~S} 2$ & 3.47 & $1 \mathrm{U} 4$ & 3.90 \\
\hline $1 \mathrm{~S} 4$ & 3.85 & $1 \mathrm{U} 1$ & 4.15 \\
\hline $1 \mathrm{~S} 1$ & 4.12 & & \\
\hline
\end{tabular}

Table 12. Location and dose of stressed and unstressed grade PCEA creep samples in the 3 ksi channels.

\begin{tabular}{|c|c|c|c|}
\hline \multicolumn{3}{|c|}{ Grade PCEA } \\
\hline \multicolumn{2}{|c|}{ Stressed Samples } & \multicolumn{2}{c|}{ Control Samples } \\
\hline Location & Dose (dpa) & Location & $\begin{array}{c}\text { Dose } \\
\text { (dpa) }\end{array}$ \\
\hline $3 \mathrm{~S} 15$ & 1.39 & $3 \mathrm{U} 14$ & 1.35 \\
\hline $1 \mathrm{~S} 14$ & 1.91 & $1 \mathrm{U} 13$ & 1.92 \\
\hline $5 \mathrm{~S} 12$ & 2.10 & $5 \mathrm{U} 11$ & 2.15 \\
\hline $5 \mathrm{~S} 11$ & 2.30 & $5 \mathrm{U} 11$ & 2.15 \\
\hline $5 \mathrm{~S} 9$ & 2.66 & $5 \mathrm{U} 9$ & 2.58 \\
\hline $3 \mathrm{~S} 6$ & 3.08 & $3 \mathrm{U} 6$ & 3.10 \\
\hline
\end{tabular}


Table 12 (cont.)

\begin{tabular}{|c|c|c|c|}
\hline \multicolumn{3}{|c|}{ Grade PCEA } \\
\hline \multicolumn{2}{|c|}{ Stressed Samples } & \multicolumn{2}{c|}{ Control Samples } \\
\hline Location & Dose (dpa) & Location & $\begin{array}{c}\text { Dose } \\
\text { (dpa) }\end{array}$ \\
\hline $5 \mathrm{~S} 4$ & 3.32 & $5 \mathrm{U} 4$ & 3.33 \\
\hline $1 \mathrm{~S} 6$ & 3.59 & $1 \mathrm{U} 6$ & 3.62 \\
\hline $1 \mathrm{~S} 2$ & 4.05 & $1 \mathrm{U} 2$ & 4.09 \\
\hline
\end{tabular}

Table 13. Location and dose of stressed and unstressed grade IG-430 creep samples in the 3 ksi channels.

\begin{tabular}{|c|c|c|c|}
\hline \multicolumn{4}{|c|}{ Grade IG-430 } \\
\hline \multicolumn{2}{|c|}{ Stressed Samples } & \multicolumn{2}{c|}{ Control Samples } \\
\hline Location & $\begin{array}{c}\text { Dose } \\
\text { (dpa) }\end{array}$ & Location & $\begin{array}{c}\text { Dose } \\
\text { (dpa) }\end{array}$ \\
\hline 5 S10 & 2.49 & $5 \mathrm{U} 10$ & 2.37 \\
\hline $1 \mathrm{~S} 10$ & 2.87 & $1 \mathrm{U} 10$ & 2.79 \\
\hline $3 \mathrm{~S} 7$ & 2.95 & $3 \mathrm{U} 7$ & 2.95 \\
\hline $3 \mathrm{~S} 5$ & 3.20 & $3 \mathrm{U} 5$ & 3.22 \\
\hline $3 \mathrm{~S} 4$ & 3.31 & $3 \mathrm{U} 4$ & 3.33 \\
\hline $3 \mathrm{~S} 3$ & 3.40 & $3 \mathrm{U} 3$ & 3.43 \\
\hline $5 \mathrm{~S} 2$ & 3.49 & $5 \mathrm{U} 2$ & 3.50 \\
\hline $1 \mathrm{~S} 5$ & 3.73 & $1 \mathrm{U} 5$ & 3.77 \\
\hline
\end{tabular}

Table 14. Location and dose of stressed and unstressed grade IG-110 (reference) creep samples in the 3 ksi channels.

\begin{tabular}{|c|c|c|c|}
\hline \multicolumn{4}{|c|}{ Grade IG-110 } \\
\hline \multicolumn{2}{|c|}{ Stressed Samples } & \multicolumn{2}{c|}{ Control Samples } \\
\hline $\begin{array}{c}\text { Dose } \\
\text { Location }\end{array}$ & 1.89 & Location & $\begin{array}{c}\text { Dose } \\
\text { (dpa) }\end{array}$ \\
\hline $5 \mathrm{~S} 13$ & 2.64 & $5 \mathrm{U} 12$ & 1.90 \\
\hline $3 \mathrm{~S} 9$ & 3.07 & $3 \mathrm{U} 9$ & 2.59 \\
\hline $1 \mathrm{~S} 9$ & 3.43 & $1 \mathrm{U} 9$ & 3.04 \\
\hline $1 \mathrm{~S} 7$ & 3.54 & $1 \mathrm{U} 7$ & 3.45 \\
\hline $5 \mathrm{~S} 1$ & & $5 \mathrm{U} 1$ & 3.56 \\
\hline
\end{tabular}


Table 15. Location and dose of stressed and unstressed grade H-451 (reference) creep samples in the $3 \mathrm{ksi}$ channels.

\begin{tabular}{|c|c|c|c|}
\hline \multicolumn{4}{|c|}{ Grade H-451 } \\
\hline \multicolumn{2}{|c|}{ Stressed Samples } & \multicolumn{2}{c|}{ Control Samples } \\
\hline Location & $\begin{array}{c}\text { Dose } \\
\text { (dpa) }\end{array}$ & Location & $\begin{array}{c}\text { Dose } \\
\text { (dpa) }\end{array}$ \\
\hline $1 \mathrm{~S} 15$ & 1.64 & $1 \mathrm{U} 14$ & 1.57 \\
\hline $3 \mathrm{~S} 10$ & 2.46 & $3 \mathrm{U} 10$ & 2.39 \\
\hline $5 \mathrm{~S} 7$ & 2.97 & $5 \mathrm{U} 7$ & 2.94 \\
\hline $1 \mathrm{~S} 8$ & 3.26 & $1 \mathrm{U} 8$ & 3.26 \\
\hline $3 \mathrm{~S} 1$ & 3.53 & $3 \mathrm{U} 1$ & 3.55 \\
\hline
\end{tabular}

Table 16. Summary of the stressed/unstressed creep samples by graphite grade ( 2 ksi channels).

\begin{tabular}{|c|c|c|c|c|c|c|c|}
\hline \multirow[b]{3}{*}{ Graphite Grade } & \multicolumn{6}{|c|}{2 KSI Channels } & \multirow[b]{3}{*}{ Samples per grade } \\
\hline & \multicolumn{2}{|c|}{$\begin{array}{c}\text { South } \\
\text { (4) }\end{array}$} & \multicolumn{2}{|c|}{$\begin{array}{c}\text { North-East } \\
\text { (2) }\end{array}$} & \multicolumn{2}{|c|}{$\begin{array}{c}\text { North-West } \\
\text { (6) }\end{array}$} & \\
\hline & Stressed & Control & Stressed & Control & Stressed & Control & \\
\hline NGB-17 & 3 & 2 & 3 & 3 & 3 & 3 & 17 \\
\hline NGBG-18 & 3 & 3 & 3 & 2 & 3 & 3 & 17 \\
\hline PCEA & 3 & 3 & 3 & 3 & 3 & 2 & 17 \\
\hline IG-430 & 2 & 2 & 3 & 3 & 3 & 3 & 16 \\
\hline IG-110 (Ref) & 2 & 2 & 2 & 2 & 1 & 1 & 10 \\
\hline H-451 (Ref) & 2 & 2 & 1 & 1 & 2 & 2 & 10 \\
\hline Totals & 15 & 14 & 15 & 14 & 15 & 14 & 87 \\
\hline
\end{tabular}

Table 17. Location and dose of stressed and unstressed grade NBG-17 creep samples in the $2 \mathrm{ksi}$ channels.

\begin{tabular}{|c|c|c|c|}
\hline \multicolumn{3}{|c|}{ Grade NBG-17 } \\
\hline Stressed Samples & \multicolumn{2}{c|}{ Control Samples } \\
\hline $\begin{array}{c}\text { Dose } \\
\text { Location }\end{array}$ & 1.60 & Location & $\begin{array}{c}\text { Dose } \\
\text { (dpa) }\end{array}$ \\
\hline $6 \mathrm{~S} 15$ & 1.93 & $6 \mathrm{U} 14$ & 1.50 \\
\hline $4 \mathrm{~S} 12$ & 2.12 & $4 \mathrm{U} 11$ & 2.01 \\
\hline $4 \mathrm{~S} 11$ & 2.60 & $4 \mathrm{U} 11$ & 2.01 \\
\hline $4 \mathrm{~S} 8$ & 2.76 & $4 \mathrm{U} 8$ & 2.59 \\
\hline $2 \mathrm{~S} 10$ & 3.15 & $2 \mathrm{U} 10$ & 2.69 \\
\hline $6 \mathrm{~S} 8$ & 3.46 & $6 \mathrm{U} 8$ & 3.09 \\
\hline $2 \mathrm{~S} 6$ & 3.71 & $2 \mathrm{U} 6$ & 3.49 \\
\hline $2 \mathrm{~S} 4$ & 3.95 & $2 \mathrm{U} 4$ & 3.76 \\
\hline $6 \mathrm{~S} 1$ & & $6 \mathrm{U} 1$ & 3.96 \\
\hline
\end{tabular}


Table 18. Location and dose of stressed and unstressed grade NBG-18 creep samples in the $2 \mathrm{ksi}$ channels.

\begin{tabular}{|c|c|c|c|}
\hline \multicolumn{3}{|c|}{ Grade NBG-18 } \\
\hline \multicolumn{2}{|c|}{ Stressed Samples } & \multicolumn{2}{c|}{ Control Samples } \\
\hline Location & $\begin{array}{c}\text { Dose } \\
(\mathrm{dpa})\end{array}$ & Location & $\begin{array}{c}\text { Dose } \\
\text { (dpa) }\end{array}$ \\
\hline $4 \mathrm{~S} 14$ & 1.52 & $4 \mathrm{U} 13$ & 1.52 \\
\hline $6 \mathrm{~S} 13$ & 2.11 & $6 \mathrm{U} 12$ & 3.12 \\
\hline $2 \mathrm{~S} 12$ & 2.32 & $2 \mathrm{U} 11$ & 2.43 \\
\hline $2 \mathrm{~S} 11$ & 2.54 & $2 \mathrm{U} 11$ & 2.43 \\
\hline $4 \mathrm{~S} 7$ & 2.74 & $4 \mathrm{U} 7$ & 2.74 \\
\hline $4 \mathrm{~S} 5$ & 3.98 & $4 \mathrm{U} 5$ & 3.00 \\
\hline $6 \mathrm{~S} 6$ & 3.46 & $6 \mathrm{U} 6$ & 3.45 \\
\hline $6 \mathrm{~S} 3$ & 3.80 & $6 \mathrm{U} 3$ & 3.82 \\
\hline $2 \mathrm{~S} 2$ & 3.90 & $2 \mathrm{U} 2$ & 3.94 \\
\hline
\end{tabular}

Table 19. Location and dose of stressed and unstressed grade PCEA creep samples in the 2 ksi channels.

\begin{tabular}{|c|c|c|c|}
\hline \multicolumn{3}{|c|}{ Grade PCEA } \\
\hline \multicolumn{2}{|c|}{ Stressed Samples } & \multicolumn{2}{c|}{ Control Samples } \\
\hline Location & $\begin{array}{c}\text { Dose } \\
\text { dpa })\end{array}$ & Location & Dose (dpa) \\
\hline $4 \mathrm{~S} 15$ & 1.30 & $4 \mathrm{U} 14$ & 1.25 \\
\hline $2 \mathrm{~S} 14$ & 1.82 & $2 \mathrm{U} 13$ & 1.84 \\
\hline $6 \mathrm{~S} 12$ & 2.35 & $6 \mathrm{U} 11$ & 2.40 \\
\hline $6 \mathrm{~S} 11$ & 2.57 & $6 \mathrm{U} 11$ & 2.40 \\
\hline $4 \mathrm{~S} 6$ & 2.87 & $4 \mathrm{U} 6$ & 2.88 \\
\hline $2 \mathrm{~S} 8$ & 3.14 & $2 \mathrm{U} 8$ & 3.13 \\
\hline $4 \mathrm{~S} 1$ & 3.29 & $4 \mathrm{U} 1$ & 3.31 \\
\hline $6 \mathrm{~S} 4$ & 3.71 & $6 \mathrm{U} 4$ & 3.71 \\
\hline $2 \mathrm{~S} 1$ & 3.97 & $2 \mathrm{U} 1$ & 4.00 \\
\hline
\end{tabular}

Table 20. Location and dose of stressed and unstressed grade IG- 430 creep samples in the 2 ksi channels.

\begin{tabular}{|c|c|c|c|}
\hline \multicolumn{3}{|c|}{ Grade IG-430 } \\
\hline \multicolumn{2}{|c|}{ Stressed Samples } & \multicolumn{2}{c|}{ Control Samples } \\
\hline Location & $\begin{array}{c}\text { Dose } \\
(\mathrm{dpa})\end{array}$ & Location & $\begin{array}{c}\text { Dose } \\
(\mathrm{dpa})\end{array}$ \\
\hline $2 \mathrm{~S} 15$ & 1.55 & $2 \mathrm{U} 14$ & 1.51 \\
\hline $4 \mathrm{~S} 10$ & 2.29 & $4 \mathrm{U} 10$ & 2.22 \\
\hline $6 \mathrm{~S} 10$ & 2.78 & $6 \mathrm{U} 10$ & 2.65 \\
\hline $2 \mathrm{~S} 9$ & 2.95 & $2 \mathrm{U} 9$ & 2.92 \\
\hline $4 \mathrm{~S} 3$ & 3.16 & $4 \mathrm{U} 3$ & 3.19 \\
\hline
\end{tabular}


Table 20 (cont.)

\begin{tabular}{|c|c|c|c|}
\hline \multicolumn{3}{|c|}{ Grade IG-430 } \\
\hline \multicolumn{2}{|c|}{ Stressed Samples } & \multicolumn{2}{c|}{ Control Samples } \\
\hline Location & $\begin{array}{c}\text { Dose } \\
(\mathrm{dpa})\end{array}$ & Location & $\begin{array}{c}\text { Dose } \\
\text { (dpa) }\end{array}$ \\
\hline $2 \mathrm{~S} 15$ & 1.55 & $2 \mathrm{U} 14$ & 1.51 \\
\hline $6 \mathrm{~S} 7$ & 3.31 & $6 \mathrm{U} 7$ & 3.38 \\
\hline $2 \mathrm{~S} 3$ & 3.82 & $2 \mathrm{U} 3$ & 3.86 \\
\hline $6 \mathrm{~S} 2$ & 3.88 & $6 \mathrm{U} 2$ & 3.90 \\
\hline
\end{tabular}

Table 21. Location and dose of stressed and unstressed grade IG-110 (reference) creep samples in the 2 ksi channels.

\begin{tabular}{|c|c|c|c|}
\hline \multicolumn{4}{|c|}{ Grade IG-110 } \\
\hline \multicolumn{2}{|c|}{ Stressed Samples } & \multicolumn{2}{|c|}{ Control Samples } \\
\hline Location & Dose (dpa) & Location & Dose (dpa) \\
\hline $6 \mathrm{~S} 14$ & 1.86 & 6U13 & 1.82 \\
\hline $4 \mathrm{~S} 9$ & 2.45 & 4U9 & 2.41 \\
\hline $4 \mathrm{~S} 4$ & 3.08 & $4 \mathrm{U} 4$ & 3.10 \\
\hline $2 \mathrm{~S} 7$ & 3.31 & $2 \mathrm{U} 7$ & 3.32 \\
\hline $2 \mathrm{~S} 5$ & 3.59 & 2U5 & 3.63 \\
\hline
\end{tabular}

Table 22. Location and dose of stressed and unstressed grade H-451 (reference) creep samples in the 2 ksi channels.

\begin{tabular}{|l|c|c|c|}
\hline \multicolumn{4}{|c|}{ Grade H-451 } \\
\hline \multicolumn{2}{|c|}{ Stressed Samples } & \multicolumn{2}{c|}{ Control Samples } \\
\hline Location & Dose (dpa) & Location & Dose (dpa) \\
\hline $4 \mathrm{~S} 13$ & 1.73 & $4 \mathrm{U} 12$ & 1.77 \\
\hline $2 \mathrm{~S} 13$ & 2.07 & $2 \mathrm{U} 12$ & 2.15 \\
\hline $6 \mathrm{~S} 9$ & 2.97 & $6 \mathrm{U} 9$ & 2.88 \\
\hline $4 \mathrm{~S} 2$ & 3.23 & $4 \mathrm{U} 2$ & 3.25 \\
\hline $6 \mathrm{~S} 5$ & 3.59 & $6 \mathrm{U} 5$ & 3.59 \\
\hline
\end{tabular}

Tables 23 and 24 summarize the piggyback samples in the 3 and 2 ksi stress levels, respectively, and report the number of piggyback samples by grade in each channel. Tables 25 through Table 40 report the location and dose (dpa) of all the piggyback samples by grade in the AGC-1 peripheral channels.

Table 23. Summary of the piggyback samples by grade included in the 3 ksi peripheral channels.

\begin{tabular}{|c|c|c|c|c|}
\hline & \multicolumn{3}{|c|}{3 ksi Channels } & \multirow{2}{*}{ Piggyback Samples Per Grade } \\
\cline { 2 - 4 } & $\begin{array}{c}\text { North } \\
\text { Graphite Grade }\end{array}$ & $\begin{array}{c}\text { South-East } \\
(1)\end{array}$ & $\begin{array}{c}\text { South-West } \\
(5)\end{array}$ & 10 \\
\hline NBG-17 & 4 & 6 & 0 & 10 \\
\hline NBG-18 & 6 & 4 & 0 & Pigg \\
\hline
\end{tabular}


Table 23 (cont.)

\begin{tabular}{|l|c|c|c|c|}
\hline & \multicolumn{3}{|c|}{3 ksi Channels } & \multirow{2}{*}{ Piggyback Samples Per Grade } \\
\cline { 2 - 4 } Graphite Grade & $\begin{array}{c}\text { North } \\
(1)\end{array}$ & $\begin{array}{c}\text { South-East } \\
(3)\end{array}$ & $\begin{array}{c}\text { South-West } \\
(5)\end{array}$ & 10 \\
\hline PCEA & 4 & 6 & 0 & 8 \\
\hline IG-430 & 4 & 4 & 0 & 4 \\
\hline IG-110 & 2 & 2 & 0 & 5 \\
\hline H-451 & 3 & 2 & 0 & 3 \\
\hline HOPG & 1 & 0 & 2 & 2 \\
\hline A3 matrix & 0 & 0 & 2 & 1 \\
\hline HLM & 0 & 0 & 1 & 1 \\
\hline PGX & 0 & 0 & 1 & 3 \\
\hline PPEA & 0 & 0 & 3 & 4 \\
\hline NBG-25 & 0 & 0 & 4 & 3 \\
\hline 2020 & 0 & 0 & 3 & 3 \\
\hline PCIB & 0 & 0 & 3 & 6 \\
\hline BAN & 1 & 1 & 4 & 2 \\
\hline NBG-10 & 0 & 0 & 2 & 75 \\
\hline Total & 25 & 25 & 25 & \\
\hline
\end{tabular}

Table 24. Summary of the piggyback samples by grade included in the 2 ksi peripheral channels.

\begin{tabular}{|l|c|c|c|c|}
\hline & \multicolumn{3}{|c|}{ KSI Channels } & \multirow{2}{*}{ Piggyback Samples Per Grade } \\
\cline { 2 - 4 } Graphite Grade & $\begin{array}{c}\text { North-East } \\
(2)\end{array}$ & $\begin{array}{c}\text { South } \\
(4)\end{array}$ & $\begin{array}{c}\text { North-West } \\
(6)\end{array}$ & 10 \\
\hline NBG-17 & 3 & 7 & 0 & 10 \\
\hline NBG-18 & 5 & 5 & 0 & 10 \\
\hline PCEA & 5 & 5 & 0 & 10 \\
\hline IG-430 & 6 & 4 & 0 & 5 \\
\hline IG-110 & 3 & 2 & 0 & 4 \\
\hline H-451 & 2 & 1 & 1 & 3 \\
\hline HOPG & 0 & 0 & 3 & 4 \\
\hline A3 matrix & 0 & 0 & 4 & 4 \\
\hline HLM & 0 & 0 & 4 & 3 \\
\hline PGX & 0 & 0 & 3 & 2 \\
\hline PPEA & 0 & 0 & 2 & 1 \\
\hline NBG-25 & 0 & 0 & 1 & 2 \\
\hline 2020 & 0 & 0 & 2 & 2 \\
\hline PCIB & 0 & 0 & 2 & 3 \\
\hline BAN & 1 & 1 & 1 & 2 \\
\hline NBG-10 & 0 & 0 & 2 & 75 \\
\hline Total & 25 & 25 & 25 & \\
\hline
\end{tabular}


Table 25. Summary of Grade NBG-17 piggyback specimens located in the peripheral channels of AGC-1.

\begin{tabular}{|c|c|}
\hline \multicolumn{2}{|c|}{ Grade NBG-17 } \\
\hline Location & Dose, dpa \\
\hline 1PB1 & 0.52 \\
\hline 4PB4 & 0.55 \\
\hline 3PB4 & 0.57 \\
\hline 4PB6 & 0.65 \\
\hline 2PB6 & 0.77 \\
\hline 3PB8 & 0.79 \\
\hline $4 \mathrm{~PB} 10$ & 0.85 \\
\hline 1PB7 & 0.90 \\
\hline $4 \mathrm{~PB} 12$ & 0.95 \\
\hline 3PB12 & 1.00 \\
\hline $4 \mathrm{~PB} 14$ & 1.04 \\
\hline 3PB13 & 1.06 \\
\hline $4 \mathrm{~PB} 15$ & 1.09 \\
\hline $3 \mathrm{~PB} 15$ & 1.16 \\
\hline 1PB12 & 1.21 \\
\hline 2PB15 & 1.30 \\
\hline $4 \mathrm{~PB} 16$ & 3.36 \\
\hline 3PB16 & 3.61 \\
\hline 2PB16 & 4.06 \\
\hline $1 \mathrm{~PB} 16$ & 4.21 \\
\hline
\end{tabular}

Table 26. Summary of Grade NBG-18 piggyback specimens located in the peripheral channels of AGC-1.

\begin{tabular}{|c|c|}
\hline \multicolumn{2}{|c|}{ Grade NBG-18 } \\
\hline Location & Dose, dpa \\
\hline 3PB1 & 0.40 \\
\hline 4PB2 & 0.44 \\
\hline 3PB5 & 0.63 \\
\hline 1PB3 & 0.65 \\
\hline 1PB4 & 0.72 \\
\hline 4PB8 & 0.75 \\
\hline 4PB25 & 0.80 \\
\hline 3PB9 & 0.84 \\
\hline 2PB9 & 0.95 \\
\hline 1PB25 & 1.01 \\
\hline 1PB9 & 1.03 \\
\hline 4PB23 & 1.05 \\
\hline 2PB11 & 1.07 \\
\hline
\end{tabular}


Table 26 (cont.)

\begin{tabular}{|c|c|}
\hline \multicolumn{2}{|c|}{ Grade NBG-18 } \\
\hline Location & Dose, dpa \\
\hline 2PB24 & 1.12 \\
\hline 2PB13 & 1.18 \\
\hline 1PB14 & 1.32 \\
\hline 4PB18 & 3.36 \\
\hline 3PB18 & 3.61 \\
\hline 2PB18 & 4.07 \\
\hline 1PB18 & 4.22 \\
\hline
\end{tabular}

Table 27. Summary of Grade PCEA piggyback specimens located in the peripheral channels of AGC-1.

\begin{tabular}{|c|c|}
\hline \multicolumn{2}{|c|}{ Grade PCEA } \\
\hline Location & Dose, dpa \\
\hline 4PB1 & 0.39 \\
\hline 3PB3 & 0.51 \\
\hline 4PB5 & 0.60 \\
\hline 2PB4 & 0.64 \\
\hline 2PB5 & 0.70 \\
\hline 3PB7 & 0.74 \\
\hline 4PB9 & 0.80 \\
\hline 3 PB25 & 0.88 \\
\hline $4 \mathrm{~PB} 24$ & 0.93 \\
\hline 1PB8 & 0.96 \\
\hline $2 \mathrm{~PB} 10$ & 1.01 \\
\hline 3PB14 & 1.11 \\
\hline $3 \mathrm{~PB} 23$ & 1.14 \\
\hline 1PB24 & 1.17 \\
\hline 2PB14 & 1.24 \\
\hline $1 \mathrm{~PB} 13$ & 1.32 \\
\hline $4 \mathrm{~PB} 17$ & 3.36 \\
\hline $3 \mathrm{~PB} 17$ & 3.61 \\
\hline 2PB17 & 4.07 \\
\hline 1PB17 & 4.22 \\
\hline
\end{tabular}


Table 28. Summary of Grade IG-430 piggyback specimens located in the peripheral channels of AGC-1.

\begin{tabular}{|c|c|}
\hline \multicolumn{2}{|c|}{ Grade IG-430 } \\
\hline Location & Dose, dpa \\
\hline 3PB2 & 0.46 \\
\hline 4PB3 & 0.49 \\
\hline 2PB3 & 0.58 \\
\hline 3PB6 & 0.68 \\
\hline 4PB7 & 0.70 \\
\hline 2PB7 & 0.83 \\
\hline 2PB8 & 0.89 \\
\hline 4PB11 & 0.90 \\
\hline $2 \mathrm{~PB} 25$ & 0.97 \\
\hline 3РB24 & 1.01 \\
\hline $1 \mathrm{~PB} 10$ & 1.09 \\
\hline 2PB12 & 1.13 \\
\hline 1PB23 & 1.32 \\
\hline 1PB15 & 1.38 \\
\hline 4PB19 & 3.36 \\
\hline 3PB19 & 3.61 \\
\hline 2PB19 & 4.06 \\
\hline 1PB19 & 4.21 \\
\hline
\end{tabular}

Table 29. Summary of Grade IG-110 piggyback specimens located in the peripheral channels of AGC-1.

\begin{tabular}{|c|c|}
\hline \multicolumn{2}{|c|}{ Grade IG-110 } \\
\hline Location & Dose, dpa \\
\hline 2PB1 & 0.45 \\
\hline 1PB6 & 0.84 \\
\hline 3PB10 & 0.90 \\
\hline 4PB13 & 1.00 \\
\hline 2PB23 & 1.19 \\
\hline 4PB21 & 3.34 \\
\hline 3PB21 & 3.59 \\
\hline 2PB21 & 4.05 \\
\hline 1PB21 & 4.20 \\
\hline
\end{tabular}


Table 30. Summary of Grade H-451 piggyback specimens located in the peripheral channels of AGC-1.

\begin{tabular}{|c|c|}
\hline \multicolumn{2}{|c|}{ Grade H-451 } \\
\hline Location & Dose, dpa \\
\hline 2PB2 & 0.52 \\
\hline 1PB2 & 0.59 \\
\hline 1PB5 & 0.78 \\
\hline 3PB11 & 0.95 \\
\hline 1PB11 & 1.15 \\
\hline 4PB20 & 3.35 \\
\hline 3PB20 & 3.60 \\
\hline 6PB21 & 4.01 \\
\hline 2PB20 & 4.06 \\
\hline
\end{tabular}

Table 31. Summary of Grade HOPG piggyback specimens located in the peripheral channels of AGC-1.

\begin{tabular}{|c|c|}
\hline \multicolumn{2}{|c|}{ Grade HOPG } \\
\hline Location & Dose, dpa \\
\hline 5PB1 & 0.44 \\
\hline 6PB5 & 0.77 \\
\hline 6PB15 & 1.35 \\
\hline 5PB21 & 3.60 \\
\hline 6PB16 & 4.03 \\
\hline 1PB20 & 4.21 \\
\hline
\end{tabular}

Table 32. Summary of A3 Matrix piggyback specimens located in the peripheral channels of AGC-1.

\begin{tabular}{|c|c|}
\hline \multicolumn{2}{|c|}{ Grade A3 Matrix } \\
\hline Location & Dose, dpa \\
\hline 5PB2 & 0.50 \\
\hline 6PB6 & 0.83 \\
\hline 6PB14 & 1.30 \\
\hline 5PB22 & 3.58 \\
\hline 6PB22 & 3.99 \\
\hline 6PB17 & 4.03 \\
\hline
\end{tabular}

Table 33. Summary of Grade HLM piggyback specimens located in the peripheral channels of AGC-1.

\begin{tabular}{|c|c|}
\hline \multicolumn{2}{|c|}{ Grade HLM } \\
\hline Location & Dose, dpa \\
\hline 5PB3 & 0.56 \\
\hline 6PB7 & 0.89 \\
\hline 6PB24 & 1.11 \\
\hline 6PB13 & 1.24 \\
\hline 6PB18 & 4.03 \\
\hline
\end{tabular}


Table 34. Summary of Grade PGX piggyback specimens located in the peripheral channels of AGC-1.

\begin{tabular}{|c|c|}
\hline \multicolumn{2}{|c|}{ Grade PGX } \\
\hline Location & Dose, dpa \\
\hline 5PB4 & 0.61 \\
\hline 6PB8 & 0.95 \\
\hline 6PB12 & 1.18 \\
\hline 6PB19 & 4.03 \\
\hline
\end{tabular}

Table 35. Summary of Grade PPEA piggyback specimens located in the peripheral channels of AGC-1.

\begin{tabular}{|c|c|}
\hline \multicolumn{2}{|c|}{ Grade PPEA } \\
\hline Location & Dose, dpa \\
\hline 5PB5 & 0.67 \\
\hline 5PB25 & 0.86 \\
\hline 6PB9 & 1.01 \\
\hline 5PB15 & 1.20 \\
\hline 6PB20 & 4.02 \\
\hline
\end{tabular}

Table 36. Summary of Grade NBG-25 piggyback specimens located in the peripheral channels of AGC-1.

\begin{tabular}{|c|c|}
\hline \multicolumn{2}{|c|}{ Grade NBG-25 } \\
\hline Location & Dose, dpa \\
\hline 5PB6 & 0.72 \\
\hline 5PB24 & 0.99 \\
\hline 6PB10 & 1.06 \\
\hline 5PB14 & 1.15 \\
\hline 5PB16 & 3.62 \\
\hline
\end{tabular}

Table 37. Summary of Grade 2020 piggyback specimens located in the peripheral channels of AGC- 1 .

\begin{tabular}{|c|c|}
\hline \multicolumn{2}{|c|}{ Grade 2020 } \\
\hline Location & Dose, dpa \\
\hline 6PB4 & 0.70 \\
\hline 5PB7 & 0.78 \\
\hline 5PB13 & 1.10 \\
\hline 6PB23 & 1.26 \\
\hline 5PB17 & 3.62 \\
\hline
\end{tabular}


Table 38. Summary of Grade PCIB piggyback specimens located in the peripheral channels of AGC-1.

\begin{tabular}{|c|c|}
\hline \multicolumn{2}{|c|}{ Grade PCIB } \\
\hline Location & Dose, dpa \\
\hline 6PB3 & 0.64 \\
\hline 5PB8 & 0.83 \\
\hline 6PB25 & 0.97 \\
\hline 5PB12 & 1.04 \\
\hline 5PB18 & 3.62 \\
\hline
\end{tabular}

Table 39. Summary of Grade BAN piggyback specimens located in the peripheral channels of AGC-1.

\begin{tabular}{|c|c|}
\hline \multicolumn{2}{|c|}{ Grade BAN } \\
\hline Location & Dose, dpa \\
\hline 6PB2 & 0.58 \\
\hline 5PB9 & 0.89 \\
\hline 5PB11 & 0.99 \\
\hline 5PB23 & 1.12 \\
\hline 4PB22 & 3.33 \\
\hline 3PB22 & 3.58 \\
\hline 5PB19 & 3.61 \\
\hline 2PB22 & 4.03 \\
\hline 1PB22 & 4.18 \\
\hline
\end{tabular}

Table 40. Summary of Grade NBG-10 piggyback specimens located in the peripheral channels of AGC-1.

\begin{tabular}{|c|c|}
\hline \multicolumn{2}{|c|}{ Grade NBG-10 } \\
\hline Location & Dose, dpa \\
\hline 6PB1 & 0.52 \\
\hline 5PB10 & 0.94 \\
\hline 6PB11 & 1.12 \\
\hline 5PB20 & 3.61 \\
\hline
\end{tabular}

Tables 41 through 50 summarize the center channel (piggyback) samples by graphite grade and report the estimated dose (dpa) per specimen.

Table 41. Summary of Grade HOPG piggyback specimens located in the central channel of AGC-1.

\begin{tabular}{|c|c|}
\hline \multicolumn{2}{|c|}{ Grade HOPG } \\
\hline Location & Dose, dpa \\
\hline CPB1 & 0.42 \\
\hline CPB-191 & 0.90 \\
\hline CPB-11 & 1.00 \\
\hline CPB-21 & 1.53 \\
\hline CPB-181 & 1.57 \\
\hline
\end{tabular}


Table 41 (cont.)

\begin{tabular}{|c|c|}
\hline \multicolumn{2}{|c|}{ Grade HOPG } \\
\hline Location & Dose, dpa \\
\hline CPB-31 & 2.01 \\
\hline CPB-171 & 2.15 \\
\hline CPB-41 & 2.45 \\
\hline CPB-161 & 2.64 \\
\hline CPB-51 & 2.83 \\
\hline CPB-151 & 3.04 \\
\hline CPB-61 & 3.15 \\
\hline CPB-141 & 3.36 \\
\hline CPB-71 & 3.42 \\
\hline CPB-131 & 3.59 \\
\hline CPB-81 & 3.62 \\
\hline CPB-121 & 3.75 \\
\hline CPB-91 & 3.76 \\
\hline CPB-111 & 3.82 \\
\hline CPB-101 & 3.83 \\
\hline
\end{tabular}

Table 42. Summary of Grade A3-Matrix piggyback specimens located in the central channel of AGC-1.

\begin{tabular}{|c|c|}
\hline \multicolumn{2}{|c|}{ Grade A3 Matrix } \\
\hline Location & Dose, dpa \\
\hline CPB-2 & 0.48 \\
\hline CPB-192 & 0.83 \\
\hline CPB-12 & 1.05 \\
\hline CPB-182 & 1.51 \\
\hline CPB-22 & 1.58 \\
\hline CPB-32 & 2.06 \\
\hline CPB-172 & 2.10 \\
\hline CPB-42 & 2.49 \\
\hline CPB-162 & 2.60 \\
\hline CPB-52 & 2.87 \\
\hline CPB-152 & 3.01 \\
\hline CPB-62 & 3.18 \\
\hline CPB-142 & 3.33 \\
\hline CPB-72 & 3.44 \\
\hline CPB-132 & 3.57 \\
\hline CPB-82 & 3.64 \\
\hline CPB-122 & 3.73 \\
\hline CPB-92 & 3.77 \\
\hline CPB-112 & 3.82 \\
\hline CPB-102 & 3.83 \\
\hline & \\
\hline & \\
\hline & \\
\hline
\end{tabular}


Table 43. Summary of Grade HLM piggyback specimens located in the central channel of AGC-1.

\begin{tabular}{|c|c|}
\hline \multicolumn{2}{|c|}{ Grade HLM } \\
\hline Location & Dose, dpa \\
\hline CPB-3 & 0.54 \\
\hline CPB-13 & 1.11 \\
\hline CPB-183 & 1.45 \\
\hline CPB-23 & 1.63 \\
\hline CPB-173 & 2.05 \\
\hline CPB-33 & 2.11 \\
\hline CPB-43 & 2.53 \\
\hline CPB-163 & 2.55 \\
\hline CPB-53 & 2.90 \\
\hline CPB-153 & 2.97 \\
\hline CPB-63 & 3.21 \\
\hline CPB-143 & 3.30 \\
\hline CPB-73 & 3.46 \\
\hline CPB-133 & 3.55 \\
\hline CPB-83 & 3.65 \\
\hline CPB-123 & 3.72 \\
\hline CPB-93 & 3.78 \\
\hline CPB-113 & 3.81 \\
\hline CPB-103 & 3.83 \\
\hline
\end{tabular}

Table 44. Summary of Grade PGX piggyback specimens located in the central channel of AGC-1.

\begin{tabular}{|c|c|}
\hline \multicolumn{2}{|c|}{ Grade PGX } \\
\hline Location & Dose, dpa \\
\hline CPB-4 & 0.59 \\
\hline CPB-14 & 1.16 \\
\hline CPB-184 & 1.38 \\
\hline CPB-24 & 1.68 \\
\hline CPB-174 & 1.99 \\
\hline CPB-34 & 2.15 \\
\hline CPB-164 & 2.51 \\
\hline CPB-44 & 2.57 \\
\hline CPB-54 & 2.93 \\
\hline CPB-154 & 2.93 \\
\hline CPB-64 & 3.24 \\
\hline CPB-144 & 3.27 \\
\hline CPB-74 & 3.49 \\
\hline CPB-134 & 3.53 \\
\hline
\end{tabular}


Table 44 (cont.)

\begin{tabular}{|c|c|}
\hline \multicolumn{2}{|c|}{ Grade PGX } \\
\hline Location & Dose, dpa \\
\hline CPB-84 & 3.67 \\
\hline CPB-124 & 3.71 \\
\hline CPB-94 & 3.79 \\
\hline CPB-114 & 3.81 \\
\hline CPB-104 & 3.83 \\
\hline
\end{tabular}

Table 45. Summary of Grade PPEA piggyback specimens located in the central channel of AGC-1.

\begin{tabular}{|c|c|}
\hline \multicolumn{2}{|c|}{ Grade PPEA } \\
\hline Location & Dose, dpa \\
\hline CPB-5 & 0.65 \\
\hline CPB-15 & 1.21 \\
\hline CPB-185 & 1.32 \\
\hline CPB-25 & 1.73 \\
\hline CPB-175 & 1.93 \\
\hline CPB-35 & 2.20 \\
\hline CPB-165 & 2.46 \\
\hline CPB-45 & 2.61 \\
\hline CPB-155 & 2.89 \\
\hline CPB-55 & 2.97 \\
\hline CPB-145 & 3.24 \\
\hline CPB-65 & 3.27 \\
\hline CPB-75 & 3.51 \\
\hline CPB-135 & 3.51 \\
\hline CPB-85 & 3.68 \\
\hline CPB-125 & 3.69 \\
\hline CPB-95 & 3.79 \\
\hline CPB-115 & 3.80 \\
\hline CPB-105 & 3.83 \\
\hline
\end{tabular}

Table 46. Summary of Grade NBG-25 piggyback specimens located in the central channel of AGC-1.

\begin{tabular}{|c|c|}
\hline \multicolumn{2}{|c|}{ Grade NBG-25 } \\
\hline Location & Dose, dpa \\
\hline CPB-6 & 0.71 \\
\hline CPB-186 & 1.25 \\
\hline CPB-16 & 1.27 \\
\hline CPB-26 & 1.78 \\
\hline CPB-176 & 1.88 \\
\hline
\end{tabular}


AGC-1 Experiment and Final

INL/EXT-05-00622

Preliminary Design Report

Revision 2

Table 46 (cont.)

\begin{tabular}{|c|c|}
\hline \multicolumn{2}{|c|}{ Grade NBG-25 } \\
\hline Location & Dose, dpa \\
\hline CPB-36 & 2.24 \\
\hline CPB-166 & 2.41 \\
\hline CPB-46 & 2.65 \\
\hline CPB-156 & 2.85 \\
\hline CPB-56 & 3.00 \\
\hline CPB-146 & 3.21 \\
\hline CPB-66 & 3.29 \\
\hline CPB-136 & 3.49 \\
\hline CPB-76 & 3.53 \\
\hline CPB-126 & 3.68 \\
\hline CPB-86 & 3.70 \\
\hline CPB-116 & 3.79 \\
\hline CPB-96 & 3.80 \\
\hline CPB-106 & 3.83 \\
\hline
\end{tabular}

Table 47. Summary of Grade 2020 piggyback specimens located in the central channel of AGC-1.

\begin{tabular}{|c|c|}
\hline \multicolumn{2}{|c|}{ Grade 2020} \\
\hline Location & Dose, dpa \\
\hline CPB-7 & 0.77 \\
\hline CPB-187 & 1.18 \\
\hline CPB-17 & 1.32 \\
\hline CPB-177 & 1.82 \\
\hline CPB-27 & 1.83 \\
\hline CPB-37 & 2.28 \\
\hline CPB-167 & 2.36 \\
\hline CPB-47 & 2.68 \\
\hline CPB-157 & 2.81 \\
\hline CPB-57 & 3.03 \\
\hline CPB-147 & 3.18 \\
\hline CPB-67 & 3.32 \\
\hline CPB-137 & 3.46 \\
\hline CPB-77 & 3.55 \\
\hline CPB-127 & 3.66 \\
\hline CPB-87 & 3.71 \\
\hline CPB-117 & 3.79 \\
\hline CPB-97 & 3.81 \\
\hline СРB-107 & 3.83 \\
\hline
\end{tabular}


Table 48. Summary of Grade PCIB piggyback specimens located in the central channel of AGC-1.

\begin{tabular}{|c|c|}
\hline \multicolumn{2}{|c|}{ Grade PCIB } \\
\hline Location & Dose, dpa \\
\hline CPB-8 & 0.83 \\
\hline CPB-188 & 1.11 \\
\hline CPB-18 & 1.37 \\
\hline CPB-178 & 1.76 \\
\hline CPB-28 & 1.87 \\
\hline CPB-168 & 2.31 \\
\hline CPB-38 & 2.32 \\
\hline CPB-48 & 2.72 \\
\hline CPB-158 & 2.77 \\
\hline CPB-58 & 3.06 \\
\hline CPB-148 & 3.15 \\
\hline CPB-68 & 3.35 \\
\hline CPB-138 & 3.44 \\
\hline CPB-78 & 3.57 \\
\hline CPB-128 & 3.65 \\
\hline CPB-88 & 3.72 \\
\hline CPB-118 & 3.78 \\
\hline CPB-98 & 3.81 \\
\hline CPB-108 & 3.83 \\
\hline
\end{tabular}

Table 49. Summary of Grade BAN piggyback specimens located in the central channel of AGC-1.

\begin{tabular}{|c|c|}
\hline \multicolumn{2}{|c|}{ Grade BAN } \\
\hline Location & Dose, dpa \\
\hline CPB-9 & 0.88 \\
\hline CPB-189 & 1.04 \\
\hline CPB-19 & 1.43 \\
\hline CPB-179 & 1.70 \\
\hline CPB-29 & 1.92 \\
\hline CPB-169 & 2.26 \\
\hline CPB-39 & 2.37 \\
\hline CPB-159 & 2.73 \\
\hline CPB-49 & 2.76 \\
\hline CPB-59 & 3.09 \\
\hline CPB-149 & 3.11 \\
\hline CPB-69 & 3.37 \\
\hline CPB-139 & 3.41 \\
\hline CPB-79 & 3.59 \\
\hline
\end{tabular}


Table 49 (cont.)

\begin{tabular}{|c|c|}
\hline \multicolumn{2}{|c|}{ Grade BAN } \\
\hline Location & Dose, dpa \\
\hline CPB-129 & 3.63 \\
\hline CPB-89 & 3.74 \\
\hline CPB-119 & 3.77 \\
\hline CPB-99 & 3.82 \\
\hline CPB-109 & 3.83 \\
\hline
\end{tabular}

Table 50. Summary of Grade NBG-10 piggyback specimens located in the central channel of AGC-1.

\begin{tabular}{|c|c|}
\hline \multicolumn{2}{|c|}{ Grade NBG-10 } \\
\hline Location & Dose, dpa \\
\hline CPB-10 & 0.94 \\
\hline CPB-190 & 0.97 \\
\hline CPB-20 & 1.48 \\
\hline CPB-180 & 1.64 \\
\hline CPB-30 & 1.97 \\
\hline CPB-170 & 2.21 \\
\hline CPB-40 & 2.41 \\
\hline CPB-160 & 2.69 \\
\hline CPB-50 & 2.79 \\
\hline CPB-150 & 3.08 \\
\hline CPB-60 & 3.12 \\
\hline CPB-140 & 3.39 \\
\hline CPB-70 & 3.40 \\
\hline CPB-80 & 3.60 \\
\hline CPB-130 & 3.61 \\
\hline CPB-90 & 3.75 \\
\hline CPB-120 & 3.76 \\
\hline CPB-100 & 3.82 \\
\hline CPB-110 & 3.83 \\
\hline
\end{tabular}


Table 51 summarizes the $\mathrm{SiC}$ temperature monitors location within the center channel of AGC-1 and reports the estimated neutron dose (dpa) per specimen.

Table 51. Location and dose of the SiC temperature monitors in the central channel of AGC-1.

\begin{tabular}{|c|c|}
\hline \multicolumn{2}{|c|}{ SiC Temperature Monitors } \\
\hline Location & Dose, dpa \\
\hline Cluster 1 & 0.74 \\
\hline Cluster 2 & 1.30 \\
\hline Cluster 3 & 1.81 \\
\hline Cluster 4 & 2.26 \\
\hline Cluster 5 & 2.67 \\
\hline Cluster 6 & 3.02 \\
\hline Cluster 7 & 3.21 \\
\hline Cluster 8 & 3.54 \\
\hline Cluster 9 & 3.71 \\
\hline Cluster 10 & 3.81 \\
\hline Cluster 11 & 3.83 \\
\hline Cluster 12 & 3.79 \\
\hline Cluster 13 & 3.67 \\
\hline Cluster 14 & 3.48 \\
\hline Cluster 15 & 3.20 \\
\hline Cluster 16 & 3.83 \\
\hline Cluster 17 & 2.39 \\
\hline Cluster 18 & 1.85 \\
\hline Cluster 19 & 1.22 \\
\hline
\end{tabular}




\section{MATERIALS PRECHARACTERIZATION}

Graphite preirradiation examination and characterization will be performed at ORNL to take advantage of existing facilities and expertise. The graphite billets purchased ${ }^{9}$ for capsule AGC-1 will be sectioned and specimens machined in accordance with cutting plans that take into account textural variations within the graphite billets. The cutting plans will be reported in the preirradiation examination report. All graphite samples will be laser engraved with a unique number identifying the graphite grade, location within the billet, and orientation with respect to the forming direction. For the AGC-1 capsule, all graphite piggyback specimens will be cut with their length direction parallel to the forming direction (with-grain). However, HOPG will be an exception and will be machined with its length (thickness) parallel to the crystallographic $<\mathrm{c}>$-axis and its diameter parallel to the $<\mathrm{a}>$-axis. The stressed/unstressed creep specimens will not all be cut parallel to the forming direction. Approximately one-third of the samples per grade will be machined with their length parallel to the against-grain direction. This will yield both with-grain (WG) and against-grain (AG) creep strain data. Both specimen orientations are required to demonstrate that the creep coefficient is independent of orientation.

The codes in Table 52 will be used to designate the graphite grades included in capsule AGC-1.

Table 52. Graphite grade marking codes to be used for the AGC series of experiments.

\begin{tabular}{|c|l|}
\hline Graphite Code Letter & Graphite Grade \\
\hline A & NBG-17 \\
\hline B & NBG-18 \\
\hline C & H-451 \\
\hline D & PCEA \\
\hline E & IG-110 \\
\hline F & IG-430 \\
\hline G & HOPG \\
\hline H & A3-MATRIX \\
\hline J & HLM \\
\hline K & PGX \\
\hline L & PPEA \\
\hline M & NBG-25 \\
\hline N & 2020 \\
\hline$P$ & PCIB \\
\hline$R$ & BAN \\
\hline S & NBG-10 \\
\hline
\end{tabular}

All machined specimens shall be subjected to visual inspection to check for damage and confirm the clarity of the laser marking and full dimensional inspection. Those specimens to be encapsulated in AGC-1 will be set aside, and only nondestructive testing shall be performed on them. The remaining specimens (controls) shall be tested to determine key physical properties as detailed below. Where possible, the testing will be carried out in accordance with the appropriate American Society for Testing and Materials (ASTM) specification(s). ${ }^{10}$ Figure 19 schematically shows the preirradiation test program. 
Nondestructive measurements to be performed include:

- Dimensions

- Mass (hence bulk density)

- Elastic modulus by the dynamic (fundamental frequency) technique and sonic velocity method, yielding Young's modulus, Shear modulus, and Poisson's ratio

- Thermal flash diffusivity at room temperature and as a function of temperature $\left(25-1200^{\circ} \mathrm{C}\right)$, and hence the thermal conductivity

- Thermal expansion $\left(25-1200^{\circ} \mathrm{C}\right)$ and hence the coefficient of thermal expansion (creep specimens only)

- Electrical resistivity (potentially useful as an indicator of structure and crystallinity).

These measurements will be made on all the specimens to be encapsulated in AGC-1 with the exception of the elevated temperature thermal diffusivity, which will be performed on a statistically representative sample of the piggyback specimens. Additional destructive tests to be performed on the companion samples include:

- X-ray diffraction (XRD) on powdered samples of the graphites (and hence the crystallographic parameters a, c, la, lc).

- Microstructural characterization via optical microscopy, scanning electron microscopy, and Hg-porosymmetry (hence grain and pore size distributions).

- Strength tests of the specimens, the test type being dependant on the specimen geometry, will provide compressive and flexural strength data.

The determination of which tests are applied to which specimens is influenced by a number of considerations, including sample geometry, graphite texture, statistical factors, test equipment availability, test duration and complexity, and cost/budget. The data that are produced will support not only the NGNP irradiation effects program but will provide valuable data for ongoing efforts in code and model development (e.g., the ASME design code for graphite core components). Analysis of the preirradiation data must take into account factors such as statistical variations, textural effects, and volume effects (irradiation specimens are of necessity very small volume).

The preirradiation characterization and testing of graphites for the AGC-1 experiment will be reported in a preirradiation data report and in electronic format (spreadsheets). The preirradiation report will include details of the following:

- Graphite grades and billet sizes

- Cutting plans

- Specimen numbering scheme

- Test/experimental methods

- Revised AGC-1 layouts (loading plans) with specimens identity numbers

- Tabulated data by grade

- Specific preirradiation data on the AGC-1 encapsulated specimens

- Preirradiation data from AGC-1 control specimens

- Analysis and discussion of the preirradiation data. 


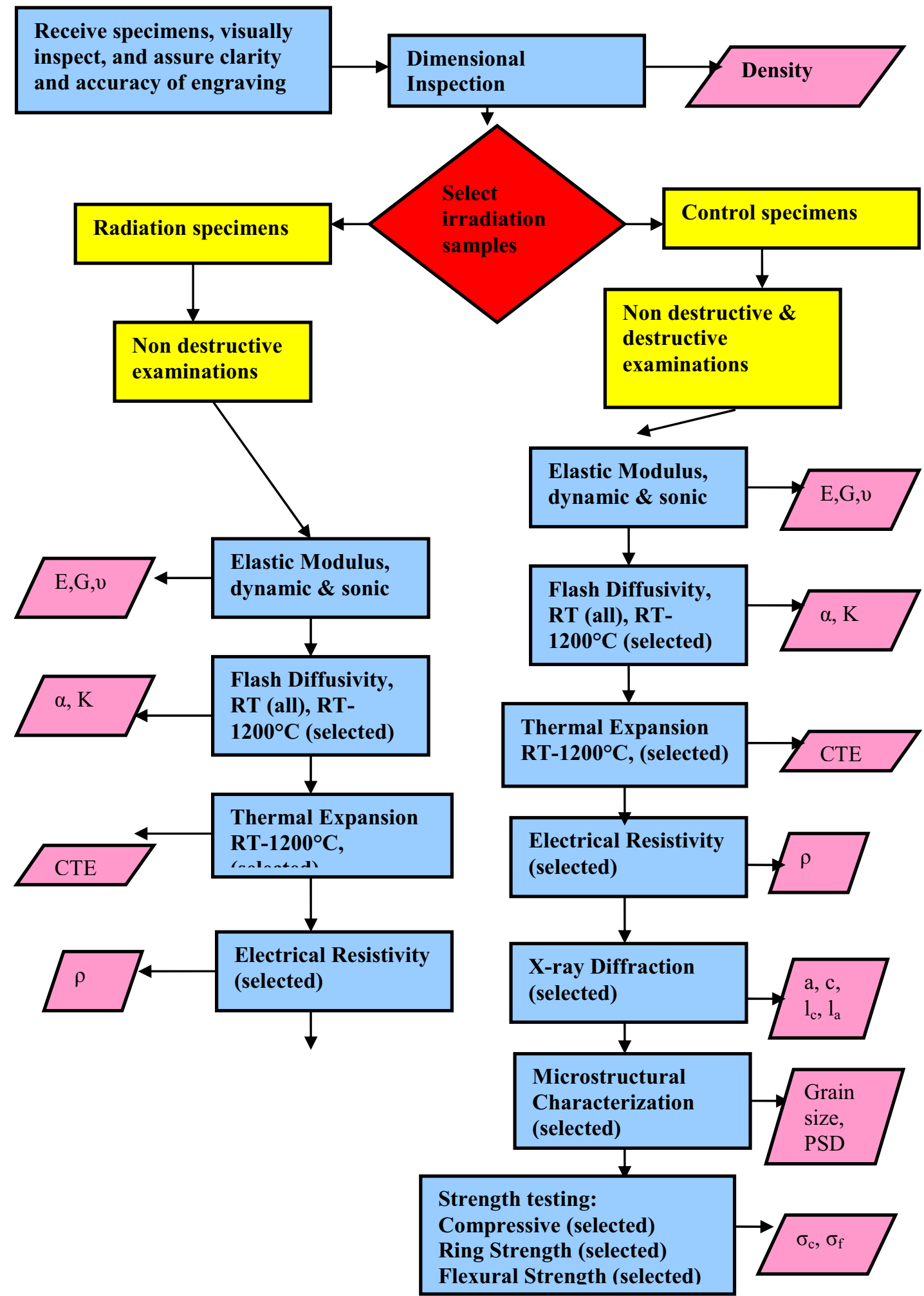

Figure 19. Preirradiation data process flow chart for irradiation creep experiment AGC-1. 


\section{POSTIRRADIATION EXAMINATION}

Following completion of the specified irradiation period, the AGC-1 capsule contents will be subjected to PIE. The anticipated PIE process is illustrated in Figure 20.

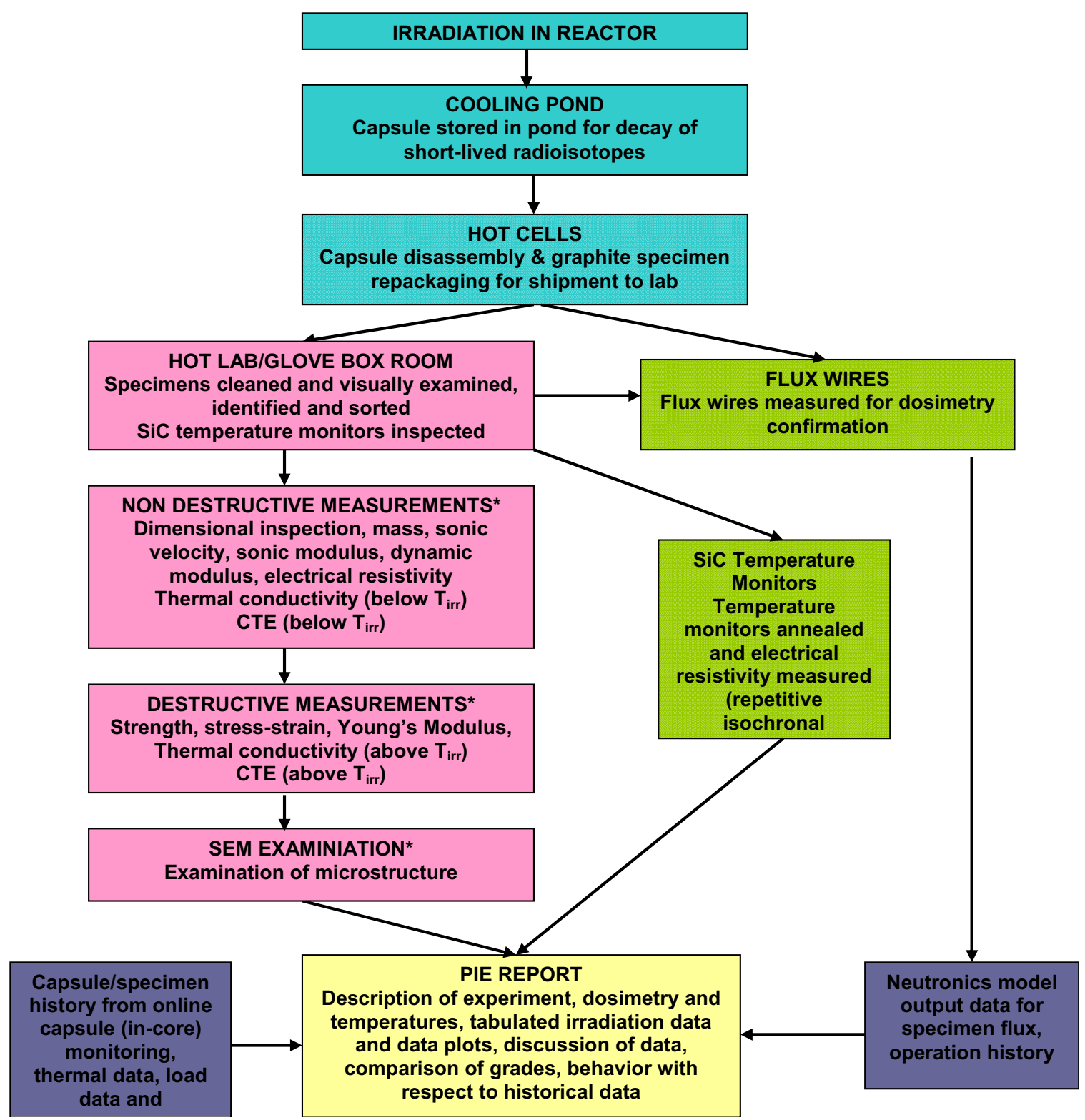

Figure 20. The postirradiation examination process for ATR experiment AGC-1.

After the requisite time in the cooling ponds at ATR, the capsule will be shipped in a commercial cask to the Hot Fuels Examination Facility at the Idaho National Laboratory (INL) for disassembly. The flux wires will be retained by INL for testing (gamma scans), and the data will be used to calibrate the flux model (see Section 4.2). The graphite specimens and $\mathrm{SiC}$ temperature monitors will be visually inspected and packaged for shipment to ORNL where PIE will be conducted. Prudent engineering practice dictates that the PIE should be conducted at the same laboratory as the preirradiation examination. This precludes the occurrence of bias in the data that can originate from differences in test 
methods and machines, instruments, and personnel. PIE of the SiC temperature monitors in the manner described in Section 4.2 will provide additional data to calibrate the thermal model and allow accurate determinations of the irradiation temperature.

All the samples will be subjected to full dimensional analysis and will be weighed for bulk density determinations. The exact nature and order of the PIE measurements depends on irradiation sample geometry, the destructive tests being performed last. Critical PIE data for the AGC-1 experiment are those data related to the irradiation induced creep behavior and its analysis (as described in Section 2). These data include:

- Dimensional changes of the stressed and unstressed creep specimens, and hence the apparent creep strain as a function of dose

- The dimensional changes of HOPG in the with-grain $(<\mathrm{a}>)$ direction and against-grain $(<\mathrm{c}>)$ direction, and hence the parameter XT as function of dose

- The thermal expansion of the stressed and unstressed creep samples, and hence the coefficient of thermal expansion and the term $\left(\alpha_{x}^{\prime}-\alpha_{x}\right)$.

These PIE data will allow the complete analysis of the irradiation induced creep data and estimation of the creep coefficient from the linear creep model (Equation 2). Data on the effects of creep strain on coefficient of thermal expansion will also be highly beneficial for the ASME design code currently being developed for graphite components. AGC-1 graphite PIE data will support model development in the areas of irradiation-induced dimensional change behavior, thermal conductivity, and fracture behavior. Additional PIE data to be obtained from the graphite creep specimens include:

- Dimensional change data

- Elastic constants (E, G, v)

- Electrical resistivity

- Thermal conductivity, room temperature, and elevated temperature

- Strength

- Microstructural characterization.

Moreover, similar data on the effects of neutron dose will be obtained from PIE of the graphite piggyback specimens, including dimensional and density changes. The amount of PIE to be performed is budget dependant. PIE measurements are considerably more complex (and hence costly) than preirradiation measurements, because the samples must be handled and tested in gloveboxes.

The PIE data shall be reported in a PIE report that will give details of the measurements made, the experimental flux and thermal data, the revised dosimetry and temperature estimates, graphite PIE data and analysis, and revised creep models and creep coefficient. 


\section{GRAPHITE IRRADIATION}

\subsection{Graphite Qualification Program}

Graphite irradiated mechanical and thermal properties are required to design a nuclear reactor core using graphite as the structural material. Unlike the nuclear fuel that is replaced on a periodic basis, the graphite structure remains in-place. The length of time the graphite remains in the core depends on the fluence accumulation, the service temperature and the grade of graphite used. The perspective graphite candidates have no irradiation history. The reactor candidates for the NGNP will use graphite as the structural material for the cores. The range of normal operating temperatures is bounded for a prismatic core between 600 and $1200^{\circ} \mathrm{C}$ with a maximum prototypical neutron fluence of 6 to 7 dpa with $\mathrm{E}>0.1$ $\mathrm{MeV}$. The prismatic reactors historically saw graphite fuel blocks with peak doses of 5 to $6 \mathrm{dpa}$. The peak fluence requirement could go higher if the decision is made to reuse the fuel blocks. The PBR expects to see peak doses in the inner graphite reflector of approximately 34 dpa for a 35 effective full power year life. The discrepancy in the two dose levels is due to the PBR retaining its reflector for a much longer period of time.

A third of the graphite fuel blocks would be replaced every 2 years in a prismatic core. Therefore, some fuel blocks would see irradiation exposures up to 6 years. Prismatic graphite reflectors blocks would usually be replaced every 6 years. Based on this information, the AGC-1 will support the prismatic core and not directly the pebble bed core. Although the upper limit of $7 \mathrm{dpa}$ in the AGC capsule series is an incremental step toward reaching the higher doses, a different series of the experiments would have to be performed to reach the higher doses to support the pebble bed core.

A program of six irradiation experiments has been proposed to acquire the irradiated mechanical and thermal properties of these candidate graphites. There are six graphite irradiation capsules planned for irradiation in ATR. There will be two capsules irradiated at $600,900,1200^{\circ} \mathrm{C}$, respectively. For each temperature, there will be one capsule irradiated from 0.5 to 4 dpa and the second capsule irradiated from 4 to $7 \mathrm{dpa}$. Each capsule will be assembled with unirradiated specimens to acquire the full dose in a continuous irradiation. AGC-1 will be the lead off capsule for the series and will be irradiated at a temperature of $900^{\circ} \mathrm{C}$ with a dose of 1 to $4 \mathrm{dpa}$.

The primary objective of irradiation capsule AGC-1 is to provide irradiation creep design data, and data for the effects of irradiation creep on key physical properties, for the NGNP candidate graphites as well as for other graphites. These other graphites will be used to gather additional information on irradiated graphite behavior to supplement computational graphite performance modeling for the NGNP program. Such data include:

- Dimensional changes

- Strength

- Elastic modulus

- Thermal conductivity

- Coefficient of thermal expansion over the neutron dose range $0.53 \times 10^{21} \mathrm{n} / \mathrm{cm}^{2}-3.9 \times 10^{21} \mathrm{n} / \mathrm{cm}^{2}$ [E>0.1 MeV] or 0.39-4.2 displacements per atom (dpa) at an irradiation temperature of $900^{\circ} \mathrm{C}$.

Moreover, this experiment will provide valuable data on the single crystal irradiation behavior of graphites to be derived from the inclusion of HPOG in this experiment. 
As stated in Section 2, the graphites grades to be included in the AGC-1 capsule can be categorized as follows.

\section{A. Major Grades}

NGNP has selected grades NBG-18 for the PBR and PCEA for the prismatic reactor design. These grades are most likely to receive reasonably large neutron doses in their lifetime and will be subjected to significant stresses in operation. Consequently, these grades occupy the stressed and companion unstressed position in the capsule and yield irradiation creep data. The other major grades are NBG-17 and IG-430. These grades will be used to broaden the graphite performance models. Two historical (reference) grades H-451 and IG-110 are included since these are grades used in the past gas reactors. Historical data is available for these grades which can be used for comparison.

B. Minor Grades

These grades are relevant to the NGNP graphite component design by providing irradiation data on different graphite grades. The irradiation information will be used to further the understanding of all graphite irradiation behavior in computational graphite performance models used to predict graphite lifetimes for different grades.

\section{Alternate Grades}

These grades are chosen to evaluate the difference in irradiation performance between petroleum and coal coke and between extruded and iso-molded grades. The irradiation information will be used to further the understanding of all graphite irradiation behavior in computational graphite performance models used to predict graphite lifetimes fordifferent grades.

D. Experimental Grades

Two experimental graphites are included in AGC-1 (BAN and A3 matrix). BAN is an experimental grade, secondary coke graphite whose manufacturing process and raw materials are such that it should offer superior irradiation stability. BAN will be studied for future use as well as an analog to recycled graphite. A3 matrix is the blend of graphites and carbonized phenolic resin used as the matrix in the NGNP fuel compact or fuel pebble. Samples of A3 are to be obtained from the AFCI/AGR fuel program and will be produced at ORNL.

\section{E. Single-Crystal Graphite}

The dimensional change behavior of graphite is particularly significant to the behavior of polycrystalline (polygranular) graphites. Therefore, samples of HOPG are included in AGC-1.

A more complete description of all the graphite samples included in capsule AGC-1 is given in Sections 4 and 5 of this report.

\subsection{Experimental Position in the Advanced Test Reactor}

The AGC-1 will be located in the south flux trap in the ATR shown in Figure 21. Only the three available flux trap positions can support the graphite irradiation because of the requirement of space above and below the core and the inherent fast flux levels in the experimental positions (see Figure 22). The east flux trap has an established program already operating in the location. The center flux trap is being planned for a future irradiation program. The other ATR positions have insufficient fast flux and 
space above and below the core. The south flux trap is usually operated at higher power levels than the north flux traps. The final configuration of the ATR core is not known for the expected insertion time period beginning FY-08. In fact, there is ongoing planning for experiments in position around the south flux trap that will affect the current assumptions used to design the AGC-1 experiment. A final thermal analysis can not be completed until the ATR core configuration is known for the reactor cycles for which the experiment will be inserted. For this reason, much of the capsule design in this report is preliminary, and the final analyses will be incomplete until the final ATR core configuration is known.

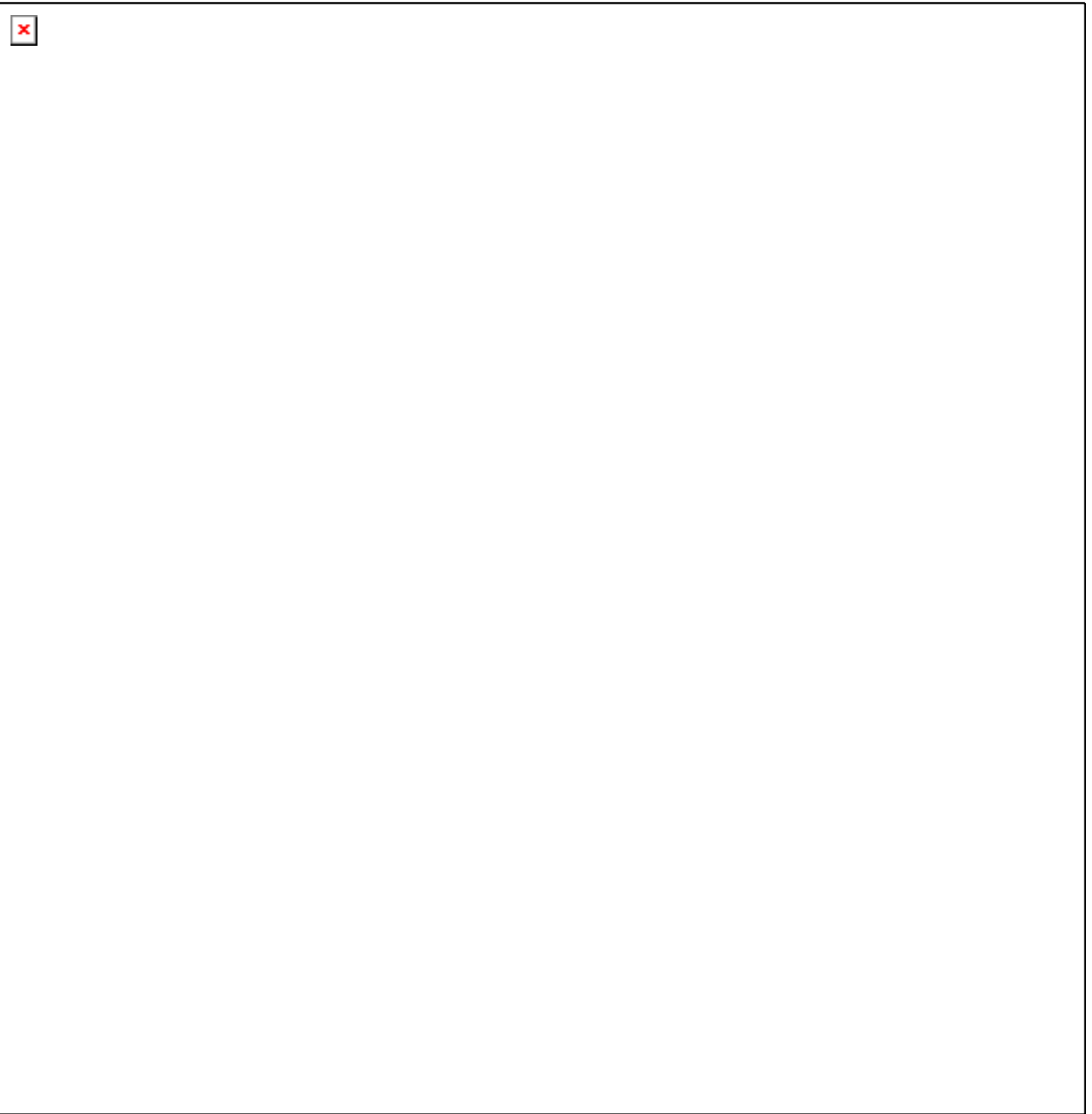

Figure 21. Experimental positions in the Advanced Test Reactor core. 

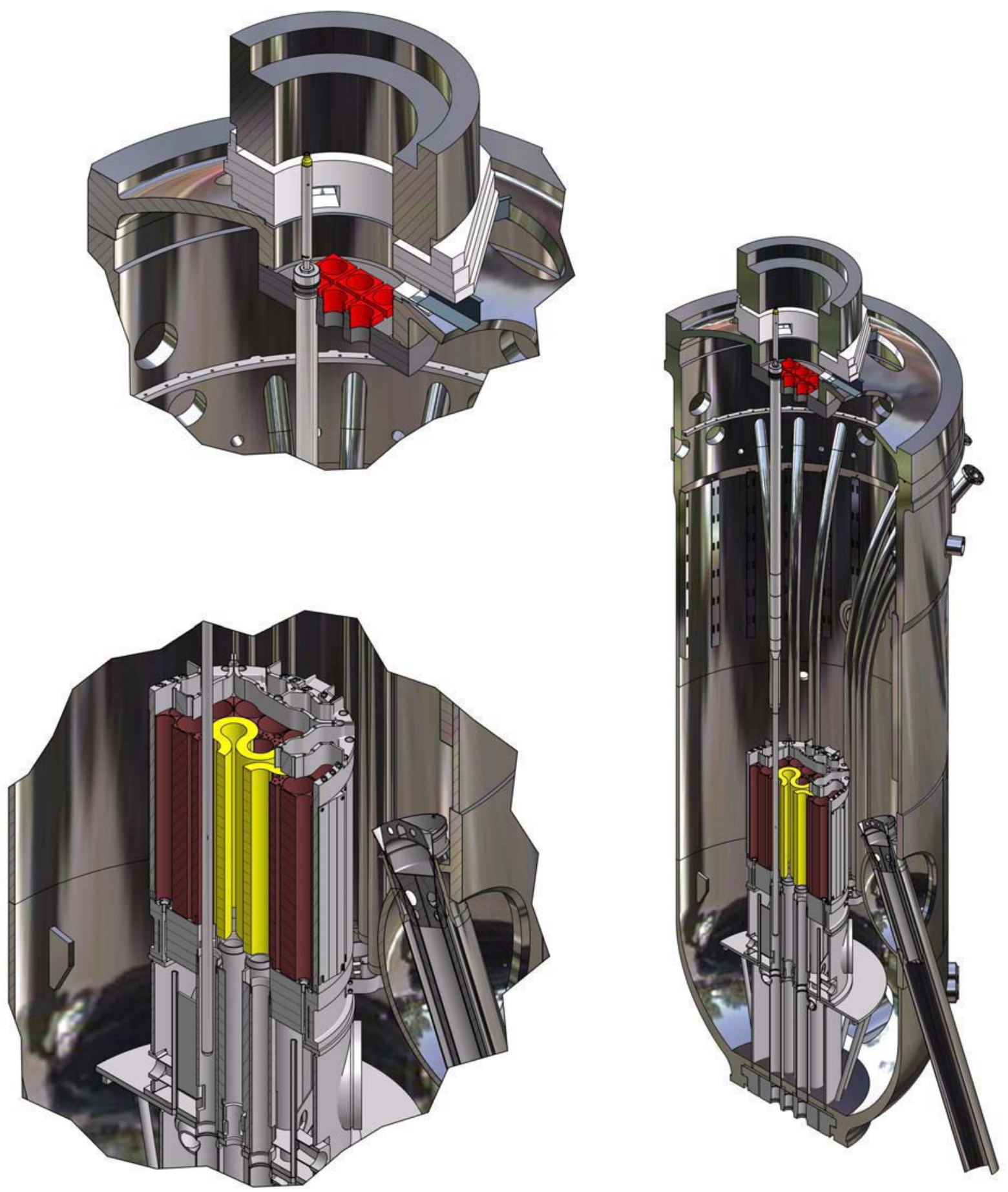

Figure 22. Cutaway of the ATR core showing the space above and below the experiment will occupy. 


\section{AGC-1 CREEP CAPSULE REQUIREMENTS}

The AGC-1 irradiation capsule will apply two stress levels: $13.8 \mathrm{MPa}$ (2 ksi) and $20.7 \mathrm{MPa}$ (3 ksi). These stress levels were chosen based on previous graphite compressive capsules irradiated at the ORNL in the 1970s and 1980s (see References 3 and 11 and detailed discussions with reactor vendors via the ASME graphite core design project team). To measure the irradiation-induced creep, companion unstressed graphite specimens are required. The apparent irradiation creep strain may thus be determined from the difference in the dimensional changes between a stressed and unstressed sample pair irradiated at the same temperature and to the same neutron damage dose. There are also a large number of smaller, piggyback samples of VHTR relevant graphites. These piggyback specimens do not provide irradiation creep data, but do provide valuable physical properties data. The center channel of capsule AGC-1 additionally accommodates a large number of piggyback samples as well as $\mathrm{SiC}$ temperature monitors whose purpose is to provide a postirradiation check on the irradiation temperature and thus allow for affirmation of the real time temperature data from the capsule thermocouples.

During operation, the capsule will maintain a constant compressive load and specimen temperature during reactor power level changes. A constant axial temperature is achieved by adjusting the mixture of two sweep gases used to set up a quasi-stagnant gas conduction gap between objects. To a lesser extent radiation heat transfer also controls the temperature. The axial cosine flux shape reduces gamma heat generation in the ends of the experiment. To offset the decrease of temperature in the ends of the experiment, the temperature drop across the gaps between bodies must linearly increase axially toward the ends. At core centerline, the gaps are at their narrowest and then increase to their maximum separation at the top and bottom of the capsule. Twelve thermocouples are distributed along the 48-in. axial length. Any one of the 12 thermocouples signals can be used as input for the temperature control system. SiC temperature monitors will be installed in the interior of the experiment and will be interrogated during Post Irradiation Exam for the maximum temperature in the experiment.

Six flux wires $(2 \mathrm{Fe}, 2 \mathrm{Ni}$, and $2 \mathrm{Nb}$ ) will be used to assess the neutron fluence for $\mathrm{E}>0.1 \mathrm{MeV}$ along the length of the experiment. The expected irradiation duration is approximately 170 full power reactor days. 


\section{AGC-1 DESIGN}

Prior graphite compressive creep capsule irradiations performed at ORNL and INL used pneumatically loaded graphite specimens in columns distributed in a graphite body. The most extensive series of graphite compressive creep irradiations were the OC series performed at ORNL. A lesson learned from these experiments will be incorporated into the AGC series of capsules. In the OC series, corrugated bellows were used to impart forces on the graphite specimens and were later installed in the bottom of the experiment to move the graphite specimens upwards to prevent specimens sticking in the graphite experiment body. If the specimens become jammed in the graphite body the stack of graphite specimens become unresponsive to the applied load. This type of arrangement of bellows above and below the core could only be achieved in the ATR flux traps because no other positions in the ATR core have the space above and below the core.

The use of bellows in the AGC capsule series is considered a greater risk than using off-the-shelf common pneumatic cylinders or rams. To make a bellow perform like a pneumatic ram requires that metal plates be welded on both ends of corrugated bellows stock with one of the plates taped for a pressure fitting. The welded bellows then has to be calibrated for displacement and force versus applied pressure. The bellows used in the OC capsules were 1 in. in diameter and operated at high pressures, 4.89 $\mathrm{MPa}$ (854 psig), to obtain the force necessary to achieve the desired compressive loads. The use of those bellows in the ATR core could pose safety issues, because the bellows are not ASME-certified pressure vessels. Commercially available pneumatic rams will be used in the AGC capsules that operate at pressures less than $1.7 \mathrm{MPa}(250 \mathrm{psig})$ and provide the same mechanical force as the 1-in. bellows. The commercial pneumatic cylinders are larger than the bellows. Nevertheless, space exists in the experiment to house all six cylinders above the core. The size of the pneumatic rams used in the bottom of the experiment is much smaller, because they only need to lift the stack of graphite without the applied load of the upper rams. These cylinders will be located below the core (see Figure 23).

The experiment is contained in a modified loop-experiment in-pile assembly (see Figure 24). This configuration was chosen to establish a dry isolated chamber inside the reactor vessel and core. The experiment tube becomes a pressure vessel inside the ATR reactor vessel and maintains the seep gas at an internal pressure of one atmosphere while the ATR operational pressure of 26.2 atmospheres is applied to the external boundary. ATR technical specifications limit the outer temperature of the tube to prevent departure of nucleate boiling in the reactor coolant. The tube wall temperature is controlled by convecting cooling on the outside of the tube and the temperature drop across the gap between the heat shield and the inner surface of the pressure boundary. The temperature drop is controlled by the variable sweep gas composition of He and Ar.

The in-pile tube hangs from the vessel head approximately 26 feet into the vessel cavity and core and is fabricated from 304L stainless steel pipe. The first 13 feet has an outer diameter of five inches. The second 13 feet has a short transition from five inches to 2.5 inches. A section of tube with a 2.5 -inch outer diameter runs the remainder of the length. The vessel formed by the in-pile tube is designed and analyzed to ASME Section III, Class 3 pressure vessel specifications. 


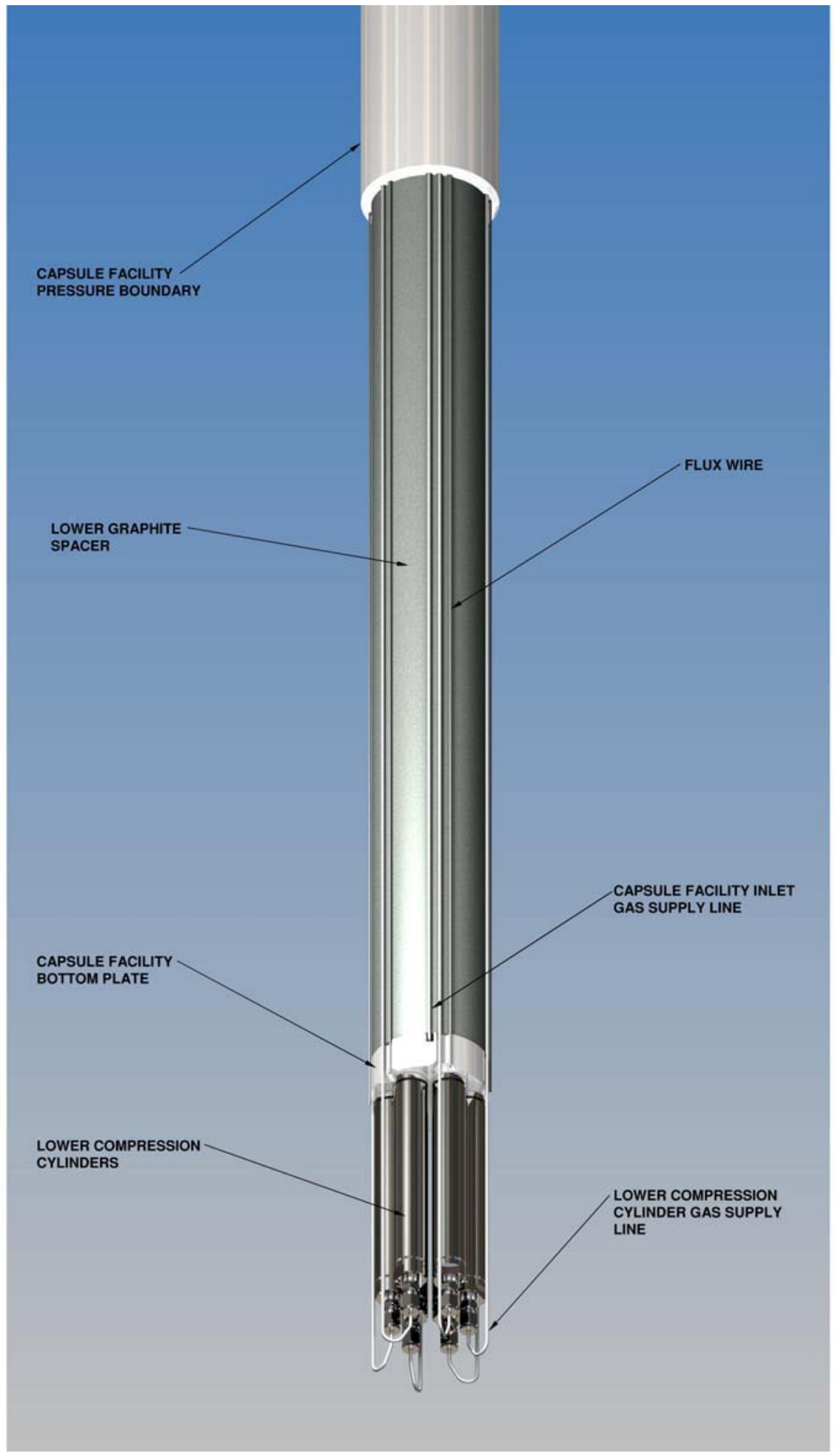

Figure 23. Arrangement of the lower pneumatic rams used to upset the graphite specimens during outages. 

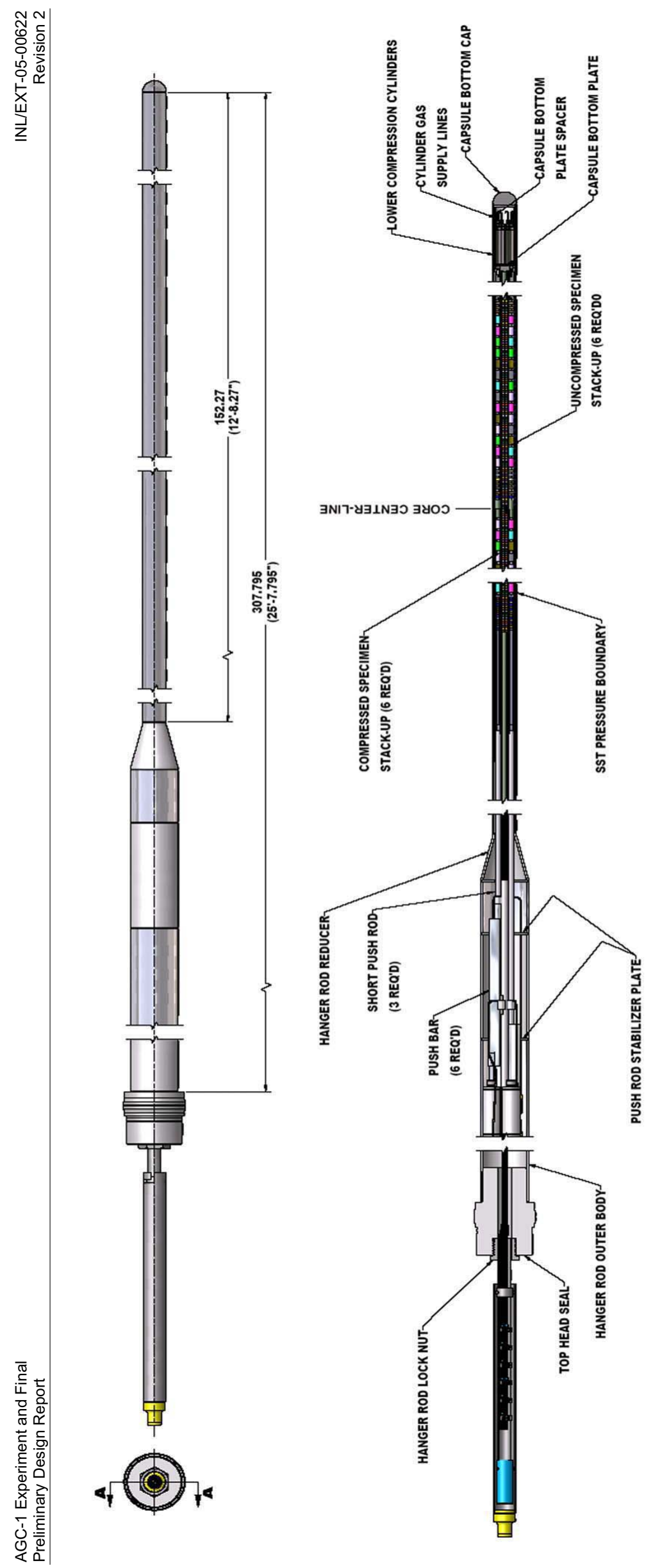

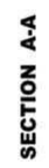


To accommodate the gas tubing and flux wires passage through the 4-foot core section, a 6-foot section of the 2.5-inch outer pressure tube spanning the 4-ft core section will have grooves machined into the inside wall by a broaching procedure developed by the ATR machine shop (see Figure 25a, b, and c). The grooves serve two purposes: (1) acting as guides to keep the flux wires and gas lines align down through the core and (2) reducing the temperature of the flux wires and gas lines. The tube wall thickness was increased to accommodate the grooves without reducing the tube thickness below the ASME required minimum wall thickness. The 6-ft. tube will be fabricated in two, 3-foot sections to accommodate machining limitations to obtain the accuracy required over the length of the tube. The gas gaps between the reactor and the outer diameter of the pressure tube and the gap between the inner diameter of the pressure boundary and the outer diameter of the graphite body play a major role in controlling the temperature.
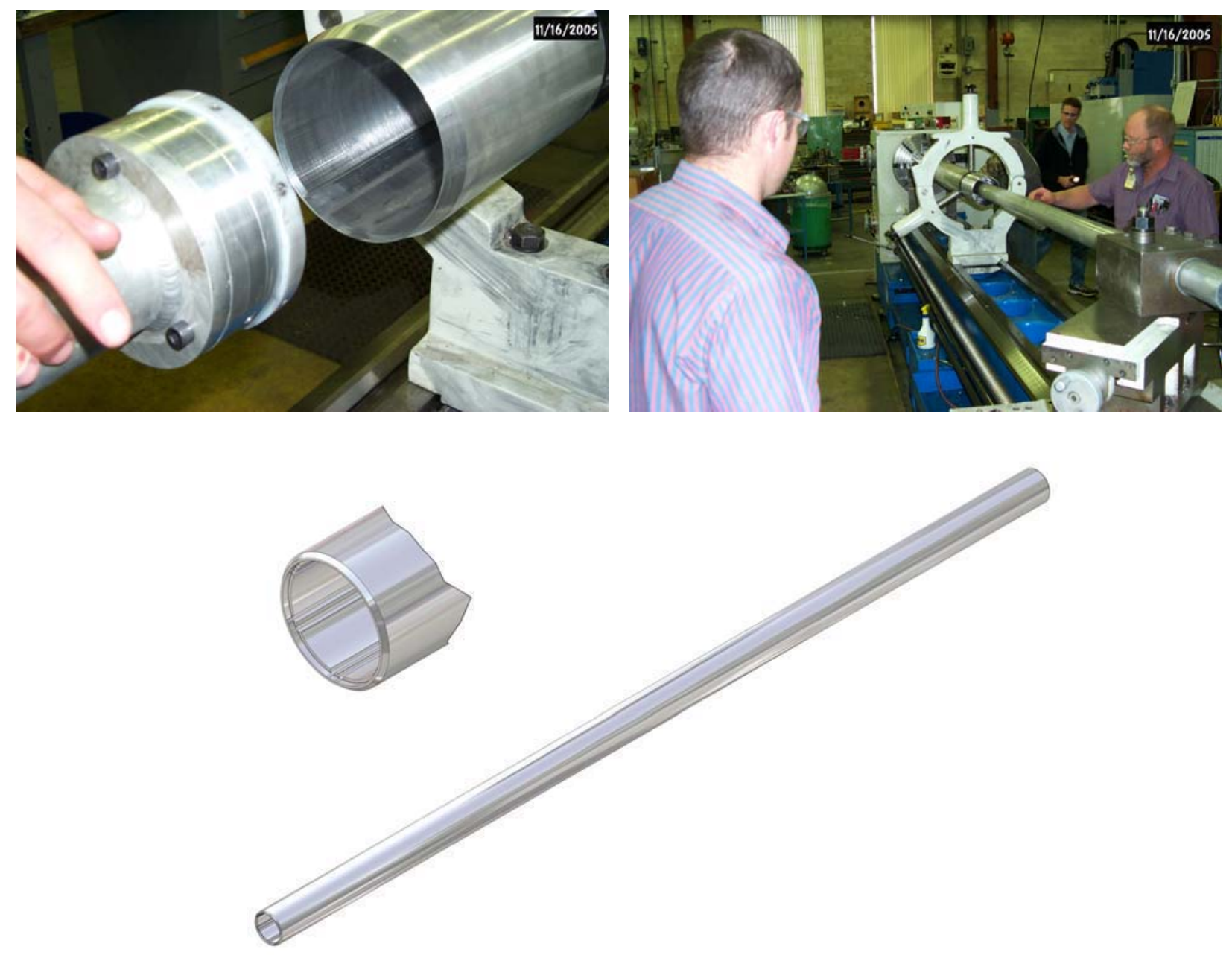

Figure 25a, b, and c. Grooved AGC-1 pressure boundary and broaching operation at the ATR machine shop

Different proposed designs were assessed for the arrangement of the specimens in the core. The arrangement chosen was six graphite specimen columns layed out in a circular pattern in the periphery of a cylindrical graphite body holder. An additional specimen column is located in the center of the graphite body (see Figure 26). 


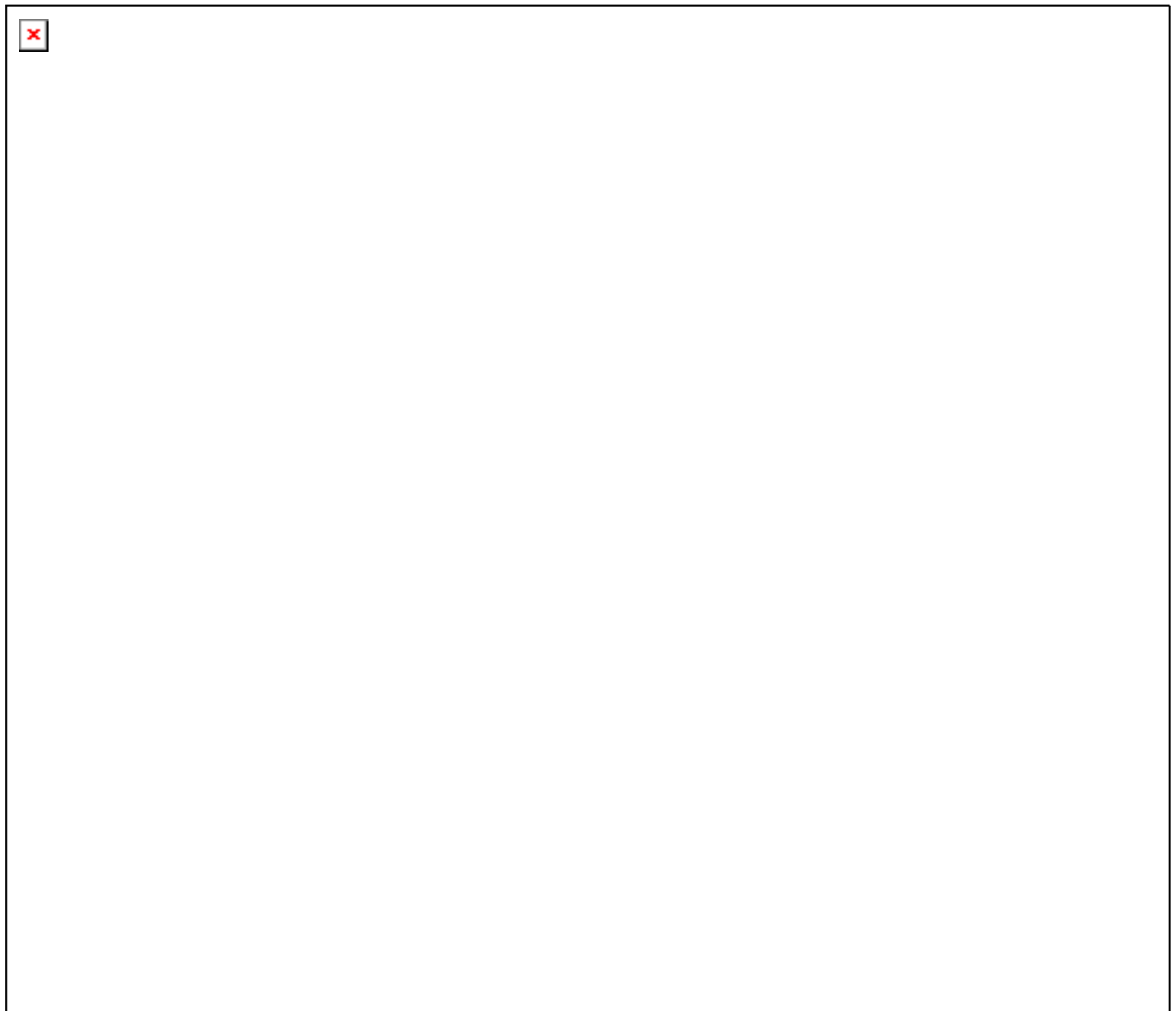

Figure 26. Cross section of the AGC-1 capsule located in the ATR core.

The graphite body provides a thermally similar material around the specimens and acts as a heat spreader distributing the generated gamma heat around all the specimens. Gamma heat is generated in the graphite specimens. Without the graphite body surrounding the specimens, the temperature gradients in the specimens would be large. Figure 27 shows the three graphite bodies that make up the graphite holder body and its support. The three bodies are machined from SGL NBG-25graphite, which has been purified to less than $3 \mathrm{ppm}$ of ash content. The three bodies are constructed from smaller sections which are glued together with a special graphitic adhesive. The smaller sections were necessary to maintain the accuracy of the runout and diameter of the 0.5 -inch specimen columns. Each of the glued-up bodies is heated to over $600{ }^{\circ} \mathrm{C}$ to cure and outgas. The adhesive was developed for graphite pieces in the electronics industry where outgasing at higher temperatures can not be tolerated. The smaller sections use annular dowels to align the three pieces. The dowels fit in the thermocouple holes which transverse the both holder bodies. The thermocouples do not go beyond the lower graphite support spacer. The upper and lower graphite holder bodies contain the graphite specimens. The outer diameter of the upper and lower graphite specimen holder varies with the height of the experiment. The variable outer diameter forms the variable gaps between the graphite and heat shield. The outer diameter of the two specimen holders is at their largest at the core centerline where the two graphite pieces are joined. The outer diameter reduces further away from the core centerline joint. The lower graphite spacer supports the two graphite experiment bodies by resting on the plate mounting the lower pneumatic rams. The lower support spacer also supports the heat shield. 

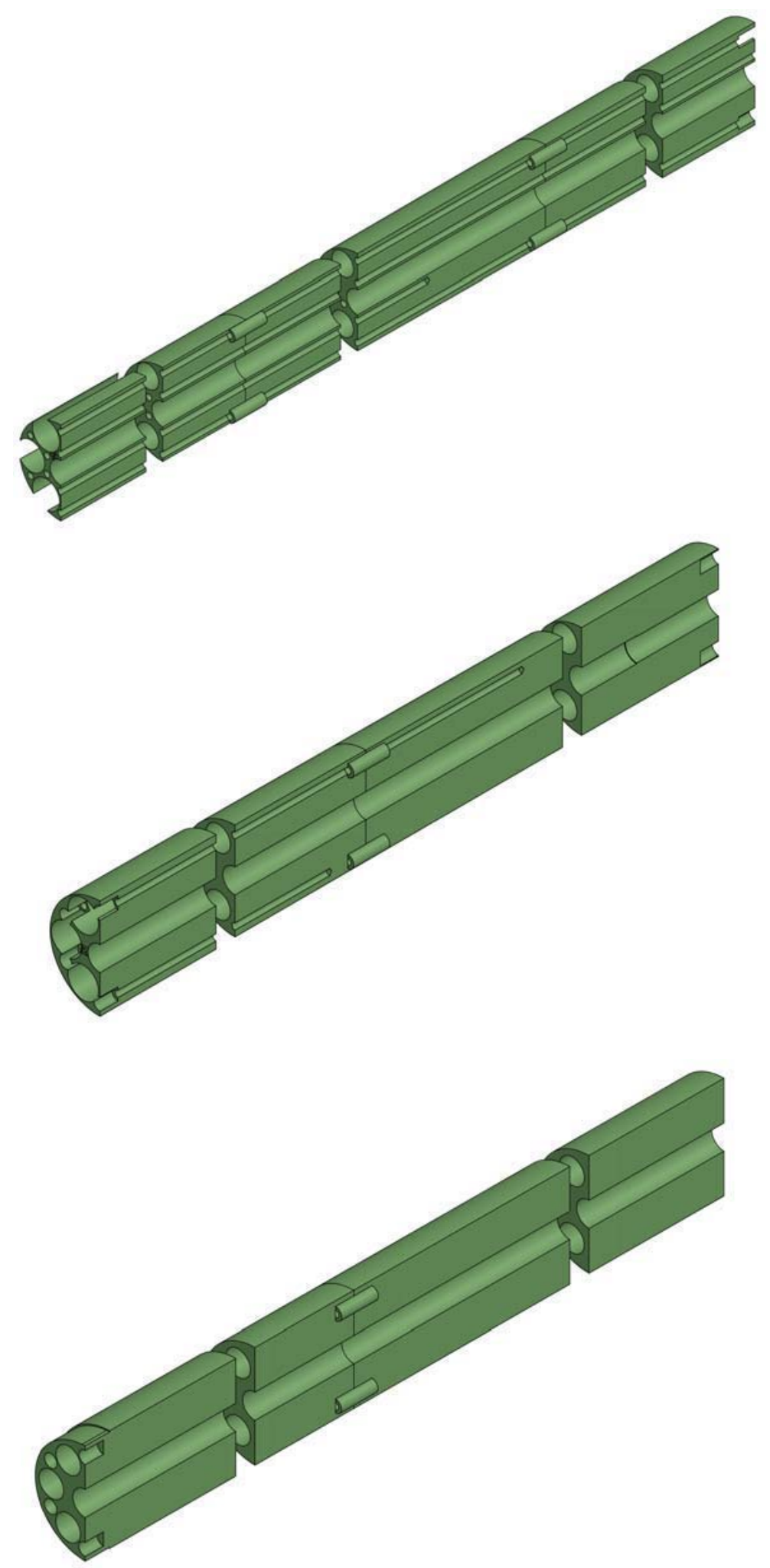

Figure 27. From top to bottom: graphite upper holder body, graphite lower holder body, and graphite lower spacer body 
In the OC series of irradiations, one entire column of graphite specimens was loaded with another adjacent column left unloaded to obtain the companion stressed and unstressed samples needed to irradiation induced creep. A review of flux wires assays in a previous south flux trap experiment, SFT-1, showed the flux gradient from north to south is large. Figure 28 shows the fast flux in the northeast and southeast location in the SFT-1 experiment in the south flux trap. The vertical bars are the percent difference between the fast fluxes at the same elevation for the northeast and southeast flux wires. These data show that loading one entire column in the northeast position and irradiating an unloaded column in the southeast position would yield a 30 to $35 \%$ difference in the fluence, which is too large for the data obtained to be useful. Therefore, the AGC capsules will use the symmetry of the flux buckling to irradiate the companion stressed and unstressed samples.

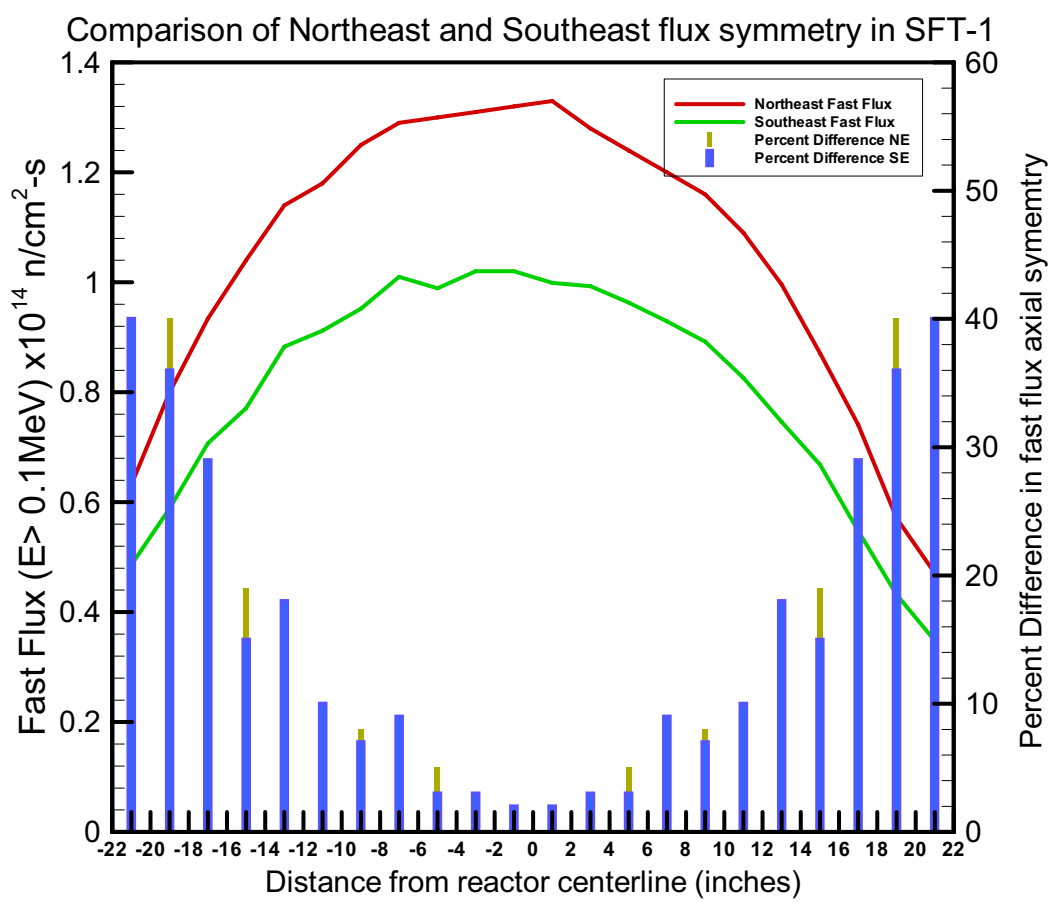

Figure 28. Symmetry of the axial flux profile in the south flux trap.

Figure 29 plots the same fast flux in the northeast and southeast location in SFT-1. The vertical bars show the percent difference in the fast flux at the same axial location above and below core centerline. This error represents symmetry in the axial cosine flux shape. The percent difference from \pm 15 in. from core centerline is acceptable fast flux symmetry to irradiate companion graphite specimens. This dictates having each capsule contain stressed and unstressed specimens to achieve the smallest difference in fast fluence between corresponding stressed and unstressed specimens. This is accomplished by isolating the load on the stressed specimens from the unstressed specimens at the centerline of the reactor. This feature increases versatility of the design. 


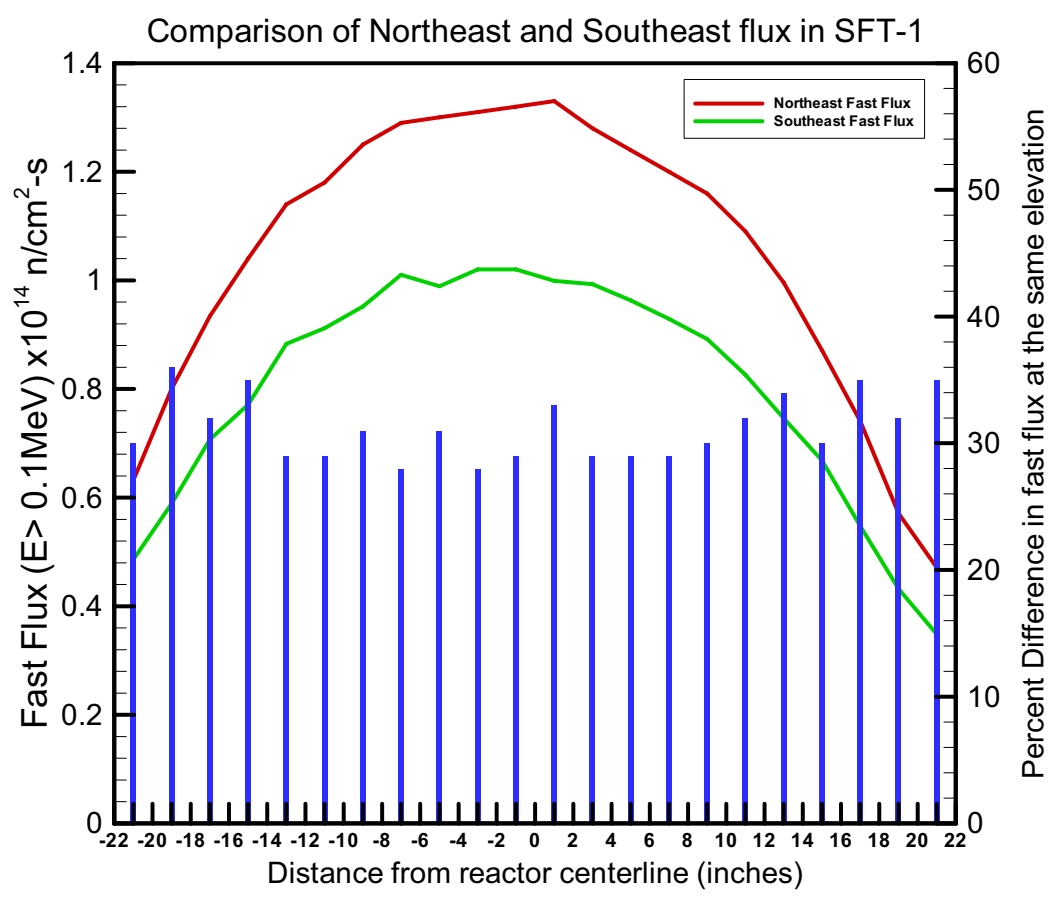

Figure 29. Comparison of the symmetry between the northeast and southeast position in the south flux trap. The vertical bars are the percent difference in the fast flux symmetry.

The heat transferred from the graphite body holder directly to the stainless steel outer pressure boundary would result in graphite temperatures less than $900^{\circ} \mathrm{C}$. Adding a metallic shield between the graphite body and the outer pressure boundary will reduce the heat transferred to the outer pressure boundary by thermal radiation and increase the temperature in the graphite body (see Figure 30).

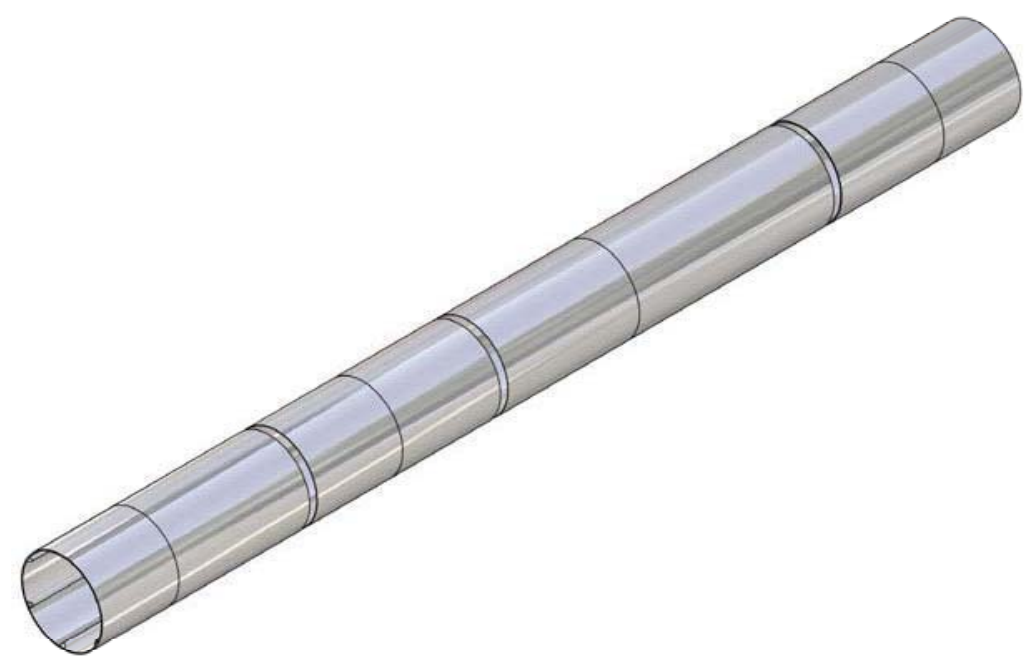

Figure 30. Haynes 230 thermal radiation shield. The spaces between pieces are drafting breaks to signified material removed to accommodate space on the page. 
The metallic shield will also generate additional heat because of gamma heating. The gamma heating is proportional to the flux, thus the amount of internal heat generated drops dramatically at the ends of the experiment. The thickness of the thermal radiation shield is varied from $0.025 \mathrm{in}$. at the top and bottom to $0.005 \mathrm{in}$. at the core's midsection. In this way, additional heat is generated at the ends where it is needed to compensate for the axial flux buckling. The material chosen for the radiation heat shield is alloy Haynes 230 . The maximum operational temperature is $1200^{\circ} \mathrm{C}$ for the metal; therefore it can be used in the $1200^{\circ} \mathrm{C}$ capsules. The heat shield is a tube of constant outer diameter and a varying inner diameter. The inner diameter is the largest at the core center of the tube where the tube wall thickness is 0.005 inches. The inner diameter decreases as a function of the distance from the core centerline. The tubes wall thickness increases to 0.025 inches at the top and bottom of the core. The accuracy of the tube requires the tube be machined from wrought annealed bar to minimize distortion from machining. The tube will be fabricated in smaller sections, which will be welded together by laser. The laser weld is accomplished by fabricating a lap joint between the smaller sections by means of electrode discharge machining. The lap joint is used to protect the graphite during welding. The power of the laser is adjusted to only penetrate just beyond one side of the lap joint to join the two pieces. The Figures $31 \mathrm{a}$ and $31 \mathrm{~b}$ show the setup of the lap joint used for laser welding and the heat affected zone of two 0.010 inch Haynes 230 coupons laser welded.
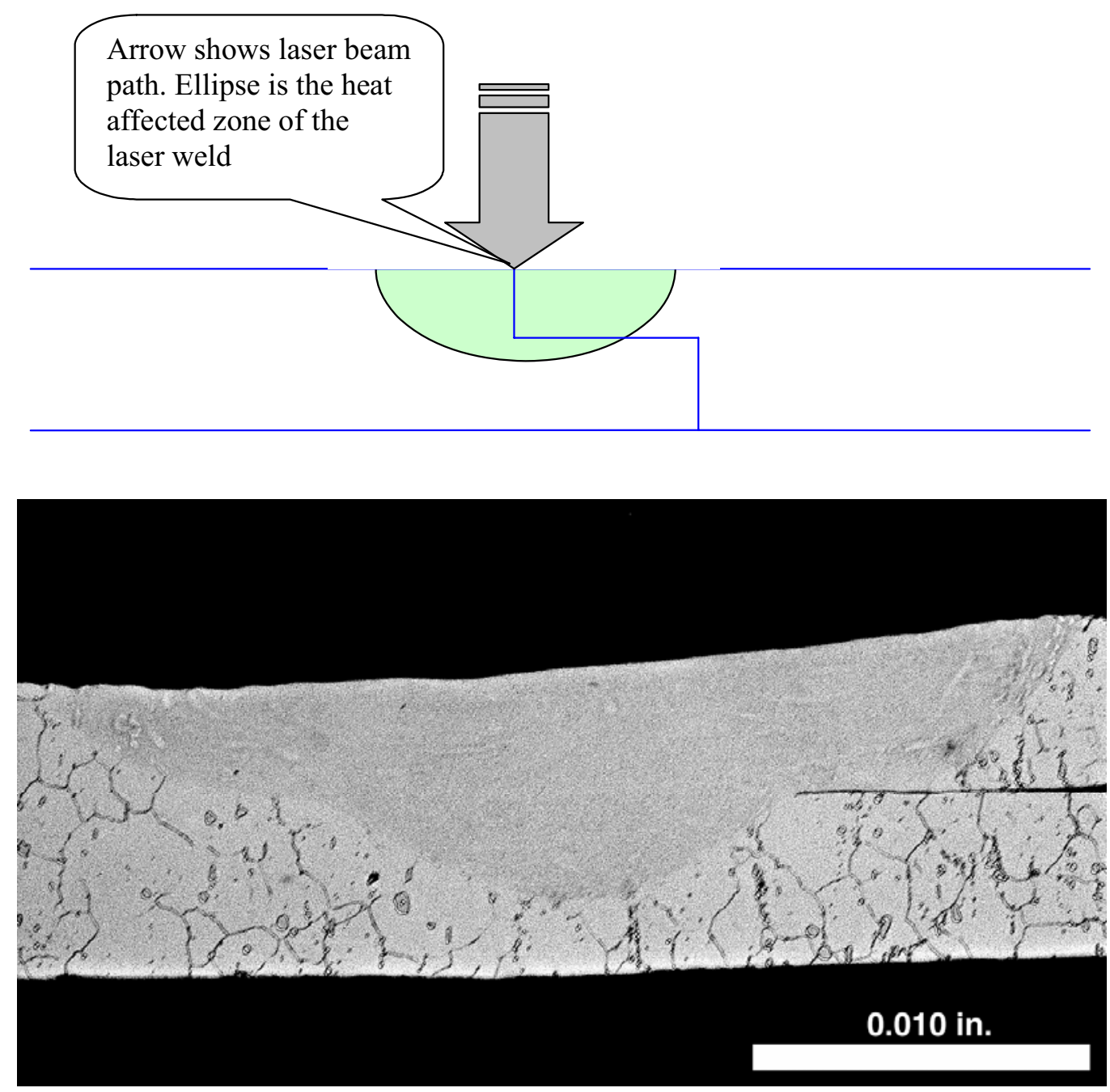

Figure $31 \mathrm{a}$ and $\mathrm{b}$. Laser weldment of two Haynes 2300.010 inch foil coupons 
During reactor power level changes, temperature control is achieved by varying the amount of argon in the helium sweep gas. This gas mixture controls the temperature drop across the gaps between the graphite body, thermal radiation shield, and outer pressure boundary by varying the conductivity of the gas. Figure 32 is a cutaway of the upper portion of the experiment above the core. The six cylinders are staged in two groups of three with the upper set offset by 60 degrees to allow access to space in between the lower set of three. The rams are joined to the upper stainless steel push rods by an oval push rod. The oval geometry was chosen to resist bending moments by offset connection to the upper stainless steel pushrod. The offset is required to align the push rod directly above the graphite specimen column. In-line load cells are installed in the ends of the stainless steel push rods, which will read the force exerted by the push rod on the graphite specimen column. The reading from the load cell will be used to control the loading on the specimen column. The gas lines for the lower pneumatic rams and sweep gas are routed down the outer wall of the pressure boundary and then branch out to the sides to be routed in the guide tubes.

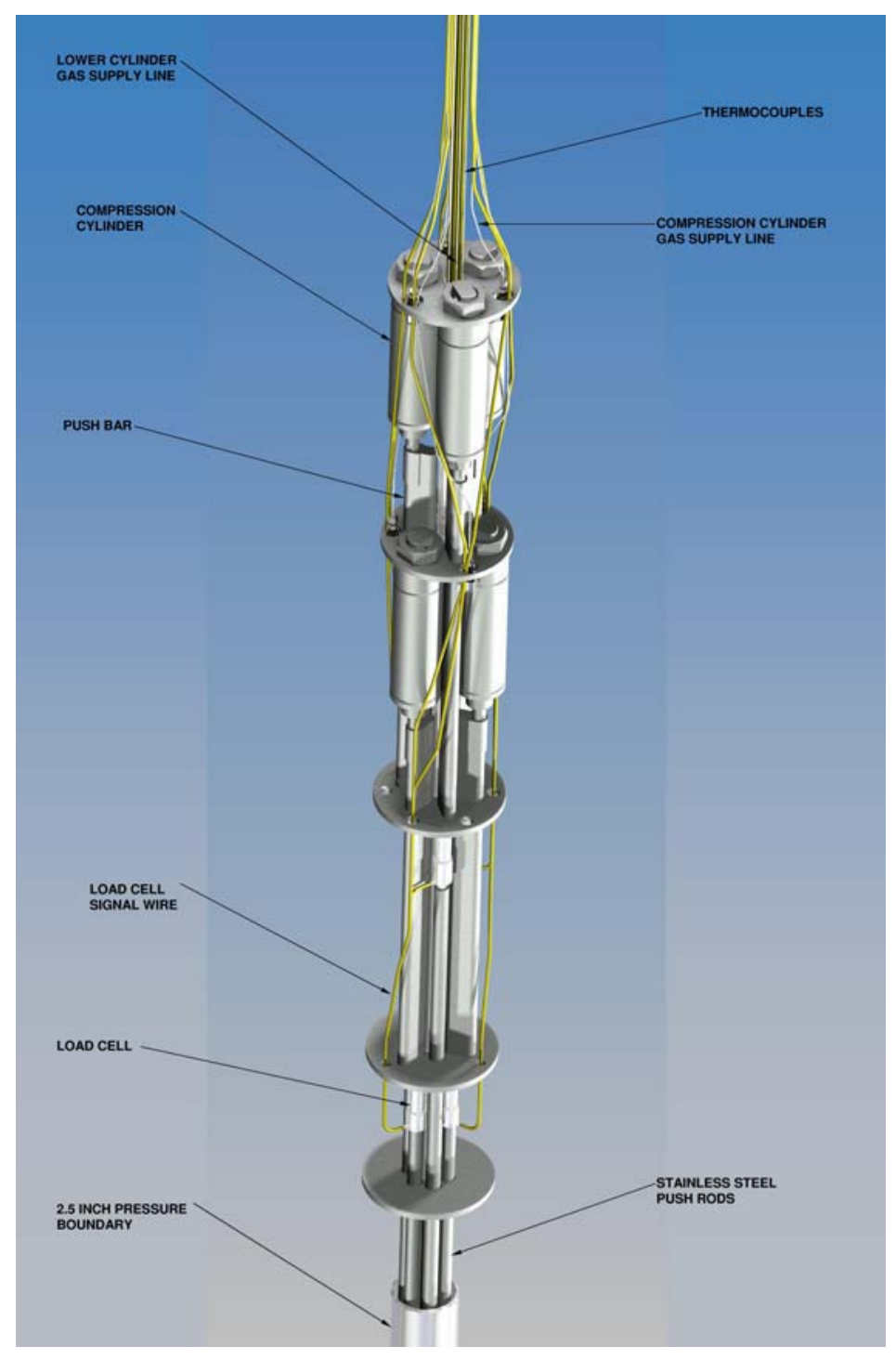

Figure 32. Cutaway of the out of core portion of the experiment showing the six pneumatic rams and pushrods. The yellow leads from the oval couplers are for the load cells in the couplers. 
Figure 33 shows the stainless push rods proceeding into the graphite holder body above the core. The rods meet up with the graphite push rods that transfer the load to the specimens in the core. Graphite push rods must be used in the core because the temperature in the core is in excess of the temperature limit of stainless steel. The graphite push rods are hollow in the core region allowing small piggyback samples to reside in the upper portion of the core.

Figure 34 shows the specimen layout for the in-core portion of the experiment. The graphite push rod loads the upper portion of the stack only. At the core centerline, there is a graphite separator that bottoms out over the hole of the lower stack preventing the transfer of the load to the lower specimen column (see Figure 35). This graphite part has one end that fits in the 0.5 -in. diameter hole in the upper stack, but the lower half has a diameter of $5 / 8$ in. As the upper stack is loaded, the larger diameter end will bottom out over the $0.5 \mathrm{in}$. hole in the lower stack. When the lower push rods lift the stacks from the bottom, the upper end of the separator will slide into the 0.5 -in. hole in the upper stack. This arrangement is necessary to achieve the irradiation of companion graphite specimens at the same temperature and fluence. These companion specimens provide the means to measure the irradiation-induced creep. Figure 35 shows the larger stressed and unstressed creep specimens, the smaller unloaded piggyback samples (used to determine irradiated properties), and the spacers between the samples. The spacers have axial pins that fit into the central holes in the specimens, thereby maintaining alignment within the columns in the graphite holder body.

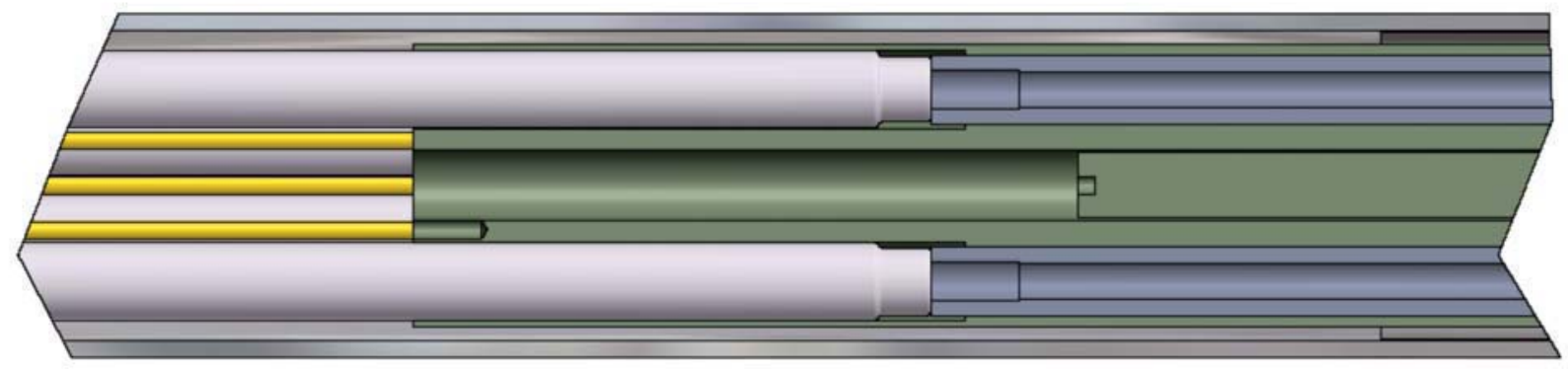

Figure 33. Cutaways showing the stainless steel pushrods entering the graphite holder body above the core and meeting the graphite push rods that will transfer the load on the specimens in the core. The center column is unloaded. 

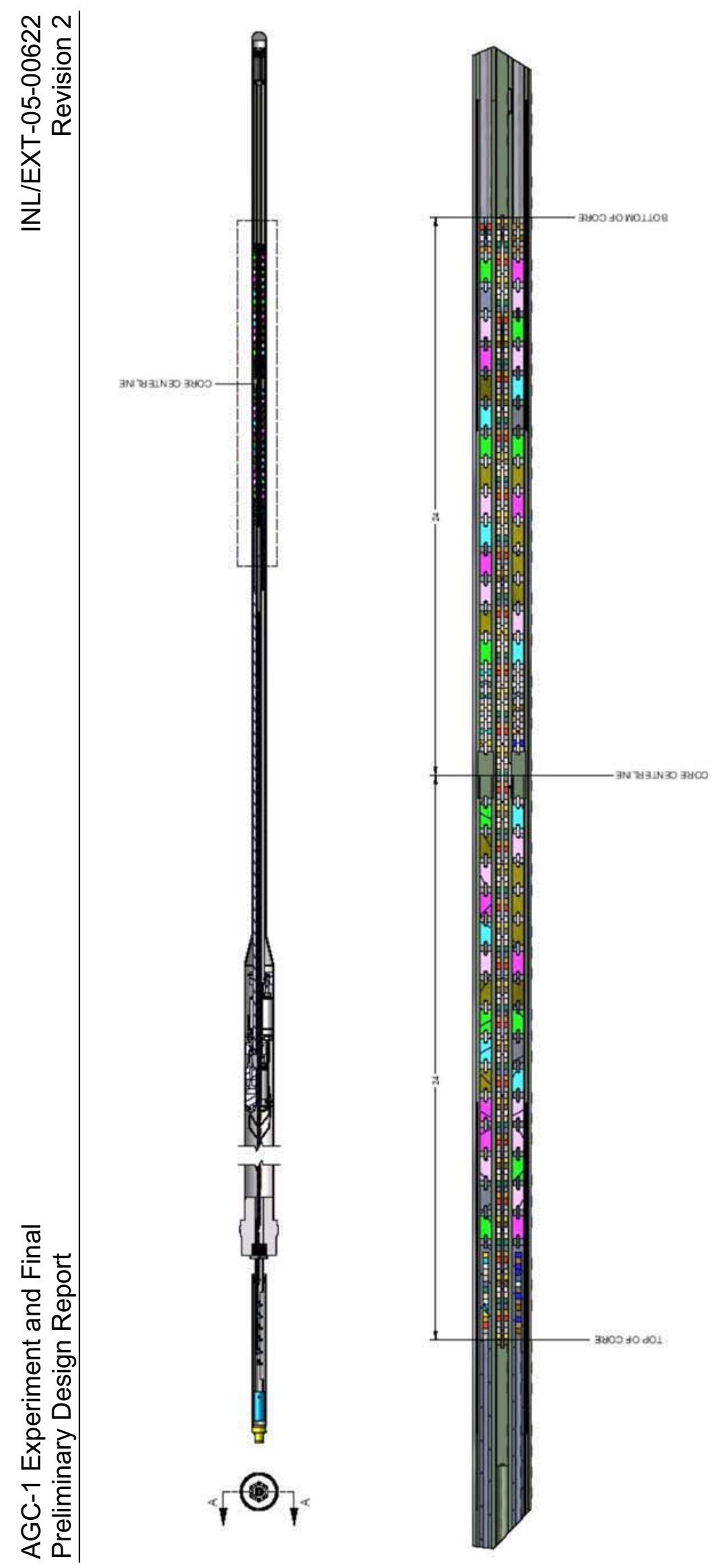

$\widehat{0}$

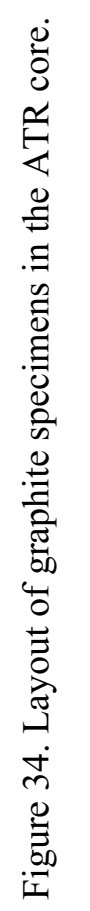




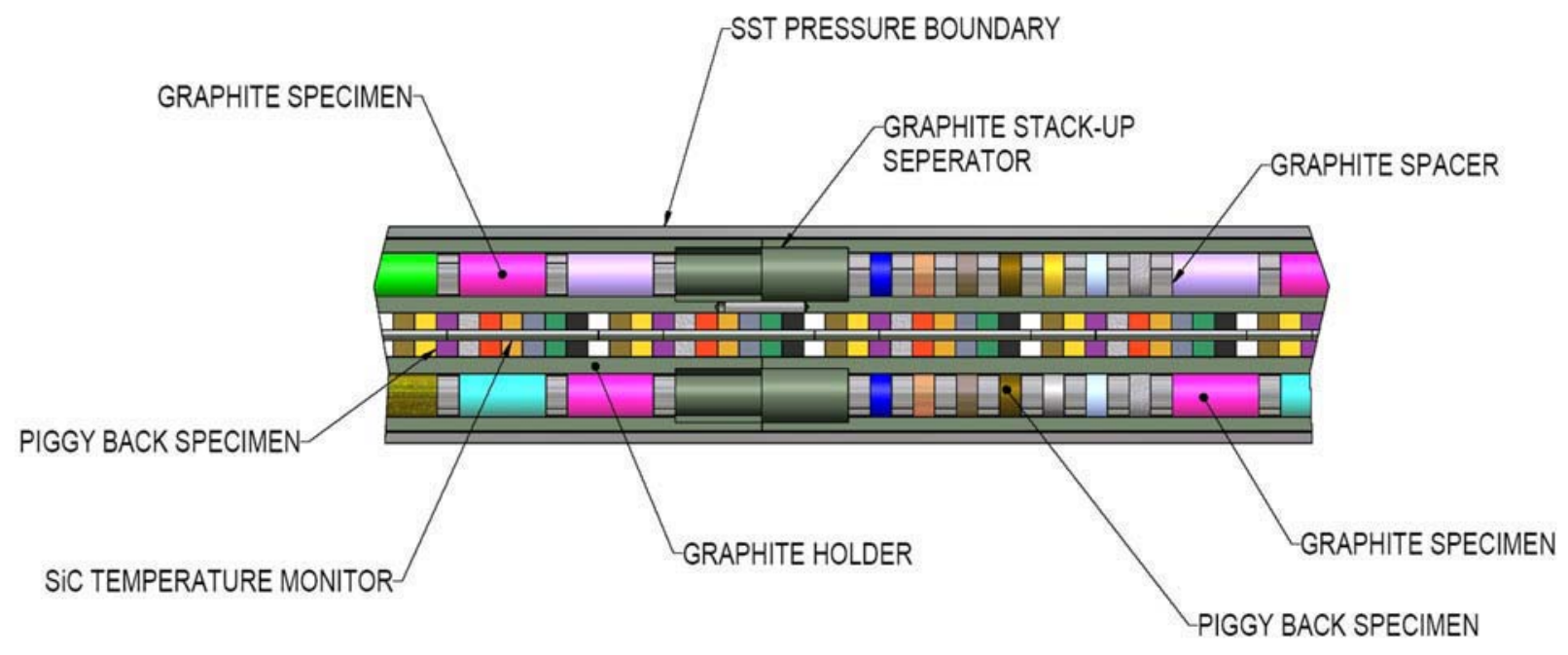

Figure 35. Sketch showing the specimen layout at core centerline. This sketch shows the separator which allows the loading of the upper portion and keeps the lower portion unloaded. 


\section{AGC-1 NEUTRONIC ANALYSIS}

\subsection{ATR Core Model}

The neutronic analysis is being performed using MCNP Version 5. A Monte Carlo N-Particle Transport Code (MCNP) three dimensional model for the ATR is being used to calculate the gamma heat and dpa distribution in the south flux trap. Insertion into ATR is not expected before November 2007. The core configuration for the first quarter of FY-08 is not known at this time. Therefore, in this preliminary model, there are no fuel tests or experiment models except the AGC-1 in the MCNP model of the ATR. The assumed power levels for the different regions of the core are shown in Figure 36.

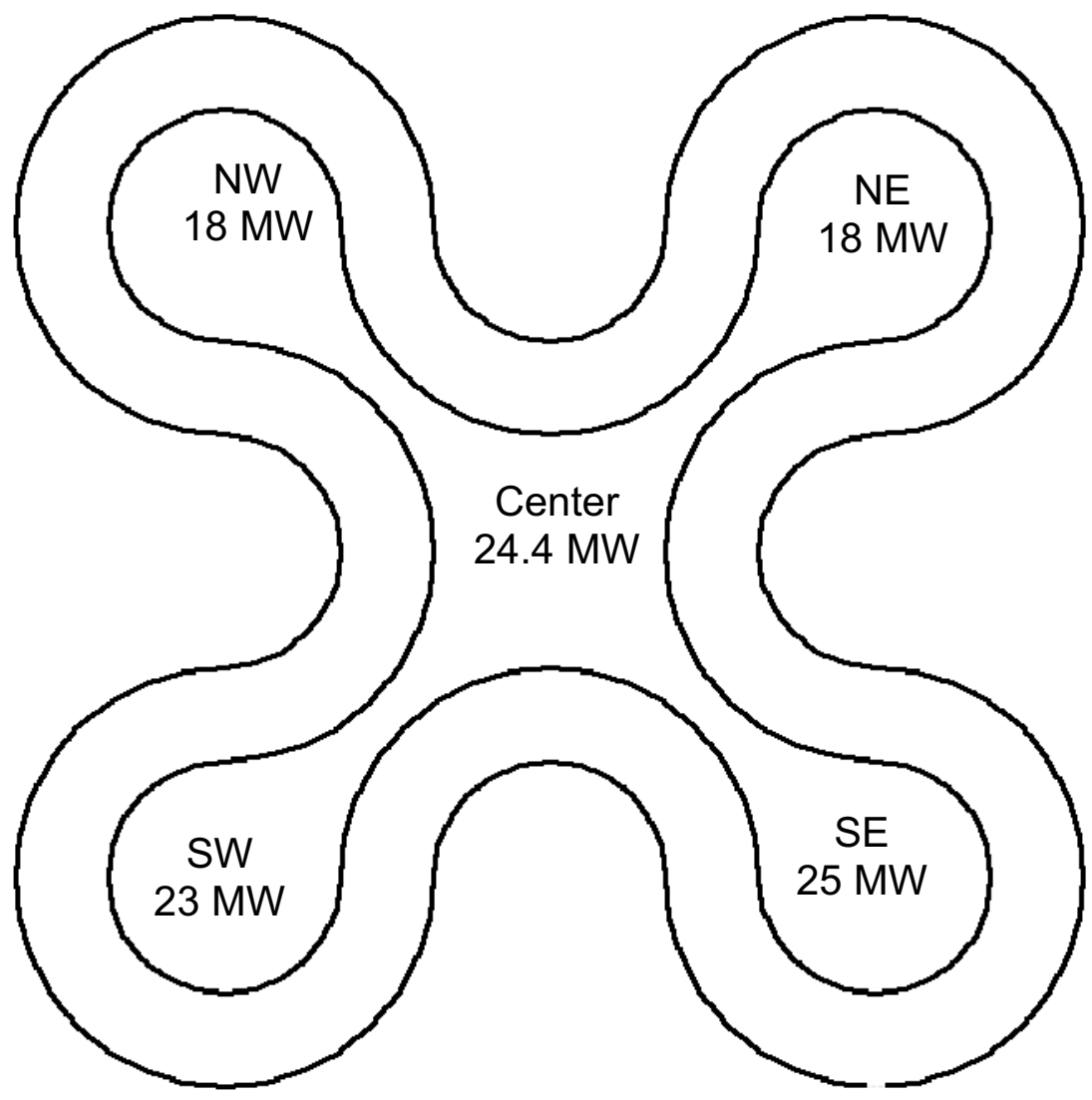

Figure 36. Standard power levels in the ATR core. All values are in MW and total to $108.4 \mathrm{MW}$. North is straight up on the page.

The AGC-1 capsule will remain in the core for ATR PALM cycles, which typically last from 5 to 14 days. The power levels during the PALM cycles are shown in Figure 37. During the PALM cycles the power level goes up from 25 to $55 \mathrm{MW}$ in the south flux trap. When the ATR core configuration is know for reactor insertion, the MCNP model will be updated and rerun for the final gamma heat distribution, dpa distribution, and flux wire predictions. 


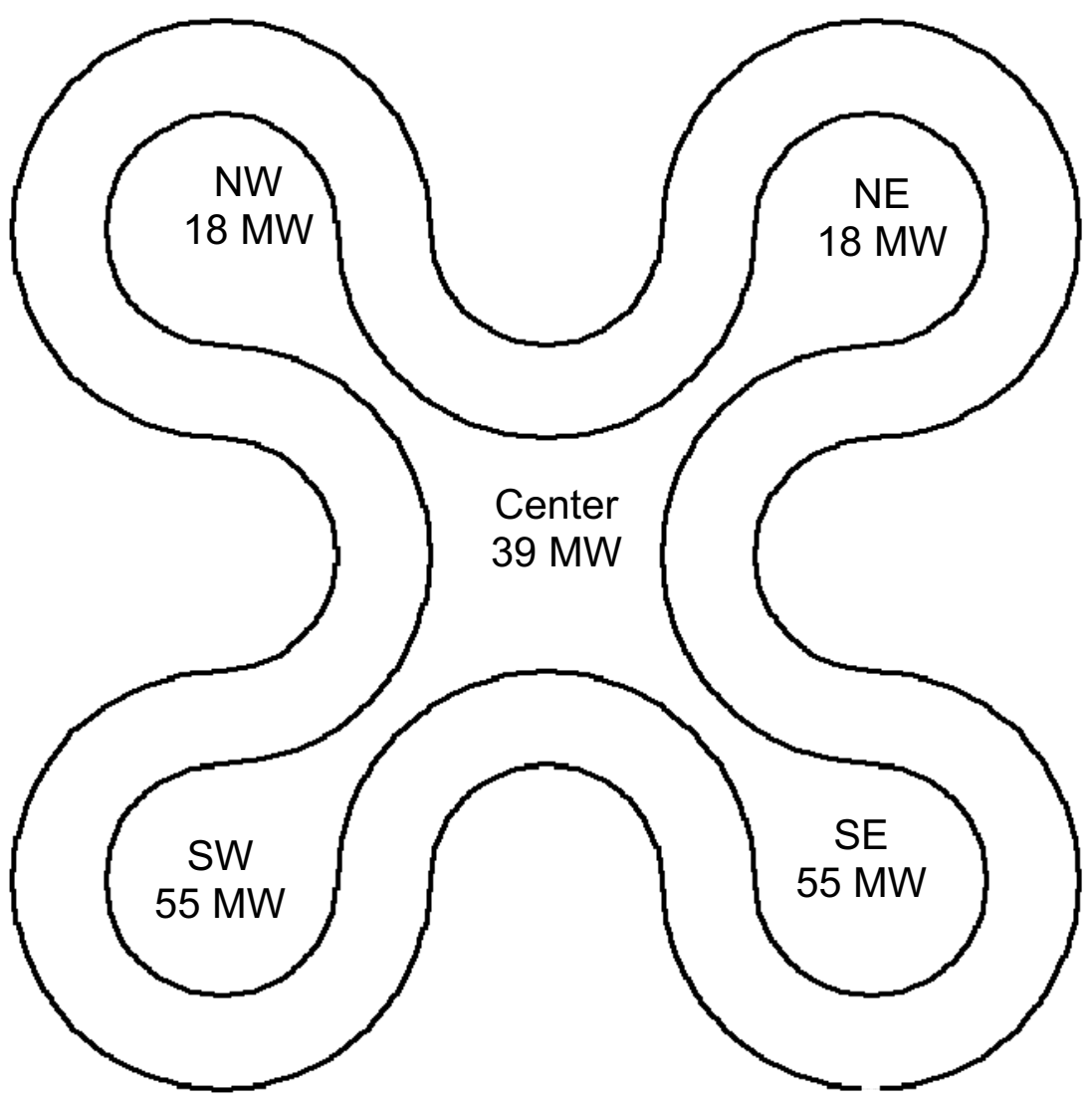

Figure 37. ATR PALM cycle power levels. All power levels are in megawatts and total to $185 \mathrm{MW}$. North is vertically straight up

\subsection{AGC-1 MCNP model}

There are two neutron flux gradients in the experiment. The largest gradient is from north to south, because the south flux trap has fuel on three sides without experiments. The fourth side is void of fuel. The power level in these lobes can vary from cycle to cycle and even double in the case of a PALM cycle. The north/south power gradient is even higher in the PALM cycles. The gamma heat distribution in the experiment will be asymmetrical. Figure 38 shows the individual features that have been included in the MCNP model. Figure 39 shows the cross section separated into 6 azimuthal tally regions. There are 49 tallies in the cross section. Only the thermal couples were smeared all other features were modeled explicitly. A tally is the means by which MCNP tracks random walking particles in a geometrical volume and correlates to nuclear reactions per source particle. The geometry of the model does take into account the varying diameters of the graphite and thermal radiation heat shield. Each section has a gamma heat value for the center specimen, the inner graphite body, the graphite specimen, outer graphite body, the thermal radiation shield, and the stainless steel pressure boundary. The guide tubes generate gamma heat from the wall of the guide tube, the gas tube, and the flux wire. Because the flux is not perfectly symmetrical about the axial core centerline, sampling must be performed over the entire axial length of the experiment and extending one foot above and below the core. The tallies are evaluated at every quarter of an inch in the core region and every 1 inch above and below the core for a total of 216 axial positions in the experiment. Therefore, there are 10,584 gamma heat values to be used as input in the thermal analysis. 


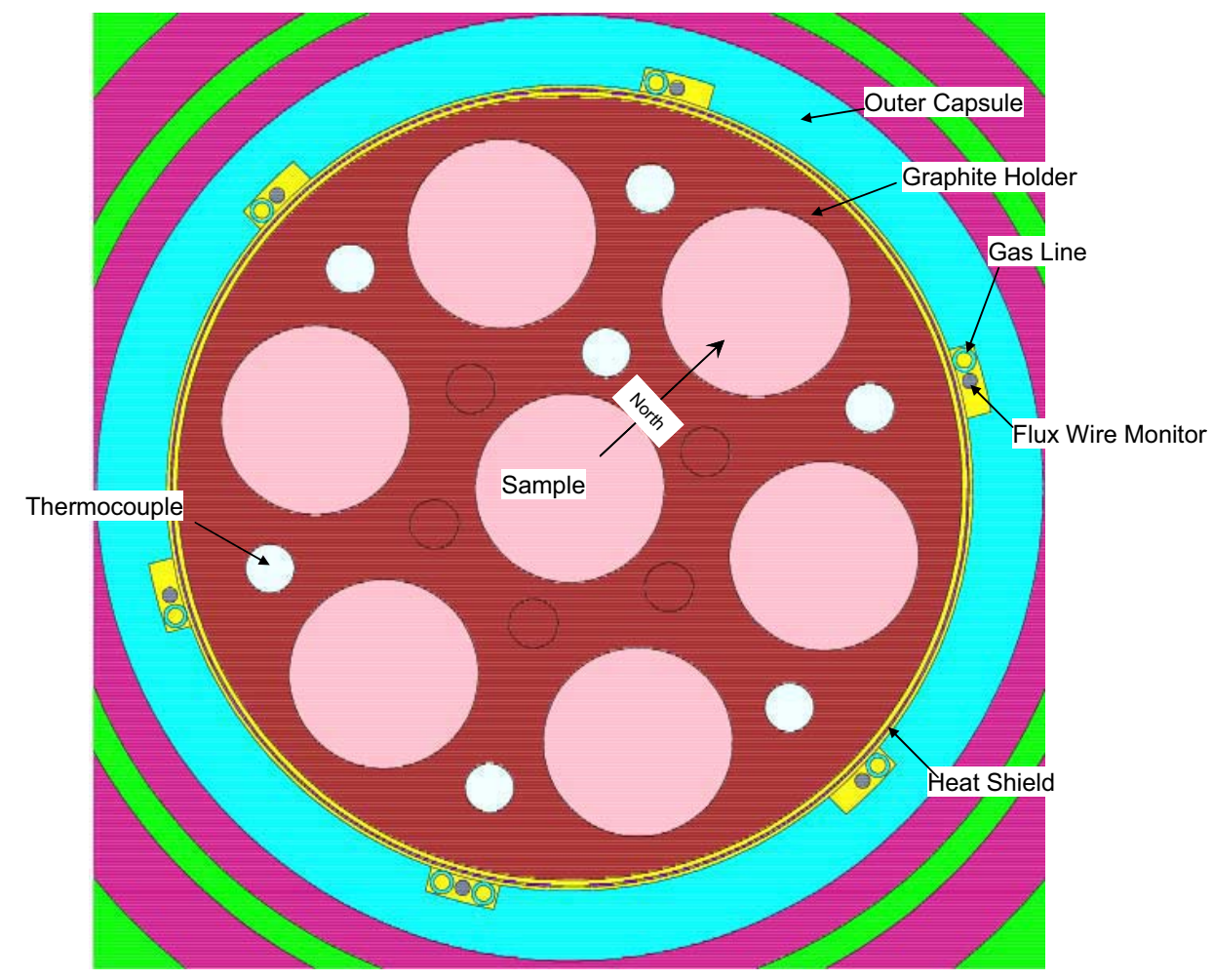

Figure 38. Tally map for the AGC-1 capsule cross section. Each color is a explicitly modeled feature.

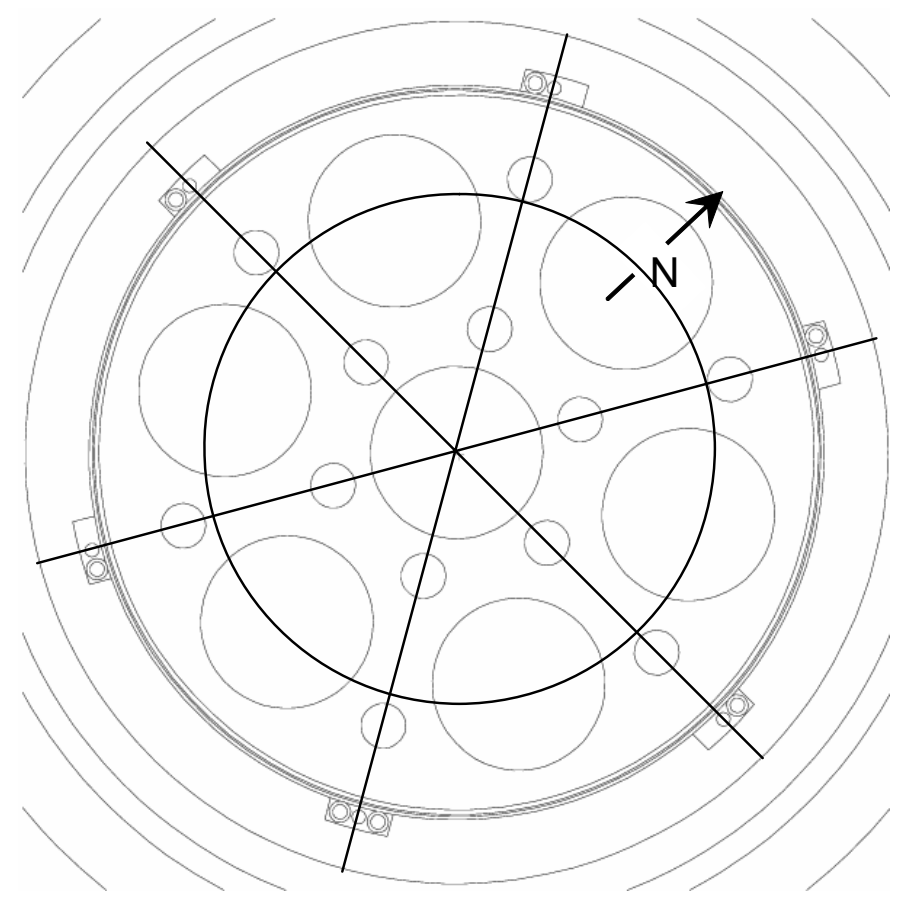

Figure 39. MCNP model separated into 6 azimuthal tally regions. Center specimen stack is not divided into azimuthal regions. 


\section{AGC-1 THERMAL ANALYSIS}

The thermal analysis of the AGC-1 experiment was performed using ABAQUS and an INL developed data translator between MCNP and ABAQUS. The ABAQUS model contains 210,000 elements and 144,000 nodes. Figures 40 through 44 show the finite element models for the capsule pressure boundary, graphite holder, thermal heat shield, specimen stacks 1 through 6 , and center specimen stack. The finite element model is complete after the individual models are assembled. The next step in the analysis is to assign gamma heat values from the MCNP analysis to the individual elements. This is done using the MCNP translator developed at the INL. The translator reads the 10, 584 gamma heat values from the MCNP output and constructs a three dimensional mesh different from the ABAQUS three dimensional mesh. A FORTRAN program was written that links with ABAQUS to lookup the gamma heat associated from the translator mesh and assigns the gamma heat value to the individual ABAQUS finite element. ABAQUS then proceeds with the calculation of the temperature distribution in the capsule. If this translator wasn't used, this process of assigning gamma heats to the individual finite elements would have to be done by hand consuming a large amount of time. The translator allows for a faster design process, since changes in the core configuration can be quickly translated to ABAQUS for thermal analysis

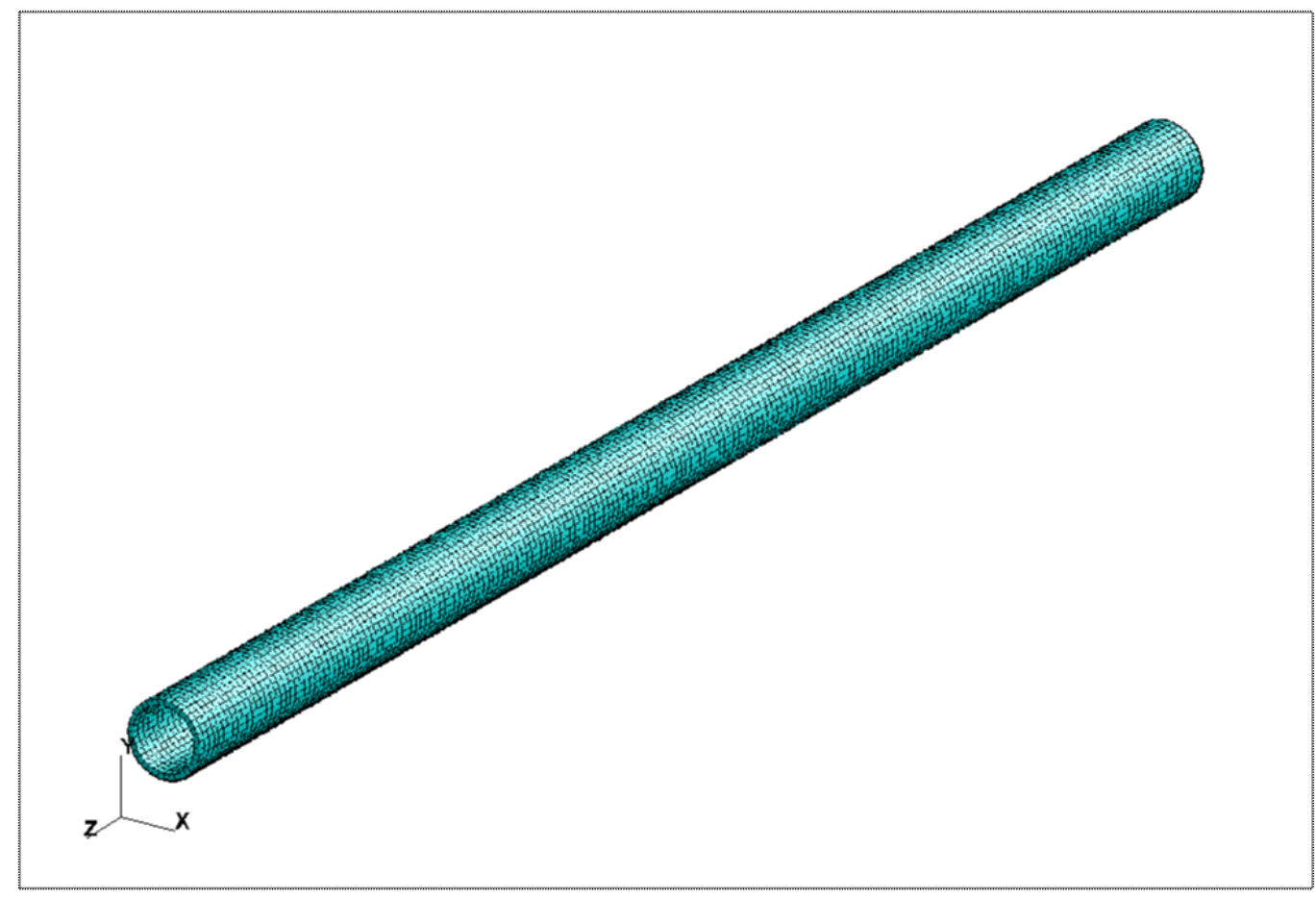

Figure 40 Finite element model for the capsule pressure boundary 


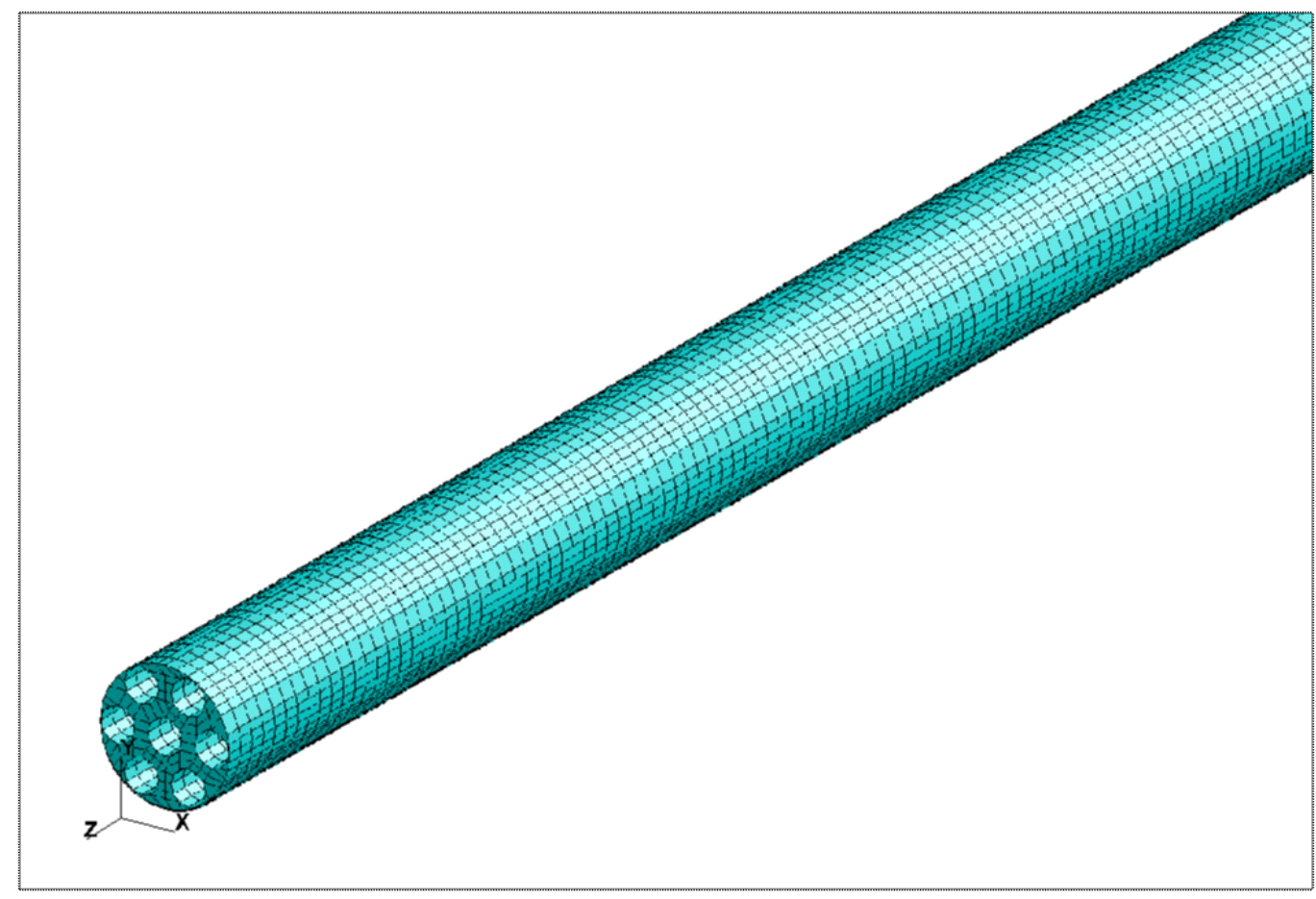

Figure 41. Finite element model for the graphite holder body

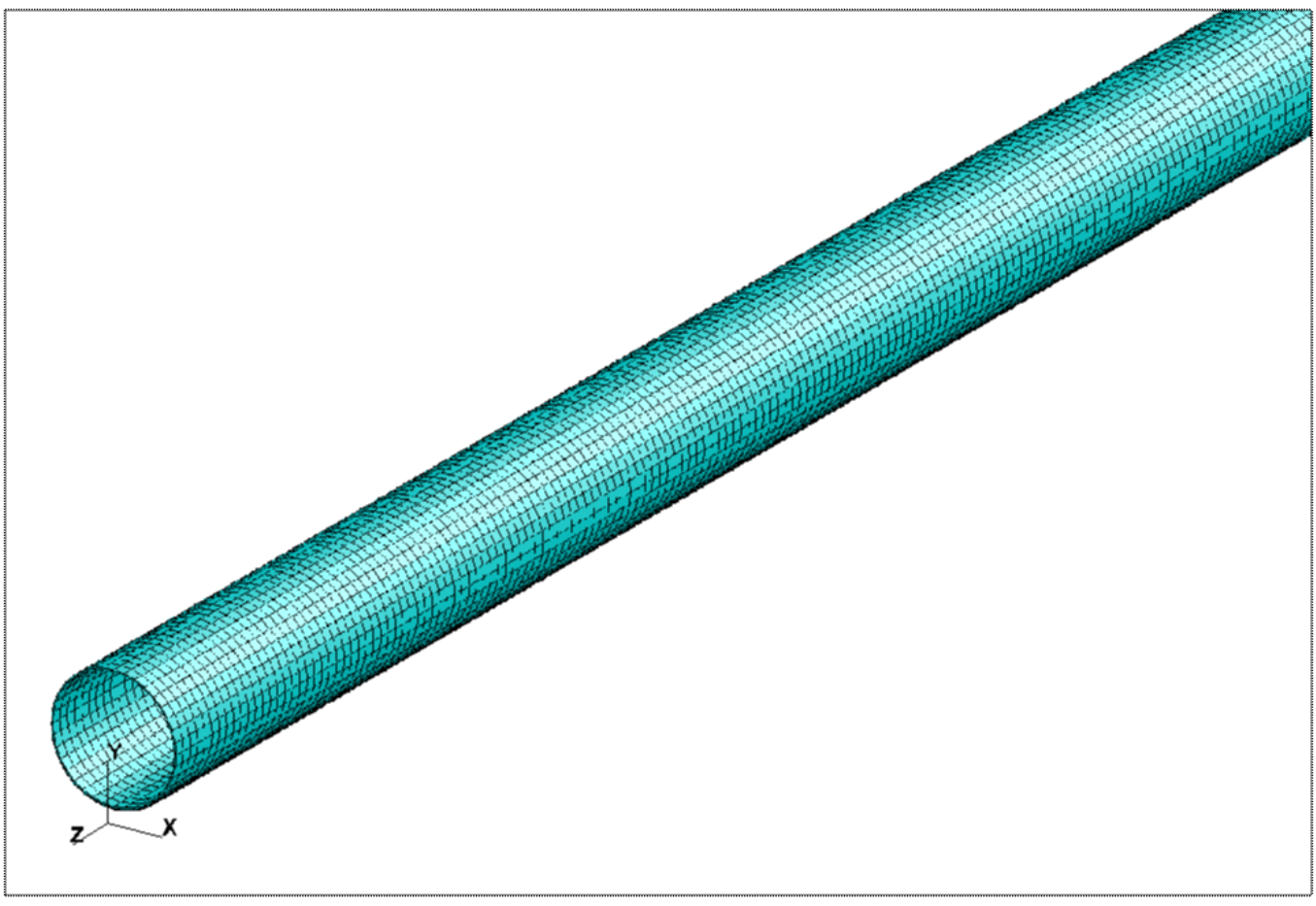

Figure 42. Finite element model for the thermal heat shield 


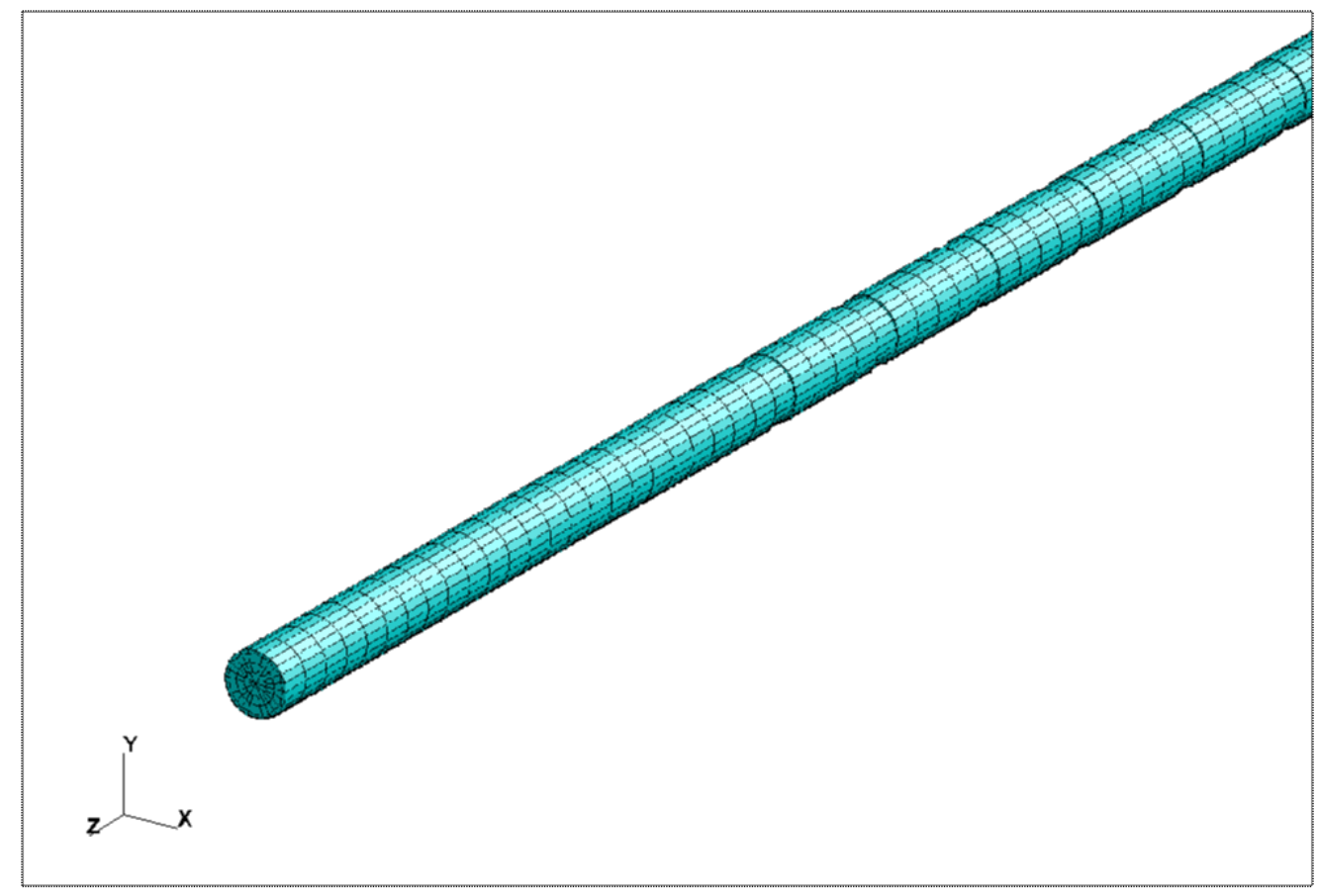

Figure 43. Finite element model for the specimen stacks 1 through 6 . Note the smaller spacers between the graphite specimens.

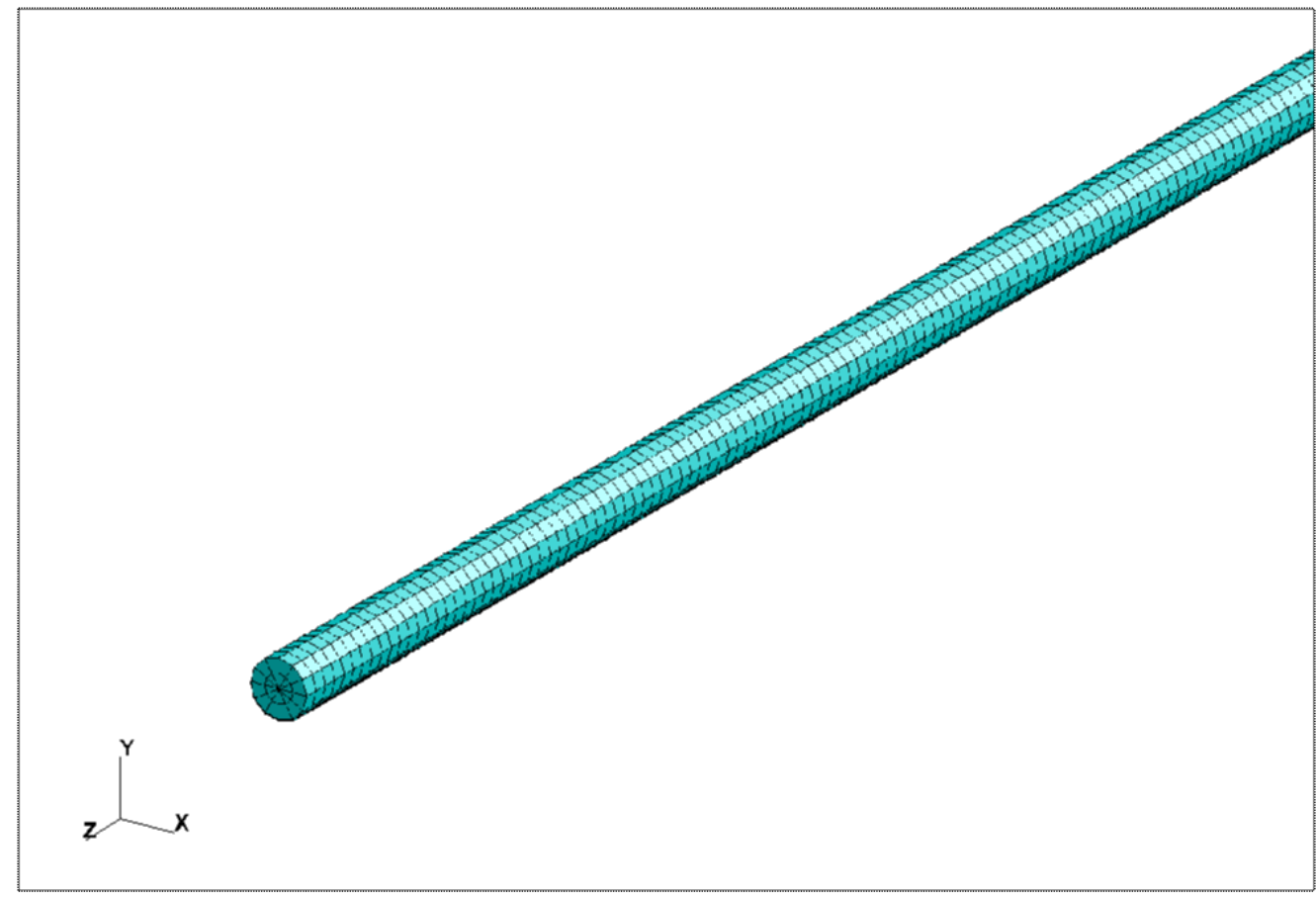

Figure 44. Finite element model for the center specimen stack 
The asymmetry of the flux distribution in the AGC-1 is shown Figures 45 and 46. Similarly, the gamma heat distribution in the AGC-1 is shown in Figures 47 and 48. Flux units are neutrons $/ \mathrm{cm}^{2} / \mathrm{sec}$ and the gamma heat units are $\mathrm{MeV} / \mathrm{gm}$. North is at two o'clock. In Figures 45 through 48 note the gradient seen in the direction of north to south. In Figures 47 and 48 note the high gamma heat per gram for the heat shield. Figures $47 \mathrm{a}$ and $\mathrm{b}$ are the thermal analysis

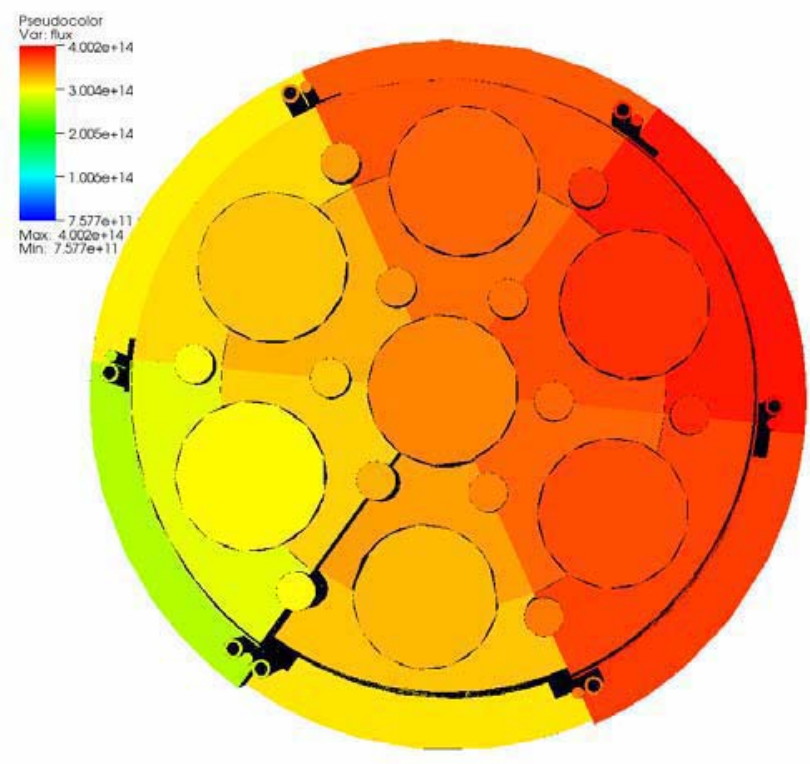

Figure 45. Fast Flux distribution in the AGC-1 in the south flux trap. Units are neutrons $/ \mathrm{cm} 2 / \mathrm{sec}$. North is at two o'clock 

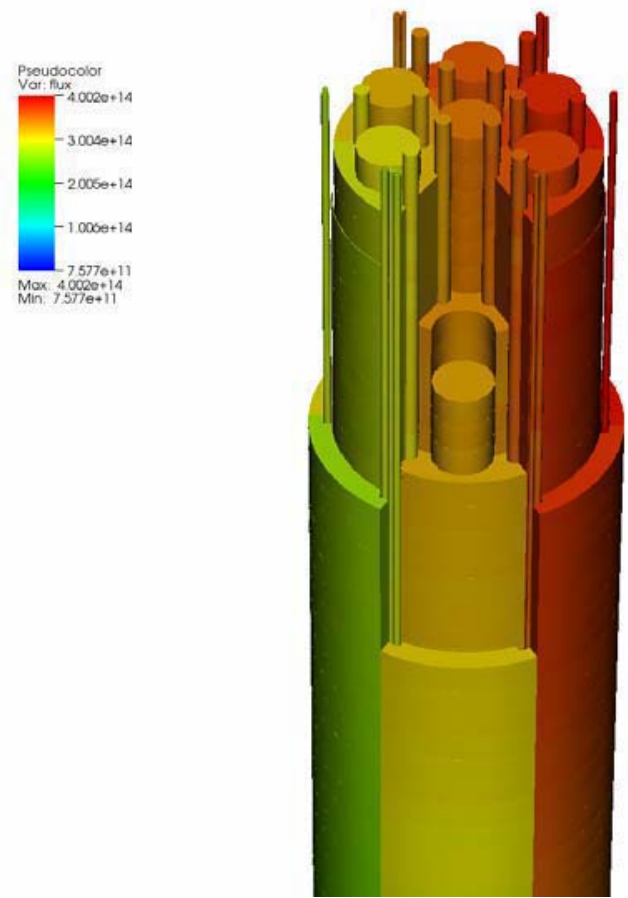

Figure 46. Fast flux distribution in the AGC-1 capsule in the south flux trap. Units are neutrons $/ \mathrm{cm} 2 / \mathrm{sec}$

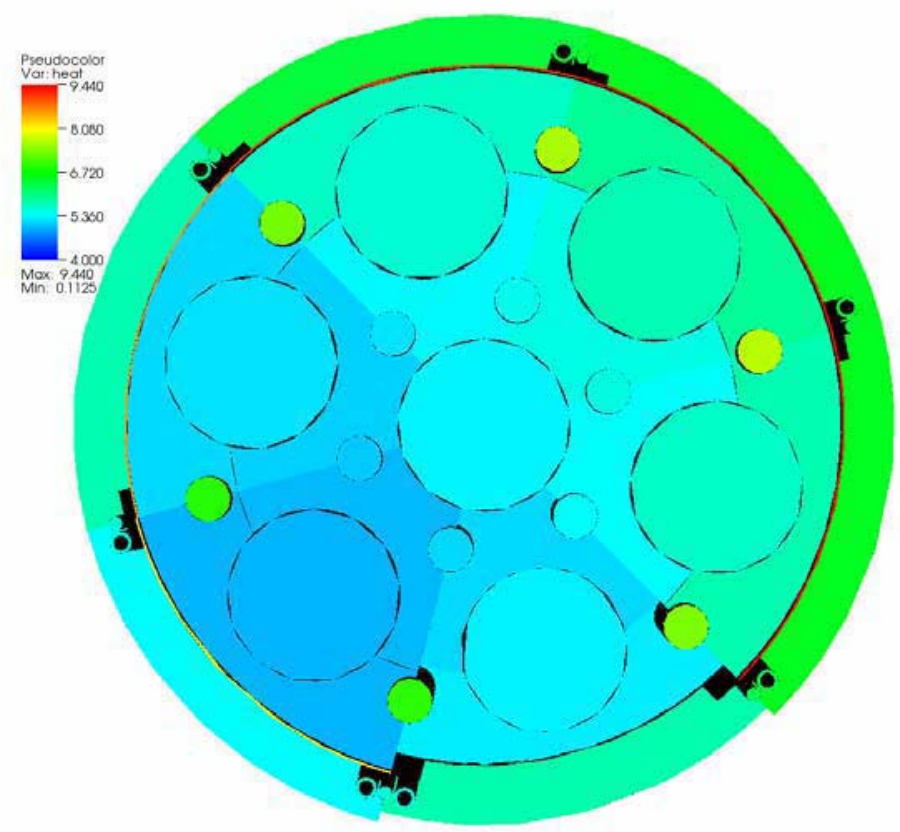

Figure 47. Gamma heat distribution in the AGC-1 capsule in the south flux trap. Units are MeV/gm. North is at two o'clock 


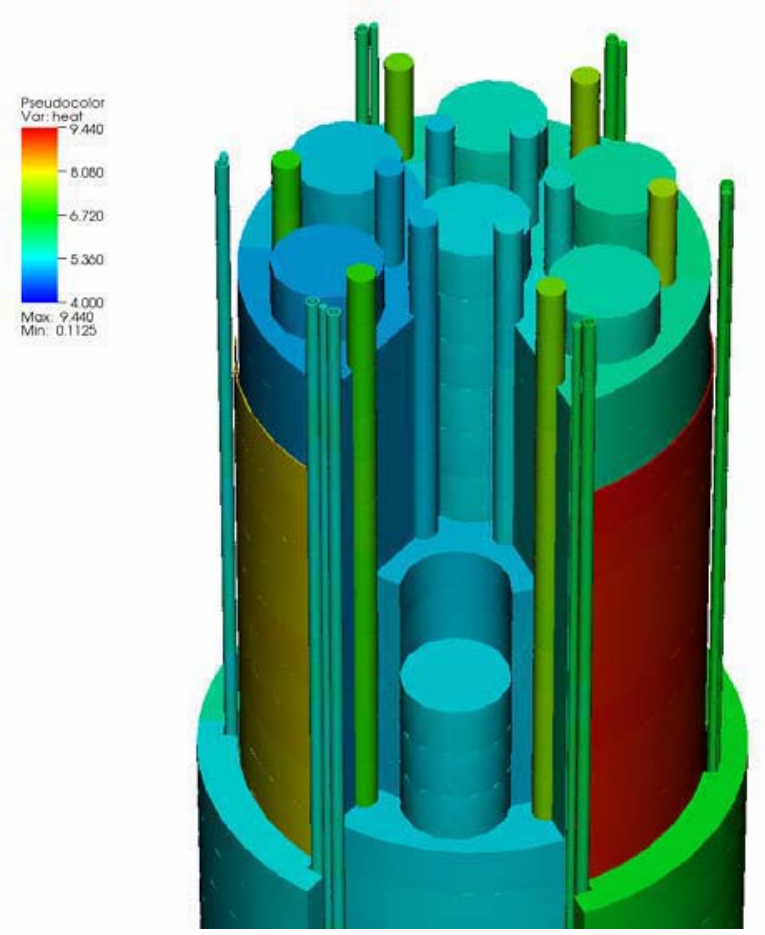

Figure 48. Gamma heat distribution in the AGC-1 capsule. Units are MeV/gm

The thermal model represents just the 4-ft. core section. The forms of heat transfer used in the model are thermal conduction in the graphite solids, thermal conduction in the gas gaps, and radiation heat transfer between the graphite surfaces. Thermal gas conduction and radiation heat transfer is used between the graphite experiment body and heat shield and similarly between the heat shield and outer pressure boundary. Convective heat transfer is used to model the heat deposited in the coolant flowing between the pressure boundary and the chopped dummy in-pile tube. Temperature dependent thermal conductivity is used for all materials. Figures $49 \mathrm{a}$ and $\mathrm{b}$ are the temperature distributions in one of the six specimen stacks. All six specimen stacks have similar temperature patterns. The temperatures are in degrees Fahrenheit. The target temperature is $900{ }^{\circ} \mathrm{C}$ which is $1652^{\circ} \mathrm{F}$. From figure $49 \mathrm{a}$ the bottom half of the specimen stack is at a temperature greater than $900^{\circ} \mathrm{C}$. Figure $49 \mathrm{~b}$ shows the top half of the stack is running cooler than $900^{\circ} \mathrm{C}$. The upper end of the stacks is running about $350^{\circ} \mathrm{C}$ colder, while the lower end of the stack is running $240^{\circ} \mathrm{C}$ colder. 

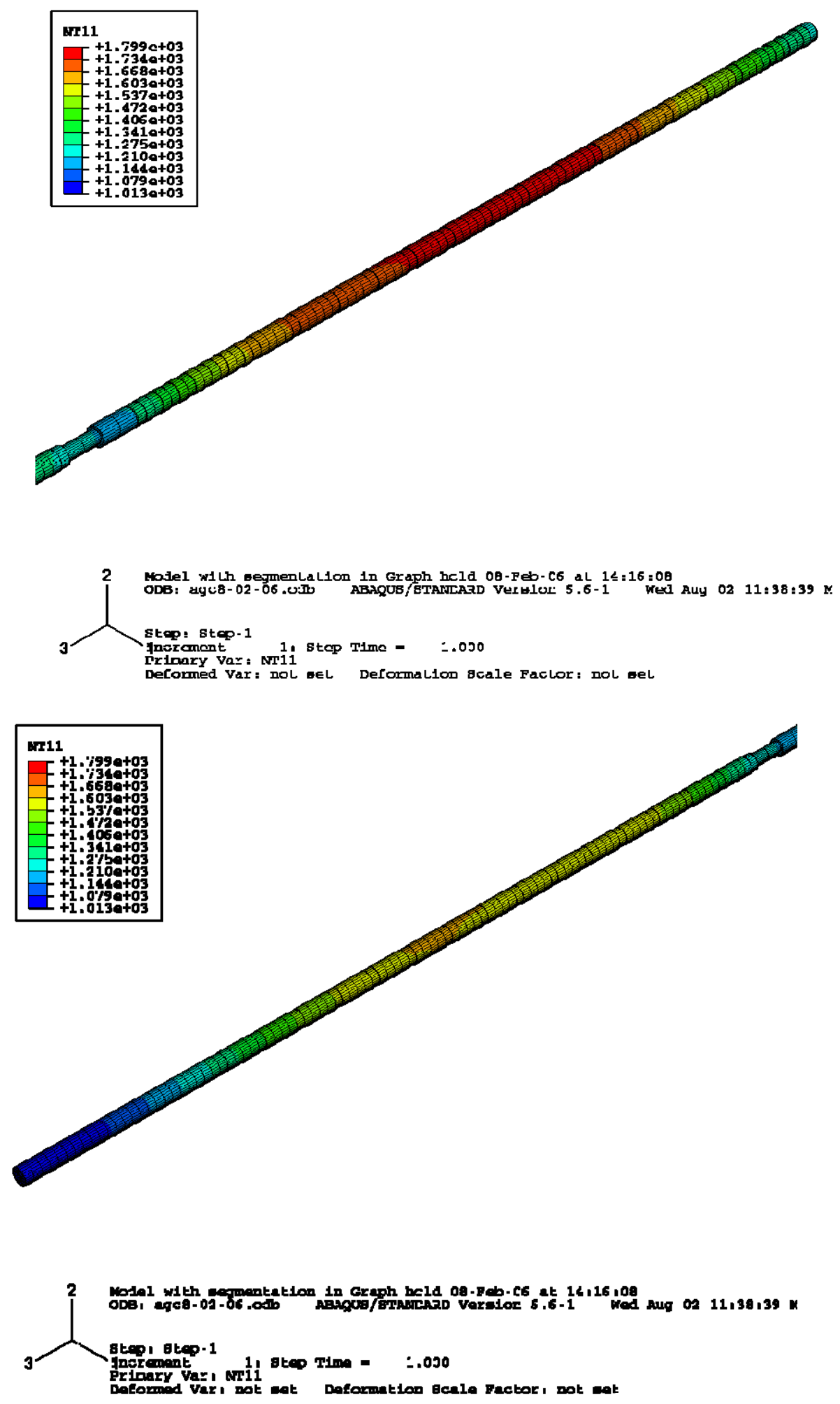

Figures 49a and $\mathrm{b}$. Temperature distribution in specimen stack. Upper figure is the top of the stack. The lower figure is the bottom of the stack. Temperatures are in degrees F. 


\section{AGC-1 MECHANICAL ANALYSIS}

This section outlines the mechanical analysis necessary for reactor insertion and support of the safety analysis report found in Engineering Design File - 5925, "Structural Evaluation of the ATR Advanced Graphite Experiment AGC-1",May 2006 (draft). The detailed calculations will not be repeated here. The reader can review the detail calculations in the report in Appendix I. This report presents the detail calculations supporting:

- ASME design of the reactor head penetration and capsule boundary

- ANSI B31.1 analysis of gas lines in the capsule

- Capsule seismic analysis

- Thermal stress analysis

- Other component evaluations 


\section{STATUS OF AGC-1 DESIGN}

This report details the status as of the Preliminary Design Review held May 31, 2006 in Idaho Falls, ID. The Design Review Chairman's report on the Preliminary Design Review is attached in Appendix J. 


\section{SCHEDULE}

The planned schedule for Capsule AGC-1 is:

\begin{tabular}{|l|l|}
\hline \multicolumn{1}{|c|}{ Task } & \multicolumn{1}{c|}{ Due Date } \\
\hline Complete preirradiation examination of AGC-1 graphite specimens & March 31, 2007 \\
\hline Complete assembly of AGC-1 & June 30, 2007 \\
\hline Complete AGC-1 out of core shake-down testing & September 30, 2007 \\
\hline Reactor insertion & November, 2007 \\
\hline Complete irradiation & June 30, 2008 \\
\hline Complete hot cell disassembly & September 30, 2008 \\
\hline Ship graphite specimens to ORNL for PIE & October 31, 2008 \\
\hline Complete graphite PIE & June 30, 2009 \\
\hline Issue draft AGC-1 PIE report & September 30, 2009 \\
\hline
\end{tabular}




\section{REFERENCES}

1. Senn, R. L., W. H. Cook, J. A. Conlin, W. P. Eatherly, "Design, Operation, and Initial Results from a Series of Graphite Creep Irradiation Experiments," J. Nucl. Mater. 65, 1997, pp. 96-106.

2 Burchell, T., and R. Bratton, Physical based models of the behavior of Nuclear Graphite Under Irradiation, ORNL/TM-2005/509 June 2005

3. Gray, W. J., "Constant Stress Irradiation-Induced Compressive Creep of Graphite at High Fluences," Carbon, Vol. 11, 1973, pp. 383-392.

4. Perks, A. J. , and J. H. W. Simmons, "Dimensional changes and radiation creep of graphite at very high neutron doses," Carbon 4, 1966, pp. 85-98.

5 Burchell, T. D., "Fission Reactor Applications of Carbon", In Carbon Materials for Advanced Technologies, Ed. T. D. Burchell, pp.429-484, Pub. Elsevier Science (1999)

6. Kelly, B. T., and T. D. Burchell, "The Analysis of Irradiation Creep Experiment on Nuclear Reactor Graphite," Carbon 32, 1994, pp. 119-25.

7. Kelly, B. T., "Irradiation Creep in Graphite - Some New Considerations and Observations," Carbon 30, 1992, pp 379-383.

8. Snead, L., A. M. Williams, and A. L. Qualls, "Revisiting the use of SiC as a Post Irradiation Temperature Monitor," Effects of Irradiation on Materials, ASTM STP 1447, M. L. Grossbeck, Ed, ASTM International, West Conshohocken, Pennsylvania, 2003.

9. Bratton, R., and T. Burchell, Milestone Report: NGNP Graphite Selection Strategy, INL/EXT-05-00269, 2005.

10. ASTM C-781 "Standard Practice for Testing Graphite and Boronated Components for HighTemperature Gas-Cooled Nuclear Reactors," ASTM Standards, Vol. 05.05, ASTM International, West Conshohocken, Pennsylvania, 2003.

11. Senn, R. L., et al., Design, Operation, and Initial Results from Capsule OC-1, the First of a Series of Graphite Creep Capsule Irradiation Experiments,” ORNL/TM-5798, May 1977. 
Appendix A

AGC-1 Channel 1 (North) Specimen Layout [3 ksi] 


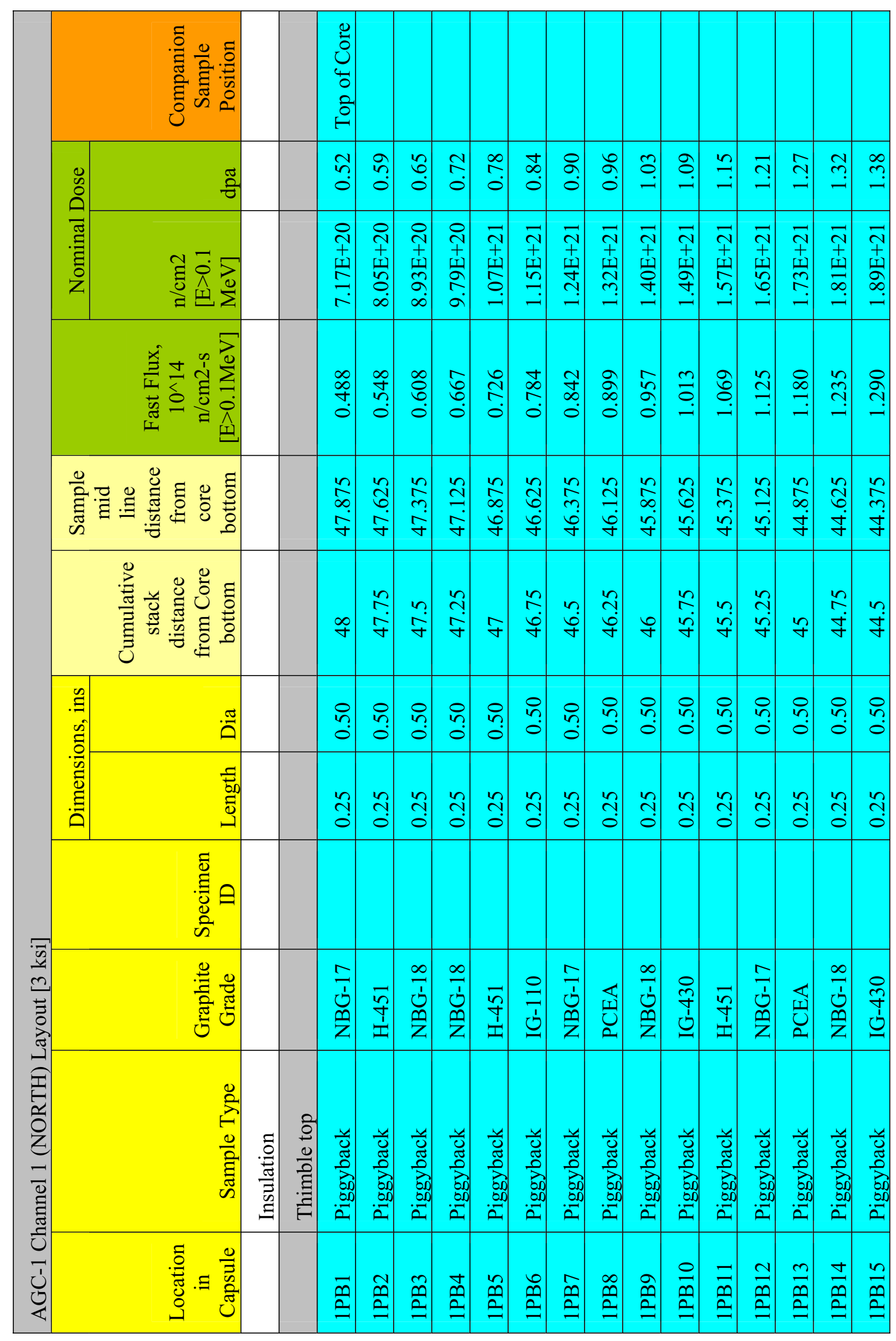




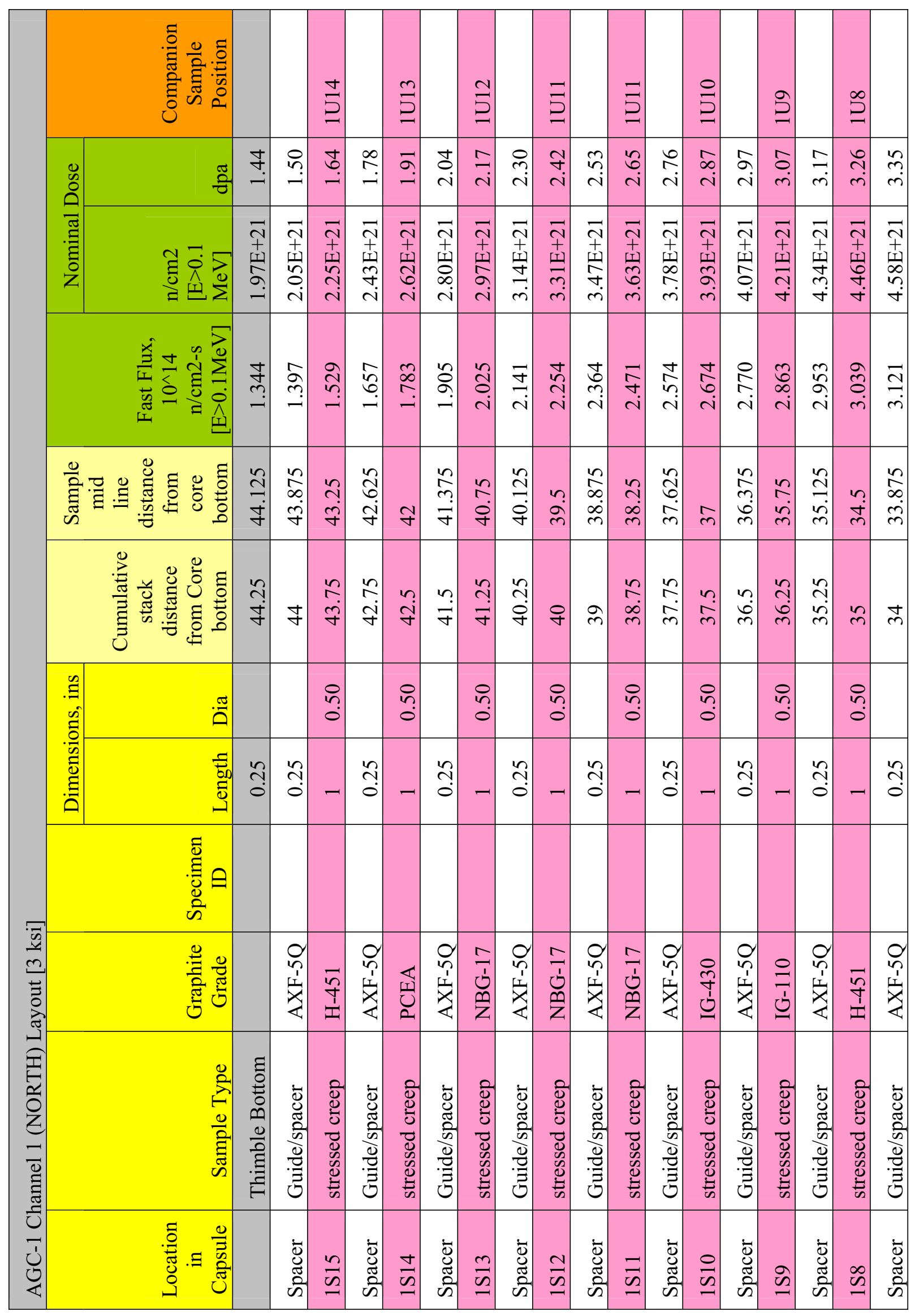




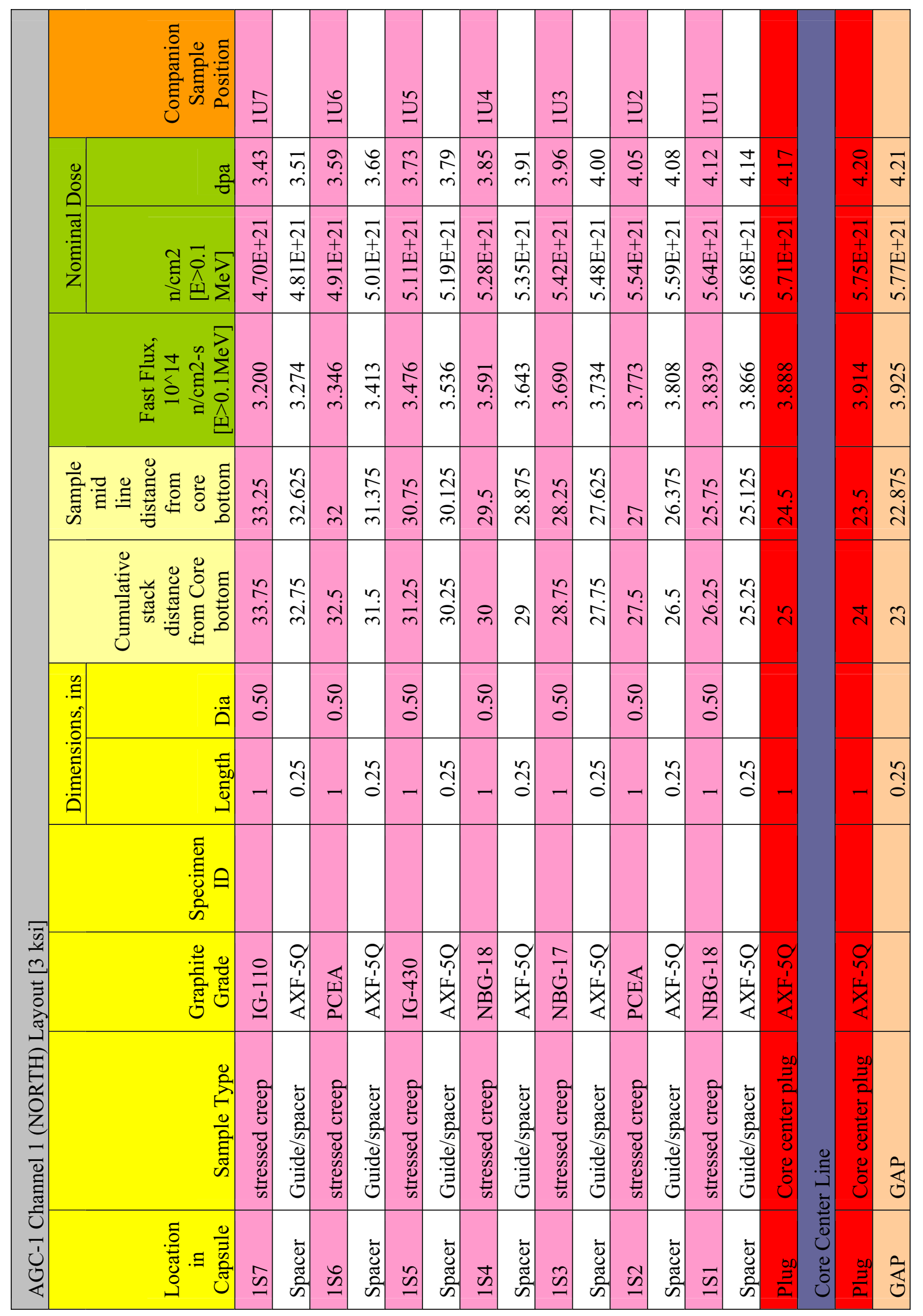




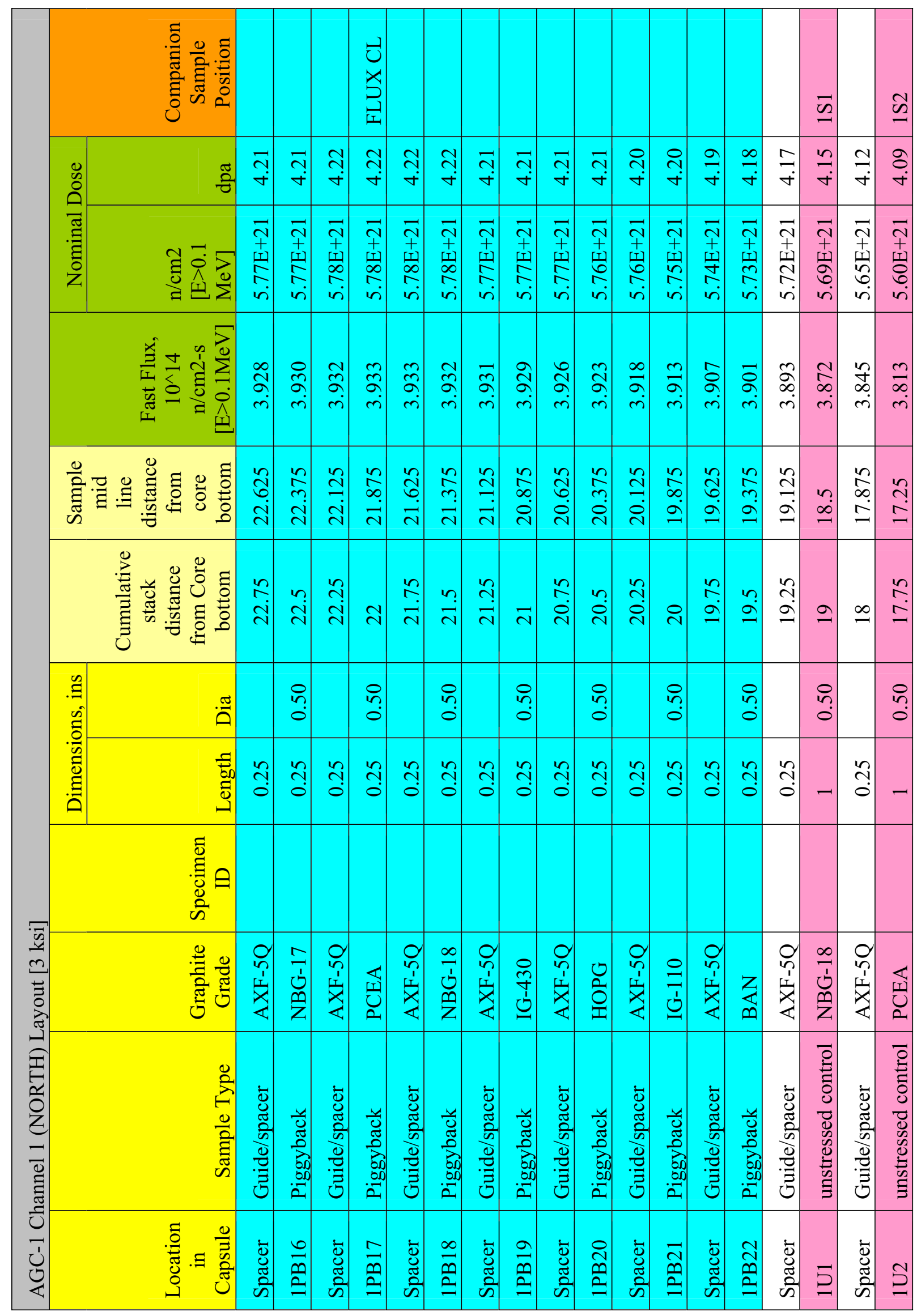




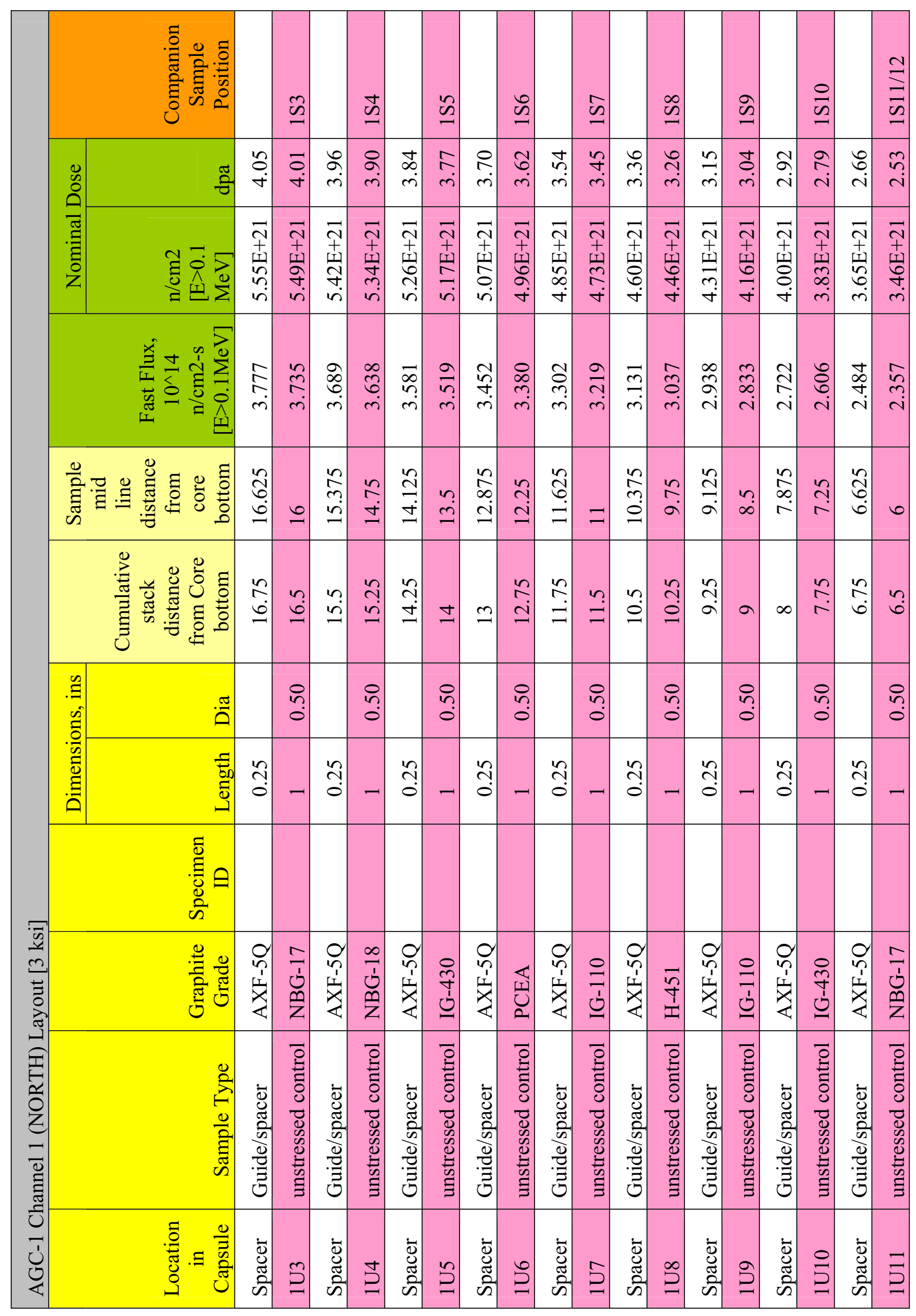




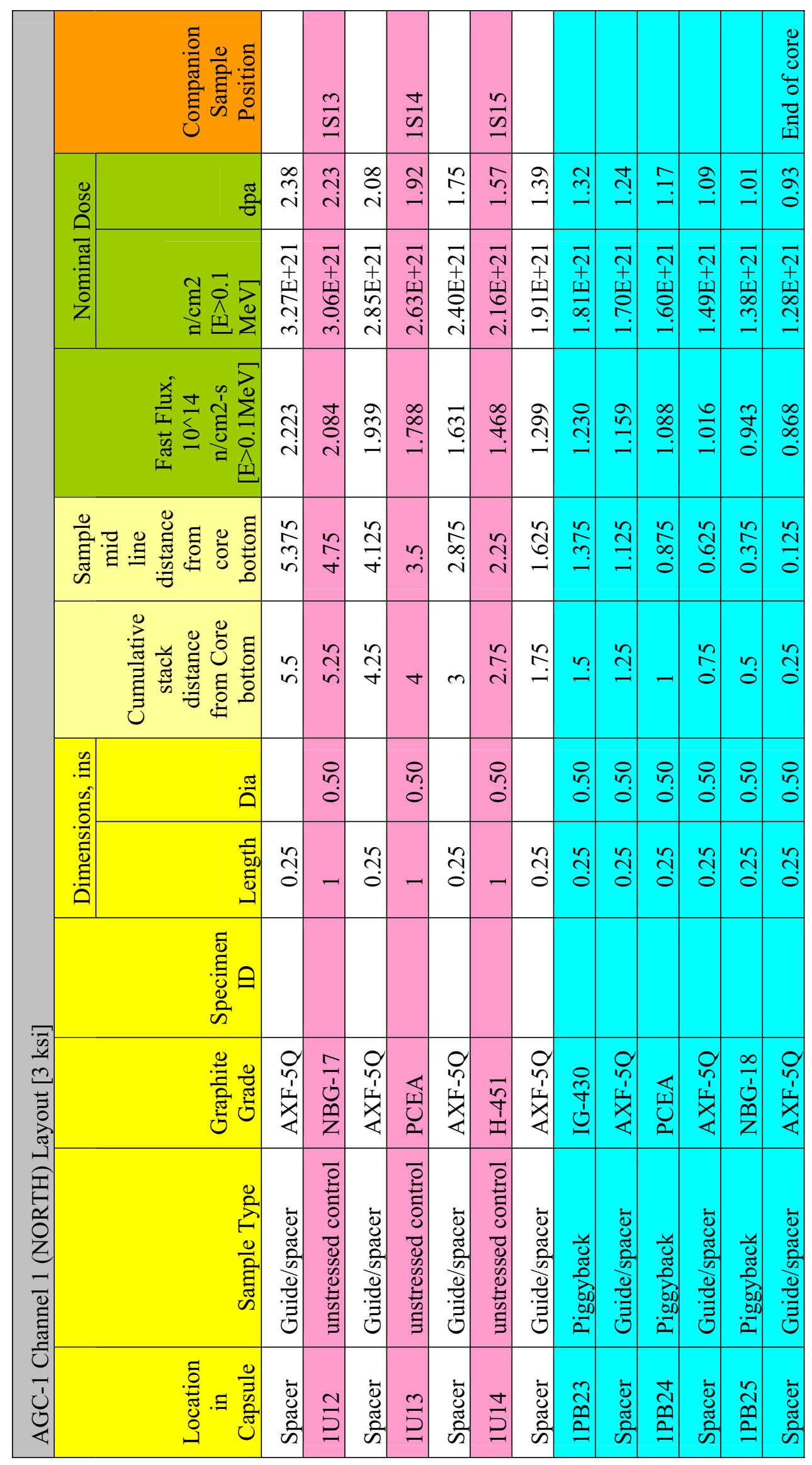


Appendix B

AGC-1 Channel 2 (North-East) Specimen Layout [2 ksi] 


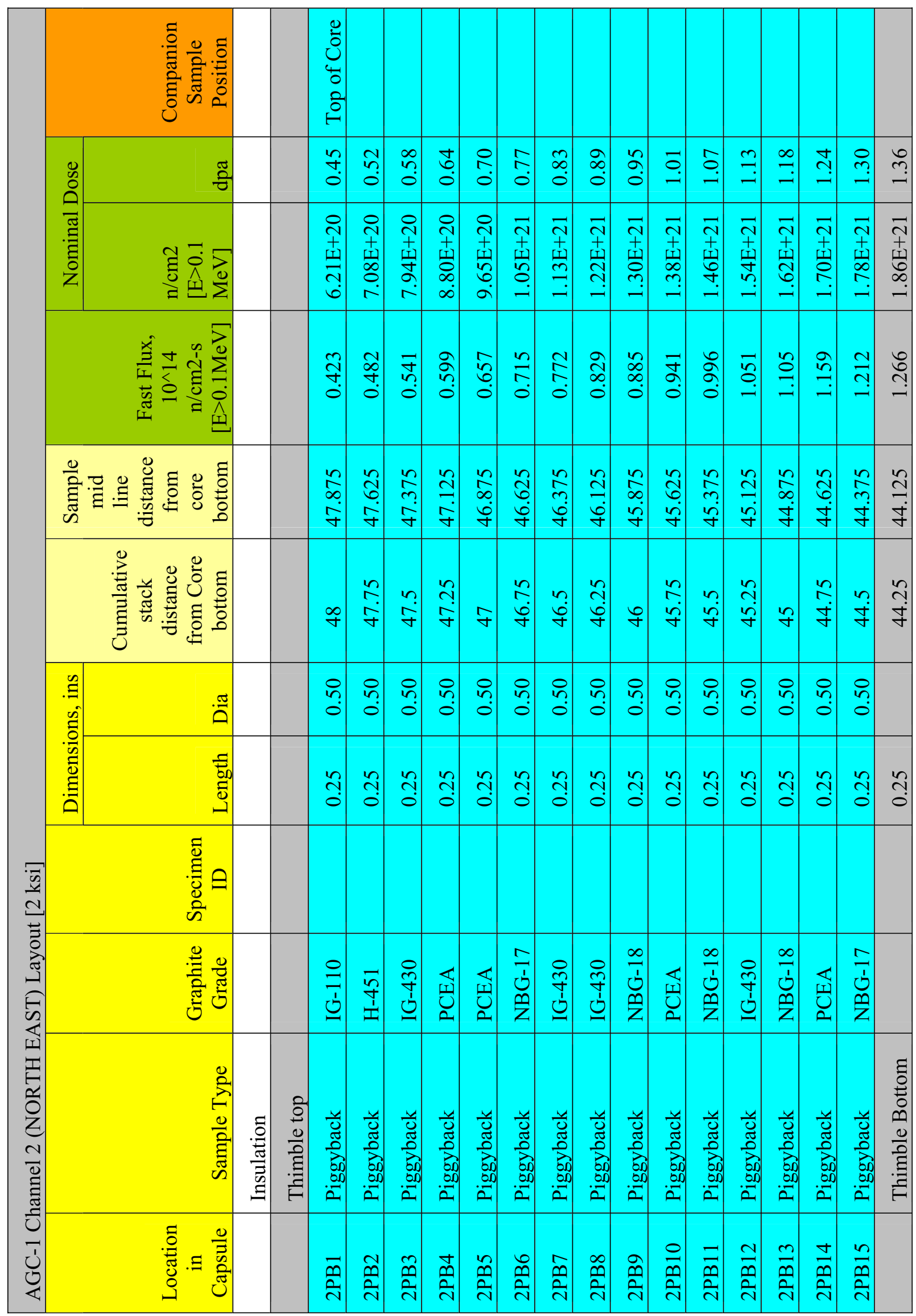




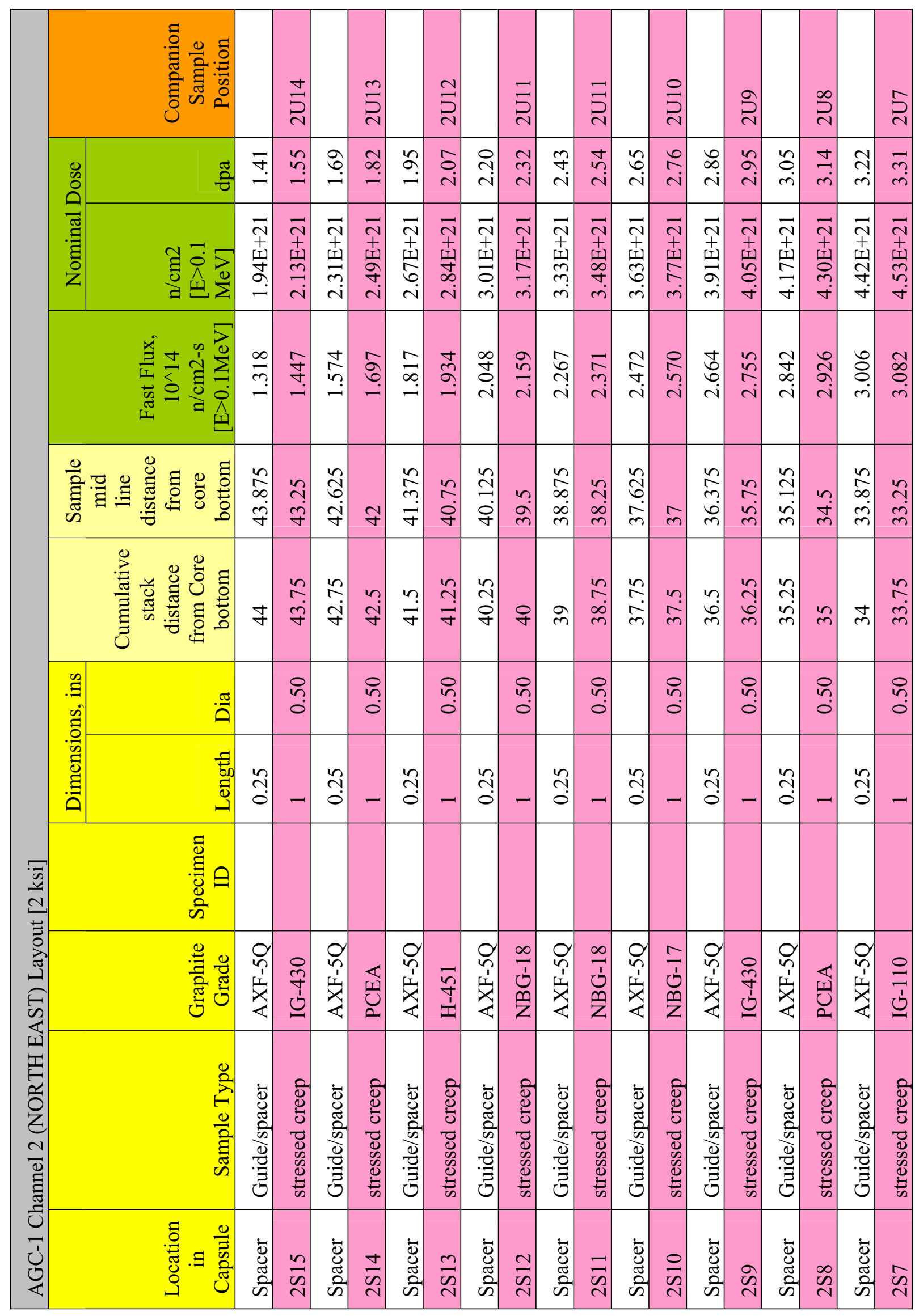




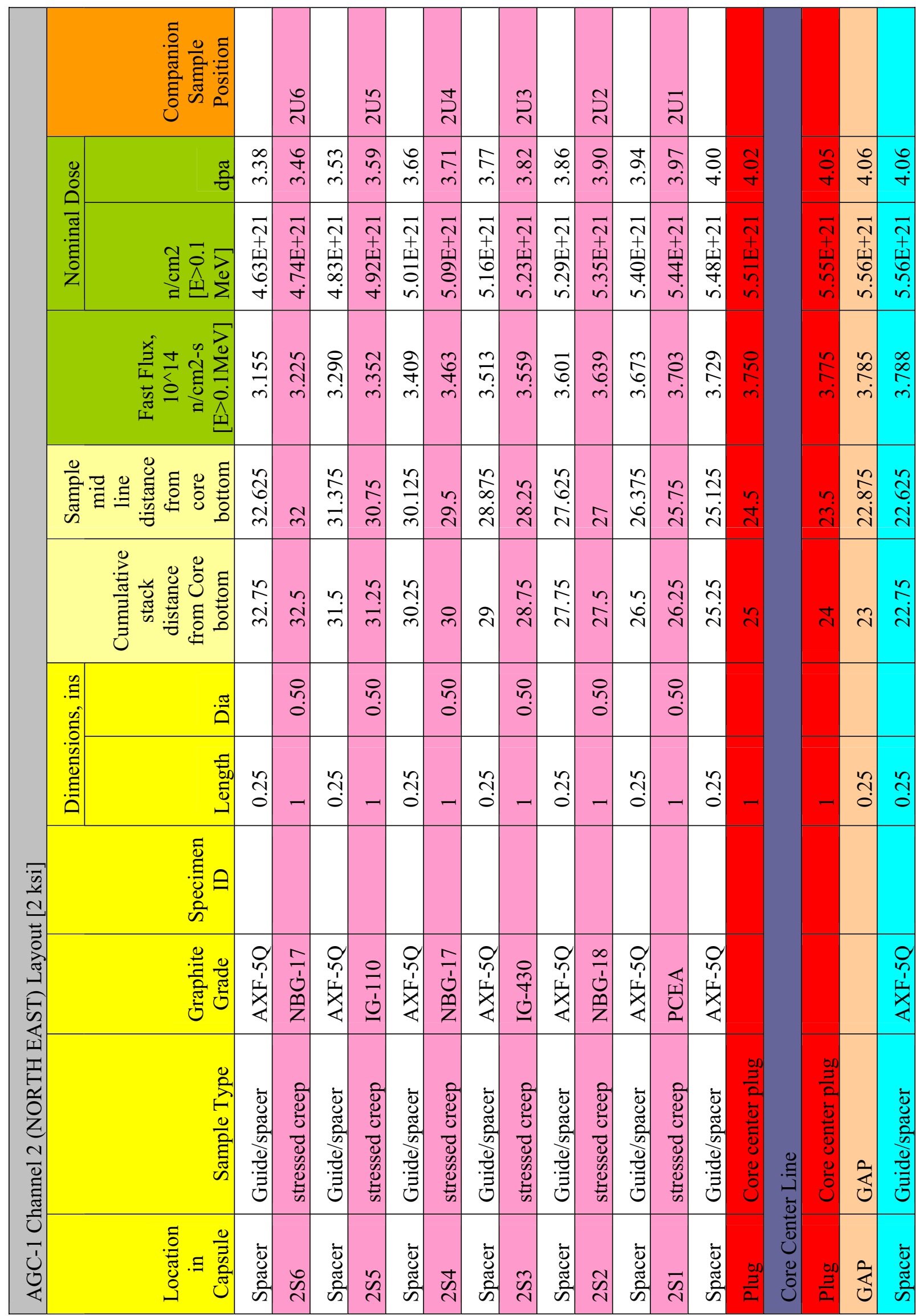




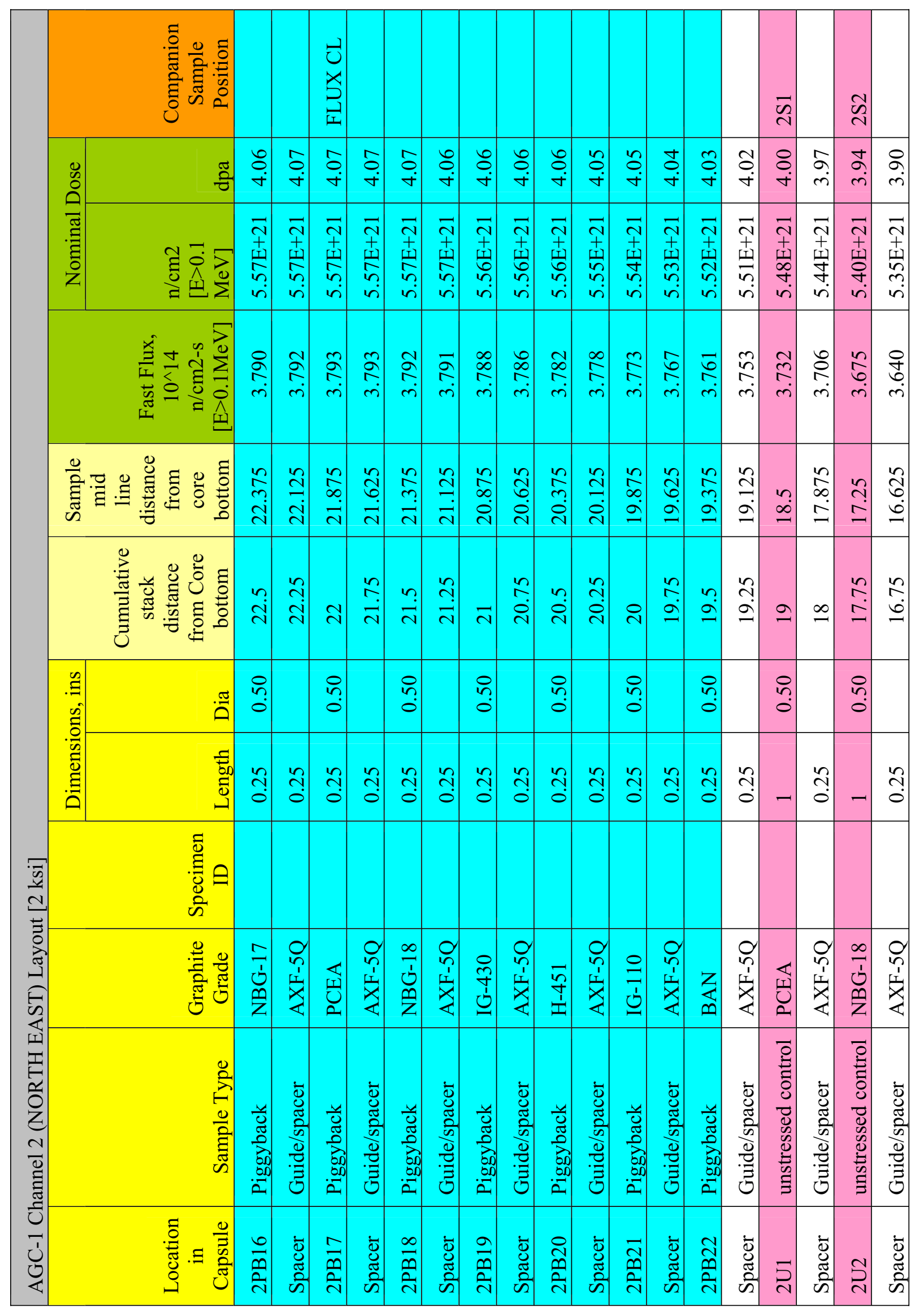




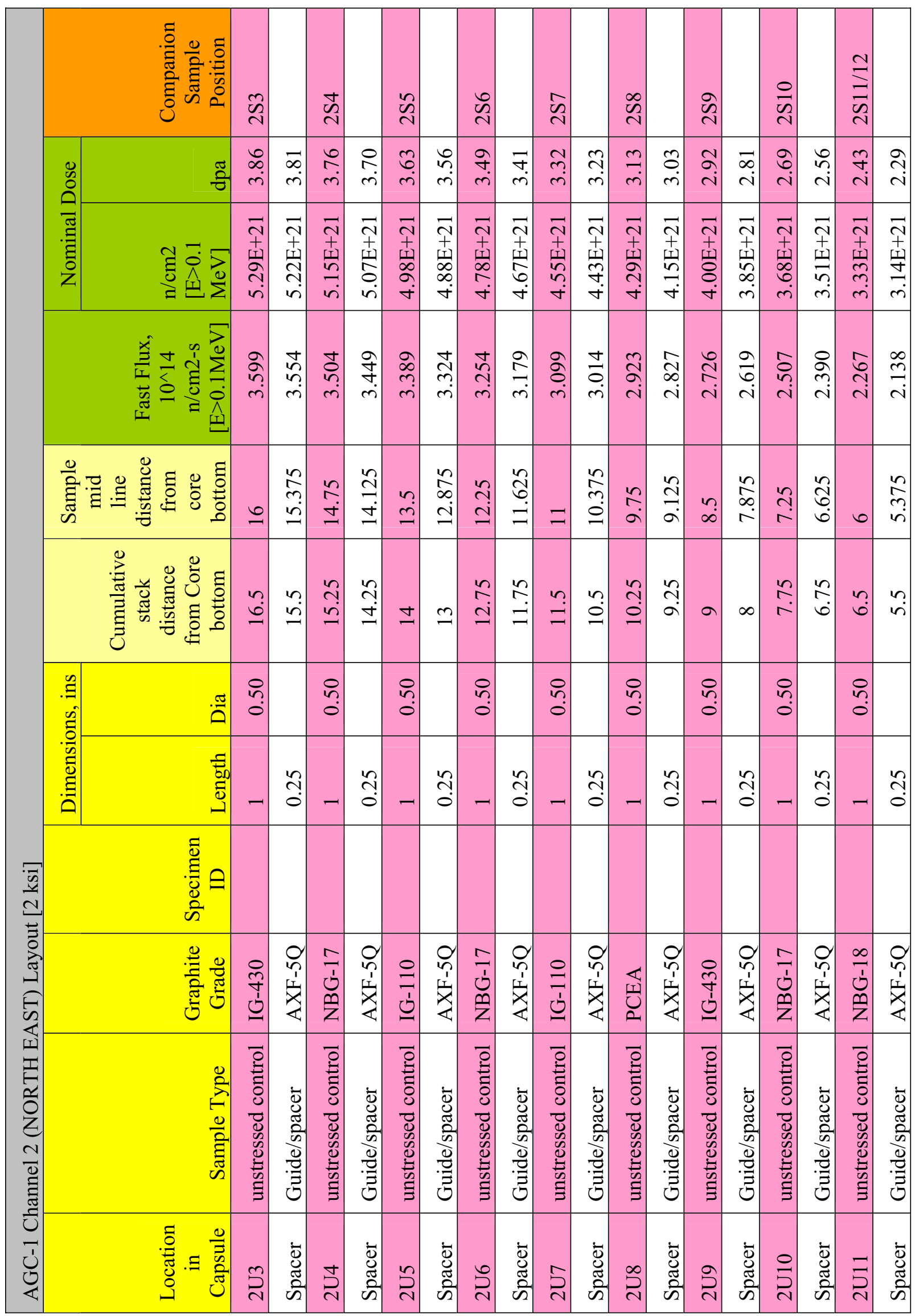




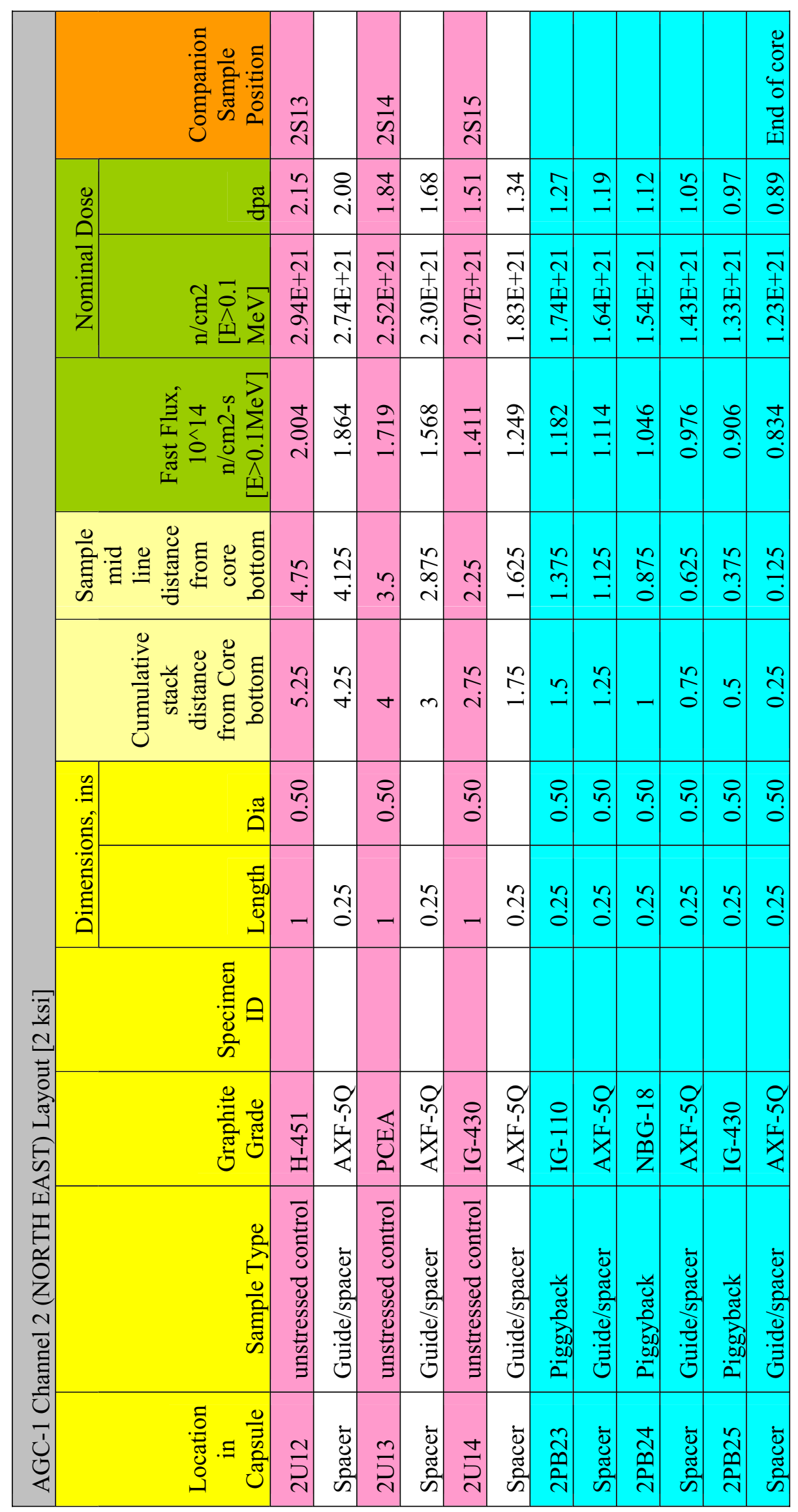




\section{Appendix C}

\section{AGC-1 Channel 3 (South-East) Specimen Layout [3 ksi]}




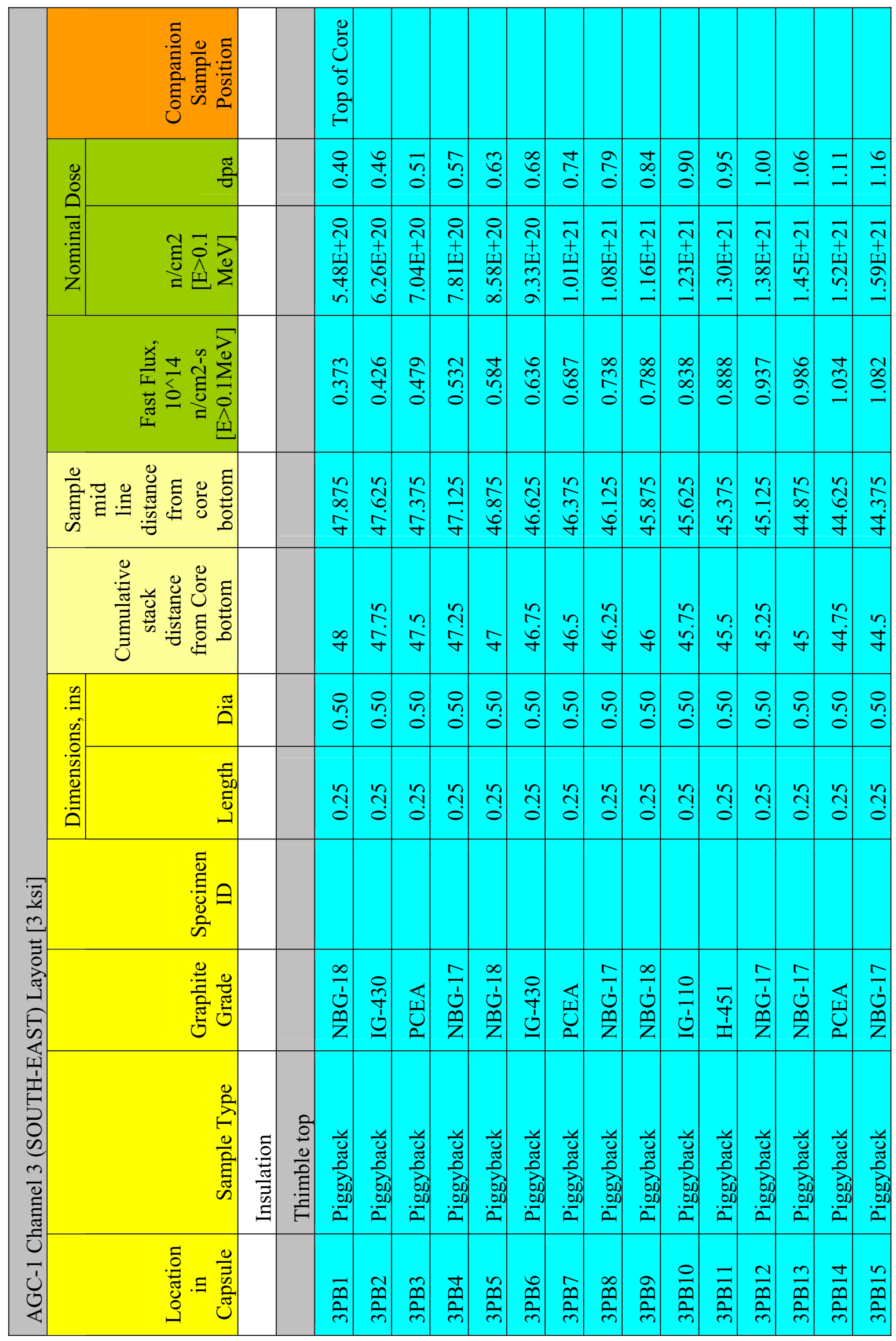




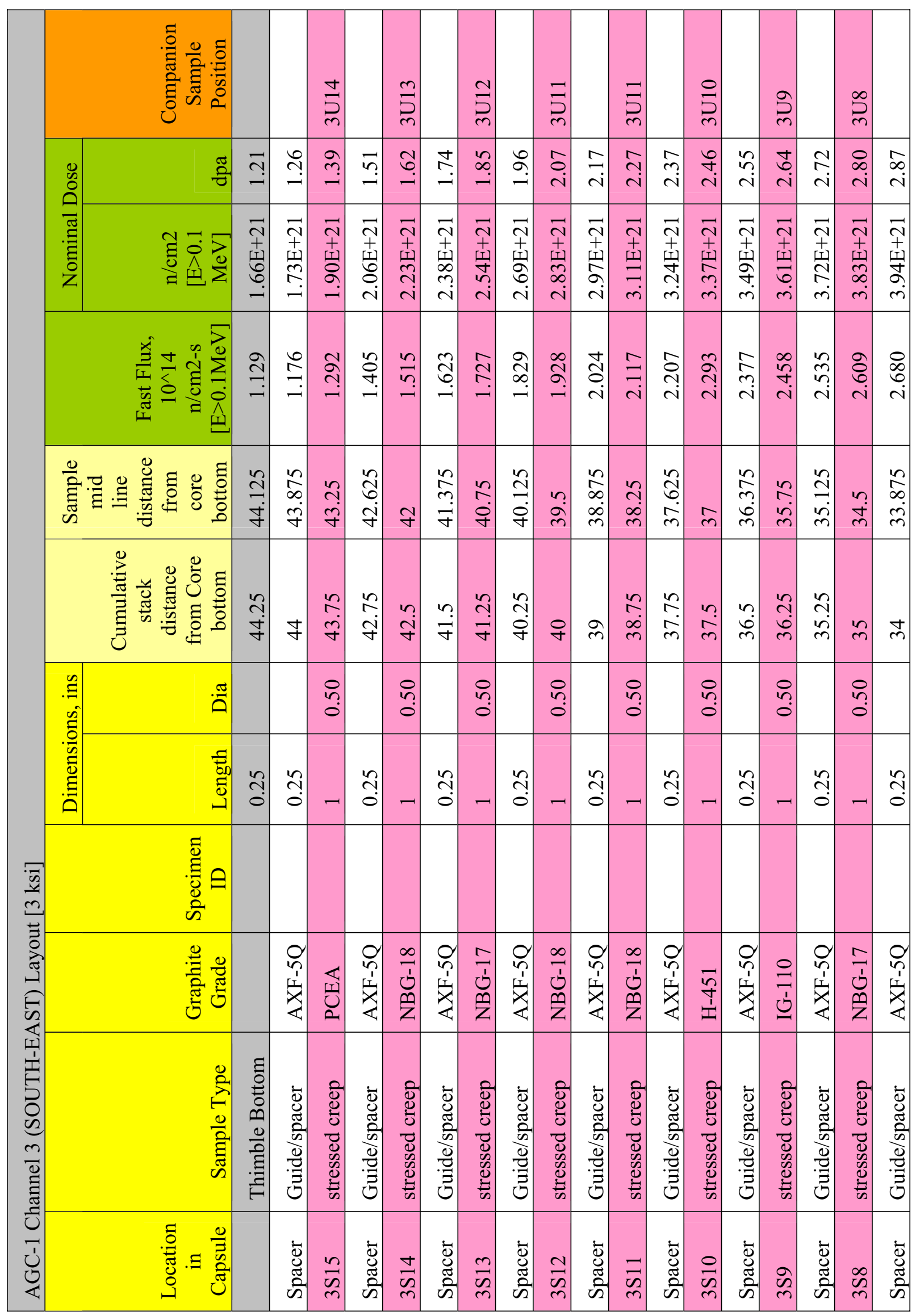




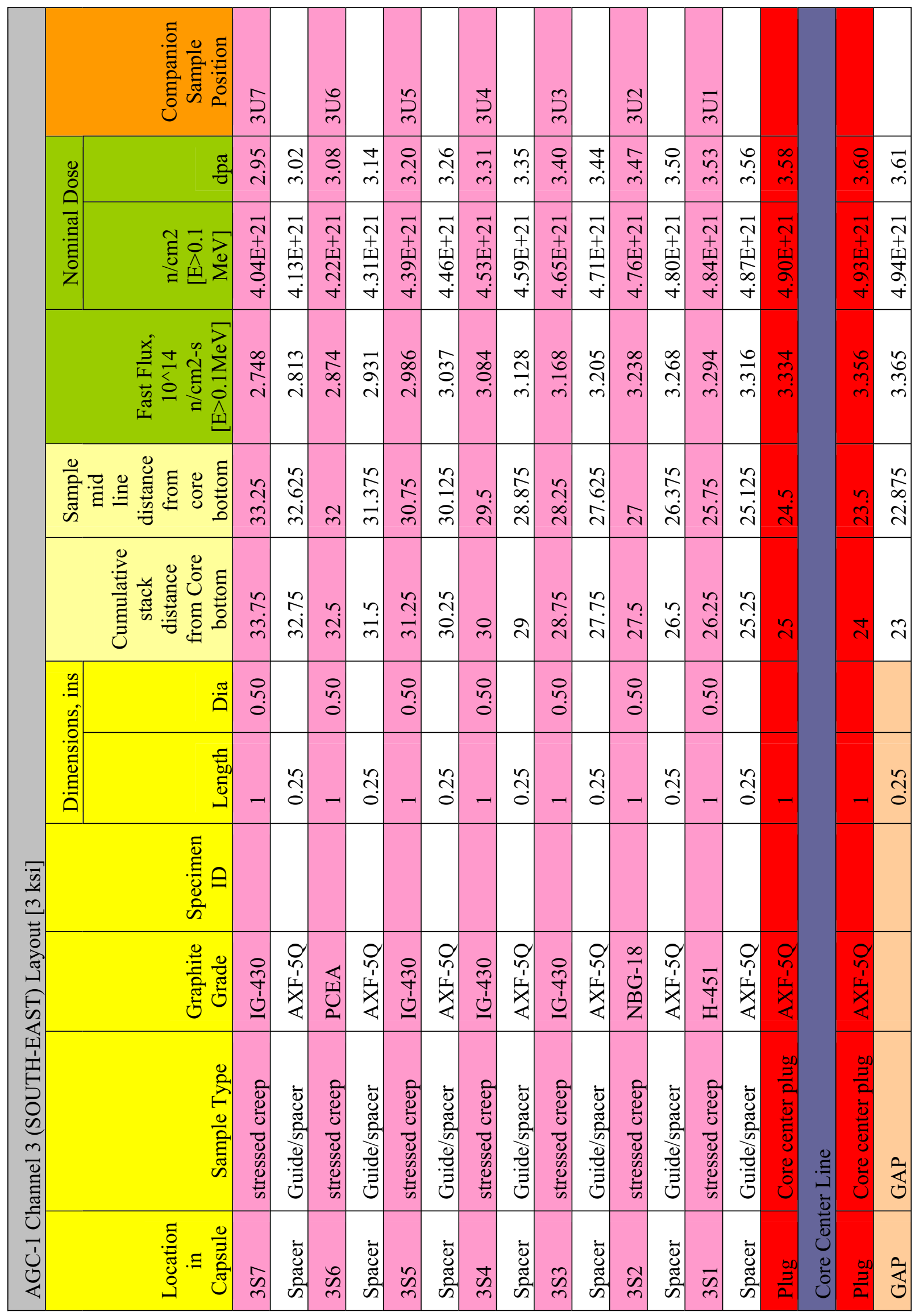




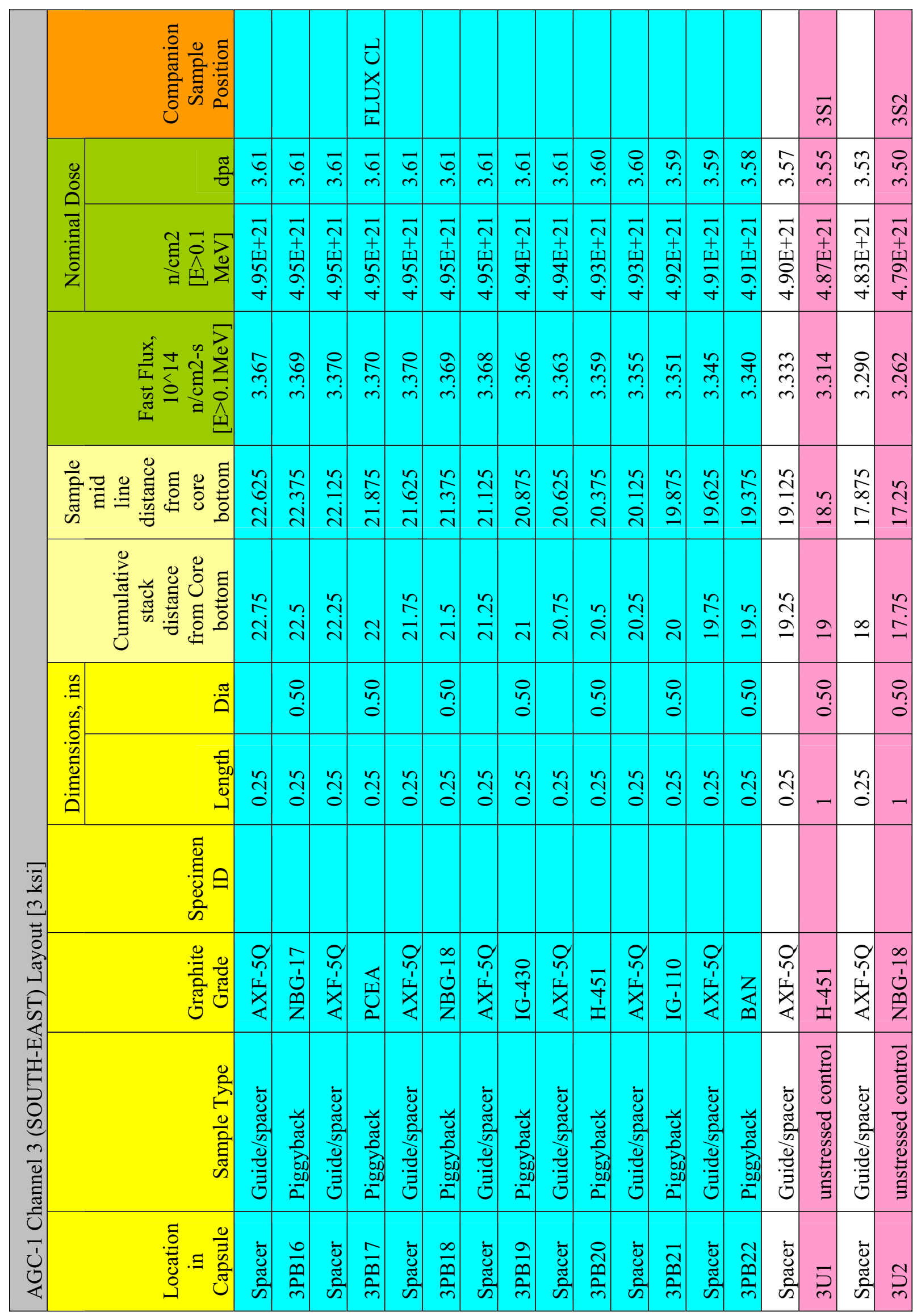




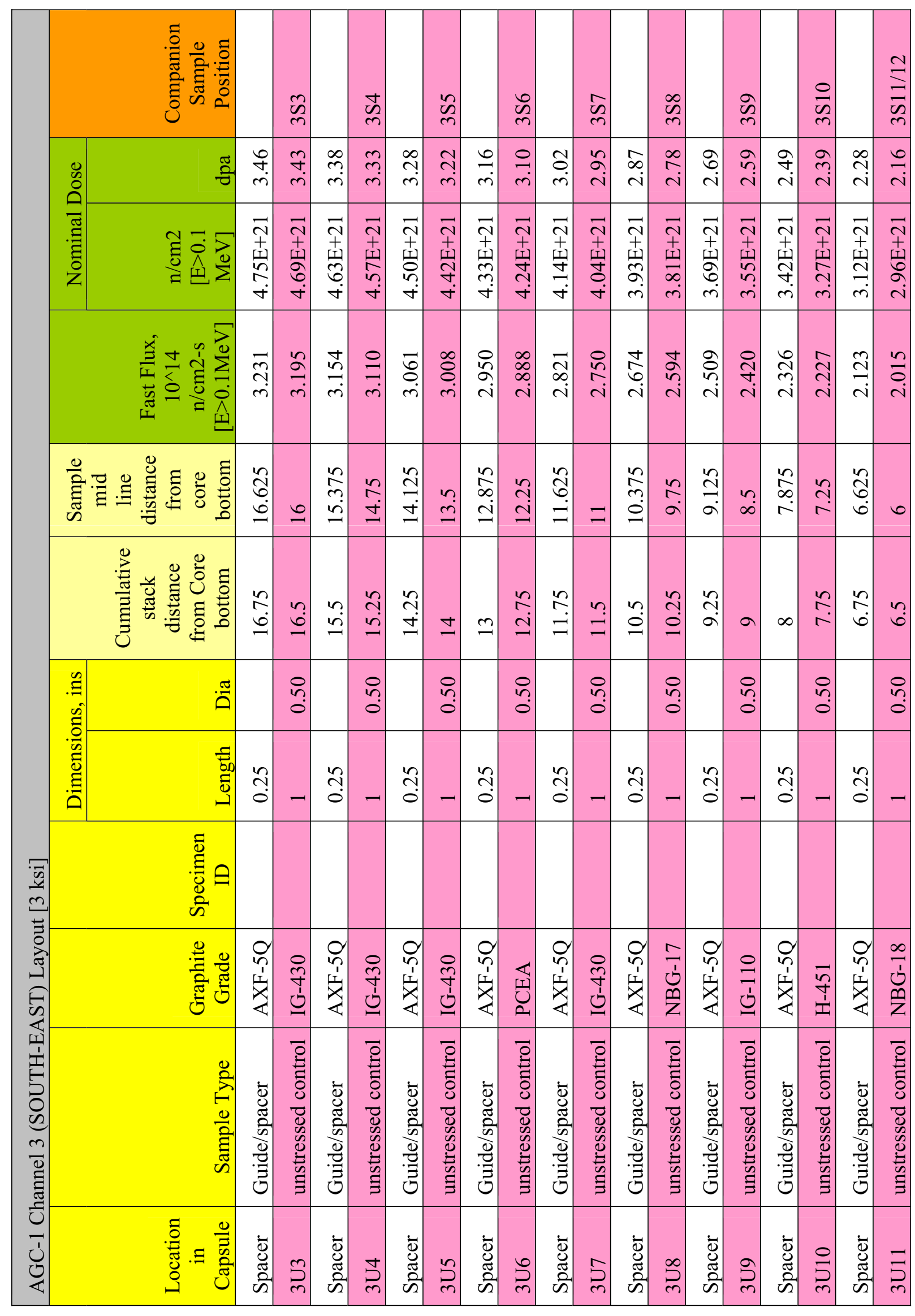




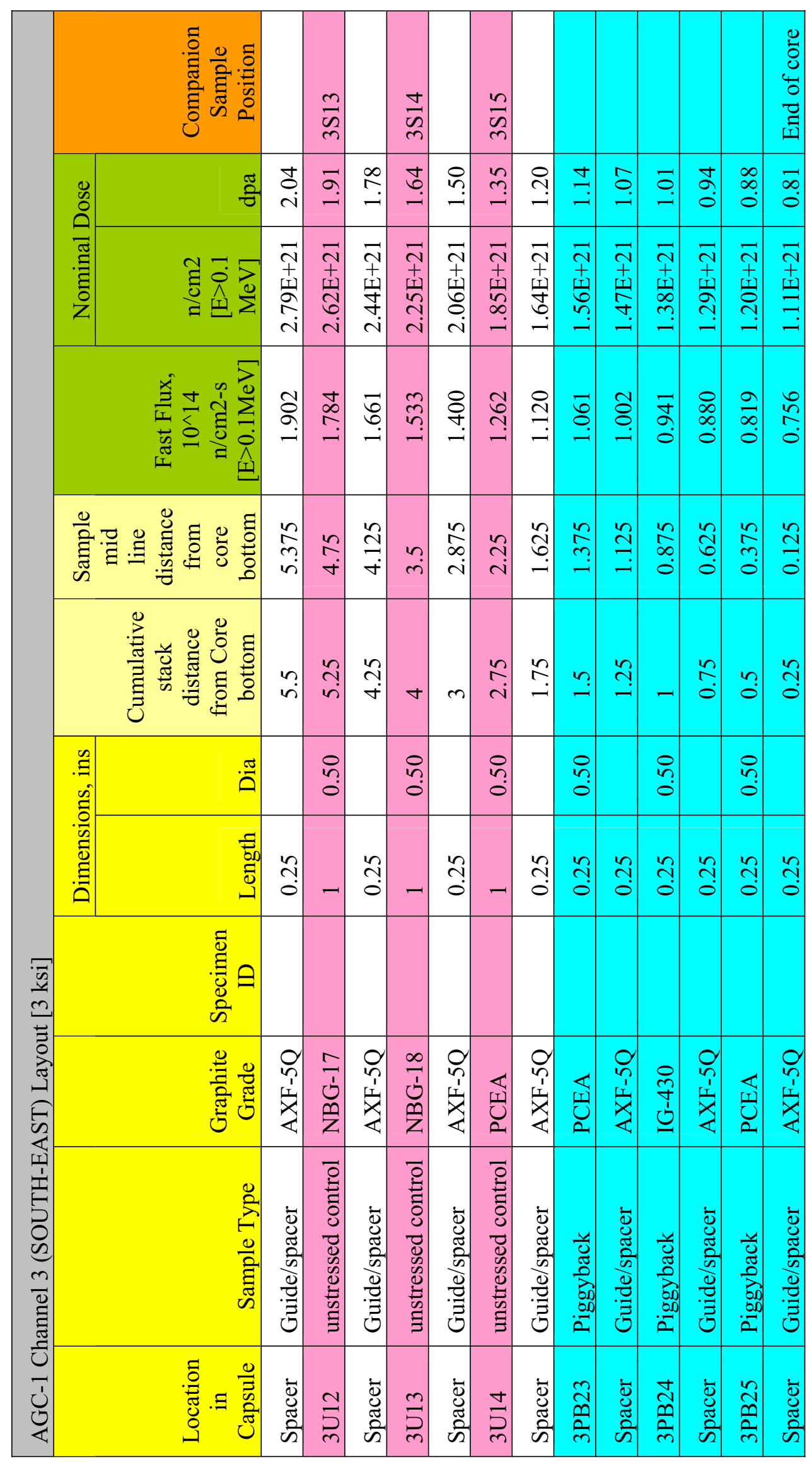


Appendix D

AGC-1 Channel 4 (South) Specimen Layout [2 ksi] 


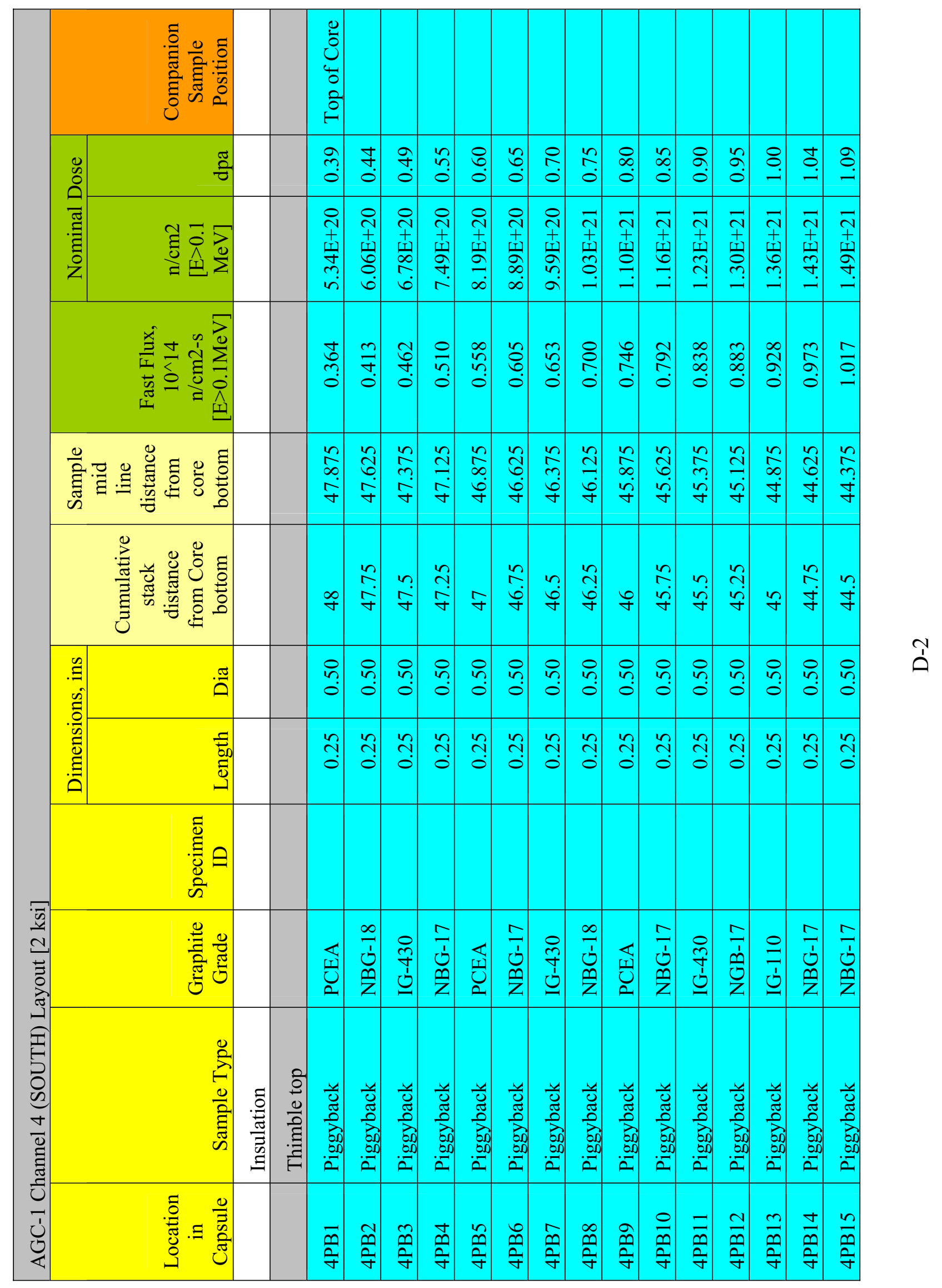




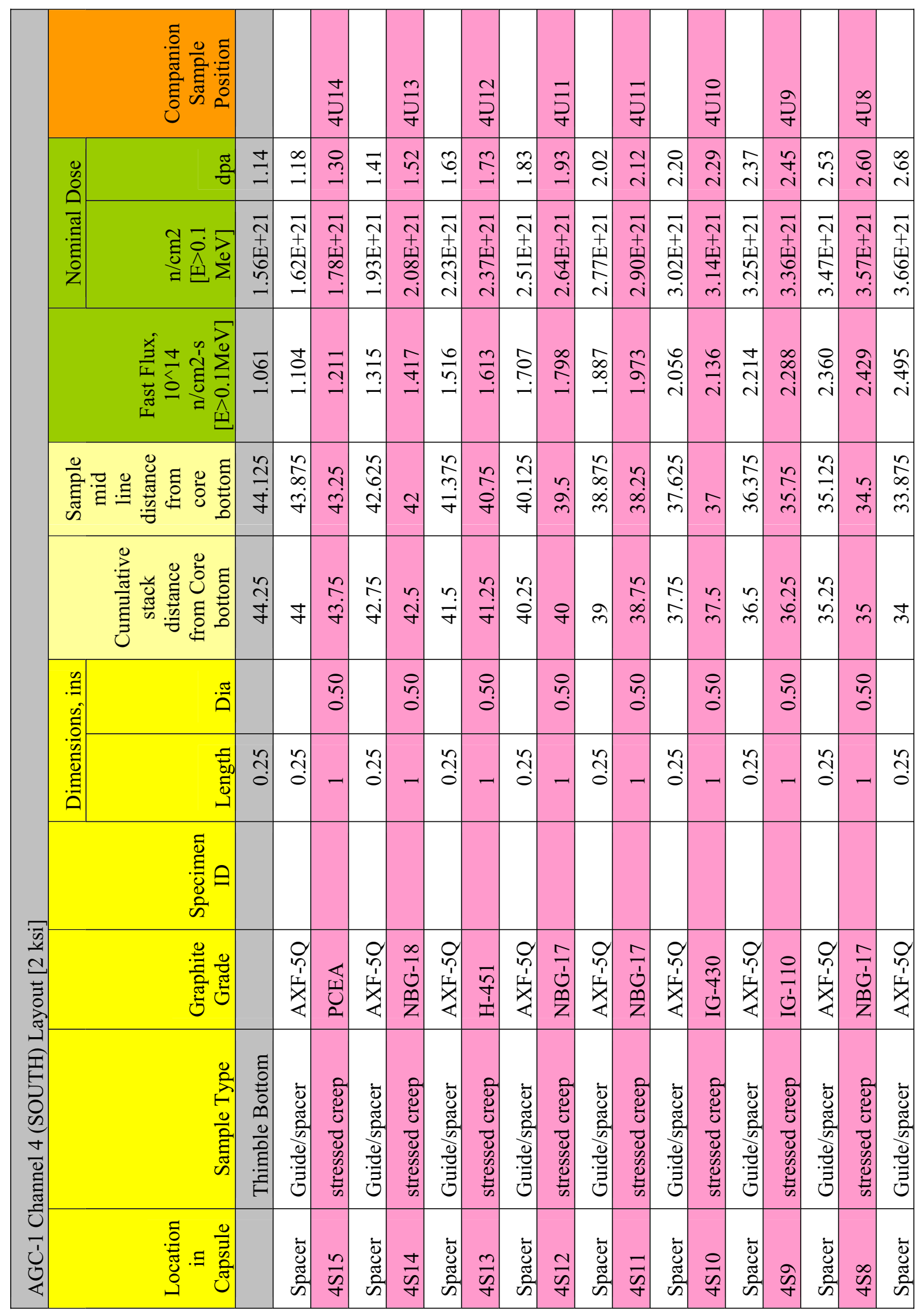




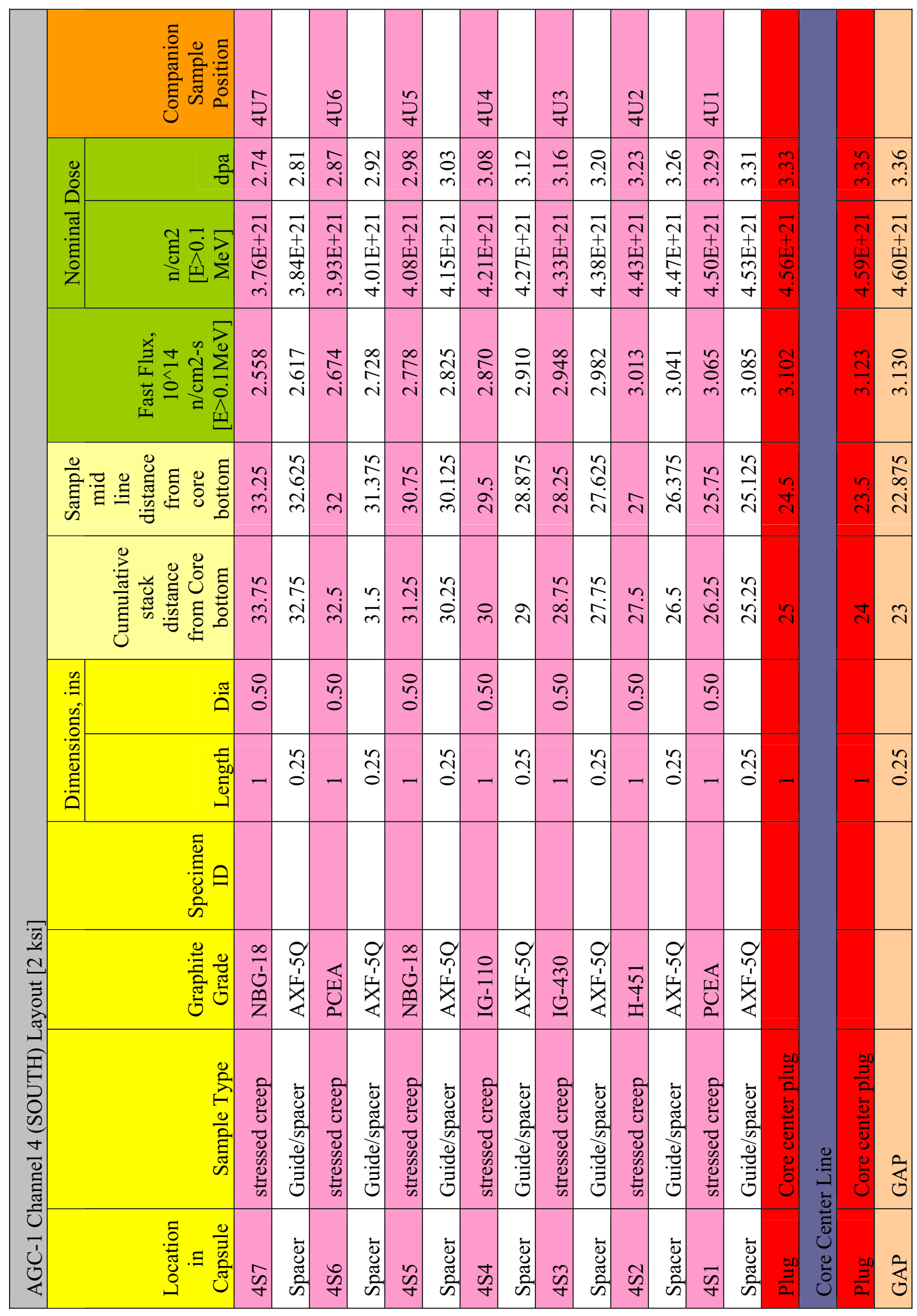




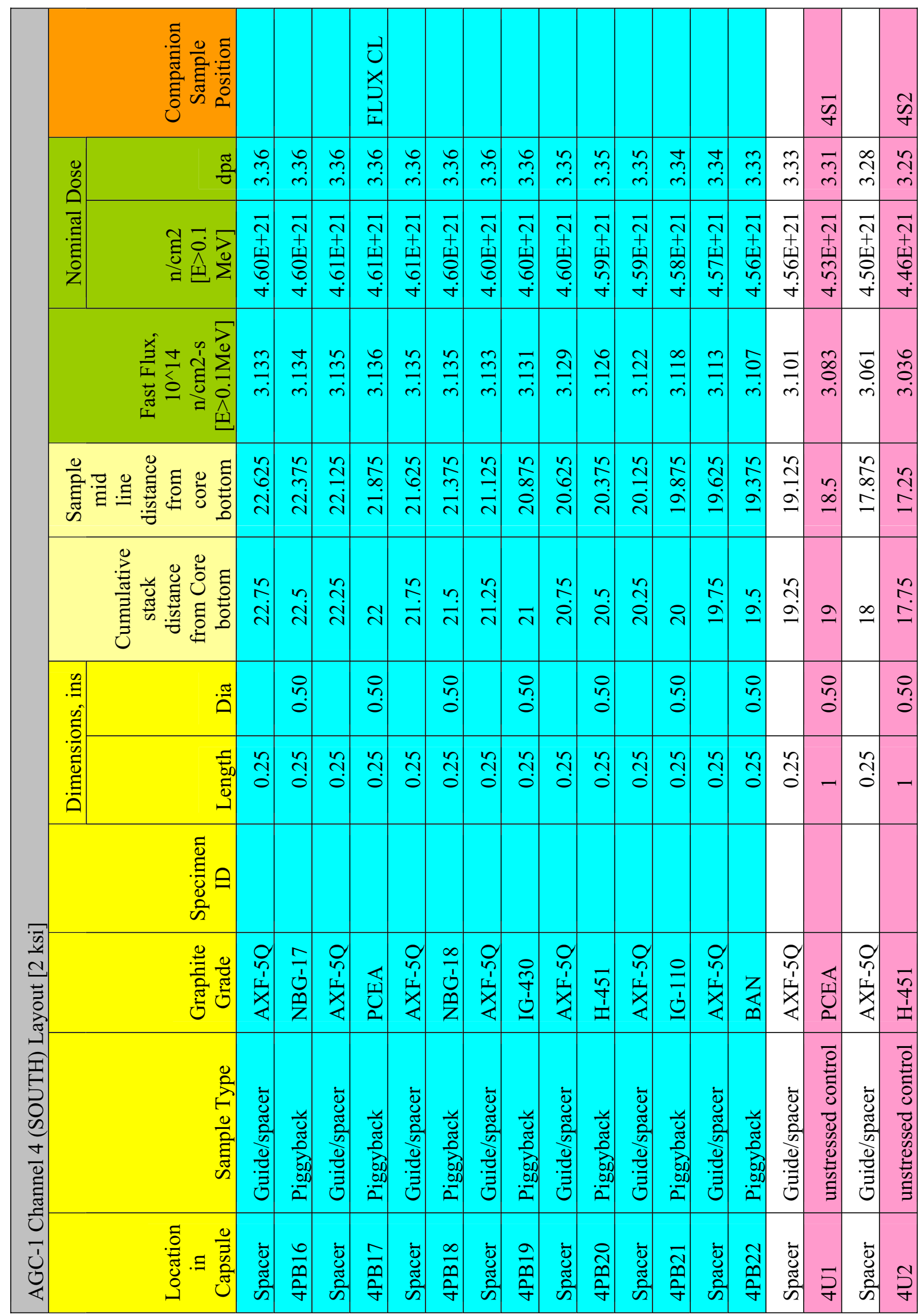




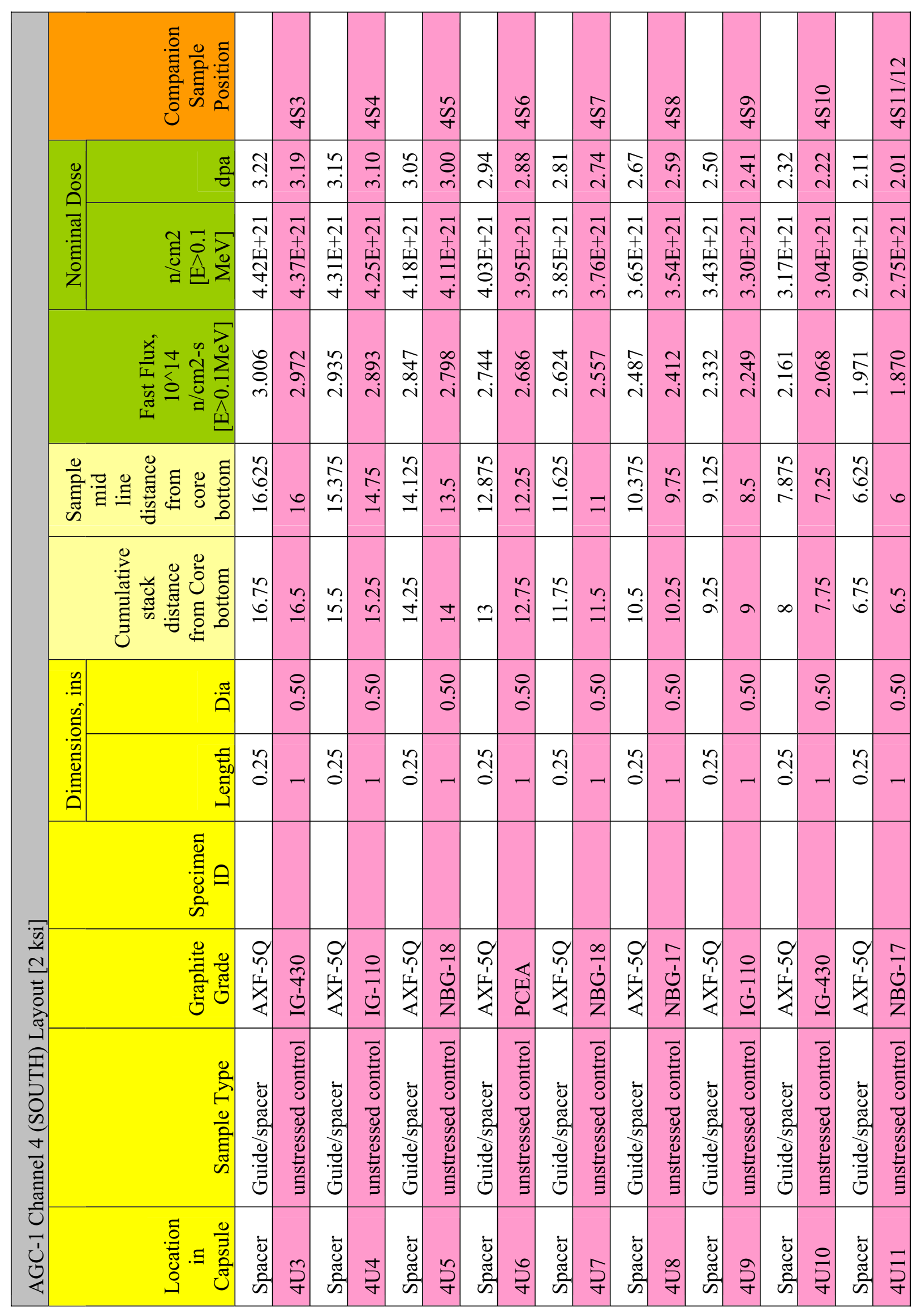




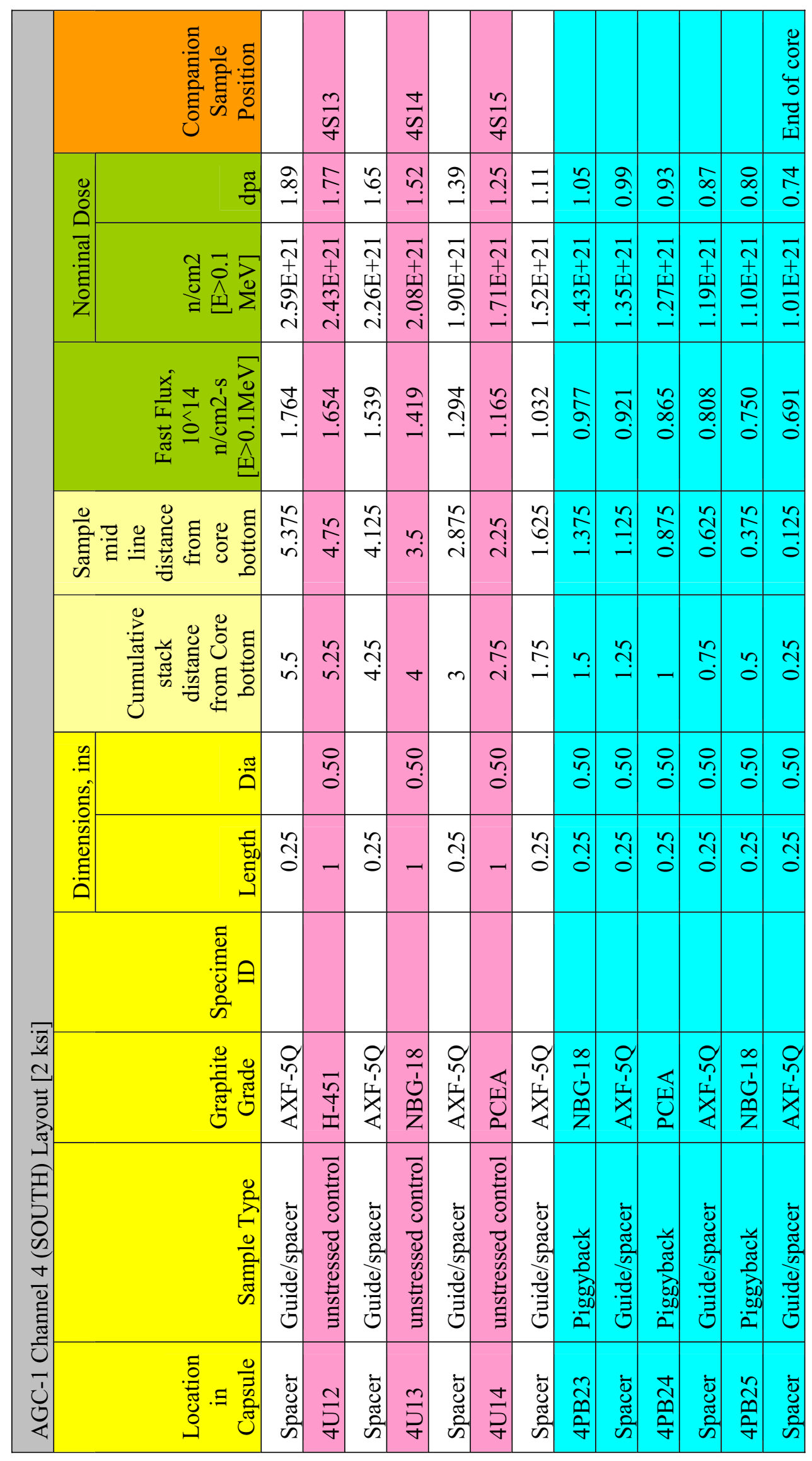




\section{Appendix E}

\section{AGC-1 Channel 5 (South-West) Specimen Layout [3 ksi]}




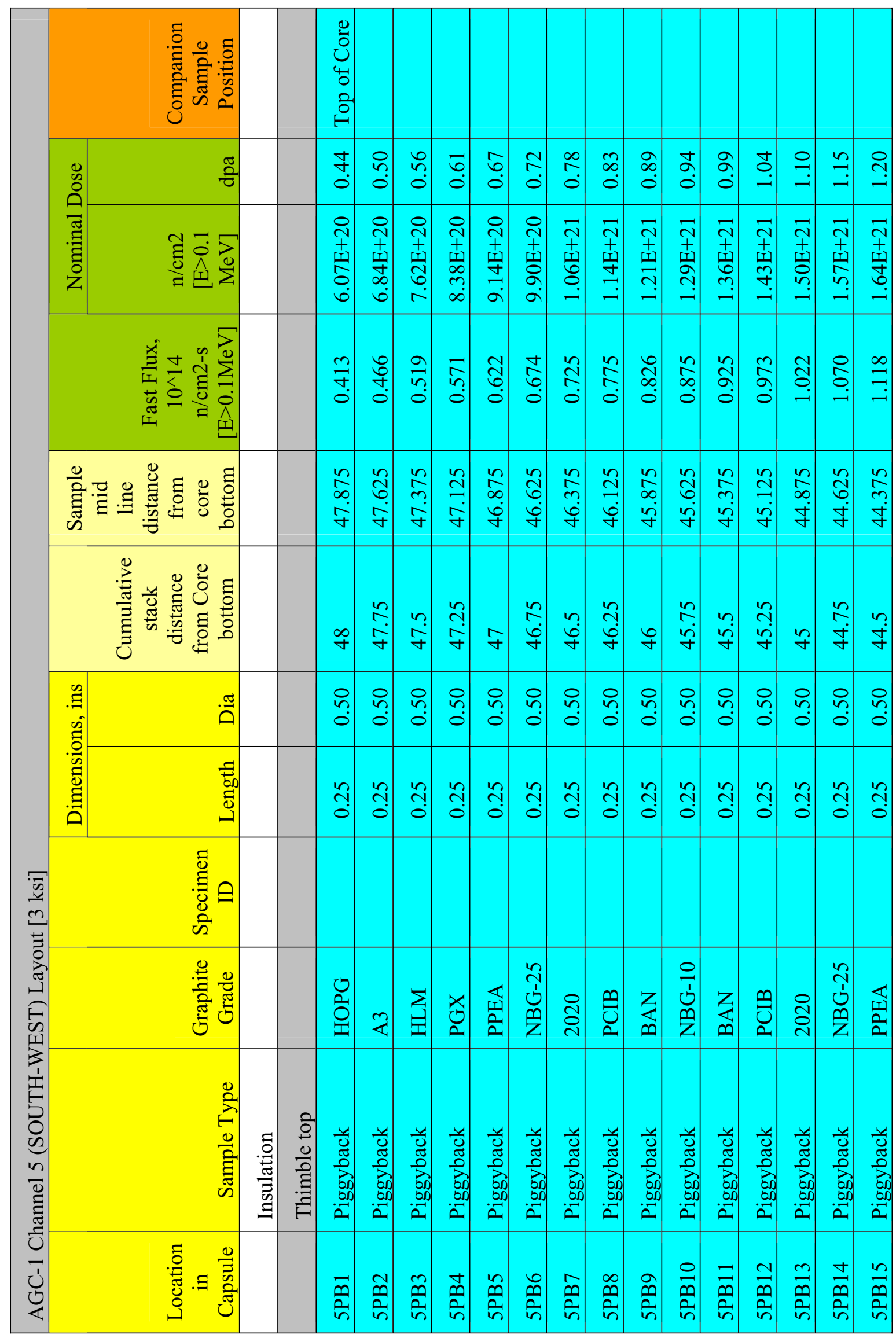




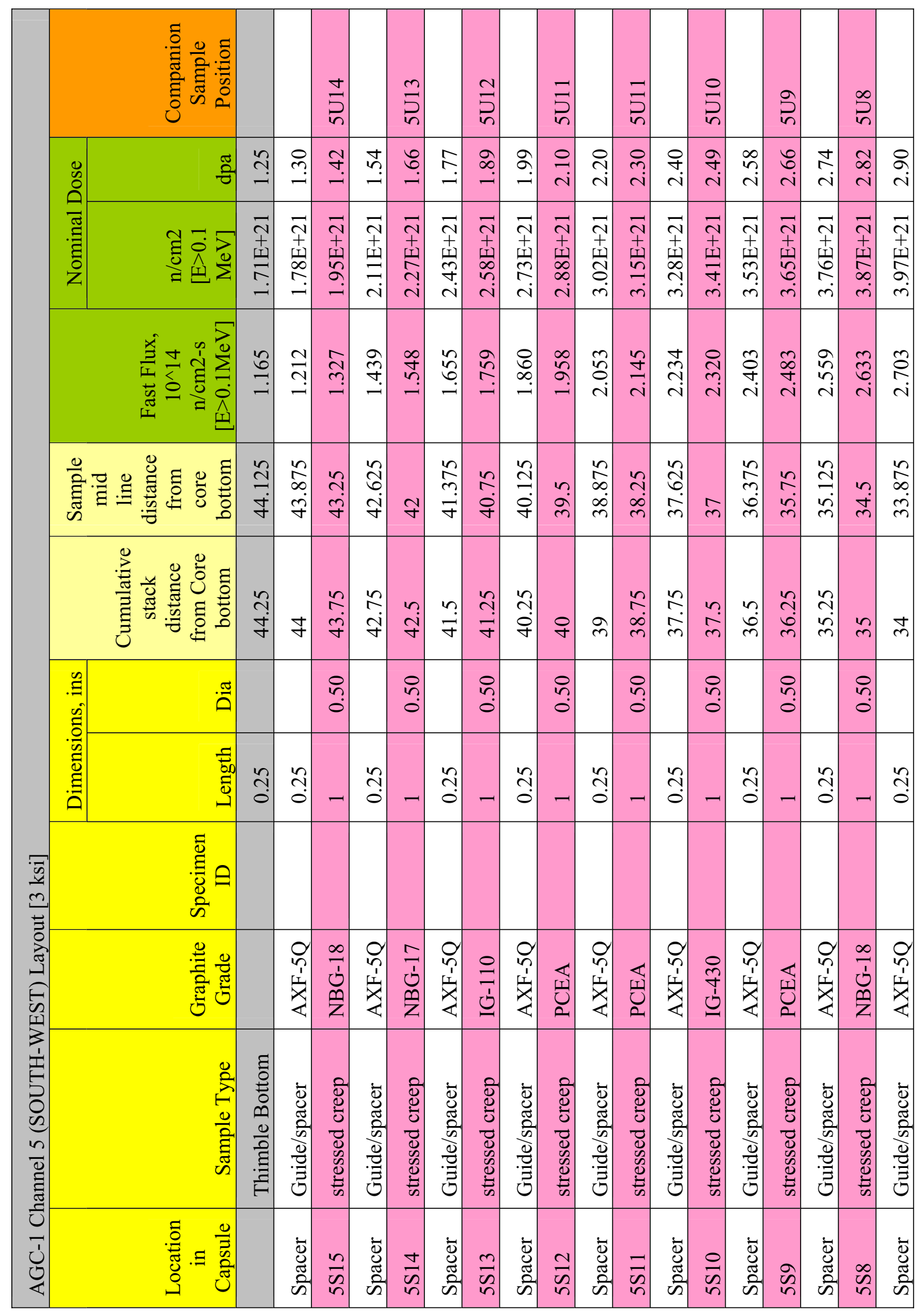




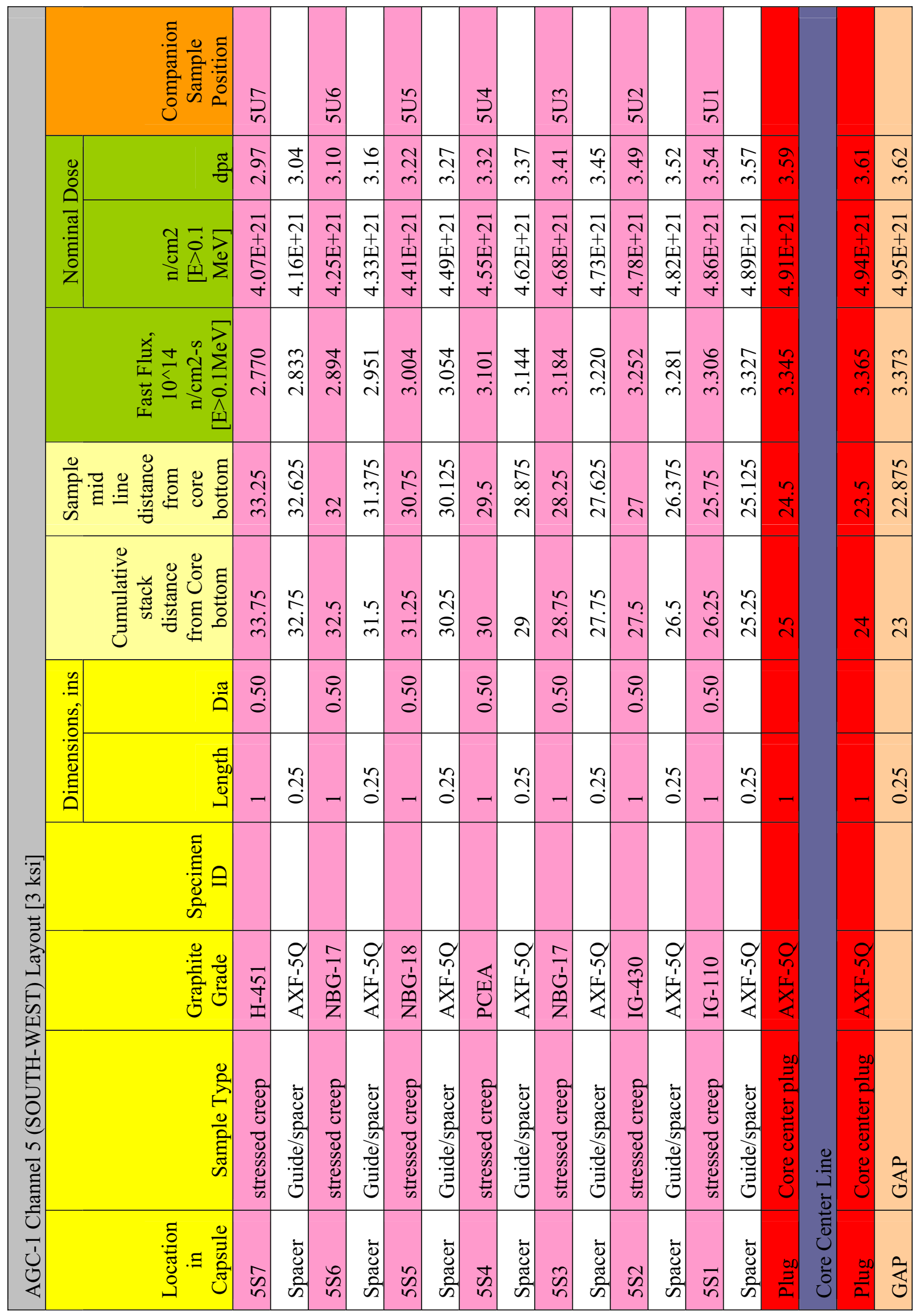




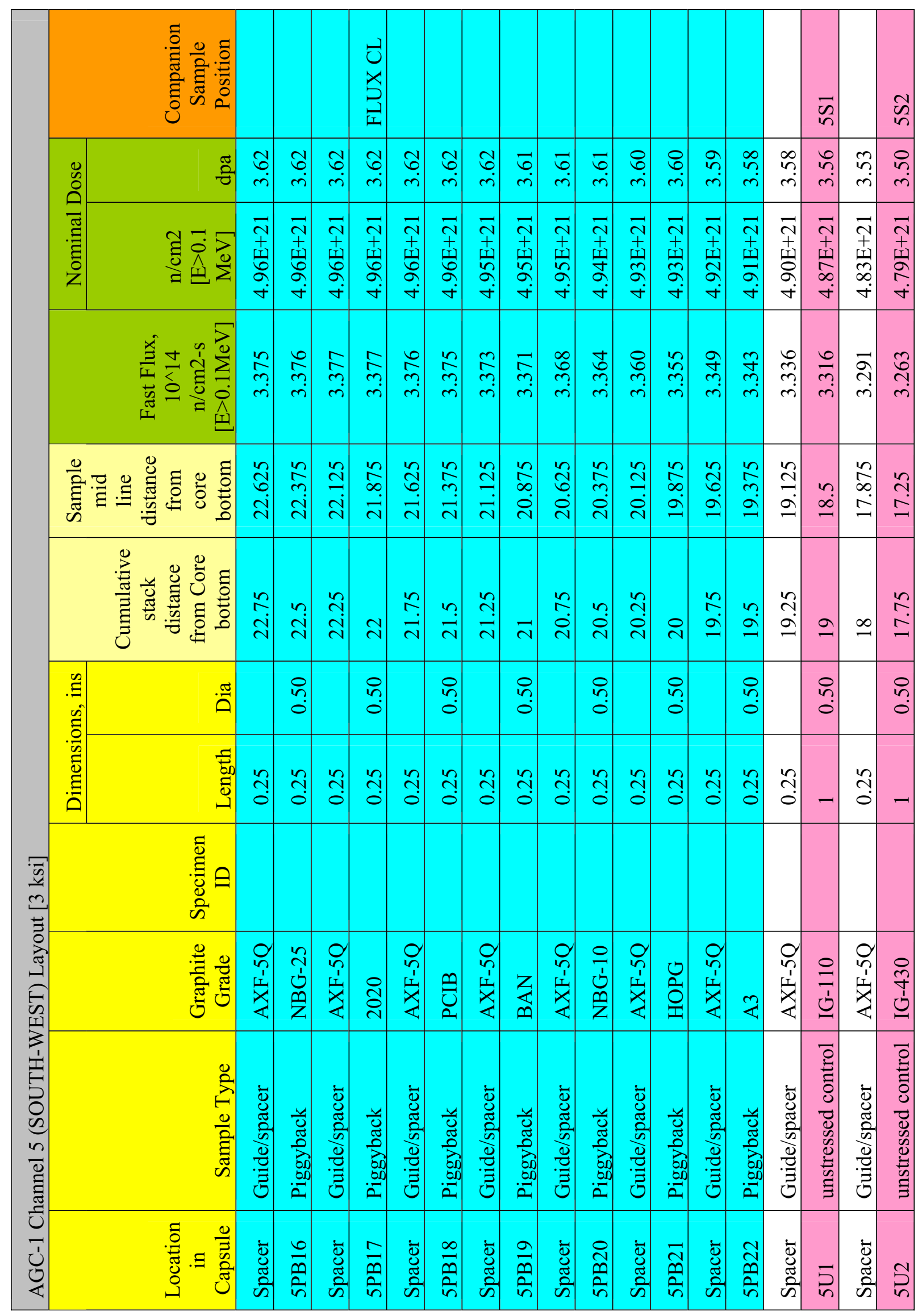




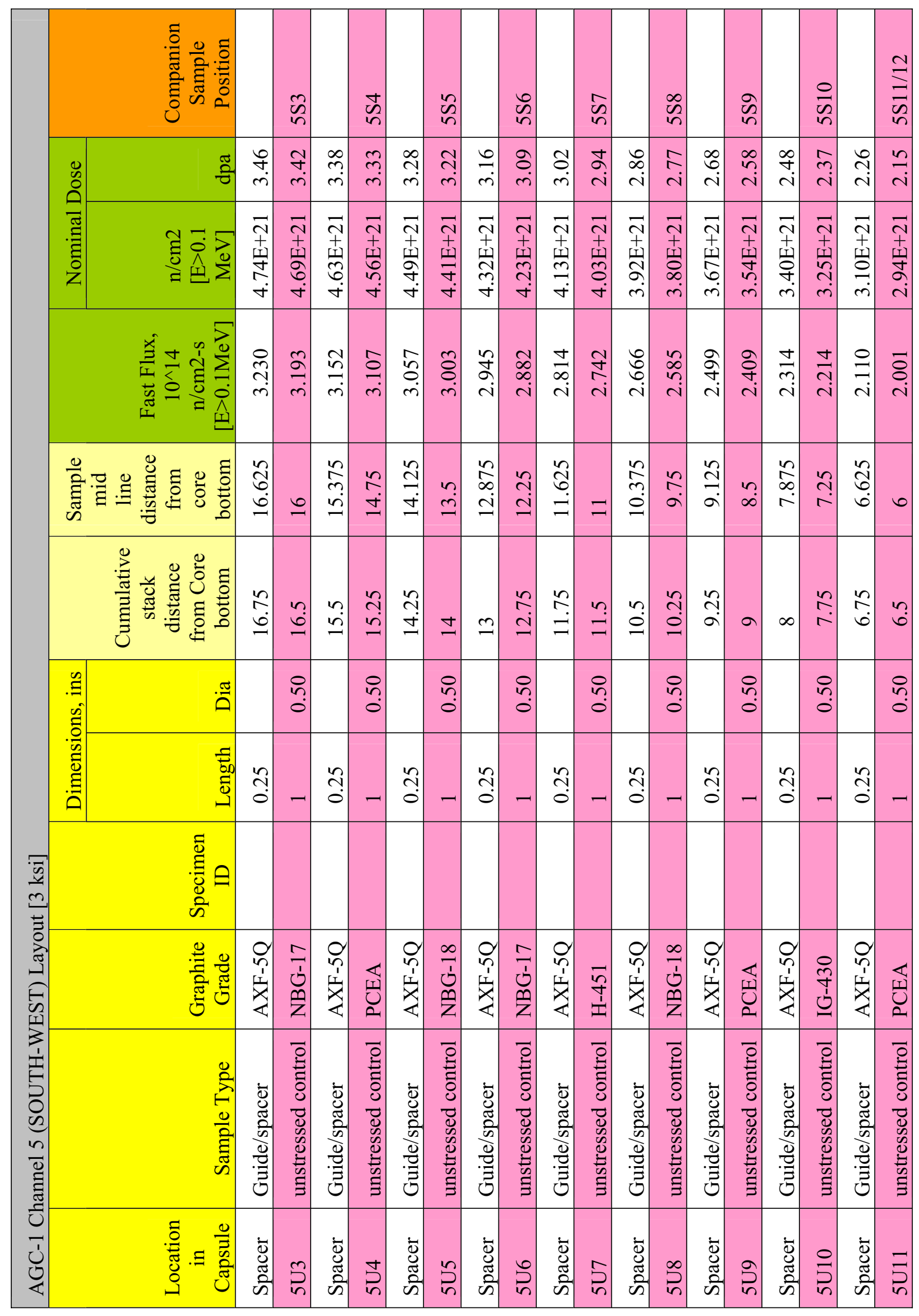




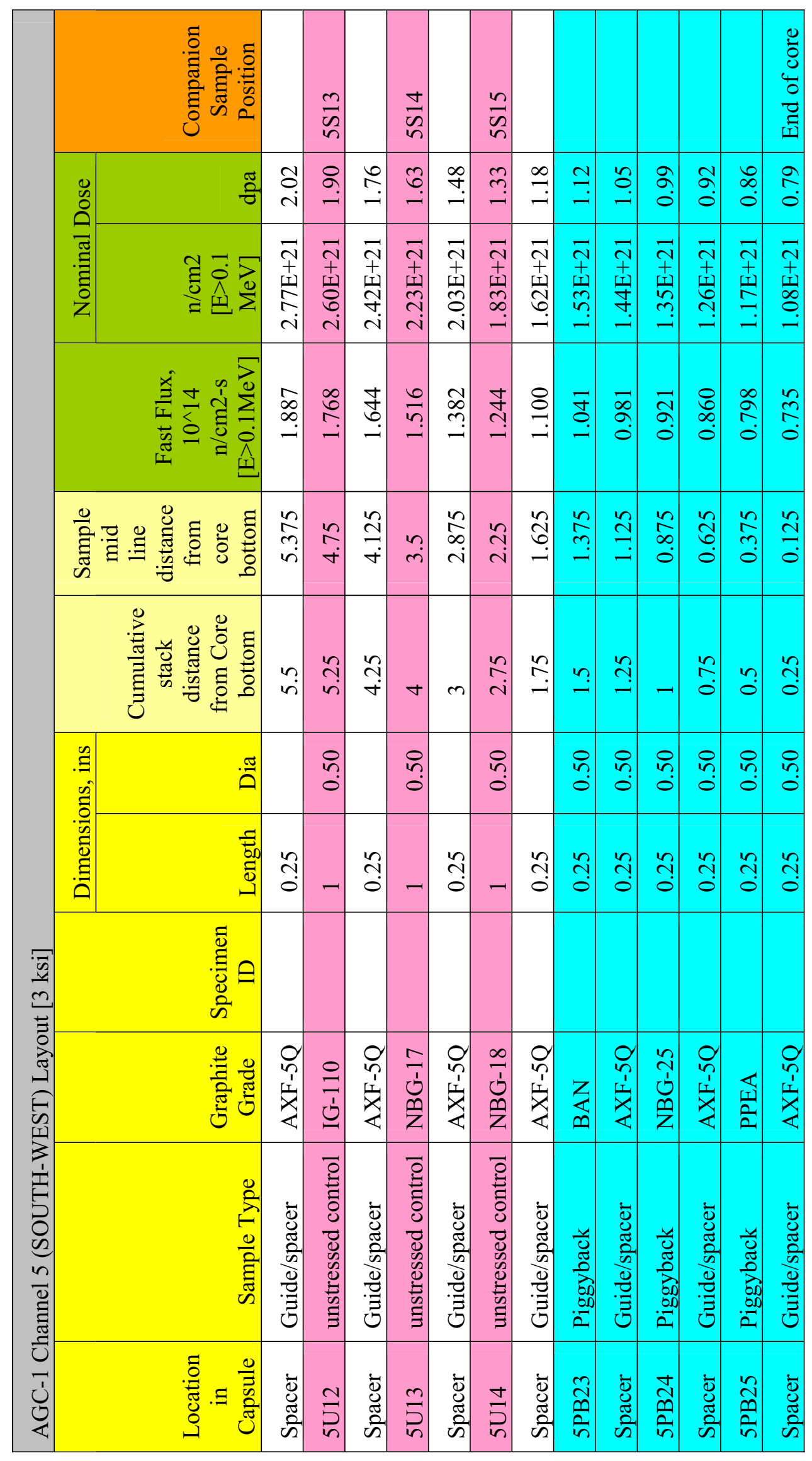




\section{Appendix F}

\section{AGC-1 Channel 6 (North-West) Specimen Layout [2 ksi]}




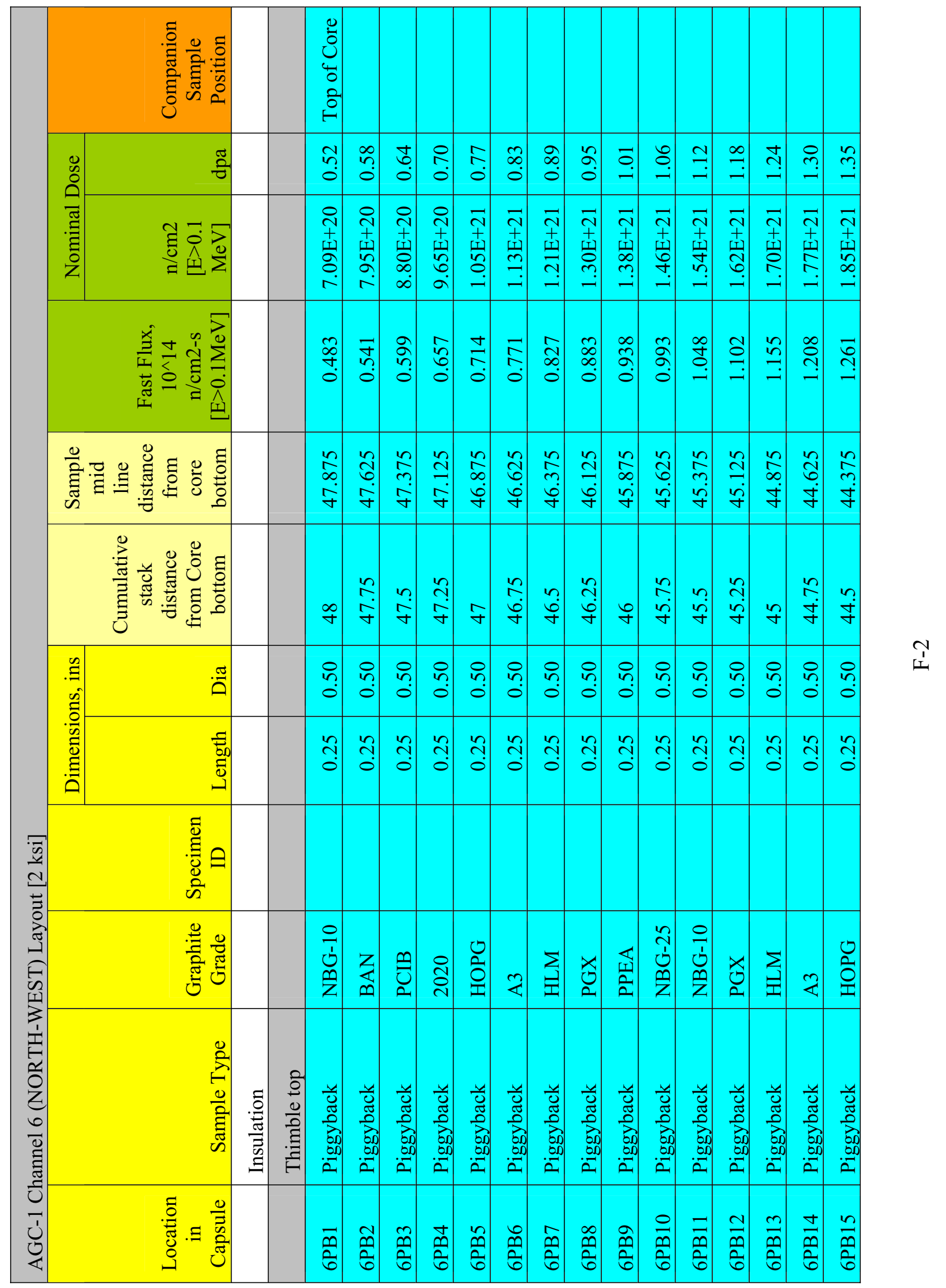




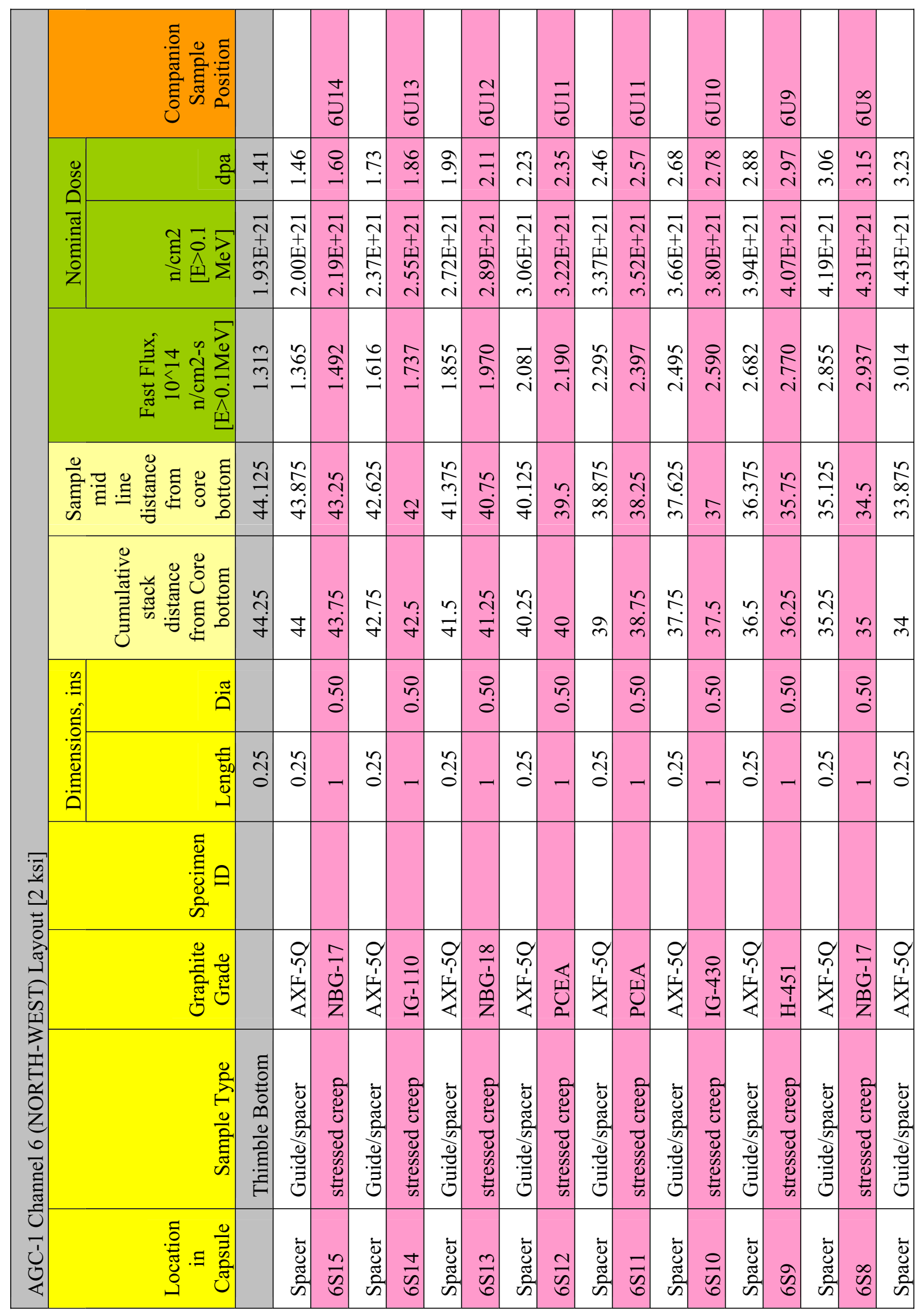




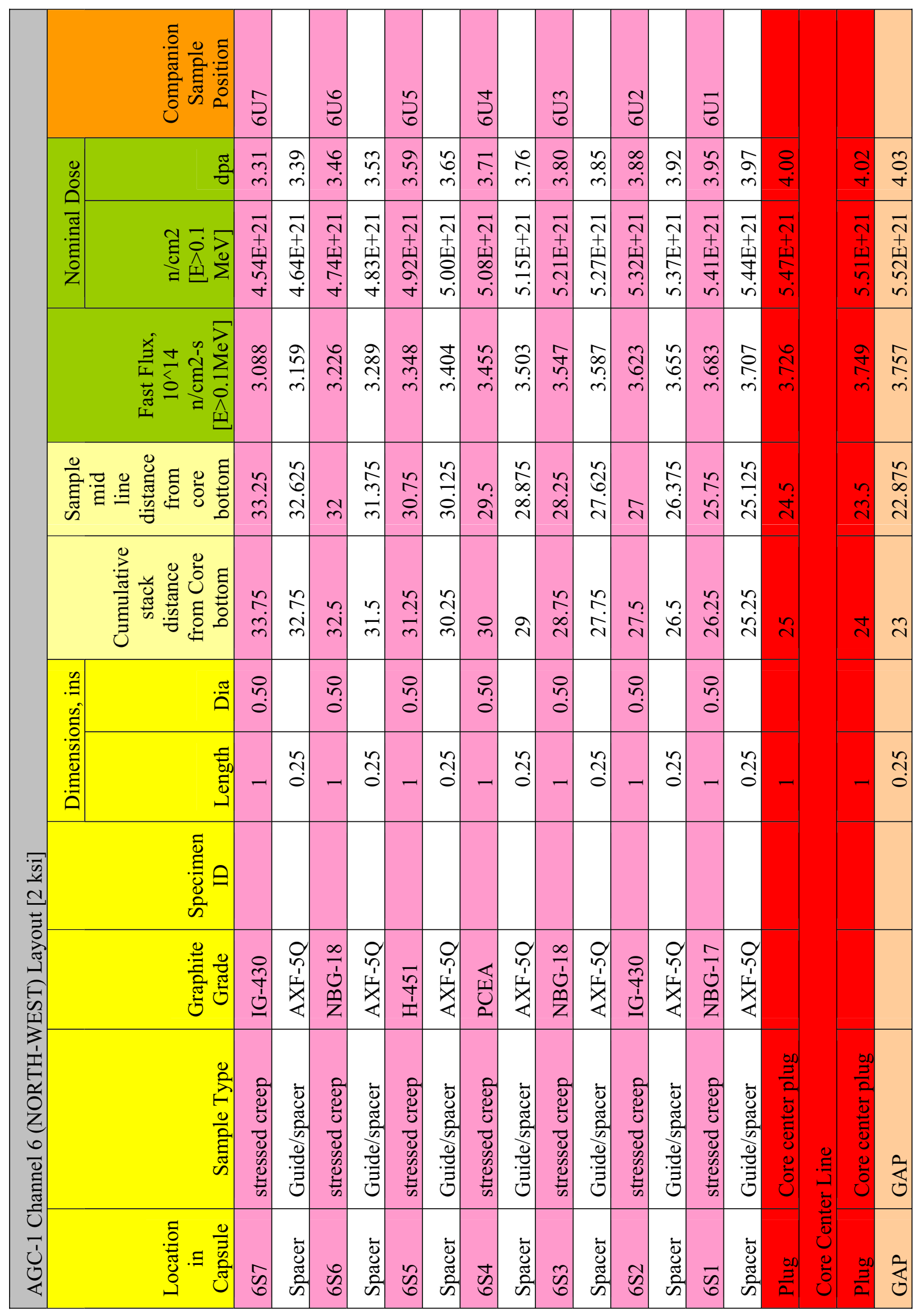




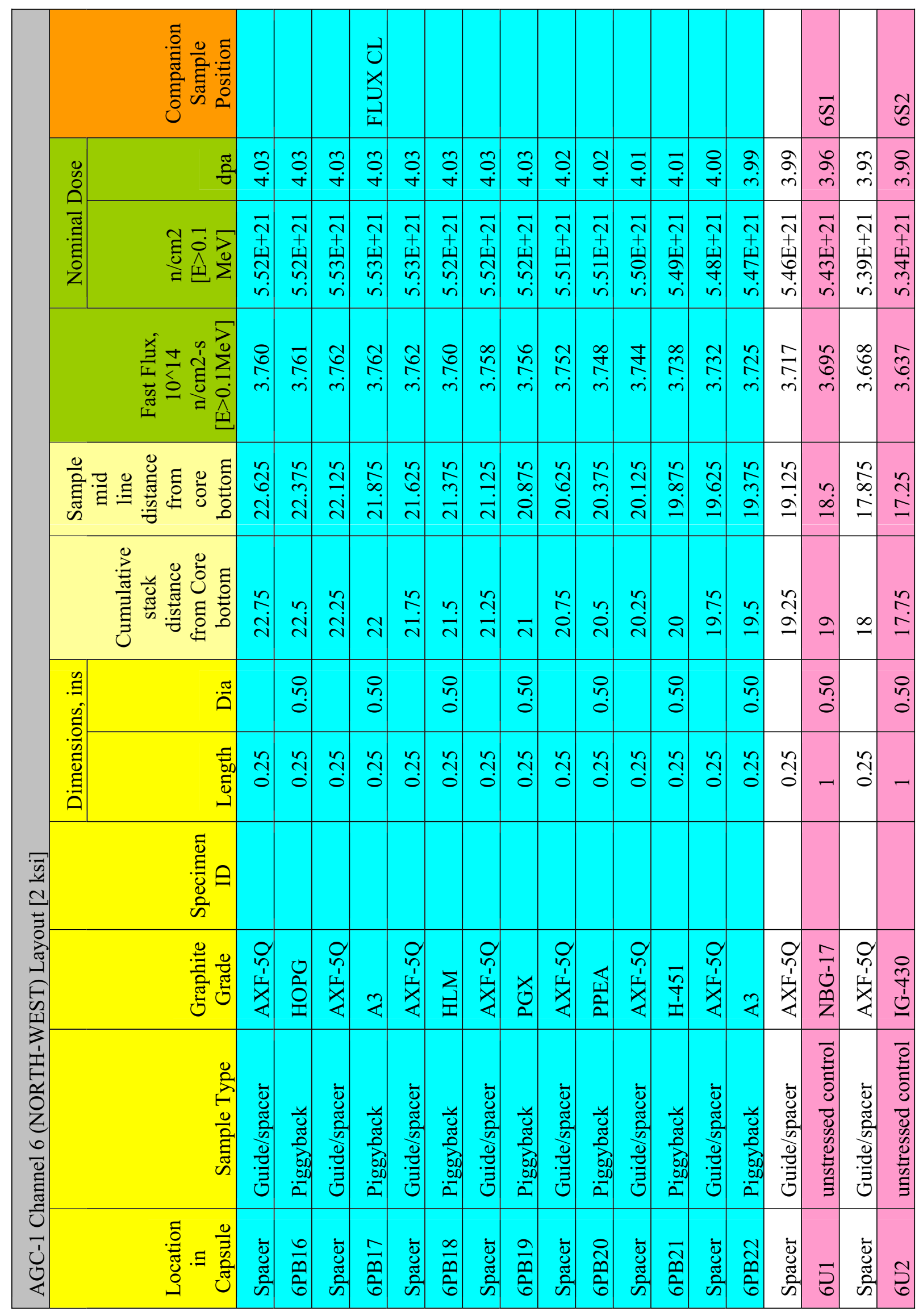




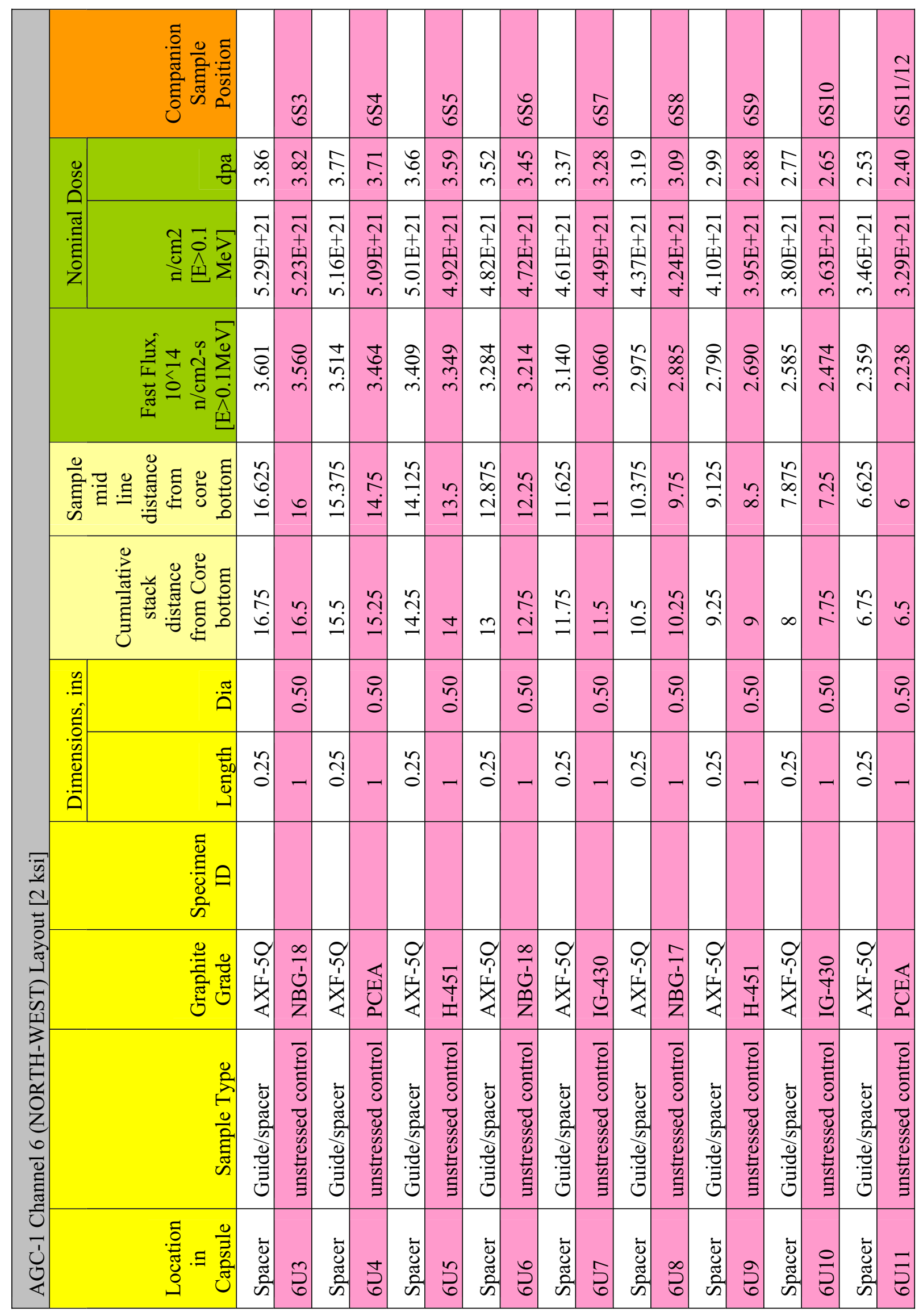




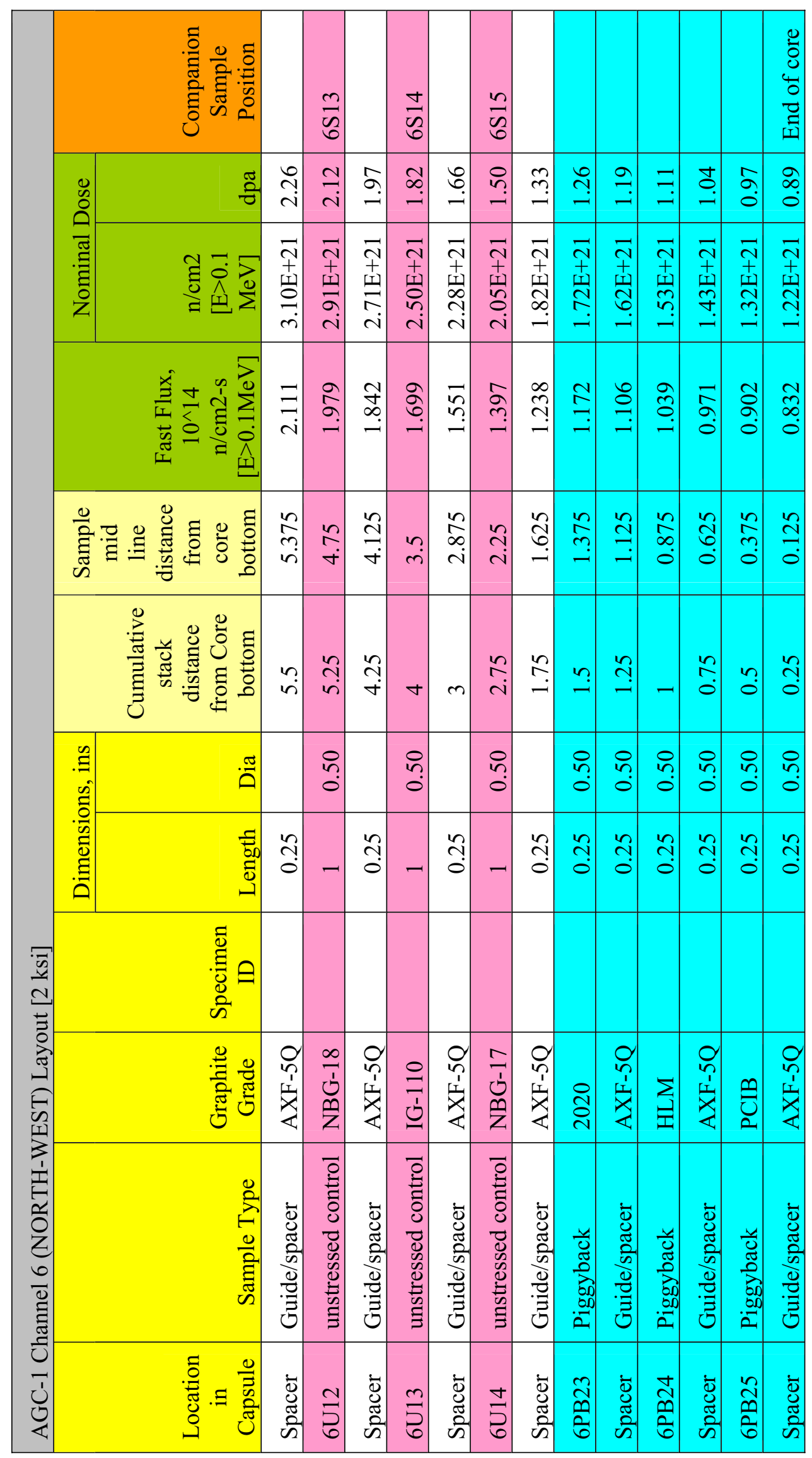


Appendix G

AGC-1 Central Channel Specimen Layout [2 ksi] 


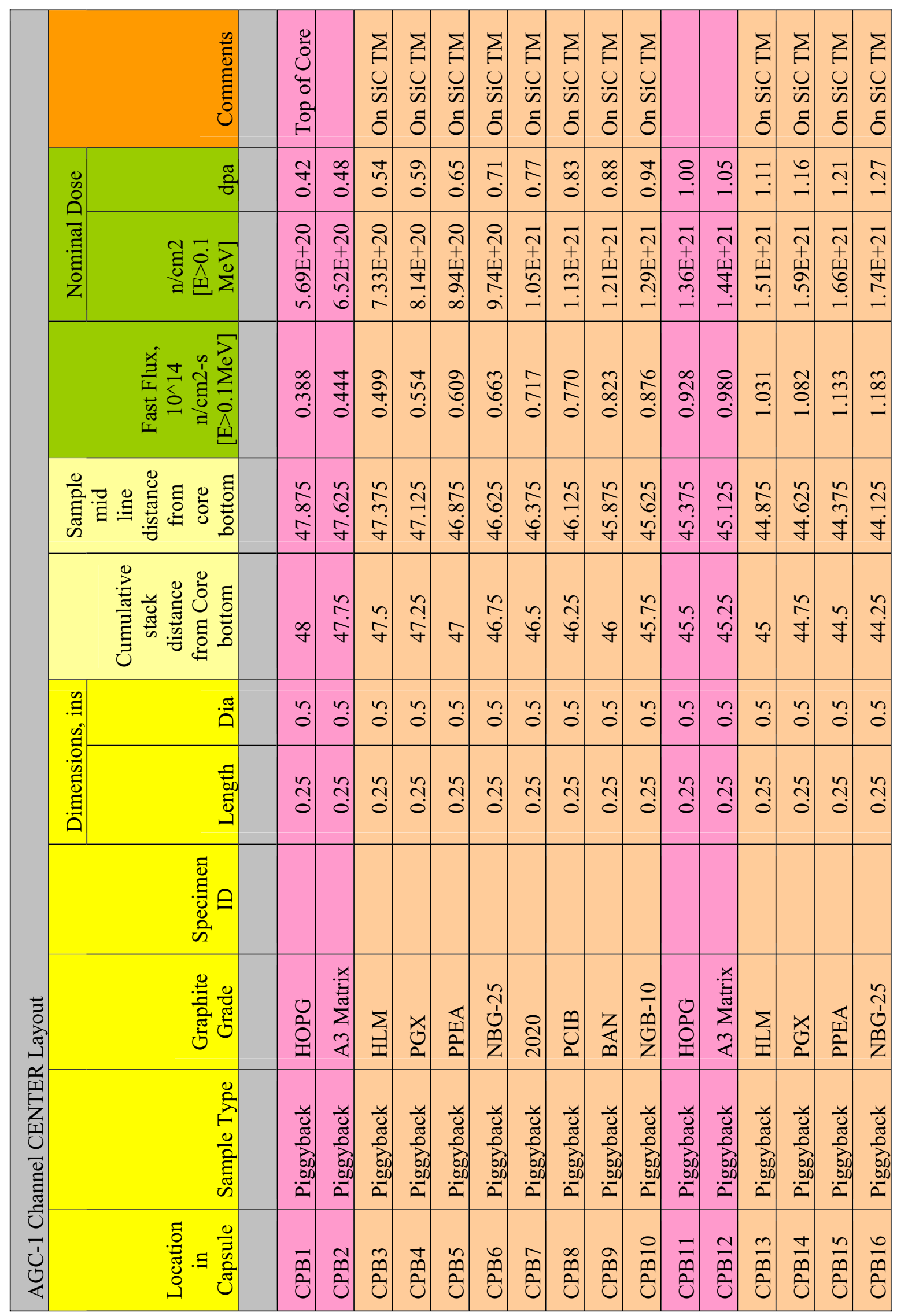




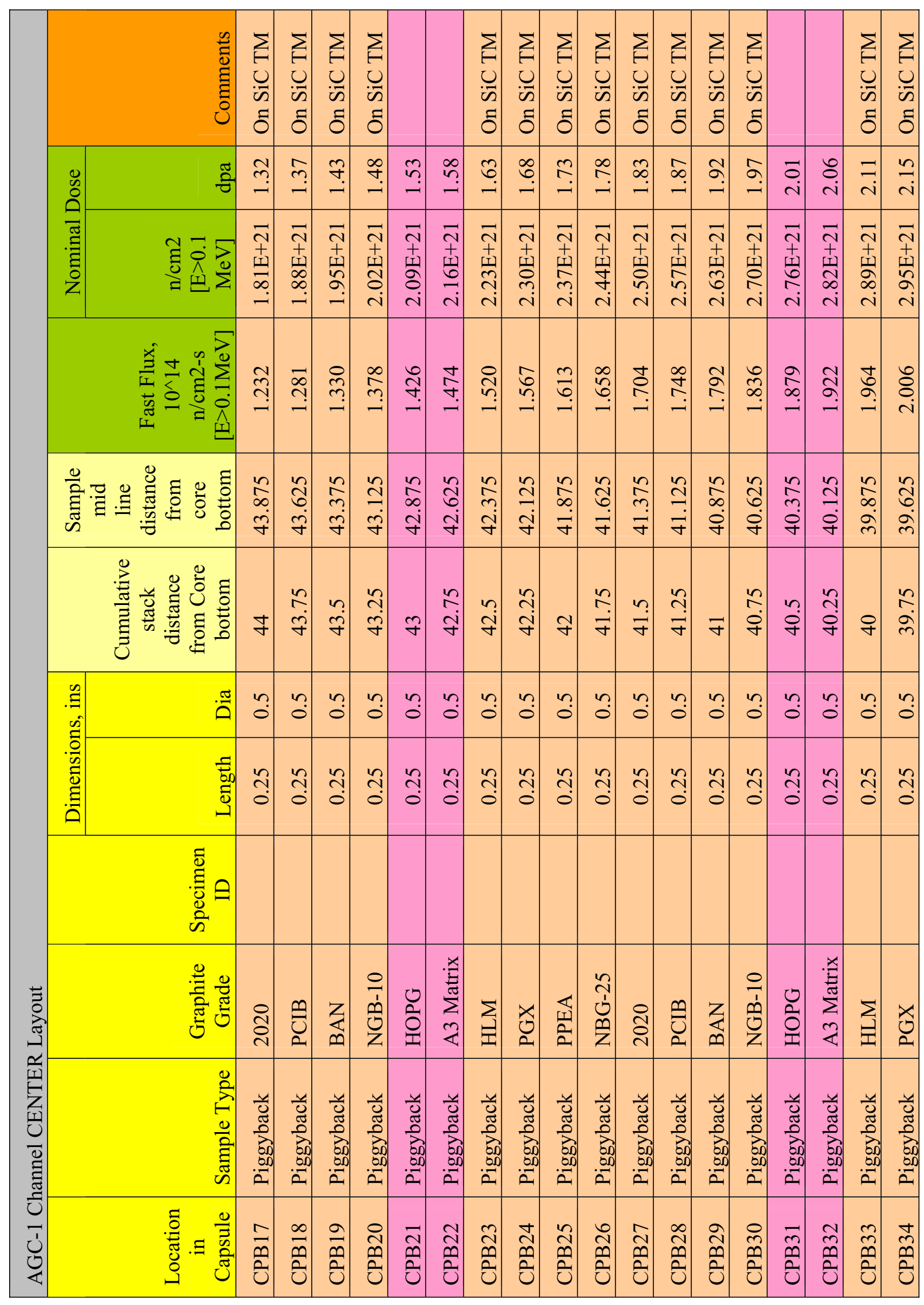




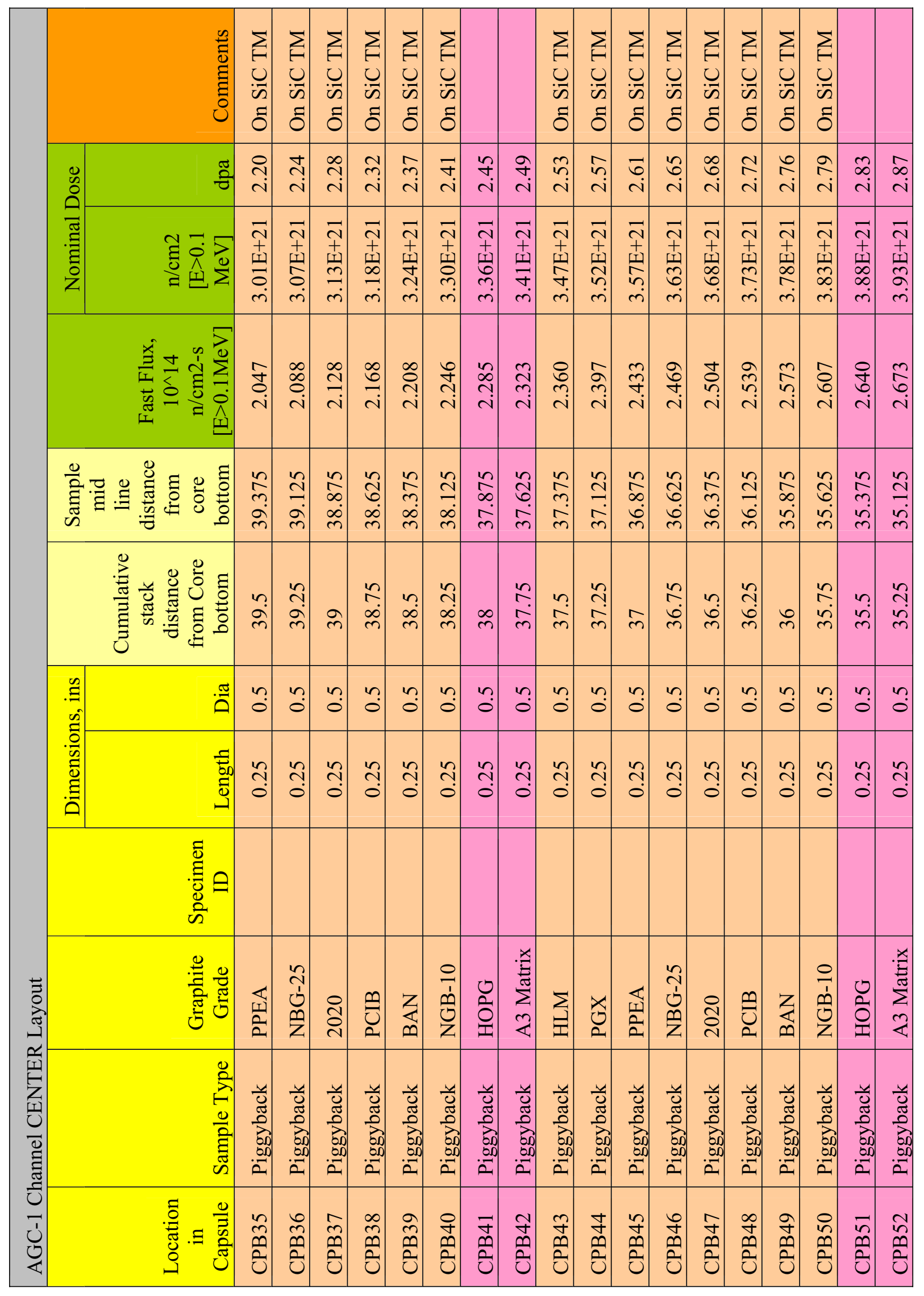




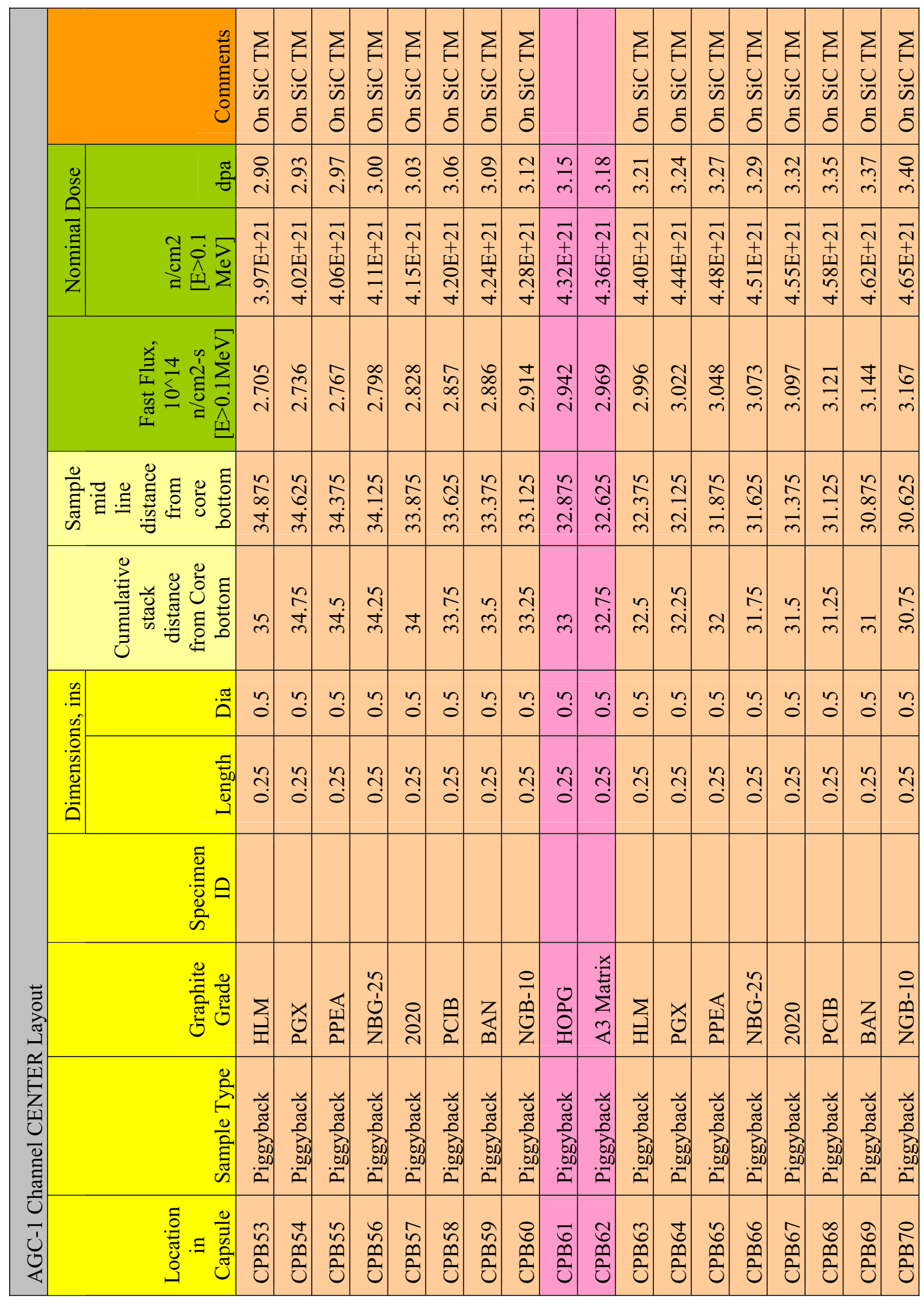




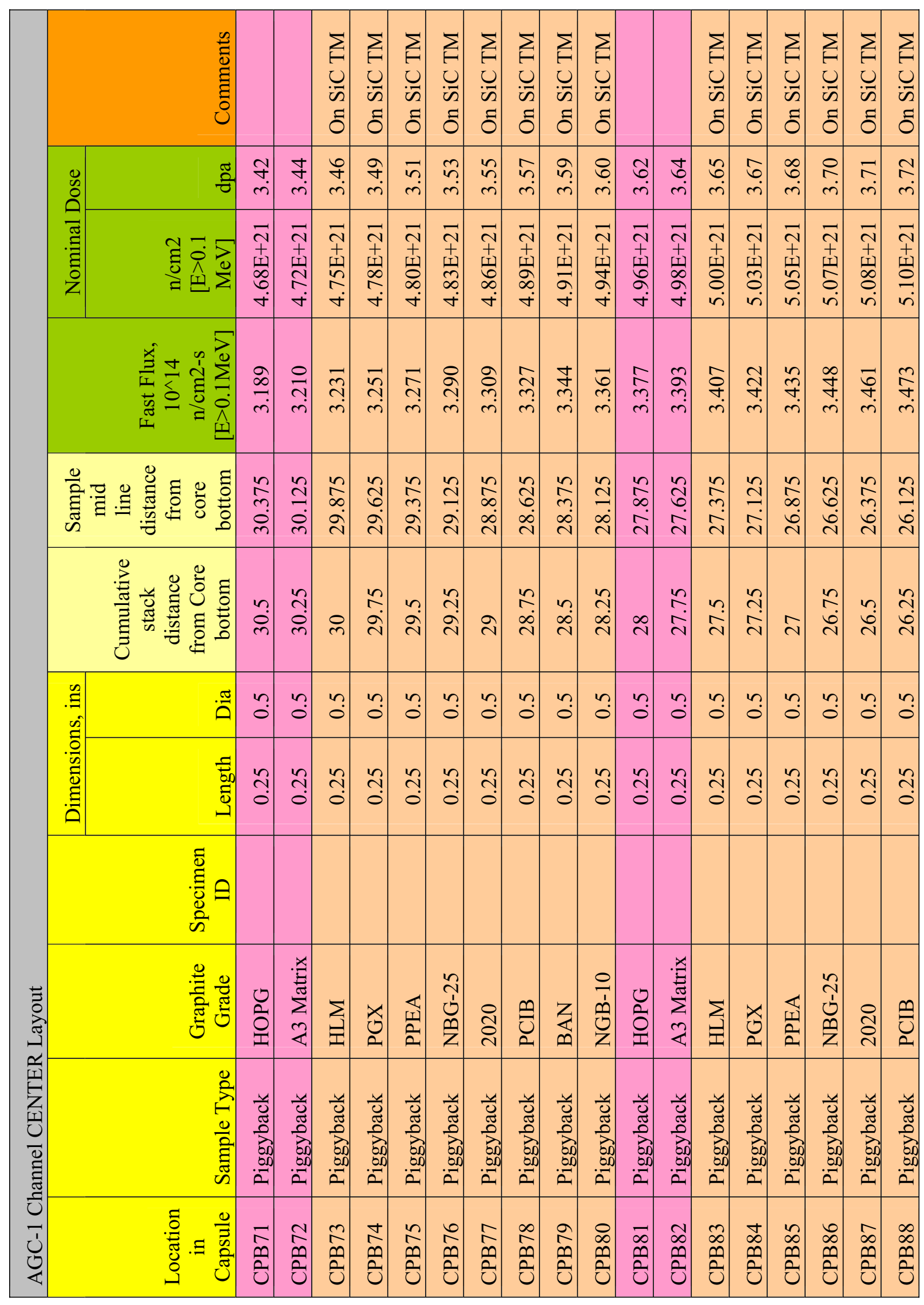




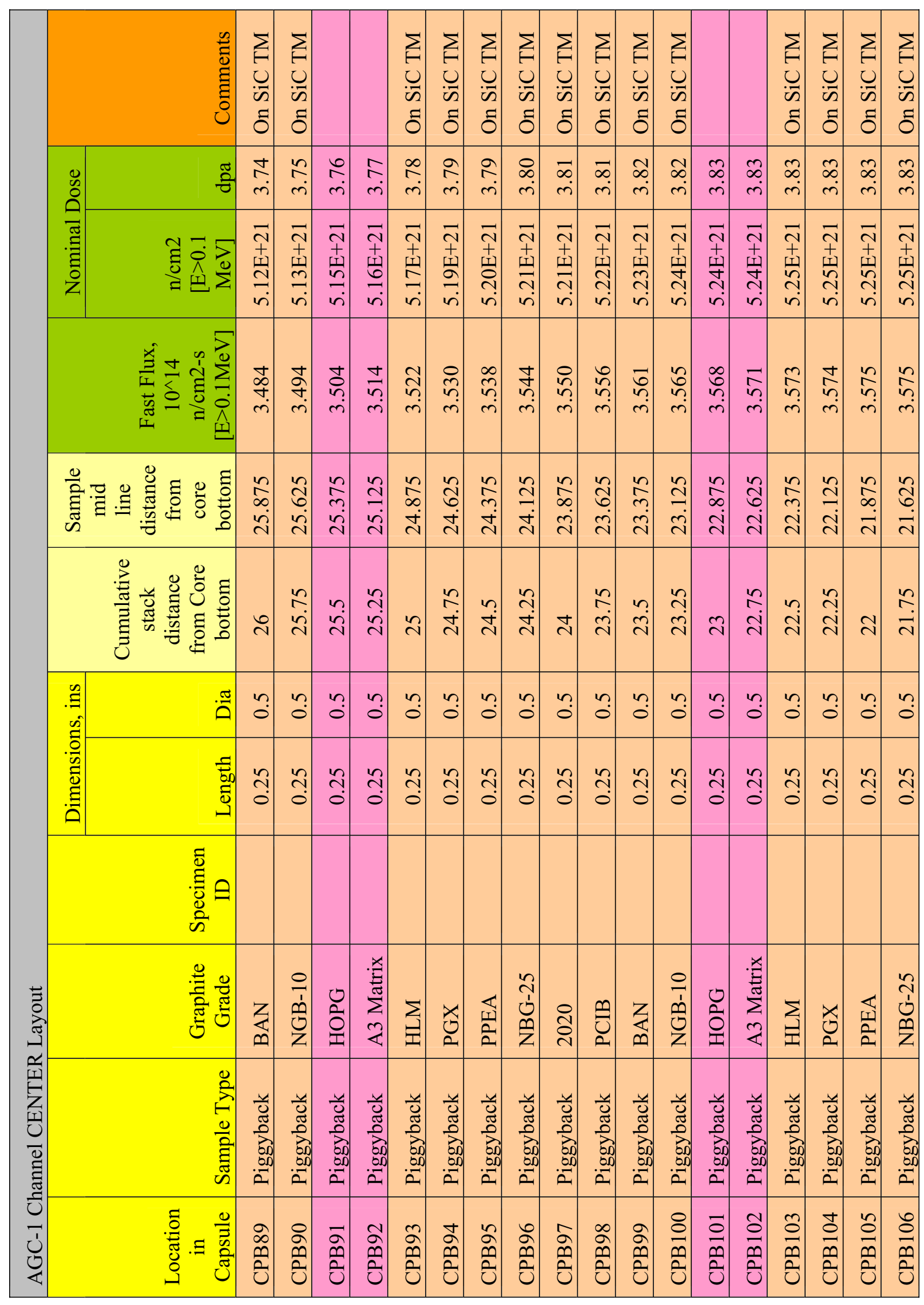




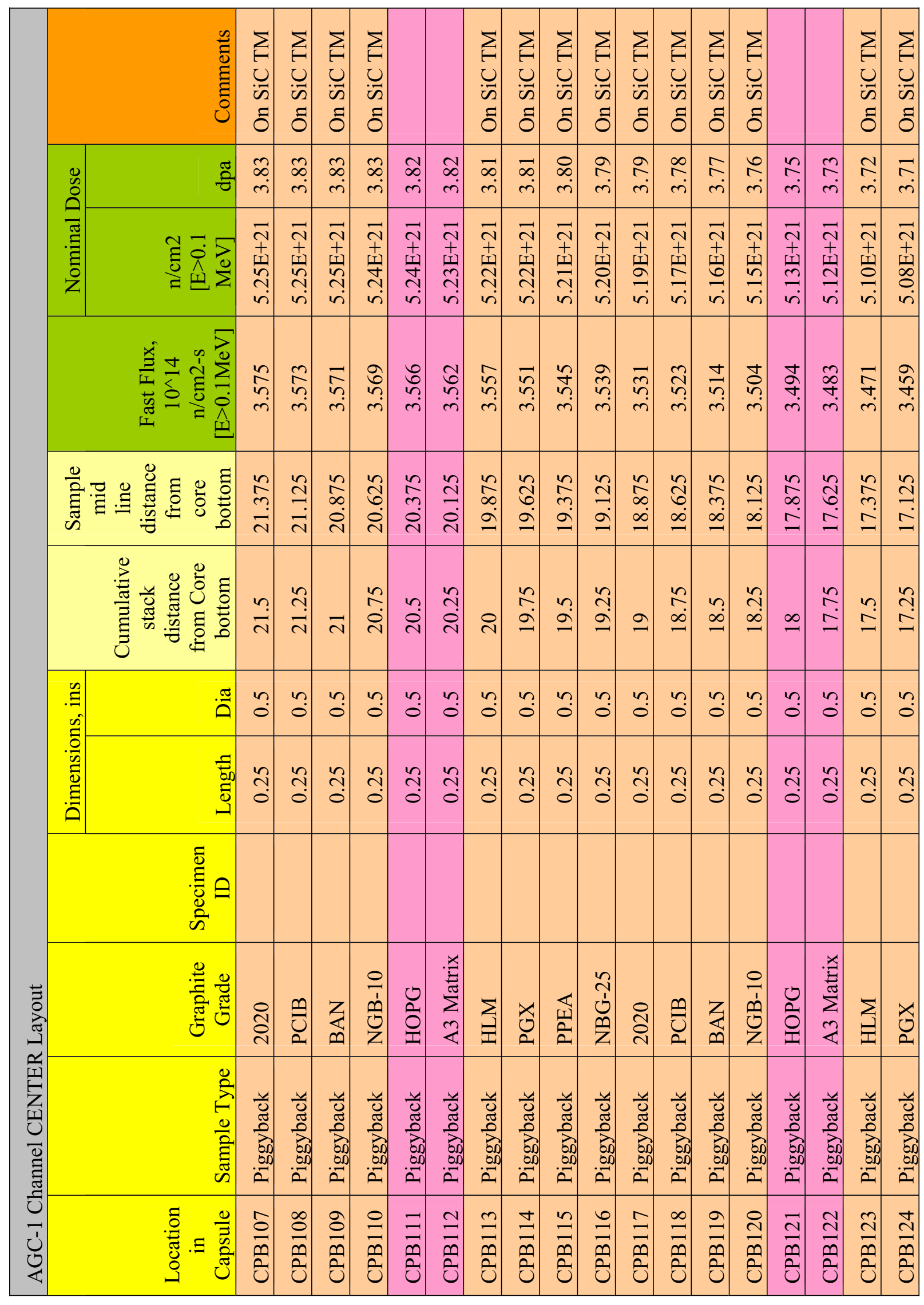




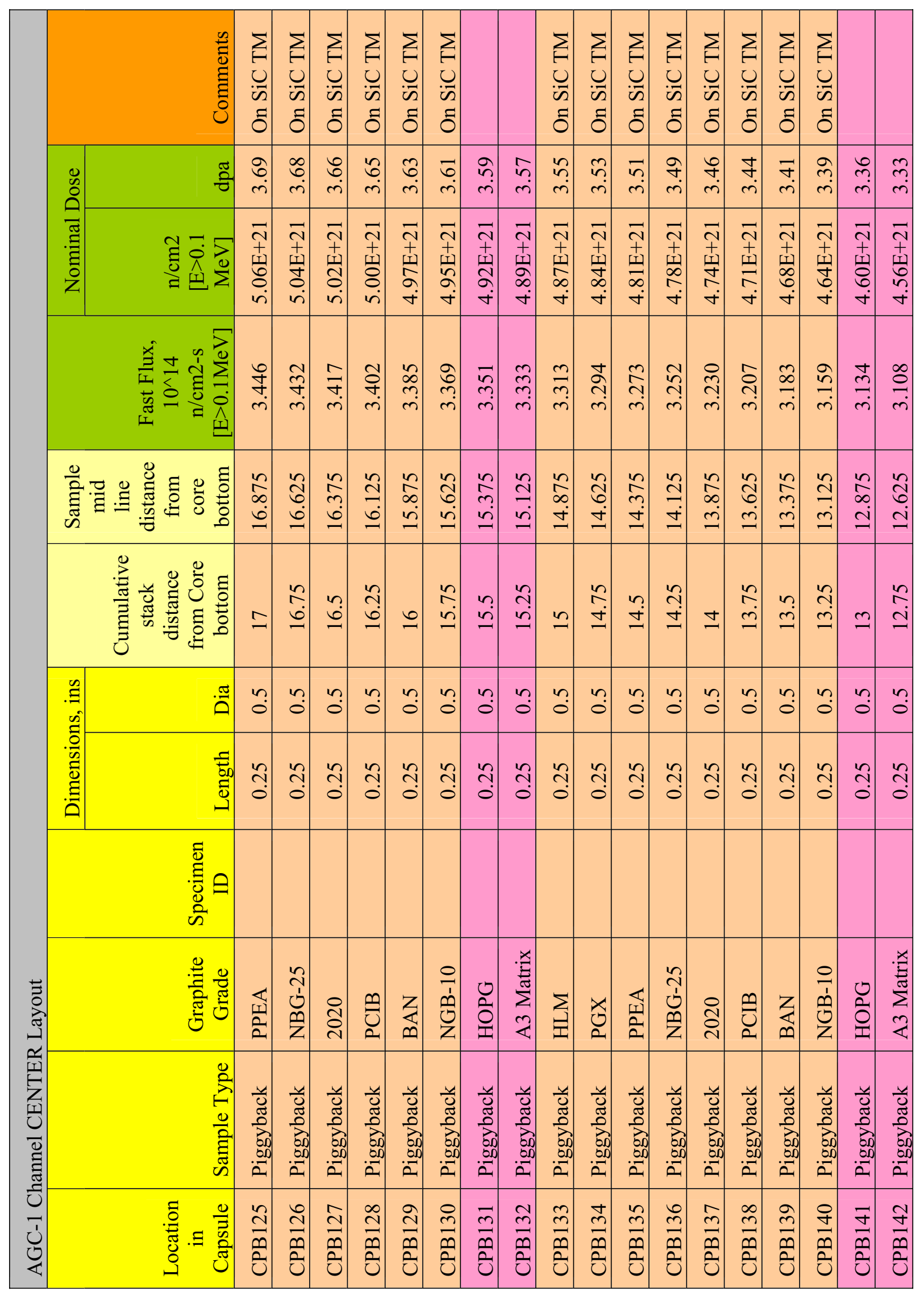




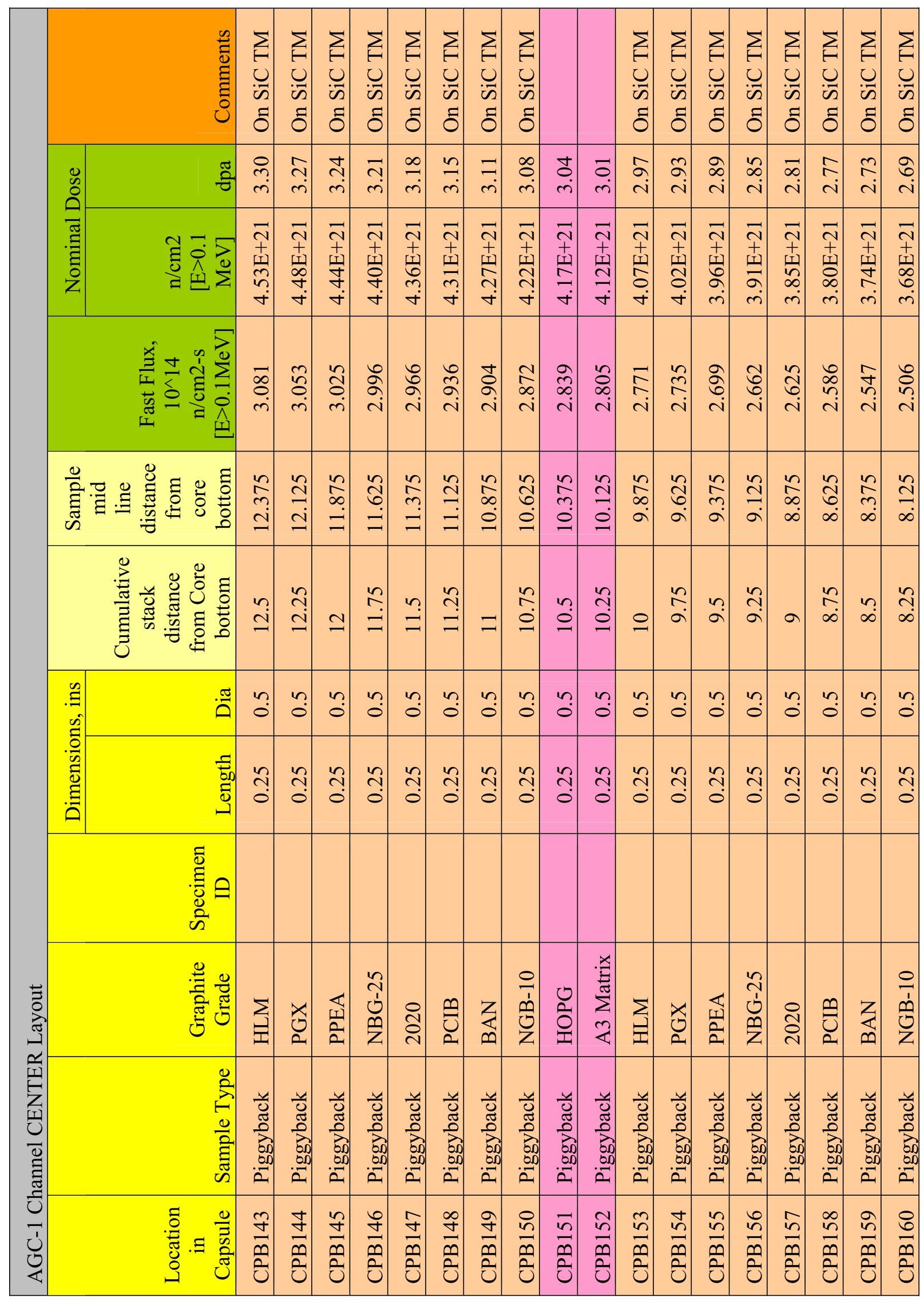




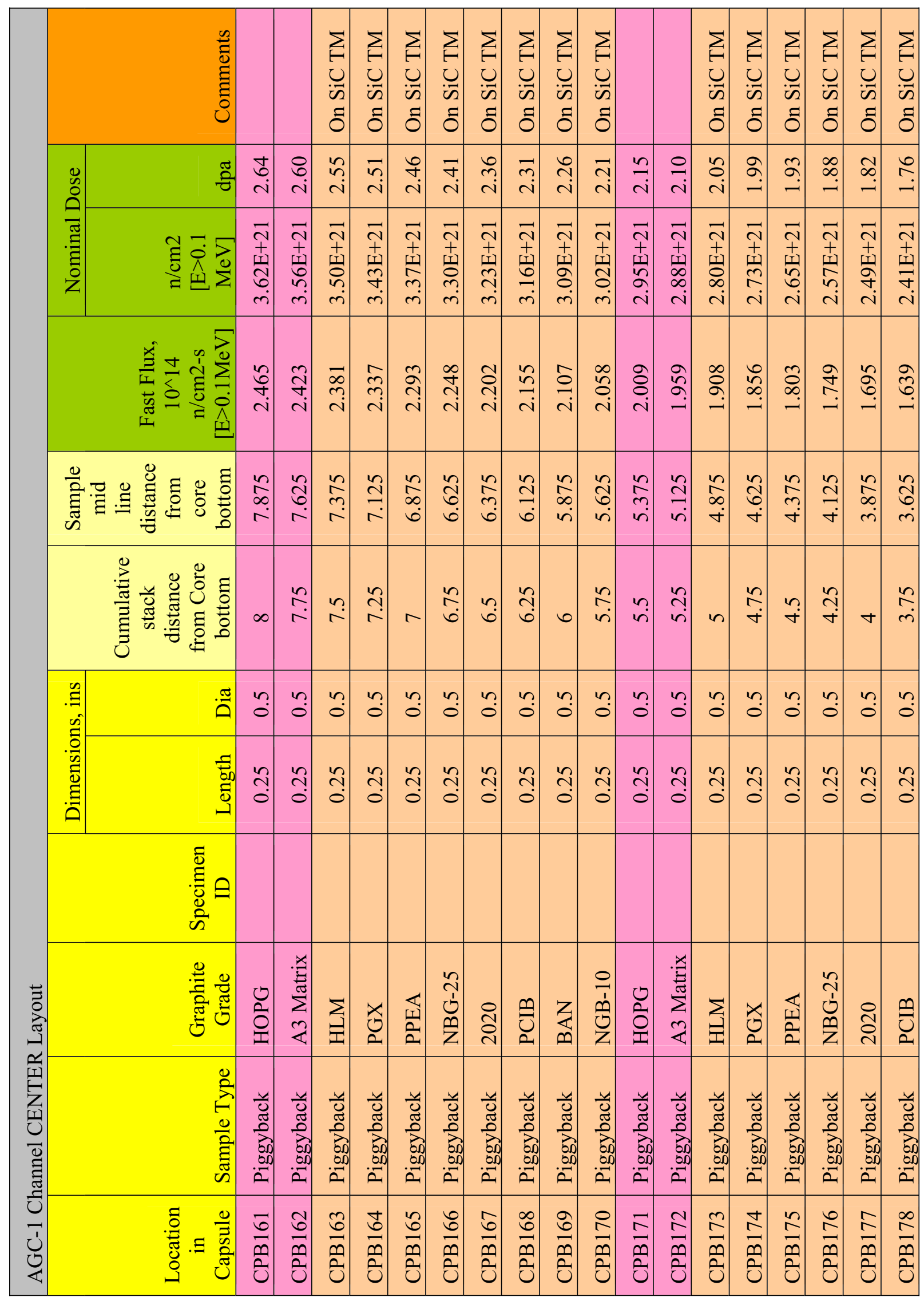




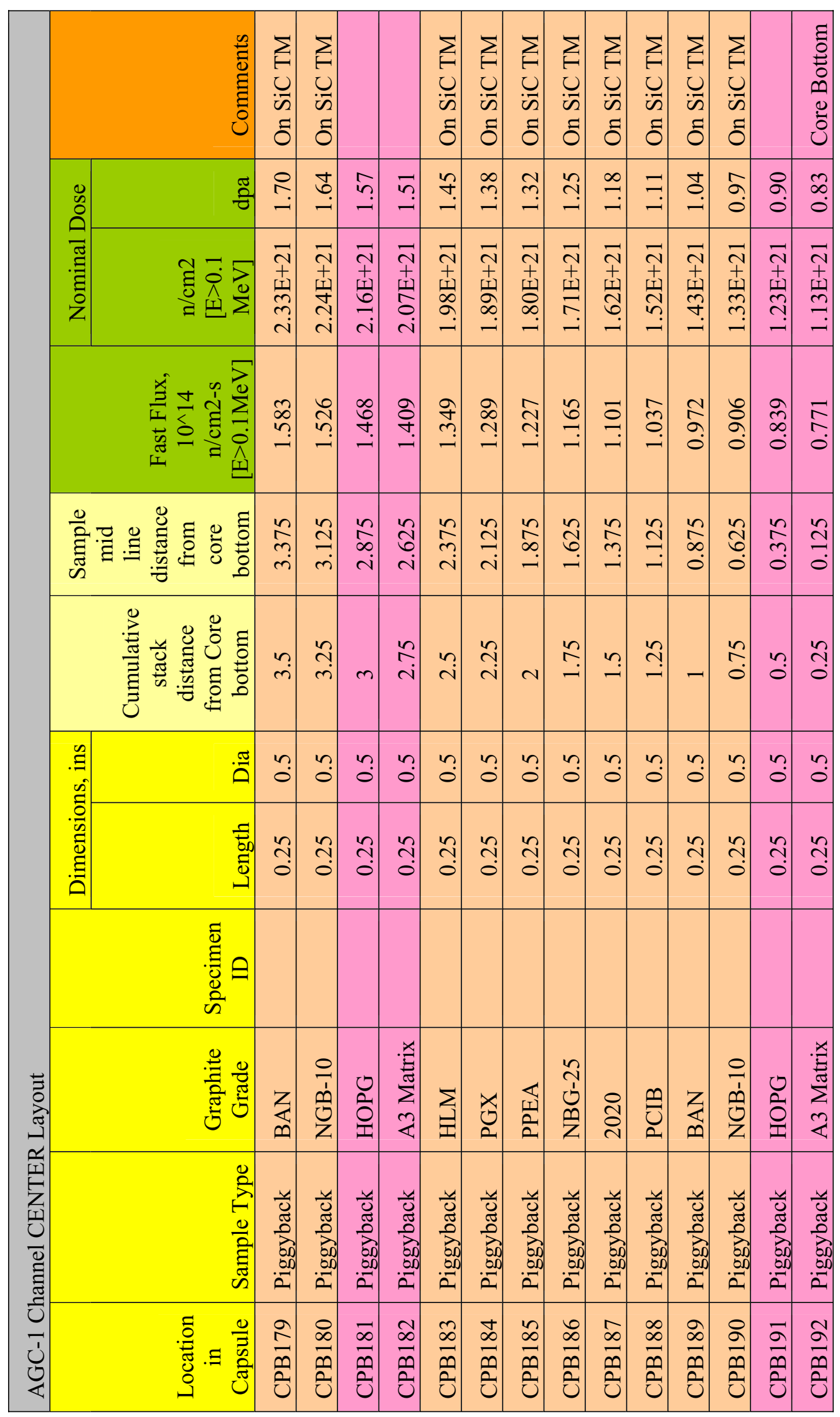


Appendix $\mathrm{H}$

AGC-1 Capsule Drawings 


\section{Appendix I}

\section{Structural Evaluation of the ATR}

Advanced Graphite Creep Experiment AGC-1 


\section{Engineering Design File}

\section{Structural Evaluation of the ATR Advanced Graphite Creep Experiment AGC-1}

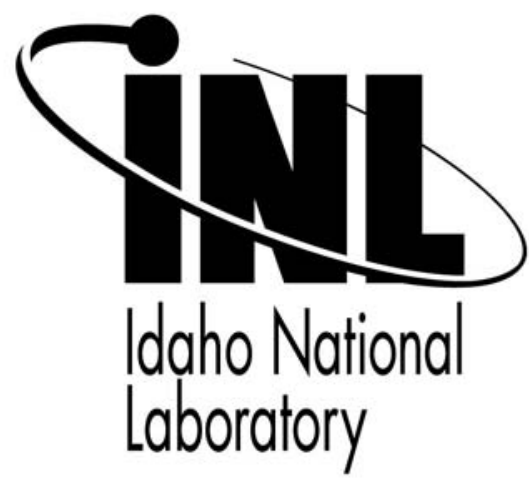


EDF No.: 5925

EDF Rev. No.: 0

Project File No.: 23747

1. Title: Structural Evaluation of the ATR Advanced Graphite Creep Experiment AGC-1

2. Index Codes:

Building/Type TRA 670 SSC ID N/A

Site Area 533

3. NPH Performance Category: $\mathrm{PC} 4$ or $\square$ N/A

4. EDF Safety Category: $\quad$ SC or $\square$ N/A SCC Safety Category: CG or $\square$ N/A

5. Summary:

6. Review (R) and Approval (A) and Acceptance (Ac) Signatures:

(See instructions for definitions of terms and significance of signatures.)

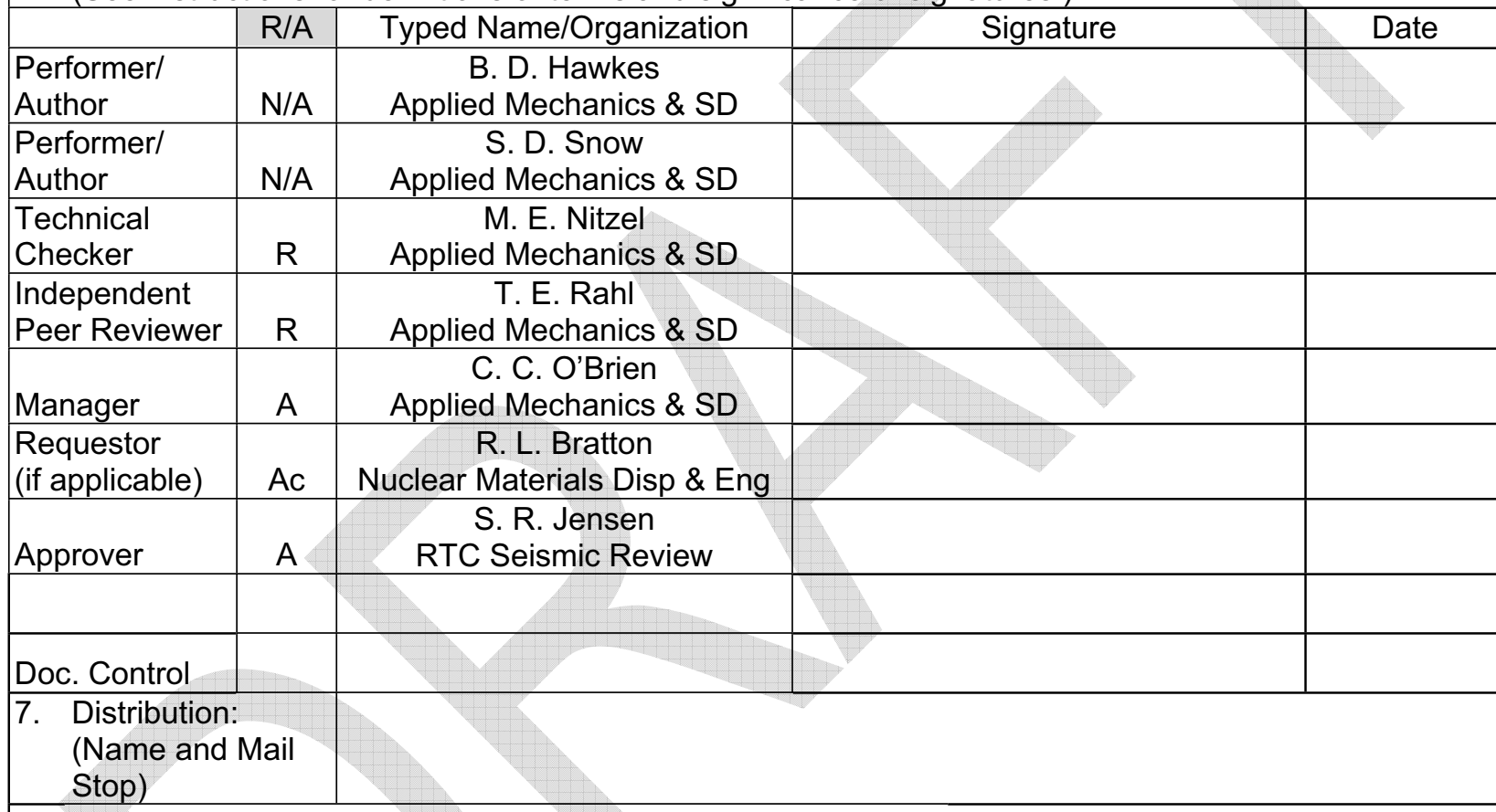

8. Does document contain sensitive unclassified information? $\square$ Yes $\square$ No If Yes, what category:

9. Can document be externally distributed? $\square$ Yes $\square$ No

10. Uniform File Code: $0250 \quad$ Disposition Authority: A16-1.1

Permanent. Cut off

when superseded,

Record Retention Period: obsolete, or canceled.

11. For QA Records Classification Only: $\square$ Lifetime $\quad \square$ Nonpermanent $\square$ Permanent Item and activity to which the QA Record apply:

12. NRC related? $\square$ Yes $\square$ No 
431.02

ENGINEERING DESIGN FILE

EDF-5925

$01 / 30 / 2003$

Revision 0

Rev. 11

Page 2 of 17

EDF No.: 5925

EDF Rev. No.: 0

Project File No.: 23747

1. Title: Structural Evaluation of the ATR Advanced Graphite Creep Experiment AGC-1

2. Index Codes:

Building/Type TRA 670

SST ID NRA

Site Area 533

13. Registered Professional Engineer's Stamp (if required) N/A 


\section{CONTENTS}

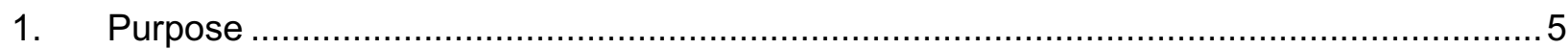

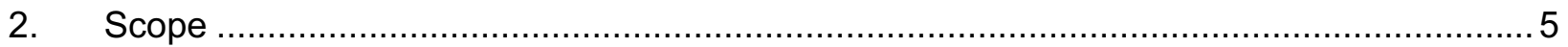

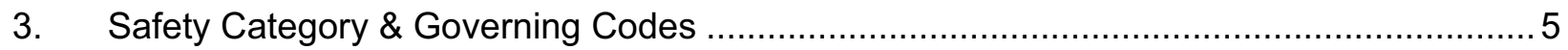

4. Natural Phenomena Hazards Performance Category .............................................. 5

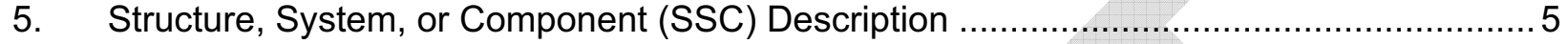

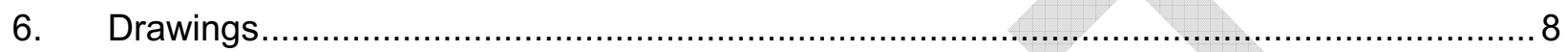

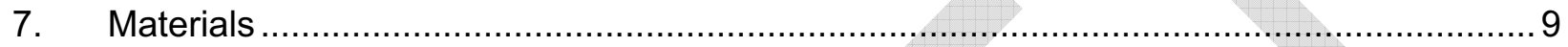

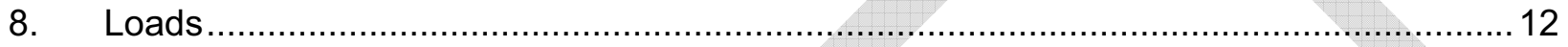

8.1 Design Load Conditions....................................................................... 12

8.2 Service Level Conditions …..................................................................... 12

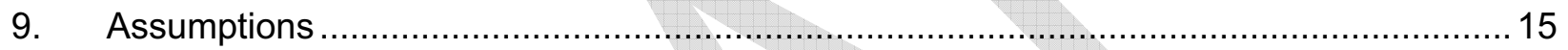

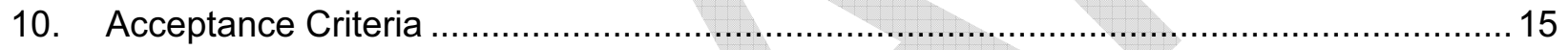

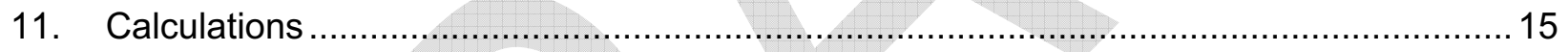

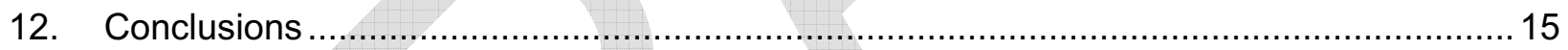

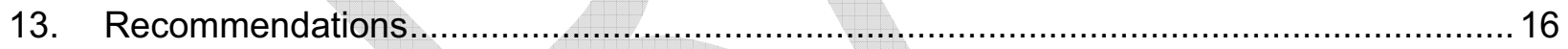

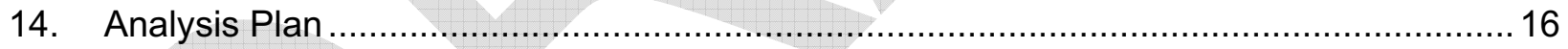

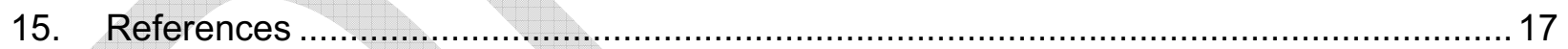

\section{APPENDICES}

A. Computer Software Validation \& Verification .................................................................... A1

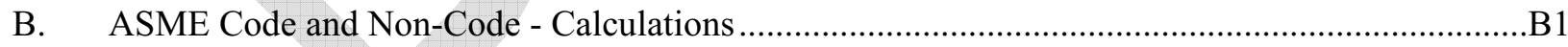

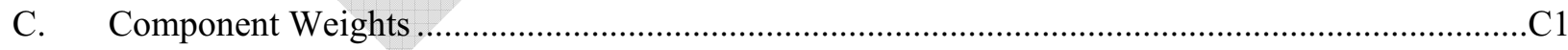

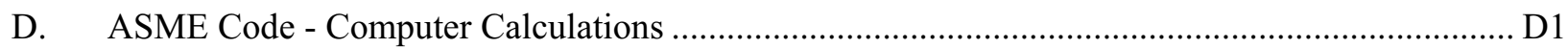

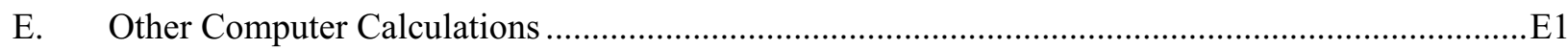

F. Thermal Stress Analysis of the Capsule Reactor Core Components...........................................F1 


\section{Figures}

Figure 1. Advanced test reactor with the AGC-1 experiment assembly installed. .................... 6

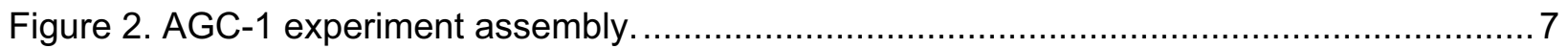

Figure 3. Comparison of horizontal response spectra, 5\% damping. ................................. 14

Figure 4. Comparison of vertical spectra, $5 \%$ damping. .................................................... 14

\section{Tables}

Table 1. INL design drawings.

Table 2. Material properties for 304 and $304 \mathrm{~L}$ stainless steels......................................... 10

Table 3. Material properties for Haynes 230 alloy. ................................................. 10

Table 4. Material properties for graphite POCO AXF-5Q. ............................................. 11

Table 5. Enveloping response spectra for the ATR seismic event. ...................................... 15 


\section{PURPOSE}

The Advanced Graphite Creep Experiment (AGC-1) has been designed for installation into the Advanced Test Reactor (ATR) at the Idaho National Laboratory (INL) Reactor Technology Complex (RTC). The purpose of this EDF is to document the structural evaluation of the components of the AGC-1 experiment. This will include an evaluation of the test facility assembly including the reactor penetration components.

\section{SCOPE}

This EDF applies only to the AGC-1 facility experiment components as listed above. Evaluations of the gas and other control systems external to the reactor were not performed herein.

\section{SAFETY CATEGORY \& GOVERNING CODES}

The safety categories for the various components in this AGC-1 experiment were defined in the Technical \& Functional Requirements document (Ref.1). Those components subjected to reactor pressure (top head seal plug, hanger rod, capsule boundaries, etc.) are categorized as Safety Class (SC). The gas control system is specified as Safety Significant (SS), while the pneumatic rams, graphite support plates, and the heat shield are listed as Low Safety Consequence (LSC). Internal components such as pushrods, load cells, graphite body and specimens, and stainless steel guide plates are considered Consumer Grade (CG).

The reactor penetration is greater than 3 inches in diameter and will be evaluated to the requirements of the ASME Boiler and Pressure Vessel Code (hereafter referred to as the ASME Code) Section III, Class 1 (Ref.2).

The hanger rod and capsule boundaries will be evaluated according to the requirements of the ASME Code Section III, Class 3 (Ref.3).

The gas lines and hanger rod assembly external to the reactor will be evaluated to the requirements of ANSI B31.1 (Ref.4).

Low Safety Class and Consumer Grade components will be evaluated using industry standard design codes.

\section{NATURAL PHENOMENA HAZARDS PERFORMANCE CATEGORY}

Per Reference 1, the reactor penetration, hanger rod, and capsule pressure boundary components shall be evaluated for Natural Phenomena Hazards Performance Category 4 (PC-4) requirements.

\section{STRUCTURE, SYSTEM, OR COMPONENT (SSC) DESCRIPTION}

The AGC-1 experiment begins with the hanger rod assembly outside of the reactor. This hanger rod assembly is threaded into the experiment top head seal plug which is clamped to reactor at the top head closure plate with a standard loop seal flange. Welded to the reactor side of the top head seal plug is the in-vessel hanger rod extension tube, followed by four transition tubes (all 5-inch diameter tubing) which are about 12-1/2 feet in total length. Those in-vessel 
hanger rod tubes then join through a reducer to the capsule facility body (2-1/2 inch diameter tubing), which is about $12-1 / 2$ feet in total length. The capsule facility body passes through the reactor core area by way of the South Flux Trap, where it terminates just beyond the core region. Figure 1 shows the AGC-1 experiment assembly in the ATR vessel. Figure 2 shows the AGC-1 experiment assembly.

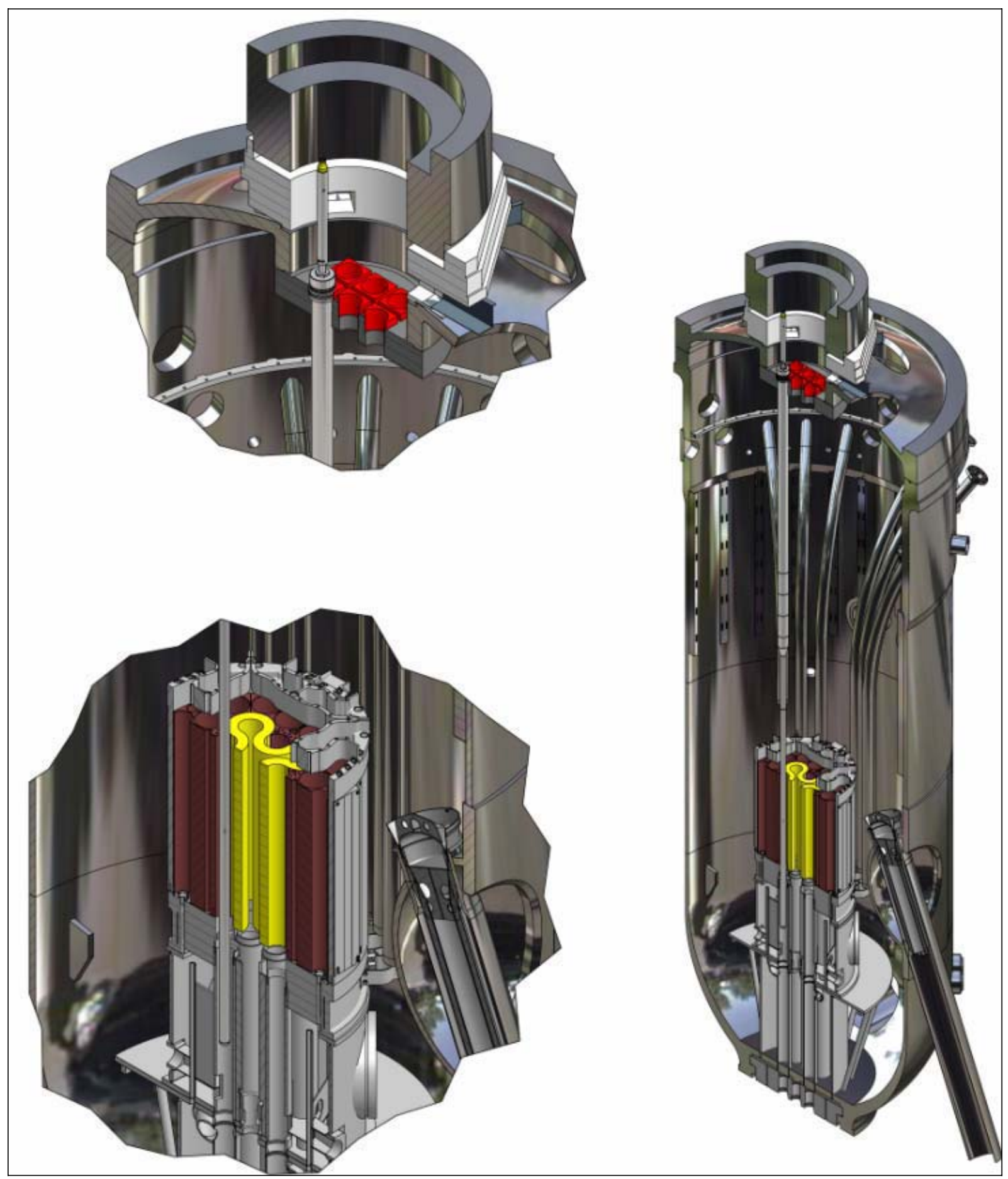

Figure 1. Advanced test reactor with the AGC-1 experiment assembly installed. 

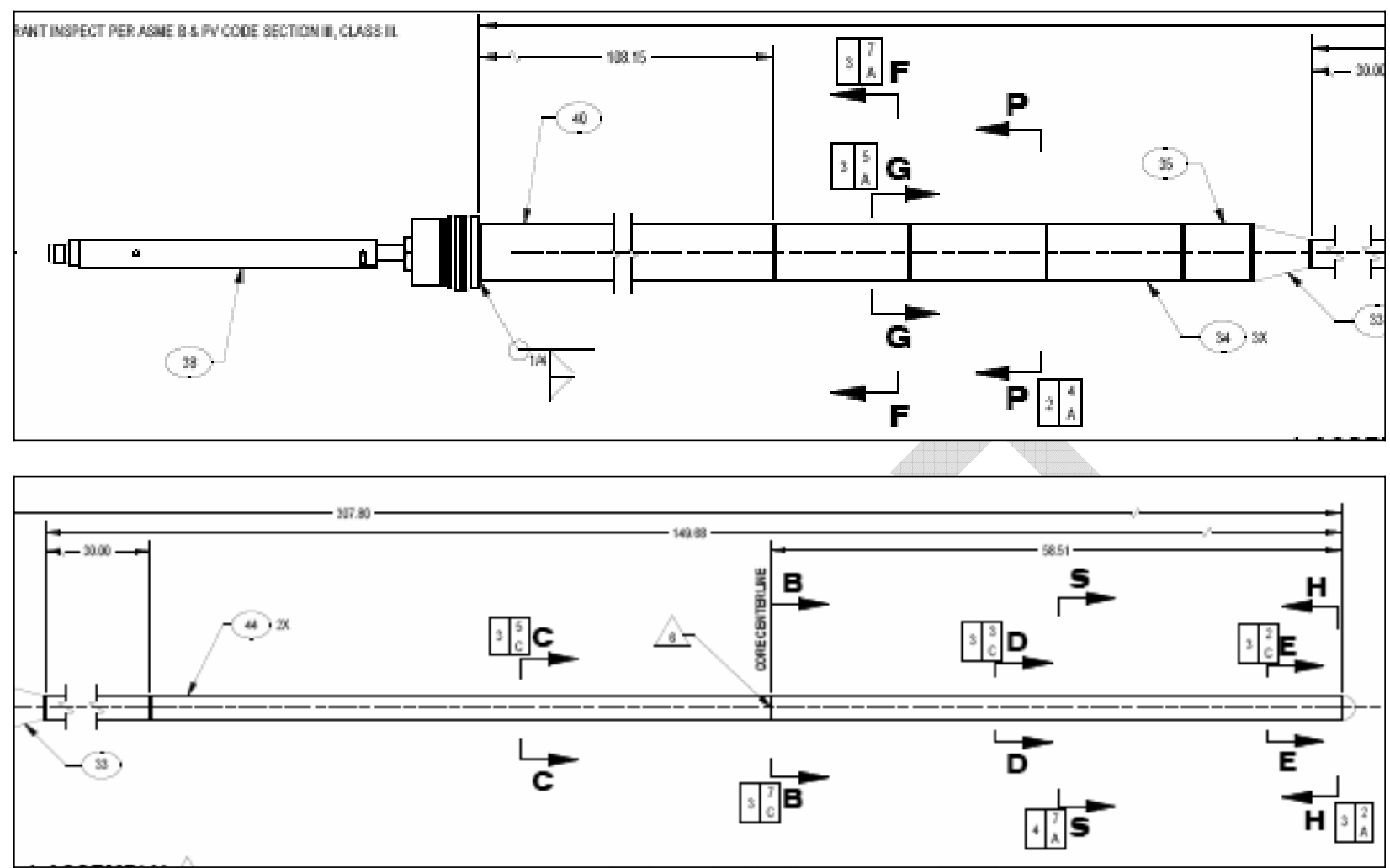

Figure 2. AGC-1 experiment assembly.

Within the capsule facility body are seven channels of graphite specimens, specimen holders, a heat shield, gas lines, thermocouples, and other related components. Actuators are placed in the hanger rod transition tubes and in the bottom of the capsule facility body to allow for load and movement to be applied, by way of push rods, to six of the seven graphite specimen channels.

The hanger rod assembly, top head seal plug, in-reactor hanger rod extension and transition tubes, and capsule facility body are all made of stainless steel (SST). Components within the experiment are made primarily of SST, graphite, or Haynes 230.

The next two sections list the design drawings and materials employed in this evaluation. 


\section{DRAWINGS}

Table 1. INL design drawings.

\begin{tabular}{|l|l|l|}
\hline $\begin{array}{l}\text { Drawing } \\
\text { Number }\end{array}$ & Drawing Title & Revision \\
\hline 630427 & ATR Advanced Graphite Test Graphite Component Details & Draft \\
\hline 630428 & $\begin{array}{l}\text { ATR 7 Hole Graphite Test Stainless Steel Component Assemblies } \\
\text { and Details }\end{array}$ & Draft \\
\hline 630429 & ATR 7 Hole Graphite Test Hanger Rod Assemblies and Details & Draft \\
\hline 630430 & ATR 7 Hole Graphite Test Capsule Facility Assembly & Draft \\
\hline 630431 & $\begin{array}{l}\text { ATR Advanced Graphite Test Graphite Specimen Stack-up } \\
\text { Arrangements }\end{array}$ & Draft \\
\hline 630432 & $\begin{array}{l}\text { Advanced Graphite Test (AGC) Transitioned Thermal Heat Shield } \\
\text { Details and Assembly }\end{array}$ & Draft \\
\hline 120438 & $\begin{array}{l}\text { ATR Advanced Graphite Capsule (AGC) Capsule Facility In-Core } \\
\text { Pressure Boundary Tube }\end{array}$ & Draft \\
\hline 120446 & $\begin{array}{l}\text { ATR Reactor Vessel Top Head Closure Plate and Instrument } \\
\text { Thimbles }\end{array}$ & 8 \\
\hline 443027 & $\begin{array}{l}\text { ATR Reactor Vessel Top \& Bottom Closure Plate Penetration } \\
\text { Closures and Seals }\end{array}$ & 3 \\
\hline
\end{tabular}

"Draft" drawings were not yet released at the time of this evaluation. 


\section{MATERIALS}

The primary components of the AGC-1 experiment that were specifically evaluated herein employed the following materials:

- $\quad$ Hanger Rod Assembly: 304 SST (ASME SA-240 and SA-213, Dwg. 630429)

- $\quad$ Top Head Seal Plug: 304 SST (ASME SA-240, Dwg. 630429)

- $\quad$ Loop Seal Flange: 304 SST (Dwg. 120446)

- Loop Seal Flange Bolts or Studs: 304 SST (SA-193, Dwg. 120446 Notes 2 \& 8)

- $\quad$ Hanger Rod Extension Tube: 304 SST (ASME SA-213, Dwg. 630430)

- $\quad$ Hanger Rod Transition Tubes: 304 SST (ASME SA-213, Dwg. 630428)

- $\quad$ Funnel Transition Tube: 304 SST (ASME SA-213, Dwg. 630428)

- $\quad$ Transition Funnel: 304 SST (ASME SA-479, Dwg. 630428)

- $\quad$ Capsule Facility Body: 304 SST (ASME SA-213, Dwg. 630430)

[In-core pressure boundary tube: 304 SST (ASME SA-213, Dwg. 630434)]

- $\quad$ Test Facility Bottom Cap: 304 SST (ASME SA-479, Dwg. 630428)

- $\quad$ Upper Cylinder Mounting Plates: 304 SST (ASME SA-240, Dwg. 630428)

- $\quad$ Push Rod Alignment Plates: 304 SST (ASME SA-240, Dwg. 630428)

- $\quad$ Upper Cylinder Push Rods/Bars: 304 SST (ASME SA-479, Dwg. 630428)

- $\quad \quad \quad$ Upper Cylinder Load Cell Attach Bolts: 304 SST (ASME SA-479, Dwg. 630428)

- $\quad$ Lower Spacer Tube: 304 SST (ASME SA-213, Dwg. 630428)

- $\quad$ Capsule Bottom Plate: 304 SST (ASME SA-479, Dwg. 630428)

- $\quad$ Graphite Components: graphite (POCO AXF-5Q1, Dwg. 630427)

- $\quad$ Heat Shield: Haynes 230 (Dwg. 630432)

- $\quad$ Channel Through Tubes: 304L SST (ASME SA-213, Dwg. 630430)

- $\quad$ Gas Lines: 304L SST (ASME SA-213, Dwg. 630430)

The following tables list the material properties that were employed in the evaluation of these primary components and assemblies. 
Table 2. Material properties for 304 and $304 \mathrm{~L}$ stainless steels.

\begin{tabular}{|c|c|c|c|c|}
\hline \multirow{2}{*}{ Material Property } & \multicolumn{4}{|c|}{ Material Properties at Temperature } \\
\hline & $100^{\circ} \mathrm{F}$ & $180^{\circ} \mathrm{F}$ & $200^{\circ} \mathrm{F}$ & $240^{\circ} \mathrm{F}$ \\
\hline $\begin{array}{l}\text { Thermal Expansion ó'T (in./ft.) going } \\
\text { from } 70^{\circ} \mathrm{F} \text { to specified temperature }{ }^{1}\end{array}$ & 0.003 & 0.0116 & 0.014 & 0.0188 \\
\hline Modulus of Elasticity $\mathrm{E}\left(\mathrm{x} 10^{6} \mathrm{psi}\right)^{2}$ & 28.3 & 27.7 & 27.6 & 27.4 \\
\hline $\begin{array}{rr}\text { Minimum Yield Strength } S_{y}(k s i)^{3} & 304 \\
& 304 L \\
\end{array}$ & $\begin{array}{l}30.0 \\
25.0\end{array}$ & $\begin{array}{l}25.7 \\
21.9\end{array}$ & $\begin{array}{l}25.0 \\
21.4\end{array}$ & $\begin{array}{l}23.9 \\
20.4\end{array}$ \\
\hline $\begin{array}{lr}\text { Design Stress Intensity for } & 304 \\
\text { Class 1 Components } \mathrm{S}_{\mathrm{m}}(\mathrm{ksi})^{4} & 304 \mathrm{~L} \\
& 304 \text { Bolts }^{6}\end{array}$ & $\begin{array}{l}20.0 \\
16.7 \\
10.0\end{array}$ & $\begin{array}{l}20.0 \\
16.7 \\
8.6\end{array}$ & $\begin{array}{l}20.0 \\
16.7 \\
8.3\end{array}$ & $\begin{array}{l}20.0 \\
16.7 \\
8.0\end{array}$ \\
\hline $\begin{array}{l}\text { Allowable Stress for Class } 3 \\
\text { Components S (ksi) }\end{array}$ & $\begin{array}{l}20.0 \\
16.7 \\
\end{array}$ & $\begin{array}{l}20.0 \\
16.7\end{array}$ & $\begin{array}{l}20.0 \\
16.7\end{array}$ & $\begin{array}{l}20.0 \\
16.7\end{array}$ \\
\hline $\begin{array}{l}\text { Allowable Stress for B31.1 } \\
\text { Components S (ksi) }\end{array}$ & $\begin{array}{l}18.8 \\
15.7\end{array}$ & $\begin{array}{l}16.3 \\
13.9\end{array}$ & $\begin{array}{l}15.7 \\
13.4\end{array}$ & $\begin{array}{l}15.1 \\
12.8\end{array}$ \\
\hline
\end{tabular}

All Table properties found in Ref. 5 except for B31.1 properties which were found in Ref. 4.

1. Table TE-1 for Group 3 materials.

2. Table TM-1 for Group G materials.

3. Table $Y-1$

4. Table $2 A$.

5. Table $1 \mathrm{~A}$.

6. Table 4.

7. ASME B31.1, Table A-3.

Table 3. Material properties for Haynes 230 alloy.

\begin{tabular}{|c|c|c|c|}
\hline \multirow{2}{*}{ Material Property } & \multicolumn{3}{|c|}{ Material Properties at Temperature } \\
\hline & $100^{\circ} \mathrm{F}$ & $200^{\circ} \mathrm{F}$ & $400^{\circ} \mathrm{F}$ \\
\hline $\begin{array}{l}\text { Mean Coefficient of Thermal } \\
\text { Expansion going from } 70^{\circ} \mathrm{F} \text { to } \\
\text { specified temperature (in./in.- }{ }^{\circ} \mathrm{F} \text { ) }\end{array}$ & - & .0000065 & .0000069 \\
\hline Modulus of Elasticity E (x10 $\mathrm{psi})$ & 30.6 & 30.1 & 29.3 \\
\hline Typical Yield Strength $\mathrm{S}_{\mathrm{y}}(\mathrm{ksi})$ & 61.3 & & \\
\hline Typical Ultimate Strength $\mathrm{S}_{\mathrm{u}}(\mathrm{ksi})$ & 121.6 & & \\
\hline
\end{tabular}

Properties specified by the manufacturer (www.haynesintl.com).

The Table 3 properties were published by the manufacturer (Haynes International). Haynes 230 is used in constructing the thermal heat shield and will not experience any pressure loadings. The heat shield must merely remain in place and intact to be acceptable. No ASME Code evaluation is required for the heat shield. 
Table 4. Material properties for graphite POCO AXF-5Q.

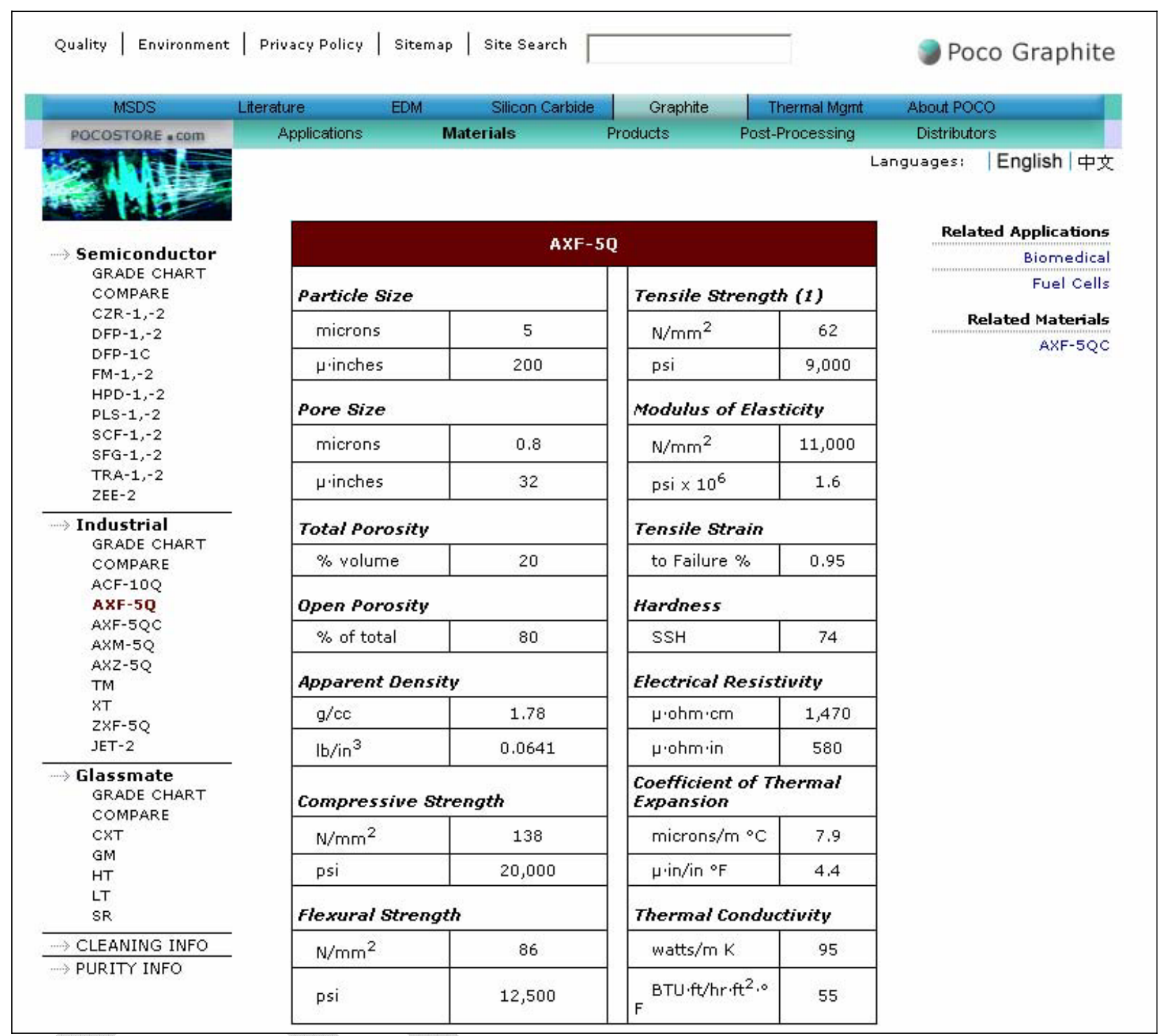

http://www.poco.com/us/Graphite/axf.asp (Manufacturer: POCO Graphite)

The Table 4 properties were published by the manufacturer. This graphite will be used in the lower graphite spacer, the lower and upper graphite specimen holders, the graphite specimen separators (stop blocks), and graphite spacer and push rods. These components are not required to meet ASME Code requirements, but will be evaluated using the above properties and engineering judgment (i.e., maintenance of a factor of safety against material failure).

The manufacturer does not list higher temperature properties for this graphite. However, Reference 6 states that the compressive strength increases (to almost double the room temperature value) with temperature up to about 2500 deg. C. (4500 deg. F.). Strength also increases with irradiation (Ref.7). 


\section{LOADS}

\subsection{Design Load Conditions}

\subsubsection{Reactor Vessel Penetration Components}

The design conditions for the reactor vessel penetration components are:

- Design Life: 1.5 years for seal plug, 14 years for loop seal flange and bolts (Ref. 1)

- Design Temperature: $240^{\circ} \mathrm{F}$ (Ref. 8)

- Design Pressure: 390 psig in reactor, 0 psig external to reactor (Ref. 8)

- Corrosion Allowance: zero (Ref. 1)

\subsubsection{In-Vessel Pressure Boundary Components}

The design conditions for the hanger rod extension and transition tubes and the capsule boundary components are:

- Design Life: 1.5 years (Ref. 1 )

- Design Temperature: $240^{\circ} \mathrm{F}$ (Ref. 8)

- Design Pressure: 390 psig external pressure (Ref. 8), 200 psig internal pressure (Ref. 1)

- Corrosion Allowance: zero (Ref. 1)

- Sustained loadings under design conditions include flow-induced vibrations, flow lift/drag, and a 100 psig pressure drop across the core (flow velocity past capsule of $27.1 \mathrm{ft} / \mathrm{sec}$., Ref. 9).

\subsubsection{Gas Lines (In-Vessel) and Hanger Rod Assembly (Out-of-Reactor) Components}

The design conditions for the gas lines and hanger rod assembly (out-of-reactor) components are:

- Design Life: 14 years (Ref. 1)

- Design Temperature: Gas Lines at $240^{\circ} \mathrm{F}$ (Ref. 8)

Hanger Rod Assembly at $240^{\circ} \mathrm{F}$ (conservative)

- Design Pressure: Gas Lines at 250 psig internal, 0 psig external (Ref. 1)

Hanger Rod Assembly- 0 psig internal and external (Ref. 1)

- Corrosion Allowance: zero (Ref. 1)

\subsection{Service Level Conditions}

\subsubsection{Service Level Conditions (Level A - Normal Operation)}

- Design Pressure: 390 psi reactor pressure (Ref. 8)

- Operating Temperature: $125^{\circ} \mathrm{F}$ reactor (Ref. 8) 
- Startup-to-Steady State-to-Shutdown Frequency: 18 per year (Ref. 8)

\subsubsection{Level B (Upset) Service Conditions}

- Pressure: 429 psi reactor pressure (10\% overpressure, Ref. 8)

- Temperature: $240^{\circ} \mathrm{F}$ reactor (Ref. 8)

- Frequency: 30 per year (Ref. 8)

\subsubsection{Level C (Emergency) Service Conditions}

- Pressure: 468 psi reactor pressure (20\% overpressure, Ref. 8)

- Temperature: $240^{\circ} \mathrm{F}$ reactor (Ref. 8)

- Frequency: 10 times per 20 year period (Ref. 8)

\subsubsection{Level D (Faulted) Service Conditions}

\section{- ATR Seismic Event, Performance Category 4 (PC-4)}

For a number of years the ATR Safe Shutdown Event (SSE) was defined (Ref. 10) using USNRC Regulatory Guide 1.60 Response Spectra (Ref. 11) scaled to $0.24 \mathrm{~g}$ zero period acceleration (zpa horizontal, and 0.16 g's zpa vertical), with Pressure Vessel Research Council (PVRC) damping (ASME Code Case N-411-1, Ref. 12, which was a $5 \%$ damping curve transitioning to $2 \%$ damping curve). The Regulatory Guide 1.60 spectra were used because sitespecific spectra were not available. Numerous experiments have been evaluated using that ATR SSE definition (e.g., Ref.'s 13 and 14). More recently, the ASME Code discarded the PVRC damping in favor of Appendix $\mathrm{N}$ damping (Ref. 15, Table N-1230-1, or 5\% damping for piping).

Currently, site-specific PC-4 rock spectra (Ref. 16) are available for the Test Reactor Area [name recently changed to Reactor Technology Complex (RTC)] and are recommended for use by the TRA Seismic Review team (Ref. 17). These site-specific spectra are to be used with an amplification factor (1.25) on PC-4 SSCs per DOE-STD-1020 (Ref. 18), though the TRA Seismic Review Team has more recently allowed for a lower amplification factor (1.0, per Ref. 19). However, this current analysis used the 1.25 amplification factor to ensure conservatism. (Note that because the ATR vessel is supported on a substantial concrete structure which is founded on bedrock, no further amplification was deemed applicable.)

Figure 3 shows the comparison of the Reg. Guide 1.60 horizontal spectra, scaled to $0.24 \mathrm{~g}$ 's zpa, and the site-specific rock spectra with the PC-4 scale factor of 1.25 . Both use $5 \%$ damping. Figure 4 shows the same for the vertical spectra. From these figures it can be seen that neither spectra entirely envelopes the other. This current analysis of the AGC-1 experiment conservatively enveloped both spectra by following the Reg. Guide 1.60 spectra until it met the rock spectra, and then following the rock spectra (switching back to the Reg. Guide 1.60 spectra at $50 \mathrm{~Hz}$. for horizontal only). Table 5 shows the enveloping spectra points that were employed in this AGC-1 experiment evaluation. 


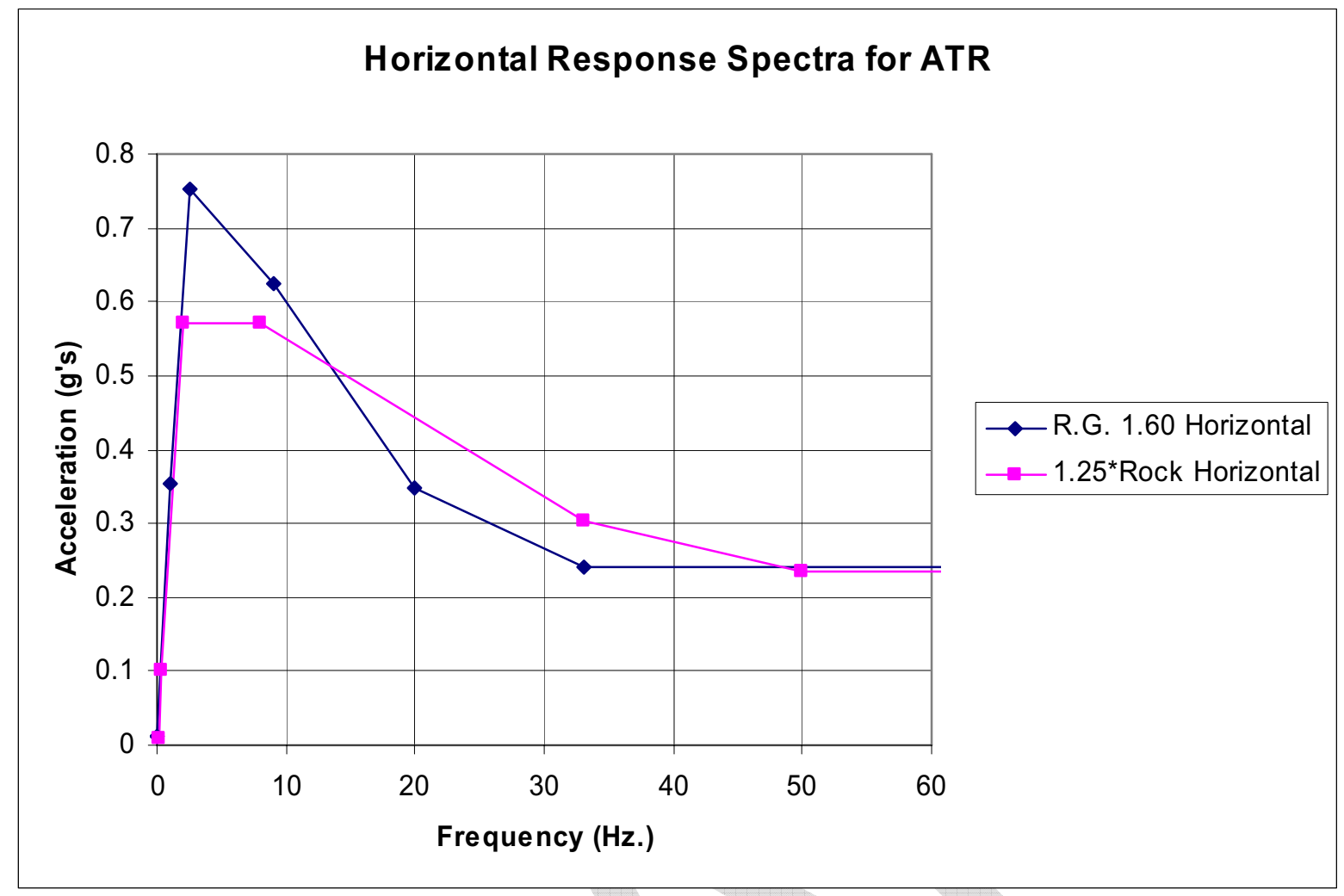

Figure 3. Comparison of horizontal response spectra, 5\% damping.

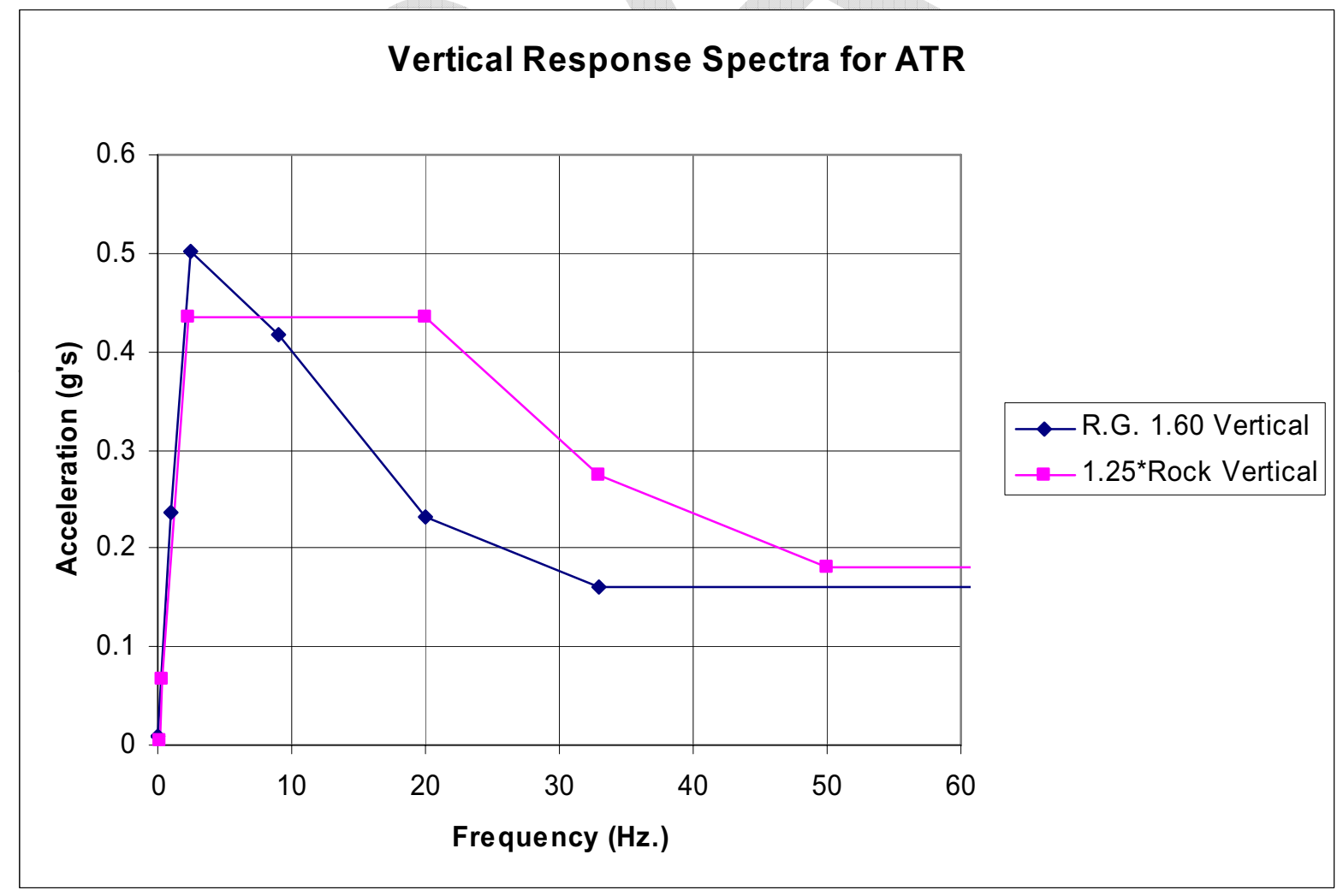

Figure 4. Comparison of vertical spectra, $5 \%$ damping. 
Table 5. Enveloping response spectra for the ATR seismic event.

\begin{tabular}{|c|c|c|c|}
\hline Frequency (Hz.) & $\begin{array}{c}\text { Horizontal } \\
\text { Accelerations (g), } \\
5 \% \text { Damping }\end{array}$ & $\begin{array}{c}\text { Frequency } \\
\text { (Hz.) }\end{array}$ & $\begin{array}{c}\text { Vertical } \\
\text { Accelerations (g) } \\
5 \% \text { Damping } \\
\end{array}$ \\
\hline 0.001 & 0.013 & 0.001 & 0.009 \\
\hline 1.0 & 0.354 & 1.0 & 0.236 \\
\hline 2.5 & 0.751 & 2.5 & 0.501 \\
\hline 9.0 & 0.626 & 7.63 & 0.435 \\
\hline 13.5 & 0.512 & 20.0 & 0.435 \\
\hline 33.0 & 0.303 & 33.0 & 0.274 \\
\hline 50.0 & 0.240 & 50.0 & 0.180 \\
\hline 100.0 & 0.240 & 100.0 & 0.180 \\
\hline
\end{tabular}

\section{ASSUMPTIONS}

Assumptions used within the evaluation will be stated when employed.

\section{ACCEPTANCE CRITERIA}

The ASME Code, Section III, Subsection NB (Ref. 2), is used for Class 1 Components. ASME Code, Section III, Subsection ND (Ref. 3) is the governing code for Class 3 components which include most of the in-vessel components. The gas lines and hanger rod Assembly outside of the reactor must meet the ASME B31.1 (Power Piping) Code requirements (Ref. 4).

\section{CALCULATIONS}

Calculations are contained in the Appendices.

- Appendix A - Computer Software Validation \& Verification

- Appendix B - ASME Code and Non-Code - Calculations

- Appendix C - Component Weights

- Appendix D - ASME Code - Computer Calculations

- Appendix E - Other Computer Calculations

- Appendix F - Thermal Stress Analysis of the Capsule Reactor Core Components

\section{CONCLUSIONS}

The calculations show that all components meet their respective code requirements for the specified design conditions and service levels. 


\section{RECOMMENDATIONS}

None.

\section{ANALYSIS PLAN}

This analysis plan was agreed to by the customer's representative (R. L. Bratton) at the beginning of the analysis efforts.

\section{Objective:}

Provide structural analysis in support of the AGC-1 experiment to meet the applicable requirements for its installation and operation in the Advanced Test Reactor (ATR) south flux trap.

\section{Work Scope:}

Evaluate the reactor penetration, the in-reactor capsule facility pressure boundary, and the incapsule structural components.

\section{Requirements (and SSC Category):}

Reactor Vessel Penetration - ASME B\&PV Code Section III, Class 1, 2001 Ed. w/2003 Addenda, (Safety Class)

Capsule Boundaries - ASME B\&PV Code Section III, Class 3, 2001 Ed. w/ 2002 Addenda, (Low Safety Consequence)

Gas Lines and Hanger Rod Assembly (out-of reactor) - ASME B31.1, 1998 Ed., (Consumer Grade)

Loads environment and conditions as defined in the T\&FR.

Performance Category (seismic loadings):

Performance Category 4 (PC-4, per T\&FR).

\section{Assumptions:}

Thermal loadings to be provided by the project.

\section{Controlling Documents:}

INL Drawings 630427, 630428, 630429, 630430, and 630431 - all in draft form at this time.

Technical \& Functional Requirements (T\&FR) document - in draft form at this time.

\section{Calculation Software:}

ABAQUS/Standard Version 6.4-1, PipeStress Version 3.5.1 +026, and I-DEAS Version 10 (all currently validated and verified per MCP-3039).

\section{Required Reviews:}

Technical Checker (per MCP-2374) and Independent Peer Reviewer (Per MCP-2374, required for seismic calculations).

\section{Deliverables:}

Engineering Design File (EDF) report. 


\section{REFERENCES}

1 T\&FR-XXX, Functional and Operational Requirements for the AGC-1 Irradiation Test, Draft.

2 ASME Boiler and Pressure Vessel Code, Section III, Division 1, Subsection NB - Class 1 Components, 2001 Ed. with 2003 Addenda, American Society of Mechanical Engineers.

3 ASME Boiler and Pressure Vessel Code, Section III, Division 1, Subsection ND - Class 3 Components, 2001 Ed. with 2002 Addenda, American Society of Mechanical Engineers.

4 ASME B31.1, Power Piping, 1998 Ed., American Society of Mechanical Engineers.

5 ASME Boiler and Pressure Vessel Code, Section II, Part D - Material Properties, 2001 Ed. with 2002 Addenda, American Society of Mechanical Engineers.

6 Mechanical Properties of Artificial Graphites - A Survey Report, ORNL-4327, December 1968, Oak Ridge National Laboratory.

7 R. J. Price, Mechanical Properties of Graphite for High-Temperature Gas-Cooled Reactors: A Review, General Atomic Report GA-A13524, 9/22/1975.

8 S. Fershtut, G. W. Holman, ATR Primary Coolant System Piping Design Specification for Modifications, PR-T-78-003, Rev. 6, May 1989.

9 Flow data provided by R. G. Ambrosek on June 2, 2005.

10 V. W. Gorman, Recommended Interim Safe Shutdown Earthquake Criteria for ATR, PG-T-89-012, May 1989.

11 U.S. Atomic Regulatory Commission, Regulatory Guide 1.60, Design Response Spectra for Seismic Design of Nuclear Power Plants, Rev. 1, December 1973.

12 ASME Boiler and Pressure Vessel Code, Code Case N-411-1, Alternate Damping Values for Response Spectra Analysis of Class 1, 2, and 3 Piping, Section III, Div. 1, 2/20/1986.

13 S. D. Snow, Structural Evaluation of the ATR Irradiation Capsule Experiment (ICE) Test and Facility, EDF TRA-ATR-1275, Rev. 0, Nov. 1997.

14 R. K. Blandford, Structural Evaluation of the ATR Multiple Irradiation Capsule Experiment (MICE) Test Train, Facility and Support Equipment, EDF-TRA-ATR-1512, Rev. 0, 10/1999.

15 ASME Boiler and Pressure Vessel Code, Section III, Division 1 - Appendices, 2001 Edition, American Society of Mechanical Engineers.

16 Payne, S. J., et al., Development of Probabilistic Design Basis Earthquake (DBE) Parameters for Moderate and High Hazard Facilities at INEEL, INEL/EXT-99-0075, Rev. 2, June 1, 2002.

17 T. A. Thatcher email of 1/22/2004, Seismic Team (ICARE 35644) Draft Guidance.

18 DOE Standard, Natural Phenomena Hazards Design and Evaluation Criteria for Department of Energy Facilities, DOE-STD-1020-2002, January 2002.

19 S. R. Jensen email of 4/3/2006, Updated Guidance on RTC Seismic Analysis. 


\section{Appendix A}

\section{Computer Software Validation \& Verification}


- $\quad$ ABAQUS/Standard Version 6.4-1 (Ref. 16)

-Tracking Number 125097

-EDF-4549, ABAQUS Version 6.4-1 Standard and Explicit Validation and Verification, Feb. 2004

- Computer Used: Tomcat

- I-DEAS 10 (Ref. 17)

-Tracking Number 112379

-EDF-3883, Mechanical and Structural Engineering Software Validation for I-DEAS 10, Mar. 2004

-Computer Used: ZION

- $\quad$ PipeStress Version3.5.1+026 (Ref. 18)

-Tracking Number 176056

-EDF-5719, Validation of PIPESTRESS Version 3.5.1+026 Piping Analysis Software on INL Computers ZION and MIRA, Aug. 2005.

-Computer Used: MIRA

\section{Software Justification}

ABAQUS, I-DEAS 10, and PipeStress were each used for this analysis because (1) they are readily available, and (2) they were designed and purchased to perform the type of analyses for which they were used herein. 


\section{Appendix B}

\section{ASME Code \& Non-Code - Calculations}




\section{Contents}

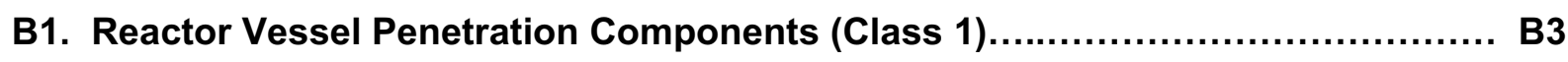

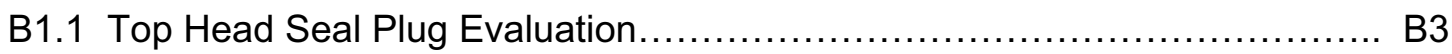

B1.2 Loop Seal Flange and Attachment Bolts Evaluation.................... B6

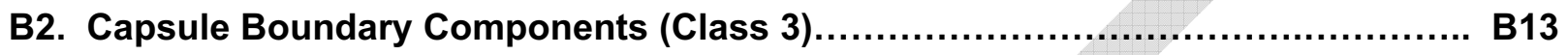

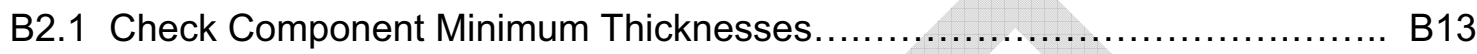

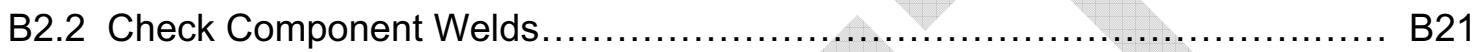

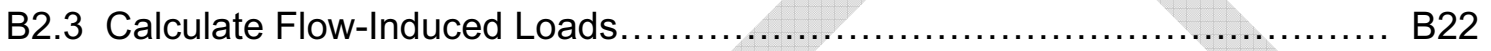

B3. ATR Gas Lines and Hanger Rod Assembly (out-of-reactor) Components (B31.1) B24

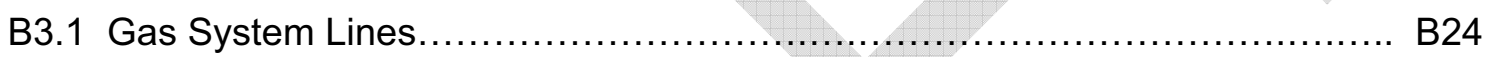

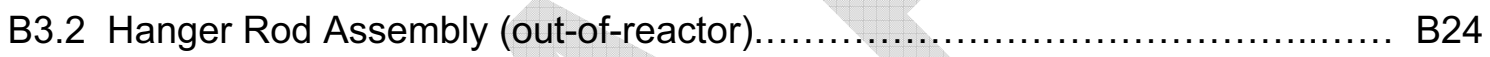

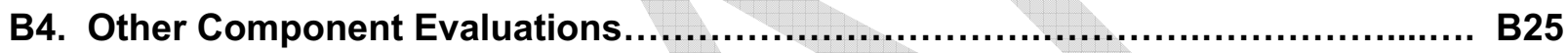

B4.1 Evaluate Components Under Upper Cylinder Loads..................... B25

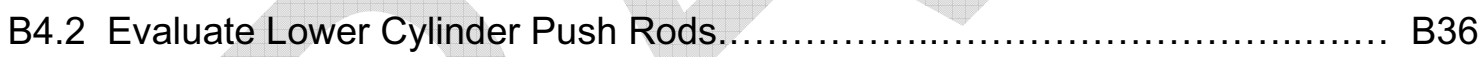

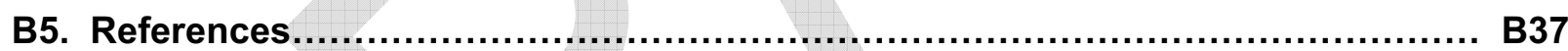




\section{B1. Reactor Vessel Penetration Components (Class 1)}

The reactor vessel penetration components for the Advanced Graphite Creep Experiment AGC-1 consists of the following items: one loop seal flange with four attachment bolts (3/4 in.-10UNC, or studs with nuts), and one top head seal plug.

The top head seal plug rests on a ledge within the reactor top head closure plate (Ref. drawings 120438 and 120446). Movement upward is impeded by the loop seal flange which is bolted to the reactor top head closure plate. The AGC-1 facility is welded to the seal plug on the in-reactor side. All reactor pressure boundary components (seal plug, loop seal flange and bolting) must meet the ASME B\&PV Code, Section III, Class 1 requirements (Ref. B1).

\section{B1.1 Top Head Seal Plug Evaluation}

The seal plug is basically a 10-inch long 304 stainless steel bar, 6-1/2-inches maximum diameter, with a 1.39-inch diameter through hole. Design loadings on the seal plug are as follows:

(1) Load from AGC-1 facility assembly weight minus buoyancy (see Appendix C): [the self-weight of the seal plug plus the weight in-reactor and out-of-reactor (hanger rod assembly) components, calculated at $347 \mathrm{lbs}$, minus the buoyancy of the in-vessel components, at $135 \mathrm{lbs}$, gives a total net weight acting on the seal plug of $204 \mathrm{lbs}$ ],

$$
\mathrm{W}_{\text {net }}:=211 \cdot \mathrm{lbf} \quad \mathrm{W}_{\text {net }}=\text { wet weight of facility (from weights calculation }
$$
section - Appendix C)

(2) Load from reactor design pressure:

$$
\begin{aligned}
\mathrm{P}_{\mathrm{d}}:=390 \cdot \frac{\mathrm{lbf}}{\mathrm{in}^{2}} & \mathrm{P}_{\mathrm{d}}=\text { reactor design pressure } \\
\mathrm{D}_{\max }:=6.0 \cdot \mathrm{in} & \mathrm{D}_{\max }=\text { O.D. of reactor top head closure } \\
\mathrm{F}_{\mathrm{rp}}:=\mathrm{P}_{\mathrm{d}} \cdot \frac{\pi}{4} \cdot\left(\mathrm{D}_{\max }{ }^{2}\right) & \begin{array}{l}
\mathrm{F}_{\mathrm{rp}}=\text { force due to reactor design pressure } \\
\text { plug }
\end{array} \\
\mathrm{F}_{\mathrm{rp}}=11027 \mathrm{lbf} &
\end{aligned}
$$

(3) Load from loop seal flange attachment bolts:

$$
\begin{array}{cl}
f_{\text {torque }}:=55 \cdot \mathrm{ft} \cdot \text { lbf } & f_{\text {torque }}=\text { torque on bolts (Ref.'s B2 \& B3) } \\
D_{\text {bolt }}:=0.75 \cdot \text { in } & D_{\text {bolt }}=\text { bolt O.D. } \\
F_{\text {bolt }}:=\frac{f_{\text {torque }}}{0.2 \cdot D_{\text {bolt }}} & F_{\text {bolt }}=\text { force per bolt } \\
F_{\text {bolt }}=4400 \mathrm{lbf} &
\end{array}
$$




\section{B1.1.1 Check Ledge on Reactor Closure Plate and Seal Plug}

Design Conditions: The dimensions of the overlap between the seal plug and the reactor top head penetration are as follows:
$D_{\text {rth }}:=6.0 \cdot$ in
$D_{\text {rth }}=$ reactor top head penetration diameter
$\mathrm{D}_{\mathrm{spl}}:=6.28 \cdot \mathrm{in}$
$D_{\text {spl }}=$ seal plug ledge outer diameter

The maximum bearing stress on the reactor top head penetration ledge is:

$$
\begin{gathered}
\sigma_{\text {rledge }}:=\frac{W_{\text {net }}+4 \cdot F_{\text {bolt }}}{\frac{\pi}{4} \cdot\left(D_{\text {spl }}{ }^{2}-D_{\text {rth }}{ }^{2}\right)} \quad \sigma_{\text {rledge }}=\text { bearing stress on reactor ledge } \\
\sigma_{\text {rledge }}=6595 \mathrm{psi}
\end{gathered}
$$

(Note that the bearing stress due to weight and bolt preloading plus the reactor design pressure would be less than calculated above because the pressure force is upward directed.)

The allowable bearing stress (NB-3227.1) is the yield strength $\left(S_{y}\right)$ of the reactor top head and seal plug material (both 304 stainless steel) at the design temperature $(240 \mathrm{~F})$, which is $23.9 \mathrm{ksi}$ (Ref. Table 2 from report main body). The calculated bearing stress above is less than the allowable of $23.9 \mathrm{ksi}$. This indicates that the bearing stress in the reactor top head and seal plug is acceptable.

The seal plug must also be checked to assure that a ring of plug material (through the seal region) does not shear off under these design loads.

$$
\begin{array}{cl}
t_{\text {shear }}:=2.75 \cdot \text { in } & \begin{array}{l}
t_{\text {shear }}=\text { thickness of seal plug from the reactor ledge } \\
\text { through the sealing region }
\end{array} \\
\tau_{\text {plug }}:=\frac{W_{\text {net }}+4 \cdot F_{\text {bolt }}}{\pi \cdot D_{\text {rth }} \cdot t_{\text {shear }}} & \tau_{\text {plug }}=\text { shear stress through seal plug } \\
\tau_{\text {plug }}=344 \text { psi } &
\end{array}
$$

The allowable shear stress (NB-3227.2) is $60 \%$ of $S_{m}(20 \mathrm{ksi}$ as listed in Table 2 of the report main body), or $12 \mathrm{ksi}$. This allowable shear stress exceeds that calculated above.

:Top head seal plug ledge is acceptable for design conditions. 
Service Levels A through C Conditions: Service Levels A through C conditions for the seal plug include increased reactor pressures only. Pressure loads would only reduce the loading on the plug/plate ledge.

:Top head seal plug ledge is acceptable for Service Levels A through C conditions.

\section{Service Level D Conditions:}

The Service Level D condition includes the specified ATR SSE event. The AGC-1 experiment components are not expected to see much more than zero period acceleration in the vertical direction $(0.16 \mathrm{~g}$ 's). This would create vertical forces on the seal plug/closure plate that would be negligible in comparison to the loop seal flange attachment bolts preload. Horizontal seismic motion would be transferred directly to the reactor top head closure plate through the base of the seal plug. As far as fatigue is concerned, it will be shown in the loop seal flange evaluation that service temperature and normal pressure conditions and fluctuations are such that a fatigue evaluation is not necessary. This applies to the seal plug as well.

:Top head seal plug ledge is acceptable for Service Level D conditions.

\section{B1.1.2 Overall Seal Plug Structure Evaluation}

Design Conditions: The seal plug is a 4.75-inch to 6.5-inch diameter stainless steel bar, 10 inches long, with one 1.39-inch diameter centered through hole. The design loadings would create, in a worst case, compressive membrane stresses in the plug body of:

$$
\begin{array}{ll}
\mathrm{D}_{4.75}:=4.75 \cdot \text { in } & \mathrm{D}_{4.75}=\text { minimum diameter of seal plug } \\
\mathrm{D}_{1.39}:=1.39 \cdot \mathrm{in} & \mathrm{D}_{1.39}=\text { seal plug through hole diameter } \\
\sigma_{\mathrm{m}}:=\frac{\mathrm{W}_{\mathrm{net}}+\mathrm{F}_{\mathrm{rp}}+4 \cdot \mathrm{F}_{\text {bolt }}}{\frac{\pi}{4} \cdot\left(\mathrm{D}_{4.75}{ }^{2}-\mathrm{D}_{1.39}{ }^{2}\right)} & \sigma_{\mathrm{m}}=\text { compressive membrane stress } \\
\sigma_{\mathrm{m}}=1780 \mathrm{psi} &
\end{array}
$$

The allowable membrane stress (NB-3221.1) is $S_{m}$, which is $20 \mathrm{ksi}$ (per Table 2 of the main report. This is much greater than the calculated membrane stress above.

:Top head seal plug overall structure is acceptable for design conditions. 
Service Level A through D Conditions: The seal plug will only see an increase in reactor pressure for Service Levels A through $\mathrm{C}$ conditions. However, that pressure increase $(10 \%$ and $20 \%)$ will not significantly increase the design-calculated compressive membrane stress. The Service Level D event is the ATR seismic event. Since the seal plug is very sturdy in comparison to the in-vessel hanger rod extension/transition tube and capsule tube, any seismic loads that are carried by those in-vessel components will be carried as a much lower stress level in the seal plug. A detailed evaluation of the seal plug under seismic loads is not considered necessary. As far as fatigue is concerned, it will be shown in the loop seal flange evaluation that service temperature and normal pressure conditions and fluctuations are such that a fatigue evaluation is not required.

:Top head seal plug overall structure is acceptable for Service Level A through D conditions.

\section{B1.2 Loop Seal Flange and Attachment Bolts Evaluation}

\section{B1.2.1 Loop Seal Flange Evaluation}

The ASME Code, Section III, Subsection NB-3647 defines the requirements for the pressure design of flanged joints. However, the loop seal flange is not designed like the type of flanges that this section addresses. It expects regular piping-type flanges or blanks. The following sketch shows the configuration of the loop seal flange.

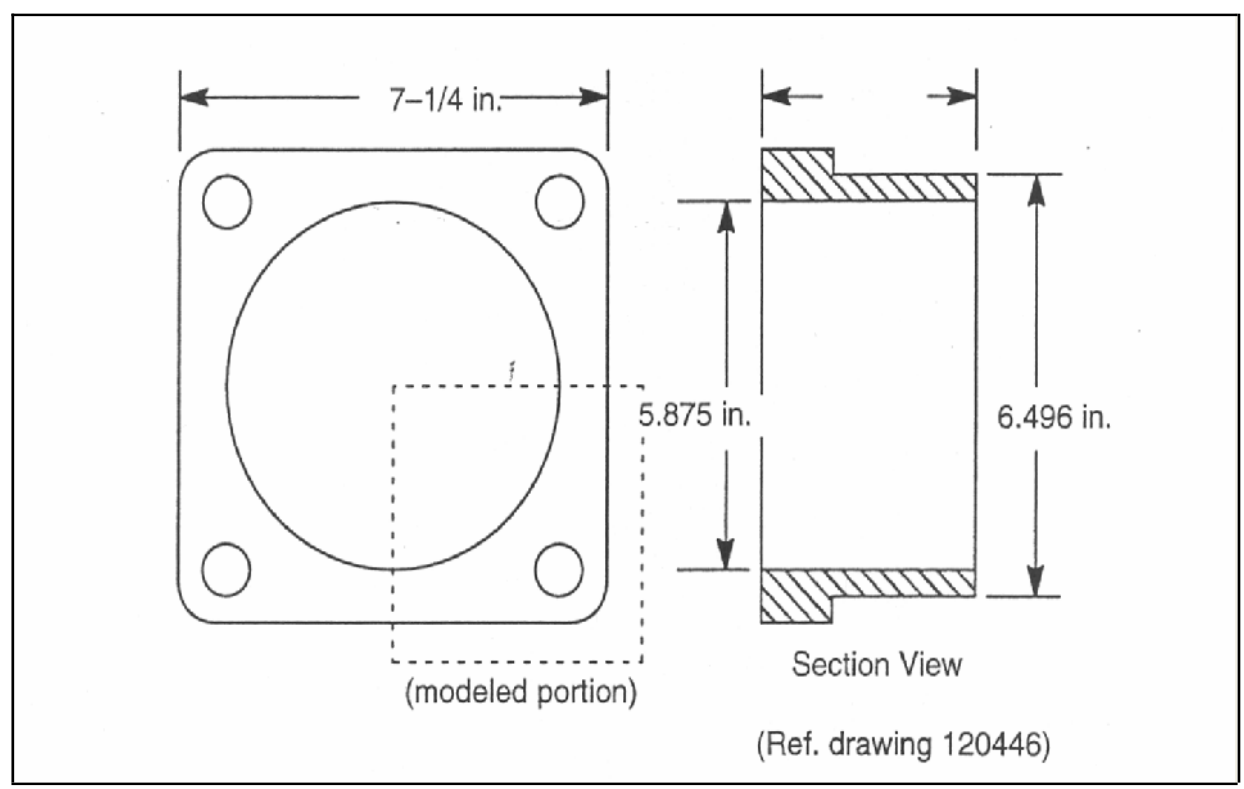

The loop seal flange sees reactor pressure by way of the seal plug as a "ring" load. It appears more appropriate to evaluate this loop seal flange under the rules of NB-3220 "Stress Limits for Other than Bolts." 
Design Conditions: The design loadings on this flange are due to the reactor pressure load of 390 psig transmitted through the top head seal plug, minus the weight of the ACG-1 facility assembly, plus the preload torques on the flange bolts. That gives a total load of:

$$
\begin{gathered}
F_{\text {flange }}:=F_{r p}-W_{\text {net }}+4 \cdot F_{\text {bolt }} \quad F_{\text {flange }}=\text { total design load on flange } \\
F_{\text {flange }}=28416 \mathrm{lbf}
\end{gathered}
$$

Reference B2 employed a finite element model to evaluate this loop seal flange under a ring load of $33,167 \mathrm{lbf}$. The resulting maximum stress intensity due to primary bending plus peak stresses was 12,400 psi. Because that evaluation was performed using linear analysis methods, the equivalent stress in the loop seal flange used for the AGC-1 experiment would be:

$$
\begin{gathered}
\sigma_{f}:=\frac{F_{\text {flange }}}{33167 \cdot \mathrm{lbf}} \cdot 12400 \cdot \mathrm{psi} \quad \sigma_{\mathrm{f}}=\text { primary bending plus peak stress in flange } \\
\sigma_{\mathrm{f}}=10624 \mathrm{psi}
\end{gathered}
$$

The ASME Code allows for the basic stress intensity at $20 \mathrm{ksi}$ (Table 2 of report main body) for general primary membrane stress intensity alone (NB-3221.1) The allowable for membrane plus bending is even higher $\left(1.5 \mathrm{~S}_{\mathrm{m}}\right.$ giving $30 \mathrm{ksi}$, NB-3221.3) This flange experiences a maximum stress intensity level that is below the allowable value under design conditions.

:Loop seal flange is acceptable for design conditions.

Service Level A Conditions: Weight and pressure loadings during normal operation are enveloped by the design conditions. Thermal growth of components is not impeded by the structure, so Service Level A thermal conditions do not affect the flange. However, fatigue concerns must be evaluated.

\section{Fatigue Investigation}

The loop seal flange is governed by the rules for Class 1 components. However, a full fatigue analysis does not need to be performed provided that it can be shown that the requirements of NB-3222.4(d) are satisfied. Those requirement are:

\section{Atmospheric to Service Pressure Cycle}

$$
\begin{aligned}
& S_{m}:=20000 \cdot p s i \\
& \mathrm{~S}_{\mathrm{m}}=\text { allowable design stress intensity } \\
& \mathrm{S}_{\mathrm{a}}:=3 \cdot \mathrm{S}_{\mathrm{m}} \\
& \mathrm{S}_{\mathrm{a}}=\text { alternating stress } \\
& \mathrm{S}_{\mathrm{a}}=60000 \mathrm{psi}
\end{aligned}
$$


$\mathrm{N}_{\text {allowed }}:=15000$

$\mathrm{N}_{\text {allowed }}=$ allowed lifetime cycles (Fig. I-9.2.1)

$\mathrm{N}_{\text {actual }}:=18 \cdot \frac{\text { cycles }}{\text { year }} \cdot 14 \cdot$ year

$\mathrm{N}_{\text {actual }}=$ actual cycles $=252$ cycles

For conservatism, use $\mathrm{N}_{\text {actual }}=1000$ cycles .

:Allowed cycles are much greater than the actual cycles. OK.

Normal Service Pressure Fluctuation

$$
\begin{array}{cl}
\mathrm{S}_{\mathrm{a} 10 \_6}:=28000 \cdot \mathrm{psi} & \mathrm{S}_{\mathrm{a} 10 \_6}=\text { stress at } 10^{6} \text { service cycles } \\
\mathrm{P}_{\mathrm{f}}:=\frac{\mathrm{P}_{\mathrm{d}}}{3} \cdot \frac{\mathrm{S}_{\mathrm{a} 10 \_6}}{\mathrm{~S}_{\mathrm{m}}} & \mathrm{P}_{\mathrm{f}}=\text { pressure fluctuation } \\
\mathrm{P}_{\mathrm{f}}=182 \mathrm{psi} &
\end{array}
$$

Normal service pressure fluctuation will not exceed 182 psi. OK.

Temperature Difference - Startup and Shutdown

$$
\begin{array}{ll}
\mathrm{S}_{\mathrm{a} 1000}:=80000 \cdot \mathrm{psi} & \mathrm{S}_{\mathrm{a} 1000}=\text { alternating stress at } 1000 \text { service } \\
\text { cycles (Fig. l-9.2.1) } & \\
\mathrm{E}:=27400000 \cdot \mathrm{psi} & \begin{array}{l}
\mathrm{E}=\text { modulus of elasticity at } 240 \mathrm{~F} \text { (Table } 2 \text { of } \\
\text { main report) }
\end{array} \\
\alpha:=9.23 \cdot 10^{-6} & \begin{array}{l}
\alpha=\text { instantaneous thermal expansion } \\
\text { coefficient (in./in./F) }
\end{array} \\
\Delta \mathrm{T}_{\mathrm{SS}}:=\frac{\mathrm{S}_{\mathrm{a} 1000}}{2 \cdot \mathrm{E} \cdot \alpha} & \begin{array}{l}
\Delta \mathrm{T}_{\text {ss }}=\text { maximum allowed temperature } \\
\text { difference between any two adjacent points } \\
\text { during startup or shutdown }
\end{array} \\
& \Delta \mathrm{T}_{\mathrm{SS}}=158 \mathrm{~F}
\end{array}
$$

Maximum temperature difference will not exceed 158 deg. $F$ between two adjacent points. OK.

Temperature Difference - Normal Service

$$
\Delta \mathrm{T}_{\mathrm{ns}}:=\frac{\mathrm{S}_{\mathrm{a} 10 \_6}}{2 \cdot \mathrm{E} \cdot \alpha} \quad \begin{aligned}
& \Delta \mathrm{T}_{\mathrm{ns}}=\text { maximum allowed temperature } \\
& \text { difference between any two adjacent points } \\
& \text { during normal service }
\end{aligned}
$$

Maximum temperature difference between any two adjacent points will not exceed 55 deg. F. OK.

\section{Temperature Difference - Dissimilar Materials}

Not applicable - no dissimilar materials. OK. 


\section{Mechanical Loads}

Mechanical loads exclude pressure, but do include piping reactions. This design is such that the flange will not carry the piping loads (they are transferred through the top head seal plug into the reactor top head closure plate directly). The only other load that the flange will carry is due to the bolt preload torque - which is constant (not cyclic). OK.

:Loop seal flange does not require analysis for cyclical service, and is therefore acceptable for Service Level A conditions.

Service Level B Conditions: Service Level B conditions are only slightly increased over design conditions due to the specified $10 \%$ overpressure. However, this overpressure only increases the total flange load by $4 \%$. This is considered acceptable without further evaluation. Service Level B fatigue conditions are enveloped by the Service Level A fatigue evaluation.

:Loop seal flange is acceptable for Service Level B conditions.

Service Level C Conditions: Service Level C conditions include an overpressure event of 468 psi with a design frequency of 10 times every 20 years. This is a $20 \%$ pressure increase over design, but only $8 \%$ increase in the total flange load. Flange stresses will only increase by $8 \%$ because of this overpressure, which will still be below the design allowable stress values (Service Level $\mathrm{C}$ stress limits are at or greater than design limits). Service Level $C$ stress levels in the flnage are therefore acceptable. Note that the fatigue evaluation under Service Level A conditions allowed for a range of pressure fluctuations of 182 psi. This Service Level C overpressure event falls within that allowable pressure fluctuation range.

:Loop seal flange is acceptable for Service Level C conditions.

Service Level D Conditions: The Service Level D conditions include the ATR seismic event. Because of the fit between the seal plug and the reactor head, horizontal and moment loadings will not be transferred into the seal flange. The calculation in Appendix D resulted in negligibly small upward vertical loadings on the seal plug, and thus the flange.

:Loop seal flange is acceptable for Service Level D conditions.

\section{B1.2.2 Loop Seal Flange Attachment Bolts Evaluation}

Design Conditions: The ASME Code (NB-3231) indicates that the stresses in the bolts (3/4-in.-10UNC) due only to the design pressure load must be less than the basic allowable stress (8000 psi at 240 deg. $F$, from Table 2 in main report). (Appendix $E$ of the ASME Code is not applicable to this loop seal flange since the flange is not required to compress a gasket - seal is maintained by o-rings on the seal plug.) Note that these may not be bolts, but studs with nuts. If existing studs are used, then the stud material is still expected to be 304 SST as noted in the report main body. The nuts would then be SA-194 Grade 8 (see Ref. 22 listed in Reference B2). The following evaluation will apply to both bolts and studs with nuts. The design pressure will create the following primary stress: 


$$
\begin{array}{cl}
A_{\text {bolt }}:=0.334 \cdot \text { in }^{2} & A_{\text {bolt }}=\text { tensile area of 3/4-inch bolt } \\
\sigma_{\text {bolt_design }}:=\frac{\frac{F_{r p}}{4}}{A_{\text {bolt }}} & \begin{array}{l}
\sigma_{\text {bolt_design }}=\text { primary stress in bolts under } \\
\text { design pressure, where the tensile area of a } \\
\text { 3/4-inch bolt is } 0.334 \text { in. }{ }^{\wedge} 2
\end{array} \\
\sigma_{\text {bolt_design }}=8254 \mathrm{psi} &
\end{array}
$$

The above design stress is $3 \%$ above the allowable stress value of 8000 psi. This will be considered acceptable. (This is consistent with the conclusions of Ref. B2.) The normal operating temperature of these bolts will be no more than $125 \mathrm{deg} . \mathrm{F}$, at which temperature the allowable stress is 10000 psi.

:Loop seal flange bolts are considered acceptable for Design Conditions.

Service Level A Conditions: The ASME Code (NB-3232) indicates that the loop seal flange bolts must be able to carry actual service loads due to bolt preload, weight, and pressure with stresses below two times the basic allowable stress. The service loadings on the bolts, and the resulting average tensile stresses are:

$$
\mathrm{F}_{\text {bolt }}=4400 \mathrm{lbf}
$$

Calculate the load due to pressure:

$$
L_{b}:=1.25 \cdot \text { in }
$$

$$
\mathrm{K}_{\mathrm{b}}:=\mathrm{A}_{\mathrm{bolt}} \cdot \frac{\mathrm{E}}{\mathrm{L}_{\mathrm{b}}}
$$

$$
\begin{array}{r}
A_{m}:=\frac{1}{4} \cdot \frac{\pi}{4} \cdot\left(6.497^{2}-5.875^{2}\right) \cdot \mathrm{in}^{2} \\
A_{m}=1.511 \mathrm{in}^{2}
\end{array}
$$

$\mathrm{L}_{\mathrm{m}}:=1.25 \cdot \mathrm{in}$

$\mathrm{K}_{\mathrm{m}}:=\mathrm{A}_{\mathrm{m}} \cdot \frac{\mathrm{E}}{\mathrm{L}_{\mathrm{m}}}$

$$
\mathrm{F}_{\text {rp_bolts }}:=\frac{\mathrm{F}_{\mathrm{rp}}}{4} \cdot\left(\frac{\mathrm{K}_{\mathrm{b}}}{\mathrm{K}_{\mathrm{b}}+\mathrm{K}_{\mathrm{m}}}\right)
$$$$
\mathrm{F}_{\text {rp_bolts }}=499 \mathrm{lbf}
$$

$\mathrm{F}_{\text {bolt }}=$ preload in each bolt, calculated previously

$L_{b}=$ length of bolt not engaged in threads

(1.25-inches flange thickness)

$K_{b}=$ stiffness of bolt

$A_{m}=$ area of narrow part of flange

$L_{m}=$ length of flange under bolt

$\mathrm{K}_{\mathrm{m}}$ = stiffness of flange

$E=27400000 p s i$

$F_{\text {rp_bolts }}=$ load actually transferred into each bolt 


$$
\begin{array}{cl}
F_{\text {bolt_total }}:= & F_{\text {bolt }}+F_{\text {rp_bolts }}+\frac{-W_{\text {net }}}{4} \quad F_{\text {bolt_total }}=\text { maximum bolt load per bolt } \\
& F_{\text {bolt_total }}=4846 \mathrm{lbf} \quad \text { Per Bolt } \\
\sigma_{\text {bolt_Level_A }}:=\frac{F_{\text {bolt_total }}}{A_{\text {bolt }}} & \sigma_{\text {bolt_Level_A }}=\text { Level A stress in each bolt } \\
\sigma_{\text {bolt_Level_A }}=14510 p s i &
\end{array}
$$

The allowable stress level of 2 times $S_{m}$ (at 240 deg. $F$ ), or $2 * 8000$ psi $=16,000$ psi, exceeds the above Service Level A stress.

:Loop seal flange attachment bolts with a $55 \mathrm{ft}$.-lbf preload torque are acceptable under Service Level A conditions.

Service Level A Fatigue Evaluation: The ASME Code (NB-3232.3) indicates that the bolts that are installed on components that meet all the conditions of NB-3222.4(d) require no fatigue evaluation. The above flange analysis shows that those conditions are met.

:Service Level A fatigue conditions are satisfied.

:Loop seal flange bolts (or studs with nuts) are acceptable for Service Level A conditions.

Service Level B Conditions: Service Level B conditions are the same as for Level A but with the specified $10 \%$ overpressure (429 psig). This will increase the bolt stresses as caculated next:

$$
\begin{gathered}
F_{\text {bolt_Level_B }}:=F_{\text {bolt }}+F_{\text {rp_bolts }} \cdot \frac{429}{390}+\frac{-W_{\text {net }}}{4} \\
F_{\text {bolt_Level_B }}=4896 \mathrm{lbf} \\
\sigma_{\text {bolt_Level_B }}:=\frac{F_{\text {bolt_Level_B }}}{A_{\text {bolt }}} \quad F_{\text {bolt_Level_B }}=\text { Level B forces in bolts } \\
\sigma_{\text {bolt_Level_B }}=14659 \text { psi }
\end{gathered}
$$

The above Level B stress in the bolts is below the Code allowable of 16,000 psi (NB-3233).

The addition of 30 cycles of 429 psi per year for a 14 year life is insignificant as far as fatigue is concerned.

:Loop seal flange bolts (or studs with nuts) are acceptable for Service Level B conditions. 
Service Level C Conditions: Service Level C conditions include a reactor overpressure event of 468 psi designed to occur 10 times in a 20 year period This will increase the bolt stresses by:

$$
\begin{gathered}
F_{\text {bolt_Level_C }}:=F_{\text {bolt }}+F_{\text {rp_bolts }} \cdot \frac{468}{390}+\frac{-W_{\text {net }}}{4} \\
F_{\text {bolt_Level_C }}=4946.119 \mathrm{lbf} \quad F_{\text {bolt_Level_c }}=\text { Level B forces in bolts } \\
\sigma_{\text {bolt_Level_C }}:=\frac{F_{\text {bolt_Level_C }}}{A_{\text {bolt }}} \quad \sigma_{\text {bolt_Level_c }}=\text { Level C stress in each bolt } \\
\sigma_{\text {bolt_Level_C }}=14809 \text { psi }
\end{gathered}
$$

The above Level C stress in the bolts is below the Code allowable of 16,000 psi (NB-3234).

The addition of 10 cycles of 468 psi per year for a 14 year life is insignificant as far as fatigue is concerned.

:Loop seal bolts (or studs with nuts) are acceptable for Service Level C conditions.

Service Level D Conditions: Service Level D conditions include the specified ATR seismic event. This event should not load the flange bolts since the piping loads are transferred directly into the reactor upper head closure plate through the seal plug.

:Loop seal flange bolts (or studs with nuts) are acceptable for Service Level D conditions.

:Top head closure assembly meets the ASME Code structural requirements. 


\section{B2. Capsule Boundary Components (Class 3)}

\section{B2.1 Check Component Minimum Thicknesses}

The pressure boundary of the in-vessel components include the hanger rod extension and transition tubes, the funnel transition tube, the transition funnel, the capsule facility body, and the bottom cap. A check for minimum thickness on these components will be performed next. (A maximum of 200 psig internal and 390 psig external design pressures are defined for these components.)

\section{B2.1.1 Check Hanger Rod Extension \& Transition Tubes, and the Transition Funnel Thickness}

Because the design external pressure is so much larger than the internal pressure, it is suspected that external pressure will control the design and will therefore be checked first.

Design Conditions - External Pressure: The hanger rod extension \& transition tubes and the transition funnel are made of 304 stainless steel. Following the requirements of the ASME Code, ND-3133.3 (Ref. B4, as directed by ND-3641.2) for tubular products under external pressure:

$\mathrm{D}_{\mathrm{O} \_ \text {hrt }}:=5.00 \cdot \mathrm{in}$

$t_{\text {hrt }}:=0.188 \cdot$ in

$$
\begin{aligned}
& \frac{D_{\text {O_hrt }}}{t_{\text {hrt }}}=26.5957 \\
& L_{\text {hret }}:=108.15 \cdot \mathrm{in} \\
& L_{\text {hrtt }}:=12 \cdot \mathrm{in} \\
& \frac{L_{\text {hret }}}{D_{\text {O_hrt }}}=21.63 \\
& \frac{L_{\text {hrtt }}}{D_{\text {O_hrt }}}=2.4 \\
& A_{\text {hret }}:=0.0017 \\
& A_{\text {hrtt }}:=0.0045 \\
& B_{\text {hret }}:=9500 \cdot \mathrm{psi} \\
& B_{\text {hrtt }}:=11500 \cdot \mathrm{psi}
\end{aligned}
$$

$\mathrm{D}_{\mathrm{o}_{\text {hrt }}}=$ outside diameter of hanger rod extension \& transition tubes, funnel transition tube $t_{\text {hrt }}=$ nominal thickness of these tubes

\section{Diameter-to-thickness ratio $>10$}

$L_{\text {hret }}=$ maximum unsupported length of hanger rod extension tube

$L_{\text {hrtt }}=$ maximum unsupported length of hanger rod transition tubes (funnel transition tube enveloped by the transition tubes) Length-to-diameter ratio for extension tube Length-to-diameter ratio for transition tubes $A_{\text {hret }}$ from Figure G (Section II, Part D, extension tube)

$A_{\text {hrtt }}$ from Figure $G$ (transition tubes)

$B_{\text {hret }}$ from Figure HA-1 (Section II, Part D, @

$240 \mathrm{~F}$., extension tube)

$B_{\text {hrtt }}$ from Figure HA-1 (Section II, Part D, transition tubes) 
The "B" value for the extension tube, because of its length, is lower than for transition tubes. Only the hanger rod extension tube and its $B_{\text {hret }}$ value will be used now.

$$
\begin{aligned}
P_{\text {a_hret }}:=\frac{4}{3} \cdot \frac{B_{\text {hret }}}{\frac{D_{\text {O_hrt }}}{t_{\text {hrt }}}} & \begin{array}{l}
P_{\text {a_hrt }}=\text { maximum allowable external pressure } \\
\text { on hanger rod extension tube }
\end{array} \\
P_{\text {a_hret }}=476 \mathrm{psi} &
\end{aligned}
$$

The above shows that a 5-inch diameter tube made of 304 stainless steel, 108 inches long with a 0.188 -inch thick wall, can support 476 psig external pressure and satisfy the ASME Code for Class 3 components. This is greater than the design pressure of 390 psig. OK.

Check the hanger rod extension \& transition tubes and the funnel transition tube as cylinders under compressive load due to the external design pressure on the bottom cap and transition funnel (ND-3133.6).

Two equations must be checked:

(1) Calculate the compressive stress and compare to the design allowable stress level.

$$
\begin{aligned}
& \mathrm{F}_{\mathrm{C}}:=\mathrm{P}_{\mathrm{d}} \cdot \frac{\pi}{4} \cdot \mathrm{D}_{\mathrm{O} \_\mathrm{hrt}}{ }^{2} \quad \mathrm{~F}_{\mathrm{C}}=7658 \mathrm{lbf} \\
& \sigma_{\text {hrt_comp }}:=\frac{F_{C}}{\frac{\pi}{4} \cdot\left[D_{\text {o_hrt }}{ }^{2}-\left(D_{\text {o_hrt }}-2 \cdot t_{h r t}\right)^{2}\right]} \\
& \sigma_{\text {hrt_comp }}=2694 \text { psi }
\end{aligned}
$$

(The above is conservative since the design pressure acts only on the transition funnel, and is 100 psig lower on the bottom cap due to the pressure drop across the core.)

The above calculated compressive stress due to the external design pressure on the hanger rod extension \& transition tubes and the funnel transition tube is below the Class 3 allowable stress S of $20 \mathrm{ksi}$ (304 SST) at $240 \mathrm{deg}$. F from Table 2 of the main report body). OK

(2) Use tables:

$$
\begin{aligned}
& A_{\text {hrt_c }}:=\frac{0.125}{D_{0} \text { hrt }} \quad A_{\text {hrt_c }} \text { value used to enter external pressure } \\
& \text { table } \\
& \frac{2}{t_{\text {hrt }}} \quad A_{\text {hrt_c }}=0.009 \\
& B_{\text {hret_c }}:=12300 \cdot p s i \quad B_{\text {hret_c }} \text { from Table HA-1 (Section II, Part }
\end{aligned}
$$

The compressive stress in these tubes is less than the $B_{\text {hret_c }}$ value calculated above. OK 
:Hanger rod extension \& transition tubes and funnel transition tube with a 0.188 -inch wall thickness are acceptable for the compressive stresses caused by the design pressure.

Design Conditions - Internal Pressure: Following the requirements of the ASME Code, ND-3641.1 for piping under internal pressure, the minimum thickness is calculated as follows:

$$
\begin{array}{ll}
\mathrm{E}_{\text {joint }}:=0.80 & \mathrm{E}_{\text {joint }}=\text { weld joint efficiency per Table } 3613.4-1 \\
\mathrm{y}:=0.4 & \mathrm{y}=\text { required coefficient } \\
\mathrm{P}_{\text {des_int }}:=200 \cdot \mathrm{psi} & \mathrm{P}_{\text {des_int }}=\text { internal design pressure } \\
\mathrm{S}_{\mathrm{C} 3 \mathrm{~L}}:=20000 \cdot \mathrm{psi} & \mathrm{S}_{\mathrm{c} 3 \mathrm{~L}}=\text { allowable Class } 3 \text { stress for } 304 \mathrm{~L} \text { pipe } \\
\mathrm{t}_{\min }:=\frac{\mathrm{P}_{\text {des_int }} \mathrm{D}_{\mathrm{O}_{-} \text {hrt }}}{2 \cdot\left(\mathrm{S}_{\mathrm{C} 3 \mathrm{~L}} \cdot \mathrm{E}_{\text {joint }}-\mathrm{P}_{\text {des_int }} \mathrm{y}\right)} & \begin{array}{l}
\mathrm{t}_{\text {min }}=\text { minimum thickness to support the internal } \\
\text { design pressure }
\end{array} \\
\mathrm{t}_{\min }=0.031 \text { in } &
\end{array}
$$

Clearly, the internal pressure is adequately carried by the 0.188 -inch thick extension and transition tubes.

:Hanger rod extension \& transition tubes and funnel transition tube with a 0.188 -inch wall thickness are acceptable for design internal pressure conditions.

In addition to the internal pressure load, the maximum line cylinder load of $6{ }^{*} 600 \mathrm{lbf}$, or $3600 \mathrm{lbf}$, will be applied to these tubes as a tensile load. If this occurs with the external design pressure, it will be entirely negated by that compressive load. Alone, this $3600 \mathrm{lbf}$ tensile load will create the following stress in the transition tubes:

$$
\sigma_{\mathrm{t} \_h r t t}:=\frac{3600 \cdot \mathrm{lbf}}{\pi \cdot \mathrm{D}_{\mathrm{O} \_} \mathrm{hrt} \cdot t_{\mathrm{hrt}}} \quad \sigma_{\mathrm{t} \_ \text {hrtt }}=1219 \mathrm{psi}
$$

$\sigma_{\mathrm{t} \_ \text {hrtt }}=$ tensile stress in hanger rod transition tubes under the maximum line cylinder loading

The above tensile load is very low, expecially when compared to the basic Class 3 allowable stress of $20 \mathrm{ksi}$ for 304 SST materials.

:Hanger rod and funnel transition tubes with a 0.188-inch wall thicknes are acceptable for the maximum cylinder line loads.

Service Level A Conditions: The Service Level A conditions are enveloped by the design conditions.

:Hanger rod extension and transition tubes with a 0.188 -inch wall thickness meet the Level A conditions.

Service Level B Conditions: The Service Level B conditions only include a 10\% increase in external design pressure, or 429 psig. However, the design calculations showed that the allowable external pressure to prevent buckling was: 
$P_{\text {a_hret }}=476 p s i$

which is greater than the 429 psig Level B condition.

:Hanger rod extension and transition tubes with a 0.188 -inch wall thickness meet the Level B conditions.

Service Level C Conditions: The Service Level D conditions only include a $20 \%$ increase in external design pressure, or $468 \mathrm{psig}$. This pressure is also less than the allowable external pressure calculated for design conditions.

:Hanger rod extension and transition tubes with a 0.188 -inch wall thickness meet the Level C conditions.

Service Level D Conditions: The results of the Service Level D conditions evaluation on the hanger rod extension and transition tubes will be discussed in Appendix D.

\section{B2.1.2 Check Capsule Facility Body Thickness}

Because the design external pressure is so much larger than the internal pressure, it is suspected that external pressure will control the design and will therefore be checked first.

Design Conditions - External Pressure: The capsule facility body is made of 304 stainless steel, about 150 inches long, and with an outer diameter of 2.5 inches. About half of the length has a wall thickness of 0.120 inches while the other half has a thickness of 0.188 inches but with thirteen grooves on the inner diameter (referred to as the "in-core pressure boundary tube"). The minimum thickness of this grooved tube is 0.115 inches. It will be conservative to use the minimum thickness of 0.115 inches for the following calculations. Following the requirements of the ASME Code, ND-3133.3 (as directed by ND-3641.2) for tubular products under external pressure:

$$
\begin{array}{ll}
D_{O_{-} c f b}:=2.500 \cdot \text { in } & \begin{array}{l}
D_{o_{-} c f b}=\text { outside diameter of capsule facility } \\
\text { body }
\end{array} \\
t_{c f b}:=0.115 \cdot \text { in } & \begin{array}{l}
t_{c f b}=\text { minimum thickness of capsule facility body } \\
\frac{D_{O_{-} c f b}}{t_{c f b}}=21.7391
\end{array} \\
L_{c f b}:=150 \cdot \text { in } & \begin{array}{l}
L_{c f b}=\text { maximum unsupported length of capsule } \\
\text { facility body - assumed unsupported on its } \\
\text { entire length - very conservative. }
\end{array} \\
\frac{L_{c f b}}{D_{O_{-} c f b}}=60 & \begin{array}{l}
\text { Length-to-diameter ratio } \\
A_{c f b}:=0.0025
\end{array} \\
B_{c f b}:=10500 \cdot p s i & A_{c f b} \text { from Figure G (Section II, Part D) }
\end{array}
$$




$$
\begin{gathered}
P_{\text {a_cfb }}:=\frac{4}{3} \cdot \frac{B_{c f b}}{\frac{D_{D_{-} f b}}{t_{c f b}}} \\
P_{\text {a_cfb }}=644 \mathrm{psi}
\end{gathered}
$$$$
\mathrm{P}_{\mathrm{a}_{\mathrm{C}} \mathrm{ffb}}=\text { maximum allowable external pressure }
$$$$
\text { on capsule facility body }
$$

The above maximum allowable external pressure on the capsule facility body exceeds the ATR design pressure of 390 psig.

:Capsule facility body minimum thickness is sufficient for carrying the design pressure as an external load.

Check the capsule facility as a cylinder under compressive load due to the design pressure on the bottom cap (ND-3133.6).

Two equations must be checked:

(1) Calculate the compressive stress and compare to the design allowable stress level.

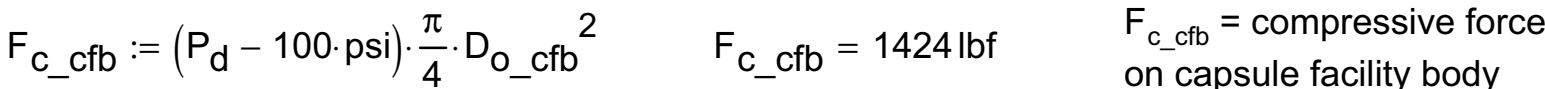

$$
\begin{aligned}
& \sigma_{\mathrm{cfb} \_c o m p}:=\frac{\mathrm{F}_{\mathrm{C} \_\mathrm{cfb}}}{\frac{\pi}{4} \cdot\left[\mathrm{D}_{\mathrm{O} \_\mathrm{cfb}}{ }^{2}-\left(\mathrm{D}_{\mathrm{O} \_\mathrm{cfb}}-2 \cdot \mathrm{t}_{\mathrm{cfb}}\right)^{2}\right]} \quad \sigma_{\mathrm{cfb} \_ \text {comp }}=\text { compressive stress } \\
& \sigma_{\text {cfb_comp }}=1652 \mathrm{psi}
\end{aligned}
$$

The above calculated compressive stress due to the design pressure on the capsule facility body lower cap is below the Class 3 allowable stress S of $20 \mathrm{ksi}$ (304 SST) at $240 \mathrm{deg}$. F (from Table 2 of the main report body). OK

(2) Use tables:

$$
\begin{aligned}
& A_{c f b \_c}:=\frac{0.125}{\underline{D_{\text {o_cfb }}}} \quad \begin{array}{l}
A_{\text {cfb_c }} \\
\text { table }
\end{array} \\
& \frac{2}{t_{c f b}} \\
& A_{\text {cfb_c }}=0.0115 \\
& \mathrm{~B}_{\mathrm{cfb} \_\mathrm{c}}:=12000 \cdot \mathrm{psi} \quad \mathrm{B}_{\mathrm{cfb}_{-} \mathrm{c}} \text { from Table HA-1 (Section II, Part D) }
\end{aligned}
$$

The compressive stress in the capsule facility body is less than the $B_{\text {cfb_c }}$ value calculated above. OK

:Capsule facility body is acceptable for the compressive stresses caused by the design external pressure. 
Design Conditions - Internal Pressure: Following the requirements of the ASME Code, ND-3641.1 for piping under internal pressure, the minimum thickness is calculated as follows:

$$
\begin{aligned}
& E_{\text {joint }}=0.8 \\
& \mathrm{E}_{\text {joint }}=\text { weld joint efficiency per Table 3613.4-1 } \\
& y=0.4 \\
& y=\text { required coefficient } \\
& P_{\text {des_int }}=\text { •psi } \\
& \mathrm{P}_{\text {des_int }}=\text { internal design pressure } \\
& \mathrm{S}_{\mathrm{C} 3}:=20000 \cdot \mathrm{psi} \\
& S_{c 3}=\text { allowable Class } 3 \text { stress for } 304 \text { pipe } \\
& t_{\text {min_i }}:=\frac{P_{\text {des_int }} \cdot D_{O \_h r t}}{2 \cdot\left(S_{c 3} \cdot E_{\text {joint }}-P_{\text {des_int }} \cdot y\right)} \\
& t_{\text {min_i }}=\text { minimum thickness to support the internal } \\
& t_{\min \_i}=0.031 \text { in } \\
& \text { design pressure }
\end{aligned}
$$

Clearly, the internal pressure is adequately carried by capsule facility body.

:Capsule facility body is acceptable for design internal pressure conditions.

Note that the line cylinders, discussed later, may apply a maximum combined tensile load of $600 \mathrm{lbf}{ }^{*} 6$ cylinders, or $3600 \mathrm{lbf}$, to the capsule facility body. If this maximum line cylinder load occurs with the external pressure load, it will entirely negate that axial compressive load. If the line cylinder maximum load occurs alone, the resulting tensile stresses will exist in the capsule facility body:

$$
\begin{array}{r}
\sigma_{\mathrm{cfb} \_c y l i n d e r s}:=\frac{3600 \cdot \mathrm{lbf}}{\pi \cdot D_{\mathrm{o} \_\mathrm{cfb}} \cdot \mathrm{t}_{\mathrm{cfb}}} \\
\sigma_{\mathrm{cfb} \text { cylinders }}=3986 \mathrm{psi}
\end{array}
$$

$\sigma_{\text {cfb_cylinders }}=$ tensile stress in capsule facility body under the line cylinder maximum load

The above maximum tension stress in the capsule faciltiy body under the maximum line cylinder loading is well below the $20 \mathrm{ksi}$ Class 3 basic allowable stress for the 304 SST material.

:Capsule facility body is accepable under the maximum line cylinder tension loading.

Service Level A Conditions: The Service Level A conditions are enveloped by the design conditions.

:Capsule facility body meets the Level A conditions.

Service Level B Conditions: The Service Level B conditions only include a $10 \%$ increase in external design pressure, or 429 psig. However, the design calculations showed that the allowable external pressure to prevent buckling was:

$$
P_{\text {a_cfb }}=644 \text { psi }
$$

which is greater than the 429 psig Level B condition.

:Capsule facility body meets the Level B conditions. 
Service Level C Conditions: The Service Level D conditions only include a $20 \%$ increase in external design pressure, or 468 psig. This pressure is also less than the allowable external pressure calculated for design conditions.

:Capsule facility body meets the Level C conditions.

Service Level D Conditions: The results of the Service Level D conditions evaluation on the capsule facility body will be discussed in Appendix D.

\section{B2.1.3 Check Transition Funnel Thickness}

The 304 stainless steel transition funnel has a 5 -inch outer diameter on one end and a 2.5-inch diameter on the other end, is 0.225 -inches thick, and is 5.375-inches long. Because of the hanger rod alignment plate, welded at the large end of this funnel, the funnel is supported against buckling on that end. The funnel thickness $(0.225$-inch) also exceeds that of the hanger rod tubes (3/16-inch) and the capsule facility body $(0.120$-inch). Therefore, the transition funnel is expected to support a much greater external pressure load than the hanger rod tubes and the capsule facility body. However, the following calculation will assume no support at the large end of the funnel.

Design Conditions - External Pressure: The transition funnel is made of 304 stainless steel. Following the requirements of the ASME Code, ND-3133.4(e) for conical sections under external pressure:

$$
\begin{array}{ll}
D_{\text {If }}:=5.000 \cdot \text { in } & D_{\text {If }}=\text { diameter of funnel large end } \\
t_{\text {If }}:=0.225 \cdot \text { in } & t_{\text {If }}=\text { nominal thickness of funnel } \\
\frac{D_{\text {If }}}{t_{\text {If }}}=22.2222 & \text { Diameter-to-thickness ratio } \\
L_{\text {If }}:=5.375 \cdot \text { in } & L_{\text {If }}=\text { length of funnel. } \\
\frac{L_{\text {If }}}{D_{\text {If }}}=1.075 & \\
A_{\text {If }}:=0.013 & \text { Length-to-diameter ratio } \\
B_{\text {If }}:=125000 \cdot p s i & A_{\text {If }} \text { from Figure G (Section II, Part D) } \\
P_{\text {a If }}:=\frac{4}{3} \cdot \frac{B_{\text {If }}}{D_{\text {If }}} & B_{\text {If }} \text { from Figure HA-1 (Section II, Part D) } \\
t_{\text {If }} & P_{\text {alf }}=\text { maximum allowable external pressure on } \\
\text { transition funnel }
\end{array}
$$

The above maximum allowable external pressure on the transition funnel exceeds the ATR design pressure.

:Transition funnel design is sufficient for carrying the design external pressure. 
Design Conditions - Internal Pressure: The transition funnel must have the required thickness for the internal design pressure, as calculated using ASME Code, ND-3324.9:

$$
\begin{aligned}
& \alpha_{f}:=\tan \left(\frac{\frac{4.550-2.050}{2}}{5.375}\right) \quad \alpha_{f}=13.5701 \mathrm{deg} \quad \alpha_{f}=\text { angle of funnel } \\
& P_{\text {des_int }}=200 \text { psi } \quad P_{\text {des_int }}=\text { internal design pressure } \\
& S_{C 3 L}=20000 \text { psi } \quad S_{c 3 L}=\text { Class } 3 \text { allowable stress for } 304 \\
& E_{\text {joint }}=0.8 \quad E_{\text {joint }}=\text { joint efficiency } \\
& t_{c \_ \text {int }}:=\frac{P_{\text {des_int }} \cdot D_{\text {If }}}{2 \cdot \cos (\alpha) \cdot\left(S_{C 3 L} \cdot E_{\text {joint }}-0.6 \cdot P_{\text {des_int }}\right)} \quad \begin{array}{l}
t_{c_{-} \text {int }}=\text { required thickness for internal } \\
\text { pressure }
\end{array} \\
& \mathrm{t}_{\mathrm{C} \text { _int }}=0.031 \mathrm{in}
\end{aligned}
$$

The above thickness required for carrying the internal design pressure is well below the funnel thickness of 0.225 -in.

:Transition funnel design is acceptable for design internal pressure conditions.

Note that the maximum load of the line cylinders of 6 * $600 \mathrm{lbf}$, or $3600 \mathrm{lbf}$, will also be carried through the funnel. The previous sections showed that the capsule facility body and the hanger rod tubes carried that load with low resulting stresses. The funnel, which is thicker than the attaching tubes, will also carry that load with low resulting tensile stresses. No further calculations will be performed on the funnel under the line cylinder loads.)

Service Level A Conditions: The Service Level A conditions are enveloped by the design conditions.

:Transition funnel meets the Level A conditions.

Service Level B Conditions: The Service Level B conditions only include a $10 \%$ increase in external design pressure, or 429 psig. However, the design calculations showed that the allowable external pressure to prevent buckling was:

$$
\mathrm{P}_{\mathrm{a} \_ \text {If }}=7500 \mathrm{psi}
$$

which is greater than the 429 psig Level B condition.

:Transition funnel meets the Level B conditions.

Service Level C Conditions: The Service Level D conditions only include a $20 \%$ increase in external design pressure, or 468 psig. This pressure is also less than the allowable external pressure calculated for design conditions.

:Transition funnel meets the Level C conditions. 
Service Level D Conditions: The results of the Service Level D conditions evaluation on the transition funnel will be discussed in Appendix D.

\section{B2.1.4 Check Capsule Bottom Cap Thickness}

The bottom cap is solid 304 stainless steel, and clearly very stout when compared to the capsule facility body to which it is attached. Thickness is considered acceptable without further calculations.

\section{B2.2 Check Component Welds}

The in-vessel components are welded together at several locations: hanger rod extension tube to the seal plug, hanger rod extension tube to the hanger rod transition tube, transition tubes together, hanger rod transition tube to the funnel transition tube, funnel transition tube to transition funnel, transition funnel to capsule facility body, capsule facility body welds, capsule facility body to end cap. NB-3661 indicates that because these are piping welds, that the requirements of NB-4200 are in force with girth butt welded joints being either type 1, 2, or 3 (ND-4245).

\section{B2.2.1 Weld: Seal Plug-to-Hanger Rod Extension Tube}

The weld that attaches the hanger rod extension tube to the seal plug is identified as a full penetration groove weld with a 1/4-inch fillet cap (Dwg. 630430). This weld could be viewed as a single butt welded joint with the use of a backing ring (Type 2 per ND-4245, albeit a huge backing ring) with an additional fillet weld. This is considered an acceptable Class 3 weld.

\section{B2.2.2 Welds: Transition Tubes}

The weld that attaches the hanger rod extension tube to the first transition tube, the weld between transition tubes, and the weld between the funnel transition tube and the transition funnel, are identified as full penetration groove welds (Dwg. 630430) ground flush. These welds are Type 2 welds per ND-4245 because of the built-in backing provided by the upper cylinder mounting plates and the push rod alignment plates that span these joints. These are considered acceptable Class 3 welds.

\section{B2.2.3 Weld: Transition Funnel-to-Capsule Facility Body}

The weld that attaches the transition funnel to the capsule facility body is identified as a full penetration groove weld (Dwg. 630430) ground flush. This weld is a Type 3 weld per ND-4245 because of no built-in backing. This is considered an acceptable Class 3 weld.

\section{B2.2.4 Weld: Capsule Facility Body-to-End Cap}

The weld that attaches the capsule facility body to the end cap is identified as a full penetration groove weld (Dwg. 630430) ground flush. This weld is a Type 2 weld per ND-4245 because of the built-in backing provided as part of the end cap. This is considered an acceptable Class 3 weld.

\section{B2.2.5 Welds: Capsule Facility Body}

The weld that connects two pieces of the capsule facility body at the lowest hanger rod alignment plate is a full-penetration groove weld (Dwg. 630430) ground flush. This weld is a Type 2 weld per ND-4245 because of the built-in backing provided by the alignment plate that spans this joint. This is considered an acceptable Class 3 weld. 


\section{B2.3 Calculate Flow-Induced Loads}

The capsule facility body will see reactor coolant flow in cross flow and paralled flow as follows.

\section{B2.3.1 Coolant Cross Flow}

Coolant flow occurs in a cross flow orientation from the top of the core to a maximum level of 4.5 feet above the core, at a rate of 5.5 feet/second (Ref.'s B5 \& B6). However, the capsule facility body is within the chopped dummy in-pile tube in that region. [The chopped dummy in-pile tube (Ref. Dwg. 443027) begins 2 inches above the locater tie (which is at 4-feet and 7 -inches above the top of the core) and passes through the 4-ft. long core section and on another 12 feet.] The chopped dummy in-pile tube is a 3-inch Sch. 160 aluminum pipe, machined to include external fins and through slots, as well as other features. It is expected that any loading due to coolant cross flow on the chopped dummy in-pile tube will be supported by the tube itself, and that transfer of any such loading to the AGC-1 capsule facility body will be negligibly small.

:Loading on the capsule facility body due to coolant cross flow is negligible.

\section{B2.3.2 Coolant Parallel Flow}

Coolant flow will occur between the outside of the AGC-1 capsule facility body and the inside diameter of the chopped dummy in-pile tube in a parallel flow orientation. This will create two loadings on the capsule facility body: transverse loading due to vibration, and flow drag.

Vibration: The radial gap between the capsule facility body and the chopped dummy in-pile tube is 0.062 -inches. (Actually, as far as the capsule body is concerned, spacers on the body will eliminate the gap at regular intervals.) The in-vessel portion of this experiment (hanger rod extension and transition tubes and the capsule facility body) is about 24-1/2 feet long and is suspended from the top head seal plug. In this configuration, the assembly looks like a very long cantilever beam fixed at the top end and free until it enters the chopped dummy in-pile tube. At that point, the capsule facility body is regularly supported in all transverse directions, with a 0.062-inch radial gap between supports. This small gap will limit the vibration potential of the assembly due to parallel-flowing coolant and the resulting stresses to negligible levels.

:Vibration due to parallel flow is not considered a problem.

Flow Drag: The coolant flowing parallel to the capsule facility body will create a drag force. The magnitude of that force will be estimated as follows (Ref. B7):

$$
\begin{array}{ll}
\rho_{\mathrm{C}}:=9.34 \cdot 10^{-5} \cdot \frac{\mathrm{lbf} \cdot \mathrm{sec}^{2}}{\mathrm{in}^{4}} & \begin{array}{l}
\rho_{\mathrm{c}}=\text { mass density of coolant (at } 240 \mathrm{~F} \text { under } \\
\text { pressure) }
\end{array} \\
\mathrm{V}_{\mathrm{C}}:=27.1 \cdot \frac{\mathrm{ft}}{\mathrm{sec}} & \mathrm{V}_{\mathrm{c}}=\text { velocity of coolant (Ref. B8) }
\end{array}
$$


$\mathrm{L}_{\text {total }}:=134.75 \cdot \mathrm{in}$

$\mu_{\mathrm{c}}:=3.472 \cdot 10^{-8} \cdot \mathrm{lbf} \cdot \frac{\mathrm{s}}{\mathrm{in}^{2}}$

$\mathrm{R}_{\mathrm{el}}:=\frac{\rho_{\mathrm{c}} \cdot \mathrm{V}_{\mathrm{c}} \cdot \mathrm{L}_{\text {total }}}{\mu_{\mathrm{c}}}$

$$
\mathrm{R}_{\mathrm{el}}=117881722
$$

$\mathrm{C}_{\mathrm{D}}:=\frac{0.074}{\mathrm{R}_{\mathrm{el}}{ }^{0.2}}$

$C_{D}=0.0018$

$A_{D}:=\pi \cdot D_{\text {O_cfb }} \cdot L_{\text {total }}$

$$
A_{D}=1058 \mathrm{in}^{2}
$$

$F_{\text {Drag }}:=\frac{1}{2} \cdot C_{D} \cdot \rho_{C} \cdot V_{C}^{2} \cdot A_{D}$

$F_{\text {Drag }}=9.4 \mathrm{lbf}$
$\mathrm{L}_{\text {total }}=$ total length of capsule facility body subject to parallel flow (57 in. above core, 48 in. through core, 29.75 in. below core)

$\mu_{\mathrm{c}}=$ dynamic viscosity of coolant (liquid at $240 \mathrm{~F}$ )

$\mathrm{R}_{\mathrm{el}}=$ Reynold's number

A Reynold's number of less than $5 \times 10^{5}$ is laminar in flow, turbulent in flow if greater. The Reynold's number calculated is clearly turbulent.

$C_{D}=$ drag coefficient (Ref. B7, Eqn. 7.18)

$A_{D}=$ drag area (surface area of capsule body)

$F_{\text {Drag }}=$ drag force

The above flow drag force will create the following tensile stress in the capsule facility body:

$$
\begin{gathered}
\sigma_{\text {Drag }}:=\frac{F_{\text {Drag }}}{\frac{\pi}{4} \cdot\left[D_{O_{-} \mathrm{cfb}}{ }^{2}-\left(D_{O_{-} \mathrm{cfb}}-2 \cdot \mathrm{t}_{\mathrm{cfb}}\right)^{2}\right]} \quad \begin{array}{l}
\sigma_{\text {Drag }}=\text { capsule facility body tensile } \\
\text { stress due to drag force }
\end{array} \\
\sigma_{\text {Drag }}=11 \mathrm{psi}
\end{gathered}
$$

This tensile stress in the capsule facility body due to the parallel flow-induced drag force is negligible.

:Loading on the capsule facility body due to coolant parallel flow is negliglble. 


\section{B3. ATR Gas Lines and Hanger Rod Assembly (out-of-reactor) Components (B31.1 Evaluation)}

\section{B3.1 Gas System Lines}

The gas system is not designed at this stage but will be in the future. The only evaluation of the gas system that will be performed herein is a check for the minimum required wall thickness for the tubing (Dwg. 630430) that will run through the seal plug, through the hanger rod extension and transition sections, and into the capsule facility capsule. Only design conditions will be evaluated. This tubing is specified as 304L SST.

$$
\begin{array}{ll}
D_{0 \_g}:=0.0625 \cdot \text { in } & D_{o \_g}=\text { gas tubing O.D. } \\
t_{g}:=0.010 \cdot \text { in } & t_{g}=\text { tubing wall thickness } \\
P_{d \_g}:=250 \cdot p s i & P_{d \_g}=\text { gas system design pressure } \\
S_{g}:=12800 \cdot p s i & S_{g}=\text { allowable stress for 304L SST at } 240 \mathrm{~F}, \\
y_{g}:=0.4 & \text { per ASME B31.1 (Ref. 9) } \\
E_{g}:=1.0 & y_{g}=\text { per ASME B31.1 Table 104.1.2(A) } \\
\left.t_{m}:=\frac{P_{d} g}{2 \cdot\left(S_{g} \cdot E_{g}+P_{d} \_g\right.} \cdot y_{g}\right) & E_{g}=\text { joint effeciency, assume 1 } \\
t_{m}=0.0006 \text { in } & t_{m}=\text { minimum thickness to support the design } \\
\text { pressure, eqn. (3) per ASME B31.1 }
\end{array}
$$

The minimum thickness $t_{m}$ to support the design pressure is less than the actual thickness $t_{g}$.

:Gas system 1/6-inch diameter by 0.010 -inch thick tubing is acceptable under design conditions.

\section{B3.2 Hanger Rod Assembly (out-of-reactor)}

No evaluation on the hanger rod assembly outside of the reactor will be performed because the design conditions do not provide any appreciable loading conditions. Connections for gas lines and other components are contained within that assembly. The appropriate time for any evaluation of those components would be when the gas system design has been completed. 


\section{B4. Other Component Evaluations}

The following components are inside of the pressure boundary of this design. Therefore, the ASME Code requirements do not have to be met for these components (though they may be used to judge component adequacy in performing the intended functions).

\section{B4.1 Evaluate Components Under Upper Cylinder Loads}

Inside of the capsule facility are pnumatic line cylinders. The components that are loaded by these line cylinders are as follows:

-upper cylinder mounting plates (to be evaluated after the push rods)

-upper push bar

-load cell attachment bolt and load cell

-upper push rod

-compressed specimen stack (graphite push rod, specimen stack)

-graphite specimen separators (stop blocks)

-lower graphite specimen holder

-lower graphite spacer

-capsule bottom plate

-lower spacer tube

-capsule bottom cap

This section will evaluate these components under the upper cylinder loadings.

\section{B4.1.1 Upper Push Bars}

Calculate line cylinder force

$$
\begin{aligned}
& \mathrm{PF}:=2.4 \cdot \mathrm{in}^{2} \\
& \mathrm{P}_{\text {ulc }}:=250 \cdot \mathrm{psi} \\
& \mathrm{F}_{\text {ulc }}:=\mathrm{PF} \cdot \mathrm{P}_{\mathrm{ulc}} \\
& \mathrm{F}_{\text {ulc }}=600 \mathrm{lbf} \\
& \Delta_{\text {off }}:=0.695 \cdot \mathrm{in}
\end{aligned}
$$

$\mathrm{PF}=$ power factor (the piston area) of the upper line cylinder (1-3/4" Bimba Original Line cylinder, SR-242-P-V)

$\mathrm{P}_{\mathrm{ulc}}=$ upper line cylinder maximum allowable working pressure (per manufacturer)

$\mathrm{F}_{\mathrm{ulc}}=$ line cylinder maximum output force at the maximum allowable working pressure

$\Delta_{\text {off }}=$ distance between line cylinder centerline and push rod centerline

Calculate push bar area and section modulus

$$
\begin{aligned}
& \mathrm{L}_{\mathrm{pb}}:=0.695 \cdot \mathrm{in} \\
& \mathrm{W}_{\mathrm{pb}}:=0.5 \cdot \mathrm{in} \\
& \mathrm{R}_{\mathrm{pb}}:=0.25 \cdot \mathrm{in}
\end{aligned}
$$

$\mathrm{L}_{\mathrm{pb}}=$ length of push bar cross-section minus the radius ends

$\mathrm{W}_{\mathrm{pb}}=$ overall width of push bar cross-section

$\mathrm{R}_{\mathrm{pb}}=$ radius of push bar cross-section ends 


$$
\begin{gathered}
A_{p b}:=L_{p b} \cdot W_{p b}+\pi \cdot R_{p b}{ }^{2} \\
A_{p b}=0.5438 \mathrm{in}^{2} \\
Z_{p b}:=\frac{W_{p b} \cdot\left(L_{p b}+2 \cdot R_{p b}\right)^{2}}{6} \\
Z_{p b}=0.119 \mathrm{in}^{3}
\end{gathered}
$$

$A_{p b}=$ area of push bar

$\mathrm{Z}_{\mathrm{pb}}=$ approximate section modulus of push bar (This value is slightly non-conservative, but will be considered acceptable if the bending stress in the push bar is low.)

Calculate stresses in push bar

$$
\begin{aligned}
& \sigma_{\text {a_pb }}:=\frac{F_{\text {ulc }}}{A_{p b}} \\
& \sigma_{\mathrm{a} \_p b}=\text { axial stress in push bar } \\
& \sigma_{\text {a_pb }}=1103 \mathrm{psi} \\
& \sigma_{\mathrm{b} \_\mathrm{pb}}:=\frac{\mathrm{F}_{\text {ulc }} \cdot \Delta_{\text {off }}}{\mathrm{Z}_{\mathrm{pb}}} \\
& \sigma_{b \_p b}=3504 \text { psi } \\
& \sigma_{\mathrm{pb}}:=\sigma_{\mathrm{a} \_\mathrm{pb}}+\sigma_{\mathrm{b} \_\mathrm{pb}} \\
& \sigma_{\mathrm{pb}}=\text { maximum combined stress in push bar } \\
& \sigma_{\mathrm{pb}}=4607 \mathrm{psi} \\
& \sigma_{\mathrm{b} \_\mathrm{pb}}=\text { bending stress in push bar }
\end{aligned}
$$

The above maximum combined stress in the upper push bar is well below the yield strength of 304 SST ( $23.9 \mathrm{ksi}$ ) at $240 \mathrm{deg} . \mathrm{F}$ (see Table 2 in report main body). (No buckling calculation will be performed because these bars are so short - just under 17 inches long.)

:Upper push bars are acceptable.

What force might be lost through friction as the push bar passes through the mounting/alignment plates?

Summing moments about one of the plates and equating to zero, the horizontal reaction force on the next plate is:

$$
\begin{aligned}
& F_{r \_p b}:=\frac{F_{\text {ulc }} \cdot \Delta_{\text {off }}}{12 \cdot \mathrm{in}} \\
& F_{\text {r_pb }}=34.75 \mathrm{lbf}
\end{aligned}
$$

$F_{r_{-} p b}=$ reaction force on plate 12 inches away from first plate 
Summing horizontal forces gives the same horizontal reaction force at the first plate. The loss due to friction would then be:

$$
\begin{aligned}
\mu_{\mathrm{pb}}:=0.25 & \begin{array}{l}
\mu_{\mathrm{pb}}=\text { coefficient of friction between the push } \\
\text { bar and the mounting/alignment plate assuming } \\
\text { a very smooth finish on each component }
\end{array} \\
\mathrm{F}_{\text {loss }}:=2 \cdot \mathrm{F}_{\mathrm{r} \_\mathrm{pb}} \cdot \mu_{\mathrm{pb}} & \mathrm{F}_{\text {loss }}=\text { total loss of force due to friction } \\
\mathrm{F}_{\text {loss }}=17 \mathrm{lbf} &
\end{aligned}
$$

The above loss in each line cylinder force due to friction on the push bar is acceptably small.

\section{B4.1.2 Load Cell Atachment Bolts and Load Cells}

Each load cell attachment bolt and load cell will see the maximum line cylinder axial loading of $600 \mathrm{lbf}$. The minimum cross-section is in the 1/2-inch threads (13 threads per inch) of the load cell and bolt. The compressive stress on this cross-section is:

$$
\begin{array}{cl}
A_{\min }:=0.1419 \cdot \text { in }^{2} & A_{\min }=\text { tensile stress area } \\
\sigma_{\text {Ica_bolt }}:=\frac{F_{\text {ulc }}}{A_{\min }} & \begin{array}{l}
\sigma_{\text {Ica_bolt }}=\text { compressive stress in bolt/load cell } \\
\text { at } 1 / 2 \text {-inch thread cross-section }
\end{array} \\
\sigma_{\text {Ica_bolt }}=4228 \mathrm{psi} &
\end{array}
$$

The above compressive stress on a 304 SST attachment bolt is low (yield is $23.9 \mathrm{ksi}$ at $240 \mathrm{~F}$, see Table 2 of report main body.) The load cells are rated for 2000 lbf.

:Load cell attachment bolts and load cells are acceptable.

\section{B4.1.3 Upper Push Rods}

Because the upper push bars pass through two mounting/alignment plates, the moment caused by the offset line cylinder has been reacted out at these two plates. Only the upper cylinder axial force is applied to the upper push rods.

$$
\mathrm{D}_{\mathrm{pr}}:=0.563 \cdot \mathrm{in}
$$

$D_{\mathrm{pr}}=$ diameter of push rods through most of

$$
\mathrm{L}_{\text {Ipr }}:=77.261 \cdot \text { in }
$$
length (only the bottom 0.333 inches of rod is reduced to 0.472 inches in diameter.

$$
\mathrm{L}_{\mathrm{spr}}:=65.483 \cdot \mathrm{in}
$$

$$
\begin{aligned}
& L_{l p r}=\text { length of long push rods } \\
& L_{s p r}=\text { length of short push rods }
\end{aligned}
$$

The longest unsupported length of these push rods is between the alignment plate at the top of the transition funnel and the alignment plate in the capsule facility body, at 35.375 inches. First, check these push rods for buckling.

$$
\begin{array}{ll}
\mathrm{L}_{\mathrm{S} \_ \text {eff }}:=35.375 \cdot \text { in } & \mathrm{L}_{\mathrm{s}_{-} \text {eff }}=\text { maximum unsupported push rod } \\
\text { length }
\end{array}
$$




$$
\begin{array}{cl}
\mathrm{A}_{\mathrm{pr}}:= & \frac{\pi}{4} \cdot \mathrm{D}_{\mathrm{pr}}^{2} \\
\mathrm{~A}_{\mathrm{pr}}=0.2489 \mathrm{in}^{2} & \mathrm{~A}_{\mathrm{pr}}=\text { area of push rods } \\
\mathrm{I}_{\mathrm{pr}}:= & \frac{\pi}{64} \cdot \mathrm{D}_{\mathrm{pr}}^{4} \\
\mathrm{I}_{\mathrm{pr}}=0.0049 \mathrm{in}^{4} & \mathrm{I}_{\mathrm{pr}}=\text { moment of inertia of push rods } \\
\mathrm{r}_{\mathrm{pr}}:= & \left(\frac{\mathrm{I}_{\mathrm{pr}}}{\mathrm{A}_{\mathrm{pr}}}\right)^{\frac{1}{2}} \quad \mathrm{r}_{\mathrm{pr}}=\text { radius of gyration of push rods } \\
\mathrm{r}_{\mathrm{pr}}=0.1407 \mathrm{in} &
\end{array}
$$

$$
K_{f}:=0.75
$$$$
\mathrm{K}_{\mathrm{f}} \cdot \frac{\mathrm{L}_{\mathrm{s} \_ \text {eff }}}{\mathrm{r}_{\mathrm{pr}}}=188
$$

$\mathrm{K}_{\mathrm{f}}=$ end condition factor [Ref. 10, AISC ASD Table C-C2.1, average of case (a) and case $(d)]$

$\mathrm{KL} / \mathrm{R}$ is a slenderness ratio

$$
F_{y}:=23900 \cdot p s i
$$

$F_{y}=$ yield strength of 304 SST at 240 deg. $F$

$$
E=27400000 p s i
$$

$E=$ modulus of elasticity at 240 deg. $F$

$$
\begin{gathered}
C_{C}:=\left(2 \cdot \pi^{2} \cdot \frac{E}{F_{y}}\right)^{\frac{1}{2}} \\
C_{C}=150
\end{gathered}
$$

$\mathrm{C}_{\mathrm{c}}=$ comparison equation against the slenderness ratio to dertermine the applicable equation for limiting compressive stresses

Because $\mathrm{KL} / \mathrm{r}>\mathrm{Cc}$, the following equation applies to limit the compressive stress in the push rods to prevent buckling.

$$
\begin{gathered}
\mathrm{F}_{\mathrm{a}}:=12 \cdot \pi^{2} \cdot \frac{\mathrm{E}}{23 \cdot\left[\left(\mathrm{K}_{\mathrm{f}}\right) \cdot \frac{\mathrm{L}_{\mathrm{s} \_\mathrm{eff}}}{\mathrm{r}_{\mathrm{pr}}}\right]^{2}} \\
\mathrm{~F}_{\mathrm{a}}=3971 \mathrm{psi}
\end{gathered}
$$

$\mathrm{F}_{\mathrm{a}}=$ maximum allowable compressive stress in rods to prevent buckling 
The maximum load on these push rods is $600 \mathrm{lbf}$ of compressive force (see above).

$$
\begin{array}{ll}
\mathrm{F}_{\mathrm{ulc}}=600 \mathrm{lbf} & \mathrm{F}_{\mathrm{ulc}}=600 \mathrm{lbf} \text { push rod force } \\
\sigma_{\mathrm{upr}}:=\frac{\mathrm{F}_{\mathrm{ulc}}}{\mathrm{A}_{\mathrm{pr}}} \quad \sigma_{\mathrm{upr}}=2410 \mathrm{psi} & \begin{array}{l}
\sigma v_{\mathrm{pr}}=\text { compressive stress in push rod due to } \\
600 \mathrm{lbf} \text { load }
\end{array}
\end{array}
$$

The above axial stress in the upper push bars $\left(\sigma_{\mathrm{upr}}\right)$ is below the value above which buckling would occur $\left(F_{a}\right)$.

:Upper push rods are acceptable.

\section{B4.1.4 Upper Cylinder Mounting Plates}

The two upper cylinder mounting plates (Dwg. 630428), which are 4.800-inch diameter 1/4-inch thick 304 SST plate, with three1-inch diameter mounting holes, three 0.625 -inch diameter air line holes, one 0.750 -inch diameter center hole, and three slots for push bars (lower plate only), sits on a small ledge in the end of the hanger rod extension and transition tubes. This positioning causes the upper cylinder mounting plate to act as a backing ring for the butt weld that joins a hanger rod extension tube to a transition tube or that joins the two transition tubes.

The bearing stress on the plate and tube ledges under the load of three upper cylinders applying $600 \mathrm{lbf}$ on their respective push rods is:

$$
\begin{gathered}
\sigma_{\text {ucmp_b }}:=\frac{3 \cdot F_{\text {ulc }}}{\frac{\pi}{4} \cdot\left[(4.800 \cdot \mathrm{in})^{2}-\left(D_{\mathrm{O}_{-} \mathrm{hrt}}-2 \cdot \mathrm{thrt}^{2}\right]\right.} \quad \sigma_{\text {ucmp_b }}=\text { bearing stress on ledge } \\
\sigma_{\text {ucmp_b }}=1382 \mathrm{psi}
\end{gathered}
$$

The above bearing stress is negligible. Bearing stress is not a problem.

The bending stress in the plate due to the load of the three upper cylinders applying $600 \mathrm{lbf}$ on their respective push bars/push rods, will be evaluated using finite element methods.

The mounting plate was modeled and evaluated in ABAQUS/Standard Version 6.4-1 running on computer "Tomcat" (see Appendix A for validation documentation and Appendix $E$ for the model file) using 2,828 solid elements (type C3D8R, 4 through the thickness), with the middle of the outside edge simply supported, and with $600 \mathrm{lbf}$ applied on the three mounting holes (1800 lbf total). 
The results show that the highest von Mises stress is at 15,080 psi and occurs at the ligaments between the three slots and the center hole (on the surface only) and at the perimeter weld. The bulk of the plate experiences von Mises stresses that are 10,000 psi or less. This is below the yield strength of 304 SST of $23.9 \mathrm{ksi}$ (at $240 \mathrm{~F}$, see Table 2 of main report) and is considered acceptable.

:Upper cylinder mounting plates are acceptable under the maximum 3 * $600 \mathrm{lbf}$ max. line cylinder loading.

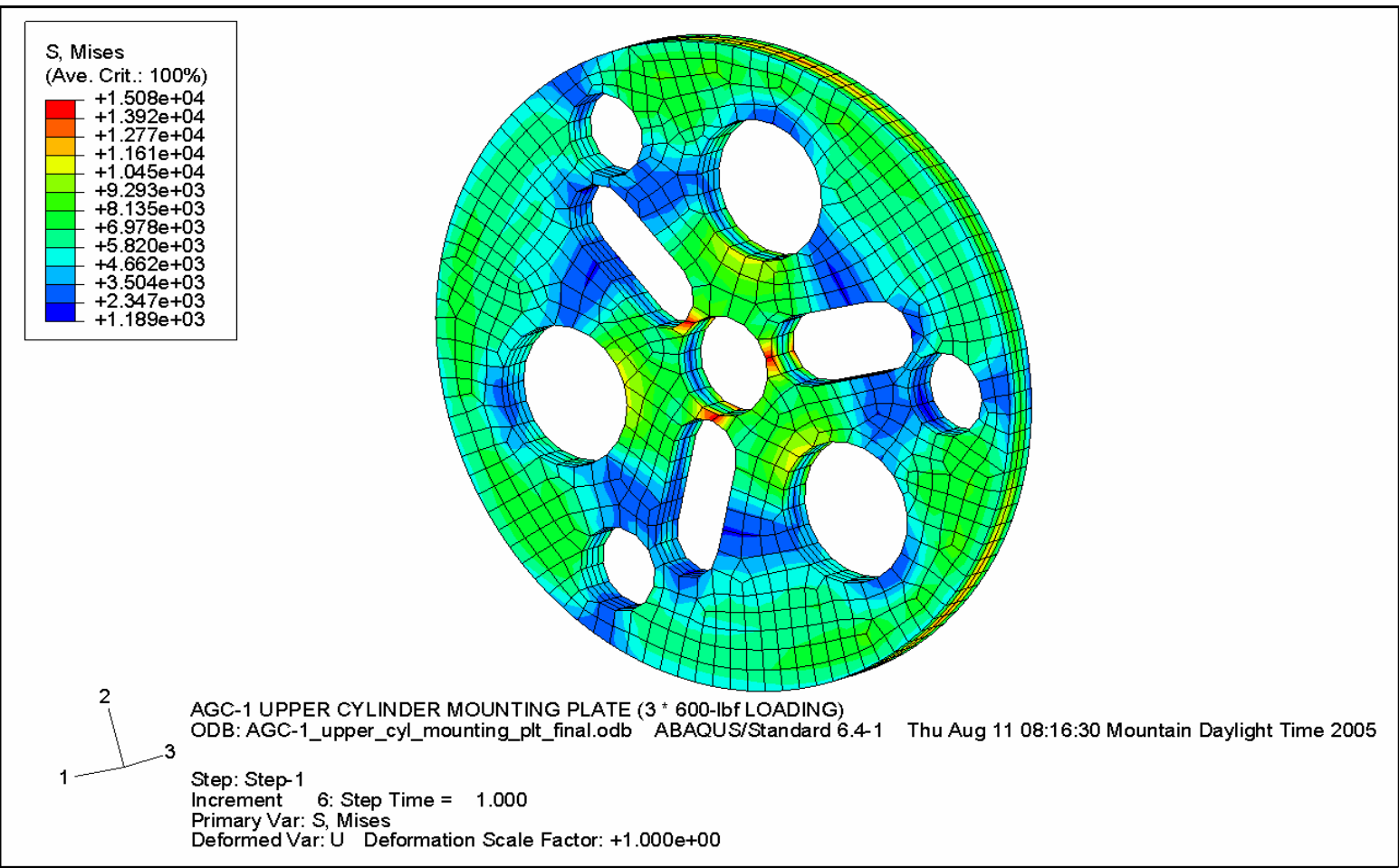

Upper cylinder mounting plate (lower plate).

\section{B4.1.5 Specimen Stack - Graphite Push Rods and Specimens}

Upper Graphite Push Rods

An upper graphite push rod (dwg. 630427, 0.500-inch O.D., 15.431-inches long) is positioned in the upper graphite specimen holder on each of the six compressed specimen stacks such that the top of a graphite pushrod is about 3-3/4 inches below the top of the holder. This places 15-inches of the graphite push rod in a cylindrical hole that is 0.505 -inches in diameter. Because of this positioning, the bottom about 5 inches of this graphite push rod is below the top of the reactor core. Each push rod will experience a compressive force equal to the maximum output of an upper line cylinder, or $600 \mathrm{lbf}$. 
Check bearing stress in the graphite rod where the upper stainless steel push rod contacts it:

$$
\begin{aligned}
& D_{\text {upr_c }}:=0.472 \cdot \text { in } \\
& D_{\text {ugpr_od }}:=0.500 \cdot \text { in } \\
& D_{\text {ugpr_idb }}:=0.285 \cdot \text { in } \\
& D_{\text {ugpr_id }}:=0.252 \cdot \text { in } \\
& A_{\text {ugpr_overlap }}:=\frac{\pi}{4} \cdot\left(D_{\text {upr_c }}{ }^{2}-D_{\text {ugpr_idb }}{ }^{2}\right) \\
& A_{\text {ugpr_overlap }}=0.1112 \text { in }^{2} \\
& \sigma_{\text {ugpr_b }}:=\frac{F_{\text {ulc }}}{A_{\text {ugpr_overlap }}} \\
& \sigma_{\text {ugpr_b }}=5397 \text { psi }
\end{aligned}
$$

$D_{\text {upr_c }}=$ diameter of upper steel push rod at the end that contacts the graphite push rod

$D_{\text {ugpr_od }}=$ O.D. of upper graphite push $\operatorname{rod}$

$D_{\text {ugpr_idb }}=$ I.D. of upper graphite push rod at contacting (bearing) end

$D_{\text {ugpr_id }}=$ I.D. in main body of upper graphite push rod

$\mathrm{A}_{\text {ugpr_overlap }}=$ area of overlap for bearing contact on graphite rod

$\sigma_{\text {ugpr_b }}=$ bearing stress in upper graphite push rod

The compressive strength of this graphite (POCO AXF-5Q) at room temperature is 20,000 psi (per Table 4 of report main body). Therefore, at room temperature (70 deg. $F$ ) this bearing stress is well below the compressive strength. Per Reference 6 of the report main body, the compressive strength will increase (to almost double the room temperature value) with increasing temperature up to about $2500 \mathrm{deg}$. C.

Check the main body compressive stress in the upper graphite push rod:

$$
\begin{gathered}
A_{\text {ugpr }}:=\frac{\pi}{4} \cdot\left(D_{\text {ugpr_od }}{ }^{2}-D_{\text {ugpr_id }}{ }^{2}\right) \\
A_{\text {ugpr }}=0.1465 \text { in }^{2} \\
\sigma_{\text {ugpr }}:=\frac{F_{\text {ulc }}}{A_{\text {ugpr }}} \\
\sigma_{\text {ugpr }}=4096 \mathrm{psi}
\end{gathered}
$$$$
\sigma_{\text {ugpr }}=\text { compressive stress in main }
$$$$
\text { body of upper graphite push rod }
$$$$
\mathrm{A}_{\mathrm{ugpr}}=\text { area of upper graphite push rod }
$$$$
\text { through the main body }
$$ 
The above compressive stress in the main body of the upper graphite push rod is well below the compressive strength at room temperature (70 deg. F) of 20,000 psi (per Table 4 of report main body). The lower end of this push rod may be heated because it is just below the top of the core. However, the compressive strength increases with increasing temperature to about $2500 \mathrm{deg}$. C. This push rod is acceptable.

Check buckling in the upper graphite push rod:

The graphite push rod cannot buckle in the classical column buckling mode because it is basically supported at its outer diameter (with a 0.0025-inch radial gap) through its entire length. Additionally, the ratio of the outer radius to the thickness is 2 , indicating that this looks like a very thick-walled member which would be not be subject to local wall buckling. Column buckling and local wall buckling at compressive stresses well below the material compressive strength are not a concern.

:Graphite push rods are acceptable.

\section{Graphite Specimens}

The purpose of this experiment is to place a load on the graphite specimens for a period of time and evaluate the creep. The compressive stress on the specimens due to the $600 \mathrm{lbf}$ line cylinder load is:

$$
\begin{aligned}
& D_{\text {CS }}:=0.501 \cdot \text { in } \\
& D_{c s}=\text { average diameter of specimen } \\
& \mathrm{A}_{\mathrm{CS}}:=\frac{\pi}{4} \cdot \mathrm{D}_{\mathrm{CS}}{ }^{2} \\
& \mathrm{~A}_{c s}=\text { area of specimen } \\
& A_{c s}=0.1971 \mathrm{in}^{2} \\
& \sigma_{\mathrm{CS}}:=\frac{\mathrm{F}_{\text {ulc }}}{\mathrm{A}_{\mathrm{CS}}} \\
& \sigma_{\mathrm{cs}}=\text { compressive stress on specimen } \\
& \sigma_{\mathrm{cs}}=3044 \mathrm{psi} \\
& \mathrm{F}_{\text {ulc }}=600 \mathrm{lbf}
\end{aligned}
$$

The target maximum stress for these specimens is 3000 psi. This is acceptable. 


\section{B4.1.6 Specimen Separators (Stop Blocks)}

The specimen separators transfer the upper line cylinder load into the top of the lower graphite specimen holder. The specimen separator, or stop block, will experience a compressive stress through the main body as well as a bearing stress on the ledge in the lower graphite specimen holder.

$$
\begin{aligned}
& D_{\text {sb_min }}:=0.472 \cdot \text { in } \\
& \mathrm{D}_{\mathrm{sb} \_ \text {min }}=\text { minimum diameter of block } \\
& D_{\text {sb_max }}:=0.625 \cdot \text { in } \\
& D_{s b \_m a x}=\text { maximum diameter of block } \\
& D_{\text {lgsh_th }}:=0.506 \cdot \text { in } \\
& D_{\text {lgsh_th }}=\text { hole diameter in lower graphite } \\
& A_{s b \_c}:=\frac{\pi}{4} \cdot D_{s b \_m i n}{ }^{2} \\
& A_{s b \_c}=\text { stop block area for compressive } \\
& A_{s b \_c}=0.175 \mathrm{in}^{2} \\
& \text { stresses } \\
& A_{s b \_b}:=\frac{\pi}{4} \cdot\left(D_{\text {sb_max }}{ }^{2}-D_{\text {lgsh_th }}{ }^{2}\right) \\
& A_{\text {sb_b }}=0.1057 \mathrm{in}^{2} \\
& \sigma_{\text {sb_c }}:=\frac{F_{\text {ulc }}}{A_{\text {sb_c }}} \\
& \sigma_{\text {sb_c }}=3429 \mathrm{psi} \\
& \sigma_{\text {sb_b }}:=\frac{F_{\text {ulc }}}{A_{\text {sb_b }}} \\
& \sigma_{s b \_b}=\text { maximum bearing stress in stop } \\
& \sigma_{\text {sb_b }}=5676 p s i
\end{aligned}
$$

The above compressive and bearing stresses in the stop block are well below the compressive strength at room temperature (70 deg. F) of 20,000 psi (per Table 4 of report main body). Per Reference 6 of the report main body, the compressive strength will increase (to almost double the room temperature value) with increasing temperature up to about 2500 deg. C.

:Specimen separators (stop blocks) are acceptable. 


\section{B4.1.7 Lower Graphite Specimen Holder}

The lower graphite specimen holder will carry the load from six upper line cylinders through the stop blocks to the lower graphite spacer. The bearing stress on the lower graphite specimen holder is that calculated for the stop blocks. Additionally, the compressive stress through the main body of the lower graphite specimen holder will be lower than the bearing stress.

:Lower graphite specimen holder is acceptable.

\section{B4.1.8 Lower Graphite Spacer}

The lower graphite spacer will carry the load from the six upper line cylinders (applied through the lower graphite specimen holder). This spacer is below the reactor core and will be cooler and is somewhat thicker (larger outer envelope diameter) than the specimen holder. Therefore, because the compressive stresses in the lower graphite specimen holder were acceptable, those compressive stresses in the main body of the lower graphite spacer will also be acceptable.

The lower graphite spacer rests on the capsule bottom plate. The capsule bottom plate is flat, with channels cut into it for gas flow purposes. Most of the area of the bottom surface of the lower graphite spacer will be supported by the bottom plate, thus minimizing the bearing stresses. (For comparative purposes, the bearing area of the lower graphite spacer on the bottom plate is, by inspection, much greater than the total bearing area of the six specimen separators. Therefore, the bearing stress on the bottom of the lower graphite separator will be less than that of the specimen separators - which stress was shown acceptable.)

:Lower graphite spacer is acceptable.

\section{B4.1.9 Capsule Bottom Plate}

As discussed in the previous section, the lower graphite spacer rests on the capsule bottom plate. The bottom plate sits on a ledge in the top of the lower spacer tube which is supported by the bottom cap. The capsule bottom plate (Dwg. 630428) is 3/4-inches thick, made of 304 SST, and has an O.D. of 2.148-inches, six through holes at 0.313 -inches diameter (one under each perimeter specimen stack), and six outside perimeter slots of a 0.095 -inch radius.

The outer diameter-to-thickness ratio $(2.148$ / 0.75) for the bottom plate is less than 3 , which means that it will respond to the load from the six upper line cylinders through the lower graphite spacer with negligible bending. Compressive stresses will also be small. The only stress of significance on this bottom plate will be in bearing where it sits on the ledge in the lower spacer tube. The bearing stress is calculated as follows:

$$
\begin{array}{ll}
D_{\text {O_Ist }}:=2.230 \cdot \text { in } & D_{\text {o_lst }}=\text { outside diameter of lower spacer tube } \\
D_{\text {o_bp }}:=2.148 \cdot \text { in } & D_{\text {o_bp }}=\text { outside diameter of bottom plate } \\
D_{\text {i_lst }}:=2.010 \cdot \text { in } & D_{\text {i_lst }}=\text { inside diameter of spacer tube }
\end{array}
$$




$$
\begin{array}{cl}
\sigma_{\text {Ist_b }}:=\frac{6 \cdot F_{\text {ulc }}}{\frac{\pi}{4} \cdot\left(D_{\text {o_bp }}{ }^{2}-D_{i \_l s t}{ }^{2}\right)} & \begin{array}{l}
F_{\text {ulc }}=600 \mathrm{lbf} \\
\sigma_{\text {Ist } b}=\text { bearing stress on lower spacer tube } \\
\text { ledge for the bottom plate }
\end{array} \\
\sigma_{\text {Ist_b }}=7988 \mathrm{psi} &
\end{array}
$$

The capsule bottom plate and the lower spacer tube are made of 304 SST which has a minimum yield strength of $23.9 \mathrm{ksi}$ at $240 \mathrm{deg}$. F. The above bearing stress is below that yield strength.

:Capsule bottom plate is acceptable.

\section{B4.1.10 Lower Spacer Tube}

The lower spacer tube will be loaded by the force of all six upper cylinders through the bottom plate and into the top ledge in the tube. This will cause bearing stresses on the ledge and compressive stresses in the tube. The previous section showed that the bearing stresses were acceptably low. The lower spacer tube is made of 304 SST.

Check buckling in the lower spacer tube under the six upper line cylinder loads:

$$
\begin{aligned}
& \sigma_{\text {Ist_c }}:=\frac{6 \cdot F_{\text {ulc }}}{\frac{\pi}{4} \cdot\left(D_{\text {o_lst }}{ }^{2}-D_{\text {i_lst }}{ }^{2}\right)} \\
& \sigma_{\text {Ist_c }}=\text { compressive stress on lower spacer } \\
& \sigma_{\text {Ist_c }}=4914 \mathrm{psi} \\
& \text { tube }
\end{aligned}
$$

Using ND-3133.6 (Cylinders Under Axial Compression) as a guide to determine if the lower spacer tube will buckle under this loading/compressive stress:

$$
\begin{array}{rlr}
t_{\text {Ist }}:= & \frac{D_{\text {O_Ist }}-D_{\text {i_Ist }}}{2} & \\
& t_{\text {Ist }}=0.110 \mathrm{in} & \\
R_{\text {Ist }}:= & \frac{D_{\text {i_lst }}}{2} & R_{\text {Ist }}=\text { inside radius } \\
& R_{\text {Ist }}=1.005 \mathrm{in} &
\end{array}
$$$$
\begin{array}{ll}
A_{\text {Ist }}:=\frac{0.125}{\frac{R_{\text {Ist }}}{t_{\text {Ist }}}} \quad A_{\text {Ist }}=0.0137 & A_{\text {lst }}=\text { value to enter charts with } \\
B_{\text {Ist }}:=12500 \cdot p s i & \text { B = value from Figure HA-1 (ASME Code } \\
& \text { Section II, Part D) }
\end{array}
$$

The lower spacer tube compressive stress $\left(\sigma_{\text {Ist_c }}\right)$ is less than that allowed $\left(B_{\text {Ist }}\right)$ for a Class 3 component to prevent buckling. Tube will not buckle.

:Lower spacer tube is acceptable. 


\section{B4.1.11 Capsule Bottom Cap}

The bottom cap is a Class 3 component and was previously evaluated and accepted. This calculation will merely calculate the stress in the attachment weld under the load of 6 upper cylinders pushing at maximum force each. This weld is a full penetration groove weld.

$$
\begin{gathered}
\sigma_{\text {bc_w }}:=\frac{6 \cdot F_{\text {ulc }}}{\frac{\pi}{4} \cdot\left[D_{\text {o_cfb }}{ }^{2}-\left(D_{\text {o_cfb }}-2 \cdot t_{\mathrm{cfb}}\right)^{2}\right]} \\
\sigma_{\text {bc_w }}=4178 \mathrm{psi}
\end{gathered}
$$

$$
\mathrm{F}_{\text {ulc }}=600 \mathrm{lbf}
$$$$
\sigma_{\mathrm{bc} \_w}=\text { tensile stress in weld }
$$

The weld stress calculated above is small when compared to the Class 3 allowable stress for 304 SST of 20,000 psi at 240 deg. F.

:Bottom cap weld under the maximum load of six upper cylinders is acceptable.

\section{B4.2 Evaluate Lower Cylinder Push Rods}

The lower cylinders are 9/16-inch Bimba Original Line cylinders (SR-022-P-V) with a maximum delivered force (250 psi maximum allowable working pressure times the piston area of 0.25 ) of $63 \mathrm{lbf}$ each. The lower cylinder pushrods are made of graphite. The compressive stress in these rods under the maximum load from a lower cylinder is:

$$
\begin{aligned}
& \mathrm{D}_{\text {lcpr }}:=0.435 \cdot \mathrm{in} \\
& D_{\text {Icpr }}=\text { diameter of lower push rod } \\
& \mathrm{A}_{\text {lcpr }}:=\frac{\pi}{4} \cdot \mathrm{D}_{\mathrm{lcpr}}{ }^{2} \\
& A_{l c p r}=\text { area of lower push rod cross-section } \\
& A_{\text {lcpr }}=0.1486 \text { in }^{2} \\
& \mathrm{~F}_{\text {Ilc }}:=0.25 \cdot \mathrm{in}^{2} \cdot 250 \cdot \mathrm{psi} \\
& F_{\text {IIc }}=\text { lower line cylinder maximum force } \\
& \mathrm{F}_{\text {Ilc }}=62.5 \mathrm{lbf} \\
& \sigma_{\text {lcpr }}:=\frac{F_{\text {llc }}}{A_{\text {lcpr }}} \\
& \sigma_{\mathrm{lcpr}}=\text { compressive stress on lower push } \\
& \sigma_{\text {Icpr }}=421 \mathrm{psi} \\
& \text { rod }
\end{aligned}
$$

The compressive stress calculated above $\left(\sigma_{\mathrm{lcpr}}\right)$ is negligible.

:Lower push rods are acceptable.

(Note that the lower line cylinders will not be operated at the same time as the upper line cylinders. Their purpose is merely to move the specimen stacks enough to assure that the specimens have not swelled to the point of binding in the specimen holders.) 


\section{B5. References}

B1. ASME Boiler and Pressure Vessel Code, Section III, Division 1, Subsection NB - Class 1 Components, 2001 Ed. with 2003 Addenda, American Society of Mechanical Engineers.

B2. S. D. Snow, EDF ATR-TRA-1275, Rev. 0, Structural Evaluation of the ATR Irradiation Capsule Experiment (ICE) Test and Facility, November 1997.

B3. R. K. Blandford, EDF TRA-ATR-1512, Rev. 0, Structural Evaluation of the ATR Multiple Irradiation Capsule Experiment (MICE) Test Train, Facility and Support Equipment, September 1999.

B4. ASME Boiler and Pressure Vessel Code, Section III, Division 1, Subsection ND - Class 3 Components, 2001 Edition with 2003 Addenda, American Society of Mechanical Engineers.

B5. G. K. Miller, An Evaluation of Flow Induced Vibration of the ATR Large In-Pile Tube with Locater Tie Removed, PG-T-85-016, May 1986.

B6. R. A. Goodell, Design Report for the ATR Instrumented Lead Facility (NPR/SWR Lithium Program), PG-T-89-015, June 1989.

B7. J. E. A. John, W. Haberman, Introduction to Fluid Mechanics, Prentice-Hall Inc., 1971.

B8. Flow data provided by R. G. Ambrosek on June 2, 2005.

B9. ASME B31.1, Power Piping, 1998 Ed., American Society of Mechanical Engineers.

B10. AISC Steel Construction Manual, Allowable Steel Design (ASD), Ninth Edition, American Institute of Steel Construction, 1989.

B11. ASME Boiler and Pressure Vessel Code, Section II, Part D - Material Properties, 2001 Edition with 2003 Addenda, American Society of Mechanical Engineers. 
431.02

$01 / 30 / 2003$

Rev. 11
ENGINEERING DESIGN FILE

EDF-5925

Revision 0

Page $\mathrm{C} 1$ of 27

Appendix C

Component Weights 


\section{Contents}

\section{C1. Calculation of Capsule Facility Component Weights................................. C4}

C1.1 Hanger Rod Extension \& Transition Tubes.................................. C4

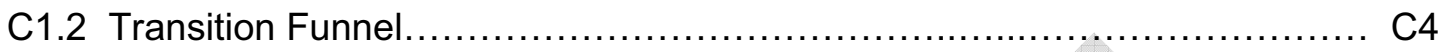

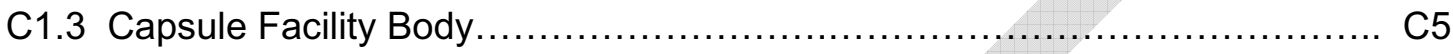

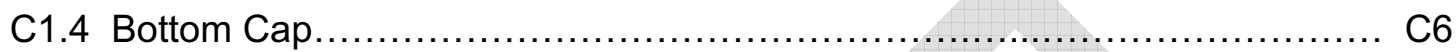

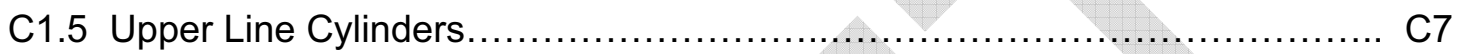

C1.6 Upper Line Cylinder Mounting Plates............................................ C7

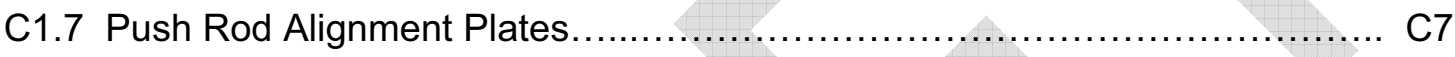

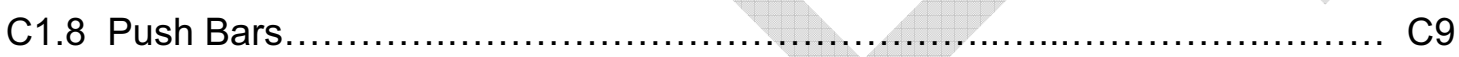

C1.9 Upper Push Rods................................................................. C9

C1.10 Upper Cylinder Load Cell Attachment Bolts.................................... C9

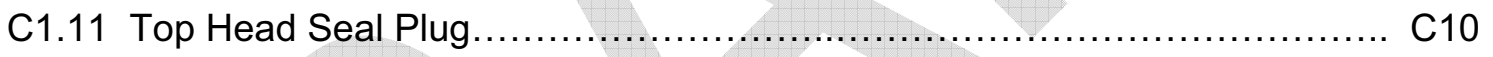

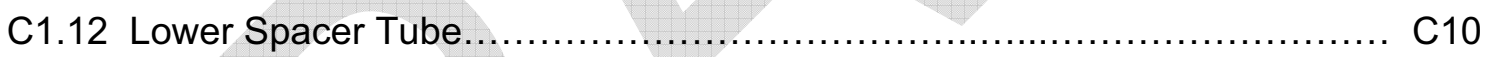

C1.13 Capsule Bottom Plate ............................................................. C11

C1.14 Lower Graphite Spacer..................................................... C11

C1.15 Lower Graphite Specimen Holder.............................................. C12

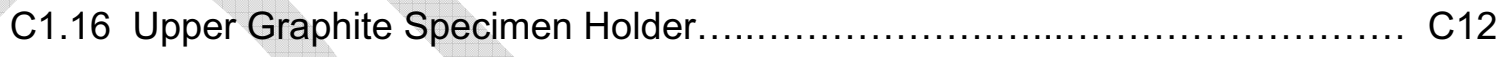

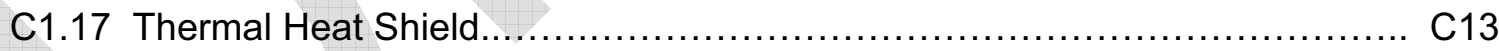

C1.18 Typical Upper Compressed Specimen Stack.................................. C15

C1.19 Typical Lower Uncompressed Specimen Stack.............................. C17

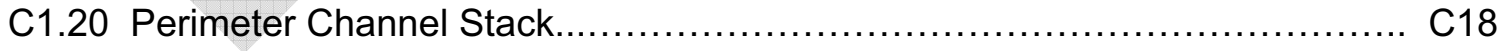

C1.21 Center Channel Uncompressed Specimen Stack.............................. C18

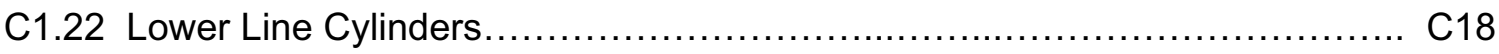

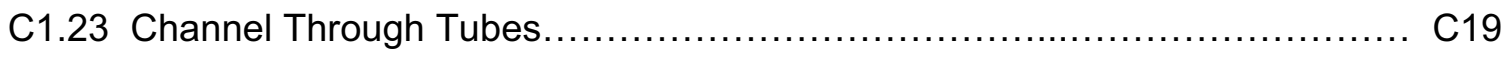

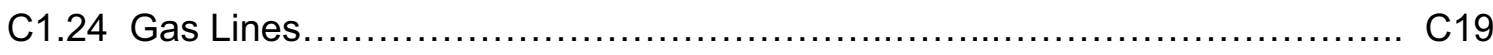


C1.25 Thermocouple Lines and Other Wires................................... C19

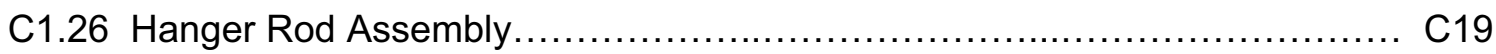

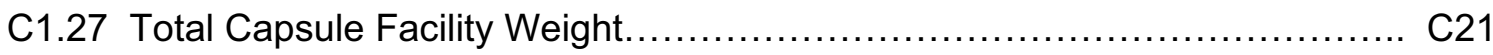

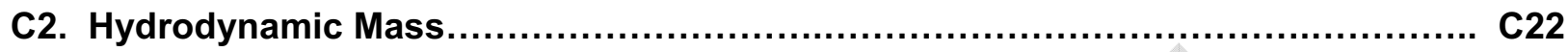

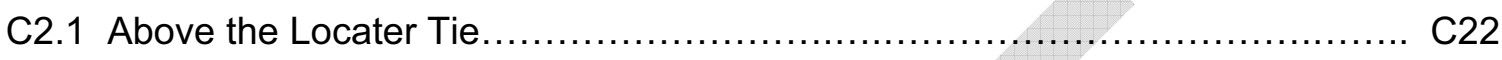

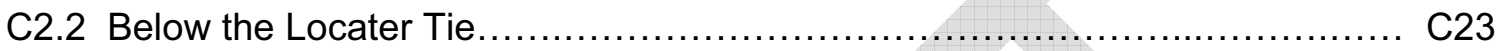

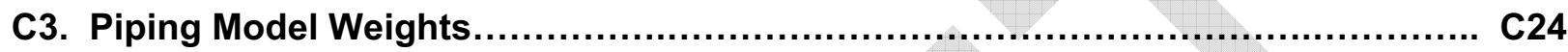

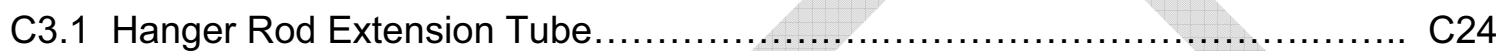

C3.2 Hanger Rod Transition Tubes \& Funnel Transition Tube ..................... C24

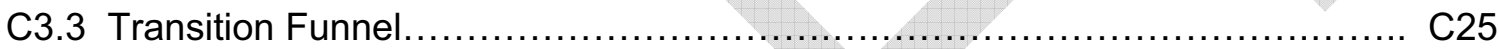

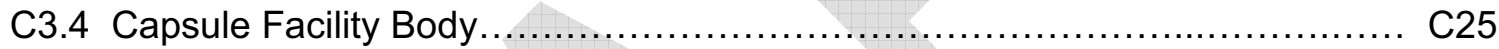

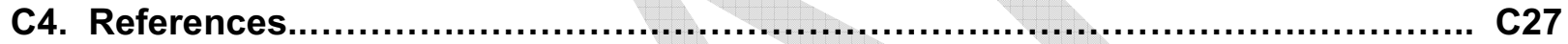




\section{C1. Caclulation of Capsule Facility Component Weights}

\section{C1.1 Hanger Rod Extension \& Transition Tubes and Funnel Transition} Tube (Tube, 5-in. O.D., 0.188-in. wall, 304 SST, Dwg. 630430 \& 630428)

$$
\begin{aligned}
& L_{\text {HRET }}:=108.15 \cdot \text { in } \\
& \mathrm{L}_{\text {HRET }}=\text { length of the hanger rod extension tube } \\
& \mathrm{L}_{\mathrm{hr}}:=\left(\mathrm{L}_{\mathrm{HRET}}+3 \times 12 \cdot \mathrm{in}+6 \cdot \mathrm{in}\right) \\
& t_{w}:=0.188 \cdot \text { in } \\
& L_{h r}=150.15 \mathrm{in} \\
& D_{0}:=5 \cdot \text { in } \\
& L_{h r}=\text { total length of hanger rod extension tube, } 3 \\
& \text { transition tubes, and one funnel transition tube } \\
& \mathrm{t}_{\mathrm{w}}=\text { wall thickness } \\
& D_{o}=\text { outside diameter of tube } \\
& D_{i}:=5 \cdot \text { in }-2 \cdot t_{w} \\
& D_{i}=\text { inside diameter of tube } \\
& A_{h r}:=\frac{\pi}{4} \cdot\left(D_{o}^{2}-D_{i}^{2}\right) \\
& A_{h r}=\text { area of hanger rod tube cross-section } \\
& A_{h r}=2.842 \mathrm{in}^{2} \\
& \rho_{304 \mathrm{sst}}:=0.285 \cdot \frac{\mathrm{lbf}}{\mathrm{in}^{3}} \\
& \rho_{304 s s t}=\text { weight density of } 304 \text { stainless steel } \\
& W_{h r}:=L_{h r} \cdot A_{h r} \cdot \rho_{304 s s t} \\
& \mathrm{~W}_{\mathrm{hr}}=121.62 \mathrm{lbf}
\end{aligned}
$$

\section{C1.2 Transition Funnel (304 SST, Dwg. 630428)}

$$
\begin{array}{lll}
\mathrm{R}_{\mathrm{O}}:=2.500 \cdot \text { in } & \mathrm{R}_{\mathrm{o}}=\text { outside radius at larger end } \\
\mathrm{t}_{\mathrm{tf}}:=0.225 \cdot \text { in } & \mathrm{t}_{\mathrm{tf}}=\text { wall thickness } \\
\mathrm{R}_{\mathrm{i}}:=\mathrm{R}_{\mathrm{O}}-\mathrm{t}_{\mathrm{tf}} & \mathrm{R}_{\mathrm{i}}=2.275 \mathrm{in} & \mathrm{R}_{\mathrm{i}}=\text { inside radius at larger end } \\
\mathrm{r}_{\mathrm{O}}:=1.25 \cdot \text { in } & \mathrm{r}_{\mathrm{o}}=\text { outside radius at smaller end } \\
\mathrm{r}_{\mathrm{i}}:=\mathrm{r}_{\mathrm{O}}-\mathrm{t}_{\mathrm{tf}} & \mathrm{r}_{\mathrm{i}}=1.025 \mathrm{in} \quad \mathrm{r}_{\mathrm{i}}=\text { inside radius at smaller end } \\
\mathrm{h}_{\mathrm{tf}}:=5.375 \cdot \text { in } & \mathrm{h}_{\mathrm{tf}}=\text { height of funnel } \\
\mathrm{V}_{\mathrm{tf}}:=\frac{\pi}{3} \cdot \mathrm{h}_{\mathrm{tf}} \cdot\left(\mathrm{R}_{\mathrm{O}}{ }^{2}-\mathrm{R}_{\mathrm{i}}{ }^{2}+\mathrm{R}_{\mathrm{O}} \cdot \mathrm{r}_{\mathrm{O}}-\mathrm{R}_{\mathrm{i}} \cdot \mathrm{r}_{\mathrm{i}}+\mathrm{r}_{\mathrm{O}}{ }^{2}-\mathrm{r}_{\mathrm{i}}{ }^{2}\right) \\
\mathrm{W}_{\mathrm{tf}}:=\mathrm{V}_{\mathrm{tf}} \cdot \rho_{304 \mathrm{sst}} & \mathrm{V}_{\mathrm{tf}}=\text { volume of funnel material }
\end{array}
$$

$$
\mathrm{W}_{\mathrm{tf}}=3.817 \mathrm{lbf}
$$


C1.3 Capsule Facility Body (Tube, 2-1/2-in. O.D., 0.120-in. wall, 304 SST, Dwg. 630430)

Tube with 0.120 -inch wall section ("tube"):

$$
\begin{aligned}
& L_{b}:=149.68 \cdot \text { in } \quad L_{b}=\text { length of entire capsule facility body } \\
& \mathrm{L}_{b 1}:=77.68 \cdot \text { in } \quad \mathrm{L}_{b 1}=\text { length of tube } \\
& D_{b o}:=2.500 \cdot \text { in } \quad D_{b o}=\text { outside diameter of capsule facility body } \\
& t_{b 1}:=0.120 \cdot \text { in } \quad t_{b 1}=\text { wall thickness of remaining tube } \\
& D_{b i 1}:=D_{b o}-2 \cdot t_{b 1} \quad D_{b i 1}=\text { inside diameter of remaining tube } \\
& \mathrm{D}_{\mathrm{bi} 1}=2.26 \mathrm{in} \\
& A_{b 1}:=\frac{\pi}{4} \cdot\left(D_{b o}{ }^{2}-D_{b i 1}{ }^{2}\right) \quad A_{b 1}=\text { area of remaining tube cross-section } \\
& A_{b 1}=0.897 \mathrm{in}^{2} \\
& V_{b 1}:=A_{b 1} \cdot L_{b 1} \quad V_{b 1}=\text { volume of remaining tube } \\
& \mathrm{V}_{\mathrm{b} 1}=69.698 \mathrm{in}^{3}
\end{aligned}
$$

$\underline{\text { In core pressure tube section: }}$

$$
\begin{array}{ll}
L_{b 2}:=72 \cdot \text { in } & L_{b 2}=\text { length of in-core pressure tube } \\
t_{b 2}:=0.188 \cdot \text { in } & t_{b 2}=\text { thickness of in-core tube } \\
D_{b i 2}:=D_{b 0}-2 \cdot t_{b 2} & D_{b i 2}=\text { inside diameter of in-core tube } \\
D_{b i 2}=2.124 \text { in } & D_{\text {grooves }}=\text { diameter of } 13 \text { inside wall grooves } \\
D_{\text {grooves }}:=0.126 \cdot \text { in } & \\
A_{b 2}:=\frac{\pi}{4} \cdot\left(D_{b o}{ }^{2}-D_{b i 2}{ }^{2}-\frac{13}{2} \cdot D_{\text {grooves }}\right) \\
A_{b 2}=1.284 \text { in }^{2} & A_{b 2}=\text { area of in-core tube cross-section }
\end{array}
$$




$$
\begin{array}{cc}
V_{b 2}:=A_{b 2} \cdot L_{b 2} & V_{b 2}=\text { volume of in-core tube } \\
V_{b 2}=92.481 \mathrm{in}^{3} & \\
W_{b}:=\left(V_{b 1}+V_{b 2}\right) \cdot \rho_{304 s s t} & W_{b}=\text { weight of entire capsule facility body } \\
W_{b}=46.221 \mathrm{lbf} &
\end{array}
$$

C1.4 Bottom Cap (Rod or Bar, 2-1/2-in. O.D., 304 SST, Dwg. 630428)

$$
\begin{array}{cl}
\mathrm{R}_{\mathrm{bc}}:=1.250 \cdot \mathrm{in} & \mathrm{R}_{\mathrm{bc}}=\text { radius of sphere } \\
\mathrm{V}_{\mathrm{sp}}:=\frac{1}{2} \cdot \frac{4}{3} \cdot \pi \cdot \mathrm{R}_{\mathrm{bc}}{ }^{3} & \mathrm{~V}_{\mathrm{sp}}=\text { volume of solid half-sphere } \\
\mathrm{V}_{\mathrm{sp}}=4.091 \mathrm{in}^{3} & \mathrm{~V}_{\mathrm{tr}}=\text { volume of transition section } \\
\mathrm{V}_{\mathrm{tr}}:=0.125 \cdot \mathrm{in} \cdot \frac{\pi}{4} \cdot(2.375 \cdot \mathrm{in})^{2} & \\
\mathrm{~V}_{\mathrm{tr}}=0.554 \mathrm{in}^{3} & \\
\mathrm{~V}_{\mathrm{f}}:=0.125 \cdot \mathrm{in} \cdot \frac{\pi}{4} \cdot(2.25 \cdot \mathrm{in})^{2} & \\
\mathrm{~V}_{\mathrm{f}}=0.497 \mathrm{in}{ }^{3} & \\
\mathrm{~W}_{\mathrm{bc}}:=\left(\mathrm{V}_{\mathrm{sp}}+\mathrm{V}_{\mathrm{tr}}+\mathrm{V}_{\mathrm{f}}\right) \cdot \rho_{304 \mathrm{sst}} & \mathrm{W}_{\mathrm{bc}}=\text { volume of straight section } \\
\mathrm{W}_{\mathrm{bc}}=1.465 \mathrm{lbf} &
\end{array}
$$




\section{C1.5 Upper Line Cylinders (Dwg 630430, Bimba Online Data, SR-242-P-V)}

$\mathrm{W}_{\mathrm{ulc}}:=2.0 \cdot \mathrm{lbf}$

$\mathrm{W}_{\mathrm{ulc}}=$ weight of each of the six upper line cylinders with a 2 inch stroke or $1.6 \mathrm{lbf}$ rounded up to $2 \mathrm{lbs}$ to account for any misc. mounting hardware

C1.6 Upper Cylinder Mounting Plates (1/4-inch plate, 304 SST, Dwg. 630428)
$\mathrm{D}_{\mathrm{mpl}}:=4.800 \cdot \mathrm{in}$
$D_{\mathrm{mpl}}=$ plate diameter
$t_{\mathrm{mpl}}:=0.250 \cdot \mathrm{in}$
$\mathrm{t}_{\mathrm{mpl}}=$ plate thickness
$\mathrm{D}_{1}:=1.040 \cdot \mathrm{in}$
$D_{1}=$ diameter of three mounting holes
$D_{2}:=0.625 \cdot$ in
$D_{2}=$ diameter of three air line holes
$D_{C}:=0.755 \cdot$ in
$D_{c}=$ diameter of center hole

$A_{m p l}:=\frac{\pi}{4} \cdot\left(D_{m p l}{ }^{2}-3 \cdot D_{1}{ }^{2}-3 \cdot D_{2}{ }^{2}-D_{c}{ }^{2}\right) \quad A_{m p l}=$ area of plate minus holes

$\mathrm{W}_{\mathrm{mpl}}:=\mathrm{A}_{\mathrm{mpl}} \cdot \mathrm{t}_{\mathrm{mpl}} \cdot \rho_{304 \mathrm{sst}} \quad \mathrm{W}_{\mathrm{mpl}}=$ weight of each of 2 mounting plates

$$
\mathrm{W}_{\mathrm{mpl}}=1.01 \mathrm{lbf}
$$

(The above is the weight of mounting plate \#1. Mounting plate \#2 is slightly lighter because of the three slots for push bars. However, using this weight for both plates will be acceptable.)

C1.7 Push Rod Alignment Plates (1/4-inch plates, 304 SST, Dwg. 630428)

Alignment Plate \#1:

$$
\begin{array}{ll}
D_{\text {prap } 1}:=D_{\text {mpl }} & D_{\text {prap } 1}=\text { outer diameter of plate } \\
D_{c s}:=0.755 \cdot \text { in } & D_{c s}=\text { diameter of center hole } \\
D_{\text {ph }}:=0.375 \cdot \text { in } & D_{p h}=\text { diameter of six perimeter holes } \\
D_{\text {slots }}:=0.516 \cdot \text { in } & D_{\text {slots }}=\text { diameter of six slots } \\
L_{\text {slots }}:=\frac{(2.780-1.390) \cdot \text { in }}{2} & L_{\text {slots }}=\text { length of slots minus end radii } \\
A_{\text {prap } 1}:=\frac{\pi}{4} \cdot\left(D_{\text {prap } 1}{ }^{2}-D_{c s}{ }^{2}-6 \cdot D_{p h}{ }^{2}-6 \cdot D_{\text {slots }}{ }^{2}\right)-6 \cdot D_{\text {slots }} \cdot L_{\text {slots }} \\
A_{\text {prap1 } 1}=13.579 \text { in }^{2} & A_{\text {prap } 1}=\text { area of alignment plate \#1 } \\
t_{\text {prap }}:=0.250 \cdot \text { in } &
\end{array}
$$




$$
\begin{aligned}
\mathrm{W}_{\text {prap } 1}:= & \mathrm{A}_{\text {prap } 1} \cdot \mathrm{t}_{\text {prap }} \cdot \rho_{304 \mathrm{sst}} \quad \mathrm{W}_{\text {prap } 1}=\text { weight of alignment plate \#1 } \\
& \mathrm{W}_{\text {prap1 }}=0.967 \mathrm{lbf}
\end{aligned}
$$

Alignment Plate \#2:

Plate \#2 is identical to plate \#1 except that three of the slots are simply circular push rod holes, and it has only three perimeter holes (which are smaller in diameter).

$$
\begin{aligned}
& D_{\text {prh }}:=0.565 \cdot \text { in } \quad D_{\text {prh }}=\text { diameter of three push rod holes } \\
& \mathrm{D}_{\mathrm{ph} 1}:=0.250 \cdot \mathrm{in} \quad \mathrm{D}_{\mathrm{ph} 1}=\text { diameter of three perimeter holes } \\
& A_{\text {prap } 2}:=\frac{\pi}{4} \cdot\left(D_{\text {prap1 }}{ }^{2}-D_{c s}{ }^{2}-3 \cdot D_{\text {ph1 }}{ }^{2}-3 \cdot D_{\text {slots }}{ }^{2}-3 \cdot D_{\text {prh }}{ }^{2}\right)-3 \cdot D_{\text {slots }} \cdot L_{\text {slots }} \\
& A_{\text {prap2 }}=\text { area of alignment plate \#2 } \\
& W_{\text {prap2 }}:=A_{\text {prap2 }} \cdot t_{\text {prap }} \cdot \rho_{304 s s t} \quad W_{\text {prap2 }}=\text { weight of alignment plate \#2 } \\
& \mathrm{W}_{\text {prap2 }}=1.072 \mathrm{lbf}
\end{aligned}
$$

\section{Alignment Plate \#3:}

Plate \#3 has only the center hole and six holes for the push rods.

$$
\begin{aligned}
A_{\text {prap3 }}:= & \frac{\pi}{4} \cdot\left(D_{\text {prap1 }}{ }^{2}-D_{c s}{ }^{2}-6 \cdot D_{\text {prh }}{ }^{2}\right) \quad A_{\text {prap3 }}=\text { area of alignment plate \#3 } \\
W_{\text {prap3 }}:= & A_{\text {prap3 }} \cdot t_{\text {prap }} \cdot \rho_{304 s s t} \quad W_{\text {prap3 }}=\text { weight of alignment plate \#3 } \\
& W_{\text {prap3 }}=1.150 \mathrm{lbf}
\end{aligned}
$$

Alignment Plate \#4:

Plate \#4 has a center hole, six holes for the push rods, and six perimeter holes.

$$
\begin{array}{ll}
D_{\text {prap4 }}:=2.280 \cdot \text { in } & D_{\text {prap } 4}=\text { outer diameter of plate \#4 } \\
D_{\text {prh4 }}:=0.578 \cdot \text { in } & D_{\text {prh4 }}=\text { diameter of six push rod holes in plate \#4 } \\
D_{\text {ph4 }}:=0.189 \cdot \text { in } & D_{\text {ph4 }}=\text { diameter of six perimeter holes in plate \#4 }
\end{array}
$$

$A_{\text {prap4 }}:=\frac{\pi}{4} \cdot\left(D_{\text {prap4 }}{ }^{2}-D_{c s}{ }^{2}-6 \cdot D_{\text {prh4 }}{ }^{2}-6 \cdot D_{\text {ph4 }}{ }^{2}\right) \quad A_{\text {prap4 }}=$ area of alignment plate \#4

$\mathrm{W}_{\text {prap4 }}:=\mathrm{A}_{\text {prap4 }} \cdot \mathrm{t}_{\text {prap }} \cdot \rho_{304 \mathrm{sst}} \quad \mathrm{W}_{\text {prap4 }}=$ weight of alignment plate \#4

$$
\mathrm{W}_{\text {prap4 }}=0.135 \mathrm{lbf}
$$

Total weight of all four push rod alignment plates $\left(\mathrm{W}_{\text {prap }}\right)$ :

$$
\mathrm{W}_{\text {prap }}:=\mathrm{W}_{\text {prap1 }}+\mathrm{W}_{\text {prap2 }}+\mathrm{W}_{\text {prap3 }}+\mathrm{W}_{\text {prap4 }} \quad \mathrm{W}_{\text {prap }}=3.325 \mathrm{lbf}
$$




\section{C1.8 Push Bars (304 SST, Dwg. 630428)}

$$
\begin{aligned}
& \mathrm{D}_{\mathrm{pb}}:=0.500 \cdot \text { in } \quad \mathrm{D}_{\mathrm{pb}}=\text { push bar end diameter } \\
& \mathrm{L}_{\mathrm{pbr}}:=0.695 \cdot \text { in } \quad \mathrm{L}_{\mathrm{pbr}}=\text { length of rectangular portion of push bar } \\
& \mathrm{L}_{\mathrm{pb}}:=16.706 \cdot \text { in } \quad \mathrm{L}_{\mathrm{pb}}=\text { overall length of push bar } \\
& W_{p b}:=\left(\frac{\pi}{4} \cdot D_{p b}{ }^{2}+D_{p b} \cdot L_{p b r}\right) \cdot L_{p b} \cdot \rho_{304 s s t} \\
& \mathrm{~W}_{\mathrm{pb}}=2.589 \mathrm{lbf} \quad \mathrm{W}_{\mathrm{pb}}=\text { approximate weight of each of six push bars } \\
& \text { (Note that the threaded holes were not removed while } \\
& \text { the larger radius at the upper end was not included. } \\
& \text { The resulting inaccuracy was considered acceptably } \\
& \text { small.) }
\end{aligned}
$$

\section{C1.9 Upper Push Rods (304 SST, Dwg. 630428)}

$$
\begin{array}{rlrl}
\mathrm{D}_{\mathrm{pr}}:= & 0.563 \cdot \mathrm{in} & \mathrm{D}_{\mathrm{pr}}=\text { push rod major diameter } \\
\mathrm{D}_{\mathrm{prm}} & :=0.472 \cdot \text { in } & \mathrm{D}_{\mathrm{prm}}=\text { push rod minor diameter } \\
\mathrm{L}_{\mathrm{lpr}}:=77.261 \cdot \text { in } & \mathrm{L}_{\mathrm{lpr}}=\text { length of long push rod } \\
\mathrm{L}_{\mathrm{spr}}:=65.483 \cdot \mathrm{in} & \mathrm{L}_{\mathrm{spr}}=\text { length of short push rod } \\
\mathrm{W}_{\mathrm{lpr}}:=\frac{\pi}{4} \cdot\left[\mathrm{D}_{\mathrm{pr}}{ }^{2} \cdot\left(\mathrm{L}_{\mathrm{lpr}}-0.38 \cdot \mathrm{in}\right)+\mathrm{D}_{\mathrm{prm}}{ }^{2} \cdot 0.38 \cdot \mathrm{in}\right] \cdot \rho_{304 \mathrm{sst}} & \mathrm{W}_{\mathrm{lpr}}=\text { weight of each of } 3 \text { long push rods } \\
& \mathrm{W}_{\mathrm{lpr}}=5.474 \mathrm{lbf} & \\
\mathrm{W}_{\mathrm{spr}}:= & \frac{\pi}{4} \cdot\left[\mathrm{D}_{\mathrm{pr}}{ }^{2} \cdot\left(\mathrm{L}_{\mathrm{spr}}-0.38 \cdot \mathrm{in}\right)+\mathrm{D}_{\mathrm{prm}}{ }^{2} \cdot 0.38 \cdot \text { in }\right] \cdot \rho 304 \mathrm{sst} \\
& \mathrm{W}_{\mathrm{spr}}=4.638 \mathrm{lbf} & \mathrm{W}_{\mathrm{spr}}=\text { weight of each of } 3 \text { short push rods }
\end{array}
$$

\section{C1.10 Upper Cylinder Load Cell Attachment Bolts (304 SST, Dwg. 630428)}

$$
\begin{aligned}
& D_{\text {lcab_s }}:=0.5 \text { in } \quad D_{\text {lcab_s }}=\text { diameter of small end of bolt } \\
& D_{\text {lcab_l }}:=0.625 \cdot \text { in } \quad D_{\text {lcab_l }}=\text { diameter of large end of bolt } \\
& L_{\mid c a b \_l}:=1.690 \cdot \text { in } \quad L_{\mid c a b \_l}=\text { length of large end of bolt } \\
& L_{\text {lcab_s }}:=3.190 \cdot \text { in }-L_{\text {lcab_l }} \quad L_{\text {lcab_s }}=\text { length of small end of bolt } \\
& W_{\text {Icab }}:=\frac{\pi}{4} \cdot\left(D_{\text {lcab_s }}{ }^{2} L_{\text {Icab_s }}+D_{\text {Icab_I }} \cdot \text { LIcab_I }\right) \cdot \rho_{304 s s t} \\
& \mathrm{~W}_{\text {lcab }}=0.232 \mathrm{lbf} \quad \begin{array}{l}
\mathrm{W}_{\text {lcab }}=\text { conservative weight of each load cell } \\
\text { attachment bolt }
\end{array}
\end{aligned}
$$

(Actual load cells weigh less than $1 / 20 \mathrm{lbf}$ and will be neglected herein.) 


\section{C1.11 Top Head Seal Plug (304 SST, Dwg. 630429)}

Seal plug approximated as a bar with three sections of different diameters, with a center through hole with a threaded hole at one end.

$$
\begin{aligned}
& \mathrm{D}_{\mathrm{sn} 1}:=5.87 \cdot \mathrm{in} \quad \mathrm{D}_{\mathrm{sn} 1}=\text { diameter of first section } \\
& \mathrm{D}_{\mathrm{sn} 2}:=6.35 \cdot \mathrm{in} \quad \mathrm{D}_{\mathrm{sn} 2}=\text { diameter of second section } \\
& \mathrm{D}_{\mathrm{sn} 3}:=4.75 \cdot \mathrm{in} \quad \mathrm{D}_{\mathrm{sn} 3}=\text { diameter of third section } \\
& \mathrm{L}_{\mathrm{sn} 1}:=3.25 \cdot \mathrm{in} \quad \mathrm{L}_{\mathrm{sn} 1}=\text { length of first section } \\
& \mathrm{L}_{\mathrm{sn} 2}:=2.75 \cdot \mathrm{in} \quad \mathrm{L}_{\mathrm{sn} 2}=\text { length of second section } \\
& \mathrm{L}_{\mathrm{sn} 3}:=4.00 \cdot \mathrm{in} \quad \mathrm{L}_{\mathrm{sn} 3}=\text { length of third section } \\
& \mathrm{D}_{\mathrm{snh} 1}:=2.50 \cdot \mathrm{in} \quad \mathrm{D}_{\mathrm{snh} 1}=\text { diameter of threaded hole } \\
& \mathrm{D}_{\mathrm{snh} 2}:=1.39 \cdot \mathrm{in} \quad \mathrm{D}_{\mathrm{snh} 2}=\text { diameter of though hole } \\
& \mathrm{L}_{\mathrm{snh} 1}:=2.00 \cdot \mathrm{in} \quad \mathrm{L}_{\mathrm{snh} 1}=\text { length of threaded hole } \\
& \mathrm{L}_{\mathrm{snh} 2}:=8.00 \cdot \mathrm{in} \quad \mathrm{L}_{\text {snh2 }}=\text { length of through hole } \\
& \mathrm{V}_{\mathrm{sn}}:=\frac{\pi}{4} \cdot\left[\mathrm{D}_{\mathrm{sn} 1}{ }^{2} \cdot \mathrm{L}_{\mathrm{sn} 1}+\mathrm{D}_{\mathrm{sn} 2}{ }^{2} \cdot \mathrm{L}_{\mathrm{sn} 2}+\mathrm{D}_{\mathrm{sn} 3}{ }^{2} \cdot \mathrm{L}_{\mathrm{sn} 3}-\left(\mathrm{D}_{\mathrm{snh} 1}{ }^{2} \cdot \mathrm{L}_{\mathrm{snh} 1}\right)-\mathrm{D}_{\mathrm{snh} 2}{ }^{2} \cdot \mathrm{L}_{\mathrm{snh} 2}\right] \\
& \mathrm{W}_{\mathrm{sn}}:=\mathrm{V}_{\mathrm{sn}} \cdot \rho_{304 \mathrm{sst}} \quad \mathrm{V}_{\mathrm{sn}}=\text { volume of seal plug material } \\
& \mathrm{W}_{\mathrm{sn}}=63.831 \mathrm{lbf} \quad \mathrm{W}_{\mathrm{sn}}=\text { weight of seal plug }
\end{aligned}
$$

\section{C1.12 Lower Spacer Tube (304 SST, Dwg. 630428)}

$$
\begin{aligned}
& D_{\text {Ist } 1}:=2.230 \cdot \text { in } \quad D_{\text {lst } 1}=\text { outer diameter of lower spacer tube } \\
& \mathrm{D}_{\text {Ist2 }}:=2.010 \cdot \text { in } \quad D_{\text {lst2 }}=\text { inner diameter of tube } \\
& \mathrm{L}_{\text {Ist }}:=7.375 \cdot \text { in } \quad \mathrm{L}_{\text {Ist }}=\text { length of tube } \\
& W_{\text {lst }}:=\frac{\pi}{4} \cdot\left(D_{\text {lst1 }}{ }^{2}-D_{\text {Ist2 }}{ }^{2}\right) \cdot L_{\text {Ist }} \cdot \rho_{304 s s t} \quad W_{\text {lst }}=\text { weight of lower spacer tube } \\
& \mathrm{W}_{\text {Ist }}=1.54 \mathrm{lbf}
\end{aligned}
$$




\section{C1.13 Capsule Bottom Plate (304 SST, Dwg. 630428)}

$$
\begin{array}{ll}
\mathrm{D}_{\mathrm{cbp} 1}:=2.149 \cdot \text { in } & \mathrm{D}_{\mathrm{cbp} 1}=\text { bottom plate outer diameter } \\
\mathrm{D}_{\mathrm{cbp} 2}:=0.190 \cdot \text { in } & \mathrm{D}_{\mathrm{cbp} 2}=\text { diameter of } 6 \text { edge slots } \\
\mathrm{t}_{\mathrm{cbp}}:=0.750 \cdot \text { in } & \mathrm{t}_{\mathrm{cpb}}=\text { thickness of main plate } \\
\mathrm{D}_{\mathrm{cbp} 3}:=0.313 \cdot \text { in } & \mathrm{D}_{\mathrm{cbp} 3}=\text { diameter of } 6 \text { through holes } \\
\mathrm{W}_{\text {removed }}:=0.1 \cdot \mathrm{lbf} & \mathrm{W}_{\text {removed }}=\text { assumed weight of removed metal } \\
\mathrm{V}_{\mathrm{cbp}}:=\frac{\pi}{4} \cdot\left(\begin{array}{ll}
\mathrm{D}_{\mathrm{cbp} 1}-6 \cdot \frac{\mathrm{D}_{\mathrm{cbp} 2}}{2}-6 \cdot \mathrm{D}_{\mathrm{cbp} 3}{ }^{2} \cdot \mathrm{t}_{\text {cbp }} \\
\mathrm{V}_{\mathrm{cbp}}=2.31 \mathrm{in}{ }^{3}
\end{array}\right. & \mathrm{V}_{\mathrm{cbp}}=\text { volume plate } \\
\mathrm{W}_{\mathrm{cbp}}:=\mathrm{V}_{\mathrm{cbp}} \cdot \rho_{304 \mathrm{sst}}-\mathrm{W}_{\text {removed }} & \mathrm{W}_{\mathrm{cbp}}=\text { weight of capsule bottom plate } \\
\mathrm{W}_{\mathrm{cbp}}=0.558 \mathrm{lbf} &
\end{array}
$$

C1.14 Lower Graphite Spacer (Graphite, POCO AXF-5Q, Dwg. 630427)

Weight will be approximated (minor details will be ignored).

$$
\begin{aligned}
& \mathrm{D}_{\operatorname{lgs} 1}:=2.100 \cdot \mathrm{in} \\
& D_{\text {lgs } 1}=\text { outer diameter of spacer } \\
& \mathrm{D}_{\operatorname{lgs} 2}:=0.505 \text {. in } \quad \mathrm{D}_{\text {lgs } 2}=\text { diameter of } 7 \text { through holes } \\
& \mathrm{L}_{\text {Igs }}:=25.250 \cdot \text { in } \quad L_{\text {lgs }}=\text { length of spacer } \\
& \mathrm{V}_{\operatorname{lgs}}:=\frac{\pi}{4} \cdot\left(\mathrm{D}_{\operatorname{lgs} 1}{ }^{2}-7 \cdot \mathrm{D}_{\operatorname{lgs} 2}{ }^{2}\right) \cdot \mathrm{L}_{\operatorname{lgs}} \\
& \mathrm{V}_{\text {lgs }}=52.054 \mathrm{in}^{3} \quad \mathrm{~V}_{\text {lgs }}=\text { spacer volume } \\
& \rho_{\text {graphite }}:=0.0641 \cdot \frac{\mathrm{lbf}}{\mathrm{in}^{3}} \quad \rho_{\text {graphite }}=\text { density of graphite (from Table } 4 \text { of } \\
& \mathrm{W}_{\text {lgs }}:=\mathrm{V}_{\text {lgs }} \cdot \rho_{\text {graphite }} \quad \mathrm{W}_{\text {lgs }}=\text { weight of lower graphite spacer } \\
& \mathrm{W}_{\text {lgs }}=3.337 \mathrm{lbf}
\end{aligned}
$$




\section{C1.15 Lower Graphite Specimen Holder (Graphite, POCO AXF-5Q, Dwg. 630427)}

Weight will be approximated (minor details will be ignored).

$$
\begin{array}{ll}
D_{\text {lgsh1 }}:=2.073 \cdot \text { in } & D_{\text {lgsh1 }}=\text { maximum outer diameter of holder } \\
D_{\text {lgsh2 }}:=1.939 \cdot \text { in } & D_{\text {lgsh2 }}=\text { minumum outer diameter of holder } \\
D_{\text {lgsh_ave }}:=\frac{D_{\text {lgsh1 }}+D_{\text {lgsh2 }}}{2} & D_{\text {lgsh_ave }}=\text { average diameter } \\
D_{\text {lgsh_ave }}=2.006 \text { in } & \\
L_{\text {Igsh }}:=25.500 \cdot \text { in } & L_{\text {lgsh }}=\text { length of holder } \\
D_{\text {lgsh4 }}:=0.505 \cdot \text { in } & D_{\text {lgsh } 4}=\text { diameter of } 6 \text { perimeter through holes } \\
\text { and center hole }
\end{array}
$$

(Ignore other features.)

$$
\begin{gathered}
\mathrm{V}_{\text {Igsh }}:=\frac{\pi}{4} \cdot\left(D_{\text {lgsh_ave }}{ }^{2}-7 \cdot D_{\text {lgsh }}{ }^{2}\right) \cdot L_{\text {lgsh }} \\
V_{\text {lgsh }}=44.839 \mathrm{in}^{3} \quad \mathrm{~V}_{\text {lgsh }}=\text { lower graphite specimen holder volume } \\
\mathrm{W}_{\text {lgsh }}:=\mathrm{V}_{\text {lgsh }} \cdot \rho_{\text {graphite }} \quad \mathrm{W}_{\text {lgsh }}=\text { weight of lower graphite specimen holder } \\
\mathrm{W}_{\text {lgsh }}=2.874 \mathrm{lbf}
\end{gathered}
$$

\section{C1.16 Upper Graphite Specimen Holder (Graphite, POCO AXF-5Q, Dwg.} 630427)

Weight will be approximated (minor details will be ignored).

$$
\begin{array}{ll}
\mathrm{D}_{\text {ugsh1 }}:=2.073 \cdot \text { in } & \mathrm{D}_{\text {ugsh1 }}=\text { maximum outer diameter of holder } \\
\mathrm{D}_{\text {ugsh2 }}:=1.643 \cdot \text { in } & \mathrm{D}_{\text {ugsh2 }}=\text { minumum outer diameter of holder (approx.) } \\
\mathrm{D}_{\text {ugsh3 }}:=\frac{\mathrm{D}_{\text {ugsh1 }}+\mathrm{D}_{\text {ugsh2 }}}{2} & \mathrm{D}_{\text {ugsh3 }}=\text { average outer diameter of holder } \\
\mathrm{L}_{\text {ugsh }}:=39.00 \cdot \text { in } & \mathrm{L}_{\text {ugsh }}=\text { overall length of holder } \\
\mathrm{D}_{\text {ugsh4 }}:=0.505 \cdot \text { in } & \mathrm{D}_{\text {ugsh3 }}=\text { diameter of } 6 \text { perimeter through holes }
\end{array}
$$$$
\text { (Ignore other features.) }
$$ 


$$
\begin{aligned}
& \mathrm{V}_{\text {ugsh }}:=\frac{\pi}{4} \cdot\left(\mathrm{D}_{\text {ugsh3 }}{ }^{2}-7 \cdot \mathrm{D}_{\text {ugsh }}{ }^{2}\right) \cdot \mathrm{L}_{\text {ugsh }} \\
& \mathrm{V}_{\text {ugsh }}=51.061 \mathrm{in}^{3} \quad \mathrm{~V}_{\text {ugsh }}=\text { upper graphite specimen holder volume } \\
& \mathrm{W}_{\text {ugsh }}:=\mathrm{V}_{\text {ugsh }} \cdot \rho_{\text {graphite }} \quad \mathrm{W}_{\text {ugsh }}=\text { weight of upper graphite specimen holder } \\
& \mathrm{W}_{\text {ugsh }}=3.273 \mathrm{lbf}
\end{aligned}
$$

\section{C1.17 Thermal Heat Shield (Haynes 230, Dwg. 630432)}

This component weight will be estimated. The outer diameter is constant. The shield is made in five sections.

Top End Section:

$$
\begin{aligned}
& D_{\text {hsod }}:=2.110 \cdot \text { in } \quad D_{\text {hsod }}=\text { heat shield outer diameter } \\
& t_{h s 1}:=0.025 \cdot \text { in } \quad t_{h s 1}=\text { top end section wall thickness } \\
& D_{\text {nubs }}:=0.125 \text { in } \quad D_{\text {nubs }}=6 \text { nubs on inside diameter } \\
& \mathrm{L}_{\mathrm{hs} 1}:=2.00 \cdot \mathrm{in} \\
& L_{h s 1}=\text { length of top end section } \\
& \mathrm{V}_{\mathrm{hs} 1}:=\left(\pi \cdot \mathrm{D}_{\mathrm{hsod}} \cdot \mathrm{t}_{\mathrm{hs} 1}+3 \cdot \frac{\pi}{4} \cdot \mathrm{D}_{\mathrm{nubs}}{ }^{2}\right) \cdot \mathrm{L}_{\mathrm{hs} 1} \\
& \mathrm{~V}_{\mathrm{hs} 1}=0.405 \mathrm{in}^{3} \quad \mathrm{~V}_{\mathrm{hs} 1}=\text { volume of top end section }
\end{aligned}
$$

Upper Section:

$$
\begin{array}{ll}
t_{h s 2 a}:=0.010 \cdot \text { in } & t_{h s 2 a}=\text { end thickness of upper section } \\
t_{h s 2 b}:=0.005 \cdot \text { in } & t_{h s 2 b}=\text { middle thickness of upper section } \\
L_{h s 2}:=16.0 \cdot \text { in } & L_{h s 2}=\text { length of upper section } \\
V_{h s 2}:=\pi \cdot D_{h s o d} \cdot L_{h s 2} \cdot \frac{t_{h s 2 a}+t_{h s 2 b}}{2} & \\
V_{h s 2}=0.795 \text { in }^{3} & V_{h s 2}=\text { volume of upper section }
\end{array}
$$


Middle Section:

$$
\begin{array}{ll}
t_{h s 3 a}:=0.025 \cdot \text { in } & t_{h s 3 a}=\text { left end thickness of middle section } \\
t_{h s 3 b}:=0.010 \cdot \text { in } & t_{h s 3 b}=\text { right end thickness of middle section } \\
L_{h s 3}:=16.02 \cdot \text { in } & L_{h s 3}=\text { length of middle section } \\
V_{h s 3}:=\pi \cdot D_{h s o d} \cdot L_{h s 2} \cdot \frac{t_{h s 3 a}+t_{h s 3 b}}{2} & \\
V_{h s 3}=1.856 \text { in }^{3} & V_{h s 3}=\text { volume of middle section }
\end{array}
$$

Lower Section: Same as middle section.

\section{Bottom End Section:}

$t_{\text {hs } 4}:=0.025 \cdot$ in

$\mathrm{L}_{\mathrm{hs} 4}:=2.00 \cdot \mathrm{in}$

$\mathrm{V}_{\mathrm{hs} 4}:=\pi \cdot \mathrm{L}_{\mathrm{hs} 4} \cdot \mathrm{D}_{\mathrm{hsod}} \cdot \mathrm{t}_{\mathrm{hs} 4}$

$$
\mathrm{V}_{\mathrm{hs} 4}=0.331 \mathrm{in}^{3}
$$

$V_{\text {hs } 4}=$ volume of bottom end section

Total Heat Shield Volume and Weight:

$$
\begin{array}{cl}
\mathrm{V}_{\mathrm{hst}}:=\mathrm{V}_{\mathrm{hs} 1}+\mathrm{V}_{\mathrm{hs} 2}+2 \cdot \mathrm{V}_{\mathrm{hs} 3}+\mathrm{V}_{\mathrm{hs} 4} & \\
\mathrm{~V}_{\mathrm{hst}}=5.244 \mathrm{in}^{3} & \mathrm{~V}_{\mathrm{hst}}=\text { total volume of heat shield } \\
\rho_{\mathrm{H} 230}:=0.324 \cdot \frac{\mathrm{lbf}}{\mathrm{in}^{3}} & \rho_{\mathrm{H} 230}=\text { density of Haynes } 230 \text { (per manufacturer) } \\
\mathrm{W}_{\mathrm{hs}}:=\mathrm{V}_{\mathrm{hst}} \cdot \rho_{\mathrm{H} 230} & \mathrm{~W}_{\mathrm{hs}}=\text { estimated weight of heat shield } \\
\mathrm{W}_{\mathrm{hs}}=1.699 \mathrm{lbf} &
\end{array}
$$




\section{C1.18 Typical Upper Compressed Specimen Stack (Graphite, Dwg. 630431 \& 630427)}

Upper Graphite Push Rod (simplified)

$$
\begin{aligned}
& \mathrm{D}_{\text {ugpr1 }}:=0.500 \cdot \mathrm{D}_{\text {ugpr1 }}=\text { outer diameter of push rod } \\
& \mathrm{D}_{\text {ugpr2 }}:=0.252 \cdot \text { in } \quad \mathrm{D}_{\text {ugpr2 }}=\text { diameter of push rod hole } \\
& \mathrm{L}_{\text {ugpr1 }}:=15.431 \cdot \text { in } \quad \mathrm{L}_{\text {ugpr1 }}=\text { length of push rod } \\
& \mathrm{L}_{\text {ugpr2 }}:=14.950 \cdot \text { in } \quad \mathrm{L}_{\text {ugpr2 }}=\text { length of hole } \\
& W_{\text {ugpr }}:=\frac{\pi}{4} \cdot\left(D_{\text {ugpr1 }}{ }^{2} \cdot L_{\text {ugpr1 }}-D_{\text {ugpr2 }}{ }^{2} \cdot L_{\text {ugpr2 }}\right) \cdot \rho_{\text {graphite }} \\
& \mathrm{W}_{\text {ugpr }}=0.146 \mathrm{lbf} \quad \mathrm{W}_{\text {ugpr }}=\text { weight of upper graphite push rod }
\end{aligned}
$$

Stressed Creep Specimens (15 total)

$$
\begin{array}{cl}
\mathrm{D}_{\mathrm{ScS}}:=0.501 \cdot \mathrm{in} & \mathrm{D}_{\mathrm{scs}}=\text { diameter of stressed creep specimen } \\
\mathrm{L}_{\mathrm{scs}}:=1.00 \cdot \mathrm{in} & \mathrm{L}_{\mathrm{scs}}=\text { length of specimen } \\
\mathrm{W}_{\mathrm{ScS}}:=\frac{\pi}{4} \cdot \mathrm{D}_{\mathrm{scs}}{ }^{2} \cdot \mathrm{L}_{\mathrm{scs}} \cdot \rho_{\text {graphite }} \quad \mathrm{W}_{\mathrm{scs}}=\text { weight of stressed creep specimen } \\
\mathrm{W}_{\mathrm{ScS}}=0.013 \mathrm{lbf} \quad(\text { each })
\end{array}
$$

Specimen Spacer (16 total)

$$
\begin{array}{ll}
\mathrm{D}_{\mathrm{SS}}:=0.475 \cdot \text { in } & \begin{array}{l}
\mathrm{D}_{\mathrm{ss}}=\text { outer diameter of spacer (no nubs }- \\
\text { considered negligible) } \\
\mathrm{L}_{\mathrm{sS}}=\text { length of spacer }
\end{array} \\
\mathrm{W}_{\mathrm{SS}}:=\frac{\pi}{4} \cdot \mathrm{D}_{\mathrm{SS}}{ }^{2} \cdot \mathrm{L}_{\mathrm{SS}} \cdot \rho_{\text {graphite }} & \mathrm{W}_{\mathrm{ss}}=\text { weight of specimen spacer } \\
\mathrm{W}_{\mathrm{SS}}=0.003 \mathrm{lbf} & (\text { each })
\end{array}
$$

Graphite Specimen Separator (Stop Block)

$$
\begin{array}{ll}
\mathrm{D}_{\mathrm{gss} 1}:=0.625 \cdot \mathrm{in} & \mathrm{D}_{\mathrm{gss} 1}=\text { maximum outer diameter of separator } \\
\mathrm{L}_{\mathrm{gss} 1}:=1.00 \cdot \mathrm{in} & \mathrm{L}_{\mathrm{gss} 1}=\text { length of maximum outer diameter }
\end{array}
$$




$$
\begin{array}{rlrl}
\mathrm{D}_{\mathrm{gss} 2} & :=0.472 \cdot \mathrm{in} & \mathrm{D}_{\mathrm{gss} 2}=\text { minimum outer diameter of separator } \\
\mathrm{L}_{\mathrm{gss} 2} & :=1.00 \cdot \mathrm{in} & \mathrm{L}_{\mathrm{gss} 2}=\text { length of minimum outer diameter } \\
\mathrm{W}_{\mathrm{gss}}:=\frac{\pi}{4} \cdot\left(\mathrm{D}_{\mathrm{gss} 1}{ }^{2} \cdot \mathrm{L}_{\mathrm{gss} 1}+\mathrm{D}_{\mathrm{gss} 2}{ }^{2} \cdot \mathrm{L}_{\mathrm{gss} 2}\right) \cdot \rho_{\text {graphite }} \\
\mathrm{W}_{\mathrm{gss}}=0.031 \mathrm{lbf} \quad \mathrm{W}_{\mathrm{gss}}=\text { weight of graphite specimen separator }
\end{array}
$$

Piggy Back Specimens (15 total)

$$
\begin{aligned}
\mathrm{D}_{\mathrm{pb} 1}:=0.249 \cdot \mathrm{in} & \mathrm{D}_{\mathrm{pb} 1}=\text { diameter of piggy back specimen } \\
\mathrm{L}_{\mathrm{pb} 1}:=0.25 \cdot \mathrm{in} & \mathrm{L}_{\mathrm{pb} 1}=\text { length of piggy back specimen } \\
\mathrm{W}_{\mathrm{pb} 1}:=\frac{\pi}{4} \cdot \mathrm{D}_{\mathrm{pb} 1}{ }^{2} \cdot \mathrm{L}_{\mathrm{pb} 1} \cdot \rho_{\text {graphite }} & \mathrm{W}_{\mathrm{pb} 1}=\text { weight of piggy back specimen } \\
\mathrm{W}_{\mathrm{pb} 1}=0.001 \mathrm{lbf} &
\end{aligned}
$$

Total Weight of Upper Compressed Specimen Stack ( $\left.\mathrm{W}_{\text {ucss }}\right)$

$$
\begin{gathered}
W_{\text {ucss }}:=W_{\text {ugpr }}+15 \cdot\left(W_{\text {scs }}+W_{\text {pb1 } 1}\right)+16 \cdot W_{\text {ss }}+6 \cdot W_{g s s} \\
W_{\text {ucss }}=0.578 \mathrm{lbf}
\end{gathered}
$$

(Note that the weight of the alignment pins was not calculated. However, their weight was included in the total weight $\mathrm{W}_{\text {ucss }}$ because the pin holes in the matching components were not deducted from their individual weights.) 


\section{C1.19 Typical Lower Uncompressed Specimen Stack (Graphite, Dwg. 630431 \& 630427)}

Unstressed Control Specimens (14 total)

$$
\begin{array}{rlrl}
\mathrm{D}_{\mathrm{ucs}} & :=0.501 \cdot \mathrm{in} & \mathrm{D}_{\mathrm{ucs}}=\text { diameter of unstressed control specimen } \\
\mathrm{L}_{\mathrm{ucs}}:=1.00 \cdot \mathrm{in} & \mathrm{L}_{\mathrm{ucs}}=\text { length of specimen } \\
\mathrm{W}_{\text {ucs }}:=\frac{\pi}{4} \cdot \mathrm{D}_{\mathrm{ucs}}{ }^{2} \cdot \mathrm{L}_{\mathrm{ucs}} \cdot \rho_{\text {graphite }} & \mathrm{W}_{\text {ucs }}=\text { weight of unstressed control specimen } \\
\mathrm{W}_{\text {ucs }}=0.013 \mathrm{lbf} & \text { (each) }
\end{array}
$$

Specimen Spacer (25 total)

$$
\begin{array}{rlr}
\mathrm{D}_{\mathrm{ss} 9}:=0.475 \cdot \text { in } & \mathrm{D}_{\mathrm{ss} 9}=\text { outer diameter of spacer (no nubs) } \\
\mathrm{L}_{\mathrm{ss} 9}:=0.25 \cdot \text { in } & \mathrm{L}_{\mathrm{ss} 9}=\text { length of spacer } \\
\mathrm{W}_{\mathrm{Ss} 9}:=\frac{\pi}{4} \cdot \mathrm{D}_{\mathrm{ss}}{ }^{2} \cdot \mathrm{L}_{\mathrm{ss}} \cdot \rho_{\text {graphite }} & \mathrm{W}_{\mathrm{ss} 9}=\text { weight of specimen spacer } \\
\mathrm{W}_{\mathrm{ss} 9}=0.003 \mathrm{lbf} & \text { (each) }
\end{array}
$$

Unstressed Piggy Back Specimens (10 total)

$$
\begin{array}{rlrl}
\mathrm{D}_{\mathrm{upb}} & :=0.501 \cdot \mathrm{in} & \mathrm{D}_{\mathrm{upb}}=\text { diameter of piggy back specimen } \\
\mathrm{L}_{\mathrm{upb}}:=0.25 \cdot \mathrm{in} & \mathrm{L}_{\mathrm{upb}}=\text { length of piggy back specimen } \\
\mathrm{W}_{\mathrm{upb}}:=\frac{\pi}{4} \cdot \mathrm{D}_{\mathrm{upb}}{ }^{2} \cdot \mathrm{L}_{\mathrm{upb}} \cdot \rho_{\text {graphite }} & \mathrm{W}_{\mathrm{upb}}=\text { weight of piggy back specimen } \\
\mathrm{W}_{\text {upb }}=0.003 \mathrm{lbf} & \text { (each) }
\end{array}
$$

Lower Graphite Push Rod

$$
\begin{aligned}
\mathrm{D}_{\text {Icpr }}:=0.457 \cdot \text { in } & \mathrm{D}_{\text {Icpr }}=\text { outer diameter of lower push rod } \\
\mathrm{L}_{\text {Icpr }}:=27.262 \cdot \text { in } & \mathrm{L}_{\text {Icpr }}=\text { length of lower push rod } \\
\mathrm{W}_{\text {Icpr }}:=\frac{\pi}{4} \cdot\left(\mathrm{D}_{\text {Icpr }}{ }^{2} \cdot \mathrm{L}_{\text {Icpr }}\right) \cdot \rho_{\text {graphite }} & \\
\mathrm{W}_{\text {Icpr }}=0.287 \mathrm{lbf} & \begin{array}{l}
\mathrm{W}_{\text {Icpr }}=\text { weight of lower cylinder push rod } \\
\text { accounded for })
\end{array}
\end{aligned}
$$


Total Weight of Lower Uncompressed Specimen Stack $\left(\mathrm{W}_{\text {luss }}\right)$

$$
\begin{gathered}
W_{\text {luss }}:=14 \cdot W_{\text {ucs }}+25 \cdot W_{\text {ss } 9}+10 \cdot W_{\text {upb }}+W_{\text {lcpr }} \\
W_{\text {luss }}=0.566 \mathrm{lbf}
\end{gathered}
$$

(Note that the weight of the alignment pins was not calculated. However, their weight was included in the total weight $\mathrm{W}_{\text {luss }}$ because the pin holes in the matching components were not deducted from their individual weights.)

\section{C1.20 Perimeter Channel Stack (Upper Compressed plus Lower Uncompressed Stacks)}

$$
\begin{gathered}
\mathrm{W}_{\mathrm{pcs}}:=\mathrm{W}_{\text {ucss }}+\mathrm{W}_{\text {luss }} \quad \mathrm{W}_{\mathrm{pcs}}=\text { weigth of perimeter channel stack } \\
\mathrm{W}_{\mathrm{pcs}}=1.145 \mathrm{lbf}
\end{gathered}
$$

\section{C1.21 Center Channel Uncompressed Specimen Stack (Graphite, Dwg. 630431 \& 630427)}

This center channel consists of a upper center spacer, an uncompressed stack of piggy back specimens and spacers, and the lower center spacer. It may be looked at as a continuous stack of graphite 0.500 -inches in diameter.

$$
\begin{aligned}
& \mathrm{D}_{\mathrm{CC}}:=0.500 \cdot \mathrm{in} \quad \mathrm{D}_{\mathrm{cc}}=\text { outer diameter of stack } \\
& \mathrm{L}_{c c}:=20.75 \cdot \text { in }+48.00 \cdot \text { in }+27.030 \cdot \text { in } \quad L_{c c}=\text { stack total length } \\
& \mathrm{L}_{\mathrm{CC}}=95.78 \mathrm{in} \\
& \mathrm{W}_{\mathrm{CC}}:=\frac{\pi}{4} \cdot \mathrm{D}_{\mathrm{CC}}{ }^{2} \cdot \mathrm{L}_{\mathrm{CC}} \cdot \rho_{\text {graphite }} \quad \mathrm{W}_{\mathrm{cC}}=\text { weight of center channel stack } \\
& \mathrm{W}_{\mathrm{cc}}=1.205 \mathrm{lbf}
\end{aligned}
$$

\section{C1.22 Lower Line Cylinders (Dwg 630430, Bimba Online Data, SR-022-P-V)}

$\mathrm{W}_{\mathrm{llc}}:=0.5 \cdot \mathrm{lbf}$
$\mathrm{W}_{\mathrm{Ilc}}=0.16 \mathrm{lbf}$ weight of each of the 6 lower line cylinders with a 2 inch stroke, rounded up to $0.5 \mathrm{lbf}$ to account for any mounting hardware 


\section{C1.23 Channel Through Tubes (304L SST, Dwg. 630430)}

$$
\begin{array}{ll}
\mathrm{D}_{\mathrm{ctt}}:=0.188 \cdot \text { in } & \mathrm{D}_{\mathrm{ctt}}=\text { tube outer diameter } \\
\mathrm{t}_{\mathrm{ctt}}:=0.065 \cdot \mathrm{in} & \mathrm{t}_{\mathrm{ctt}}=\text { tube wall thickness } \\
\mathrm{L}_{\mathrm{ctt}}:=86 \cdot \mathrm{in} & \mathrm{L}_{\mathrm{ctt}}=\text { tube length } \\
\mathrm{W}_{\mathrm{ctt}}:=\pi \cdot \mathrm{D}_{\mathrm{ctt}} \cdot \mathrm{t}_{\mathrm{ctt}} \mathrm{L}_{\mathrm{ctt}} \cdot \rho_{304 \mathrm{sst}} & \mathrm{W}_{\mathrm{ctt}}=\text { weight of each of the } 6 \text { channel through tubes } \\
\mathrm{W}_{\mathrm{ctt}}=0.941 \mathrm{lbf} &
\end{array}
$$

\section{C1.24 Gas Lines (304L SST, Dwg. 630430)}

These gas lines are 1/16-inch O.D. with 0.010 -inch thick walls. Their weight is negligible.

\section{C1.25 Thermocouple Lines and Other Wires (Dwg. 630430)}

These lines and wires are also of negligible weight.

\section{C1.26 Hanger Rod Assembly (out-of-reactor, Dwg. 630429)}

Top Head Seal Nut (304 SST, ASME SA-240) - Simplified

$$
\begin{array}{rlrl}
\mathrm{D}_{\text {thsn } 1} & :=2.50 \cdot \text { in } & \mathrm{D}_{\text {thsn } 1}=\text { thread diameter } \\
\mathrm{D}_{\text {thsn } 2} & :=1.385 \cdot \text { in } & \mathrm{D}_{\text {thsn } 2}=\text { through hole diameter } \\
\mathrm{L}_{\text {thsn }}:=2.50 \cdot \text { in } & \mathrm{L}_{\text {thsn }}=\text { nut length } \\
\mathrm{W}_{\text {thsn }}:=\frac{\pi}{4} \cdot\left(\mathrm{D}_{\text {thsn } 1}{ }^{2}-\mathrm{D}_{\text {thsn2 }}{ }^{2}\right) \cdot \mathrm{L}_{\text {thsn }} \cdot \rho_{304 \mathrm{sst}} \\
& \mathrm{W}_{\text {thsn }}=2.424 \mathrm{lbf} & \mathrm{W}_{\text {thsn }}=\text { weight of top head seal nut }
\end{array}
$$

Outer Tube (304 SST, ASME SA-213)

$$
\begin{array}{ll}
\mathrm{D}_{\mathrm{ot}}:=2.375 \cdot \text { in } & \mathrm{D}_{\mathrm{ot}}=\text { tube outer diameter } \\
\mathrm{t}_{\mathrm{ot}}:=0.125 \cdot \text { in } & \mathrm{t}_{\mathrm{ot}}=\text { tube thickness } \\
\mathrm{L}_{\mathrm{ot}}:=26 \cdot \text { in } & \mathrm{L}_{\mathrm{ot}}=\text { length of tube }
\end{array}
$$




$$
\begin{aligned}
W_{\text {ot }}:= & \frac{\pi}{4} \cdot\left[D_{\text {ot }}^{2}-\left(D_{\text {ot }}-2 \cdot t_{o t}\right)^{2}\right] \cdot L_{\text {ot }} \cdot \rho_{304 \mathrm{sst}} \\
& W_{\text {ot }}=6.547 \mathrm{lbf} \quad W_{\text {ot }}=\text { weight of outer tube }
\end{aligned}
$$

Bayonet (304 SST, ASME SA-240) - Simplified

$$
\begin{array}{ll}
\mathrm{D}_{\mathrm{b} 1}:=1.75 \cdot \text { in } & \begin{array}{l}
\mathrm{D}_{\mathrm{b} 1}=\text { assumed equivalent outer diameter for } \\
\text { simplified bayonet }
\end{array} \\
\mathrm{D}_{\mathrm{b} 2}:=1.25 \cdot \mathrm{in} & \mathrm{D}_{\mathrm{b} 2}=\text { inner diameter of through hole } \\
\mathrm{L}_{\mathrm{b} 9}:=3.0 \cdot \text { in } & \mathrm{L}_{\mathrm{b} 9}=\text { length } \\
\mathrm{W}_{\mathrm{b} 9}:=\frac{\pi}{4} \cdot\left(\mathrm{D}_{\mathrm{b} 1}{ }^{2}-\mathrm{D}_{\mathrm{b} 2}{ }^{2}\right) \cdot \mathrm{L}_{\mathrm{b} 9} \cdot \rho_{304 \mathrm{sst}} \quad \mathrm{W}_{\mathrm{b} 9}=\text { weight of bayonet } \\
\mathrm{W}_{\mathrm{b} 9}=1.007 \mathrm{lbf}
\end{array}
$$

Other Components Inside the Outer Tube

Insufficient data is available to calculate the weight of the other components that are within the outer tube. Therefore, it will be assumed that those components are $5 \mathrm{lbf}$ or less.

$$
\begin{aligned}
& W_{\text {other }}:=5.0 \cdot \mathrm{lbf} \quad \mathrm{W}_{\text {other }}=\text { assumed weight of interior components } \\
& \mathrm{W}_{\text {hanger_rod }}:=\mathrm{W}_{\text {other }}+\mathrm{W}_{\mathrm{bg}}+\mathrm{W}_{\text {ot }}+\mathrm{W}_{\text {thsn }} \\
& \mathrm{W}_{\text {hanger_rod }}=14.979 \mathrm{lbf} \quad \begin{array}{l}
\mathrm{W}_{\text {hanger_rod }}=\text { total out of reactor } \\
\text { component weight }
\end{array}
\end{aligned}
$$




\section{C1.27 Total Capsule Facility Weight}

$$
\begin{aligned}
& \mathrm{W}_{\text {boundary_in }}:=\mathrm{W}_{\mathrm{hr}}+\mathrm{W}_{\mathrm{tf}}+\mathrm{W}_{\mathrm{b}}+\mathrm{W}_{\mathrm{bc}} \\
& \text { W }_{\text {boundary_in }}=173.1 \mathrm{lbf} \\
& \text { [hanger rod + transition funnel + capsule facility body + bottom cap ] } \\
& \mathrm{W}_{\text {upper_in }}:=6 \cdot \mathrm{W}_{\mathrm{ulc}}+2 \cdot \mathrm{W}_{\mathrm{mpl}}+\mathrm{W}_{\text {prap }}+6 \cdot \mathrm{W}_{\mathrm{pb}}+3 \cdot\left(\mathrm{W}_{\text {lpr }}+\mathrm{W}_{\mathrm{spr}}\right)+6 \cdot \mathrm{W}_{\text {lcab }} \\
& \mathrm{W}_{\text {upper_in }}=64.6 \mathrm{lbf} \\
& \text { [ } 6 \text { upper line cylinders }+2 \text { upper mounting plates }+4 \text { push rod alignment } \\
& \text { plates }+6 \text { push bars }+3 \text { long and } 3 \text { short push rods }+6 \text { attachment bolts] } \\
& W_{\text {lower_in }}:=W_{\text {lst }}+W_{\text {cbp }}+W_{\text {lgs }}+W_{\text {lgsh }}+W_{\text {ugsh }}+W_{\text {hs }}+6 \cdot W_{\text {pcs }}+W_{\text {cc }}+6 \cdot\left(W_{\text {llc }}+W_{\text {ctt }}\right) \\
& \text { Wlower_in }_{\text {lo }} 30 \mathrm{lbf} \\
& \text { [lower spacer tube + capsule bottom plate + lower graphite spacer + } \\
& \text { lower graphite specimen holder + upper graphite specimen holder }+ \\
& \text { heat shield }+6 \text { perimeter channel stacks }+ \text { center channel stack }+ \\
& 6 \text { lower line cylinders }+6 \text { channel through tubes] } \\
& W_{\text {total_in }}:=W_{\text {boundary_in }}+W_{\text {upper_in }}+W_{\text {lower_in }} \\
& \mathrm{W}_{\text {total_in }}=267.7 \mathrm{lbf} \quad \mathrm{W}_{\text {total_in }}=\text { total weight inside of reactor } \\
& W_{\text {total_out }}:=W_{\text {hanger_rod }}+W_{\text {sn }} \quad W_{\text {total_out }}=\text { out-of-vessel hanger rod } \\
& \mathrm{W}_{\text {total_out }}=78.8 \mathrm{lbf} \\
& W_{\text {total }}:=W_{\text {total_in }}+W_{\text {total_out }} \quad W_{\text {total }}=\text { total weight of facility } \\
& \mathrm{w}_{\text {total }}=347 \mathrm{lbf} \\
& \text { and seal plug }
\end{aligned}
$$

The weight of the displaced in-reactor water is calculated as follows:

$$
\begin{aligned}
\rho_{\text {water }} & :=62.4 \cdot \frac{\mathrm{lbf}}{\mathrm{ft}^{3}} \\
\mathrm{~W}_{\text {water }} & :=\rho_{\text {water }} \cdot\left[\frac{\pi}{4} \cdot\left(\mathrm{D}_{\mathrm{o}}{ }^{2} \cdot \mathrm{L}_{\mathrm{hr}}+\mathrm{D}_{\mathrm{bo}}{ }^{2} \cdot \mathrm{L}_{\mathrm{b}}\right)+\frac{\pi}{3} \cdot \mathrm{h}_{\mathrm{tf}} \cdot\left(\mathrm{R}_{\mathrm{o}}{ }^{2}+\mathrm{R}_{\mathrm{o}} \cdot \mathrm{r}_{\mathrm{O}}+\mathrm{r}_{\mathrm{o}}{ }^{2}\right)+\mathrm{V}_{\mathrm{sp}}\right] \\
\mathrm{W}_{\text {water }} & =135 \mathrm{lbf}
\end{aligned}
$$

Therefore, the total capsule facility weight in water is:

$$
\begin{gathered}
W_{\text {net }}:=W_{\text {total }}-W_{\text {water }} \\
W_{\text {net }}=211 \mathrm{lbf}
\end{gathered}
$$




\section{C2. Hydrodynamic Mass}

The hanger rod extension and transition tubes, the transition funnel, and the capsule facility body are inside the ATR vessel. The mass of these components, for the purposes of calculating system natural frequencies and responses due to seismic loadings, will include a "hydrodynamic mass" to account for the effects of the reactor coolant. The calculation of the hydrodynamic mass will follow that given in Reference $\mathrm{C} 1$, consistent with the analysis of previous ATR experiment evaluations (Ref.'s C2 \& C3). Above the locater tie that secures the top the chopped dummy inpile tube that is located within the South flux trap, into which the AGC-1 experiment will be inserted, the hanger rod extension and transition tubes, the transition funnel, and the capsule facility body look like "components in a large pool of water."

\section{C2.1 Above the Locater Tie}

Hanger Rod Extension and Transition Tubes, and Funnel Transition Tube

$$
\begin{aligned}
& \rho_{\text {water }}=0.036 \frac{\mathrm{lbf}}{\mathrm{in}^{3}} \\
& \rho_{\text {water }}=\text { weight of water per volume } \\
& D_{\text {O_hrt }}:=5.000 \cdot \text { in } \\
& D_{\text {o_hrt }}=\text { outside diameter of hanger rod } \\
& \text { tubes } \\
& M_{h \_h r t}:=\rho_{\text {water }} \cdot \pi \cdot\left(\frac{D_{\mathrm{o}_{-} h r t}}{2}\right)^{2} \\
& M_{h \_h r t}=8.508 \frac{\mathrm{lbf}}{\mathrm{ft}}
\end{aligned}
$$

$$
\begin{aligned}
& D_{\mathrm{O}_{f} \_ \text {average }}=\text { average diameter of } \\
& \text { funnel } \\
& \mathrm{h}_{\mathrm{f}}=\text { funnel length }
\end{aligned}
$$$$
M_{h \_f u n n e l}:=\rho_{\text {water }} \cdot \pi \cdot\left(\frac{D_{O_{-} f \_a v e r a g e}}{2}\right)^{2} \cdot h_{f} \quad \begin{aligned}
& M_{h \_ \text {funnel }}=\text { additional hydrodynamic } \\
& \text { mass (in terms of weight) of the funnel }
\end{aligned}
$$ 
Capsule Facility Body

$D_{\text {O_cfb }}:=2.500 \cdot$ in

$M_{h \_c f b}:=\rho_{\text {water }} \cdot \pi \cdot\left(\frac{D_{\text {o_cfb }}}{2}\right)^{2}$

$$
M_{h \_c f b}=2.127 \frac{\mathrm{lbf}}{\mathrm{ft}}
$$

$D_{\text {o_cfb }}=$ outer diameter of capsule

facility body tube

$\mathrm{M}_{\mathrm{h}_{\mathrm{C}} \mathrm{fb}}=$ additional hydrodynamic mass

(in terms of weight) per 1 foot of capsule faciltiy body tube length

\section{C2.2 Below the Locater Tie}

Below the locater tie the capsule facility body is within the chopped dummy in-pile tube, with transverse restraint provided by that tube. The chopped dummy in-pile tube is transversly supported by the locater tie and as it passes through the core South flux trap. No mass to account for hydrodynamic effects is necessary in this region. 


\section{C3. Piping Model Weights}

The piping model requires a weight per foot to be entered for each section/component as part of the model input. This will be calculated next.

\section{C3.1 Hanger Rod Extension Tube}

The weight per foot of hanger rod extension tube for the piping model will include the self weight of the tube and the hydrodynamic weight. (Other components in the extension tube such as gas lines, thermocouple leads, etc., are all very lightweight components and will be ignored throughout these piping weight calculations.)

$$
\begin{aligned}
& \mathrm{L}_{\text {HRET }}=108.15 \mathrm{in} \\
& \mathrm{W}_{\text {HRET }}:=\frac{\mathrm{W}_{\mathrm{hr}}}{\mathrm{L}_{\mathrm{hr}}}+\mathrm{M}_{\mathrm{h} \_\mathrm{hrt}} \\
& \mathrm{W}_{\text {HRET }}=18.228 \frac{\mathrm{lbf}}{\mathrm{ft}}
\end{aligned}
$$

$\mathrm{L}_{\text {HRET }}=$ length of hanger rod extension tube

$\mathrm{W}_{\text {HRET }}=$ model weight per foot for hanger rod extension tube length

\section{C3.2 Hanger Rod Transition Tubes \& Funnel Transition Tube}

The weight per foot of the three hanger rod transition tubes (each 12 inches long) and the funnel transition tube ( 6 inches long) will be averaged over the total length ( 42 inches). The total weight will include the weight of the tubes, two upper cylinder mounting plates, three push rod alignment plates, six upper line cylinders, six push bars, six load cell attachment bolts, and the portion of the push rods in those tubes (14 inches long for three long rods, 2 inches long for three short rods), and the hydrodynamic weight.

$$
\begin{aligned}
& \mathrm{W}_{\text {prap_tt }}:=\mathrm{W}_{\text {prap1 }}+\mathrm{W}_{\text {prap2 }}+\mathrm{W}_{\text {prap3 }} \quad \mathrm{W}_{\text {prap_tt }}=\text { alignment plates in these tubes } \\
& \mathrm{W}_{\text {prap_tt }}=3.19 \mathrm{lbf} \\
& W_{\text {hrtt_d }}:=\frac{W_{h r}}{L_{h r}} \cdot 42 i n+2 \cdot W_{\text {mpl }}+W_{\text {prap_tt }}+6 \cdot\left(W_{\text {ulc }}+W_{\text {pb }}+W_{\text {lcab }}\right)+\frac{W_{l p r}}{L_{l p r}} \cdot 3 \cdot(14 \cdot i n+2 \cdot i n) \\
& \mathrm{W}_{\text {hrtt_d }}=71.557 \mathrm{lbf} \quad \mathrm{W}_{\text {hrtt_d }}=\text { total dry weight of components } \\
& W_{\text {HRTT }}:=\frac{W_{\text {hrtt_d }}}{42 \cdot \text { in }}+M_{h \_h r t} \\
& \mathrm{~W}_{\text {HRTT }}=28.953 \frac{\mathrm{lbf}}{\mathrm{ft}}
\end{aligned}
$$

Initial runs in the PipeStress piping program showed that some internal checks within the program did not allow such a large weight per foot for this pipe size. Therefore, the workaround was to use the Hanger Rod Extension Tube weight per foot value with an additional weight placed at each cylinder mounting plate and push rod alignment plate in these tubes. 
$\mathrm{W}_{\text {upper_c }}:=\frac{\left(\mathrm{W}_{\text {HRTT }}-\mathrm{W}_{\text {HRET }}\right) \cdot 42 \cdot \text { in }}{5}$ $\mathrm{W}_{\text {upper_c }}=$ concentrated weight at each cylinder mounting and alignment plate

$\mathrm{W}_{\text {upper_c }}=7.507 \mathrm{lbf} \quad$ applied at each of the five plates

\section{C3.3 Transition Funnel}

The weight per foot of the transition funnel (which is 5.375 inches long) will include the self weight, the weight of six push rods passing through it, and the hydrodynamic weight.

$$
\begin{aligned}
& \mathrm{L}_{\mathrm{TF}}:=\mathrm{h}_{\mathrm{tf}} \quad \mathrm{L}_{\mathrm{TF}}=5.375 \mathrm{in} \quad \mathrm{L}_{\mathrm{TF}}=\text { length of transition funnel } \\
& W_{T F}:=\frac{W_{t f}+3 \cdot h_{t f} \cdot\left(\frac{W_{\text {Ipr }}}{L_{\text {Ipr }}}+\frac{W_{\text {spr }}}{L_{\text {spr }}}\right)+M_{h_{-} \text {funnel }}}{h_{t f}} \\
& \mathrm{~W}_{\mathrm{TF}}=18.408 \frac{\mathrm{lbf}}{\mathrm{ft}}
\end{aligned}
$$

\section{C3.4 Capsule Facility Body}

The weight per foot of the capsule facility body will include the weight of the tube, the weight of all internal components including the push rods, one push rod stabilizing plate, the graphite specimen holders and specimens, the lower graphite spacer, the heat shield, the capsule bottom plate, lower spacer tube, the channel through tubes, the bottom cap, and the hydrodynamic weight addition above the locater tie.

Above the Locater Tie (about 12 inches of length)

$$
\begin{aligned}
& \mathrm{L}_{\text {alt }}:=12 \cdot \text { in } \\
& \mathrm{L}_{\text {alt }}=\text { length above locater tie } \\
& W_{\text {CFB_1 }}:=\frac{W_{b}}{L_{b}}+3 \cdot\left(\frac{W_{s p r}}{L_{s p r}}+\frac{W_{l p r}}{L_{l p r}}\right)+M_{h \_c f b} \\
& \mathrm{~W}_{\text {CFB_1 }}=10.933 \frac{\mathrm{lbf}}{\mathrm{ft}}
\end{aligned}
$$

From Locater Tie to Top of the Upper Graphite Specimen Holder (40.125 inches of length, top of holder is 14.875 inches above top of core)

$$
\begin{array}{cl}
\mathrm{L}_{\mathrm{blt}}:=40.125 \cdot \mathrm{in} & \begin{array}{l}
\mathrm{L}_{\mathrm{blt}}=\text { length from locater tie to top of } \\
\text { upper specimen holder }
\end{array} \\
\mathrm{W}_{\mathrm{CFB} \_2}:=\frac{\mathrm{W}_{\mathrm{b}}}{\mathrm{L}_{\mathrm{b}}}+3 \cdot\left(\frac{\mathrm{W}_{\mathrm{spr}}}{\mathrm{L}_{\mathrm{spr}}}+\frac{\mathrm{W}_{\mathrm{Ipr}}}{\mathrm{L}_{\mathrm{Ipr}}}\right)+\frac{\mathrm{W}_{\mathrm{prap} 4}}{\mathrm{~L}_{\mathrm{blt}}} & \begin{array}{l}
\mathrm{W}_{\mathrm{CFB} 22}=\text { model weight per foot of } \\
\text { capsule facility body between locater tie } \\
\text { and top of upper specimen holder }
\end{array} \\
\mathrm{W}_{\mathrm{CFB} \_2}=8.846 \frac{\mathrm{lbf}}{\mathrm{ft}} &
\end{array}
$$


From Top of Upper Graphite Specimen Holder to Bottom Cap (97.385 inches). [In this region the weight will be evenly distributed over the length. This simplification is considered acceptable since the transverse motion is restrained by the chopped dummy inpile tube held by the reactor core. The only motion would be in the vertical direction, which will be unaffected by the simplified even distribution of weight.]

$$
\begin{aligned}
& \mathrm{L}_{8}:=8 \cdot \mathrm{in} \\
& \mathrm{L}_{8}=8 \text {-inch length of upper push rods } \\
& \text { in the top of the upper specimen holder } \\
& \mathrm{L}_{\text {remaining }}:=94.385 \cdot \mathrm{in} \\
& L_{\text {remaining }}=\text { length from top of upper } \\
& \text { specimen holder to bottom cap } \\
& W_{\text {CFB_3 }}:=\frac{W_{b}}{L_{b}}+\frac{W_{b c}+W_{\text {lower_in }}+3 \cdot\left(\frac{W_{\text {lpr }}}{L_{\text {lpr }}}+\frac{W_{\text {spr }}}{L_{s p r}}\right) \cdot L_{8}}{L_{\text {remaining }}} \\
& \mathrm{W}_{\text {CFB_3 }}=8.138 \frac{\mathrm{lbf}}{\mathrm{ft}}
\end{aligned}
$$

\section{Check to see that all weight was accounted for:}

$$
\begin{aligned}
& \mathrm{W}_{\text {check1 }}:=\mathrm{W}_{\text {HRET }} \mathrm{L}_{\text {HRET }}+5 \cdot \mathrm{W}_{\text {upper_c }}+\mathrm{W}_{\text {HRET }} \cdot 42 \cdot \text { in } \\
& \mathrm{W}_{\text {check1 }}=265.6 \mathrm{lbf} \\
& \mathrm{W}_{\text {check2 }}:=\mathrm{W}_{\text {TF }} \cdot \mathrm{L}_{\mathrm{TF}}+\mathrm{W}_{\mathrm{CFB} \_1} \cdot \mathrm{L}_{\text {alt }}+\mathrm{W}_{\mathrm{CFB} \_2} \cdot \mathrm{L}_{\mathrm{blt}}+\mathrm{W}_{\mathrm{CFB} \_3} \cdot \mathrm{L}_{\text {remaining }} \\
& \mathrm{W}_{\text {check2 }}=112.8 \mathrm{lbf} \\
& \mathrm{W}_{\text {check_total }}:=\mathrm{W}_{\text {check1 } 1}+\mathrm{W}_{\text {check2 }} \quad \mathrm{W}_{\text {check_total }}=\text { total model weight } \\
& \mathrm{W}_{\text {check_total }}=378.4 \mathrm{lbf}
\end{aligned}
$$

The total model weight $\left(\mathrm{W}_{\text {check_total }}\right)$ should equal the total in-vessel dry weight $\left(\mathrm{W}_{\text {total_in }}\right)$ plus the hydrodynamic weights of the in-vessel hanger rod tubes, transition funnel, and capsule facility body above the locater tie:

$$
\begin{array}{ll}
W_{\text {verify }}:=W_{\text {total_in }}+M_{h \_} \text {hrt } & L_{h r}+M_{h \_f u n n e l}+M_{h \_c f b} \cdot L_{a l t} \\
\qquad W_{\text {verify }}=378.5 \mathrm{lbf} & W_{\text {verify }}=\text { weight for verifying against } \\
& W_{\text {check_total }}
\end{array}
$$

:The model weight $\left(\mathrm{W}_{\text {check_total }}\right)$ is considered an acceptable match to the verified weight $\left(\mathrm{W}_{\text {verify }}\right)$. 


\section{C4. References}

C1. R. J. Fritz, The Effects of Liquids on the Dynamic Motions of Immersed Solids, Transactions of the ASME Journal of Engineering for Industry, February 1972.

C2. S. D. Snow, Structural Evaluation of the ATR Irradiation Capsule Experiment (ICE) Test and Facility, EDF ATR-TRA-1275, Rev. 0, November 1997.

C3. R. K. Blandford, Structural Evaluation of the ATR Multiple Irradiation Capsule Experiment (MICE) Test Train, Facility and Equipment, EDF ATR-TRA-1512, Rev. 0, September 1999. 


\section{Appendix D}

\section{ASME Code - Computer Calculations}


The Class 3 in-vessel portion of the AGC-1 experiment consists of the hanger rod extension and transition tubes, a funnel transition tube, a transition funnel, the capsule facility body (tube also), and a bottom cap. Appendix $B$ evaluated these components using the design by rule (specifically, for minimum thickness requirements) equations for design and Service Levels A through C conditions. Loadings considered included internal and external pressure, flow drag, and flow vibration at the condition temperature. Other Code design requirements, including Service Level D (seismic) conditions will be evaluated in this appendix using computer-based analysis methods.

This AGC-1 experiment resembles a piping system more than a traditional vessel design. The ASME Code for Class 3 components (Ref. 3 of the report main body references), Subsection ND-3600 defines the requirements for piping systems. This typically requires the evaluation of design conditions (sustained mechanical loads: ND-3652, Equation 8), Service Level A and B conditions (occasional mechanical loads: ND-3653.1, Equation 9) including thermal expansion (ND-3653.2, Equation 10), Service Level C conditions (ND-3654.2 $\rightarrow$ ND-3653.1, Equation 9), and Service Level D conditions (ND-3655 $\rightarrow$ ND-3653.1, Equation 9), each with specified allowable stress limits. In these equations, pressure stresses (where applicable) are added to the stresses produced by moments in the pipe due to sustained and occasional loadings (e.g., gravity, seismic).

However, because this experiment is a straight, vertically oriented assembly (see Figure D1), there are no moments produced in the pipe due to gravity and no moments due to thermal expansion (experiment is unrestrained longitudinally). Therefore, the minimum thicknesses calculations performed in Appendix B satisfy the design and Service Level A through C conditions and the associated required calculations. Only the Service Level D seismic conditions produce moments in the AGC-1 experiment.

Therefore, this appendix will only address the analysis of the in-vessel portion of the AGC-1 experiment under the Service Level D conditions. The following analysis employed the PipeStress computer program, run on computer MIRA, which has been validated (see Appendix A) for application to piping systems being analyzed to the requirements of the ASME Code for Class 3 piping.

The report main body defined the seismic loading which consisted of two enveloping acceleration response spectra (at $5 \%$ critical damping). The experiment was modeled consistent with the design drawings, using the piping model weights calculated in Appendix C. The ASME Code requires that Subsection ND-3653.1 Equation (9) be satisfied. That equation is as follows:

$B_{1}{ }^{*} P_{\max }{ }^{*} D_{o} / 2{ }^{*} t_{n}+B_{2}{ }^{*}\left(M_{A}+M_{B}\right) / Z \leq 3^{*} S_{h}$ or $2{ }^{*} S_{y}$ where:

$\mathrm{B}_{1}, \mathrm{~B}_{2}=$ primary stress indices for the specific product under investigation

$\mathrm{P}_{\max }=$ peak pressure (use 390 psig, even though this is external design/operating pressure)

$\mathrm{D}_{\mathrm{o}} \quad=$ outside diameter of the component

$t_{n} \quad=$ nominal thickness of the component

$\mathrm{M}_{\mathrm{A}} \quad=$ moment on the pipe due to sustained loads ( 0 in this case)

$\mathrm{M}_{\mathrm{B}} \quad$ = moment on the component due to seismic loads (to be calculated by PipeStress)

$\mathrm{S}_{\mathrm{h}} \quad=$ allowable stress at temperature $(240 \mathrm{~F}, @ 20 \mathrm{ksi}$ for 304 - see Table 2 in report $)$

$\mathrm{S}_{\mathrm{y}} \quad=$ yield strength at temperature (240 F, @ 23.9 ksi for 304)

Figure D1 shows the model of the AGC-1 experiment. 


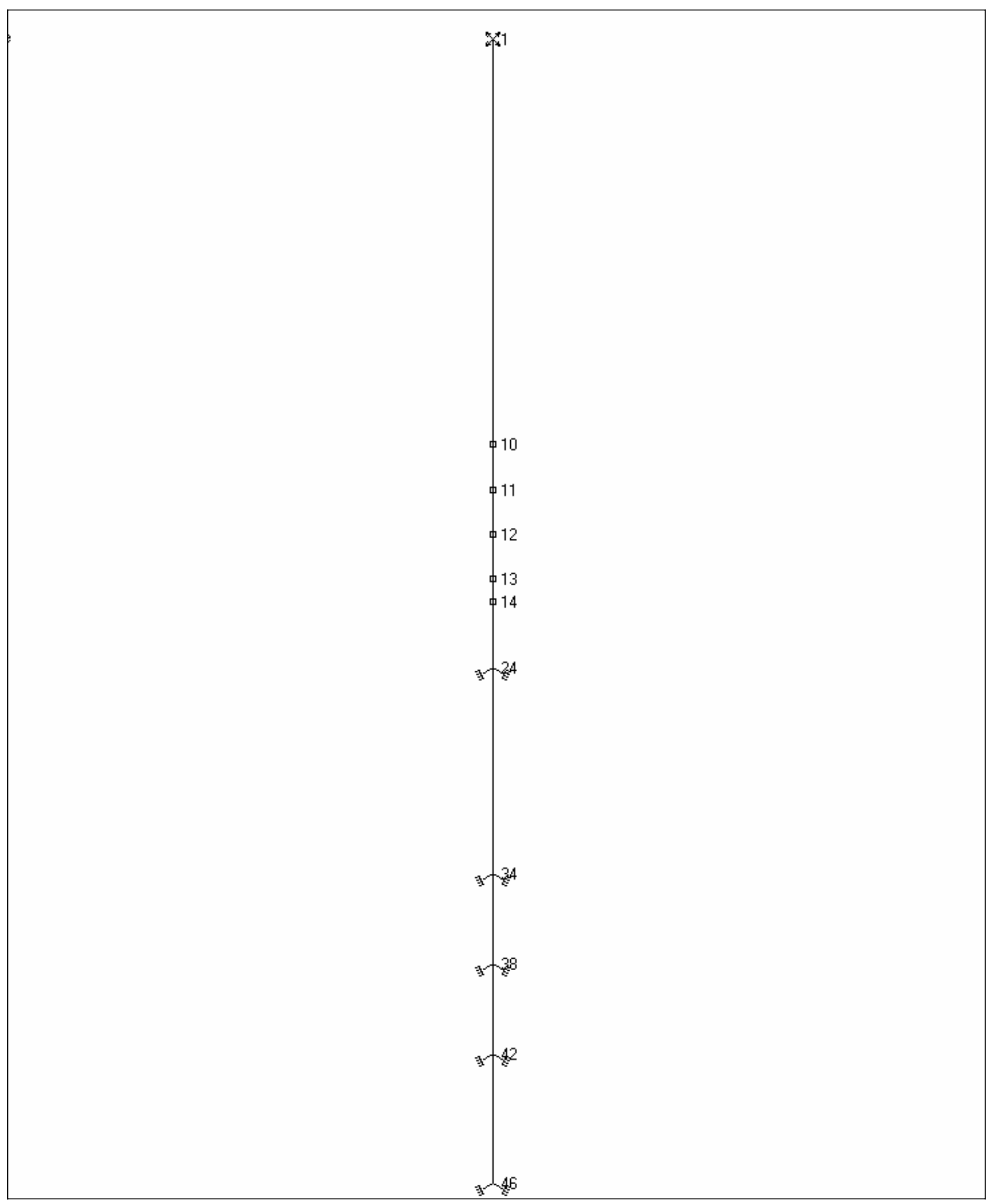

Figure D1. PipeStress model of AGC-1 experiment. (+Y up, $+X \&+Z$ Horizontal) 
On the PipeStress model (shown in Figure D1), the following represents:

- $\quad$ Point 1 represents the seal plug which is anchored (6-direction restraint),

- Points 1 through 10 represent the hanger rod extension tube,

- Points 10 through 14 represent the hanger rod and funnel transition tubes,

- Points 14 to 20 represent the transition funnel,

- Points 20 through 46 represent the capsule facility body,

- $\quad$ Point 24 represents the locater tie (horizontal restraints),

- $\quad$ Point 34 represents the top of the core (horizontal restraints),

- $\quad$ Point 38 represents the core centerline (horizontal restraints),

- $\quad$ Point 42 represents the core bottom (horizontal restraints),

- $\quad$ Point 46 represents the bottom cap (horizontal restraints).

The capsule facility body enters the chopped dummy in-pile tube at 2-inches above the locater tie and is contained within that tube through the bottom cap. The chopped dummy inpile tube essentially restrains the capsule facility body from horizontal motion, though above and below the reactor core some small motion of the in-pile tube is possible. Therefore, the capsule facility body was only restrained horizontally at the locater tie, the top, middle, and bottom of the core, and at the bottom cap. This was considered conservative since it would allow for some horizontal motion between those support points.

First, the natural frequencies of the system were calculated as follows:

\begin{tabular}{|c|c|}
\hline Mode & Frequency (Hz.) \\
\hline 1 and 2 & 20.1 \\
\hline 3 and 4 & 56.7 \\
\hline 5 and 6 & 81.2 \\
\hline
\end{tabular}

Each mode occurred twice, once in the model $+X$ horizontal direction and once in the model $+Z$ horizontal direction (because of symmetry). There were no modes below $100 \mathrm{~Hz}$. whose motion was in the vertical (model $Y$ ) direction.

Next, the acceleration response spectra were applied to the model. Again, it is noted that the external design/operating pressure of 390 psig with a 0 psig internal pressure were employed in this PipeStress model. The Equation (9) resulting stresses in the model components were as follows: 


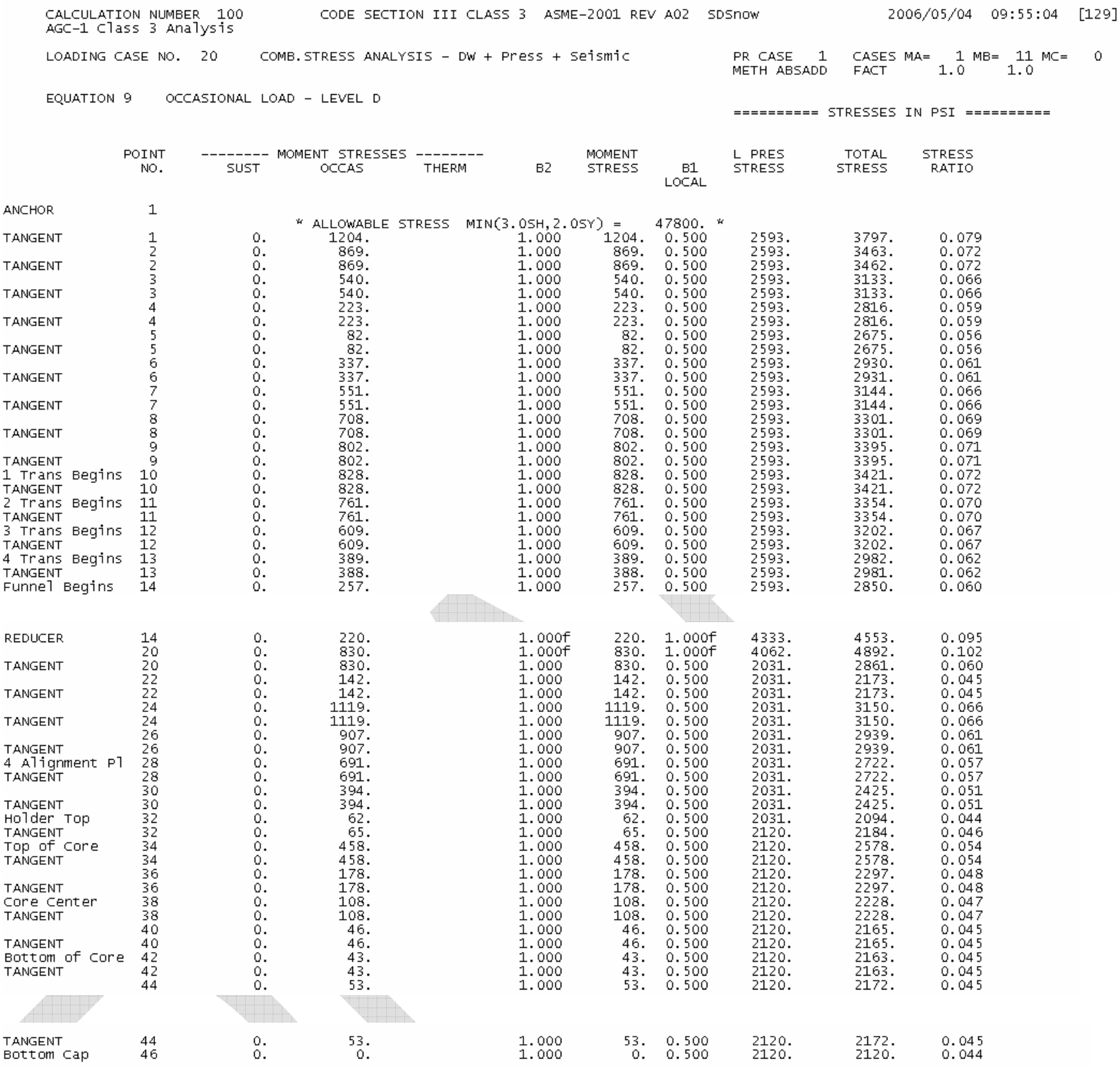

The above shows the sustained stress at zero (as expected due to no moments caused by gravity), the pressure stress due to the 390 psig external design/operating pressure, and the stresses due to the occasional (seismic) loads. The largest total Eqn. (9) stress of 4,892 psi occurred in the transition funnel at Point 20 . This is very low, especially when compared to the allowable stress of 40,800 psi (shown above).

:AGC-1 Experiment design satisfies the ASME Code for Class 3 components under the specified seismic loading. 


\section{PipeStress Input Model}

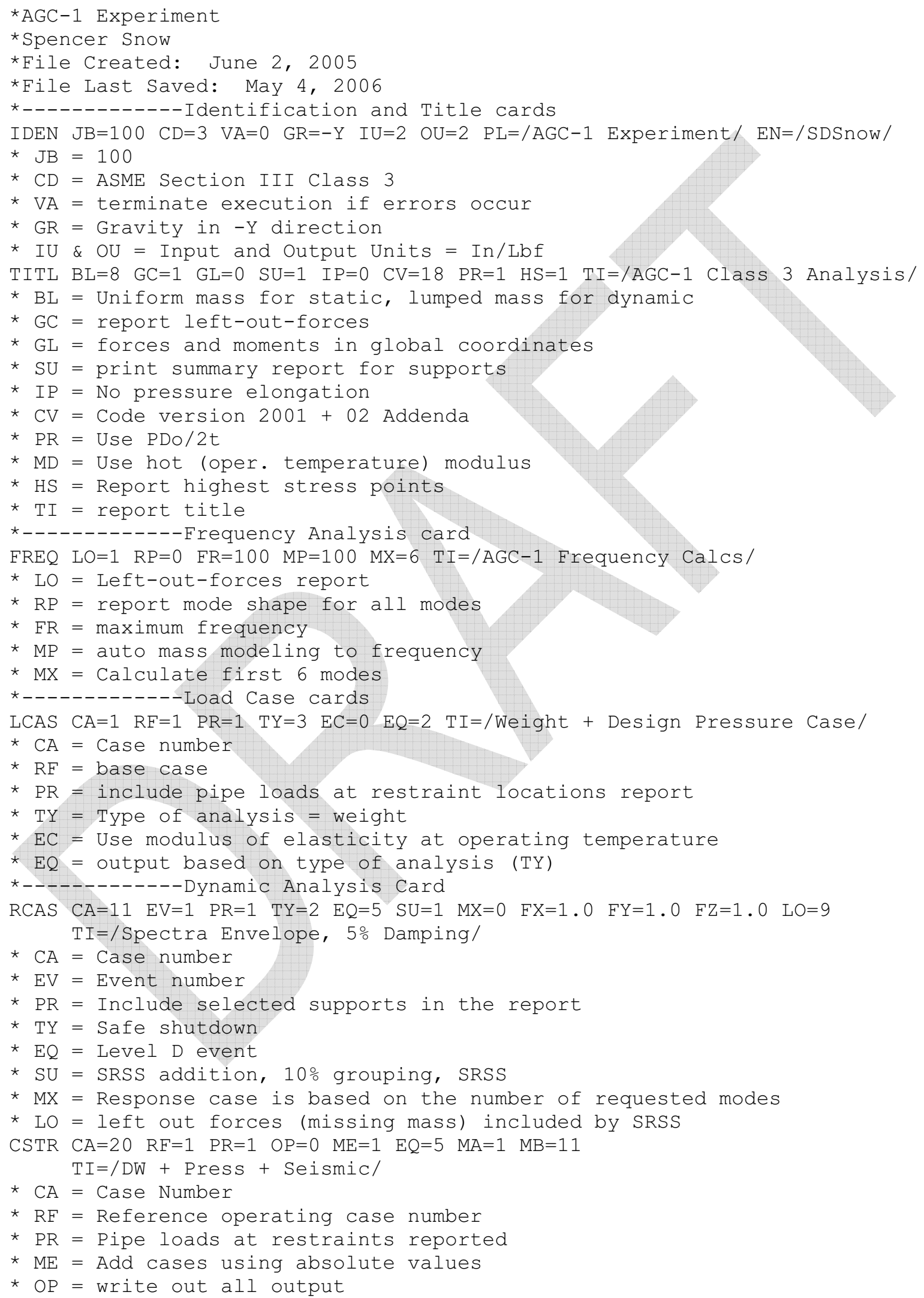


* $\mathrm{EQ}=$ ASME Equation 9

* $\mathrm{MA}=$ Case number for sustained load

* $\mathrm{MB}=$ Case number for occasional load

$\mathrm{SPEC}$ FS=ENV EV=1 RA=0 $\mathrm{FP}=0 \mathrm{ME}=1 \mathrm{BT}=5 \mathrm{TI}=/$ Spectra Envelope/

$\mathrm{LV}=1$

$\mathrm{DI}=\mathrm{XZ}$

$0.00 / 0.000 \quad 0.001 / 0.013 \quad 1.00 / 0.354 \quad 2.50 / 0.751$

$9.00 / 0.626 \quad 13.50 / 0.512 \quad 33.0 / 0.303 \quad 50.0 / 0.240$

$100.0 / 0.240$

$\mathrm{DI}=\mathrm{Y}$

$\begin{array}{llll}0.00 / 0.000 & 0.001 / 0.009 & 1.00 / 0.236 & 2.50 / 0.501\end{array}$

$7.63 / 0.435 \quad 20.00 / 0.435 \quad 33.0 / 0.274 \quad 50.0 / 0.180$

$100.0 / 0.180$

$\star \mathrm{EV}=$ Event number

* $\mathrm{RA}=$ Spectral acceleration not to exceed $10 \mathrm{~g}$

* $\mathrm{FP}=$ Spectrum is Freq. vs. Accel

* $\mathrm{ME}=$ Linear Freq vs. Iinear Accel

* $\mathrm{BT}=$ Percent critical damping $=5 \%$

*------------Define Materials

*--304L Stainless Steel for Transition Funnel

$\mathrm{MATH} C D=304 \mathrm{EX}=0 \mathrm{TY}=4 \mathrm{TX}=240.0 \mathrm{TA}=70.0 \mathrm{AL}=/ 304 \mathrm{SST} /$

* 304 Stainless steel

* $\mathrm{EX}=$ linear thermal expansion (in/100 ft)

* TY = Austennitic Stainless

* $\mathrm{TX}=$ Maximum temperature of 240 deg. $\mathrm{F}$

* $\mathrm{TA}=$ Ambient temperature of 70 deg. $\mathrm{F}$

MATD TE=70.0 EH=28.3 EX=0.0 $\mathrm{SH}=20.0 \quad \mathrm{SY}=30.0 \quad \mathrm{SM}=20.0$

MATD TE=100. $\mathrm{EH}=28.3 \quad \mathrm{EX}=0.3 \quad \mathrm{SH}=20.0 \quad \mathrm{SY}=30.0 \quad \mathrm{SM}=20.0$

MATD TE=180. EH=27.7 $\mathrm{EX}=1.16 \quad \mathrm{SH}=20.0 \quad \mathrm{SY}=25.7 \quad \mathrm{SM}=20.0$

MATD TE=200. $\mathrm{EH}=27.6 \mathrm{EX}=1.40 \quad \mathrm{SH}=20.0 \quad \mathrm{SY}=25.0 \quad \mathrm{SM}=20.0$

$\mathrm{MATD} \mathrm{TE}=240 . \mathrm{EH}=27.4 \quad \mathrm{EX}=1.88 \quad \mathrm{SH}=20.0 \quad \mathrm{SY}=23.9 \mathrm{SM}=20.0$

*----------Define OPERATING \& Design Conditions

DESN $P R=390.0 \quad \mathrm{TE}=240.0$

OPER CA=1 TE=240.0 PR=390.0

*-----------Define Piping

MATL $C D=304 \quad A L=/ 304 \quad S S T /$

CROS $\mathrm{CD}=1 \mathrm{OD}=5.000 \mathrm{WT}=0.188 \mathrm{MA}=18.228 \mathrm{SO}=0.0 \mathrm{AL}=/$ Extension Tube/

COOR PT $=1 \quad \mathrm{AX}=0.0 \quad \mathrm{AY}=0.0 \quad \mathrm{AZ}=0.0$

$\mathrm{ANCH} \quad \mathrm{PT}=1 \mathrm{EW}=2 \mathrm{AL}=/$ Seal Plug/

TANG $\mathrm{PT}=2 \quad \mathrm{DY}=-12.0$

TANG $\mathrm{PT}=3 \quad \mathrm{DY}=-12.0$

TANG $\mathrm{PT}=4 \quad \mathrm{DY}=-12.0$

TANG $\mathrm{PT}=5 \mathrm{DY}=-12.0$

TANG $\mathrm{PT}=6 \quad \mathrm{DY}=-12.0$

TANG $\mathrm{PT}=7 \quad \mathrm{DY}=-12.0$

TANG $\mathrm{PT}=8 \quad \mathrm{DY}=-12.0$

TANG $\mathrm{PT}=9 \quad \mathrm{DY}=-12.0$

TANG $\mathrm{PT}=10 \mathrm{DY}=-12.15 \mathrm{EW}=1 \mathrm{AL}=/ 1$ Trans Begins /

LUMP $\mathrm{PT}=10 \mathrm{MA}=7.526 \mathrm{AL}=/ 1$ Mounting Plt/

TANG $\mathrm{PT}=11 \mathrm{DY}=-12.0 \mathrm{EW}=1 \mathrm{AL}=/ 2$ Trans Begins /

LUMP $\mathrm{PT}=11 \mathrm{MA}=7.526 \mathrm{AL}=/ 2$ Mounting Plt/

TANG $\mathrm{PT}=12 \mathrm{DY}=-12.0 \mathrm{EW}=1 \mathrm{AL}=/ 3$ Trans Begins /

LUMP $\mathrm{PT}=12 \mathrm{MA}=7.526 \mathrm{AL}=/ 1 \mathrm{Alignment} \mathrm{Plt} /$

TANG $\mathrm{PT}=13 \mathrm{DY}=-12.0 \mathrm{EW}=1 \mathrm{AL}=/ 4$ Trans Begins /

LUMP $\mathrm{PT}=13 \mathrm{MA}=7.526 \mathrm{AL}=/ 2 \mathrm{Alignment} \mathrm{Plt} /$

TANG $\mathrm{PT}=14 \mathrm{DY}=-6.0 \mathrm{EW}=1 \mathrm{AL}=/$ Funnel Begins/ 


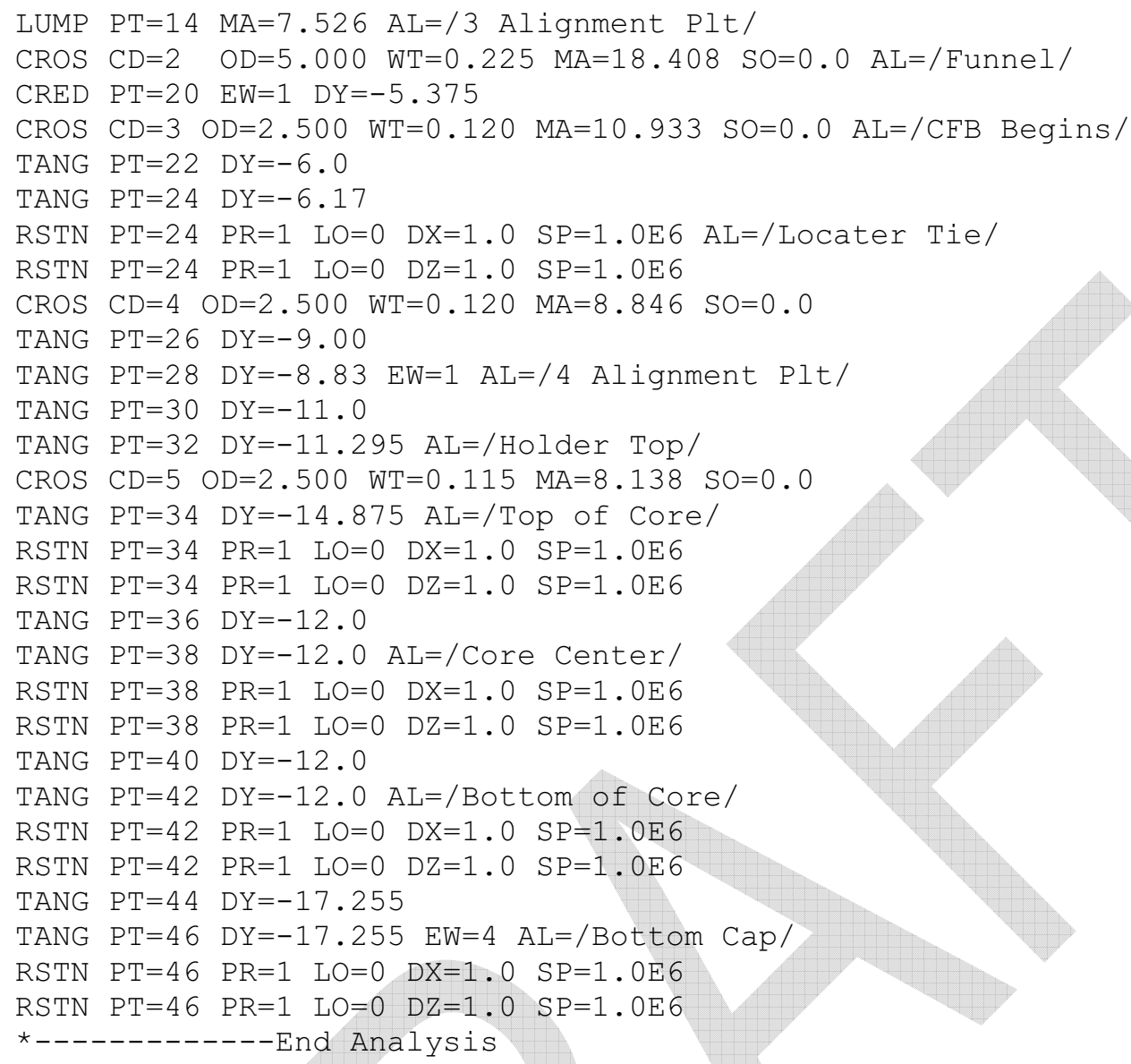


431.02

ENGINEERING DESIGN FILE

EDF-5925

Revision 0

Rev. 11

Page E1 of 4

Appendix E

Other Computer Calculations 
This appendix contain the computer model that was referenced in Appendix B.

\section{Upper Cylinder Mounting Plate Model}

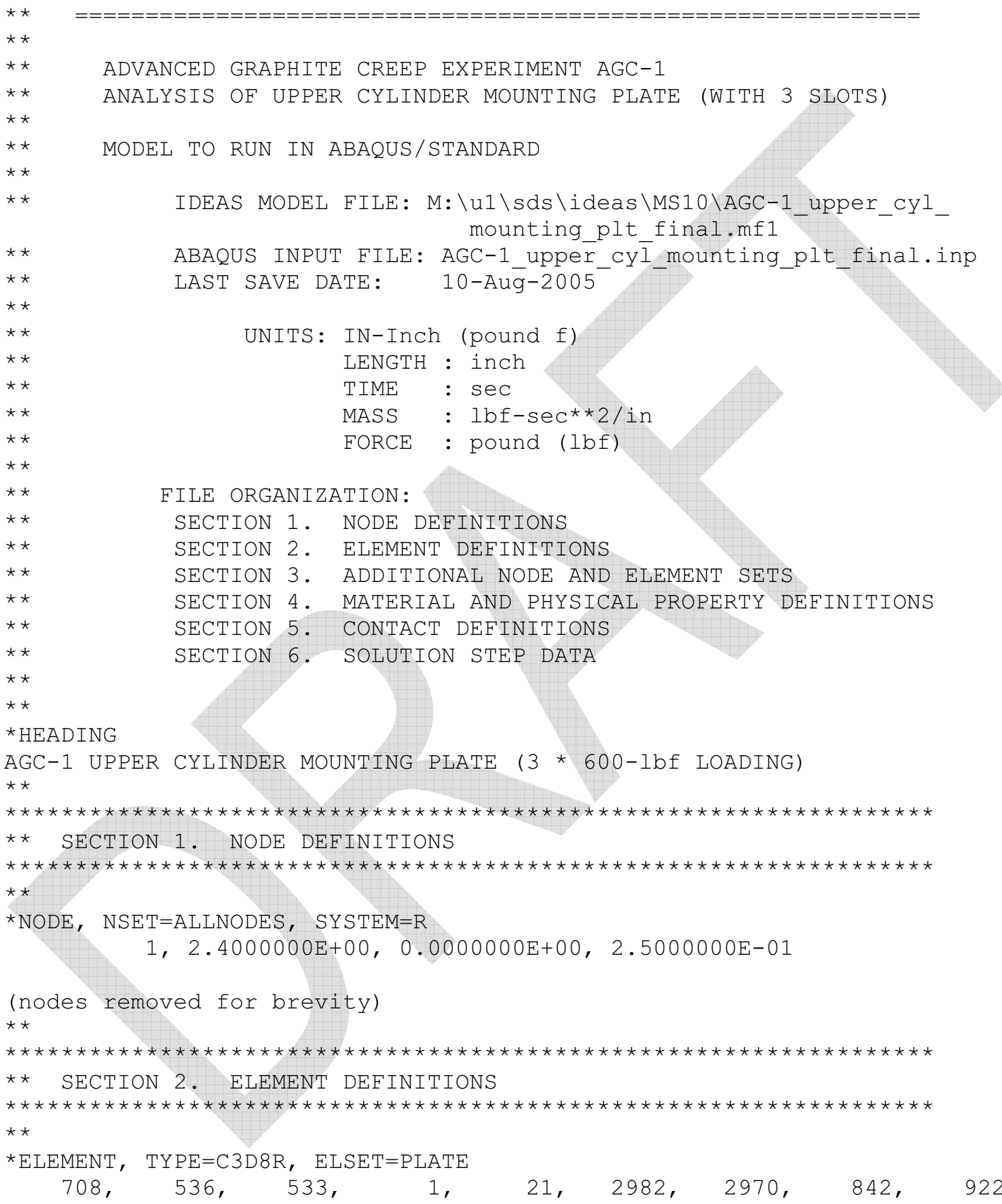

(elements removed for brevity)

$\star \star$

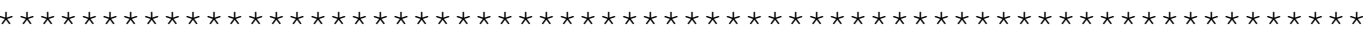

* SECTION 3. ADDITIONAL NODE AND ELEMENT SETS

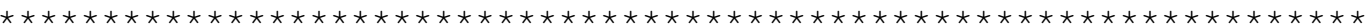

$\star \star$ 
*NSET, NSET $=\mathrm{BS} 000001$

$842,843,844,922,923,924,926,927,928,930,931,932,934,935,936,938$

$939,940,942,943,944,946,947,948,950,951,952,954,955,956,958,959$

$960,962,963,964,966,967,968,970,971,972,974,975,976,978,979,980$

$982,983,984,986,987,988,990,991,992,994,995,996,998,999,1000,1002$

$1003,1004,1006,1007,1008,1010,1011,1012,1014,1015,1016,1018,1019,1020,1022$

$1023,1024,1026,1027,1028,1030,1031,1032,1034,1035,1036,1038,1039,1040,1042$

$1043,1044,1046,1047,1048,1050,1051,1052,1054,1055,1056,1058,1059,1060,1062$

$1063,1064,1066,1067,1068,1070,1071,1072,1074,1075,1076,1078,1079,1080,1082$

$1083,1084,1086,1087,1088,1090,1091,1092,1094,1095,1096,1098,1099,1100,1102$

$1103,1104,1106,1107,1108,1110,1111,1112,1114,1115,1116,1118,1119,1120,1122$

$1123,1124,1126,1127,1128,1130,1131,1132,1134,1135,1136,1138,1139,1140,1142$

$1143,1144,1146,1147,1148,1150,1151,1152,1154,1155,1156,1158,1159,1160,1162$

$1163,1164,1166,1167,1168,1170,1171,1172,1174,1175,1176,1178,1179,1180,1182$

$1183,1184,1186,1187,1188,1190,1191,1192,1194,1195,1196,1198,1199,1200,1202$

$1203,1204,1206,1207,1208,1210,1211,1212,1214,1215,1216,1218,1219,1220,1222$

$1223,1224,1226,1227,1228,1230,1231,1232,1234,1235,1236,1238,1239,1240,1242$

$1243,1244,1246,1247,1248,1250,1251,1252,1254,1255,1256,1258,1259,1260,1262$

$1263,1264,1266,1267,1268,1270,1271,1272,1274,1275,1276,1278,1279,1280,1282$

$1283,1284,1286,1287,1288,1290,1291,1292,1294,1295,1296,1298,1299,1300,1302$

$1303,1304,1306,1307,1308,1310,1311,1312,1314,1315,1316,1318,1319,1320,1322$

1323,1324

*NSET, NSET $=\mathrm{BS} 000002$

$8,14,20,166,167,168,169,170,171,172,173,174,175,176,177,178$

$179,180,181,182,183,184,185,186,216,217,218,219,220,221,222,223$

$224,225,226,227,228,229,230,231,232,233,234,235,236,266,267,268$

$269,270,271,272,273,274,275,276,277,278,279,280,281,282,283,284$

285,286

$\star \star$

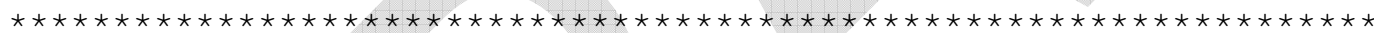

** SECTION 4. MATERIAL AND PHYSICAL PROPERTY DEFINITIONS

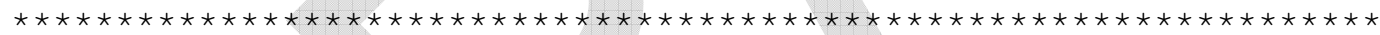

$\star \star$

$\star$ SOLID SECTION, ELSET=PLATE, MATERIAL=SSTEEL

$\star \star$

*MATERIAL, NAME=SSTEEL

*ELASTIC, TYPE=ISOTROPIC

3.00E+07, 0.29

*DENSITY

7. 32E-04,

*PLASTIC

30000,0 .

$100000,1.0$

$\star \star$

$\star \star$

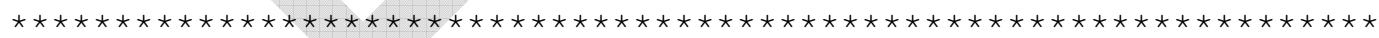

** SECTION 5. CONTACT DEFINITION

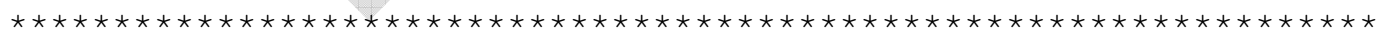

$\star * *$

$\star \star N O$ CONTACT IN MODEL

$\star \star$

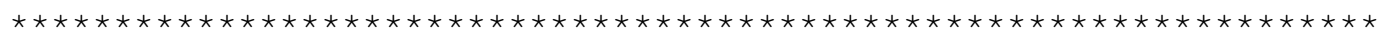

** SECTION 6 . SOLUTION STEP DATA

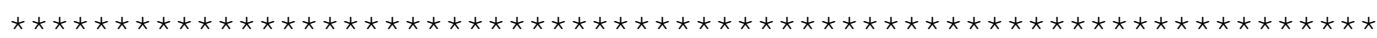

$\star \star$

$\star$ STEP, AMPLITUDE $=$ RAMP,$I N C=100$

* STATIC 
$0.1,1.0,1.0 \mathrm{E}-06$,

$\star \star$

*BOUNDARY, OP=NEW

BS000001, $1,3, \quad 0.00000 \mathrm{E}+00$

$\star \star$

* APPLy 600 LB LOAD AT 3 PLACES

$\star \mathrm{CLOAD}, \mathrm{OP}=\mathrm{NEW}$

$\mathrm{BS} 000002, \quad 3,2.7273 \mathrm{E}+01$

$\star *$

*OUTPUT, FIELD, VARIABLE=PRESELECT

*OUTPUT, HISTORY, VARIABLE=PRESELECT

$\star \star$

$\star$ END STEP

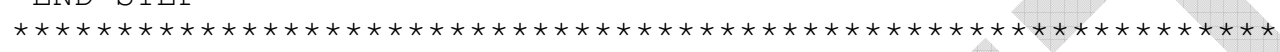


431.02

431.02
$01 / 30 / 2003$

ENGINEERING DESIGN FILE

EDF-5925

Rev. 11

Revision 0

Page F1 of?

Appendix F

Thermal Stress Analysis of the Capsule Reactor Core Components 


\section{Background}

The AGC-1 experiment will have high temperature gradients during operation (see Fig. 3 ). It is necessary to evaluate the effect of the thermal stresses caused by these gradients in the experiment. Areas of concern are the outer pressure boundary, the graphite holder and the heat shield.

\section{Thermal Stress Model}

The thermal stresses in the AGC-1 experiment will be evaluated using finite elements and analyzed using ABAQUS/Standard. The various components of in the finite element model are shown in Figures 1 and 2.

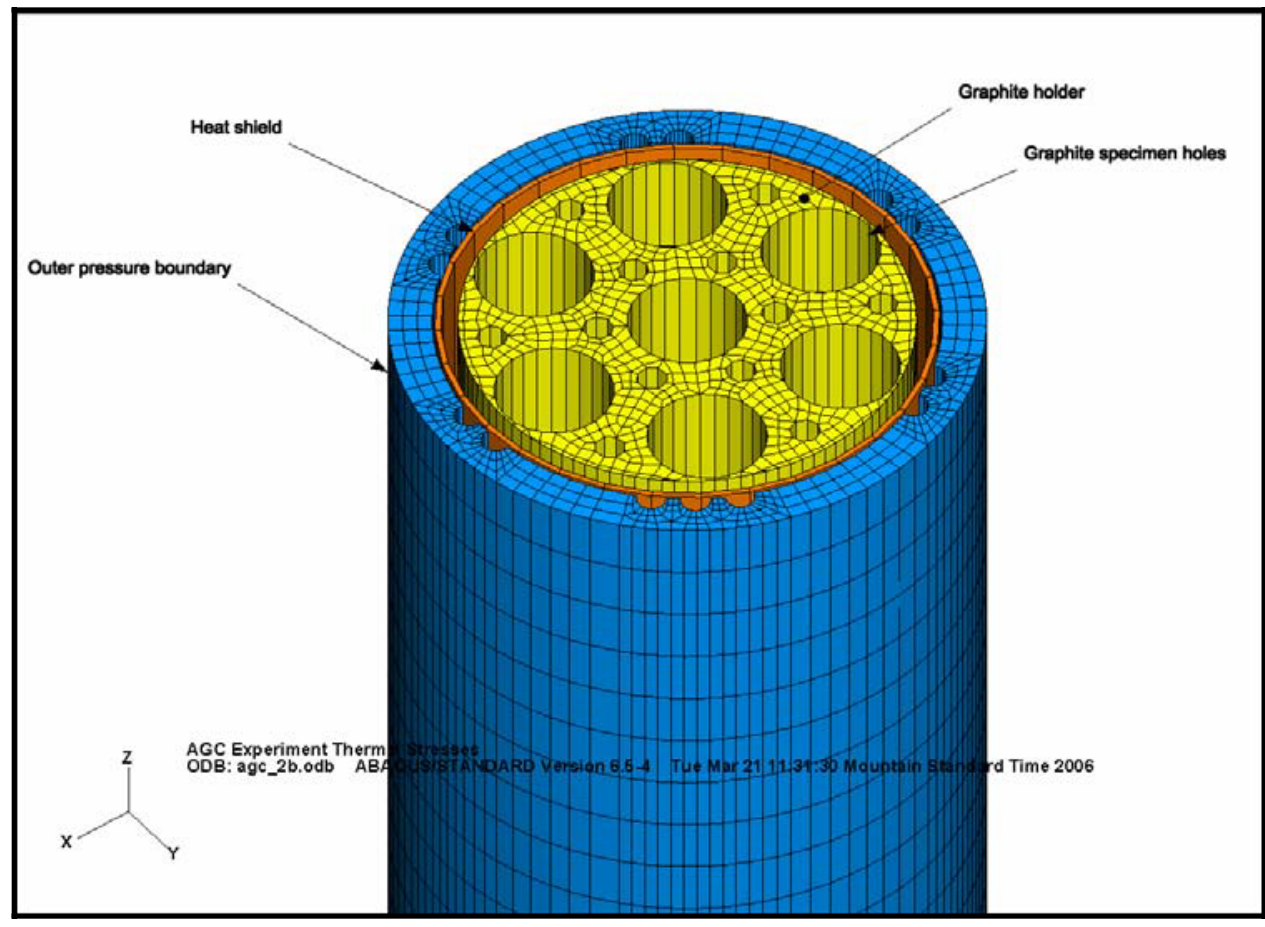

Figure 1. Finite element model of the AGC-1 experiment. 


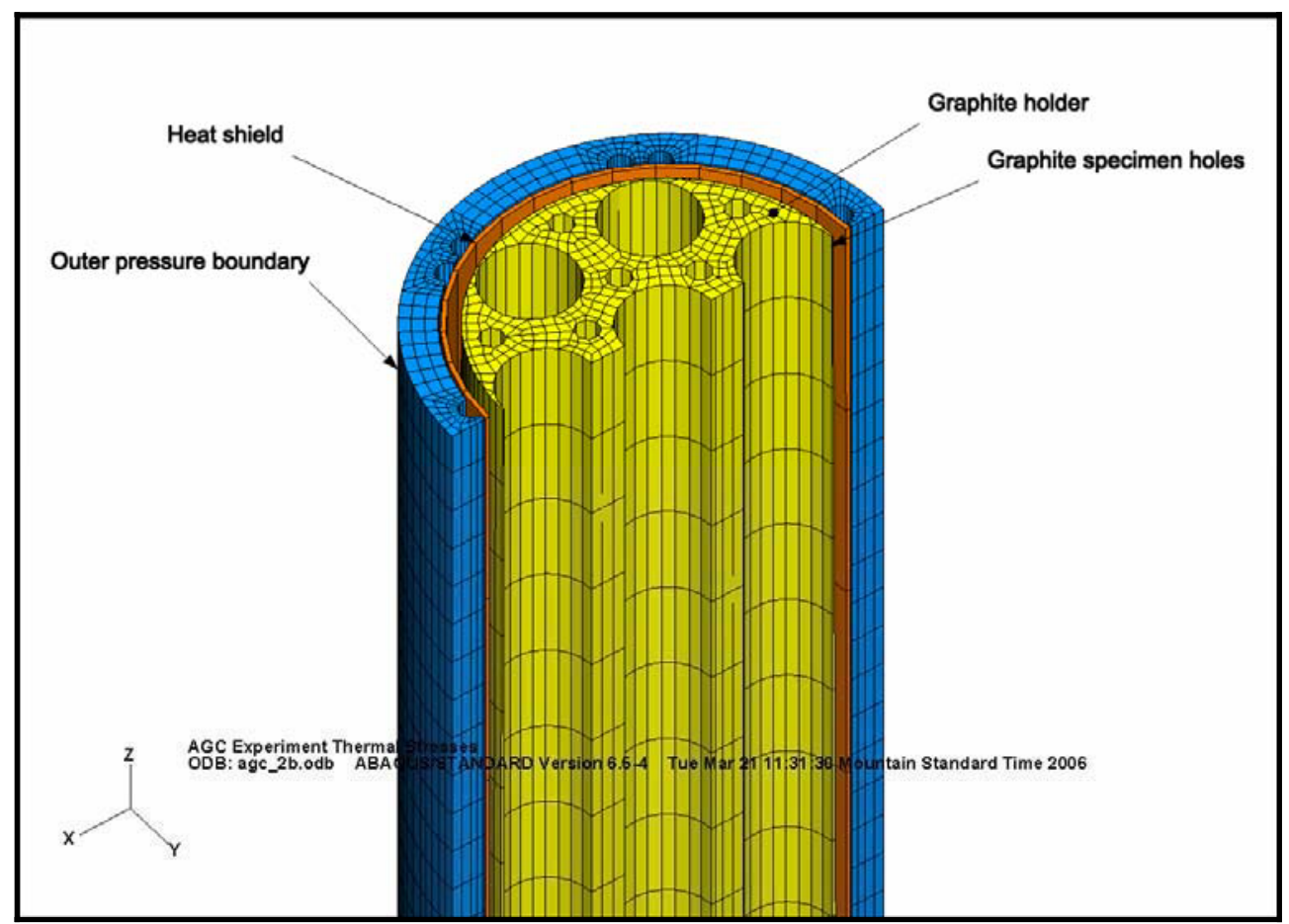

Figure 2. Cutaway view showing the inside of the experiment.

\subsection{Components}

\subsubsection{Outer Pressure Boundary}

The outer pressure boundary is 72 inches long with an outside diameter of 2.500 inches (Ref. 1). It has an inside diameter of 2.144 inches with a wall thickness of 0.178 inches. Small semi-circular grooves with a radius of 0.063 inches, parallel to the axis of the cylinder, are spaced around the inside of the tube in pairs, except for one location where three grooves are located (see Fig. 1). This outer pressure boundary is fabricated from type 304 stainless steel.

\subsubsection{Heat Shield}

The heat shield is also cylindrical. It is 52 inches long with an outer diameter of 2.110 inches (Ref. 2). The inner surface of the cylinder tapers so that at core centerline, the wall thickness is 0.005 inches. It increases in thickness upward until it is 0.025 inches at 24 inches above the core centerline at the top of the core and maintains this thickness for 2.00 more inches to the top. It tapers the same way below the core centerline. The high nickel alloy heat shield is fabricated from Haynes 230 (see Ref. 2).

\subsubsection{Graphite Holder}

The graphite holder is also cylindrical (Ref. 3). The outside has a gradual taper from 2.074-in diameter at the core centerline to about 1.913-in diameter at the top of the core. It has 6 specimen holes with a diameter of 0.635 inches on a circular pattern with a diameter of 1.390 inches. The center hole is also has a diameter of 0.635 in. There are multiple holes with a diameter of 0.132 inches interspersed among the specimen holes for gas tubes and thermocouples. The graphite holder is machined from AXF-5Q1 graphite. 


\subsection{Materials}

Material properties for the components used in this analysis are listed in Section 7 of the main body of this EDF. They are also listed in the abbreviated input file in Section 7 of this appendix.

\subsection{Modeling Details}

Temperatures calculated for this experiment are considered symmetrical about the reactor core centerline. Therefore, only the portion of the experiment from the core centerline to the top of the core was modeled. The temperatures decrease rapidly above the core and will not result in thermal stresses that are higher than those calculated for the in-core section.

The graphite specimens are not included in the thermal stress model since they are smaller than the holes. They are not predicted to swell in size and cause contact stresses in the graphite specimen holder.

The loads applied by the push rods are not applied to the finite element model because the calculations show that they do not cause high stresses in the graphite holder (see section B4.1.6 in the main EDF). Also, the graphite becomes stronger with increased temperature and irradiation. The loads will be applied to the graphite specimens which in turn transfer the load to the graphite holder just above the core centerline. This load, applied to a short section of the graphite holder, will result in negligible additional stresses.

\subsection{ABAQUS Finite Element Model}

The finite element model was created using I-DEAS (Ref. 4) and then translated to an ABAQUS/Standard (Ref. 5) input file.

The outer pressure boundary was modeled using brick elements to account for the grooves on the inside surface. The heat shield was modeled using continuum shell elements since the thickness varies along its length. These elements are modeled the same as brick elements, but they pick up their thickness from the node spacing in the thickness direction. The graphite specimen holder was modeled with brick elements. It was originally modeled with a straight outer surface. The outer node coordinates were then modified with a $\mathrm{C}$ program to move the nodes inward and give the holder the correct taper.

Contact was modeled using contact pairs since general contact is not available in ABAQUS/Standard. A generic coefficient of friction of 0.4 was used between all surfaces.

Each node was given an initial temperature of $70^{\circ} \mathrm{F}$ in the model.

\section{Temperatures}

Temperatures for this thermal stress model were calculated in an ABAQUS/Standard thermal model and then imported into the stress model (Ref. 6). Temperatures were imported component by component basis. The temperature assigned to the node in the stress model was imported from the closest node in the thermal model for that component. Figures 3 and 4 show the temperature distribution $\left({ }^{\circ} \mathrm{F}\right)$ used for this analysis. 


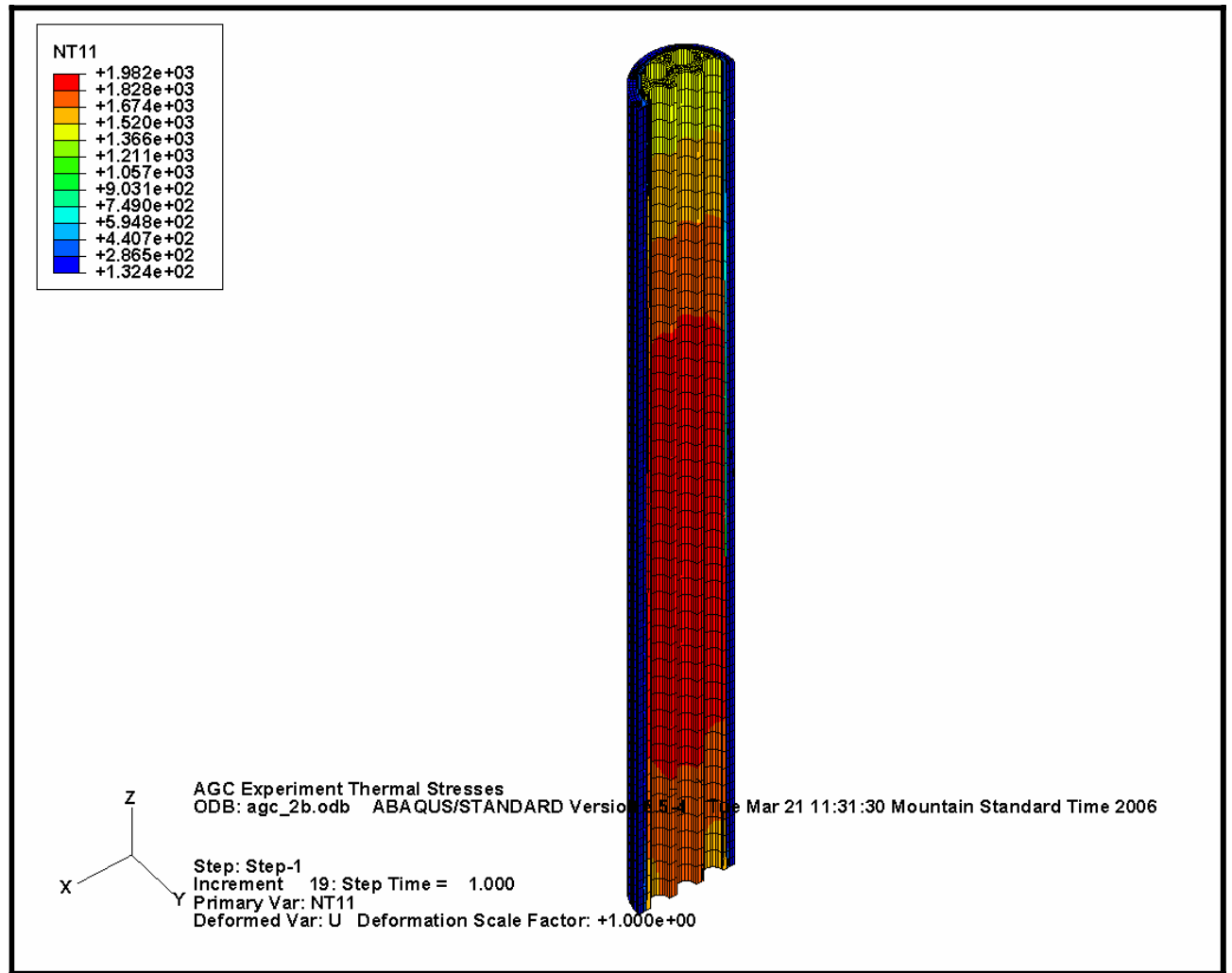

Figure 3. Temperatures $\left({ }^{\circ} \mathrm{F}\right)$ imported from the thermal model into the stress model.

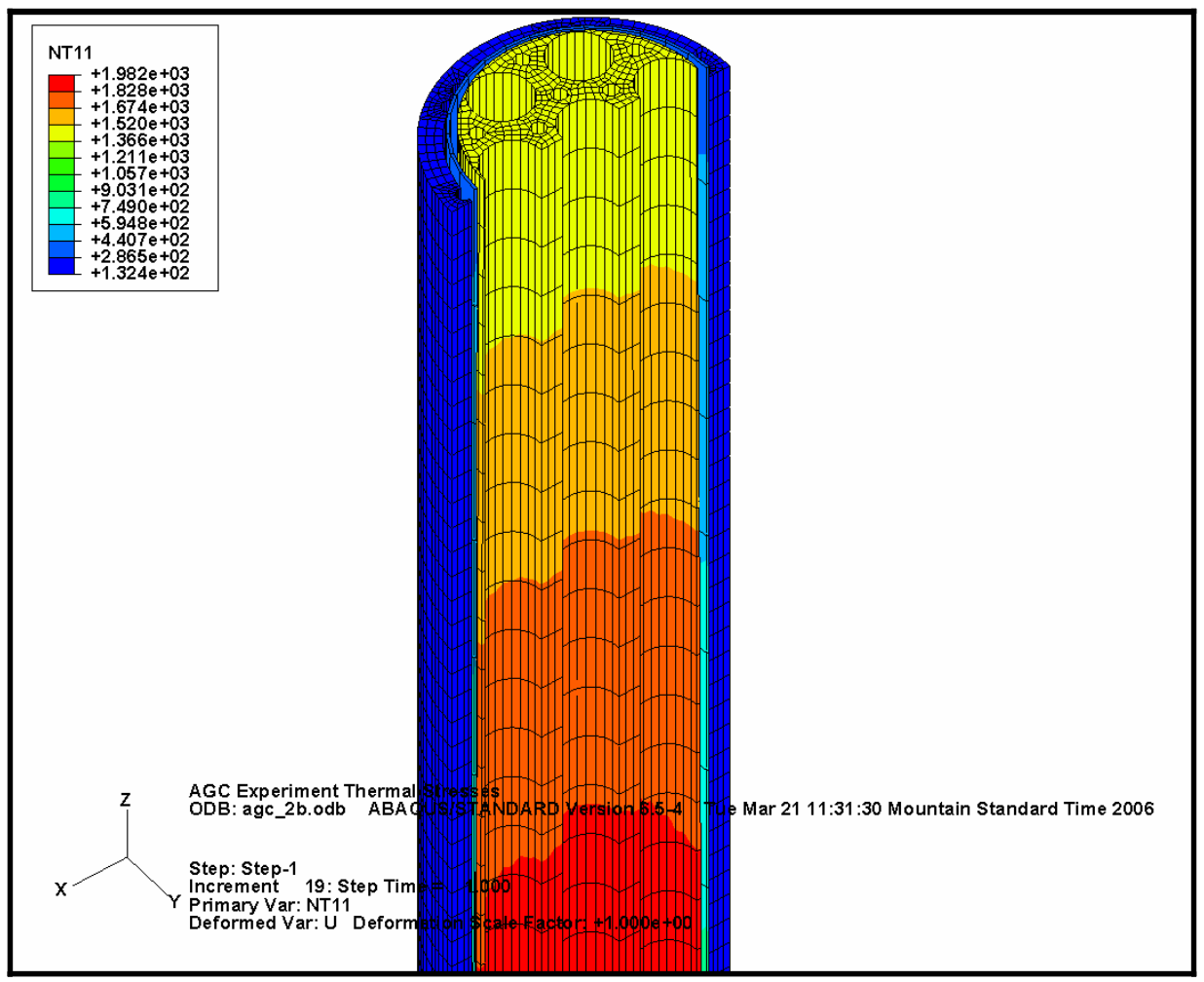

Figure 4. Close-up view of the temperature distribution. 


\section{Results}

Plastic strains, due to thermal expansion of the components, occur in the lower portion of the outer pressure boundary (Fig. 5). These strains are located at the bottom of the grooves on the inside of the outer pressure boundary and are shown in more detail in Figure 6 . The maximum calculated plastic strain is less than $0.5 \%$.

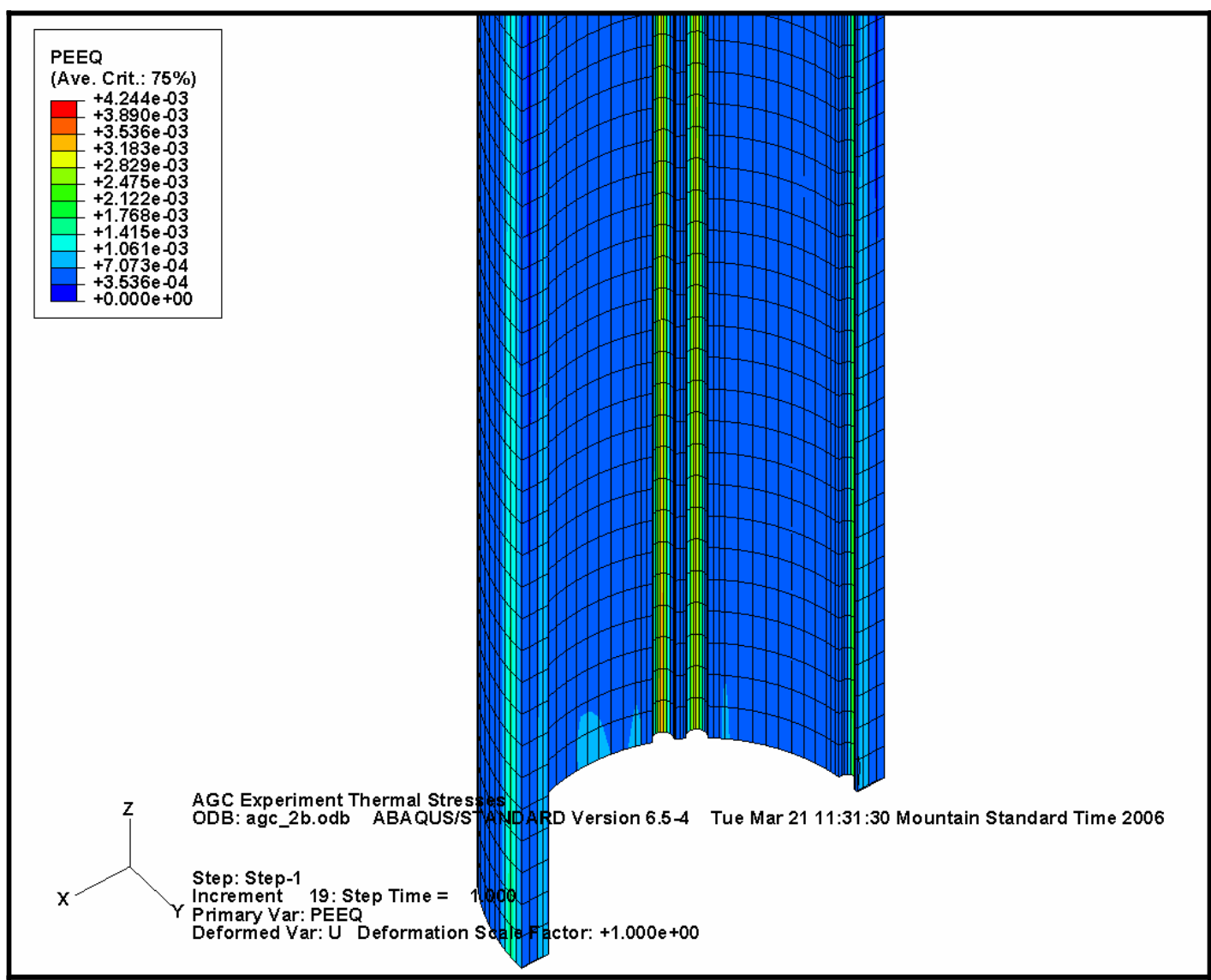

Figure 5. Plastic strains in the bottom portion of the outer pressure boundary.

These calculated temperatures are based on a reactor design temperature of $240^{\circ} \mathrm{F}$ for normal operating temperatures (Ref. 6).

These strains are produced by thermal or secondary stresses. The first time the experiment heats up to temperature the material will strain plastically (less than $0.5 \%$ ) and relieve the stresses. After this material plastically strains, the stresses will be at or below yield. On subsequent startup cycles the stresses will always be at or below yield and additional plastic straining will not occur. Thermal stresses will not cause failure of the outer pressure boundary.

Therefore, after the initial startup, subsequent thermal cycles will only produce an elastic response in this outer pressure boundary. 


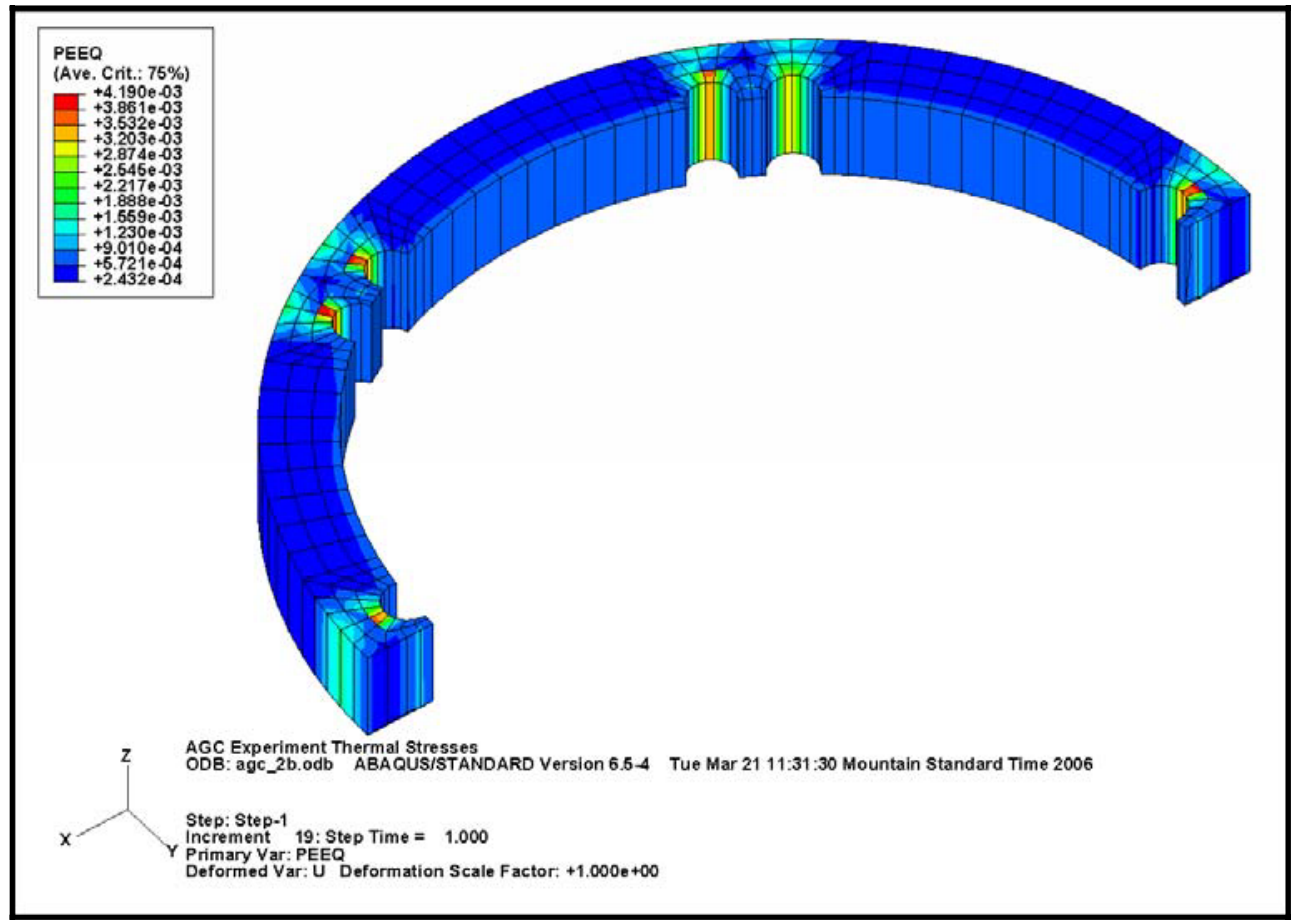

Figure 6. Plastic strain in the outer pressure boundary just above the core centerline.

The thermal stresses in the heat shield are less than $10 \mathrm{ksi}$ (Fig. 7). These low stresses indicate that there is no plastic strain in the heat shield. The maximum temperature of the heat shield is about $1142^{\circ} \mathrm{F}$ (Fig. 8). The yield strength of the Haynes 230 at this temperature is about $22.2 \mathrm{ksi}$.

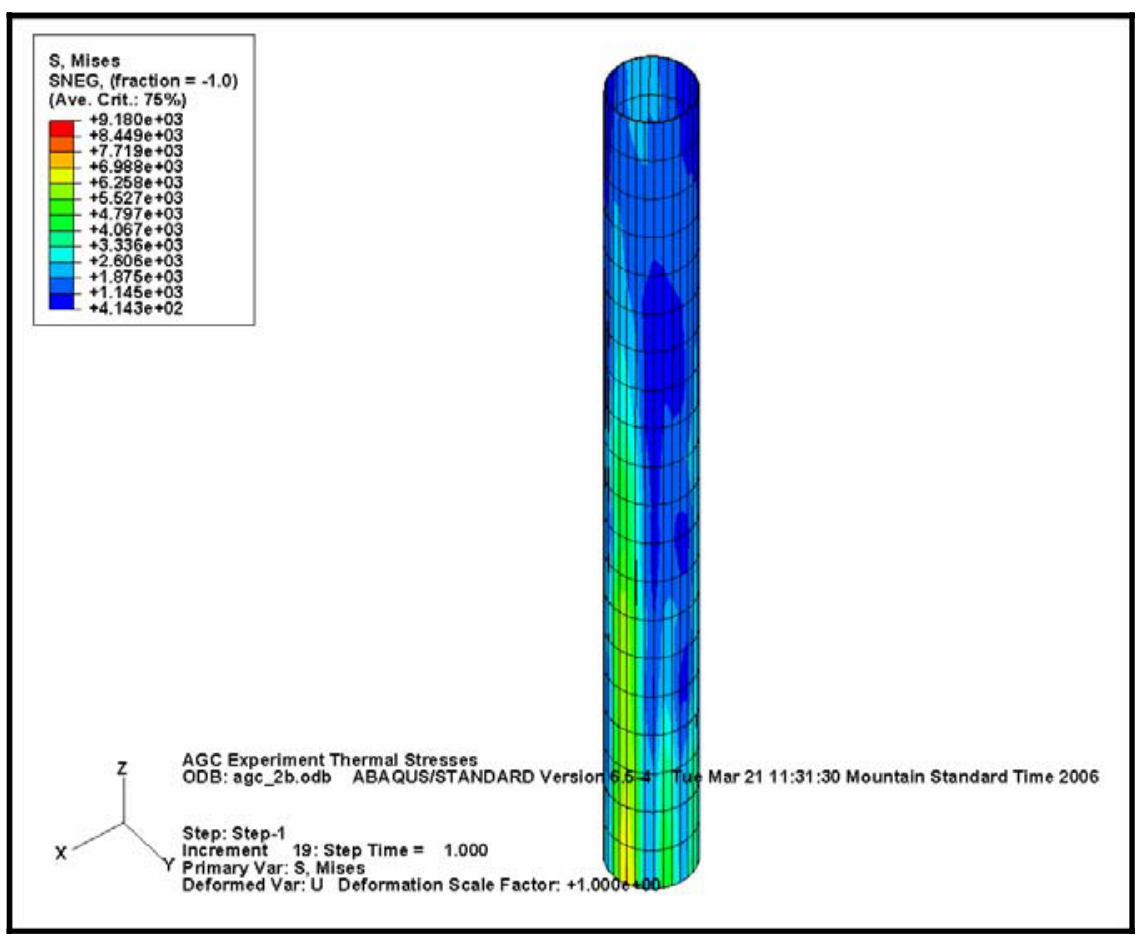

Figure 7. Stresses in the thermal heat shield. 


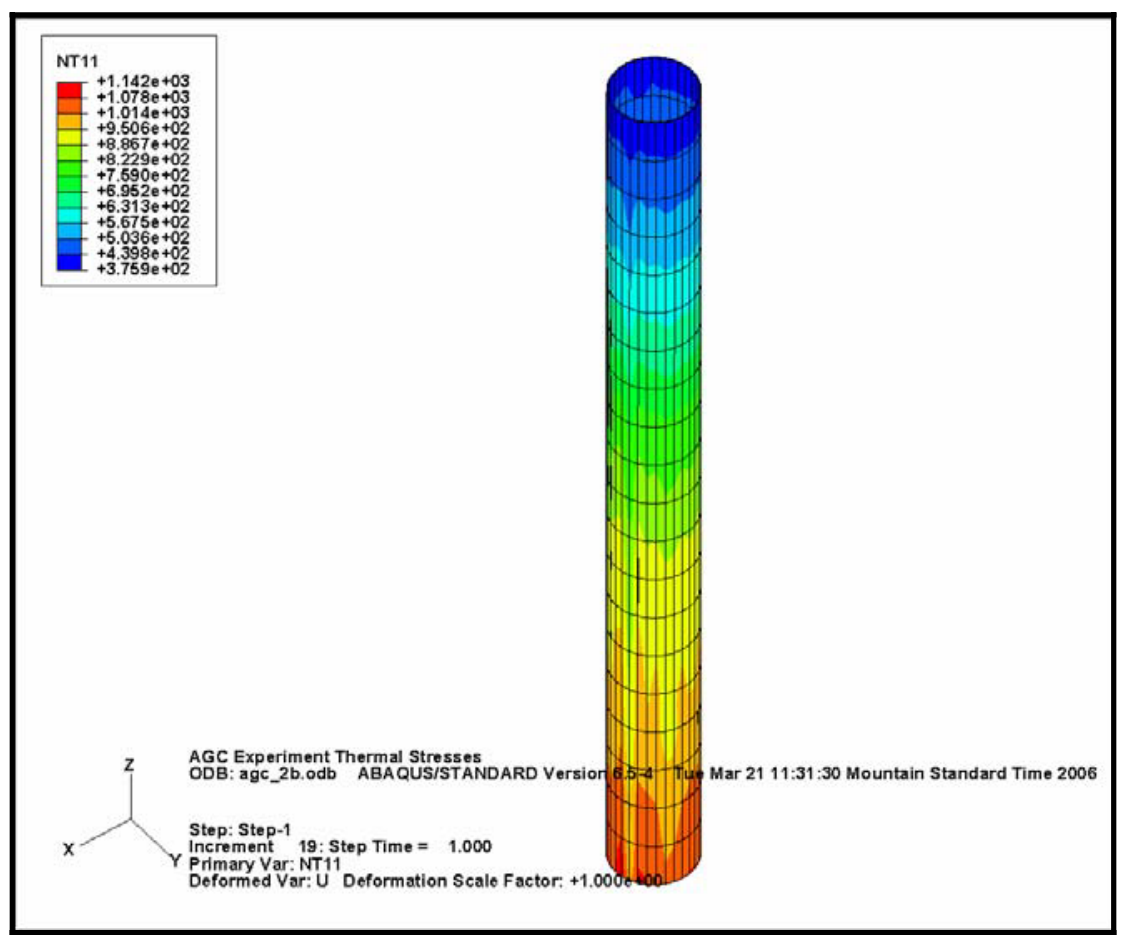

Figure 8. Temperature distribution in the heat shield.

Figure 9 shows the stresses in the graphite specimen holder. The maximum calculated stress is $621 \mathrm{psi}$. The yield strength at the maximum temperatureof $1985^{\circ} \mathrm{F}$ (Fig. 10) is 2321 psi. The thermal stresses in the graphite are not high enough to cause cracking.

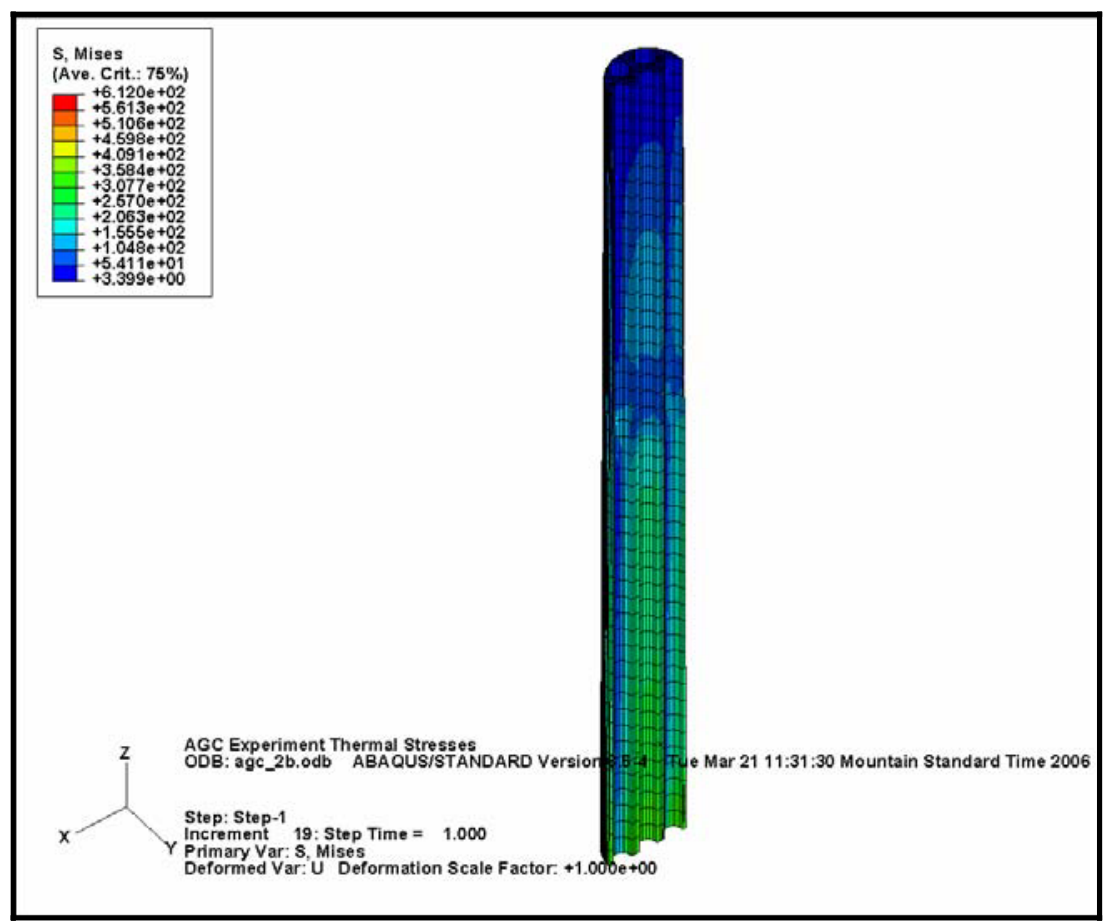

Figure 9. Cutaway view of the graphite specimen holder showing the Von Mises stress. 


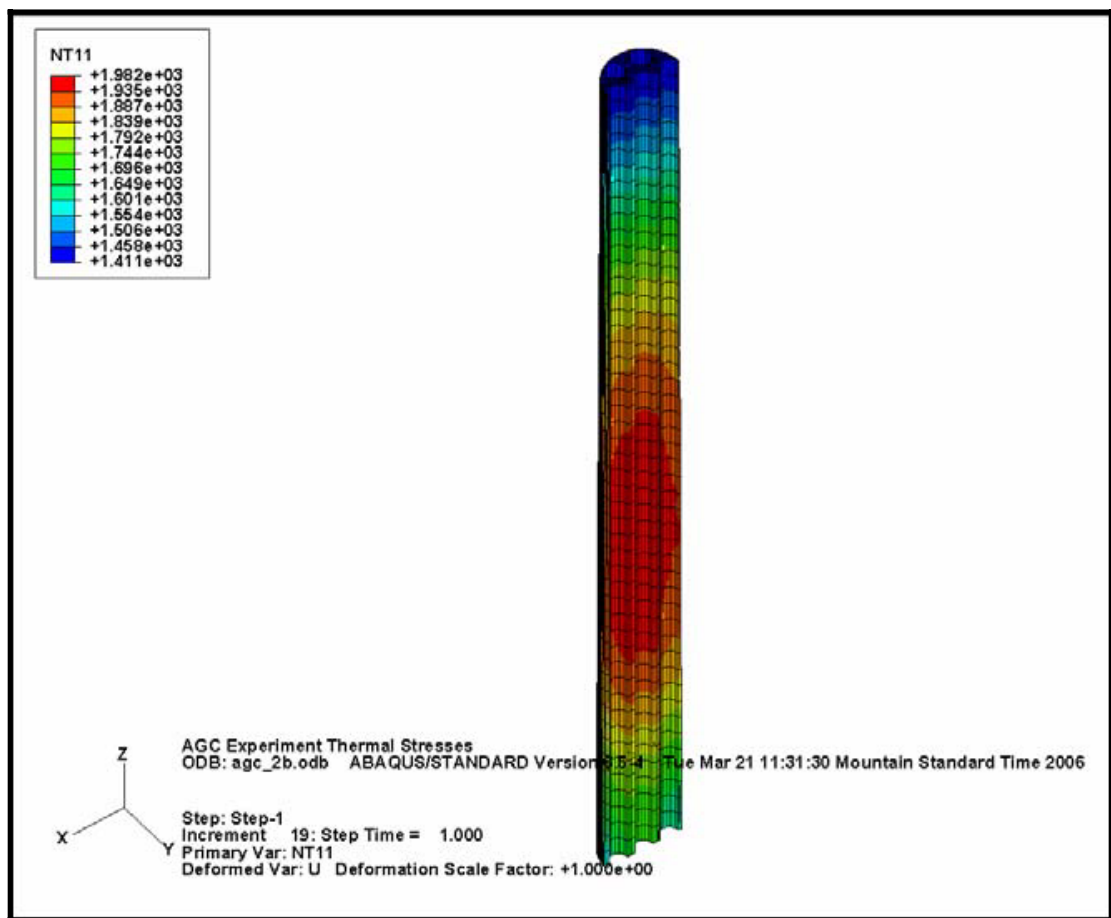

Figure 10. Temperature in the graphite specimen holder.

\section{Conclusions}

The calculated thermal stresses in the AGC-1 experiment cause some slight $(0.5 \%)$ plastic strain in the outer pressure boundary at the root of the grooves on the inner surface. These plastic strains, caused by the thermal stresses or secondary stresses will not cause failure of the outer pressure boundary. The heat shield and the graphite specimen holder have stresses well below the yield strength at their maximum temperature. These components meet the code requirements for this experiment.

\section{References}

1. INL Drawing 630434, Rev. Draft

2. INL Drawing 630432, Rev. Draft

3. INL Drawing 630427, Rev. Draft

4. I-Deas $11 \mathrm{NX}, 2005$

5. ABAQUS/Standard Version 6.5-4, 2005

6. RGA EDF

7. ASME Boiler and Pressure Vessel Code, 2001 with 2002 addenda

\section{Abbreviated ABAQUS Input File}

** file $=$ agc_2b.inp

** b version uses a node based surface for the contact with outer pressure boundary

** standard experiment with grooved outer boundary

** Second major iteration of the AGC experiment

** This file contains the experiment from the core centerline 


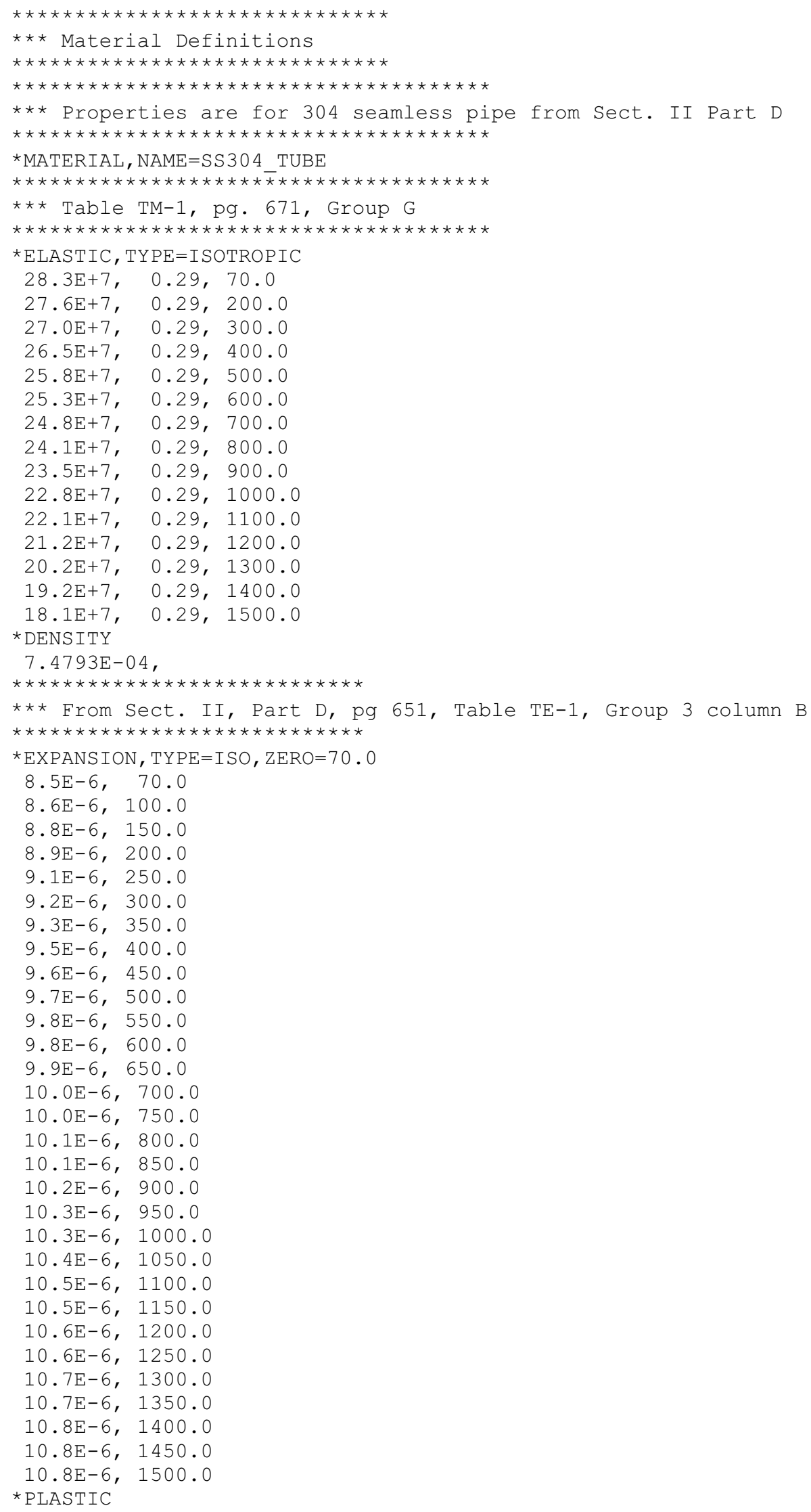


$\star \star 4.886 \mathrm{E}-6,3992.0$

$\star * 4.973 \mathrm{E}-6,4352.0$

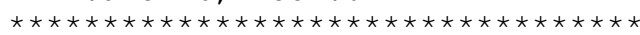

$* * *$ Inconel alloy 230 (UNS N06230)

$\star \star \star$ www.specialmetals.com

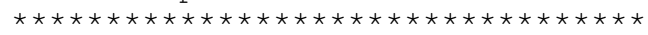

$\star$ MATERIAL, NAME $=$ INCONEL230

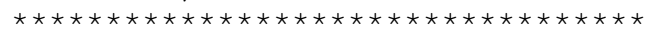

$\star * *$ Material is N06230 with 57\% Ni

$\star \star \star$ Properties. Elastic modulus from Section II, Part D,

$\star * *$ Poisson's ratio is from Vendor data

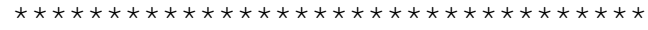

*ELASTIC, TYPE=ISOTROPIC

$30.6 \mathrm{E}+6,0.34,100.0$

$29.9 \mathrm{E}+6,0.33,200.0$

$29.5 \mathrm{E}+6,0.33,300.0$

$29.0 \mathrm{E}+6,0.34,400.0$

$28.6 \mathrm{E}+6,0.34,500.0$

$28.2 \mathrm{E}+6,0.35,600.0$

$27.7 \mathrm{E}+6,0.34,700.0$

$27.2 \mathrm{E}+6,0.34,800.0$

$26.7 \mathrm{E}+6,0.32,900.0$

$26.1 \mathrm{E}+6,0.32,1000.0$

$25.5 \mathrm{E}+6,0.33,1100.0$

$24.9 \mathrm{E}+6,0.34,1200.0$

$24.2 \mathrm{E}+6,0.33,1300.0$

$23.6 \mathrm{E}+6,0.31,1400.0$

$\star$ PLASTIC

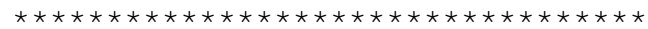

$\star \star \star$ Yield strength is from Sect. II, Part D, pg. 618 (2005 Ed.)

$\star \star \star$ Ultamate strength is from Sect. II, Part D, pg. 482 (2005 Ed.)

$* * *$ True stress and true strain calculated in Mathcad file

$* * * * * * * * * * * * * * * * * * * * * * * * * * * * * * * * * *$

$45.0 \mathrm{E}+3,0.0,100.0$

$160.6 \mathrm{E}+3,0.378,100.0$

$42.3 \mathrm{E}+3,0.0,200.0$

$160.6 \mathrm{E}+3,0.378,200.0$

$39.6 \mathrm{E}+3,0.0,300.0$

$158.4 \mathrm{E}+3,0.365,300.0$

$37.0 \mathrm{E}+3,0.0,400.0$

$154.0 \mathrm{E}+3,0.358,400.0$

$34.7 \mathrm{E}+3,0.0,500.0$

$150.9 \mathrm{E}+3,0.365,500.0$

$32.9 \mathrm{E}+3,0.0,600.0$

$149.2 \mathrm{E}+3,0.372,600.0$

$31.9 \mathrm{E}+3,0.0,700.0$

$148.3 \mathrm{E}+3,0.375,700.0$

$31.4 \mathrm{E}+3,0.0,800.0$

$147.9 \mathrm{E}+3,0.378,800.0$

$31.3 \mathrm{E}+3,0.0,900.0$

$143.0 \mathrm{E}+3,0.351,900.0$

$31.3 \mathrm{E}+3,0.0,1000.0$

$139.7 \mathrm{E}+3,0.336,1000.0$

$23.2 \mathrm{E}+3,0.0,1100.0$

$138.3 \mathrm{E}+3,0.368,1100.0$

$22.2 \mathrm{E}+3,0.0,1200.0$

$140.9 \mathrm{E}+3,0.419,1200.0$

$22.2 \mathrm{E}+3,0.0,1300.0$

$125.9 \mathrm{E}+3,0.482,1300.0$

$21.2 \mathrm{E}+3,0.0,1400.0$

$106.2 \mathrm{E}+3,0.560,1400.0$

*EXPANSION, ZERO=70.0 


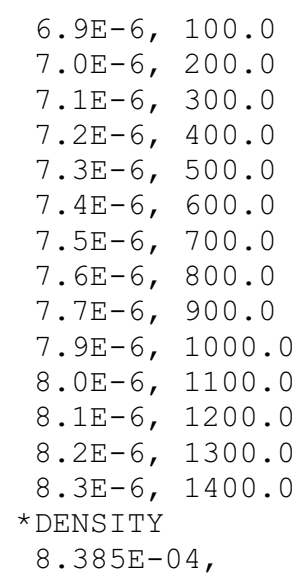


* surface, name=hs out 5 surf, type=element 


\section{Engineering Design File}

EDF-5925

Revison 0

BS000004, 2, 3,

$0.00000 \mathrm{E}+00$

Page F16 of 16

*NSET, NSET $=\mathrm{BS} 000001$

$60024,60028,60057,60058,60061,60349,60350,60359,60362,60425$

*NSET, NSET $=$ BSO00002, GENERATE

$1, \quad 43, \quad 21$

$\ldots \ldots$

$60741,60742, \quad 1$

*NSET, NSET $=\mathrm{BS} 000003$

$232,481,904,1134,12003,12402,60141,60142,60143,60144,60513,60514,60515$

60516,

*NSET, NSET $=\mathrm{BS} 000004$

$64,649,736,1302,12135,12537$

*TEMPERATURE, INPUT=rga_temperatures.inp

*OUTPUT, FIELD

* NODE OUTPUT

$\mathrm{U}, \mathrm{NT}$

*ELEMENT OUTPUT

$S, \quad P E E Q$

*END STEP 


\section{Appendix J}

The Design Review Chairman's Report on the AGC-1 Preliminary Design Review 


\section{INTEROFFICE MEMORANDUM Haho National laboratory}

Date: July 27,2006

To: $\quad$ Distribution

From: $\quad$ K. R. Estes

Subject: $\quad$ REPORT OF THE PRELIMINARY DESIGN REVIEW OF THE ADVANCED TEST REACTOR ADVANCED GRAPHITE CAPSULE GRAPHITE CREEP CAPSULE EXPERIMENT

The preliminary design review for the Advanced Test Reactor Advanced Graphite Capsule AGC-1 experiment has been completed. The preliminary design review was held at the AmeriTel Inn located at 2501 South $25^{\text {th }}$ East in Idaho Falls on May 31, 2006. The following members submitted comments and/or attended the review.

Attendees:

$\underline{\text { Name }}$

R. G. Ambrosek

S. Bader

S. L. Barrie

R. L. Bratton

M. J. Chaffin

D. E. Clark

K. R. Estes

J. A. Galbraith

B. L. Grant

L. Harrison

B. D. Hawkes

G. O. Hayner

M. M. Heberling

R. C. Howard

S. C. Johnson

E. D. King

K. K. Clayton

F. M. Marshall

G. A. Marts

J. R. Parry

S. D. Snow

T. M. Stumpf

T. A. Tomberlin

K. D. Weaver

L. M. Whitehead
Function

Presenter

Observer

Reviewer

Presenter

Reviewer

Presenter

Chairman

Observer

Reviewer

Reviewer

Presenter

Observer

Reviewer

Reviewer

Reviewer

Reviewer

Reviewer

Observer

Reviewer

Presenter

Presenter

Reviewer

Reviewer

Observer

Observer
Discipline/Organization

Analyst

Project Manager

ATR Engineering

Project Manager

ATR Quality Engineering

Welding/Materials

ATR Engineering

BEA Staff

ATR Radiological Support

ATR Engineering

BEA Applied Mechanics

NGNP Materials Manager

ATR Operations

ATR Engineering

Nuclear Maintenance Planning Manager

BEA Nuclear Operations Environmental

ATR Engineering

ATR New Business Department Manager

ATR Engineering

Irradiation Test Programs

BEA Applied Mechanics

ATR Engineering

ATR Nuclear Safety

NGNP Technical Manager

Design \& Drafting 
Distribution

July 27, 2006

Page 2

The meeting was called to order and it was determined by the design review chairman that those present consisted of an acceptable design review committee. Written comments were received by the Chairman after the review from K. K. Clayton (attached). The project design team presented the capsule, structural analysis, reactor physics, and thermal analysis aspects of the design. Unresolved committee comments were recorded during the meeting (attached). At the conclusion of this preliminary design review, as a result of insufficient information, a determination could not be made as to whether the design meets requirements.

Thank you for your participation in the review.

kre

Attachments

Distribution

R. G. Ambrosek, MS 3885

S. Bader, MS 3790

S. L. Barrie, MS 7101

R. L. Bratton, MS 3710

M. J. Chaffin, MS 7102

D. E. Clark, MS 2210

J. A. Galbraith, MS 3605

B. L. Grant, MS 7110

L. Harrison, MS 7101

B. D. Hawkes, MS 3760

G. O. Hayner, MS 3750

M. M. Heberling, MS 7106

R. C. Howard, MS 7101

S. C. Johnson, MS 7119

E. D. King, MS 7137

K. K. Clayton, MS 7101

F. M. Marshall, MS 7101

G. A. Marts, MS 7101

J. R. Parry, MS 3870

S. D. Snow, MS 3760

T. M. Stumpf, MS 7101

T. A. Tomberlin, MS 7136

K. D. Weaver, MS 3850

L. M. Whitehead, MS 3770 
Distribution

July 27, 2006

Page 3

cc: J. E. Dwight, MS 7117 (w/o Att.)

D. J. Schoonen, MS 7101

K. R. Estes Letter File (KRE-01-06)

AGC-1 Project File

Uniform File Code: 0450

Disposition Authority: N1-434-95-5-1-f-1

Retention Schedule: Cutoff at completion of project. Destroy 10 years after cutoff.

NOTE: Original disposition authority, retention schedule, and Uniform Filing Code applied by the sender may not be appropriate for all recipients. Make adjustments as needed. 


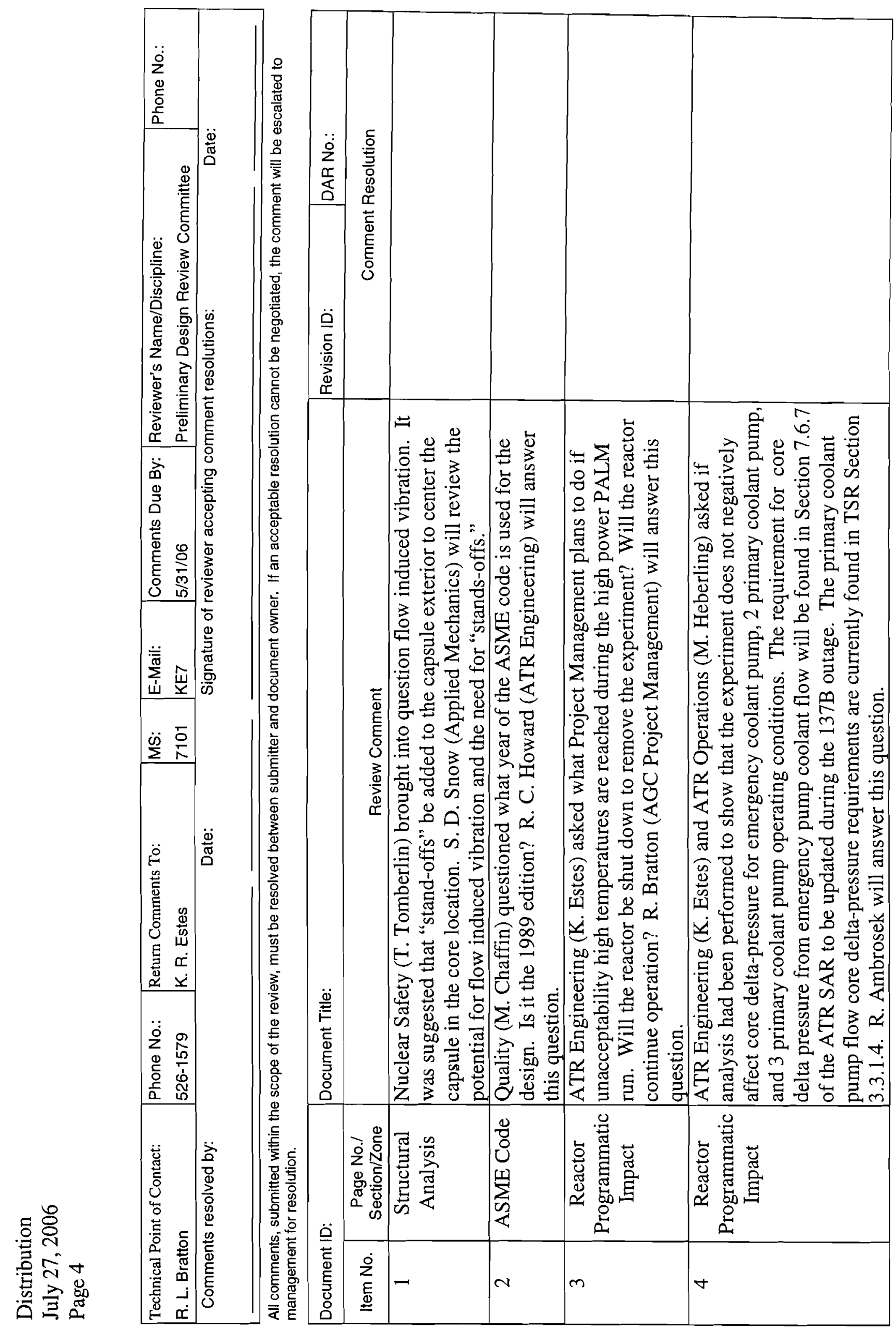




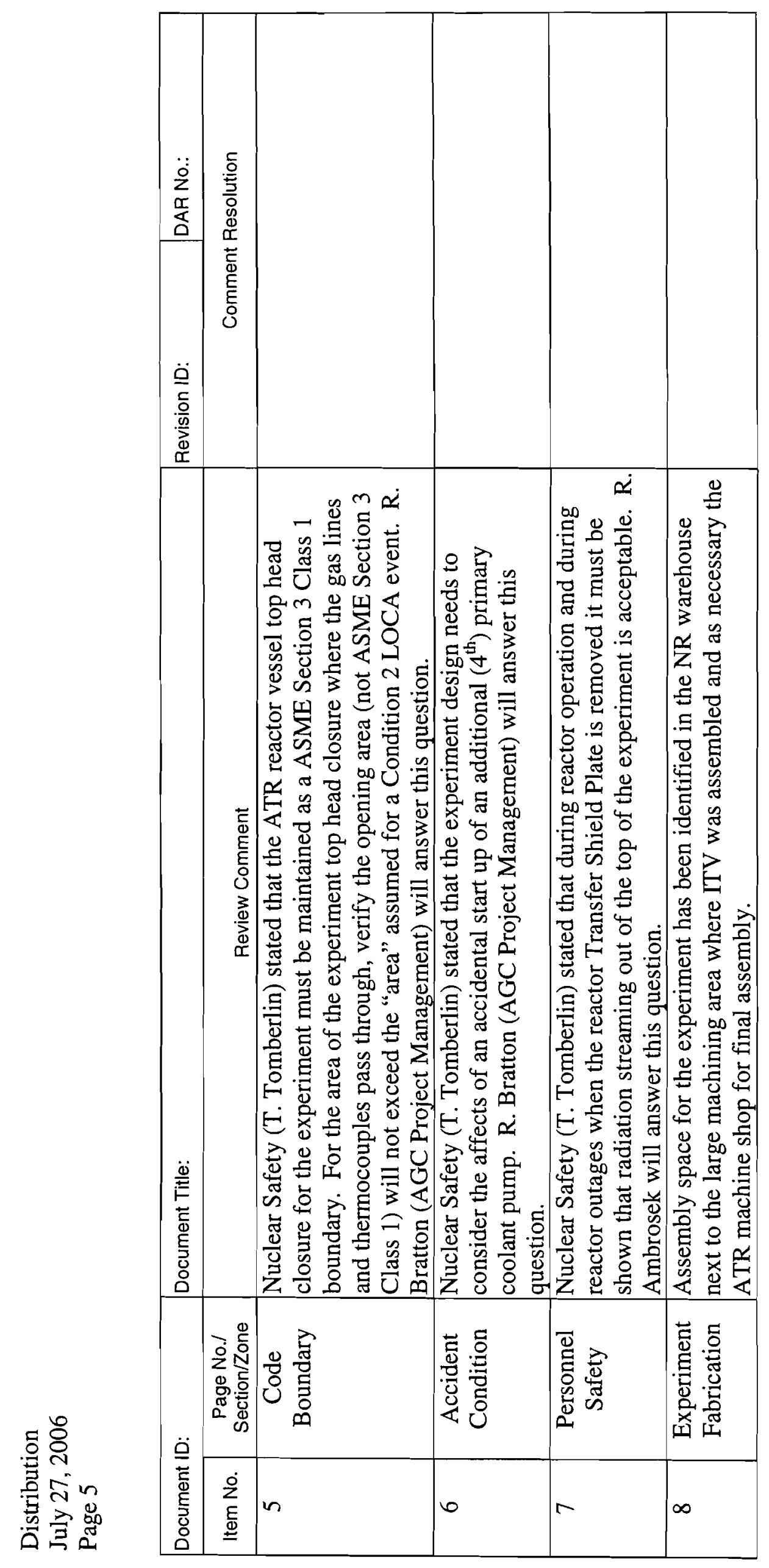




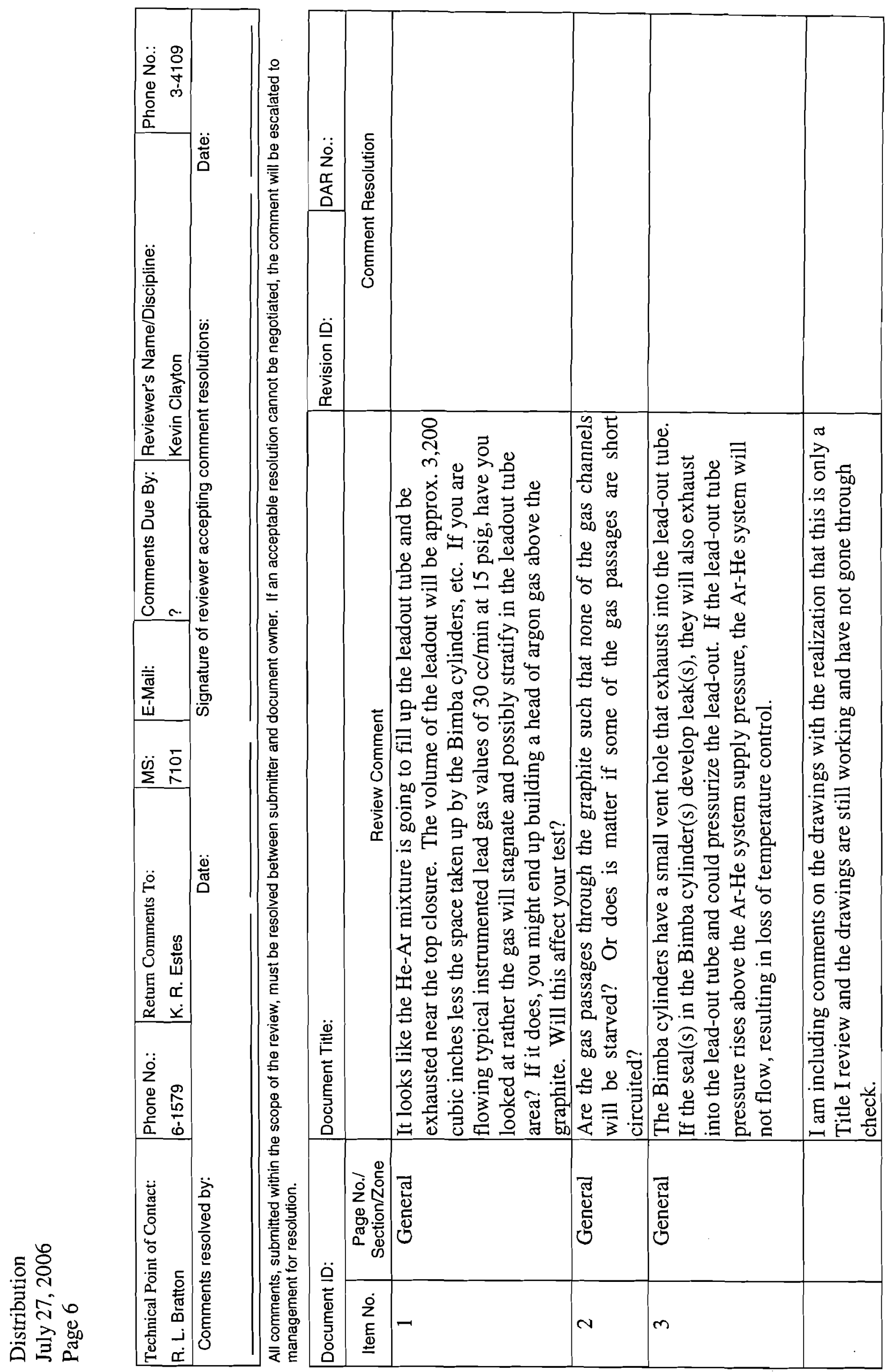




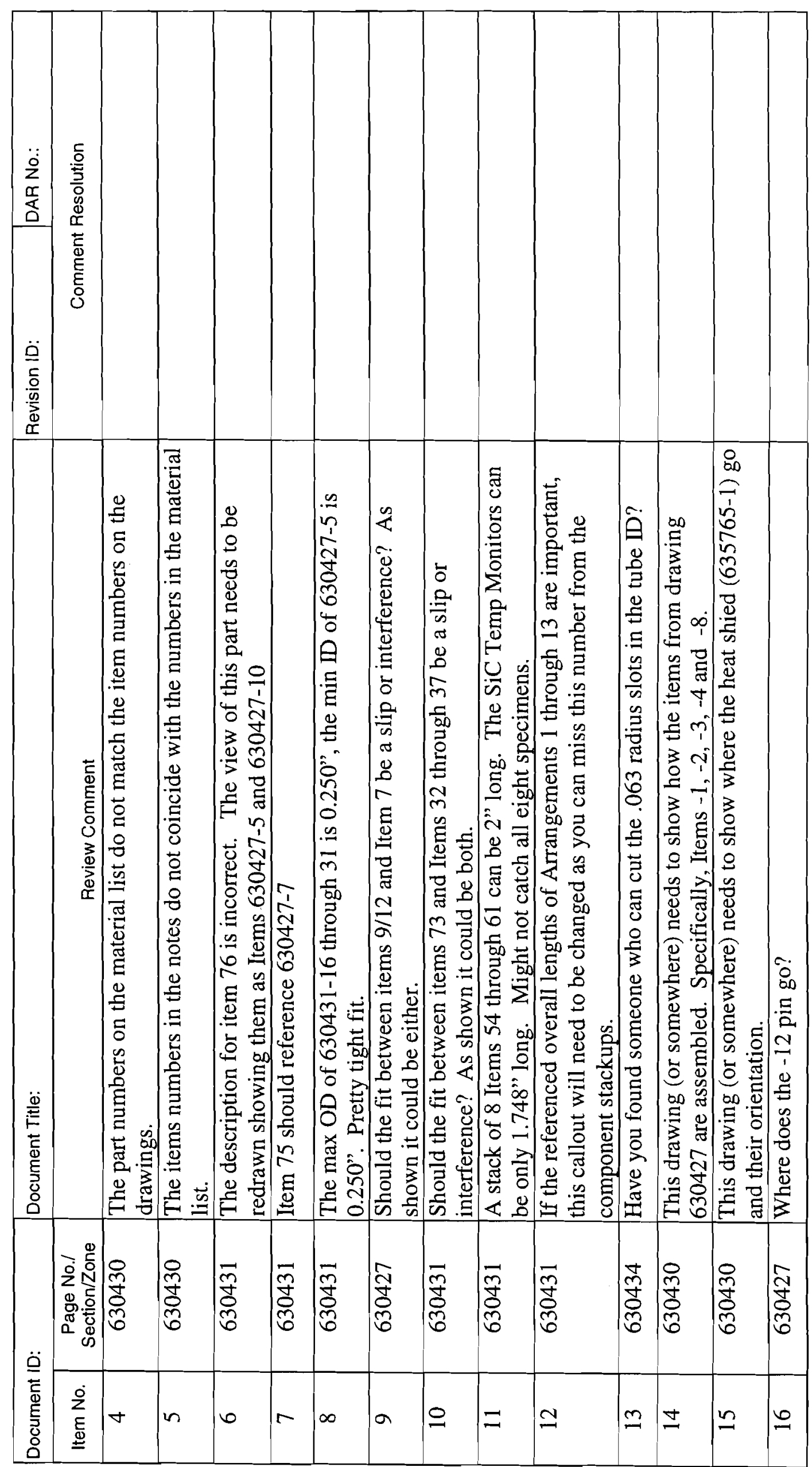




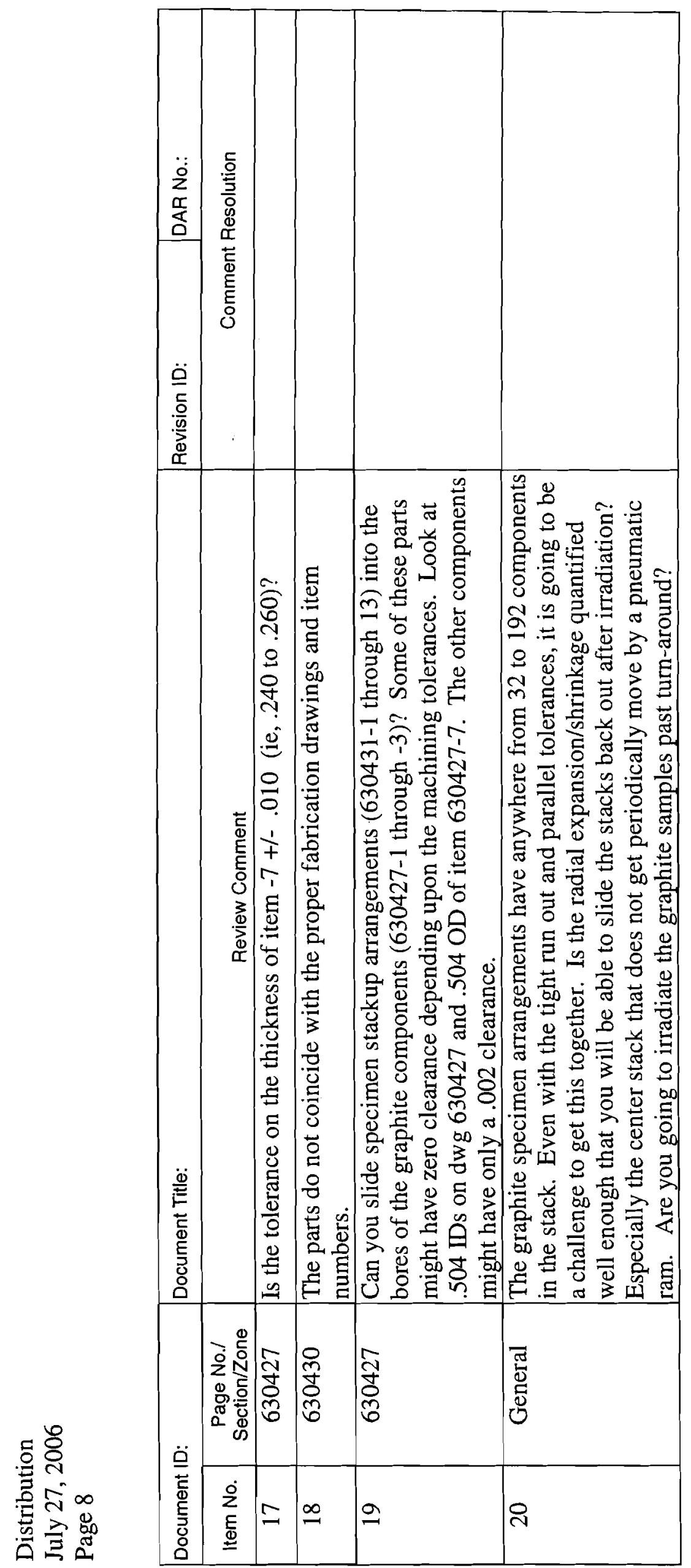

